\title{
PUNCHING SHEAR STRENGTH OF SLAB-COLUMN CONNECTIONS IN FLAT PLATE SYSTEM
}

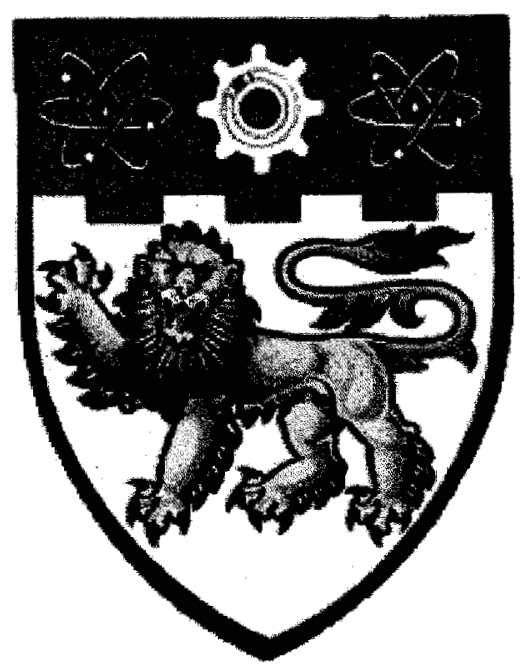

THAN THAN WAI

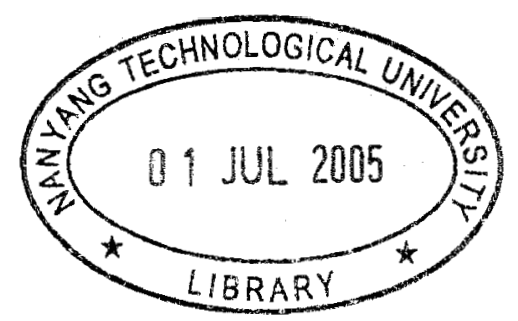

SCHOOL OF CIVIL AND ENVIRONMENTAL ENGINEERING NANYANG TECHNOLOGICAL UNIVERSITY 


\section{Punching Shear Strength of Slab-column Connections in Flat Plate System}

\section{Than Than Wai}

School Of Civil and Environmental Engineering Nanyang Technological University

A thesis submitted to the Nanyang Technological University in fulfilment of the requirement for the degree of Master of Engineering 


\section{Statement of Originality}

I hereby certify that the content of this thesis is the result of work done by me and has not been submitted for a higher degree to any other university or Institution.

Than Than Wai

Date 


\section{ACKNOWLEDGEMENTS}

I would like to express my utmost gratitude and appreciation to my supervisor, Assistant Professor Paulus Irawan, from the School of Civil and Environmental Engineering of Nanyang Technological University, for his interest, continuous support, intellectual and invaluable suggestions and encouragement throughout this study. His explanation, understanding and invaluable helps make me more eager to pursue my research work.

According to Myanmar traditional ideas, an excellent teacher should have good will, kindness, sacrificing attitude, fair to all students, like to teach and give guidance. Professor Paulus Irawan is such an excellent teacher. He helps me to master my research field. So, admiration and thanks to him are full in my heart. I am satisfied and feel honoured to obtain a chance of doing research under the supervision of such an excellent teacher.

I would like to thank my family, who has supported me whenever I need special food and medicine. And I also would like to thank my friends Naing Naing Maw, Naing Naing Aung, Sithu Htun, Khin Kyu Kyu Win, and Phyu Phyu Thant who take care of me when I am sick and make sure that I have a good health throughout the period of this research work.

I would like to extend my gratitude to Professor Er Meng Hwa - Deputy President 2 of Nanyang Technological University - and Minister U Thaung from Ministry of Science and Technology, Myanmar, Deputy Minister 2 U Nyi Hla Nge, and Dr. Htin Aung - Professor and head of Civil Engineering Department in Yangon Technological University -, for their support for me to study in Nanyang Technological University.

Lastly, I would also like to acknowledge the financial support that has been granted by Nanyang Technological University, Singapore. 


\section{TABLE OF CONTENTS}

\section{Page}

ACKNOWLEDGEMENTS

1

TABLE OF CONTENTS ii

ABSTRACT vii

LIST OF FIGURES Ix

LIST OF TABLES Xvi

LIST OF SYMBOLS Xviii

CHAPTER ONE : INTRODUCTION 1

1.1 Background 1

1.2 Objectives and scope 6

$\begin{array}{lll}1.3 & \text { Organization } & 7\end{array}$

CHAPTER TWO : $\quad$ LITERATURE REVIEWS 9

2.1 Introduction 9

2.2 Plasticity models 9

$\begin{array}{ll}\text { 2.2.1 Plasticity model by Braestrup (1976) } & 10\end{array}$

2.2.2 Plasticity model by Jiang and Shen (1986) 13

$\begin{array}{ll}\text { 2.2.3 Plasticity model by Bortolotti(1990) } & 15\end{array}$

2.2.4 Plasticity model by Kuang and Morley (1992) 18

2.2.5 Plasticity model by Yankelevsky and Leibowitz (1996) 21

2.2.6 Plasticity model by Salim and Sebastian(2002) 23

2.2.7 Summary, comparison and discussion $\quad 24$

2.3 Other analytical models $\quad 29$

2.3.1 Mechanical model by Kinnunen and Nylander (1960) 29

2.3.2 Truss model by Alexander and Simmonds (1987) 29

2.3.3 Mechanical model by Menetrey (1996) 31 
2.4 Previous research works related to openings 33

2.4.1 Study by Di Stasio and Buren (1960) 33

2.4.2 Study by Moe (1961) 35

2.4.3 Study by Hognestad, Elstner, and Hanson (1964) 37

2.4.4 Study by Mowrer and Vanderbilt (1967) 38

2.4.5 Study by Ivy, Ivey and Buth (1969) 39

2.4.6 Study by Regan (1974) 39

2.4.7 Study by Broms (1990) 40

2.4.8 Study by EI-Salakawy, Polak, and Soliman (1999) 42

2.4.9 Study by Kuang Kok Leong (2002) 43

2.5 Experimental works related to slabs with shear reinforcement 46

2.5.1 Study by Islam and Park (1976) 46

2.5.2 Study by Elgabry and Ghali (1987) 47

2.5.3 Study by Ghali (1989) 49

2.5.4 Study by Mortin and Ghali (1991) 50

2.6 Reviews on shear strength by code methods 51

2.6.1 Background 51

2.6.2 Design requirements $\quad 52$

2.6.3 American Concrete Institute ACI 318-02 52

2.6.3.1 Shearforceonly 52

2.6.3.2 Presence of unbalanced moment 53

2.6.3.3 Openinginslabs 56

2.6.4 British Standard BS 8110-97 57

2.6.4.1 Shear force only $\quad 57$

2.6.4.2 Presence of unbalanced moment 58

2.6.4.3 Opening in slabs $\quad 59$

$\begin{array}{lll}2.6 .5 & \text { Summary } & 60\end{array}$

CHAPTER 3 : EXPERIMENTAL PROGRAMME 62

3.1 Introduction 62

3.2 Slab-column specimens $\quad 62$

$\begin{array}{lll}3.2 .1 & \text { Slab notations } & 63\end{array}$

$\begin{array}{lll}\text { 3.2.2 Slab details } & 63\end{array}$

3.2.2.1 Flexural reinforcing steel 64 
3.2.2.2 Shear studs $\quad 64$

$\begin{array}{lll}\text { 3.2.2.3 Material properties } & 68\end{array}$

$\begin{array}{lll}3.3 & \text { Experimental set-up } & 69\end{array}$

$\begin{array}{lll}3.4 & \text { Instrumentation } & 71\end{array}$

$\begin{array}{lll}3.4 .1 & \text { Load cell } & 71\end{array}$

3.4.2 Linear Variable Differential Transducer (LVDT) 73

$\begin{array}{lll}3.4 .3 & \text { Strain gauges } & 74\end{array}$

$\begin{array}{lll}\text { 3.4.4 Data logging equipment } & 75\end{array}$

$\begin{array}{lll}3.5 & \text { Procedure of testing } & 76\end{array}$

\section{CHAPTER 4 : EXPERIMENTAL RESULTS AND DISCUSSION 77}

$\begin{array}{lll}4.1 & \text { Introduction } & 77\end{array}$

$\begin{array}{lll}4.2 & \text { Ultimate punching shear capacity } & 78\end{array}$

$\begin{array}{lll}\text { 4.2.1 Slab-column specimens for series A } & 79\end{array}$

$\begin{array}{lll}\text { 4.2.2 Slab-column specimens for series B } & 79\end{array}$

$\begin{array}{lll}4.2 .3 & \text { Findings } & 80\end{array}$

$\begin{array}{lll}4.3 & \text { Serviceability } & 81\end{array}$

$\begin{array}{lll}\text { 4.3.1 First cracking load } & 81\end{array}$

4.3.1.1 Slab-column specimens for series A $\quad 81$

4.3.1.2 Slab-column specimens for series B 82

$\begin{array}{lll}4.3 .1 .3 & \text { Findings } & 82\end{array}$

4.3.2 Crack patterns $\quad 83$

4.3.2.1 Slab-column specimens for series A 85

4.3.2.2 Slab-column specimens for series B 86

$\begin{array}{lll}\text { 4.3.2.3 Findings } & 87\end{array}$

$\begin{array}{lll}\text { 4.3.3 Deflection } & 94\end{array}$

4.3.3.1 Slab-column specimens for series A 95

4.3.3.2 Slab-column specimens for series B 97

4.3.3.3 Findings 99

$\begin{array}{ll}\text { 4.4 Analyzing on the strain gauge measurements } & 107\end{array}$

4.4.1 Analysis of strains for flexural reinforcements 107

4.4.1.1 Slab-column specimens for series A 109

4.4.1.2 Slab-column specimens for series B 110 
4.4.2 Analysis of strains for shear stud reinforcements 120

4.4.2.1 Slab-column specimens for series A 121

4.4.2.2 Slab-column specimens for series B 123

$\begin{array}{lll}4.4 .3 & \text { Findings } & 124\end{array}$

4.4.3.1 Slab-column specimens for series A $\quad 124$

4.4.3.2 Slab-column specimens for series B 125

$\begin{array}{lll}4.5 & \text { Summary and conclusions } & 132\end{array}$

CHAPTER 5 : PUNCHING SHEAR CAPACITY OF SLABCOLUMN CONNECTION BY THEORY OF PLASTICITY

$\begin{array}{lll}5.1 \text { Introduction } & 134\end{array}$

$\begin{array}{lll}\text { 5.2 Punching shear failure criteria of concrete } & 137\end{array}$

$\begin{array}{lll}5.3 \text { Collapse mechanism } & 142\end{array}$

$\begin{array}{lll}5.4 & \text { Principal strains along the punching crack } & 142\end{array}$

$\begin{array}{lll}5.5 & \text { Dissipation energy in failure surface } & 144\end{array}$

$\begin{array}{lll}5.6 & \text { Upper bound punching shear capacity } & 147\end{array}$

5.6.1 Slab-columnconnection with rectangularcolumn 147

5.6.1.1 Initial slope of failure surface at the compression face of slab is equal or greater than $37^{\circ} \quad 152$

5.6.1.2 Initial slope of failure surface at the compression face of slab is less than 37 degree $\quad 154$

5.6.2 Slab-column connection with opening 157

5.6.2.1 Ineffective area of failure surface by using method AI due to opening 161

5.6.2.2 Ineffective area of failure surface by using method AII due to opening 169

5.6.3 Slab-column connection with shear reinforcement 174

5.6.4 Slab-column connection with opening and shear reinforcement 177

$\begin{array}{ll}\text { 5.6.5 Critical radius of failure surface } & 179\end{array}$

5.7 Procedure for calculation of punching shear capacity 181 


\section{CHAPTER 6 : RESULTS AND DISCUSSION ON PUNCHING SHEAR} CAPACITY OF SLAB-COLUMN CONNECTIONS BY THEORY OF PLASTICITY

6.1 Introduction

6.2 Consideration on Openings

6.3 Effectiveness factor on the compressive strength of concrete 193

6.4 Effectiveness factor on the tensile strength contributed by SSR

6.5 Punching shear capacity of slab-column connections without shear reinforcement

6.5.1 With square column

6.5.2 With rectangular column

6.5.3 With rectangular column and opening

6.6 Punching shear capacity of slab-column connection

with shear reinforcement

6.6.1 With square column 208

6.6.2 With rectangular column and with or without opening

6.7 Conclusions

\section{CHAPTER 7 : SUMMARY, CONCLUSION}

AND RECOMMENDED FUTURE WORKS 217

$\begin{array}{lll}7.1 & \text { Summary } 217\end{array}$

$\begin{array}{lll}7.2 \text { Conclusion } & 218\end{array}$

7.2.1 Conclusion on experimental programme 218

7.2.2 Conclusion on proposed plasticity model 219

7.3 Recommended future works 220

REFERENCES

APPENDICES $\quad$ A1

Appendix A $\quad$ A1

Appendix B $\quad$ B1

$\begin{array}{ll}\text { Appendix C } & \mathrm{C} 1\end{array}$ 


\section{ABSTRACT}

Nowadays the flat plate floor system, which is directly supported on the top of columns without drop panels and column capitals, becomes more popular and is used in apartment buildings, car park buildings and office buildings because of the benefits achieved by using this floor system.

However, the disadvantage of this system is the vulnerability of the punching shear failure around the region of column. This failure can occur when the strength around the region of column is not enough to resist the stress concentrated in that region. The high stresses can concentrate around the slab-column connections due to shear force, unbalanced moment, and combination of shear and unbalanced moment. Some of the sources of these forces are the very high gravity forces, unsymmetrical layout of structure, wind and earthquake loading. When the slabs have openings near the column, uneven shear stresses that cause the punching shear failure can exist in the vicinity of column.

Due to the fact that the region of opening is weak against the punching shear failure and can reduce the punching shear capacity of the slab-column connection, the reduced capacity due to opening needs to be recovered. Shear reinforcement can be used for this purpose. There are many types of shear reinforcements. The shear stud reinforcements (SSR) are commonly used because they can be easily installed.

In this study, in order to obtain better understanding on the punching shear capacity of this floor system, an experimental work involving 6 slab specimens were tested to investigate the behavior of slab-column connections with opening and shear reinforcement. The columns are rectangular shapes. The opening in three specimens is located at the comer of column while the opening in the other three specimens is located at the shorter side of column width. Except the two control specimens, all specimens have different amount and arrangement of shear stud reinforcement. The specimens were loaded to fail under monotonic uniformly distributed loading. 
From test results, it can be seen that the punching shear failure is more vulnerable when the opening is located at the shorter side of column. The strength against the punching shear is different according to the location of opening around the column. The capacity regained by shear stud reinforcement is also different according to the amount and arrangement of shear studs. This experimental study shows the more effective arrangement of shear reinforcement.

As a theoretical research work, a model to predict the upper bound punching shear capacity of square and rectangular slab-column connections with or without opening and with or without shear stud reinforcement is proposed based on the theory of plasticity. First, punching shear failure criterion of concrete is established. Second, the collapse mechanism for different slab-column connections is presented. Third, the plastic strain along the punching crack is derived. Fourth, the dissipation energy in the punching shear failure surface is described. Fifth, by virtual work principle and variational calculus, the upper bound solution for punching shear capacity of slabcolumn connections is achieved.

To take into account the softening effect of concrete, an effectiveness factor on the compressive strength of concrete, which depends on slab thickness, aspect ratio of longer and shorter column widths and compressive strength of concrete, is proposed. In addition, an effectiveness factor on the tensile strength contributed by shear stud reinforcement is also recommended because all shear studs may not yield at the punching failure of slab.

The proposed plasticity model with the proposed effectiveness factors on the compressive strength and tensile strength contributed by SSR give the punching shear capacities which are in good agreement with test results for slab-column connections with square and rectangular columns, with or without opening and with or without shear stud reinforcement. 


\section{LIST OF FIGURES}

Figure 1.1 Some types of slabs (a) Flat plate and (b) Flat slab with drop panel

Figure 1.2 Sketch of punching shear failure of a reinforced concrete slab

Figure 1.3 Typical punching shear failures by Alexander and Simmonds

Figure 2.1 Collapse mechanism in punching shear failure of slab considered in plasticity models

Figure 2.2 Modified Coulomb's failure criterion for concrete (Braestrup, 1976)

Figure 2.3 Failure surface of circular slab-column connection (Braestrup, 1976)

Figure 2.4 Parabolic Mohr failure criteria for concrete (Jiang and Shen, 1986)

Figure 2.5 Modified failure criterion for concrete (Bortolotti, 1990)

Figure 2.6 Proposed failure surface (Bortolotti, 1990)

Figure 2.7 Failure criterion (Bortolotti, 1990)

Figure 2.8 Failure mechanism of laterally restrained slab subjected to concentric punching load (Kuang and Morley, 1992)

Figure 2.9 Conical failure mechanism for centrally loaded restrained circular slab (Kuang and Morley, 1992)

Figure 2.10 Strain rates and stresses of yielding slab section (Kuang and Morley, 1992)

Figure 2.11 Final failure stage of punched slab (Yankelevsky and Leibowitz, 1996)

Figure 2.12 Mechanical model (Kinnunen and Nylander, 1960)

Figure 2.13 Truss model for interior slab-column connection (Alexander and Sirnmonds, 1987)

Figure 2.14 Components of forces contributing to the punching strength (Menetrey,1996)

Figure 2.15 Interior slab-column connection (Di Stasio and Van Buren, 1960)

Figure 2.16 Opening in slab adjacent to column (Di Stasio and Buren, 1960)

Figure 2.17 Interior slab-column specimen with openings (Moe, 1961)

Figure 2.18 Projection of width of openings on to the critical perimeter (Regan, 1974)

Figure 2.19 Test specimen (Broms, 1990) 
Figure 2.20 Test specimen (Salakawy, Polak, and Soliman, 1999)

Figure 2.21 Test specimens and modified method of two projection lines for BS8110-97 (Kuang Kok Leong, 2001)

Figure 2.22 Test specimen (Islam and Park, 1976)

Figure 2.23 Test specimen (Elgabry and Ghali, 1987)

Figure 2.24 Test specimen (Mortin and Ghali, 1991)

Figure 2.25 Critical shear perimeter of critical section (ACI 318-02)

Figure 2.26 Shear stress distribution at the critical section in the vicinity of interior column (ACI 318-02)

Figure 2.27 Shear stress distributions at the critical section in the vicinity of edge column (ACI 318-02)

Figure 2.28 Shear stress distribution at the critical section in the vicinity of corner column (ACI 318-02)

Figure 2.29 Ineffective portion of the slab due to openings (ACI 318-02)

Figure 2.30 Location of shear perimeter (BS 8110-97)

Figure 2.31 Shear perimeter of slab with opening (BS 8110-97)

Figure $3.1 \quad$ Plan views of slab specimens

Figure 3.2 Detail of flexural reinforcement in slab specimens

Figure 3.3 Typical structural details for the shear studs

Figure 3.4 Arrangement of shear stud reinforcements in the slab specimens

Figure 3.5 Testing set-ups

Figure 3.6 Testing set-up complete with spreader beams and LVDTs

Figure 3.7 Plan view of testing set-up for slab

Figure 3.8 LVDT locations on slab specimens

Figure 3.9 Strain gauge locations on flexural reinforcements in slab-column specimens

Figure 4.1 Location of opening and arrangement of SSR in the slabs

Figure 4.2 Top views of slab-column specimens at failure

Figure 4.3 Crack pattern on horizontal surface of slab-column specimens for series A

Figure 4.4 Crack pattern on horizontal surface of slab-column specimens for series B

Figure 4.5 Inclined crack patterns inside the opening of slab-column specimens for series B 
Figure 4.6 Inclined crack patterns inside the opening of slab-column specimens for series B

Figure 4.7 Load vs displacement curves for slab A1

Figure 4.8 Load vs displacement curves for slab A2

Figure 4.9 Load vs displacement curve for slab A3

Figure 4.10 Load vs displacement curve for slab B1

Figure 4.11 Load vs displacement curve for slab B2

Figure 4.12 Load vs displacement curve for slab B3

Figure 4.13 Deflection vs distance graphs for A series in east-west direction

Figure 4.14 Deflection vs distance graph for A series in north-south direction

Figure 4.15 Deflection vs distance graph for B series in east-west direction

Figure 4.16 Deflection vs distance graph for B series in north-south direction

Figure 4.17 Load vs strain curve for tension bars used in slab A1

Figure 4.18 Load vs strain curve for tension bars used in slab A2

Figure 4.19 Load vs strain curve for tension bars used in slab A3

Figure 4.20 Strain vs distance from column face for tension bars for A series slabs

Figure 4.21 Load vs strain curve for tension bar for slab B1

Figure 4.22 Load vs strain curve for tension bars used in slab B2

Figure 4.23 Load vs strain curve for tension bars used in slab B3

Figure 4.24 Strain vs distance from column face for tension bars for B series slabs

Figure 4.25 Arrangement of shear studs used in series A slabs

Figure 4.26 Arrangement of shear studs used in series B slabs

Figure 4.27 Load vs strain for shear studs used in slab A2

Figure 4.28 Load vs strain for shear studs used in slab A3

Figure 4.29 Strain Vs distance from column for shear studs used in slab A2

Figure 4.30 Strain Vs distance from column for shear studs used in slab A3

Figure 4.31 Load vs strain for shear studs used in slab B2

Figure 4.32 Load vs strain for shear studs used in slab B3

Figure 4.33 Strain Vs distance from column for shear studs used in slab B2

Figure 4.34 Strain Vs distance from column for shear studs used in slab B3

Figure 5.1 Mohr's circle when siding failure occurs

Figure 5.2 Mohr's circle when separation failure occurs 
Figure 5.3 Failure condition with Mohr's circle of principal stresses in concrete at punching shear failure

Figure 5.4 Sliding failure of simple compression case

Figure 5.5 Separation failure of simple tension case

Figure 5.6 Yield condition for modified Coulomb's material in plane strain

Figure 5.7 Collapse mechanism in punching shear failure

Figure 5.8 Yield condition with flow rule for modified Coulomb's material

Figure 5.9 Simply supported slab-column connection under concentric load and punching shear failure surface

Figure 5.10 Punching shear failure surface for simply supported slab-column connection

Figure 5.11 Punching shear failure surface in curve shape for simply supported slab-column connection under concentric load

Figure 5.12 Punching shear failure surface composed with straight and curve portion for simply supported slab-column connection under concentric load

Figure 5.13 Ineffective area of failure surface in the slab due to opening confined by two projection lines

Figure 5.14 Different kinds of opening locations

Figure 5.15 Ineffective area of failure surface due to opening location (a) by using method AI

Figure 5.16 Ineffective area of failure surface due to opening location (b) by using method AI

Figure 5.17 Ineffective area of failure surface due to opening location (c) by using method AIfor case (a)

Figure 5.18 Ineffective area of failure surface due to opening location (c) by using method AIfor case (b)

Figure 5.19 Ineffective area of failure surface due to opening location (d) by using method AI for case (a)

Figure 5.20 Ineffective area of failure surface due to opening location (d) by using method AI for case (b)

Figure 5.21 Ineffective area of failure surface due to opening location (e) by using method AI 
Figure 5.22 Ineffective area of failure surface due to opening location (a) by using method AII

Figure 5.23 Ineffective area of failure due to opening location (b) by using method AII

Figure 5.24 Ineffective area of failure surface due to opening location (c) by using method AII for case (a)

Figure 5.25 Ineffective area of failure surface due to opening location (c) by using method AII for case (b)

Figure 5.26 Ineffective area of failure surface due to opening location (d) by using method AII for case (a)

Figure 5.27 Ineffective area of failure surface due to opening location (d) by using method AII for case (b)

Figure 5.28 Ineffective area of failure surface due to opening location (d) by using method AII for case (c)

Figure 5.29 Ineffective area of failure surface due to opening location (e) by using method AII

Figure 5.30 Flow chart for calculation of punching shear capacity of slab-column connections without opening and without shear reinforcement

Figure 5.31 Flow chart for calculation of punching shear capacity of slab-column connections with opening and without shear reinforcement

Figure 5.32 Flow chart for calculation of punching shear capacity of slab-column connections without opening and with shear reinforcement

Figure 5.33 Flow chart for calculation of punching shear capacity of slab-column connections with opening and shear reinforcement

Figure $6.1 \quad$ Five locations of opening

Figure 6.2 Ineffective area of failure surface due to opening

Figure 6.3 Percentage reduction in punching shear capacity due to opening

Figure 6.4 Arrangements of shear studs used in square slab-column specimens

Figure 6.5 Location of opening and arrangement of SSR in the rectangular slabcolumn specimens

Figure A1 LVDT and strain gauge locations in the slab-column specimens

Figure B-1 Punching shear failure surface for simply supported slab-column connection under concentric load 
Figure B-2 Punching shear failure surface in curve shape for simply supported slab-column connection under concentric load

Figure B-3 Punching shear failure surface composed with a straight line and a curve for simply supported slab-column connection under concentric load

Figure B-4 Ineffective area of failure surface in the slab due to opening confined by two projection lines

Figure B-5 Different kinds of opening locations

Figure B-6 Ineffective area of failure surface due to opening location (a) by using method AI

Figure B-7 Ineffective area of failure surface due to opening location (b) by using method AII

Figure B-8 Ineffective area of failure surface due to opening location (c) by using method AI for case (a)

Figure B-9 Ineffective area of failure surface due to opening location (c) by using method AI for case (b)

Figure B-10 Ineffective area of failure surface due to opening location (d) by using method AI for case (a)

Figure B-11 Ineffective area of failure surface due to opening location (d) by using method AIfor case (b)

Figure B-12 Ineffective area of failure surface due to opening location (e) by using method AI

Figure B-13 Ineffective area of failure surface due to opening location (a) by using method AII

Figure B-14 Ineffective area of failure surface due to opening location (b) by using method AII

Figure B-15 Ineffective area of failure surface due to opening location (c) by using method AII for case (a)

Figure B-16 Ineffective area of failure surface due to opening location (c) by using method AII for case (b)

Figure B-17 Ineffective area of failure surface due to opening location (d) by using method AII for case (a)

Figure B-18 Ineffective area of failure surface due to opening location (d) by using method AII for case (b) 
Figure B-19 Ineffective area of failure surface due to opening location (d) by using method AII for case (c)

Figure B-20 Ineffective area of failure surface due to opening location (e) by using method AII 


\section{LIST OF TABLES}

Table 2.1 Summary and comparison for previously developed plasticity models

Table 3.1 Details of shear studs reinforcement in slab specimens

Table 3.2 Test results of compressive concrete cylinder and cube strengths

Table 3.3 Steel bar tensile test results

Table 3.4 Distribution of strain gauges on flexural and shear stud reinforcement for slab specimens

Table 4.1 Test results for the ultimate punching capacities of the slabs

Table 4.2 Test results of first cracking load

Table 4.3 Summary of recorded information on crack patterns for slab-column specimens

Table 6.1 Detail of slab-column specimens with square column

Table 6.2 Punching shear capacity predicted by theory of plasticity for slab column specimens with square column

Table 6.3 Detail of slab-column specimens with rectangular column

Table 6.4 Upper bound solution of punching shear capacity by plasticity model for slab-column specimens with rectangular column

Table 6.5 Details of slab-column connections with rectangular column and opening

Table 6.6 Punching shear capacity for slab-column connections with rectangular column and opening (Methods AI\& AII)

Table 6.7 Percentage reduction of predicted punching shear capacity lost due to opening by theory of plasticity using the two methods

Table 6.8 Comparison in percentage reduction in punching shear capacity for slab-column connection due to opening (method AI)

Table 6.9 Comparison in percentage reduction of punching shear capacity for slab-column connections due to opening (method AII)

Table 6.10 Details of slab-column specimens with square column and shear reinforcement

Table 6.11 Punching shear capacity of slab-column specimens with square column and shear reinforcement 
Table 6.12 Details of slab-column connection with rectangular column, with or without opening, and with shear stud reinforcement

Table 6.13 Punching shear capacity of slab-column connections with rectangular column, with or without opening and with shear stud reinforcement 


\section{LIST OF SYMBOLS}

$\mathrm{c}_{\mathrm{i} 1} \& \mathrm{c}_{\mathrm{i} 2} \quad=$ incremental length of failure surface parallel to shorter column width and longer column width, respectively, in mm

c $\quad=$ cohesion of concrete material

$f_{A} \quad=$ separation resistance of material in $\mathrm{MPa}$

$f_{c 1} \quad=$ principal tensile stress in $\mathrm{MPa}$

$f_{c 2} \quad=$ principal compressive stress in $\mathrm{MPa}$

$f_{c}{ }^{\prime}=$ cylinder compressive strength of concrete in $\mathrm{MPa}$

$f_{t} \quad=$ tensile strength of slab in $\mathrm{MPa}$

$f_{c t} \quad=$ tensile strength of concrete in $\mathrm{MPa}$

$f_{s t} \quad=$ tensile strength of shear reinforcement in $\mathrm{MPa}$

$\boldsymbol{r} \quad=$ radius of failure surface in $\mathrm{mm}$

$r_{h} \quad=$ radius of failure surface at the tension face of the slab in $\mathrm{mm}$

$r_{0}{ }^{\prime} \quad=r^{\prime}(0)=$ tangent value of failure surface at the compression face of the slab

$r_{h}{ }^{\prime} \quad=r^{\prime}(h)=$ tangent value of failure surface at the tension face of the slab

$r_{c r} \quad=$ critical radius of failure surface at the tension face of slab that gives the least punching shear capacity of slab in $\mathrm{mm}$

$A, B \& C=$ constants related to radius of failure surface

$A_{c r}, B_{c r} \& C_{c r}=$ constants related to critical radius of failure surface

$\bar{A}_{f} \quad=$ net area of failure surface of slab without including ineffective area of failure surface $A_{o p}$ due to opening in $\mathrm{mm}^{2}$

$A_{f} \quad=$ total area of failure surface of slab without opening after punching in $\mathrm{mm}^{2}$

$A_{s} \quad=$ total area of shear studs passing through the failure surface in $\mathrm{mm}^{2}$

$A_{o p} \quad=$ ineffective area of failure surface due to opening in $\mathrm{mm}^{2}$

$C_{1} \& C_{2} \quad=$ shorter and longer column width, respectively, in $\mathrm{mm}$

$P \quad$ = punching shear capacity of slab-column connection without opening and without shear reinforcement in $\mathrm{kN}$ 
$P_{C} \quad=$ punching shear capacity for curved portion of failure surface from the depth $h_{0}$ to the bottom of slab in $\mathrm{kN}$

$P_{L} \quad=$ punching shear capacity for straight portion of failure surface from the top of slab to the depth $h_{0}$ in $\mathrm{kN}$

$P_{C S} \quad=$ punching shear capacity of slab-column connection without opening and with shear reinforcement for curve portion of failure surface in $\mathrm{kN}$

$P_{L S} \quad=$ punching shear capacity of slab-column connection without opening and with shear reinforcement for straight portion of failure surface in $\mathrm{kN}$ $=$ punching shear capacity of slab-column connection with opening in $\mathrm{kN}$

$\bar{P}_{o p} \quad=$ ineffective punching shear capacity of slab-column connection due to opening in $\mathrm{kN}$

$P_{o p+S}$

= punching shear capacity of slab-column connection with opening and with shear reinforcement in $\mathrm{kN}$

$P_{S}$

$=$ punching shear capacity of the slab-column connection without opening and with shear reinforcement in $\mathrm{kN}$

$\bar{P}_{S}$

$=$ punching shear capacity of slab-column connection without opening and with shear reinforcement in $\mathrm{kN}$ based on the ratio of shear stud reinforcements passing through the net area of failure surface $\bar{A}_{f}$ without including the ineffective area of failure surface $A$, due to opening

$W_{A} \quad=$ dissipation energy per unit area of failure surface

$W_{V} \quad$ = dissipation energy per one unit volume of yield region

$\tau$

$=$ shear stress in the sliding surface in $\mathrm{MPa}$

$\sigma \quad=$ normal stress in the separation surface in $\mathrm{MPa}$

$\mu \quad=$ tangent value of internal friction angle of concrete material

$\varphi \quad=$ angle of internal friction angle of concrete

$a \quad=$ slope of failure surface

$\alpha_{\text {avg }}=$ average slope of failure surface

$\varepsilon_{1} \& \varepsilon_{2} \quad=$ principal positive and negative strain, respectively 
$\varepsilon^{+} \& \varepsilon^{-} \quad=$ summation of positive principal strain and summation of negative principal strain, respectively

$\rho_{\mathrm{s}} \quad=$ ratio of shear stud reinforcement passing through the total area of failure surface $A_{f}$

$\bar{\rho}_{s} \quad=$ ratio of shear stud reinforcement passing through the net area of failure surface $\bar{A}_{f}$ of slab without including of ineffective area of failure surface $A$, due to opening

$\Delta_{1} \& \Delta_{2}=$ components of circumferential length of failure surface parallel to shorter and longer column width, respectively, in mm 
CHAPTER 1 


\section{Chapter 1}

\section{Introduction}

\subsection{Background}

A flat plate floor is essentially a flat slab structure without drop panels and column capitals. The floor systems do not use beams or walls to support the slab, but instead of these, they are directly supported on the top of the columns only. This floor system becomes more popular and is nowadays used in the buildings such as apartment buildings, car park buildings and office buildings. By using this flat plate floor system, such structures can reduce the story heights; the formwork is simple because there are no beams; it is economical on formwork and labor; the flexibility of planning can be increased and the appearance is pleasant. Some types of slabs are shown in Figure 1.1.

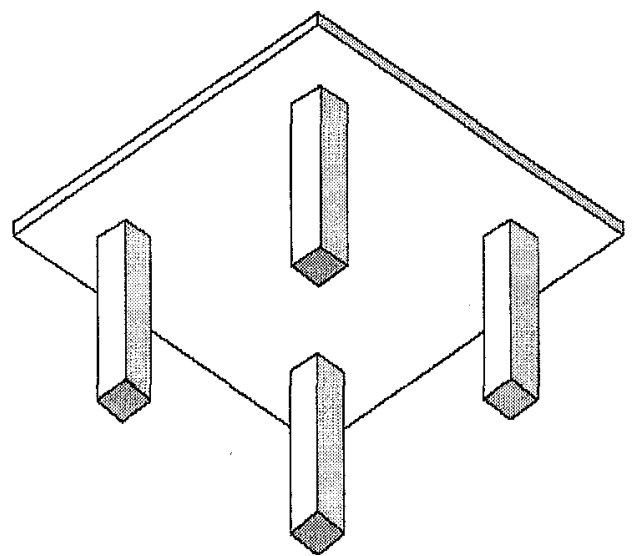

(a)

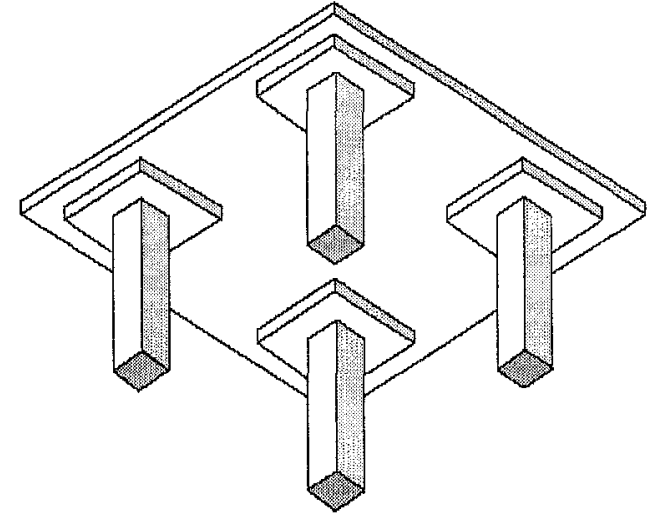

(b)

Figure 1.1 Some types of slabs

(a) Flat plate

(b) Flat slab with drop panel

However, the undesirable thing of the flat plate structures is that it may fail with brittle punching shear failure mode. This is due to the fact that in flat plate structures, high stresses are concentrated at the area near the slab-column connection where the 
column punches through the slab as shown in Figure 1.2. This failure can lead to a catastrophic damage without warning. The high shearing force can be produced by high gravity load. The unbalanced bending moment may exist due to unsymmetrical geometry layout of columns or lateral forces due to wind and earthquake loads. The high shear stress due to the combination of high shearing force and unbalanced bending moment can cause severe failure around the slab-column connection. Therefore, it must be ensured that there is enough strength at the slab-column connections, and that the column does not punch through the slab.

The punching shear failure surface observed in practice is curved that extends from the compression side of the slab at the face of the column to the tension side of the slab at some distance from the column. The slope of failure surface at the compression side of slab is usually between 25 and 30 degrees. The distance of failure surface from the column face at the tension side of slab is usually between $1.5 \mathrm{~d}$ and $4 \mathrm{~d}$, where $\mathrm{d}$ is the effective depth of slab.

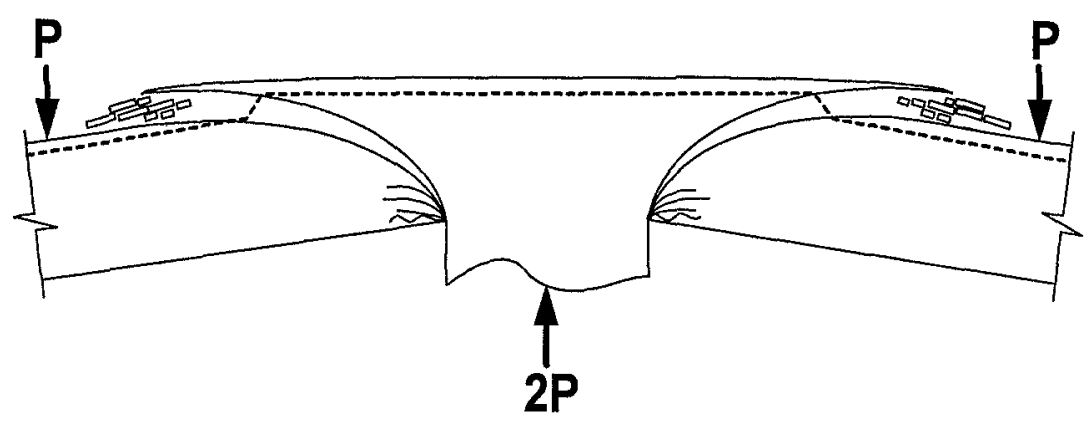

Figure 1.2 Sketch of punching shear failure of a reinforced concrete slab

There are three types of slab-column connections: interior, edge and comer slabcolumn connections. In the interior slab-column connections, if the arrangement of columns is symmetrical and there is no lateral force, there will be no unbalanced bending moment. Thus, the typical punching shear failure as the truncated cone surrounding the column will occur due to high shear stress from the shearing force only. In the case of the edge and comer slab-column connections, the unbalanced bending moment will occur and the failure occurs at the side with the highest shear stress due to the combination of shearing force and unbalanced bending moment. The punching region is confined to the area near the heavily loaded face of column. The 
plan views of three typical punching shear failures are shown in Figure 1.3. It is required that reasonable and reliable shear capacity of the slab-column connections be predicted accurately to avoid the brittle punching shear failure mode. Thus, to achieve the reasonable and reliable shear capacity of the slab-columns connections, there is a need to better understand the mechanism, behavior and failure mode occurring in the slab-column connections at ultimate load.

In flat plate structure, the holes or openings are often perforated in the vicinity of columns. Such openings are required for sanitary reasons, ventilation, heating, airconditioning, and electrical ducts, etc. The vicinity of the column is a critical zone where the concentrated shear stresses are the largest. Therefore, location of opening in this vicinity of column decreases the shear capacity of the flat plate floor system. The use of shear reinforcement can recover the shear capacity of the slabs to some extent. Many researchers such as Di Stasio and Van Buren (1960), Moe (1961), Hognestad, Elstner, and Hanson (1964), Mowrer and Vanderbilt (1967), Regan (1974), Broms (1990), EI-Salakawy, Polak, and Soliman (1999), and Kuang (2002) have done the study on the effect of openings in decreasing the punching shear capacity of the interior slab-column connections and the effect of using various types of shear reinforcement in increasing the punching shear strength. However, the method that can accurately predict the punching shear capacity of slab-column connections with opening and shear stud reinforcement is rare.

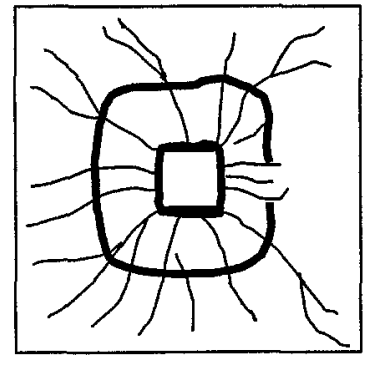

Shear only

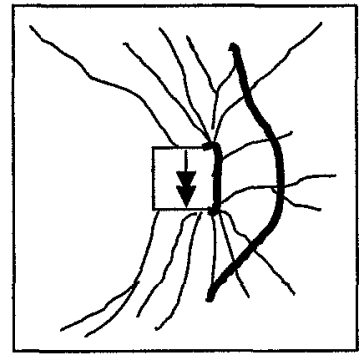

Moment and Shear

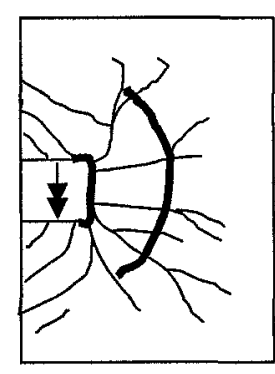

Moment and Shear

Figure 1.3 Typical punching shear failures by Alexander and Simmonds (1987)

Among the various type of shear reinforcement, the shear studs become more popular due to easy installation and less congestion with flexural reinforcement. Accordingly, research works to better understand on the behavior of slab-column connections with 
opening near column and shear stud reinforcement are needed and should be conducted. To fulfil such needs, a total of six interior slab-column specimens with rectangular column, with opening near column and with shear stud reinforcement in various amount and arrangements were tested to investigate the behavior of slabcolumn connections with opening and shear stud reinforcements.

There are many design codes to calculate the punching shear strength of slab-column connections with openings, ACI building code ACI 318-02, Australian Standard 3600-2001, British Standard BS8110-97, Canadian Standard A23.3-94, CEB/FIP model code 90, and Eurocode2 EC2, etc. Generally, these codes are experimental based and the mechanisms of forces to resist punching shear are approximated. These codes give the reduction of punching shear capacity of the slabs with openings in the vicinity of column. By simplifying the equations used in the design, the capacity of slab can be predicted to some degree, but the behavior of the slabs with openings is still needed to be studied for various locations of openings and for the use of various amounts and arrangement of shear stud reinforcement. Complex stress states occur in the vicinity of slab-column region, therefore, it is necessary to obtain better understanding the mechanism of slab-column connections, especially for slab with opening.

In addition, there are many analytical approaches to predict the punching shear capacity of slab-column connection which have been presented by many researchers in the literature; flexural capacity approach (Long, 1975), plasticity theory (Braestrup, 1976), mechanical model (Kinnunen and Nylander, 1960), truss model (Alexander and Simmonds, 1987), and analytical model (Menbtrey, 1996), etc. These models can predict the punching shear capacity of slab-column connections to some degree. However, the shape of failure surface considered in some approaches is not consistent with the experimental results. Among these models, the plasticity model can predict the upper bound punching shear capacity of slab-column connection with circular column and give the possible failure surface closely observed in the experiment. Plasticity model is based on the punching shear failure criteria assuming that the concrete material is rigid-plastic modified Coulomb's material. Equilibrium and strain compatibility conditions are also consistent in plasticity model. 
A theoretical solution to predict the punching shear capacity of slabs by theory of plasticity was developed by Braestrup in 1976. The concrete was considered rigidplastic material. Modified Mohr-Coulomb failure criterion for concrete in straight line envelop with slope of 37 degrees was established. In 1986, Jiang and Shen proposed a theoretical solution similar to Braestrup's plastic solution for the punching of concrete slab based on plasticity theory. The difference between Braestrup's and their plasticity models was that the modified Mohr-Coulomb failure criterion in second degree parabolic for concrete was assumed. Due to this assumption, their plasticity model can be used to predict the punching load of slab for any value of punching angle at the compression side of slab.

The important thing in the plasticity model that influences the accuracy of results is the consideration on effect of softening of concrete. As the development regarding to the softening of concrete in plasticity model, Bortolotti in 1990 presented the plasticity model for the punching shear strength of concrete slab by taking into account the softening process in tension and compression of concrete visualized by failure surface profile. Based on this visualization, the modifications were made in the form of modified Mohr-Coulomb failure criterion possible due to softening from tension and compression of concrete.

When the slab is laterally restrained, the punching shear capacity of slab can enhance due to compressive membrane stresses which are developed. In 1993, Kuang and Morley presented a plastic theoretical model for the punching shear failure of laterally restrained concrete slabs, in which a parabolic Mohr-Coulomb failure criterion for concrete was adopted and the effect of compressive membrane action due to lateral restraint was calculated by a membrane-modified flexural theory of elasto-plasticity developed by Braestrup (1980).

The plasticity models mentioned above are based on the shear and normal stress in the failure surface presented by the theoretically established failure criterion of concrete. In the crack surface, the shear stress and its accompanying compressive stress may be induced by the aggregate interlocking. The plasticity model for the punching shear strength of slab which was based on shear and compressive stress empirically 
presented from aggregate interlocking in the surface of established punching shear crack was developed by Yankelevsky and Leibowitz in 1996.

All plasticity models mentioned above are able to predict the punching shear capacity for the slab with circular column simply supported or laterally restrained along the circumferentialedge of the slab and can give reasonably good results compared to the experiments. However, the effect of flexural reinforcement is neglected and contribution of shear reinforcement in punching shear capacity can not be presented. When the slab has opening near the column, the punching shear capacity of slab may decrease due to opening. Due to opening, some parts of failure surface can be considered ineffective in resisting punching load. One of the methods to recover the punching shear capacity lost due to opening is the use of shear reinforcement. Plasticity model needs to be able to predict the punching shear capacity of slabcolumn connections with opening and shear reinforcement.

In this study, rigid-plastic theoretical model for the punching shear failure of simply supported slab-column connection with square or rectangular column, with or without opening near the column and with or without shear reinforcement under concentric punching load is proposed. By establishing the punching shear failure criteria with the assumption of rigid-plastic modified Coulomb's material as the plasticity model by Braestrup (1976), the plastic solutions are derived to predict the punching shear capacity of slab-column connection with square or rectangular column, with or without opening near the column and with or without shear reinforcement. The softening effect of concrete is also considered in plasticity model of this study. In the proposed plasticity model, recommendations are made on the effectiveness factor of concrete and effectiveness factor of tensile strength of shear stud reinforcement.

\subsection{Objectives and scope}

The first objective of this study is to investigate the behavior of slab-column connections with opening and shear stud reinforcement. To fulfill this objective, six interior rectangular slab-column specimens with openings and shear stud 
reinforcement were tested. There were two types of location of opening and four different arrangements of shear stud reinforcement in the specimens.

The second objective is to propose a plasticity model extended from Braestrup's plasticity model (1976). By using the extended plasticity model, the punching shear capacity of slab with square and rectangular columns, with opening near the column and with shear reinforcement can be predicted. The punching shear capacities of interior slab-column specimens collected from the literatures were predicted by the extended plasticity model.

\subsection{Organization}

Chapter one introduces the background, objective and scope of this study. Chapter two reviews the previous research works on slab-column connections.

Chapter three consists an experimental program for interior rectangular slab-column connections with opening near column and with shear stud reinforcement.

In chapter four, discussions on the experimental results from the experimental program described in chapter three are made.

Chapter five presents the plasticity model to predict the punching shear capacity of slab-column connection under concentric loading.

In chapter six, the results and discussions are made based on the comparisons of the punching shear capacity of slab-column connection predicted by plasticity model and the experimental results.

In chapter seven, summary and conclusion of this study are presented and future research works in the plasticity model are suggested.

Finally, three appendices; A, B and C, are presented. Appendix A is for the data from experimental program described in chapter three. It presents the applied loads to the 
slabs, deflections on the selected positions on the top and bottom of slabs measured by LVDTs (Linear variable transducer), and the strains occurred in the selected flexural reinforcements and all shear studs used in the slabs measured by strain gauges.

Appendix B is for the detail description of plasticity model proposed in chapter five. It presents the detailed derivation for punching shear capacity of slab-column connections under concentric punching load based on the theory of plasticity.

In appendix $\mathrm{C}$, the calculation program prepared by Matlab software to predict the punching shear capacity of square and rectangular slab-column connections with openings and with shear studs by the plasticity model proposed in chapter five is presented. 
CHAPTER 2 LITERATURE REVIEWS 


\section{Chapter 2}

\section{Literature reviews}

\subsection{Introduction}

The flat plate buildings become more widely used and more popular because of their advantages as previously described in chapter one. The vulnerability of the failure mode is brittle punching shear failure in the vicinity of slab-column connections of these buildings. This type of failure mode does not usually give the warning. It leads to a catastrophic damage. Unbalanced moment cannot be avoided in exterior and comer slab-column connections due to unsymmetrical geometry. When lateral loads due to wind or earthquake are present, there will also be unbalanced moment in interior slab-column connections.

The adequate shear strength against both shear force and unbalanced moment is needed in slab-column connections in the flat plate structures. The shear reinforcement can increase the punching shear capacity of slab-column connections to some extent. There are many methods to predict the punching shear capacity of slabcolumn connections which have been presented in the literature.

This chapter reviews the methods from previous research works to predict the punching shear capacity of slab-column connections. They are (1) plasticity models, (2) other analytical models, (3) experimental works related to slabs with openings, (4) experimental works related to shear reinforcement, and (5) methods specified by different codes.

\subsection{Plasticity models}

Some previous research works based on the theory of plasticity to obtain the upper bound solutions of the punching shear capacity for slab in the literature are reviewed. Generally, in the beginning plasticity models primarily use the modified Mohr- 
Coulomb failure criterion with straight line envelope (Braestrup, 1976). The concrete is assumed as perfectly plastic material. Later, modified Mohr-Coulomb failure criterion is modified to parabolic shaped failure criterion (Jiang and Shen, 1985). The collapse mechanism as shown in Figure 2.1 is considered that the portion confined by failure surface was punched out of slab and the remaining was rigid. Based on the related established failure criterion and collapse mechanism, the principal stresses and plastic strains on the yield surface are determined and so the dissipation energy is obtained. Finally, by using the virtual work principle and variational calculus, and the punching shear failure surface satisfies the most extreme condition, the upper bound punching shear capacity of slab under concentric punching load is achieved.

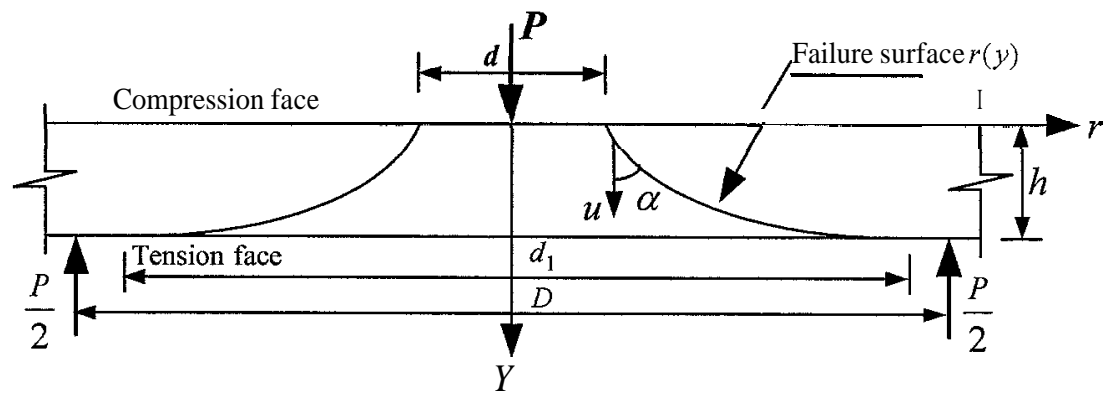

Figure 2.1 Collapse mechanism in punching shear failure of slab considered in plasticity models

\subsubsection{Plasticity model by Braestrup (1976)}

In 1976, Braestrup found a solution to predict the punching shear capacity of slabcolumn connections under concentric punching load by applying the theory of plasticity. The slab-column connection with circular column simply supported along the circular edge of slab was considered. A collapse mechanism due to punching failure was considered as shown in Figure 2.1. The effect of flexural reinforcement was neglected. The failure criterion including both the sliding and separation failure was established considering that concrete was the perfectly plastic material and shown in Figure 2.2. The failure criteria established by Braestrup was

Sliding failure:

$$
|\tau|=c-\mu \sigma
$$

Separation failure:

$$
\sigma=f_{A}
$$


where $\tau \quad=$ shear stress in the sliding surface

$\sigma \quad=$ normal stress in the separation surface

c $\quad=$ cohesion of concrete

$\mu \quad=$ tangent value of internal friction angle for concrete

$f_{A} \quad=$ separation resistance of concrete

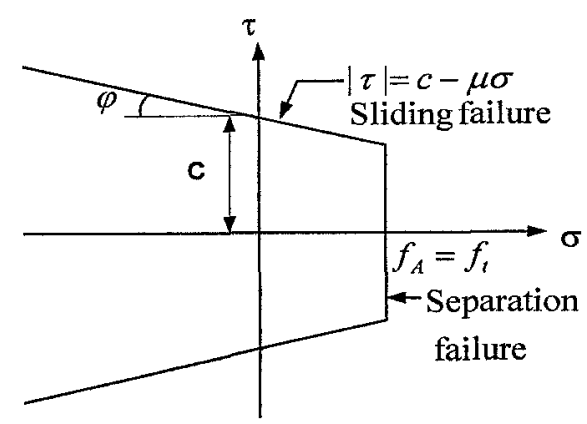

Figure 2.2 Modified Coulomb's failure criterion for concrete (Braestrup, 1976)

By applying the virtual work principle and calculus of variation, Braestrup derived the upper bound punching shear capacity of slab and its failure surface curvature in such a way that the external virtual work and the dissipation energy sustained in the failure surface considered were equalized and radius of failure surface satisfying the most extreme condition for punching shear capacity of slab was obtained. In this model, the slope of failure surface at the compression side of the slab was restricted not more than 37 degree of internal friction angle of concrete. When the slope of failure surface at the compression side of the slab was equal or greater than 37 degree, the shape of failure surface was assumed as cantenary curve. When the slope of failure surface at the compression side of the slab was less than 37 degree, the shape of failure surface was assumed as the combination of a straight line and a cantenary curve as shown in Figure 2.3.

For the slope of failure surface at the compression side of the slab was equal or greater than 37 degree, the punching shear capacity $\mathbf{P}$ was derived as

$$
P=\frac{\pi}{2} f_{c}^{\prime} L C h+L\left(\left(\frac{d_{1}}{2} \sqrt{\left(\frac{d_{1}}{2}\right)^{2}-C^{2}}-A B\right)-M\left(\left(\frac{d_{1}}{2}\right)^{2}-A^{2}\right)\right)
$$


For the slope of failure surface at the compression side of the slab was less than 37 degree, the punching shear capacity $\mathbf{P}$ was derived as

$$
\begin{aligned}
P= & \frac{\pi}{2} f_{c}^{\prime}\left(\left(\frac{\left(d \cos \varphi+h_{o} \sin \varphi\right)(1-\sin \varphi)}{\cos ^{2} \varphi}\right)\right. \\
& \left.+\left(L C\left(h-h_{o}\right)+L\left(\frac{d_{1}}{2} \sqrt{\left(\frac{d_{1}}{2}\right)^{2}-C^{2}}-A B\right)-M\left(\left(\frac{d_{1}}{2}\right)^{2}-A^{2}\right)\right)\right)
\end{aligned}
$$

where $f_{c}^{\prime} \quad=$ cylinder compressive strength of concrete

h $\quad=$ thickness of slab

$h_{0} \quad=$ vertical distance from the top of slab to intersection point of straight and curved failure surface shown in Figure 2.3

$A, B \& \mathrm{C}=$ constants related to punching shear failure surface

d $\quad=$ punch diameter or diameter of column

$d_{1} \quad=$ diameter of failure surface at the tension side of slab

$L \quad=1-2 \frac{f_{t}}{f_{c}^{\prime}} \frac{\sin \varphi}{1-\sin \varphi}$

$M \quad=1-2 \frac{f_{t}}{f_{c}^{\prime}} \frac{1}{1-\sin \varphi}$

$\varphi \quad=$ internal friction angle of concrete

$f_{t} \quad=$ tensile strength of concrete

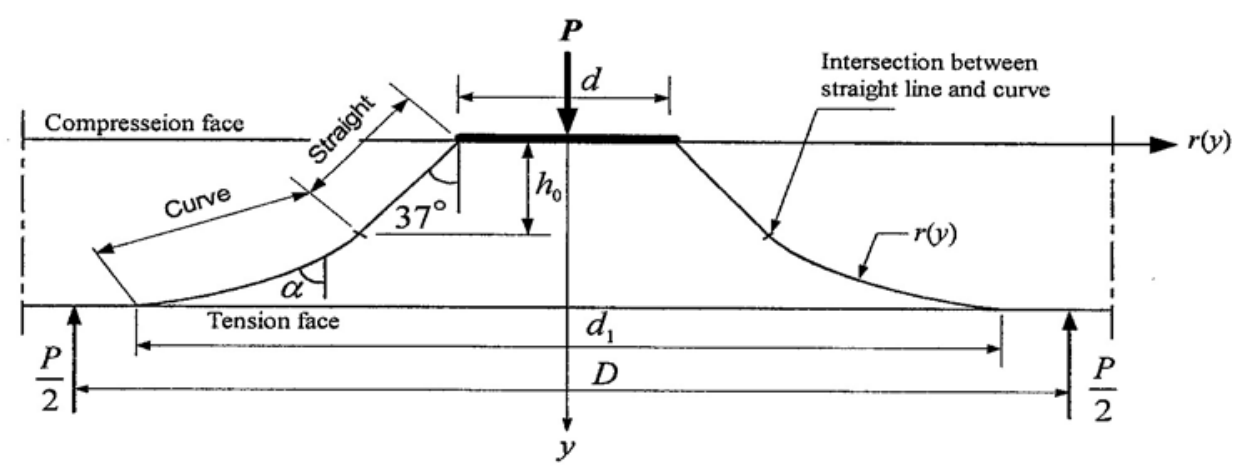

Figure 2.3 Failure surface of circular slab-column connection considered (Braestrup, 1976)

One of the most important factors on the plasticity model was the way to take into account the softening effect of concrete. The effectiveness factor $v_{c}$ on the compressive strength of concrete was considered as the softening effect of concrete. 
By applying this effectiveness factor, the plasticity model will give the optimum results on the punching shear capacity of simply supported slab-column connection with circular column under concentric loading with the tensile strength of concrete was considered zero. The effectiveness factor $v_{c}$ was considered as

$$
v_{c}=\frac{4.22}{\sqrt{f_{c}^{\prime}}}
$$

However, the optimum results on the punching shear capacity predicted by Breastrup's plasticity model (1976) using the above effectiveness factor was still large scatter. Sigurdsson in 1991 modified the effectiveness factor on the compressive strength of concrete by taking into account the scale effect and different flexural reinforcement ratios in two perpendicular directions. The modified effectiveness factor proposed by Sigurdsson was

$$
v_{c}=\frac{1.47}{\sqrt{f_{c}^{\prime}}}\left(1+\frac{0.48}{\sqrt{h}}\right)(1+0.125 r)<1
$$

where $r=\sqrt{r_{x} r_{y}}=$ flexural reinforcement ratio

$r_{x} \& r_{y}=$ flexural reinforcement ratio in $\mathrm{x}$ and $\mathrm{y}$ direction, respectively

$h \quad=$ slab thickness

\subsubsection{Plasticity model by Jiang and Shen (1986)}

In 1986, Jiang and Shen presented a solution for punching shear capacity of annularly supported concrete slab under circular punching load. In contrast to Braestrup's plasticity model, they considered that the punching shear failure might occur at the smaller punch angle or the initial slope of failure surface at the compression side of slab can be less than the internal friction angle of concrete. Therefore, they adopted a failure criterion for the concrete based on the second-degree parabola for the modified Coulomb's material as shown in Figure 2.4. By establishing the failure criterion based on second-degree parabola, the corresponding principal tensile and compressive stresses and related dissipation energy in the failure surface were determined. And, by applying virtual work principal and variational calculus, they derived the upper bound solution for the punching shear capacity of slab. The established failure criterion is: 


$$
\begin{aligned}
& \frac{\sigma_{n}}{f_{t}^{\prime}}+\frac{1}{K}\left(\frac{\tau_{n t}}{f_{c}^{\prime}}\right)^{2}=1 \\
& K=\frac{1}{4}[m+2(1-\sqrt{m+1})] \\
& m=\frac{f_{c}^{\prime}}{f_{t}^{\prime}}=\frac{v_{c} f_{c}}{v_{t} f_{t}}
\end{aligned}
$$

where $\sigma_{n} \& \tau_{n t}=$ normal and shear stress on the yield surface, respectively

$f_{c}^{\prime} \& f_{t}^{\prime}=$ effective compressive and tensile strength of concrete, respectively $f_{c} \& f_{t}=$ compressive and tensile strength of concrete measured from standard tests, respectively

$v_{c} \& v_{t}=$ factors on the compressive and tensile strength of concrete, respectively

And the upper bound solution of the punching shear capacity of slab derived as:

$$
P=\pi f_{t}^{\prime}\left(\frac{d_{1}^{2}}{4}-\frac{d^{2}}{4}+\frac{2 K h^{2}}{\ln d_{1}-\ln d}\right)
$$

where $\mathrm{d}=$ punch diameter or diameter of column

$d_{1} \quad=$ diameter of failure surface at the tension side of slab

$\mathrm{h} \quad=$ slab thickness

$\varphi \quad=$ internal friction angle of concrete

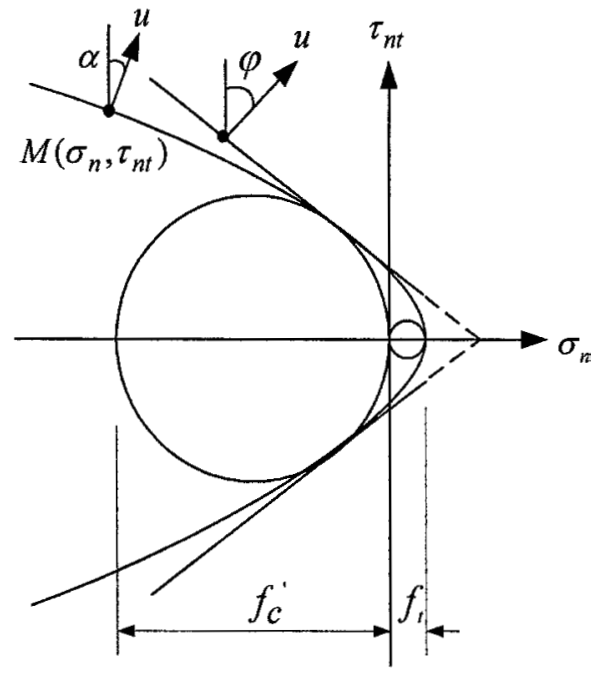

Figure 2.4 Parabolic Mohr failure criteria for concrete (Jiang and Shen, 1986) 


\subsubsection{Plasticity model by Bortolotti (1990)}

In 1990, Bortolotti proposed a theoretical solution for the punching shear strength of concrete slab by using theory of plasticity. The material was assumed rigid plastic. The Coulomb yield criterion for concrete was modified. The pure shear circle was considered as the intersection element between two failure modes: sliding and separation. In pure shear case, both sliding and separation might occur. In his pure tension and pure torsion tests, failure occurred by separation with shear failure surfaces normal to the first principal direction of stress. Based on this, he supposed that such failure involved at least all stress states. The separation failure condition was considered as $\sigma_{1}=f_{t}$ where $f_{t}$ was tensile strength of concrete, while beyond this circle and toward the compressions, the sliding failure was believed to occur. The modified Coulomb's yield criterion was expressed in normal and principal reference system as shown in Figure 2.5.

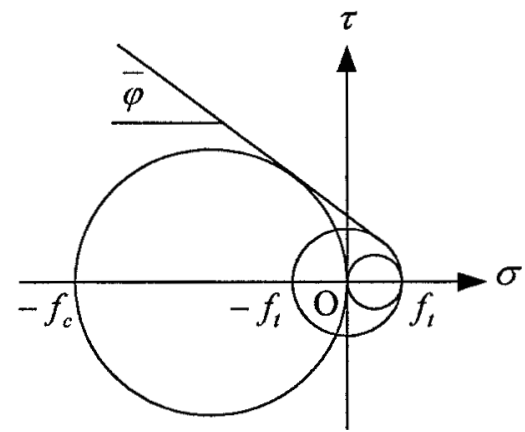

Figure 2.5 Modified failure criterion for concrete (Bortolotti, 1990)

$$
\begin{aligned}
& |\tau|+\sigma \tan \varphi-\frac{f_{t}}{\cos \bar{\varphi}}=0 \\
& \sigma_{1}(1+\sin \bar{\varphi})-\sigma_{3}(1-\sin \bar{\varphi})-2 f_{t}=0
\end{aligned}
$$

with the limitation $\quad \sigma_{1}=f_{t}$ for $-f_{t} \leq \sigma_{3} \leq f_{t}$

$$
\begin{aligned}
& f_{c}=\frac{2.6}{1-\sin \bar{\varphi}} \\
& f_{t}=f_{c} \frac{1-\sin \bar{\varphi}}{2} \\
& K=\frac{f_{t}}{f_{c}}=\frac{2}{1-\sin \bar{\varphi}}
\end{aligned}
$$


where $\sigma \& \tau=$ normal and shear stress, respectively

$\sigma_{1} \& \sigma_{3}=$ principal tensile and compressive stress, respectively

$f_{t} \& f_{c} \quad=$ tensile and cubic compressive strength of concrete, respectively

$\bar{\varphi} \quad=$ internal friction angle of concrete related to its compressive strength

He considered that the angle at each point of failure surface may be different from the internal friction angle $\bar{\varphi}$ because the plastic strains cause a softening effect in concrete. Due to this, the internal friction angle at each point of failure surface may change. Thus, he considered the effect of strain softening in compression and tension for the form of failure surface as shown in Figure 2.6. It could be seen that the instantaneous value of internal friction angle $\varphi$ along the failure surface might be lower than $\bar{\varphi}$ due to softening in compression and larger than $\bar{\varphi}$ due to tension softening. Based on above modified Coulomb's yield criterion accompanied by pure shear Mohr's circle and the effect of strain softening in compression and tension, failure criteria due to softening from compression and tension were considered as shown in Figures $2.7 \mathrm{a}$ and $2.7 \mathrm{~b}$, respectively.

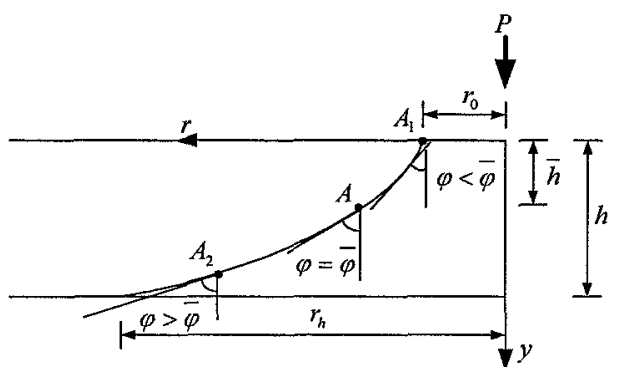

Figure 2.6 Proposed failure surface (Bortolotti, 1990)

If the stress value below the punch disk $\sigma_{p}$ was less than $f_{c}$, softening in tension only was considered. The punching shear capacity of slab was derived as

$$
\begin{aligned}
P= & \frac{\pi f_{c}}{2}\left(r_{h}^{2} \sqrt{1-\left(\frac{r_{0}}{r_{h}} \cos \bar{\varphi}\right)^{2}}-r_{0}^{2} \sin \bar{\varphi}\right. \\
& \left.+r_{0}^{2} \cos ^{2} \bar{\varphi} \ln \left(r_{h}\left(1+\sqrt{1-\left(\frac{r_{0}}{r_{h}} \cos \bar{\varphi}\right)^{2}}\right) / r_{0}(1+\sin \bar{\varphi})\right)-\left(r_{h}^{2}-r_{0}^{2}\right)\right)
\end{aligned}
$$


If the stress value below the punch disk $\sigma_{p}$ was greater than $f_{c}$, softening in both tension and compression was considered. The punching shear capacity of slab was obtained as

$$
\begin{aligned}
P= & \frac{\pi f_{c}}{2}\left(r_{h}^{2} \sqrt{1-\left(\frac{r_{0}}{r_{h}}\right)^{2}}+r_{0}^{2} \ln \left(\frac{r_{h}}{r_{0}}\left(1+\sqrt{1-\left(\frac{r_{0}}{r_{h}}\right)^{2}}\right)\right)\right. \\
& -\sin \bar{\varphi}\left(\bar{r}^{2} \sqrt{1-\left(\frac{r_{0}}{\bar{r}}\right)^{2}}+r_{0}^{2} \ln \left(\frac{\bar{r}}{r_{0}}\left(1+\sqrt{1-\left(\frac{r_{0}}{\bar{r}}\right)^{2}}\right)\right)-\left(r_{h}^{2}-\bar{r}^{2}\right)\right)
\end{aligned}
$$

where $\sigma_{p} \quad-\begin{gathered}k_{m} P_{0} \\ \pi d_{0}^{2} / 4\end{gathered}$ - stress below the punch disk

$P_{0} \quad=\pi h f_{t}\left(d_{0}+h\right)=$ theoretical punch load

$d_{0} \& r_{0}=$ punch disk diameter and radius, respectively

$k_{m} \quad=$ corrective load factor by Bortolotti (1990)

$\bar{r} \& r_{h}=$ radius of punch cone at depth $\bar{h}$ and h, respectively

$\mathrm{h} \quad=$ slab thickness

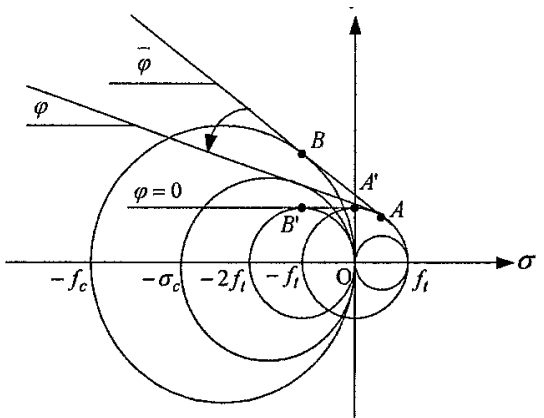

(a) Failure criterion due to softening in compression

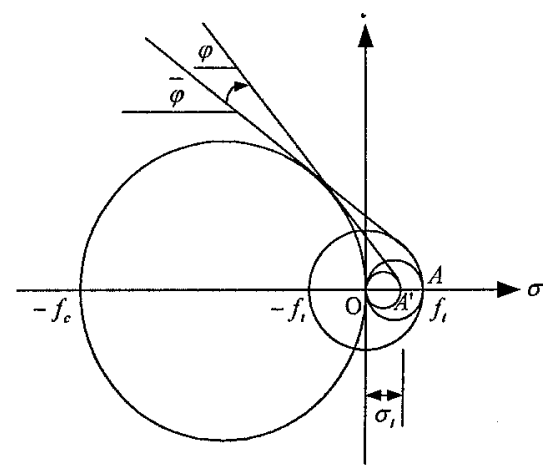

(b) Failure criterion due to softening in tension

Figure 2.7 Failure criterion (Bortolotti ,1990) 


\subsubsection{Plasticity model by Kuang and Morley (1992)}

In 1992, Kuang and Morley developed a plastically theoretical model for the punching shear failure of laterally restrained concrete slab. A parabolic Mohr failure criterion for concrete early shown in Figure 2.4 was used. The effect of compressive membrane forces was taken into account in their model by using a membranemodified flexural theory of elasto-plasticity. The failure mechanism including the effect of compressive membrane action was considered as a function of $r=r(y)$ as shown in Figure 2.8. The relative displacement $u$ was inclined at an angle $\beta$ to the vertical. In the internal virtual work, the contribution for the effect of compressive membrane forces was superimposed. By the aid of virtual work principle and variational calculus, the punching shear capacity of laterally restrained slab was achieved.

Parabolic Mohr failure criterion:

$$
\frac{\sigma}{f_{f}^{\prime}}+\left(\frac{\tau}{c_{k} f_{t}}\right)^{2}=1
$$

where $\tau \& \sigma=$ shear and normal stresses on an arbitrary plane, respectively

$f_{c} \& f_{i}=$ concrete uniaxial compressive and tensile strength, respectively

$c_{k} \quad=$ a parameter related to the ratio of compressive to tensile strength of

$$
\text { concrete }=\sqrt{1+\frac{f_{c}}{f_{t}}}-1
$$

External work,

$$
W_{E}=P u \cos \beta
$$

Internal virtual work,

$$
W_{A}=\int_{0}^{h} D_{A} 2 \pi r \sqrt{1+\left(r^{\prime}\right)^{2}} d y+N_{r s} u \sin \beta
$$

Then, the punching shear capacity of the slab was obtained as

$$
\begin{aligned}
P= & 2 \pi f_{t}\left(\frac{C_{1}^{2}}{2}\left(e^{2 C_{2} h}-1\right)-\frac{2 C_{1}}{C_{2}}\left(e^{C_{2} h}-1\right) \tan \beta+\frac{h}{C_{2}} \tan ^{2} \beta\right) \\
& +\pi f_{t} \frac{c_{k}^{2}}{2}\left(\frac{h}{C_{2}}+\frac{2 C_{1}}{C_{2}}\left(e^{C_{2} h}-1\right) \tan \beta+\frac{C_{1}^{2} \tan ^{2} \beta}{2}\left(e^{2 C_{2} h}-1\right)+\frac{\tan ^{4} \beta}{2 C_{2}^{2}}\right)+N_{r s} \tan \beta
\end{aligned}
$$


where $N_{r s} \quad=$ radial compressive membrane force

$C_{1} \& C_{2}=$ constants

$\mathrm{h} \quad=$ slab thickness

$f_{t} \quad=$ effective tensile strength of concrete

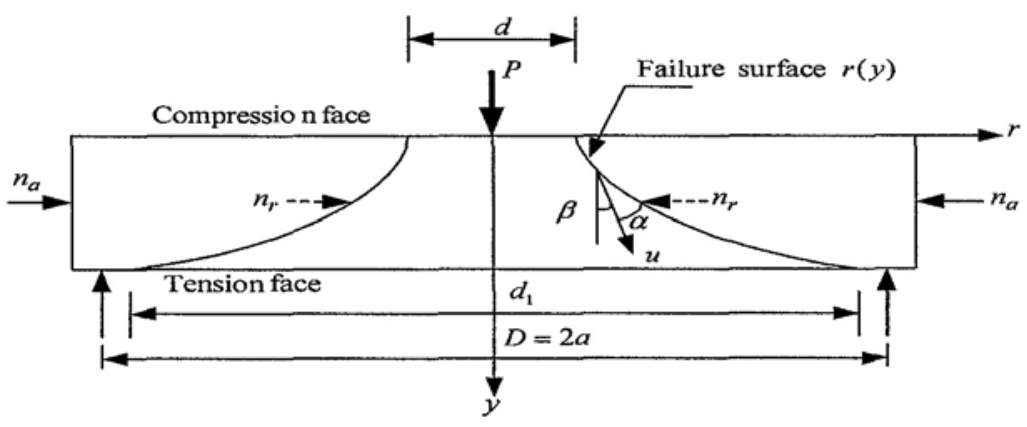

Figure 2.8 Failure mechanism of laterally restrained slab subjected to concentric punching load (Kuang and Morley, 1992)

The compressive membrane force $N_{r s}$ was determined by mean of membranemodified flexural theory of plasticity for compressive membrane action in circular reinforced concrete slabs, where an elasto-plastic analysis for arching action in restrained slabs had been developed by Braestrup and Morley in 1980. The elastoplastic restrained slab was treated by the flow theory, lumping the support stiffness and in-plane slab stiffness into a single boundary spring, and assuming membrane action to start an initial elastic deformation. A clamped circular slab with depth $\mathrm{h}$ and radius a was considered. When the concentrated load $\mathrm{P}$ was applied to the center of slab, a conical mechanism was assumed to develop with central deflection $w_{0}$, rotation $\theta$, and middle surface extension $\mathbf{A}$ as shown in Figure 2.9. Strain rates and stresses of yielding slab section were considered as shown in Figure 2.10. By using geometrical condition of compatibility, its corresponding kinematic condition, flow rule, and considering the horizontal equilibrium of the slab, the radial compressive membrane forces were derived.

$$
\begin{aligned}
& n_{a}=k \exp \left(\frac{w_{0}}{h \phi}\right)-\left(n_{0}+\frac{1}{4} \phi\right)+\frac{1}{4} \frac{w_{0}}{h} \\
& n_{r}=n_{a}+\frac{w_{0}}{2 h}\left(1-\frac{r}{a}\right) \\
& N_{r s}=2 \pi f_{c} \int_{0}^{h}\left(n_{a}+\frac{1}{2} \frac{w_{0}}{h}\left(1-\frac{r}{a}\right) r\right) d y
\end{aligned}
$$


where $\mathrm{k}$

$$
=\left(n_{0}+\frac{1}{4} \phi-\frac{1}{4} \frac{w_{i}}{h}\right) \exp \left(\frac{w_{i}}{h \phi}\right)
$$

$w_{i} \quad=$ initial deflection at which membrane action starts, taken empirically as $0.03 \mathrm{~h}$

$$
\begin{aligned}
n_{0} & =\frac{1}{h f_{c}}\left(\frac{1}{2} h f_{c}-A_{s h} f_{y}\right) \\
\phi & =\frac{a f_{c}}{2 h S}=\text { flexible factor } \\
\frac{1}{S} & =\frac{a R}{0.8 E_{c} A_{b}+E_{s} A_{s b}}+\frac{a}{E_{c} h}=\text { restraining stiffness } \\
\mathrm{R} & =\text { radius of edge beam } \\
E_{c} & =4730 \sqrt{f_{c}^{\prime}}=\text { elastic modulus of concrete } \\
f_{c}^{\prime} & =\text { cylinder compressive strength of concrete } \\
f_{c} & =0.85 f_{c}^{\prime}=\text { compressive strength of concrete } \\
\mathrm{E}_{\mathrm{s}} & =\text { elastic modulus of steel }
\end{aligned}
$$

$A_{b} \& A_{s b}=$ the sectional areas of restraining ring beam and reinforcement, respectively

$\mathrm{A}_{\mathrm{sh}} \quad=$ sectional area of steel reinforcement per unit length

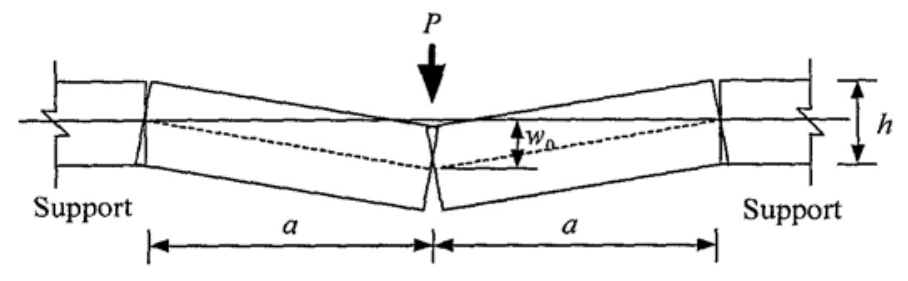

(a) Conical failure mechanism

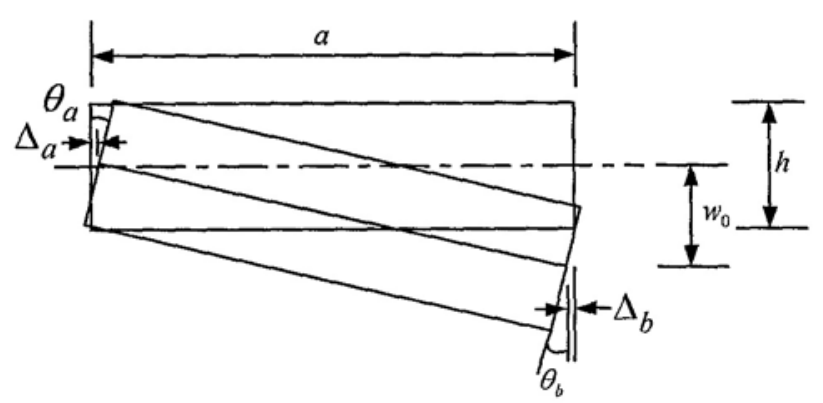

(b) Deformation of radial segment of slab

Figure 2.9 Conical failure mechanism for centrally loaded restrained circular slab (Kuang and Morley, 1992) 


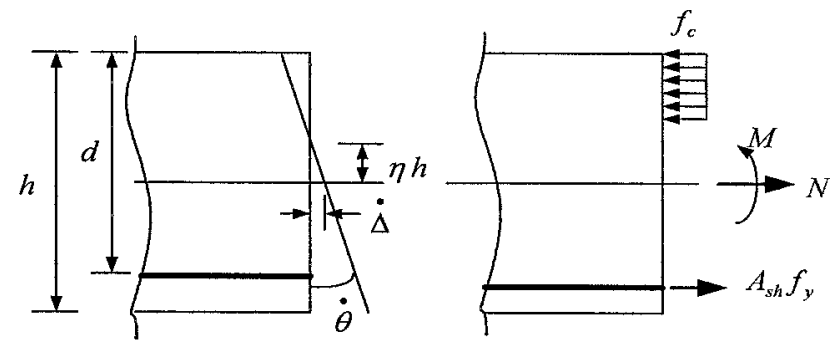

Figure 2.10 Strain rates and stresses of yielding slab section

(Kuang and Morley, 1992)

Finally, the plasticity model by Kuang and Morley gave the punching shear capacity of laterally restrained reinforced slabs in good agreement with a wide range of experimental results when they use Equation 2.7 as the plastic effectiveness factor for compressive strength and the tensile strength of concrete is equal to $1 \%$ of effective concrete compressive strength.

\subsubsection{Plasticity model by Yankelevsky and Leibowitz (1996)}

In 1996, Yankelevsky and Leibowitz proposed a model that predicted (1) the punching shear capacity of simply supported circular slab-column connections, (2) shear and normal stresses along the punching cracked surface and their distribution, (3) variation of these stresses with the axial displacement, and (4) variation of resisting force as a function of the increasing vertical displacement of slab. This proposed model was based on the theory of plasticity and rigid post-fracture behavior, utilizing the post-fracture properties of concrete at rough crack interfaces that was developed.

They considered an axi-symmetric slab simply supported along its circumference with an axi-symmetric circular column which was subjected to an axial force. The final failure stage of the slab-column system was considered as the resistance at this stage was concentrated along the failure surface. The assumptions used in their model were:

(1) A single cracked surface was already in the slab. The cracked surface was continuous and started along the column circumference. The surface geometry was presented by the function $r(y)$ as shown in Figure 2.11. 
(2) Concrete was ideally rigid and the cracked surface subdivided the slab into rigid bodies, the punched wedge and the outer slab.

(3) The contribution of reinforcement was disregarded.

(4) The deformation and the accompanied resistance were concentrated along the cracked surface.

(5) The cracked failure was rough and a mechanism of aggregate interlock was developed.

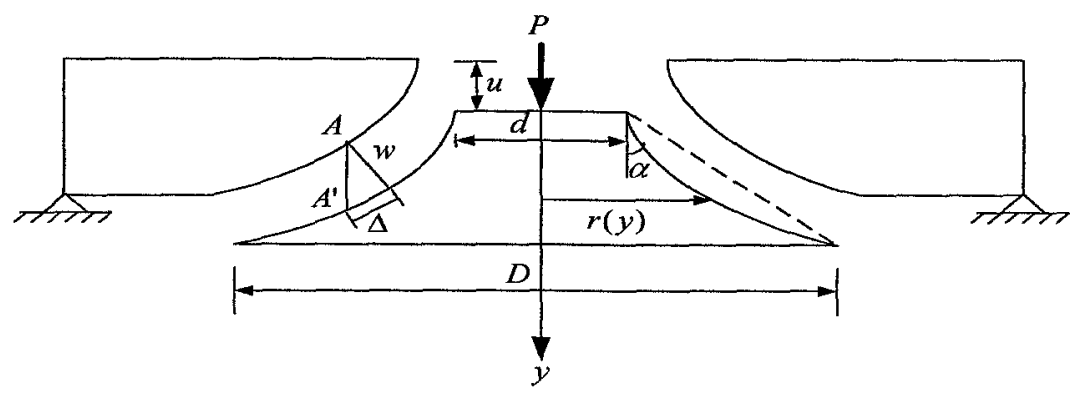

(a) Kinematics of punched slab

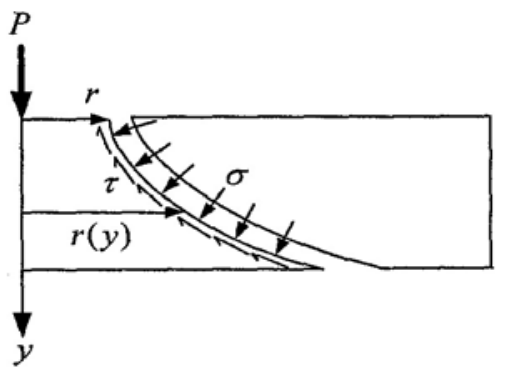

(b) Shear and normal stress along the cracked surface

Figure 2.11 Final failure stage of punched slab

(Yankelevsky and Leibowitz, 1996)

Based on the test data which had been presented by Reinhardt and Walraven in 1981, these shear and compressive stresses along the cracked surface due to aggregate interlocking developed at the final failure stage and resisted the punching, were empirically expressed as

$$
\begin{array}{rrr}
\tau & =\frac{b}{1+2 a} w^{-1.35} \Delta, & 0 \leq \tau \leq 0.5 \mathrm{~N} \mathrm{~mm}^{-2} \\
\tau=-a+b w^{-1.35} \Delta, & 0.5 \leq \tau \leq 10.0 \mathrm{~N} \mathrm{~mm}^{-2}
\end{array}
$$




$$
\begin{array}{ll}
\sigma=-0.5+\frac{A(\Delta+0.05)}{(0.5+A) w+0.05 B^{\prime}} & 0 \leq \sigma \leq 0.5 \mathrm{~N} \mathrm{~mm}^{-2} \\
\sigma=-A+B w^{-1.0} \Delta & 0.5 \leq \sigma \leq 10.0 \mathrm{~N} \mathrm{~mm}^{-2}
\end{array}
$$

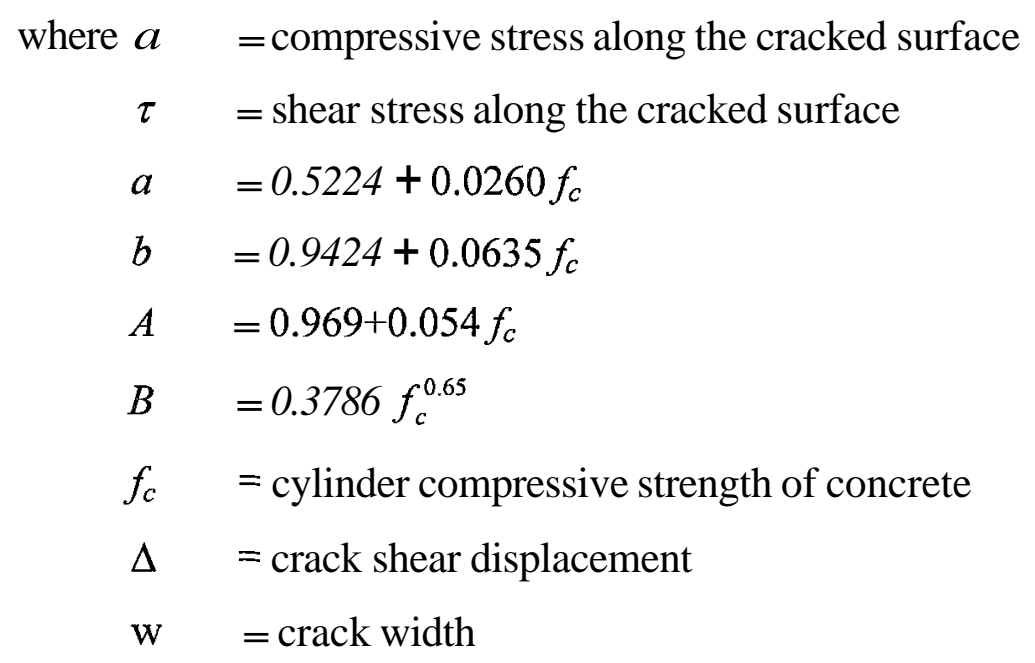

In the above expressions, the crack shear displacement $\Delta$ was less than $2 \mathrm{~mm}$ and the crack width was narrower than $2 \mathrm{~mm}$ and wider than $0.03 \mathrm{~mm}$. The punching shear capacity of slab was derived by summing up the contributions in resistance to punching of shear and compressive stresses along the cracked surface.

$$
P=2 \pi \int\left(\tau-\sigma r^{\prime}\right) r(y) d y
$$

where $\mathrm{P}=$ punching shear capacity of simply supported circular slab-column connections

$r^{\prime}=$ tangent value of radius of failure surface

\subsubsection{Plasticity model by Salim and Sebastian (2002)}

In 2002, Salim and Sebastian developed the way to predict the punching shear capacity of slabs without shear reinforcement and without in-plane restraint by employing the upper bound theory of plasticity. To take into account the variation in the angle of friction of concrete with related stress state, they adopted the parabolic Mohr failure criterion with the material being assumed rigid-perfectively plastic as previously shown in Figure 2.4 from plasticity model by Jiang and Shen (1986).

Based on the parabolic Mohr failure criterion and assumed failure mechanism, they 
established dissipation energy sustained in the failure surface. By using virtual work principle and variational calculus, the upper bound solution of slab for punching load was obtained as:

$$
P=\frac{\pi}{4} f_{t}\left(d_{1}^{2}-d^{2}+\frac{2 c_{k}^{2} h^{2}}{\ln \left(d_{1} / d\right)}\right)
$$

where $c_{k}=$ a parameter related to the ratio of compressive to tensile strength of concrete $=\sqrt{1+\frac{f_{c}}{f_{t}}}-1$

$f_{c} \quad=$ uniaxial compressivecylinder strength of concrete

$f_{t} \quad=$ uniaxial tensile cylinder strength of concrete

$d \quad=$ punch diameter or diameter of column

$d_{1}=$ diameter of failure surface at the tension side of slab

$h \quad=$ thickness of slab

Moreover, they showed that the Sigurdsson's effectiveness factor $v_{c}$ as in Equation 2.8 for the softening effect on the compressive strength of concrete and the ratio of effective compressive strength and tensile of concrete taking equal to 400 as the effectiveness factor for the softening effect on the tensile strength of concrete gave the punching shear capacity of slab predicted by plasticity model in good agreement with the test.

\subsubsection{Summary, comparison and discussion}

In order to get better understanding regarding to the plasticity models described above, a comparison between the previous plasticity models is prepared in a table as shown in Table 2.1. And, the summary, comparison and discussion on these plasticity models are summarized.

For simply supported circular slab-column connections under concentric punching load, the upper bound punching shear capacity using theory of plasticity have been developed by Braestrup (1976). The concrete is assumed as perfectly plastic material. 
And then, the punching shear failure is considered that it is a curve shape failure surface and a combined failure mode of sliding and separation failure based on the observation from the experiments. In order to derive the plastic strains at yield surface, Mob-Coulomb failure criterion with straight line envelope is established. Then, a reasonable collapse mechanism generated due to the concentric load during punching shear failure is assumed that the portion confined by failure surface is punched out of slab and the remaining is rigid. Based on the related established failure criterion and assumed collapse mechanism, the principal stresses and plastic strains on the yield surface are determined and so the dissipation energy is derived. In this case, the plastic strains are limited at the apex on the yield surface so that both sliding and separation failure are included. Finally, by using the virtual work principle and variational calculus, and the punching shear failure surface satisfies the most extreme condition, the upper bound punching shear capacity of slab under concentric punching load is achieved.

However, the Braestrup's plasticity model was valid to predict the punching shear capacity of slab only when the slope of failure surface at the compression face was equal or greater than 37 degree. Due to this, Mohr-Coulomb failure criterion was modified to parabolic shaped failure criterion by Jiang and Shen (1986). The benefit obtained from the modification of parabolic shape failure criterion by Jiang and Shen is that the plasticity model could predict the punching shear capacity of slab for such case that the initial slope of failure surface at the compression face was less than 37 degree.

Furthermore, due to the fact that the accuracy of prediction on the punching shear capacity by plasticity model depend on the consideration of softening effect which is taken into account on the compressive and tensile strength of concrete. Accordingly, based on the consideration that the failure surface generatrix can visualize the softening effect of concrete as shown in Figure 2.6, the modified Mohr's Coulomb failure criterion was modified by taking into account the softening effect on the failure criterion using the pure shear case, which can hold sliding failure as well as separation based on the experiment, by Bortolotti (1990). In his modification to the failure criteria, he used the instantaneous tensile strength, which was the decreased tensile strength due to softening effect of concrete, and the instantaneous compressive 
strength, which was the decreased compressive strength due to softening effect of concrete. The instantaneous angle of internal friction may increase from that equal to the internal friction angle of concrete to 90 degree as the tensile strength decreases due to the softening of concrete while the instantaneous angle of internal friction may decrease from that equal to the internal friction angle of concrete to zero as the compressive strength decreases due to softening effect of concrete. His established failure criterion including softening effect of concrete can be seen in Figures 2.7a and 2.7b. These figures are combined into the same figure as shown in Table 2.1 so that it can be seen clearly the softening effect of concrete on the compressive and tensile strength.

Due to the fact that when the slab is laterally restrained, the punching shear capacity of the slab can be enhanced by the membrane forces produced by restrained action, a plastic theoretical model for the punching shear failure of laterally restrained concrete slab was developed by Kuang and Morley (1992). A parabolic Mohr failure criterion for concrete shown in Figure 2.4 was used. The effect of compressive membrane forces was taken into account in their model by using a membrane-modified flexural theory of elasto-plasticity. The effectiveness factors used in their model for the softening effect of concrete on the compressive and tensile strength of concrete can be seen in Table 2.1 .

In the previous models, the principal tensile and compressive stresses on the yield surface are derived by mean of the plastic strain based on the established failure criterion. However, these models did not consider the aggregate interlocking in the crack interface. Therefore, in 1996, Yankelevsky and Leibowitz proposed a plasticity model to predict the punching shear capacity of the slab based on consideration that the shear and compressive stresses along the cracked surface due to aggregate interlocking developed at the final failure stage and these stress resisted the punching. This proposed model was based on the rigid post-fracture behavior, utilizing the postfracture properties of concrete at rough crack interfaces that was developed. Based on the test data which had been presented by Reinhardt and Walraven in 1981, the shear and normal stress were empirically derived. However, in their model, the softening effect of concrete is not considered. 
In 2002, Salim and Sebastian developed a plasticity model to predict the punching shear capacity of slabs without shear reinforcement and without in-plane restraint. To take into account the variation in the angle of friction of concrete with related stress state, they adopted the parabolic Mohr failure criterion with the material being assumed rigid-perfectively plastic. Based on the parabolic Mohr failure criterion and assumed failure mechanism, they established dissipation energy sustained in the failure surface. By using virtual work principle and variational calculus, the upper bound solution of slab for punching load was obtained. Moreover, they showed that the Sigurdsson's effectiveness factor $v_{c}$ as in Equation 2.8 for the softening effect on the compressive strength of concrete and the ratio of effective compressive strength and tensile of concrete taken equal to 400 as the effectiveness factor for the softening effect on the tensile strength of concrete gave the punching shear capacity of slab predicted by plasticity model in good agreement with the test.

However, all plasticity models previously developed could cover only to predict the punching shear strength of slab-column connections with circular column shape. In addition, they did not consider the punching shear strength of slab-column connections when the slab has rectangular column shape, opening and shear reinforcement. Thus, there are needs to propose the plasticity model to be able to predict the punching shear capacity of slab-column connections when the slab has square or rectangular column, opening, and shear reinforcement. 


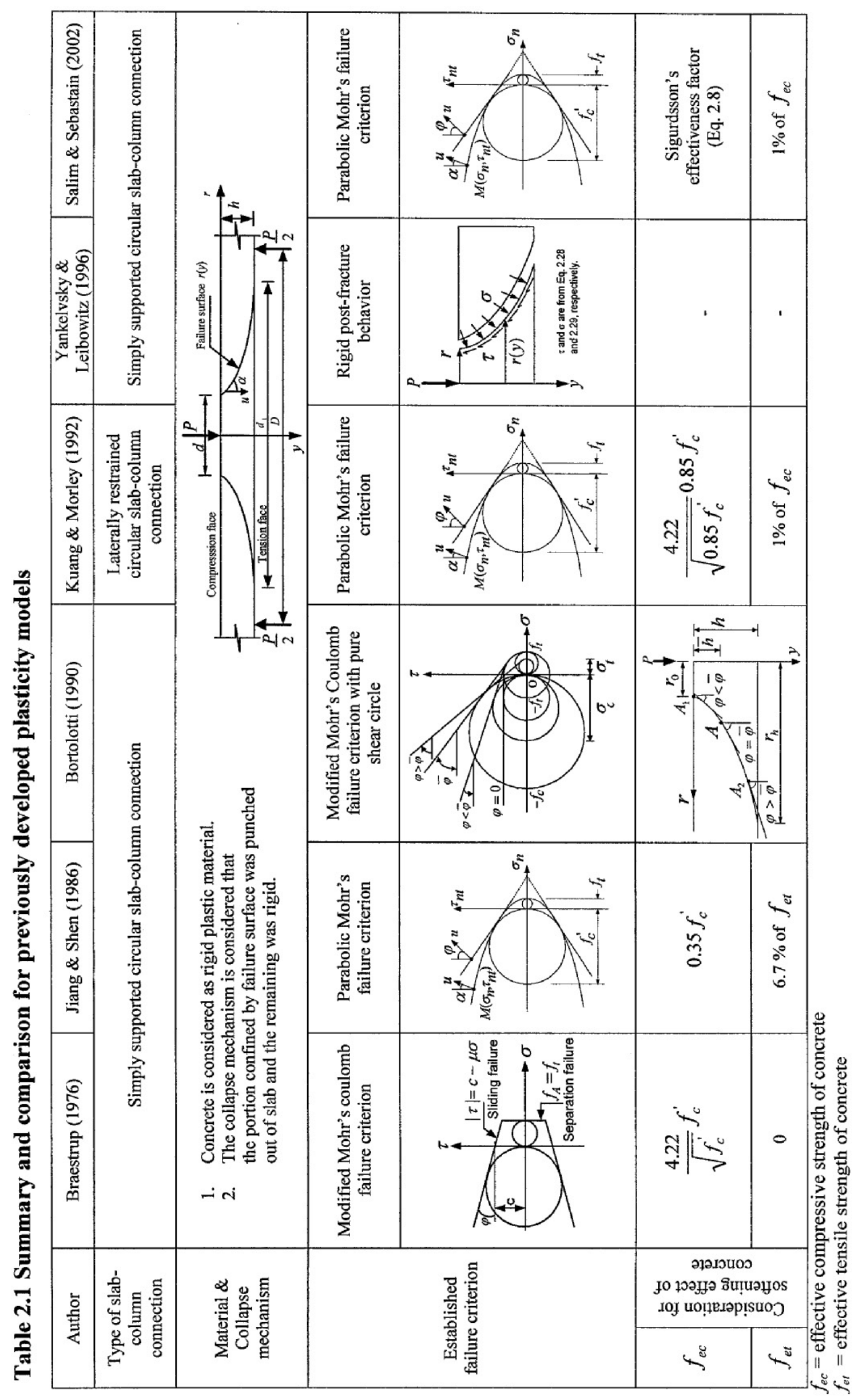




\subsection{Other analytical models}

\subsubsection{Mechanical model by Kinnunen and Nylander (1960)}

In 1960, Kinnunen and Nylander proposed a mechanical model to explain the punching shear phenomenon and to predict the failure load. A polar symmetrical slab supported on a column was used. Shear reinforcements were not included. In this model the assumptions were (1) the portion of slab outside of the failure shear cracks rotated as a rigid body; (2) the slab portion outside shear cracks was carried by a compressed conical shell which developed from the column to the root of the shear cracks; and (3) at the time that tangential concrete strains at the bottom surface of the slab reached a critical value, the failure was assumed to occur.

The equations to calculate the punching shear strength of slabs were derived by considering static vertical equilibrium and moment equilibrium on the forces acting on a segmental part of the slab, which was outside of failure shear cracks and between the radial cracks. The forces acting on the segmental part of the slab were shown in Figure 2.12.

\subsubsection{Truss model by Alexander and Simmonds (1987)}

In 1987, Alexander and Simmonds proposed the three-dimensional truss model to determine the ultimate strength of slab-column connections without shear reinforcement as shown in Figure 2.13. In this model, the flows of forces within the connection that is consistent with known cracking are described and the contribution of flexural steel to punching strength is accounted. The reliability of this model was evaluated by predicting the ultimate capacities and failure modes of 43 slab-column connections without shear reinforcement reported in the literature. This model can predict the ultimate capacity of slab-column connections under combination of shear and moment transferred. 


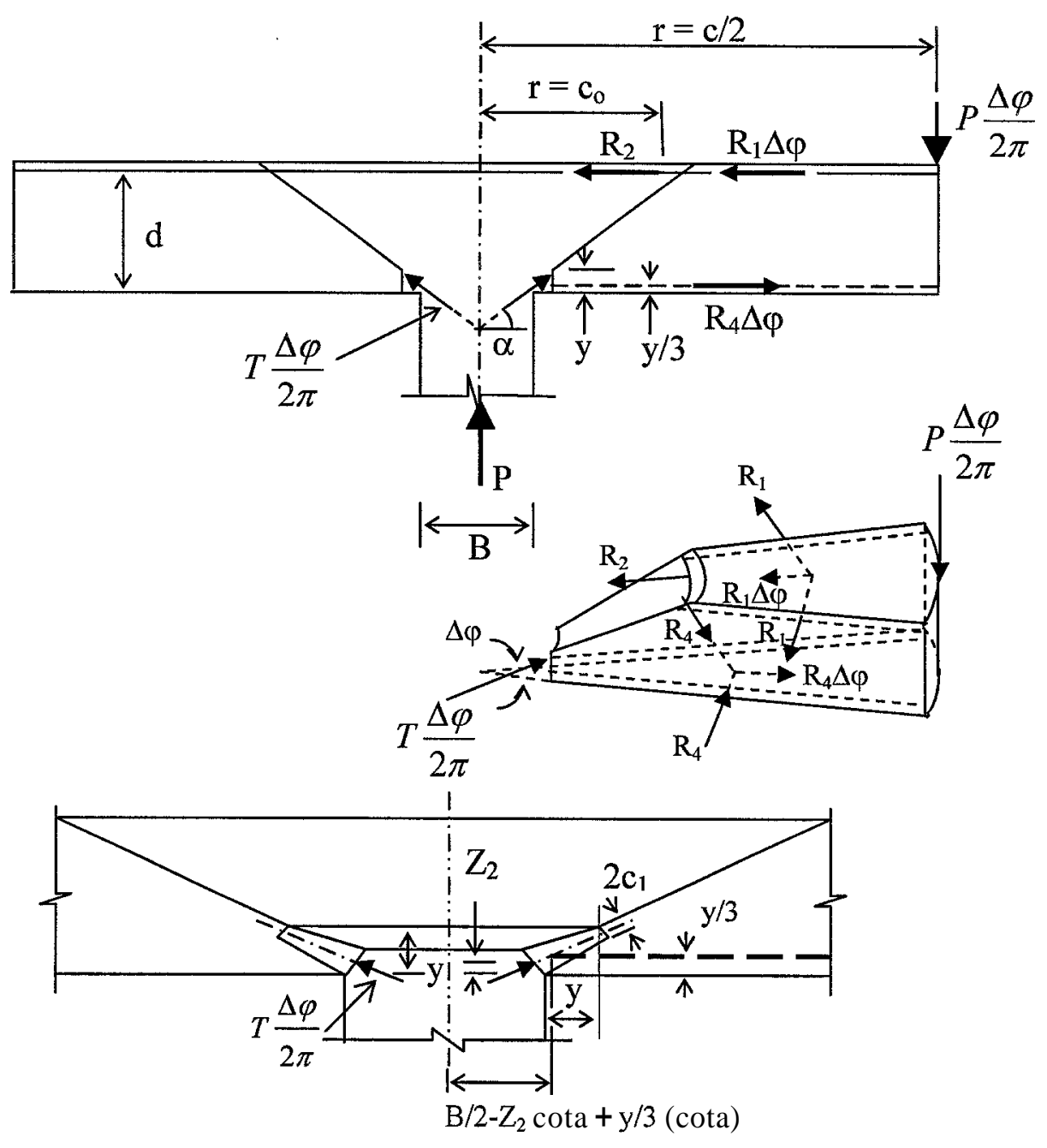

Figure 2.12 Mechanical model (Kinnunen and Nylander, 1960)

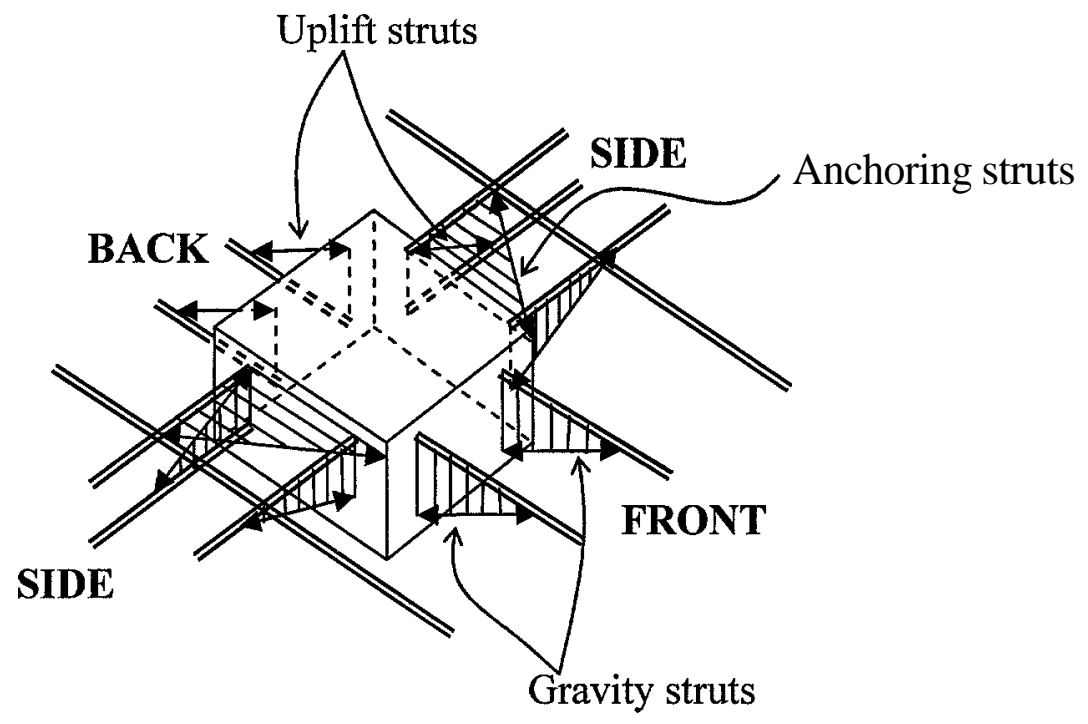

Figure 2.13 Truss model for interior slab-column connection (Alexander and Simmonds, 1987) 
By using this model, the shear moment interaction diagram is drawn to calculate the shearing capacity of the slab connection. On the shear moment interaction diagram, the point corresponding to the observed value of shear and moment at failure is plotted and connected to the origin by the straight line. The predicted failure values of shear and moment are obtained by taking the intersection point where this line meets with the interaction diagram.

\subsubsection{Mechanical model by Menétrey (1996)}

In 1996, Menétrey proposed a mechanical model to calculate the punching strength of the reinforced concrete slabs. The numerical simulations were based on finite element method. The results obtained from numerical simulation of the failure mechanism indicate that the punching strength can be computed by integrating the vertical tensile stresses around the punching crack shown in Figure 2.14. The vertical tensile stresses are assumed to be constant. The punching crack is assumed to be truncated cone in shape. His model takes into account the geometry of slab and support, concrete strength, percentage of flexural reinforcement, size effect, radius of punching crack initiation, contribution from the dowel effect, and the influence of stirrups, shear heads, and prestressing tendons. The punching strength of a general slab is expressed as summation of all the vertical tensile strength components crossing the punching cracks as follows:

$$
V_{p u n}=V_{c}+V_{d o w}+V_{s t i}+V_{p r t}
$$

where $V_{\text {pun }} \quad=$ punching strength of a general slab

$V_{c} \quad=$ concrete strength

$V_{\text {dow }}=$ resistance dowel force due to the horizontal reinforcement

$V_{p r t}=$ vertical projection of the tendon's strength

The dowel force of the horizontal reinforcement is derived as the following,

$$
V_{\text {dow }}=\frac{1}{2} \sum^{\text {bars }} \phi_{s}^{2} \sqrt{f_{c} f_{s}\left(1-\xi^{2}\right)} \sin \alpha
$$

where $\phi_{s}=$ diameter of corresponding bars

$f_{c} \quad=$ concrete cylinder compressive strength

$f_{s} \quad=$ steel yield strength 


$$
\begin{array}{ll}
\xi & =\sigma_{\mathrm{s}} / f_{s} \\
\sigma_{\mathrm{s}} & =\text { axial tensile stress in the reinforcing bars } \\
a & =\text { inclination of punching crack with horizontal }
\end{array}
$$

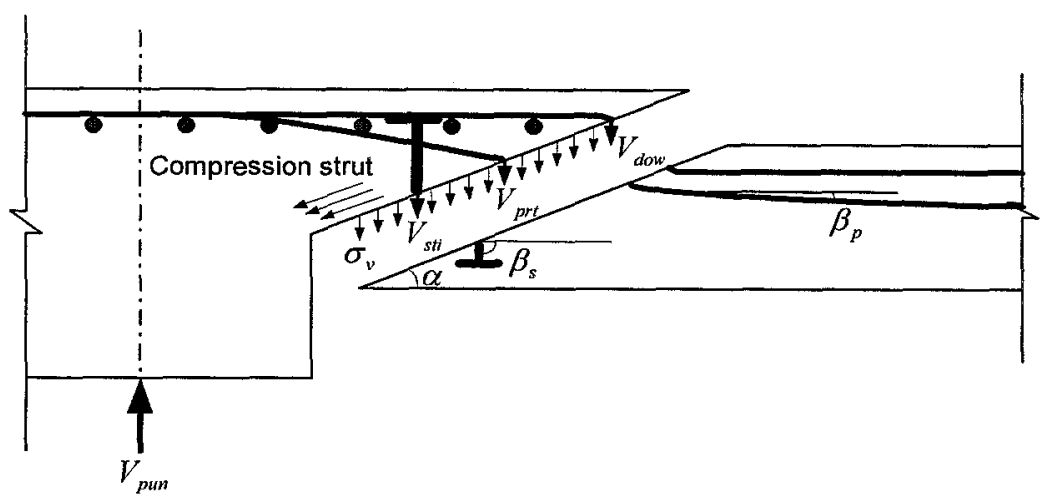

Figure 2.14 Components of forces contributing to the punching strength (Menétrey ,1996)

The effect of shear reinforcement contributed by stirrups and shear heads is calculated by the following equation,

$$
V_{s t i}=\frac{1}{2} \sum^{\text {stirrups }} A_{s w} f_{s} \sin \beta_{s}
$$

where $A_{s w} \quad=$ cross-sectionalarea of one stirrup

$\beta_{s} \quad=$ inclination of the stirrups with the plane of the slab

The vertical projection of the tendon strength is expressed as,

$$
V_{p r t}=\sum^{\text {tendons }} A_{p} f_{p} \sin \beta_{p}
$$

where $A_{p} \quad=$ area of the prestressingtendons

$f_{p} \quad=$ tensile strength of prestressing steel

$\beta_{p} \quad=$ inclination of the tendons at the intersection of the punching crack with the plane of the slab

This model shows that the predictions give great consistency with the experimental results. However, the assumption that the vertical tensile stress is uniformly distributed on the failure surface causes doubts because the inclination of the punching crack is curved. 


\subsection{Previous experimental works related to slabs with openings}

\subsubsection{Study by Di Stasio and Buren (1960)}

In 1960, Di Stasio and Van Buren presented a method to calculate the maximum unit shearing stresses, measuring both diagonal tension and punching shear, due to combined gravity load and bending in flat plate floor slabs about interior columns. First, they considered that the critical section for diagonal tension was along the perimeter at a distance (t-1\%) inch from the column face, where $t$ is slab thickness. Second, at the critical section for diagonal tension, the unbalanced moment, eccentric vertical load and torsional moment were considered to contribute the total moment at the slab-column connection. The loading condition, critical perimeter and distribution of shear stresses for interior slab-column connections are shown in Figure 2.15. Finally, by taking equilibrium of moments at the slab-column connection, the maximum shear stress at the extreme fiber of the critical section was obtained as follows.

$$
v_{2}=\frac{8 t}{7 d}\left(\frac{V_{u}}{A}+\frac{\left(M_{u}-\left(M_{1}+m\right)-\left(M_{2}-m\right)\right)}{J_{c}} x_{2}\right)
$$

When the unit shear stresses have the low permissible values in flat plate construction, considerable additional resistance can be developed through the dowel action of reinforcing bars crossing the section, and it may be reasonable to increase the assumed area of critical section and property of assume critical section by the factor $1+(\mathrm{n}-1) \rho$. On this basis,

$$
\begin{aligned}
& A=A_{c}[1+(\mathrm{n}-1) \rho] \\
& J=J_{c}[1+(\mathrm{n}-1) \rho]
\end{aligned}
$$

where $A \quad=$ effective area of peripheral section

$$
\begin{aligned}
A_{c} & = \\
J & =\text { assumed area of critical section } \\
& \text { moment of inertia }
\end{aligned}
$$

$M, M_{1}, \& M_{2}=$ maximum working stress design resisting moments over the width

$M_{u} \quad=$ unbalanced moment at center of column 


$\begin{array}{ll}V_{u} & =\text { total shear force around the critical section } \\ \boldsymbol{d} & =\text { effective depth of slab } \\ e & \text { distance of centroid of critical section from the center of } \\ & \text { column } \\ = & \text { residual balanced floor moments on width of critical section } \\ m & =\text { modular ratio } \\ \mathrm{n} & =\text { distances from centroid of critical section to extreme fibers } \\ x_{1} \& x_{2} & =\text { percentage of total (top and bottom) slab steel crossing the } \\ \rho & \end{array}$
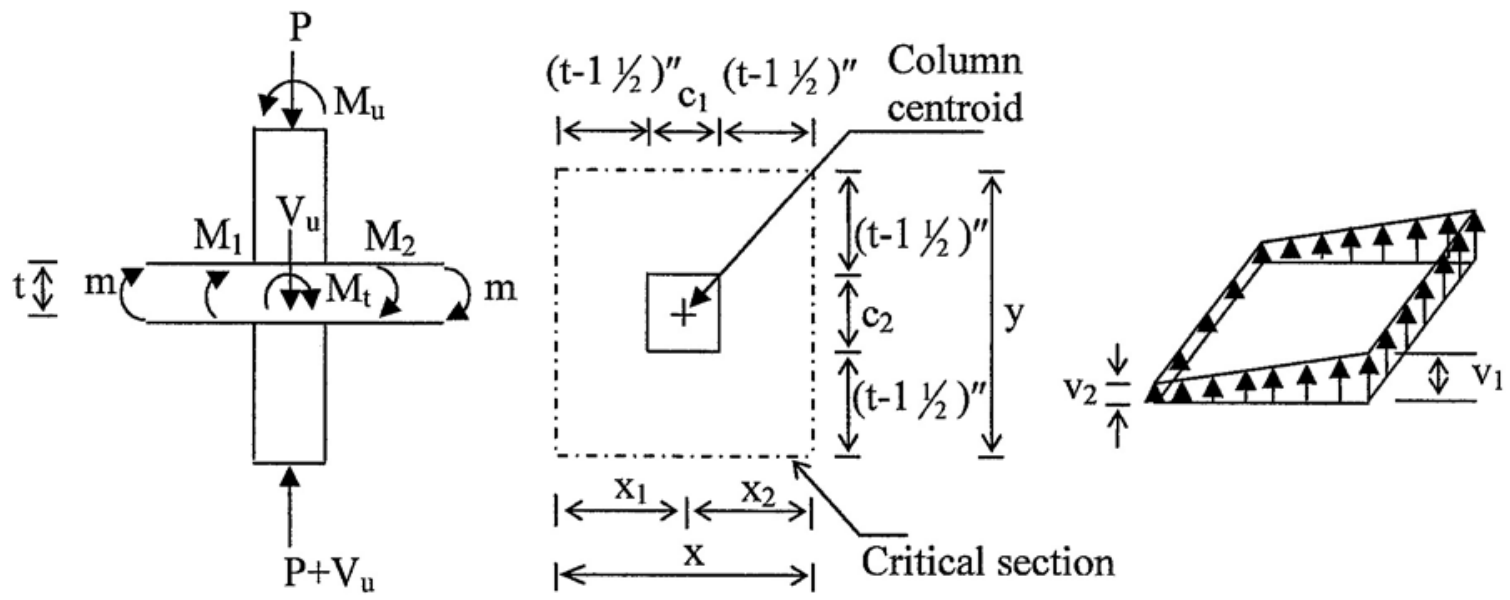

(a) Loading condition

(b) Critical perimeter

(c) Combined shear stress distribution

Figure 2.15 Interior slab-column connection (Di Stasio and Van Buren, 1960)

Furthermore, they also made a provision for the effect of openings in the vicinity of column. They provided two cases. First, any opening or series of openings of total width $\Sigma \mathrm{w}$ at the distance $\mathrm{x}$ (less than $\Sigma \mathrm{w} / 2$ ) outside an edge of the critical section, should be considered to reduce the effective length of that edge by an amount $\mathrm{O}_{1}=$ $\Sigma w-2 x$. Second, for opening extending inside the critical section, any point on the periphery at $\mathrm{t}-1 \frac{1}{2}$ in from the column face, which can not be connected by a straight line not crossing the opening with a point on the long axis of the column within a distance $\left(C_{2}-C_{1}\right) / 2$ from the column centroid, where $\mathrm{C}_{1}$ and $\mathrm{C}_{2}$, and $\mathrm{t}$ are shorter and longer column width, and slab thickness, respectively, should be excluded from the effective critical shear section. It can be seen in Figure 2.16. 


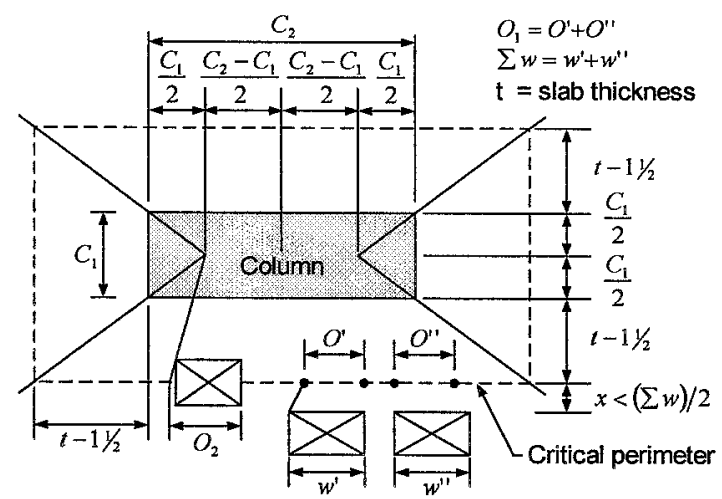

Figure 2.16 Opening in slab adjacent to column (Di Stasio and Buren, 1960)

\subsubsection{Study by Moe (1961)}

In 1961, Moe reported an investigation of shearing strength in slabs and used 15 specimens to study the effect of openings. One specimen was without opening. The remaining specimens were with openings of different pattern adjacent to the column. Pattern of holes in test specimens and details of test specimen are shown in Figure 2.17. All specimens had 10x10x10 in column stubs and 6 in thickness. The specimens were supported along four edges by a steel frame. The concentrated load was applied to the specimens from the top of column stubs. The main variables were number, size, and position of holes in the slabs. The equation of ultimate shear strength for slabs was developed as

$$
\frac{v}{\sqrt{f_{c}^{\prime}}}=\frac{V}{b d \sqrt{f_{c}^{\prime}}}=\frac{15\left(1-0.075 \frac{r}{d}\right)}{1+5.25 \frac{b d \sqrt{f_{c}^{\prime}}}{V_{\text {flex }}}}
$$

where $b \quad=$ width of critical section in shear

(1) For square openings adjacent to the column, b was taken as total periphery minus the sum of the width of the holes, measured along the periphery.

(2) For circular openings adjacent to the column, b was measured along the lines connecting the comers of the column to the periphery of the openings.

(3) When openings were placed at some distance from the column, b was measured along the straight lines from the comers of the 
column stubs to the nearest points on the periphery of the openings.

$d \quad=$ effective depth of slabs

$f_{c}{ }^{\prime}=$ concrete cylinder strength in compression

$r \quad=$ side length of loaded area of square shape

$V_{f l e x}=$ shear force at which flexure failure takes place
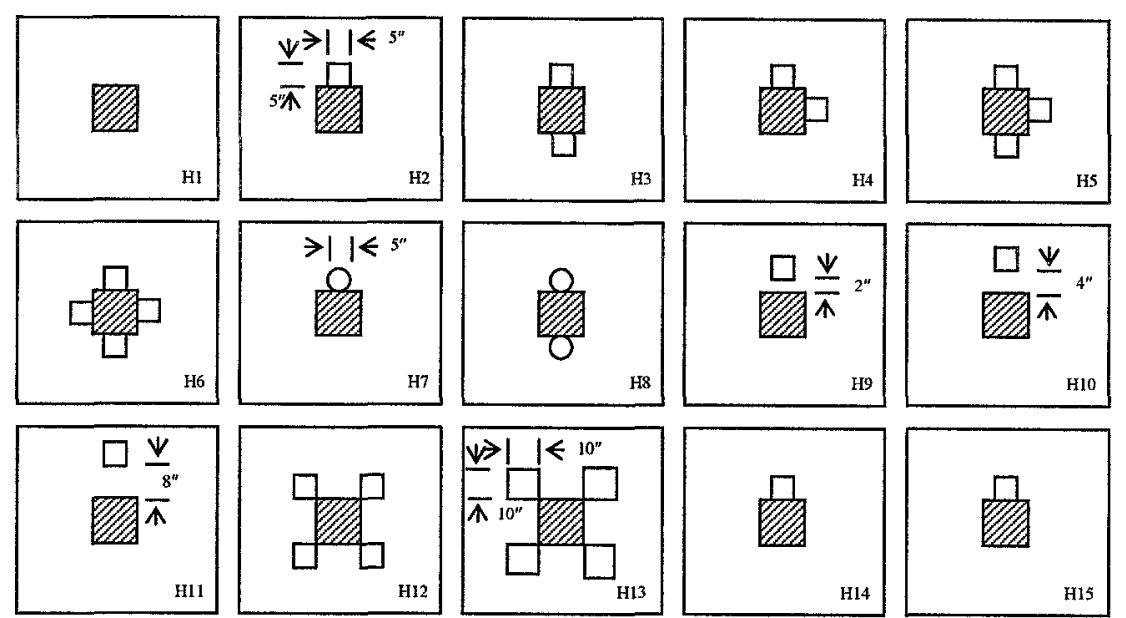

(a) Pattern of holes in test specimens

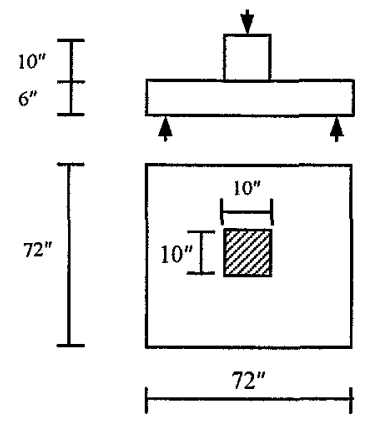

(b) Detail of test specimen

Figure 2.17 Interior slab-column specimen with openings (Moe, 1961)

The following facts were also indicated from his study,

(1) The critical section to predict the ultimate strength of slabs should be the perimeter of loaded area. If the slabs have openings, the critical section should be based on the net width of perimeter of loaded area as above specification of $b$.

(2) The shear strength of slabs depends to some extent on the flexural strength of the slabs.

(3) The tri-axial state of stress in the compression zone at the critical section greatly influences the shear strength of that section. 
(4) The unit shearing stress is highest when the column size is small compared to the slab thickness.

(5) Although the concentration of the bending reinforcement across the column increases the flexural rigidity of slabs, it was not effective on increasing the shearing strength.

\subsubsection{Study by Hognestad, Elstner, and Hanson (1964)}

In 1964, Hognestad, Elstner, and Hanson tested nine slab specimens to investigate the shear strength of slabs with lightweight concrete. Three slab specimens were made with normal weight concrete similar to Moe's specimens (1961) and six were made with two different lightweight concretes. Two types of square and rectangular columns were used. Only one square slab had four numbers of 5 in square openings adjacent to the column. The sizes of square and rectangular columns were $5 \times 5$ in and $6 \times 8$ in, respectively. All slabs were $6 \mathrm{ft}$ square and 6 in thickness and supported along four edges with comers free to lift. The load was applied through the column stubs. They modified the equation of shear stress by Moe (1961) for rectangular column shapes as the following and also recommended to be calculated for each side of column.

$$
v_{u}=\frac{V_{u}}{b d}=\left(15\left(1-0.075 \frac{r_{1}^{2}+r_{2}^{2}}{\left(r_{1}+r_{2}\right)}\right)-5.25 \phi_{0}\right) \sqrt{f_{c}^{\prime}}
$$

where $V_{u} \quad=$ ultimate shear force

$b \quad=$ peripheral of critical shear section in slabs

$d \quad=$ effective depth to tension reinforcement

$r_{1}, r_{2}=$ longest and shortest size of the column

$\phi_{0} \quad=$ ratio of $V_{\text {test }}$ or $V_{u}$ to $V_{\text {flex }}$

$V_{\text {flex }}=$ computed ultimate load controlled by flexure

They concluded that the Moe's equation (1961) could not give reliable prediction of the shear strength of reinforced concrete slabs with lightweight concrete by using concrete cylinder compressive strength. By using splitting tensile strength, $\operatorname{assuming} f_{s p}=6.7 \sqrt{f_{c}^{\prime}}$, in Moe's equation, the reliable prediction was obtained as 


$$
v_{u}=\frac{V_{u}}{b d}=\frac{2.24\left(1-0.075 \frac{r}{d}\right) f_{s p}}{1+\left(0.784 \frac{f_{s p}}{V_{f l e x}}\right)}
$$

in which for rectangular column sections, the term $r / d$ should be change with $\frac{r_{1}^{2}+r_{2}^{2}}{\left(r_{1}+r_{2}\right) d}$.

\subsubsection{Study by Mowrer and Vanderbilt (1967)}

In 1967, Mowrer and Vanderbilt tested 51 reinforced concrete interior slab-column specimens to provide more information on the shear strength of lightweight plates. Test specimens were divided into two series. In first series, 25 specimens were tested. The following variables were considered; the holes pattern around the column, amount of reinforcement, and concrete strength. The 17 specimens were for lightweight and 8 were for normal weight. The specimens were 36 in square, 3 in thickness, and had a 6 in square column stubs. In this series, all specimens were simply supported. The loads were applied through the column stubs. In the second series, 26 lightweight specimens were tested and the variables considered were the ratio of column width to effective depth, r/d, the amount of reinforcement and the edge fixity. The specimens were 48 in square and had a 5 in column stubs. Nine specimens were tested with two or four edge fixed while 17 were tested with simply supported edge with comers free to lift. Loads were applied through the column stubs.

They modified the Moe's equation (1961) for shear strength to give better prediction of results as follows,

$$
\frac{V}{b d \sqrt{f_{c}^{\prime}}}=\frac{9.7\left(1+\frac{d}{r}\right)}{1+5.25 \frac{b d \sqrt{f_{c}^{\prime}}}{V_{\text {flex }}}}
$$

They also suggested that the use of compressive strength gave better agreement between the computed and measured strength than the splitting strength, $f_{s p}$. 


\subsubsection{Study by Ivy, Ivey and Buth (1969)}

In 1969, Ivy, Ivey and Buth tested 14 specimens of full-scale lightweight concrete slabs. The variables were slab size, slab geometry and aggregate type. Ten of these were similar to Hognestad's slabs $\mathrm{H}_{1}$ and $\mathrm{H}_{6}$ slabs (1964) and had $6 \mathrm{ft}$ square and 6 in thickness with 10 in square column stubs. The $\mathrm{H}_{6}$ slabs had $5 \times 5$ in openings on each side of the column. The other four slabs were larger scale and simply supported at the boundaries and had 24 in square column and 7 in thickness. Two slabs had $6 \mathrm{ft}$ square and $10 \mathrm{ft}$ square boundaries. The other two slabs were $10 \mathrm{ft}$ square and had octagonal boundaries.

The Moe's equation and Hognestad's modified equation were used and it was found that the test data showed good prediction. Regarding the openings, they found that the ratio of $\mathrm{V}_{\text {test }}$ to $\mathrm{V}_{\text {calc }}$ were higher for slabs with openings than that without openings because of the stress concentration at the comers of the column stubs and the nominal ultimate stress tended to increase as the perimeter of the critical shear area decreased.

\subsubsection{Study by Regan (1974)}

Because the opening reduces the concrete areas against punching shear stress, the shear stress at the critical shear perimeter at a distance from the column is critically higher. Therefore, the reduced critical shear area due to opening needs to be used in checking the average shear stress at the limited critical shear parameter around the column. In 1974, Regan proposed two methods to reduce the critical shear perimeter at a distance of $1.5 \mathrm{~h}$ from the column face when the slab had opening near the column, where $\mathrm{h}$ was slab thickness. By these methods, the critical shear perimeter of slab-column connections was reduced to take into account the effect of opening in determining the average shear stress at the critical section. The proposed methods are explained by Figure 2.18. 

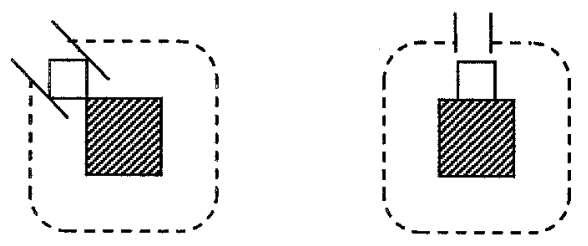

Method 1
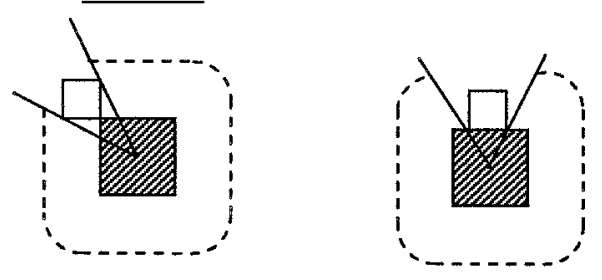

Method 2

Figure 2.18 Projection of width of openings on to the critical perimeter

(Regan, 1974)

Method 1 projects the widths of opening on the critical shear perimeter, two parallel projection lines are used and pass through two comers of opening, which can be the largest width in reducing the critical shear perimeter, while in method 2, two projection lines propagate from the center of column through two corners of opening, which can be the largest width in reducing the critical shear perimeter.

He reported that while method 1 was more realistic but did not produce safe predictions when compared to the test results from the literature, methods 2 was over conservative. He also suggested that openings near edge columns should be avoided, but if they could not be avoided it might be possible to replace the lost area of concrete by shear reinforcement placed at sides of the openings.

\subsubsection{Study by Broms (1990)}

In 1990, Broms investigated different types and arrangements of shear reinforcement at interior columns with symmetrical loadings. Eight specimens were tested. All slabs were $2600 \mathrm{~mm}$ square, $180 \mathrm{~mm}$ thickness and simply supported at eight points as shown in Figure 2.19a. Although all specimens were of the same dimensions, different reinforcement arrangements were used. Only one specimen had openings around the column as shown in Figure 2.19b. One specimen had no shear reinforcement. Three specimens had multiple U-stirrups as shear reinforcement. Two 
specimens and one specimen with openings were provided a combination of bent bars and multiple U-stirrups as shear reinforcement. The load was applied from below of the column stubs by means of hydraulic jack.

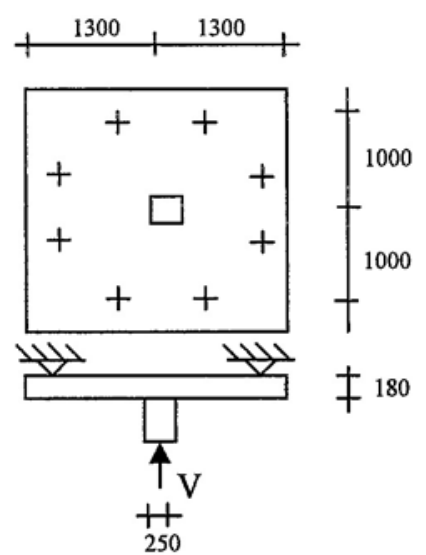

(a) Test specimen and location

of openings

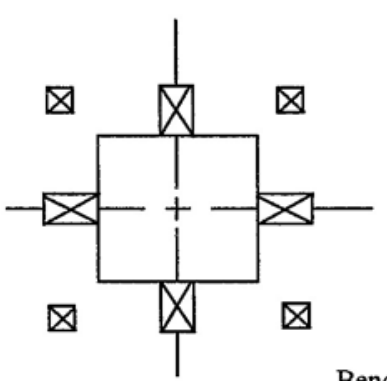

All dimensions in $\mathrm{mm}$

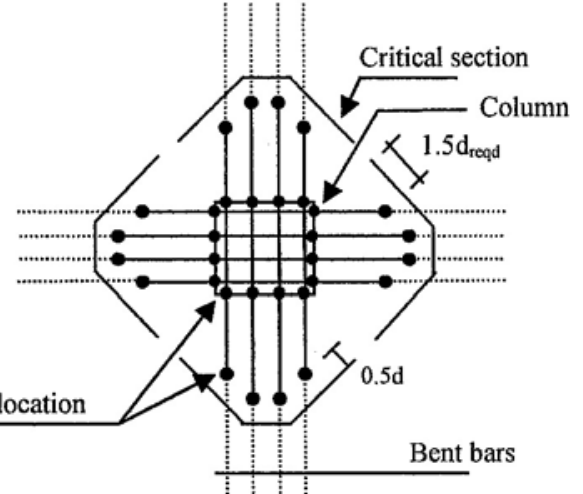

(b) Critical section for the design of stirrups

\section{Figure 2.19 Test specimen (Broms, 1990)}

He found that (1) openings in the slab inside the indicated critical perimeter as shown in Figure 2.19b affected neither the strength nor the stiffness of the slab, provided that there was space enough for the bent bars to pass within the column width, (2) ordinary shear reinforcements in the form of stirrups enclosing only the flexural reinforcement were not effective enough to give the desired ductility, and (3) a combination of bent bars and multiple U-stirrups enclosing the bottom compression reinforcement gave the specimens excellent performance.

And he recommended about the bent bars that (1) the bent bars should be distributed within the column width, (2) the inner bent of bars should be placed at the column face, (3) the inner bent bars should be given a moderate inclination so that the outer bent bars are placed at an average distance of $2 \mathrm{~d}$ from the column face, where $\mathrm{d}$ is the effective depth of the slab, and (4) in order to given the full development length, the bent bars should extend at least the distance $0.25 l_{n}$ from the face of column, where $l_{n}$ is clear span measured centre-to-centre of supports. 


\subsubsection{Study by El-Salakawy, Polak, and Soliman (1999)}

In 1999, EI-Salakawy, Polak, and Soliman studied the effect of openings on the punching shear behavior of edge slab-column connections. They tested six full-scale reinforced concrete flat plate edge connections with an opening in the vicinity of column. The main parameters of these tests were the locations and the sizes of openings. One specimen had no opening and the remaining five had various arrangements for openings around the column. The openings in the specimens were square, with sides parallel to the sides of the column. All specimens were made with normal density concrete with approximately compressive strength of $32 \mathrm{MPa}$. Two sizes of openings were used. One was the same size as column. The other was $60 \%$ of the column size. The specimens were subjected to the vertical load at the end of upper column stubs and the unbalanced moment by applying the two equal and opposite horizontal forces $\mathrm{H}$ near the colurnn ends. The specimens were simply supported along the three edges. The details of the specimen are shown in Figure 2.20.

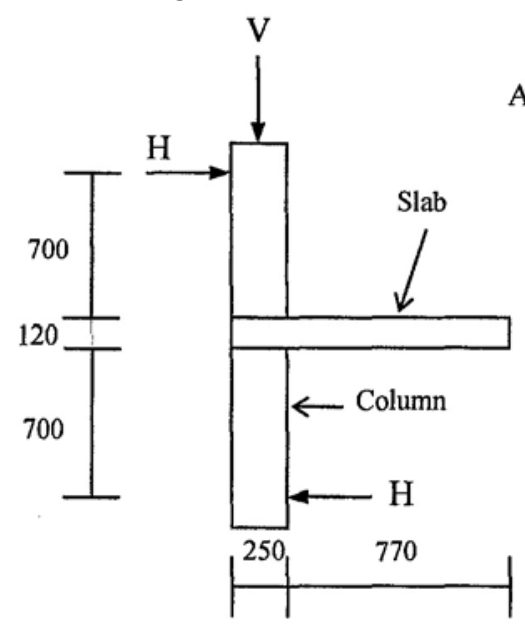

(a) Elevation
All dimensions in $\mathrm{mm}$

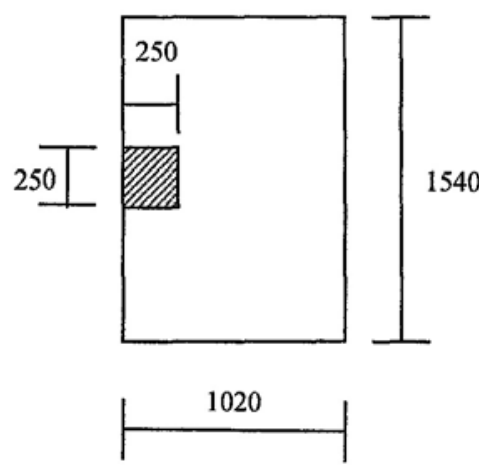

(b) Plan

Figure 2.20 Test specimen (Salakawy, Polak, and Soliman, 1999)

From the tests results, they gave the following conclusions:

(a) The opening located at the front of the column decreased the shear capacity of the connection more than the same size of opening located at the side of column.

(b) The distance of openings from the face of column influenced the capacity of connection. The closer the distance of opening from the face of column, the smaller the strength is. 
(c) The size of openings was significant in the reduction of stiffness. The smaller size of openings will give much smaller reduction in stiffness than the larger one.

(d) The CSA A233-M94 and ACI 318-95 gave more conservative strength prediction when the slabs had a larger opening.

\subsubsection{Study by Kuang (2001)}

In 2001, Kuang investigated the punching shear behavior of flat plate with opening. A total of 20 full-scale reinforced concrete slabs were tested. Four slab specimens had square columns and the remaining had rectangular columns. The main parameters of tests were different locations of opening adjacent to the column, column rectangularity, and different loading ratio. No shear reinforcements were included in all tested specimens.

Based on these parameters considered on the tested slab specimens, the slab specimens were grouped into 5 series each of which had one related control slab specimen. Series 1 was representative for square slab-column connections while series 2 and 3 were for rectangular slab-column connections with ratios of longer to shorter column width; 3 and 5, respectively. Series 4 and 5 were representative for rectangular slab-column connections with the same ratio of longer to shorter column width of 3 and with different loading ratios of $x$-direction to $y$-direction; 1.6 and 0.63 , respectively, where $\mathrm{x}$ - and $\mathrm{y}$-direction were parallel to longer and shorter column width, respectively.

There were five kinds of opening locations in the slab specimens. They were (1) opening location adjacent to the comer of column, (2) opening location parallel and adjacent to the shorter side of column, (5) opening location perpendicular and adjacent to shorter side of column, (4) opening location parallel and adjacent to middle of longer side of column and (5) opening location perpendicular and adjacent to the end of longer column side. The dimensions of opening were $200 \mathrm{~mm}$ x $400 \mathrm{~mm}$. The opening locations included in his slab specimens can be seen in Figure 2.21. 
The important conclusions that can be made based on the observation of his test results are as follows.

(1) When the openings are located at adjacent to the column in the slabs, the punching shear capacity of such slabs with opening can decrease due to opening.

(2) Among all the slabs with opening, the decrease in the ultimate punching shear capacity due to opening for the slabs with opening located adjacent to the middle of longer column side was the least as compared to other slabs with opening located elsewhere adjacent to the column.

(3) However, the location of opening parallel and adjacent to shorter side of column had the most serious effect in reducing the punching shear capacity of slab as compared to the other slabs with opening located elsewhere adjacent to the column.

(4) The punching shear capacity of slabs with rectangular column is more than that of slab with square column.

(5) The punching shear capacity of the slab with rectangular column having ratio 3 of longer to shorter column width increase about $34 \%$ more than that of the slab with square column. While The punching shear capacity of the slab with rectangular column having ratio 5 of longer to shorter column width increase about $53 \%$ more than that of the slab with square column. Therefore, the more rectangularity of the column can increase more the punching shear capacity of slab.

He proposed an extension to BS8110-97's formula in order to predict the punching shear capacity of slabs with rectangular column and with or without opening more accurately that modification was made to the critical punching shear perimeter $u$ of BS8110-97's formula. His modification was that the critical shear perimeter at a distance of $1.5 \mathrm{~d}$ from the column face between two projection lines, which propagated from the center point of the column edge section through two comers of opening, was ineffective. His proposed extension to critical shear perimeter presented by BS811097 together with his slab specimens is shown in Figure 2.21. 

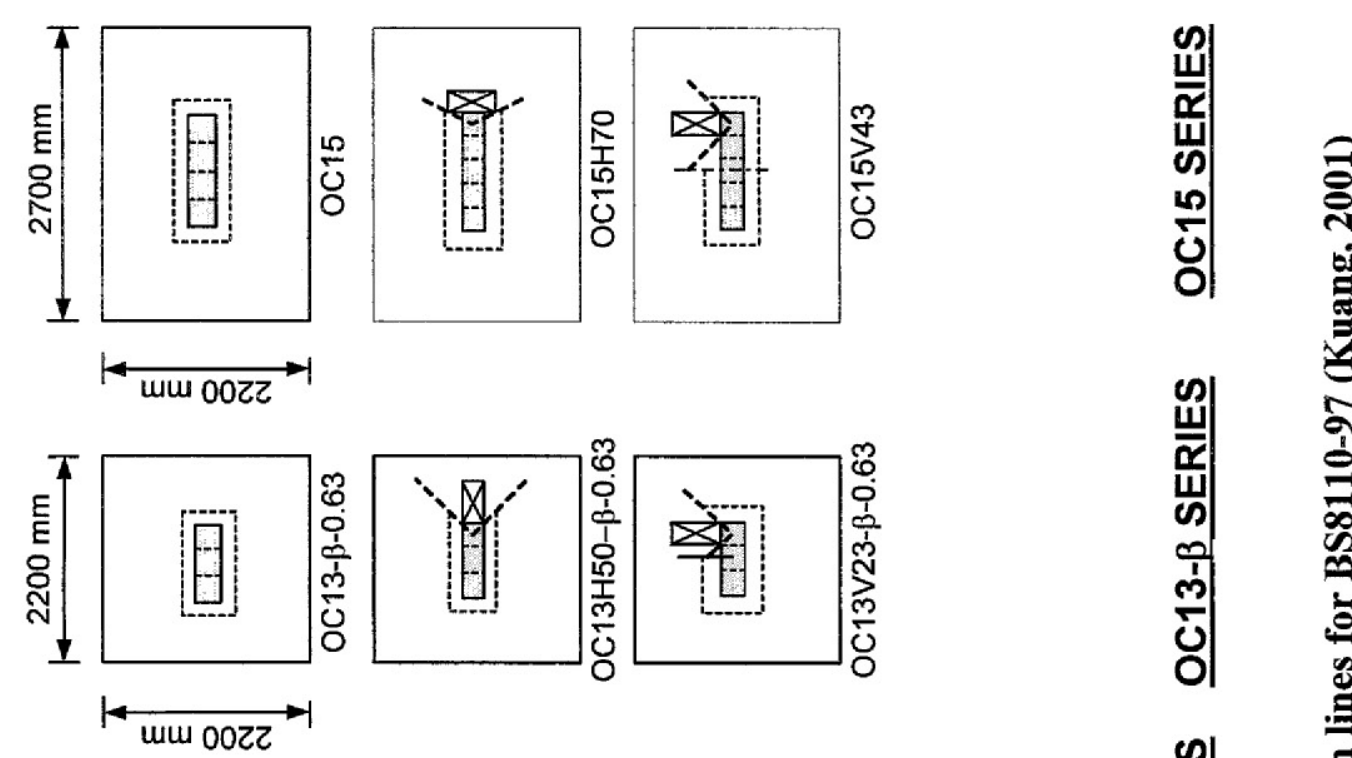

章
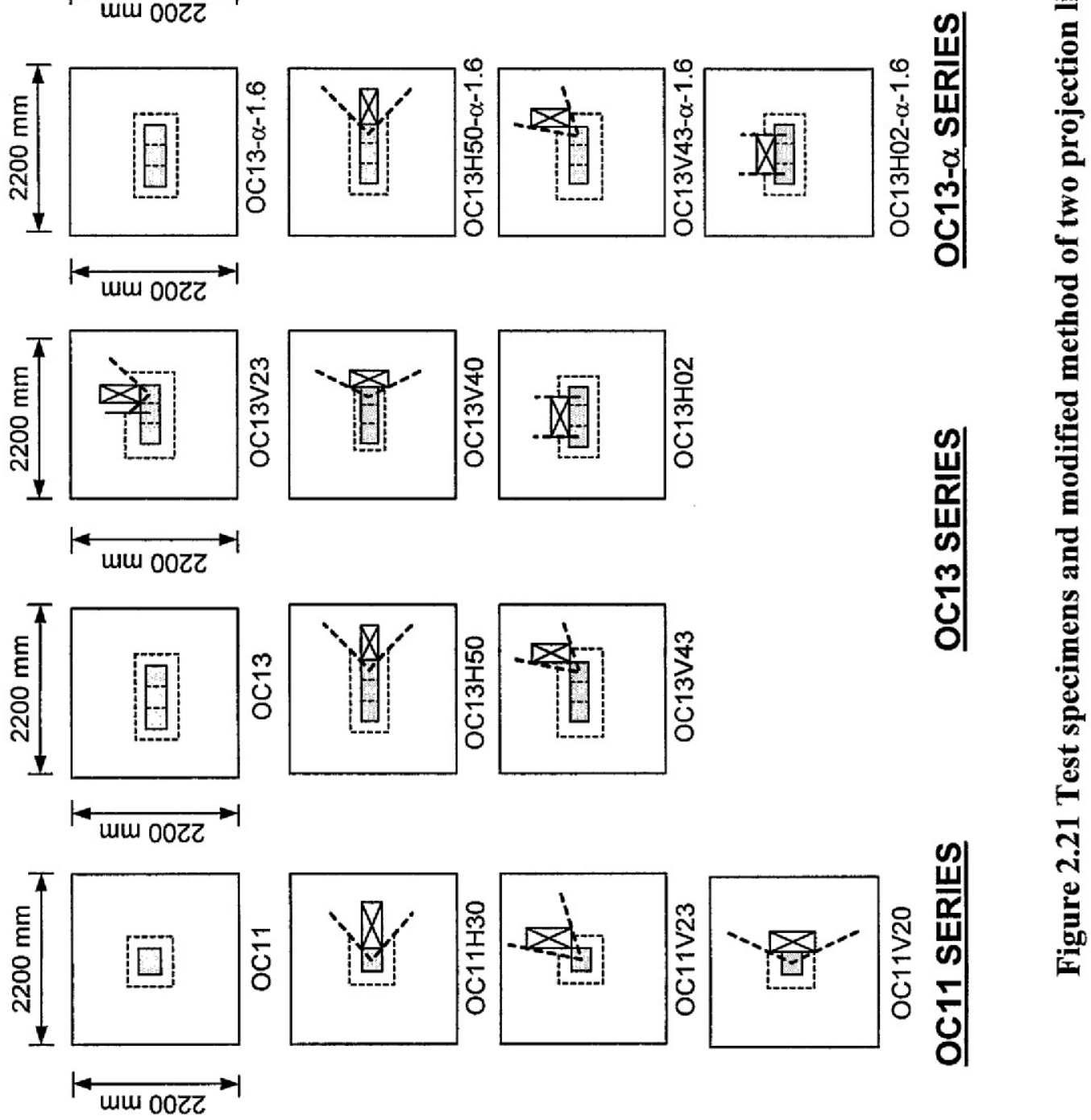


\subsection{Experimental works related to slabs with shear reinforcement}

One of the ways to increase the shear strength of slab-column connections is the use of shear reinforcement such as shear stud, stirrup, and shear heads. When the slab has openings, the shear reinforcement may be used to recover the loss of shear capacity of slab due to opening. When the slab-column connections are subjected to high shear force or combination of shear and unbalanced moment, the shear reinforcement may be used to increase the shear capacity of the connections. In design, when the factor shear force exceeds the available design shear strength without shear reinforcement, the shear reinforcement can be used.

\subsubsection{Study by Islam and Park (1976)}

In 1976, Islam and Park investigated the effect of various types of shear reinforcement on the strength and ductility of slab-column connections with shear and unbalanced moment. They tested eight half scale models of reinforced concrete interior flat plate column specimens under combined gravity and seismic type loading. Three of the specimens were without shear reinforcement. The remaining five specimens were with various arrangement of shear reinforcement. The type of shear reinforcements was used; cranked (bent up) bars, shear head reinforcement in the form of pairs of channel sections and vertical closed stirrups. The details of the specimen are shown in Figure 2.23. The four specimens were cyclic loaded, which caused reversals unbalanced bending moment simulating earthquake effects. The other specimens were loaded monotonically with increasing unbalanced moment.

They concluded that (1) the slab-column connections without any shear reinforcement had little ductility and failure occurred suddenly, (2) although the cranked bent-up bars could increase the shear strength, they did not increase the ductility, (3) the structural shear head reinforcement increased the shear strength, but gave only a limited increase in the ductility of the connection, and (4) the closed stirrups resulted in increase in the strength and a substantial increase in the ductility of the slab-column connections. 


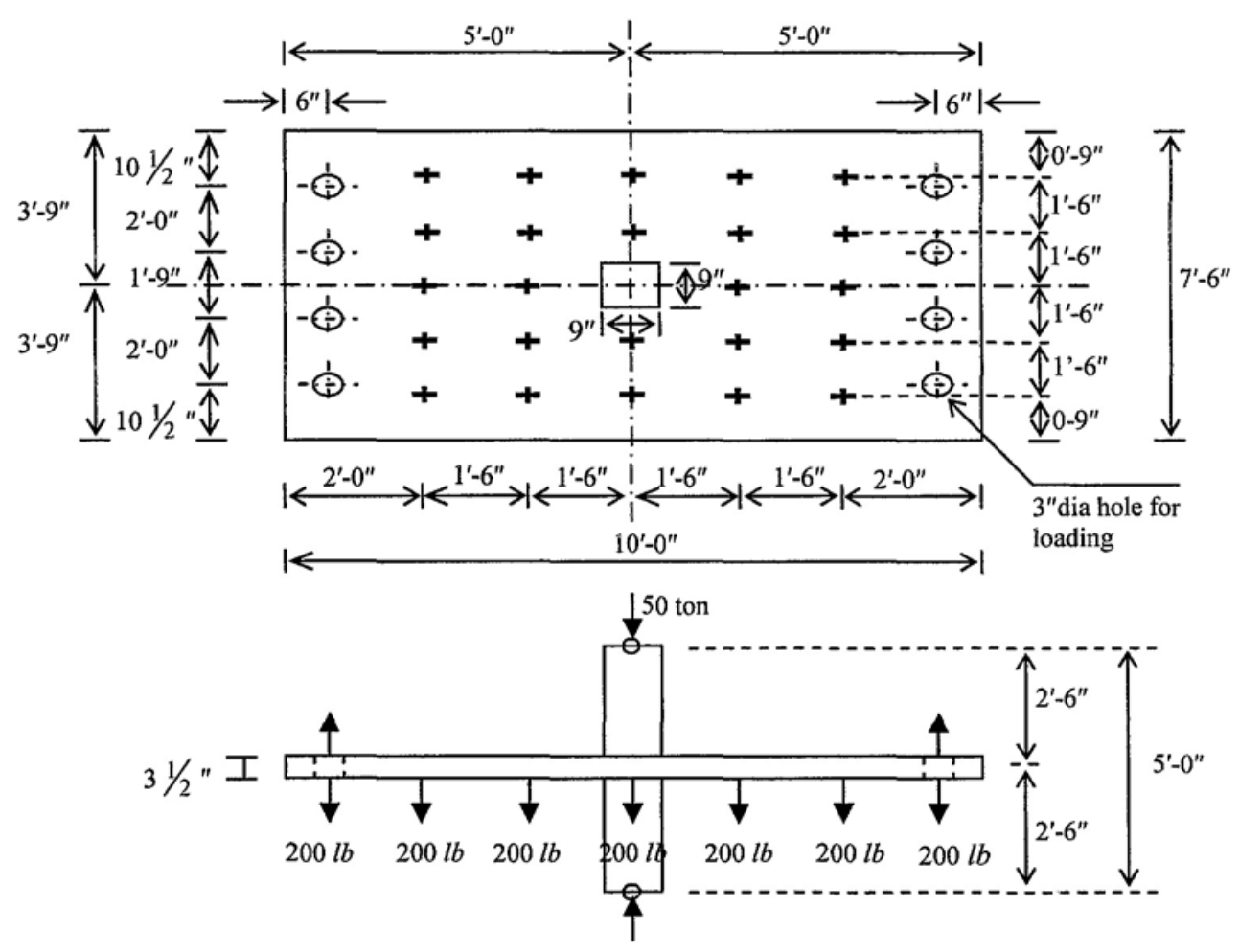

Figure 2.22 Test specimen (Islam and Park, 1976)

\subsubsection{Study by Elgabry and Ghali (1987)}

In 1987, Elgabry and Ghali investigated the shear strength of interior slab-column connections reinforced with shear studs and suggested code provisions for the design of this type of shear reinforcement. They tested five full-scale reinforced concrete flat plate connections with interior columns subjected to shear-moment transfer. One specimen had no shear reinforcement and the remaining four consisted of various arrangement of shear stud reinforcement. The detail of the test specimens are shown in Figure 2.23. The test results indicated that the well-anchored stud-shear reinforcements are effective in increasing the shear strength and ductility of slabcolumn connections subjected to shear force and unbalanced moment. They recommended the following:

(1) The distance $s_{0}$ between the first row of shear studs and the column face should not be smaller than $\mathrm{d} / 4$.

(2) The upper limits for $s_{0}$ and for spacing $s$ between the rows should be based on the value $\mathrm{v}_{\mathrm{u}}$ at a critical section at $\mathrm{d} / 2$ from the column face.

$$
\left.\begin{array}{l}
s_{0} \leq d / 2 \\
s \leq 3 d / 4
\end{array}\right\} \text { when } \quad 0.33 \sqrt{f_{c}^{\prime}}<\frac{v_{u}}{\phi} \leq 0.5 \sqrt{f_{c}^{\prime}}
$$




$$
\left.\begin{array}{l}
s_{0} \leq 0.35 d \\
s \leq 0.5 d
\end{array}\right\} \text { when } \quad 0.5 \sqrt{f_{c}^{\prime}}<\frac{v_{u}}{\phi} \leq 0.67 \sqrt{f_{c}^{\prime}}
$$

(3) The equations for shear strength at critical section within the shear reinforced zone, when the shear stud reinforcement was provided, were suggested as follows.

$$
\begin{aligned}
& v_{n}=v_{c}+v_{s} \\
& v_{c}=0.17 \sqrt{f_{c}^{\prime}}\left(1+\frac{4-\alpha}{3 \beta_{c}}\right), 0.17 \leq v_{c} \leq 0.67 \sqrt{f_{c}^{\prime}} \\
& v_{s}=\frac{A_{v} f_{y v}}{b_{o} s}
\end{aligned}
$$

where $b_{o} \quad=$ perimeter of critical section

$d \quad=$ effective depth of slab

$f_{c} \quad=$ compressive cylinder strength of concrete

$f_{y v} \quad=$ specified yield strength of shear studs

$s \quad=$ spacing between stud rows

$s_{0} \quad=$ spacing between first row of studs and column face

$v_{u} \quad=$ maximum shear stress due to factored forces

$v_{c} \quad=$ nominal shear strength provided by concrete in presence of shear studs

$v_{s}=$ nominal shear strength provided by shear studs

$\alpha \quad=$ ratio of distance between column face and critical section and effective depth of slab ( $\mathbf{a}$ is taken as one when distance between column face and critical section is less than d.)

$\beta_{c} \quad=$ ratio of longer to shorter side of column cross-section

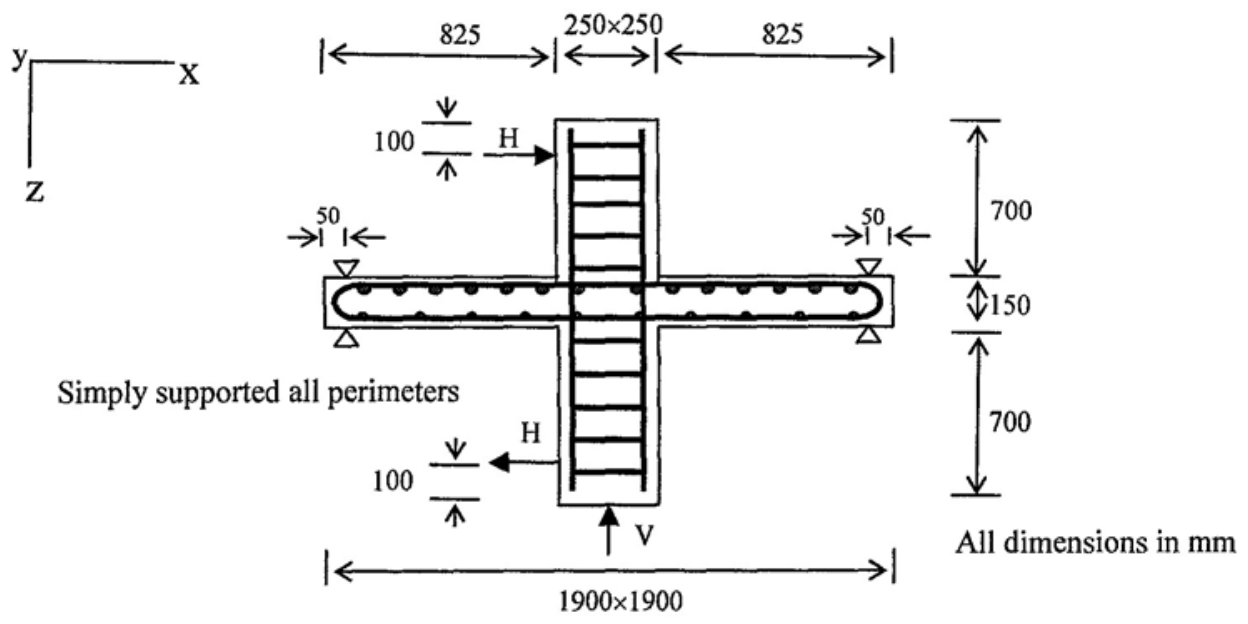

Figure 2.23 Test specimen (Elgabry and Ghali, 1987) 


\subsubsection{Study by Ghali (1989)}

In 1989, Ghali studied the shear stud reinforcement (SSR) to increase the strength and the ductility of slab-column connections and discussed its advantages. SSR was composed of vertical bars with anchor heads at their tops, welded to a steel strip at the bottom. He also discussed the disadvantages of stirrups. In practice, stirrups or structural shear heads are often used to increase the shear capacity because they are less expensive. However, some disadvantages of stirrups that he discussed are:

1. The tensile forces, which resist shear, in the vertical portions of the stirrups can not develop unless the vertical branches are anchored effectively near the top and bottom surface of the slab.

2. It is difficult to install.

3. The vertical portions of the stirrups typically is bent at the top and bottom of the slab and thus can not be fully effective in controlling the width of shear cracks close to the top and bottom surfaces.

4. It decreases the effective depth of the slab. Thus, more flexural reinforcements are required.

Some advantages of SSR are:

1. They are easy to install and control. Once the strips are placed on chair and secured to the forms, the spacing, the verticality the studs, and the concrete covers at the top and bottom are insured.

2. There is no interference of the shear reinforcement with the flexural reinforcement.

3. They are more effective in controlling the width of shear cracks that intersect the studs close to the top and bottom surfaces, because they are straight vertical and are anchored as closely as possible to the top and bottom surface of the slab.

4. The cost of materials can be reduced because the amount of steel used for the studs and strips is small compared to the amount of steel in conventional stirrups

5. The specified concrete cover can be maintained because the cover above the anchored heads is the same as the cover for the top flexural reinforcement. 
6. Higher ultimate strength and more ductile behavior of slab can be achieved due to more efficient anchorage of SSR compared to conventional stirrups.

\subsubsection{Study by Mortin and Ghali (1991)}

In 1991 Mortin and Ghali verified the effectiveness of shear stud reinforcement in improving shear strength and ductility. Shear stud reinforcement is a vertical stem mechanically anchored at top and bottom. They tested six full-scale reinforced concrete flat plate connections with edge columns subjected to shear-moment transferred. Two specimens had no shear reinforcement and the remaining four had various arrangement of stud-shear reinforcement. The specimens were rectangular, simply supported on three sides, with the column stubs located at the center of unsupported side. Test variables were the width of the stud strip, placement of the studs within the spandrel strip, the number of row of studs, the spacing of the studs, and the size of the shear reinforced zone. The details of specimens are shown in Figure 2.25.

Their results showed that shear stud reinforcement can substantially improve the ductility and shear strength of the thin, reinforced concrete, edge slab-column connections. They recommended the design rules suggested by Dilger and Ghali (1981) which were: (1) The maximum allowable shear stress in critical section at a distance $\mathrm{d} 12$ from the column face should be increased from $6 \sqrt{f_{c}^{\prime}}$ psi (allowed by ACI 318-89) to $8 \sqrt{f_{c}^{\prime}}$ psi due to the improved anchorage provided by shear studs, (2) The strength resisted by concrete within the shear reinforced zone reduced from $3 \sqrt{f_{c}^{\prime}}$ psi to $2 \sqrt{f_{c}^{\prime}}$ psi, and (3) In a critical section at $\mathrm{d} / 2$ fiom the outermost row of shear studs, the allowable shear stress should be a function of distance from the column. This function was equal to $4 \sqrt{f_{c}^{\prime}}$ psi and $2 \sqrt{f_{c}^{\prime}}$ psi at a distance from the column face $\leq \mathrm{d}$ and $\geq 4 \mathrm{~d}$, respectively, with linear variation between the two zones. They also suggested that at least two strips of studs should be placed in the spandrel strip. One of these should be adjacent to the free edge and the other along the inner face of the column to the free edge. 

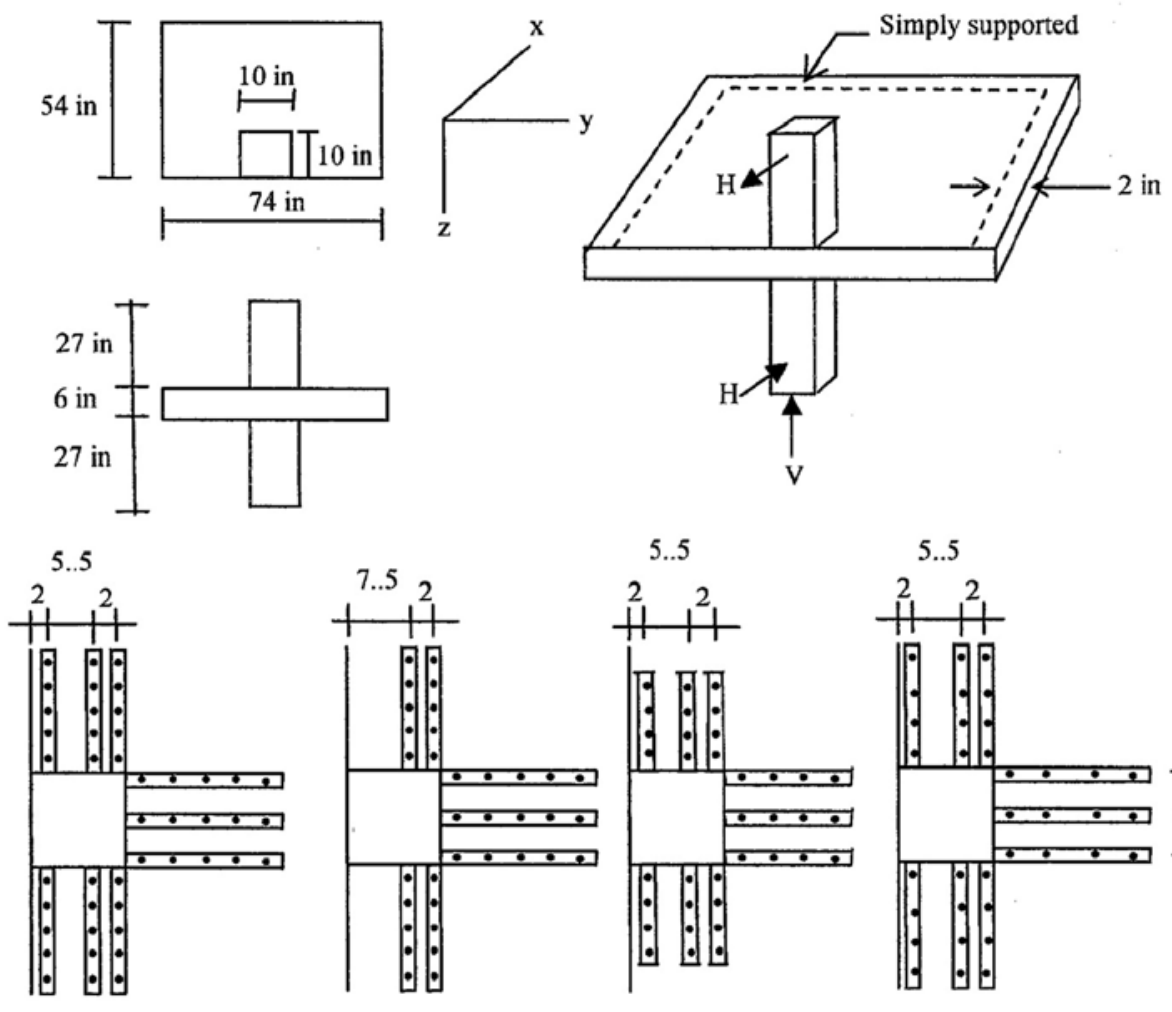

JS2

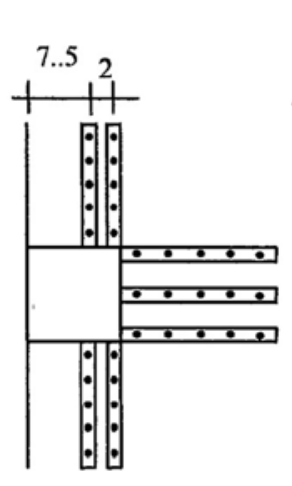

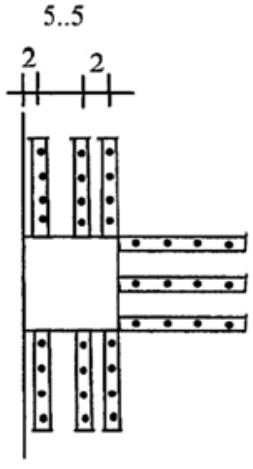

JS5

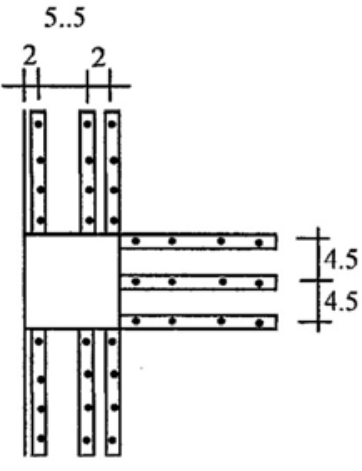

JS6

Figure 2.24 Test specimen (Mortin and Ghali, 1991)

\subsection{Reviews on punching shear strength by codes}

\subsubsection{Background}

There are many design codes to calculate the shear strength of the slab-column connections. In this chapter, six design codes are reviewed. They are ACI 318-02 and British Standard BS 8110-97. In different codes, different critical perimeter at some distance from the vicinity of column face is assumed as a control parameter. The punching shear strength is calculated based on a nominal shear stress on a critical section area. The critical sectional area is located along a critical perimeter and has a depth equal to effective depth of slabs.

If the slab-column connection includes holes or openings, the shearing strength is calculated based on the reduced critical shear perimeter due to openings. The codes reduce the critical shear perimeter by several methods. 


\subsubsection{Design requirements}

The basic equation for shear design is usually stated as:

$$
\begin{aligned}
& v_{u} \leq \phi v_{n} \\
& \phi v_{n}=\frac{\phi\left(V_{c}+V_{s}\right)}{b_{o} d} \\
& v_{u}=v_{c} b_{0} d
\end{aligned}
$$

where $b_{o} \quad=$ critical shear perimeter

$V_{u} \quad=$ factored shear force due to loads

$V_{c} \quad=$ shear force contributed by concrete

$V_{s} \quad=$ shear force contributed by shear reinforcementif any

$v_{u} \quad=$ maximum shear stress due to factor shear force or combination of factored shear force and unbalanced moment

$v_{n} \quad=$ nominal shear strength of the slabs

$v_{c} \quad=$ shear strength contributed by concrete

$v_{s} \quad=$ shear strength contributed by shear reinforcement if any

$\phi \quad=$ strength reduction factor, equals to 0.85 for shear

The shear strength contributed by concrete is derived from the nominal shear stress on the critical section located at some distance from column face according to the design codes, which will be discussed in the following sections.

\subsubsection{American Concrete Institute ACI 318-02}

\subsubsection{Shear force only}

ACI 318-02 recommends that the shear strength of slabs without shear reinforcement can be calculated based on some variables. They are concrete strength, ratio of the size of loaded area and slab thickness, loaded area aspect ratio (shape of loaded area), perimeter aspect ratio, and shear to moment ratio at slab-column connections. By considering these variables, the shear strength is given by the smallest of the following: 


$$
\begin{aligned}
& v_{c}=\frac{1}{6} \times\left(1+\frac{2}{\beta_{c}}\right) \times \sqrt{f_{c}^{\prime}} \\
& v_{c}=\frac{1}{6} \times\left(1+\frac{\alpha_{s}}{2 \beta_{0}}\right) \times \sqrt{f_{c}^{\prime}} \\
& v_{c}=\frac{1}{3} \times \sqrt{f_{c}^{\prime}}
\end{aligned}
$$

where $b_{o} \quad=$ critical shear perimeter shown in Figure 2.25 for square and rectangular column type and $\pi(D+d)$ for circular columns

$D \quad=$ diameter of column

$v_{c}=$ nominal shear strength for normal weight concrete and $0.75 \times V_{c}$ for lightweight concrete

$\beta_{c}=$ loaded area aspect ratio (longer size of loaded area to shorter size of loaded area)

$\alpha_{\mathrm{s}} \quad=$ constant, 40 for interior column

30 for edge columns

20 for comer columns

$\beta_{o} \quad=$ perimeter aspect ratio, $b_{d} / d$

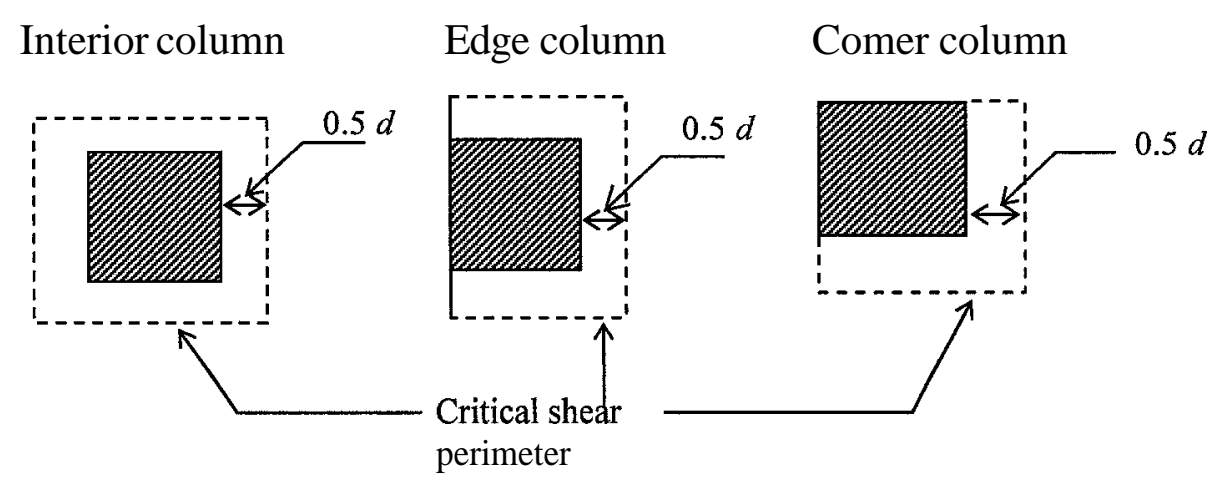

Figure 2.25 Critical shear perimeter of critical section (ACI 318-02)

\subsubsection{Presence of unbalanced moment}

ACI 318-02 recommends that the maximum factored shear stress on the critical section due to factored shear force and the unbalanced moment be calculated based on the assumption that this shear stress varies linearly on the critical peripheral line from 
the column faces as shown in Figure 2.26, 2.27, and 2.28. The equation to calculate the combined shear stress is as follows:

$$
v_{u}=\frac{V_{u}}{A_{c}} \pm \frac{\gamma_{v x} M_{u x} y}{J_{x}} \pm \frac{\gamma_{v y} M_{u y} x}{J_{y}}
$$

where $A_{c} \quad=$ critical sectional area, $b_{o} d$

$M_{u x}, M_{u y}=$ unbalanced moment in x and y directions, respectively

$J_{x}, J_{y} \quad=$ polar moment of inertia of the shear perimeter about the axis $\mathrm{x}$ and y axes, respectively

$x, y=$ coordinates of the point at which $\mathrm{v}_{\mathrm{u}}$ is calculated with respect to centroidal axes of the assumed critical sections

$\gamma_{v x} \& \gamma_{v y}=$ fraction of unbalanced moment transferred by shear in $\mathrm{x}$ and $\mathrm{y}$ directions, respectively

The polar moment of inertia of the shear perimeter about the $\mathrm{x}$ and $\mathrm{y}$ axes are given as.

\section{For interior column}

$$
\begin{aligned}
& J_{x}=d\left(\frac{l_{y}^{3}}{6}+\frac{l_{x} l_{y}^{2}}{2}\right)+\frac{l_{y} d^{3}}{6} \\
& J_{y}=d\left(\frac{l_{x}^{3}}{6}+\frac{l_{y} l_{x}^{2}}{2}\right)+\frac{l_{x} d^{3}}{6}
\end{aligned}
$$

\section{For edge column}

$$
\begin{aligned}
& J_{x}=d\left(\frac{l_{y}^{3}}{12}+\frac{l_{x} l_{y}^{2}}{2}\right)+\frac{l_{y} d^{3}}{12} \\
& J_{y}=\frac{l_{x} d}{6}\left(d^{2}+l_{x}^{2}\right)+2 d l_{x}\left(\frac{l_{x}}{2}-c_{B C}\right)^{2}+l_{y} c_{B C}^{2}
\end{aligned}
$$

where $c_{B C}=\frac{l_{x}^{2}}{21,+l_{y}}$

$=$ distance of centroidal axis of critical section parallel to $\mathrm{x}$-axis from the face BC shown in Figure 2.27 


\section{$\underline{\text { For corner column }}$}

$$
\begin{aligned}
& J_{x}=\frac{l_{y} d}{6}\left(d^{2}+l_{y}^{2}\right)+2 d l_{y}\left(\frac{l_{y}}{2}-c_{A B}\right)^{2}+d l_{x} c_{A B}^{2} \\
& J_{y}=\frac{l_{x} d}{12}\left(d^{2}+l_{x}^{2}\right)+d l_{x}\left(\frac{l_{x}}{2}-c_{B C}\right)^{2}+d l_{y} c_{B C}^{2}
\end{aligned}
$$

where $c_{A B}=c_{B C}=\frac{l_{x} l_{y}}{2\left(l_{x}+l_{y}\right)}$

$=$ distance of centroidal axis of critical section parallel to $\mathrm{X}$-axis and $\mathrm{y}$-axis from the face $\mathrm{AB}$ and $\mathrm{BC}$, respectively shown in Figure 2.28 .

And the fraction of unbalanced moment transferred by shear in $\mathrm{x}$ and $\mathrm{y}$ directions are given by the equations:

$$
\begin{aligned}
& \gamma_{v x}=1-\frac{1}{1+\frac{2}{3} \sqrt{\frac{l_{y}}{l_{x}}}} \\
& \gamma_{v y}=1-\frac{1}{1+\frac{2}{3} \sqrt{\frac{l_{x}}{l_{y}}}}
\end{aligned}
$$
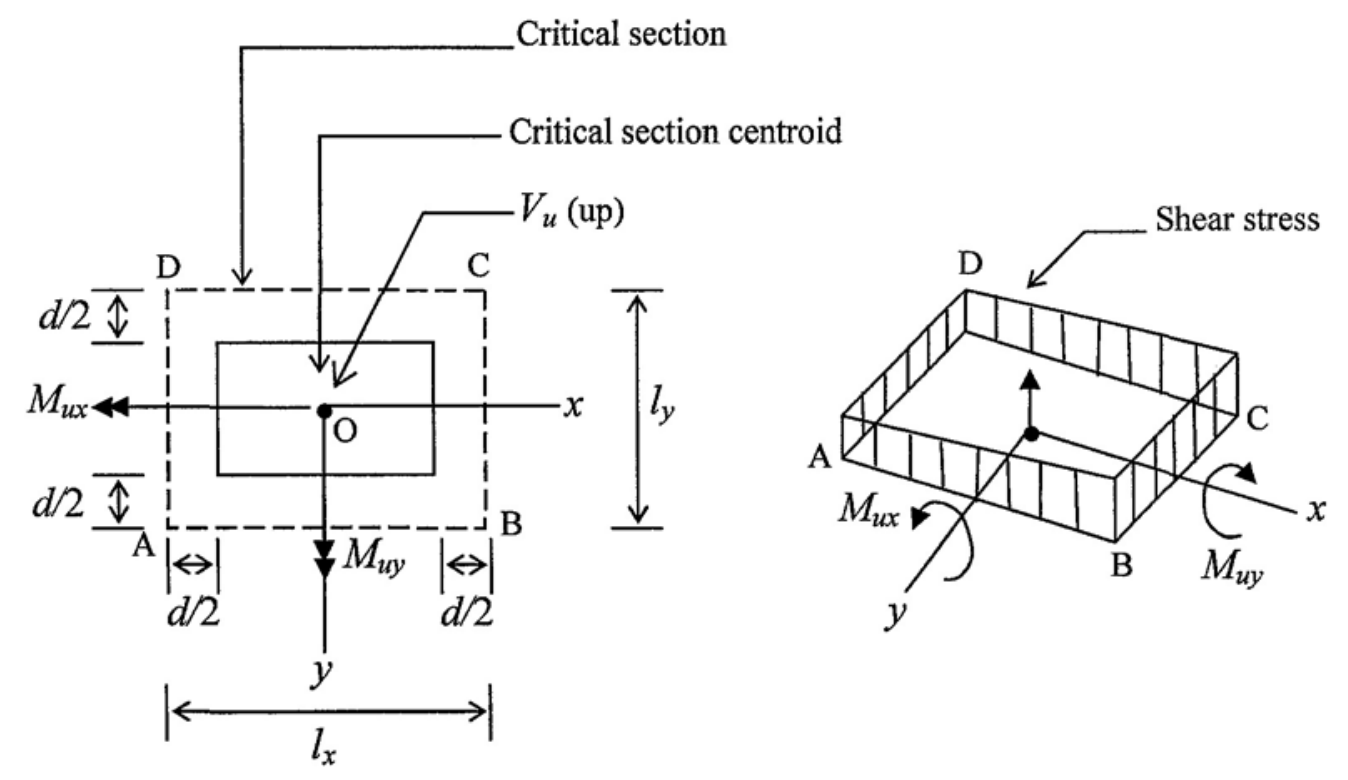

(a) Critical section

(b) Shear stress distribution

Figure 2.26 Shear stress distribution at the critical section in the vicinity of interior column (ACI 318-02) 


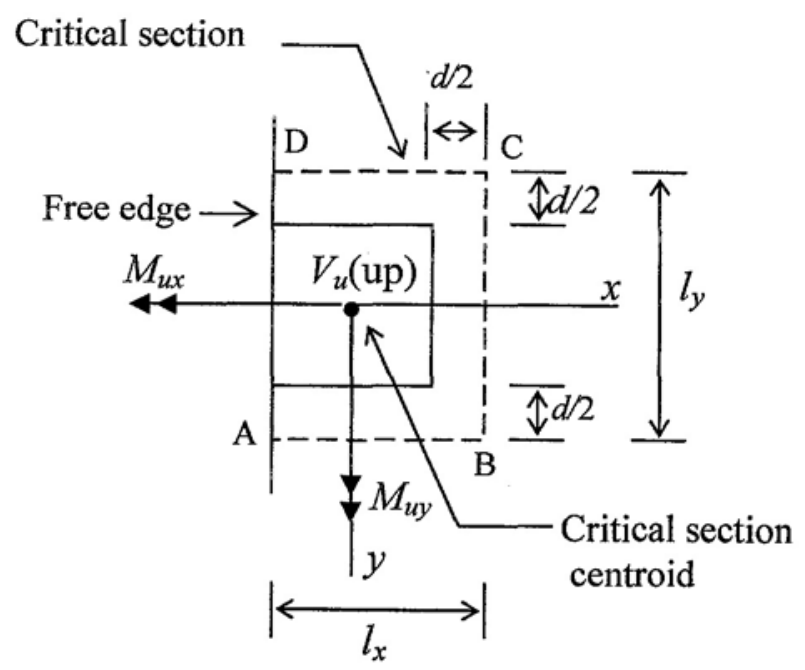

(a) Critical section

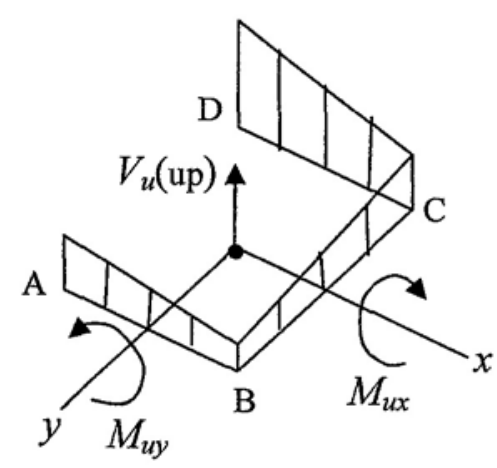

(b) Shear stress distribution

Figure 2.27 Shear stress distributions at the critical section in the vicinity of edge column (ACI 318-02)

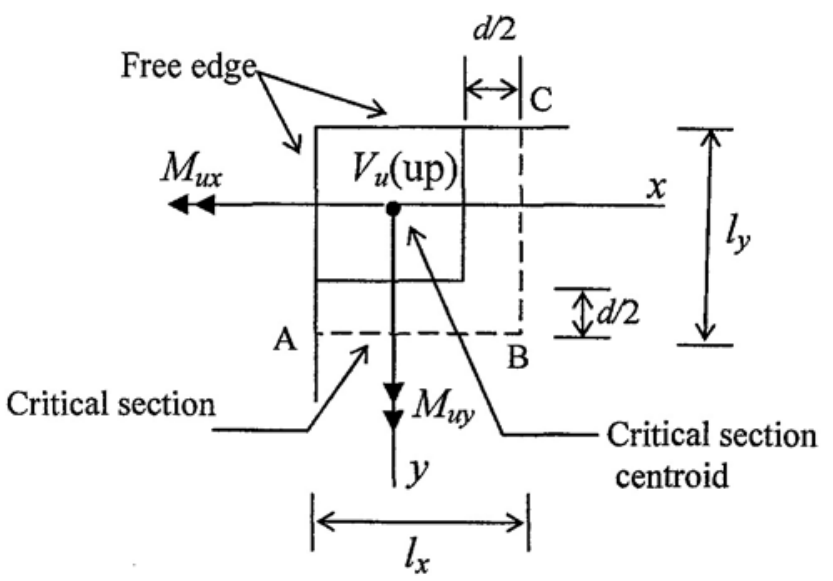

(a) Critical section

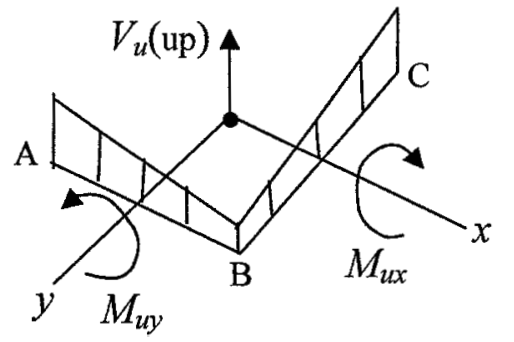

(b) Shear stress distribution

Figure 2.28 Shear stress distribution at the critical section in the vicinity of corner column (ACI 318-02)

\subsubsection{Opening in slabs}

When the openings in slabs are located at a distance closer than 10 times the slab thickness from the column, the shear strength needs to be reduced by considering the portion of the critical shear area bounded by the two straight lines projecting from the 
column centroid to the edges of the openings ineffective. The ineffective portion of the critical shear is shown in Figure 2.30.
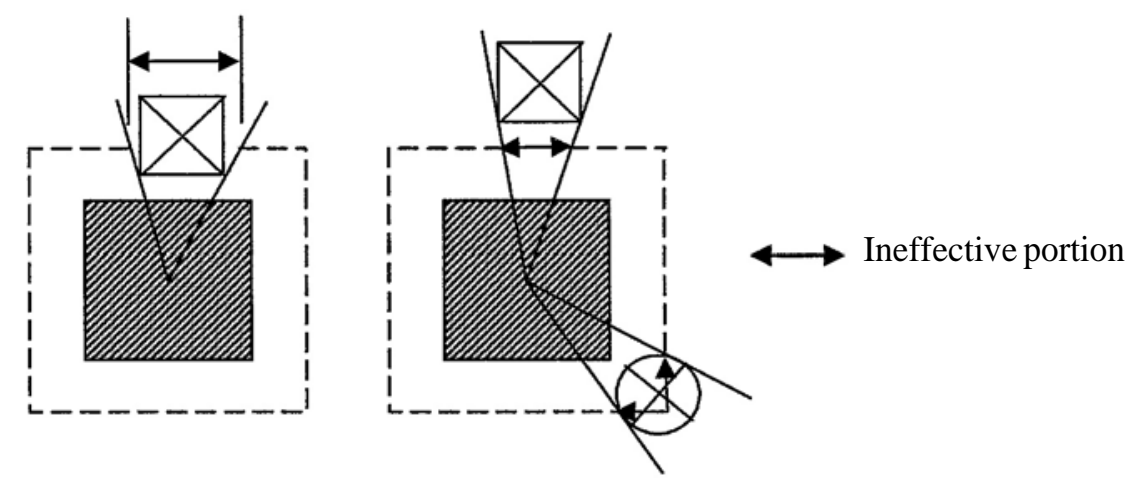

Figure 2.29 Ineffective portion of the slab due to openings (ACI 318-02)

\subsubsection{British Standard BS 8110-97}

\subsubsection{Shear force only}

In BS8110-97, the critical shear perimeter is located at $1.5 \mathrm{~d}$ distance from the column face as shown in Figure 2.30. The design punching strength of slabs without shear reinforcement is based on the shear strength of the beam which is given by:

$$
v_{c}=\frac{0.79 \rho^{\frac{1}{3}}\left(f_{c u} / 20\right)^{\frac{1}{3}}(400 / d)^{\frac{1}{4}}}{\gamma_{m}}
$$

where $\mathrm{d}=$ average effective depth of flexural reinforcement $\leq 400 \mathrm{~mm}$

$f_{c u}=$ characteristic cube strength $\leq 40 \mathrm{~N} / \mathrm{mm}^{2}$

$v_{c}=$ design punching strength of the slabs for normal weight concrete (For lightweight concrete grades of 20 or more, $v_{c}$ is multiplied by $0.8)$

$P \quad=$ flexural reinforcement ratio, $100 \mathrm{~A}_{\mathrm{s}} /(\mathrm{bd})$ along the critical section (a width of slab equal to that of loaded area plus $1.5 \mathrm{~d}$ to either side of it) $\leq 3 \%$

$\gamma_{m}=$ material safety factor for concrete in shear 
The punching shear capacity, V, due to a concentrated load from the column can be obtained as follows:

$$
V=v_{c} u d
$$

where $\mathrm{u}=$ critical perimeter

$4(D+3 d) \quad$ (For circular column)

$4(c+3 d) \quad$ (For square column)

D = diameter of circular column

$c \quad=$ side of square column

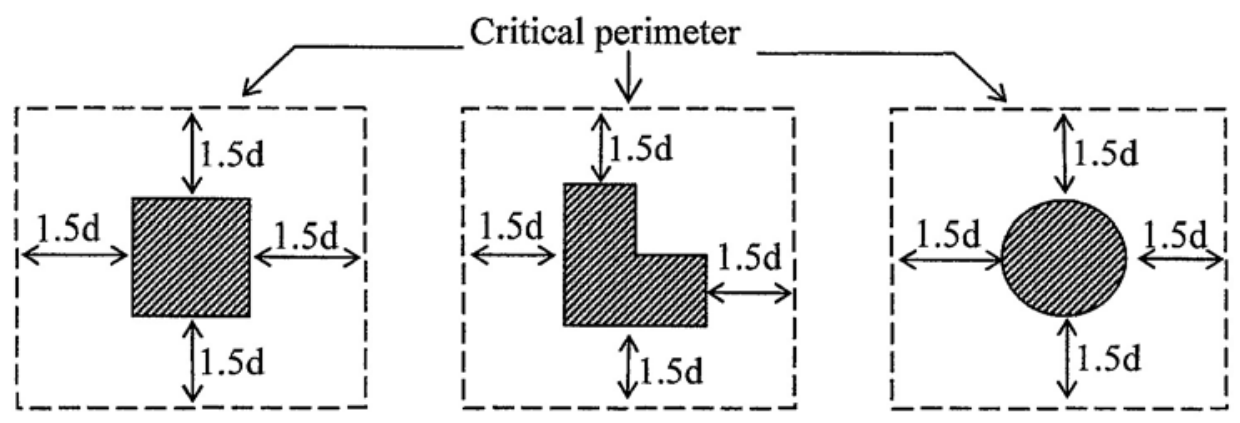

Figure 2.30 Location of shear perimeter (BS 8110-97)

\subsubsection{Presence of unbalanced moment}

When the unbalanced moment is transferred from slab to column, the design effective shear force in the vicinity of the column at the perimeter, $\mathrm{V}_{\text {eff, }}$ should be taken as:

For interior slab-column connections,

$$
V_{e f f}=V_{t}\left(1+\frac{1.5 M_{t}}{V_{t} x}\right)
$$

For comer and edge slab-column connections where the axis of the unbalanced moment parallel to the free edge,

$$
V_{e f f}=1.25 V_{t}
$$


For edge slab-column connections where the axis of the unbalanced moment perpendicular to the free edge,

$$
V_{\text {eff }}=V_{t}\left(1.25+\frac{1.5 M_{t}}{V_{t} x}\right)
$$

where

$\mathrm{x} \quad=$ length of the side of the perimeter considered parallel to the axis of bending

$M_{t} \quad=$ design moment transferred from the slab to the column at the connection

$V_{t}=$ shear force at the perimeter which is calculated on the assumption that the maximum design load is applied to all panels adjacent to the column at the connection

\subsubsection{Opening in slabs}

When opening in slabs are located at a distance less than six times the effective depth of the slabs from the edge of the concentrated load, then that part of the perimeter which is enclosed by the two radial lines projecting from the centroid of the loaded area to the edge of opening is considered as ineffective as shown in Figure 2.31.

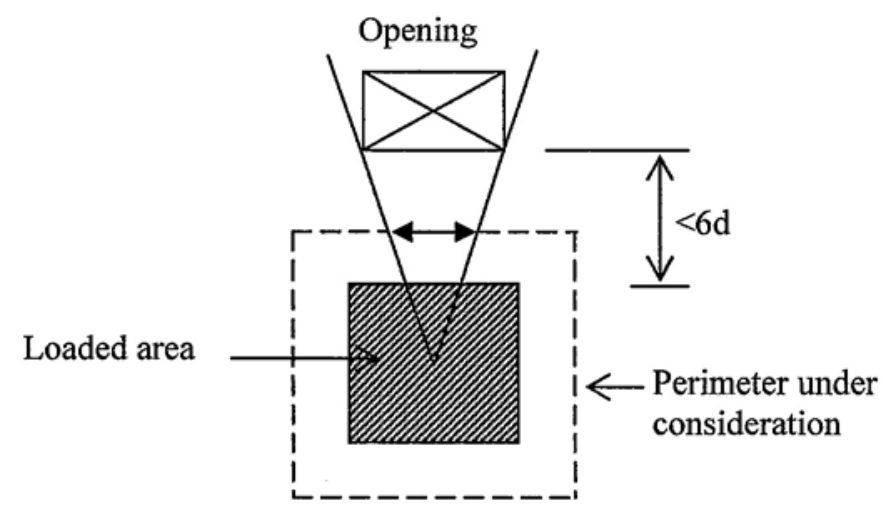

Figure 2.31 Shear perimeter of slabs with opening (BS 8110-97) 


\subsubsection{Summary}

When a slab has one or more openings in the vicinity of column region, the shear strength of the slab will be reduced by the presence of these openings. Several methods were developed and proposed in the design codes to predict the shear strength of the slab-column connections empirically. In these methods, due to the effect of openings the critical shear perimeter around the column is reduced by various ways to obtain the shear strength of the slabs with openings.

In many design codes reviewed in the previous sub-chapters, the critical perimeter at some distance from the vicinity of column face is assumed as a control parameter. The punching shear strength is calculated based on a nominal shear stress on a critical sectional area. The critical sectional area is located along a critical perimeter and has a depth equal to effective depth of slabs. Code equations are based empirically on test results and do not give the actual mechanism of slab-column connections. Regarding to the slab-column connections with holes or openings, the shearing strength is calculated based on the reduced critical shear perimeter due to openings. The effect of reinforcement that is reduced due to the presence of opening is not taken into consideration.

Many researches have been done to study the shear strength of interior slab-column connections with openings. However, data are still needed, particularly for slabcolumn connections with rectangular columns, with opening and shear reinforcement. The critical shear area around the column plays in very important role resisting the punching shear capacity of slab. Due to present of opening, some parts of critical shear area around the column may decrease or are ineffective in resisting the punching load. Therefore, it is necessary to define the critical shear area against punching correctly to predict the shear strength more reasonably. The use of suitable shear reinforcements can recover the shear strength of slab-column connections with opening.

As reviewed previously, there are many models that predict the punching shear capacity of slab-column connection. Among these models, the model based on theory 
of plasticity can give the actual collapse mechanism and nature of failure surface due to punching observed in practice. In practice, the punching shear failure surface is in curve shape. The softening effect of concrete and the variation of normal and shear stress along the failure surface play in important role in plasticity model. Previously reviewed plasticity models are for punching shear capacity of slab-connection with circular column. Thus, there are needs to extend the plasticity model for slab-column connection with square or rectangular column, with or without shear reinforcement, and with or without opening. 
CHAPTER 3 


\section{Chapter 3}

\section{Experimental programme}

\subsection{Introduction}

This experimental study is a part of research collaboration programme to study the behavior of flat plate floor systems with openings and was carried out together with two final year students, at the Nanyang Technological University, Singapore. A total of 6 normal strength concrete slabs with opening and different arrangement of shear stud reinforcement were tested. The specimens were tested to failure under monotonic loading in order to study the effectiveness of shear stud reinforcement under ultimate load conditions.

Mainly, this program aims to study (1) the behavior of slab-column connections of flat plate floor system with openings in the vicinity of column, (2) the effectiveness of shear stud reinforcement in recovering the punching strength of slab-column connections due to openings, and (3) the effectiveness on the arrangement of shear studs. To fulfill this aim, the structural behavior of specimens are examined in term of the ultimate capacity, the first cracking load, failure patterns of cracks, and the deflections of slabs.

In this chapter, the details of tested specimens are firstly presented. The arrangements of shear stud reinforcements used in the specimens are shown. The experimental setup and procedures of testing are followed.

\subsection{Slab-column specimens}

A total of six interior slab specimens supported on rectangular columns were tested. Two types of locations for openings in slabs were considered. The slab specimens were classified as two series, A and B as shown in Figure 3.1. The slabs in A-series 
had opening located at the comer of the column stub while the slabs in B-series had opening positioned at the shorter side of the column.

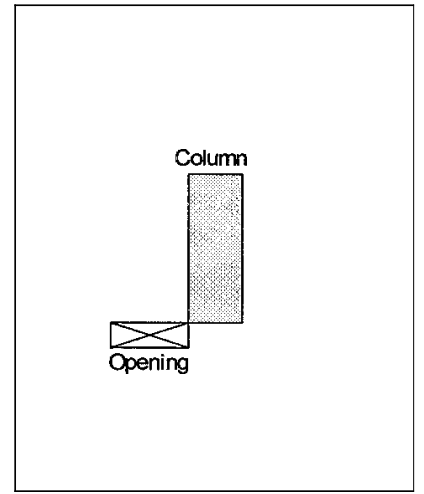

(a) A - series

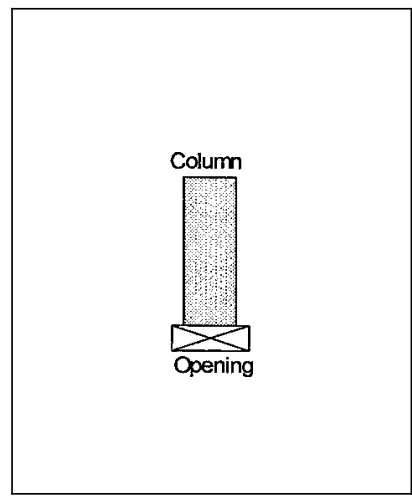

(b) B - series

Figure 3.1 Plan views of slab specimens

\subsubsection{Slab notations}

The slab specimens were labeled as "Al", "A2", "A3", "B1", "B2" and "B3". The first alphabet letter was to classify the slabs into the series. The second letter 1", "2" and " 3 " was to distinguish between the first, second and third specimen of each series.

\subsubsection{Slab details}

All the slab specimens were designed as full-scale models. Each slab had the size of $2650 \mathrm{~mm}$ by $3400 \mathrm{~mm}$, thickness of $200 \mathrm{~mm}$ and a rectangular column of $1000 \mathrm{~mm}$ by $250 \mathrm{~mm}$ cross-section with $250 \mathrm{~mm}$ depth. Each of all slabs had four free edges. The sizes of the openings in all the slab specimens were $200 \mathrm{~mm}$ by $400 \mathrm{~mm}$ and positioned at the comer and at the shorter side of column in series A and B, respectively. The slab "Al" and "B1" were control specimens without shear reinforcement for each series. Shear studs of different amount and arrangement were placed in the remaining specimens in order to investigate their effectiveness in recovering the punching shear capacity lost due to openings. 


\subsubsection{Flexural reinforcing steel}

In each slab, two layers of flexural reinforcement were placed at the top and bottom of the slab to prevent flexural failure from occurring. At the top layer, the high strength deformed T20 steel bars were placed at $125 \mathrm{~mm}$ centre-to-centre spacing in both directions. At the bottom layer, the high strength deformed T13 steel bars were placed at $200 \mathrm{~mm}$ centre-to-centre spacing in both directions. The top and bottom clear concrete cover of the slab was $20 \mathrm{~mm}$. The top and bottom layers of flexural reinforcement equivalent to that interrupted by the opening were compensated on the sides of the opening. Details of the flexural reinforcement used in the slab specimens for each of the series are shown in Figures 3.2. In the column, the ten numbers of T20 high strength deformed bars were evenly spaced with T10 links of $100 \mathrm{~mm}$ centre-tocentre spacing. The clear concrete cover of the column was $40 \mathrm{~mm}$. The flexural reinforcement provided were more than the required amount based on the predicted ultimate loads in order to ensure punching shear failure to occur before the yielding of the longitudinal reinforcement.

\subsubsection{Shear studs}

All specimens had the shear stud reinforcements except the control specimens, A1 and B1. The high strength deformed T10 vertical bars were used as shear stud reinforcement in this experimental study. One end of each shear stud had an anchorage head of $30 \mathrm{~mm}$ diameter while the other end was welded to a common rail of steel plate of $20 \mathrm{~mm}$ by $5 \mathrm{~mm}$ to keep them at right position. Overall height of shear studs including the thickness of the anchorage head was $160 \mathrm{~mm}$. The center-tocenter spacing between rows of shear studs was $0.75 \mathrm{~d}$. The "d" is effective depth of slab. The details of shear studs reinforcement in the specimens are shown in Table 3.1 and Figure 3.3. The arrangements of shear stud reinforcements are shown in Figure 3.4 . 


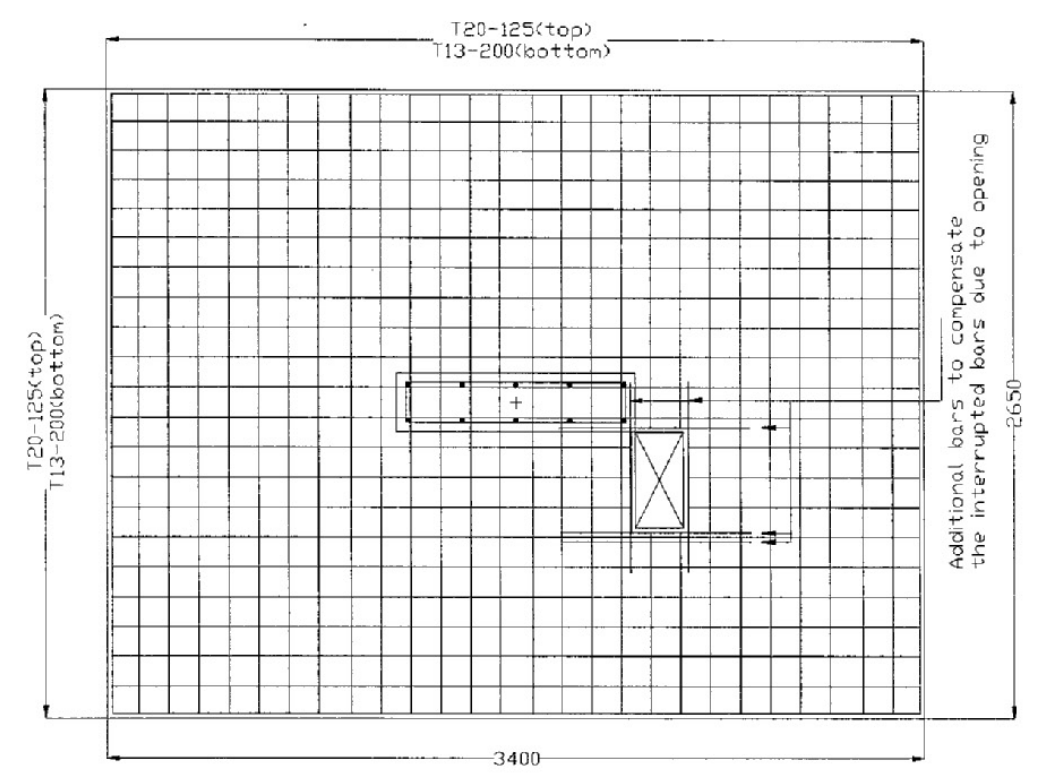

(a) A series specimens

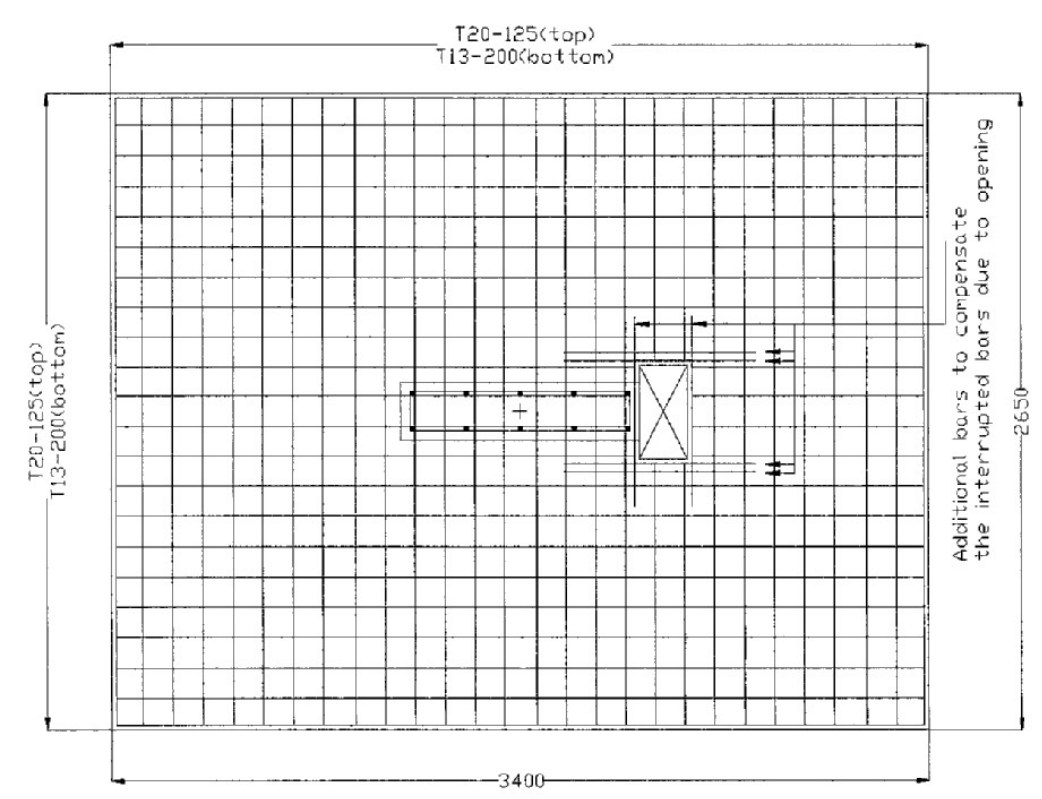

(b) $B$ series specimens

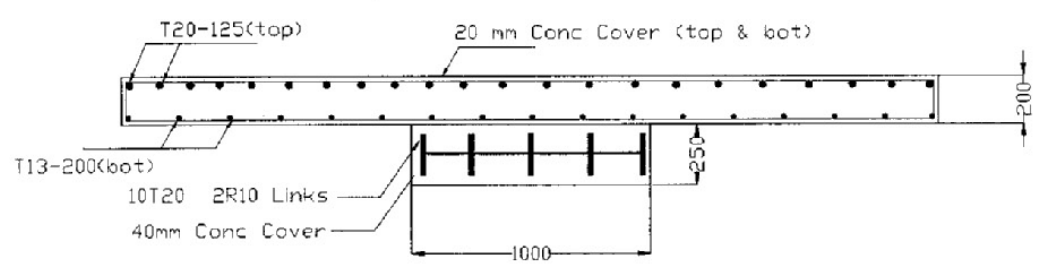

(c) Typical cross-section of all slab specimens

Figure 3.2 Details of flexural reinforcement in slab specimens 
Table 3.1 Details of shear studs reinforcement in slab specimens

\begin{tabular}{|c|c|c|c|}
\hline Specimen & $\begin{array}{c}\text { Number of rails of shear } \\
\text { stud reinforcement }\end{array}$ & $\begin{array}{c}\text { Number of shear } \\
\text { studs per rail }\end{array}$ & $\begin{array}{c}\text { Center to center spacing } \\
\text { of shear studs }\end{array}$ \\
\hline $\mathbf{A 2}$ & 5 & $\mathbf{8}$ & $0.75 \mathrm{~d}$ \\
\hline $\mathbf{A 3}$ & $\mathbf{6}$ & 5 & $0.75 \mathrm{~d}$ \\
\hline $\mathbf{B 2}$ & $\mathbf{6}$ & $\mathbf{8}$ & $0.75 \mathrm{~d}$ \\
\hline $\mathbf{B 3}$ & $\mathbf{6}$ & 5 & $0.75 \mathrm{~d}$ \\
\hline
\end{tabular}

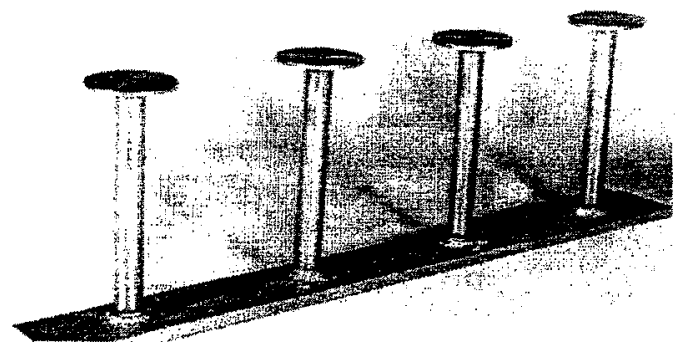

Figure 3.3 Typical structural details for the shear studs

In each series, different arrangements of shear stud reinforcement were used. The two control specimens of A1 and A2 had no shear stud reinforcement. In specimens A2, A3, B2, and B3, different amount and arrangement of shear stud reinforcements were used. The arrangements of shear studs for each specimen can be seen in Figure 3.4. The following describes the quantities of shear studs used and arranged, and the reason these arrangements were chosen.

(1) In specimen A2, five numbers of rails in which each rail consisted of 8 shear studs were used. All shear studs reinforcements were placed near the opening so that the loss in shear capacity at the lower half due to the presence of the opening might be regained and it might prevent the failure crack from intercepting the opening.

(2) In specimen A3, six numbers of rails in which each rail consisted of the minimum requirement of 5 shear studs were used. Three rails were placed around the one shorter column width and not in the middle region of the longer column widths so that the shorter column width where the stress concentrations occurred might be to strengthen. Other three rails in which two rails were placed beside the opening were placed around the remaining shorter column width. 


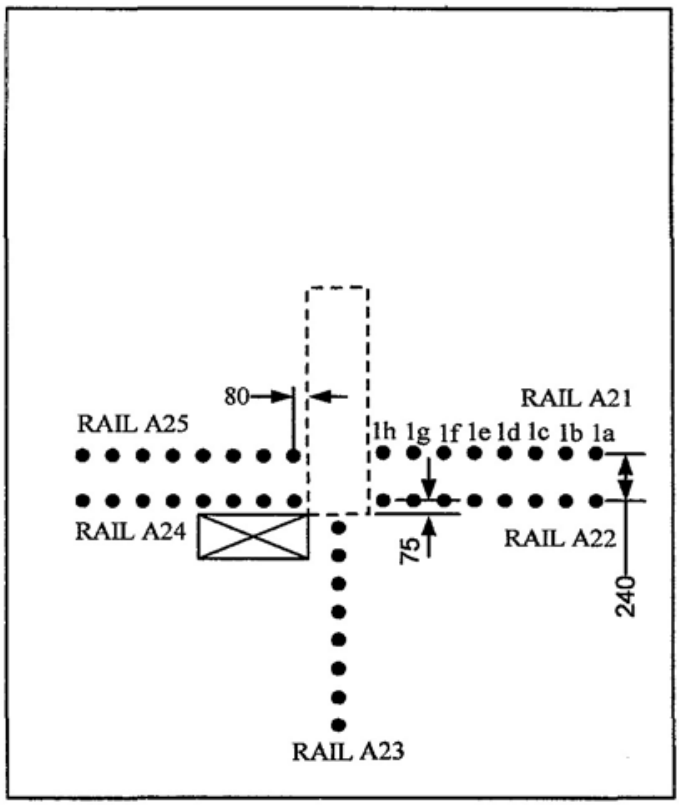

Specimen A2

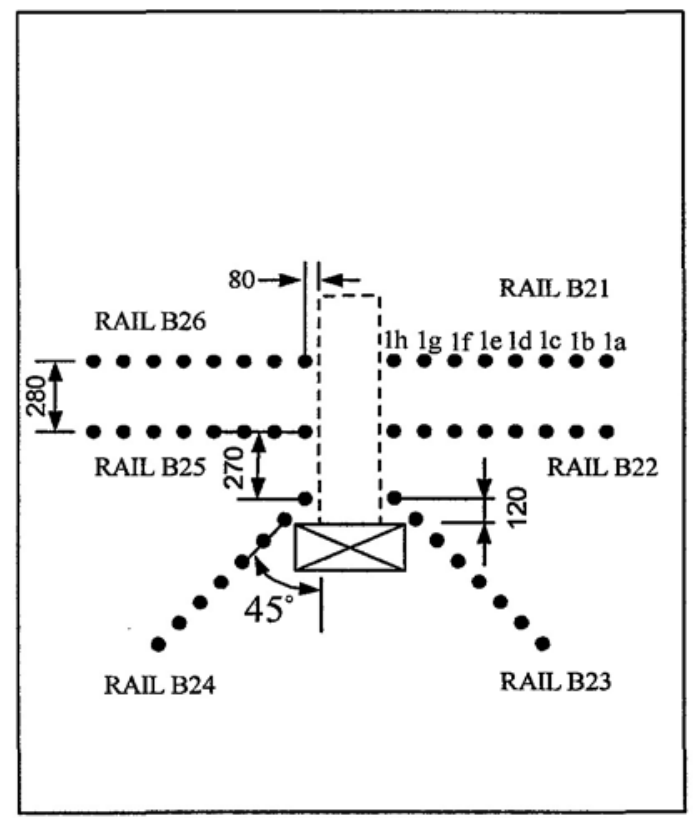

Specimen B2

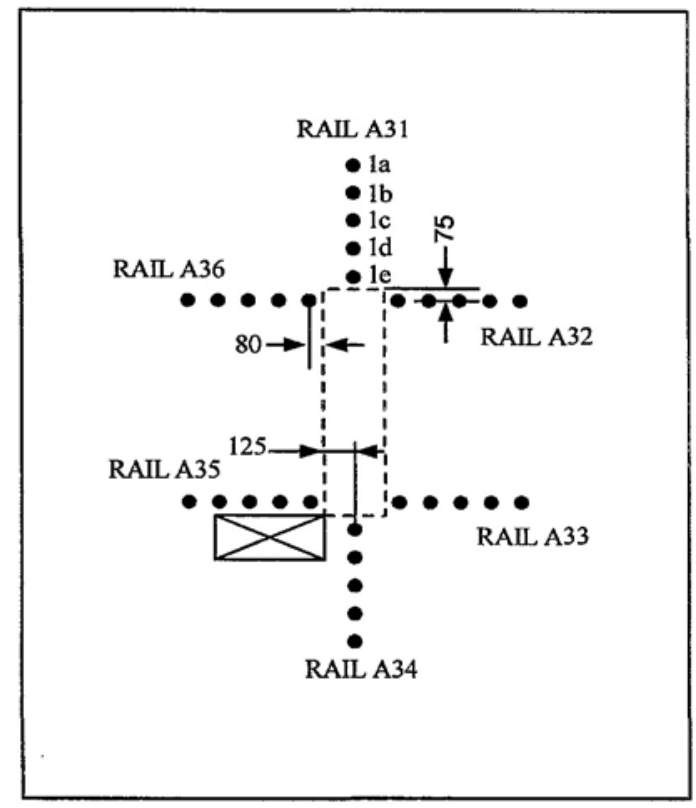

Specimen A3

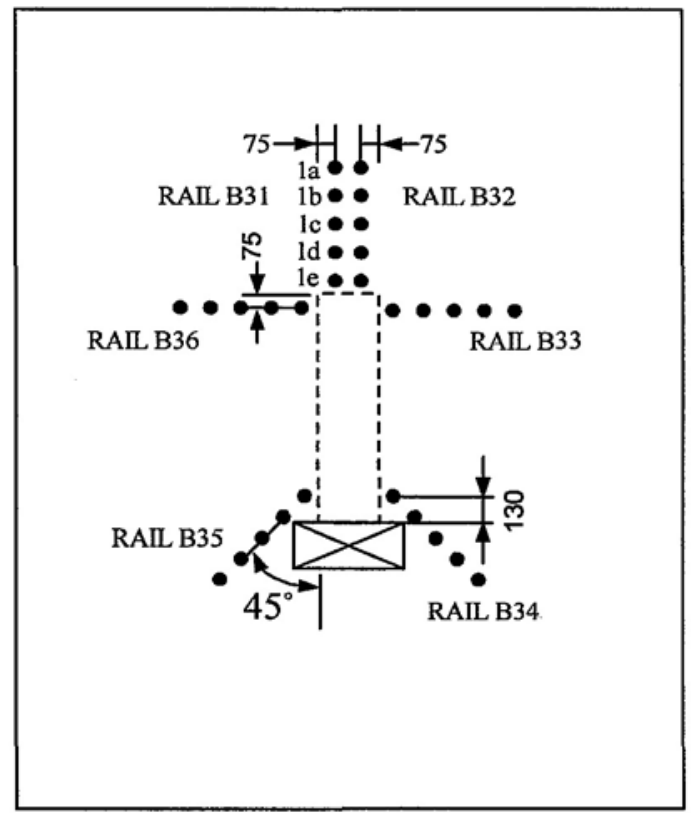

Specimen B3

Figure 3.4 Arrangement of shear stud reinforcements in the slab specimens

(3) In specimen B2, six numbers of rails in which each rail consisted of 8 shear studs were used. All the rails were placed in the region of the slab near the opening. Like specimen A2, the using longer rail was to prevent the failure crack from intercepting the opening. The tilting of two rails with 45 degrees near the opening was to provide additional stiffness in the region near the opening. 
(4) In specimen B3, six numbers of rails in which each rail consisted of the minimum requirement of 5 shear stud were used. Four rails were placed around the shorter column width to strengthen. The tilting of two rails with 45 degrees near the opening was to provide additional stiffness in the region near the opening like specimen B2.

\subsubsection{Material properties}

\section{Properties of concrete}

The design concrete specifications for all specimens are as follows:
(a) Cement
: Ordinary Portland Cement,
(b) Concrete characteristic strength : $40 \mathrm{~N} / \mathrm{mm}^{2}$ at 28 days in accordance to BS 5328,
(c) Maximum size of aggregate $: 20 \mathrm{~mm}$, and
(d) Slump of concrete
$: 100 \pm 25 \mathrm{~mm}$.

Using two batches of concrete, all specimens were prepared. Each series of specimen was cast using concrete from each batch. From each batch of concrete, the total twelve numbers of concrete cylinder and cubes were prepared and cured alongside the slab specimens. All cylinders and cubes were tested in compression to obtain the compressive cylinder strength $\left(f_{c}{ }^{\prime}\right)$ and the compressive cube strength $\left(f_{c u}\right)$. The Young's modulus of concrete $(\mathrm{E}$, ) was obtained by taking the initial slope of stress strain curve. The average $f_{c}{ }^{\prime}, f_{c u}$, and $\mathrm{E}_{\mathrm{c}}$ are shown in Table 3.2.

Table 3.2 Test results of compressive concrete cylinder and cube strengths

\begin{tabular}{|c|c|c|c|c|}
\hline $\begin{array}{c}\text { Series of } \\
\text { Specimen }\end{array}$ & Batch number & $\begin{array}{c}\text { Average } f_{\mathrm{c}} \\
\left(\mathrm{N} / \mathrm{mm}^{2}\right)\end{array}$ & $\begin{array}{c}\text { Average } \mathbf{f}_{\mathrm{cu}} \\
\left(\mathrm{N} / \mathrm{mm}^{2}\right)\end{array}$ & $\begin{array}{c}\text { Average } \mathrm{E}_{\mathrm{c}} \\
(\mathrm{GPa})\end{array}$ \\
\hline $\mathrm{A}$ & 1 & 38.2 & 47.9 & 28.5 \\
\hline $\mathrm{B}$ & 2 & 36.3 & 44.8 & 22.4 \\
\hline
\end{tabular}

\section{Properties of steel}

In all specimens, high strength deformed steel bars (T-bars) with 20, 13, and $10 \mathrm{~mm}$ diameter were used as top and bottom flexural reinforcements and shear stud reinforcement, respectively. Tensile tests on two steel bars from each diameter size 
were done in Universal Testing Machine to obtain the yield strength $\left(\mathrm{f}_{\mathrm{y}}\right)$ of these steel bars. The $0.2 \%$ off-set method was used to obtain the yield strength of steel bars. The yield strength $\left(f_{y}\right)$ and Young's Modulus $\left(\mathrm{E}_{\mathrm{c}}\right)$ of each diameter size of steel bars are shown in Table $\mathbf{3 . 3}$.

Table 3.3 Steel bar tensile test results

\begin{tabular}{|c|c|c|c|}
\hline Type of bars & Bar Marking & Average $f_{y}$ & Average $\mathrm{E}_{\mathrm{s}}$ \\
\hline Top reinforcement & $\mathrm{T} 20$ & 580 & 192.3 \\
\hline Bottom reinforcement & $\mathrm{T} 13$ & 600 & 212.4 \\
\hline Shear studs & $\mathrm{T} 10$ & 540 & 184.7 \\
\hline
\end{tabular}

\subsection{Experimental set-up}

The experimental set-up for testing of the slab specimens is shown in Figure 3.5. In each specimen, 4 numbers of holes with $80 \mathrm{~mm}$ diameter that were positioned in the middle of each edge were perforated to place the four pull-down prestressing rods vertically, which are shown in Figure 3.6. Plan view of testing set-up for slab is shown in Figure 3.7. The column stubs of the slab specimens were placed on top of a big steel plate which was anchored to the laboratory strong floor. Therefore, the test specimens were only supported on column while all edges were free.

The four spreader beams were located on the slab, which were parallel with the edge of the slabs. Each of the spreader beams was supported at their ends by two bearing supports rested on the slab. Four pull-down prestressing rods passed through the four holes of slab and the holes in the center of each spreader beam. The diameter of pulldown prestressing rod was $40 \mathrm{~mm}$ and it transferred the loads from a hydraulic jack to a spreader beam. Each load cells was installed on top of each spreader beam by a number of bolts and nuts through the pull-down prestressing rod. Below the slab, each hydraulic jack was individually supported on the laboratory strong floor by a number of holding down bolts and connected to a central controlling valve to control the total load acting on the slab specimens. 
The four $1000 \mathrm{kN}$ capacity hydraulic jacks were used to apply the vertical loads to the slab specimens through the four spreader beams. Each spreader beam distributed the applied loads to the slabs at two ends of spreader beam through the bearing plates. By this method, eight point loads were applied to the slab specimens. By placing the bearing supports under the spreader beams at equal distances away from the edge of the column, a simply supported system was performed with the spreader beams in order to transfer the loads. Besides, the load cells controlled the total applied load, which was connected directly with the prestressing rods and hydraulic jack. This load cell had a load measuring capacity of up to $1000 \mathrm{kN}$.

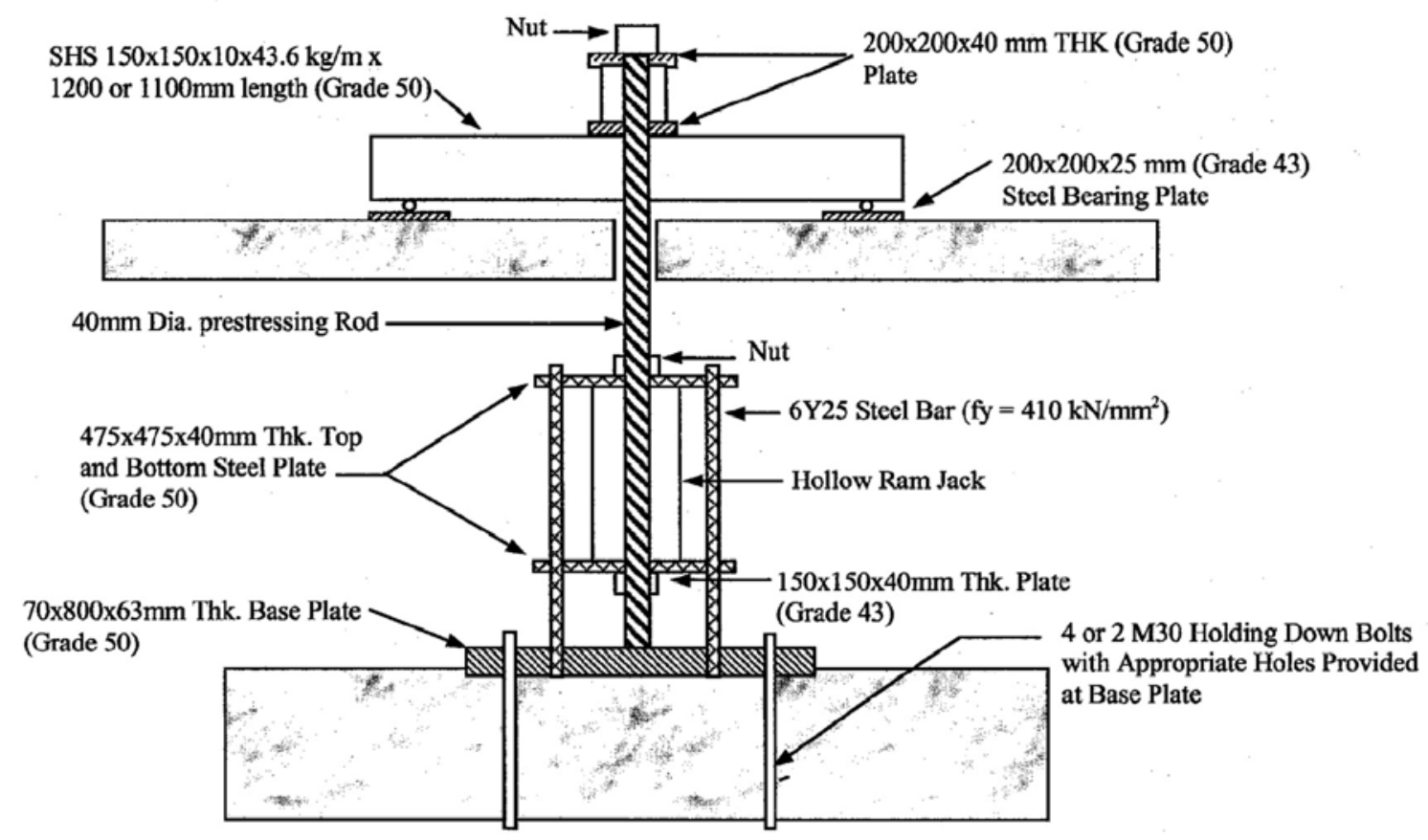

Figure 3.5 Testing set-ups 


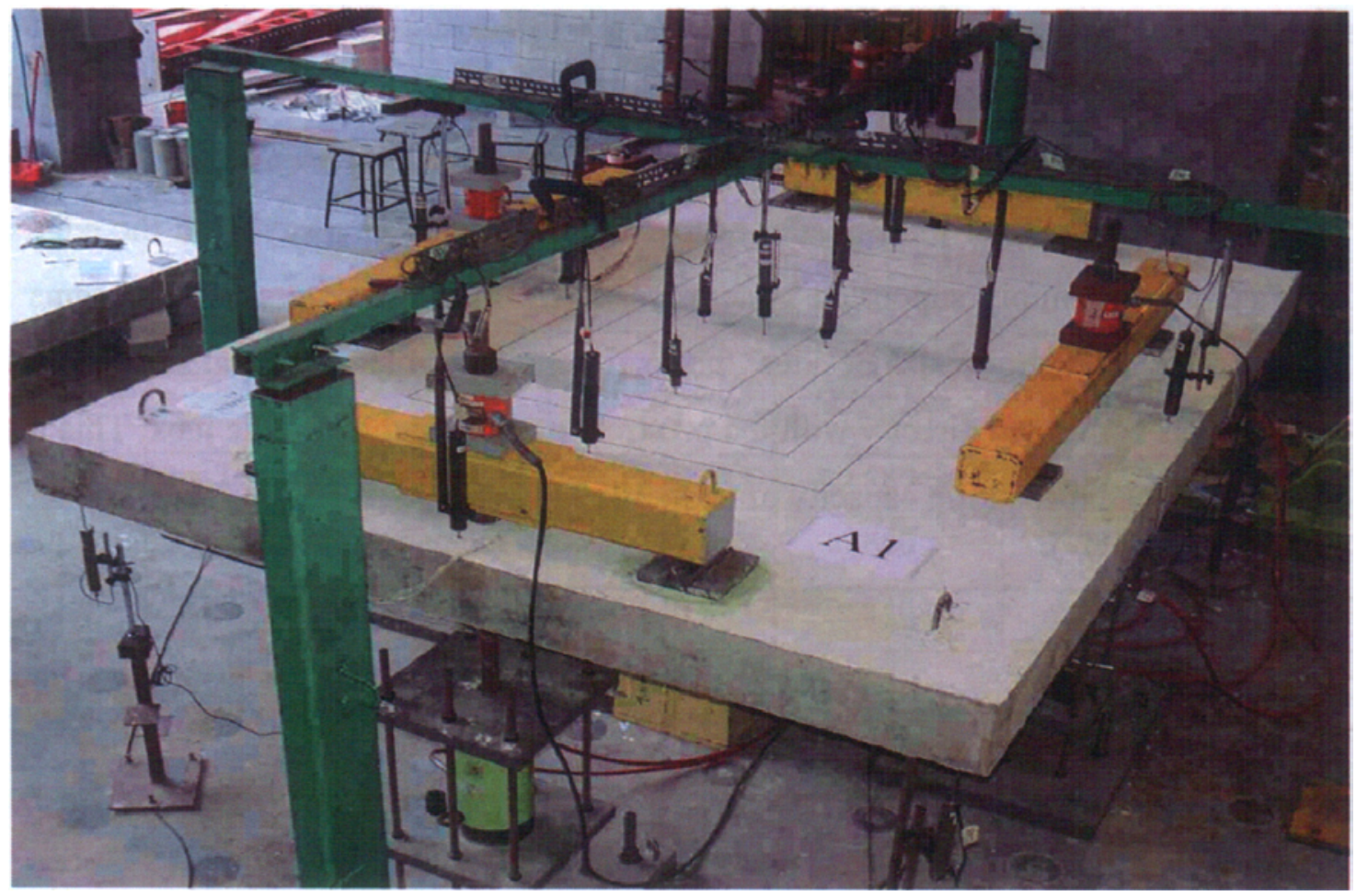

Figure 3.6 Testing set-up complete with spreader beams and LVDTs

\subsection{Instrumentation}

The instrumentation consists of

(1) four $1000 \mathrm{kN}$ load cells,

(2) a series of Linear Variable Differential Transducer (LVDT),

(3) strain gauges, and

(4) a set of data logging equipment.

Each of them serves their functions described as in the following sections.

\subsubsection{Load cell}

The function of the load cells was to measure the applied loads. Four number of load cells were used and each load cell was placed on top of a spreader beam which was directly in contact with the pre-stressing rod on the top side of the slab specimen to measure the pull-down system of the hydraulic jack. The spreader beams transferred the loads from the hydraulic jacks to the slabs. 

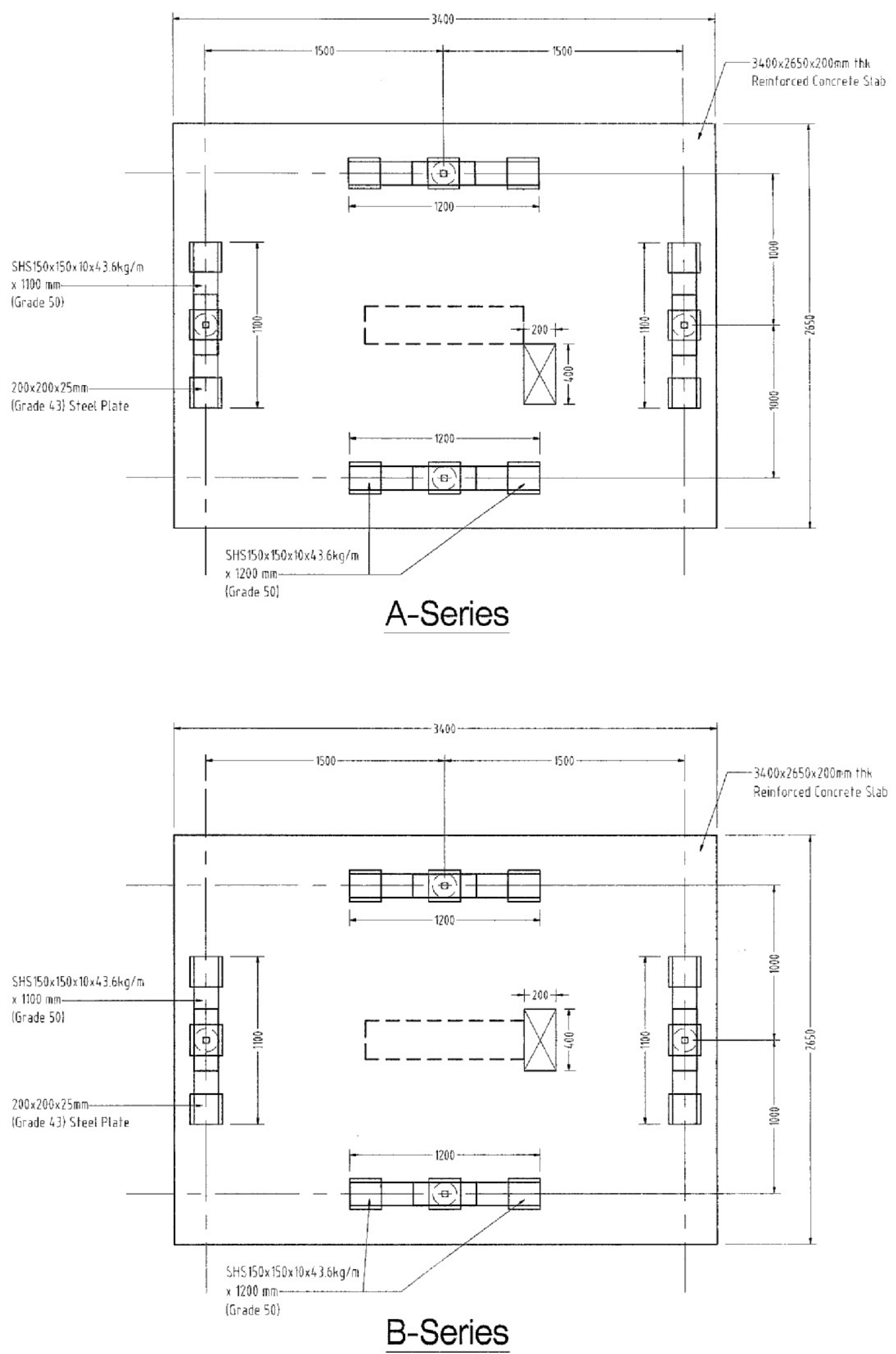


\subsubsection{Linear variable differential transducer (LVDT)}

In order to observe and measure the deflection of the tested slab-column specimens, 17 numbers of linear variable transducers were installed. The 12 numbers of LVDTs (D1 to D12) were situated at $0.5 \mathrm{~d}, 3.5 \mathrm{~d}$ and $7 \mathrm{~d}$ from the column face on top side of slab while 4 numbers of LVDTs (D13 to D16) were placed at the corners of the perimeter $7 \mathrm{~d}$ from the column face below the slab. The remaining One LVDT (D17) was located directly above the center of column to record the vertical displacement of the column itself so that the relative deflection for the rest of the locations could be calculated. In series B, LVDTs number D4 and D8 were placed at $0.5 \mathrm{~d}$ and $3.5 \mathrm{~d}$ from the edge of the opening while in series $\mathrm{A}$, at $0.5 \mathrm{~d}$ and $3.5 \mathrm{~d}$ from the face of shorter column width. All transducers were connected to the data logging equipment via electrical cables to record the data. The locations of LVDTs for all slab-column specimens can be seen Figure 3.8.
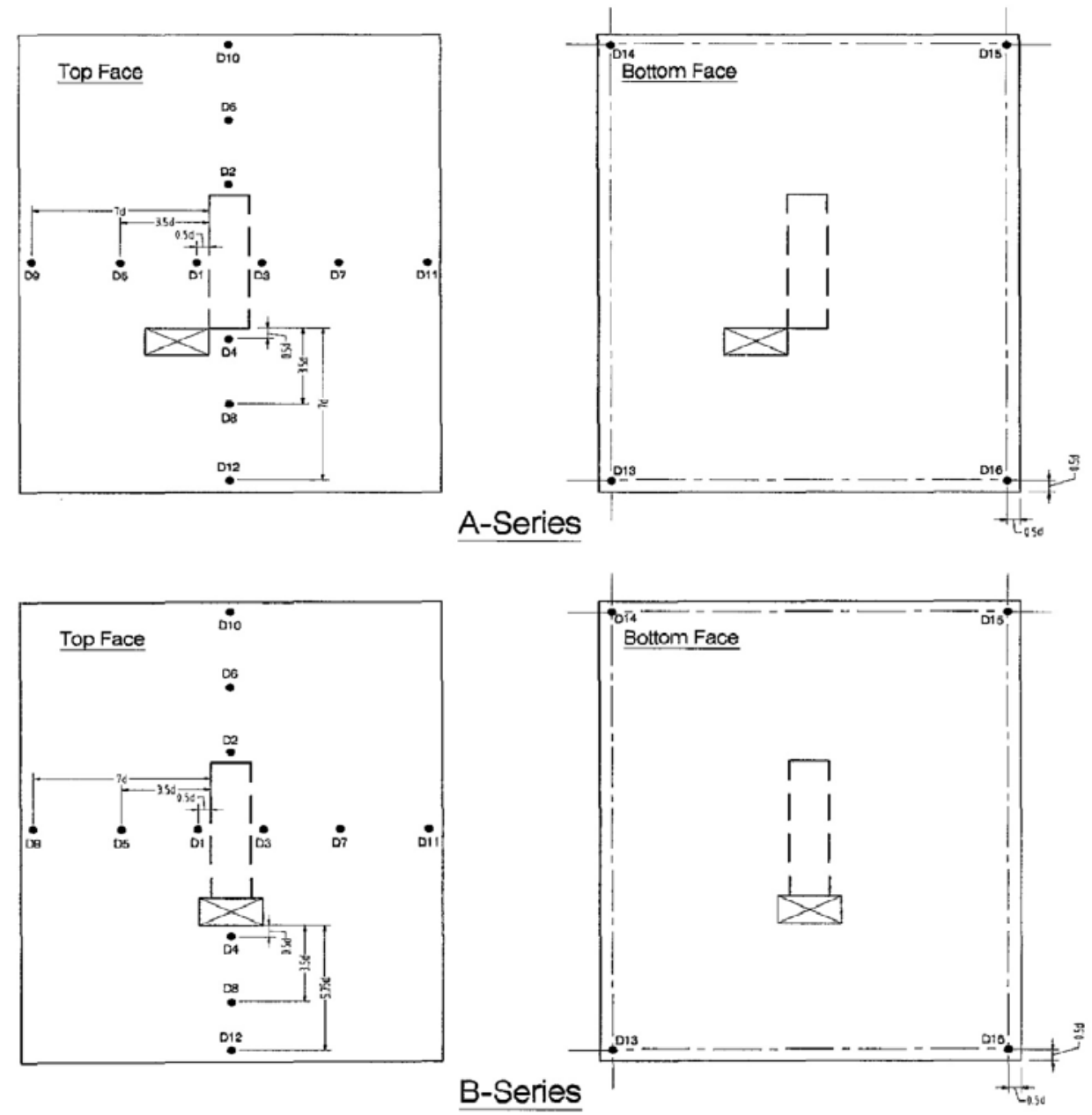

Figure 3.8 LVDT locations on slab specimens 


\subsubsection{Strain gauges}

In order to measure the strains of the flexural and shear stud reinforcement and to conclude that whether the punching shear occurred before or after the flexural reinforcement had yielded, the $5 \mathrm{~mm}$ electrical resistance strain gauges were used. Also, the strains recorded with the strain gauges could be used to investigate the stresses at different locations of the slab. These electrical resistance strain gauges were attached to the specified positions on the surface of selected flexural reinforcement and at mid height of all shear stud reinforcement. To smooth the surface, grinding was done at designated positions on selected flexural reinforcements and at the mid-height of all shear stud reinforcements. A layer of silicon gel was applied to protect all strain gauges. The strain gauges on slab specimens were positioned at distance of $1 \mathrm{~d}$ and $2 \mathrm{~d}$ from column face due to the consideration that most of the punching shear failures might occur in the vicinity of the column at a distance of $1 \mathrm{~d}$ and $2 \mathrm{~d}$ from the column face. Also, some strain gauges were installed at the critical perimeter of $0.5 \mathrm{~d}$ from the outermost peripheral of shear studs. The "d" is the effective depth of slab. The number of strain gauges installed in each specimen is shown in Table 3.4 and their locations on shear studs in the slabs can be seen at the same location of shear studs shown in Figure 3.4 and on flexural reinforcement shown in Figure 3.9.

\section{Table 3.4 Distribution of strain gauges on flexural and shear stud reinforcement for slab specimens}

\begin{tabular}{|c|c|c|}
\hline \multirow{2}{*}{ Slab Specimen } & \multicolumn{2}{|c|}{ Number of strain gauges } \\
\cline { 2 - 3 } & $\begin{array}{c}\text { on tension } \\
\text { reinforcements }\end{array}$ & $\begin{array}{r}\text { on shear stud } \\
\text { reinforcements }\end{array}$ \\
\hline A1 & 18 & 0 \\
\hline A2 & 21 & 40 \\
\hline A3 & 24 & 30 \\
\hline B1 & 12 & 0 \\
\hline B2 & 18 & 48 \\
\hline B3 & 21 & 30 \\
\hline
\end{tabular}




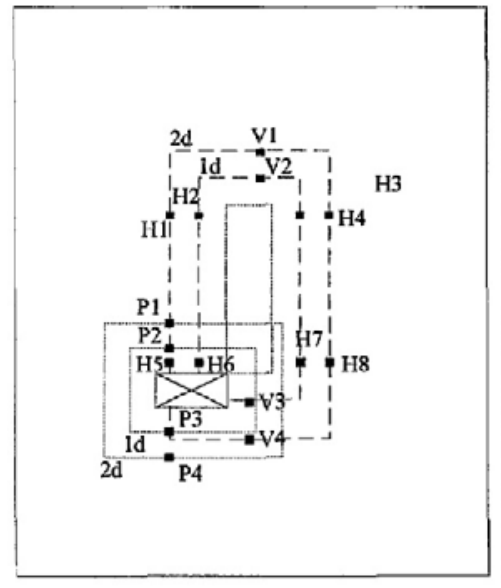

Specimen A1

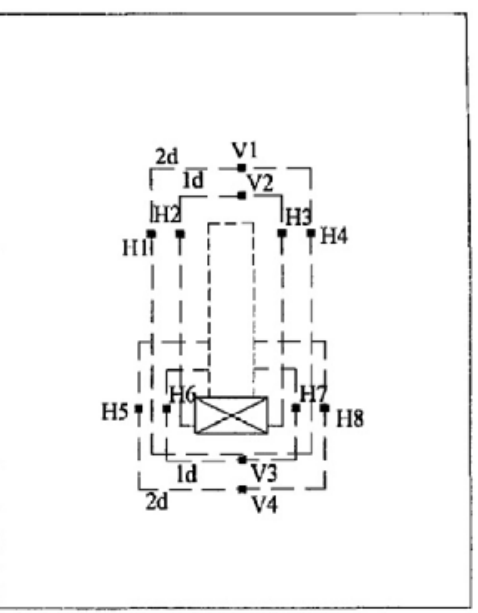

Specimen B1

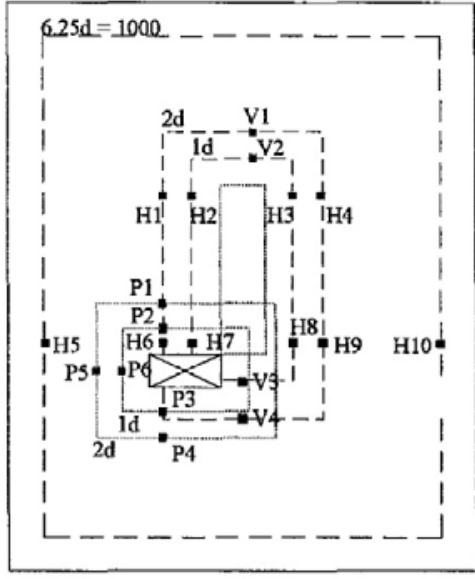

Specimen A2

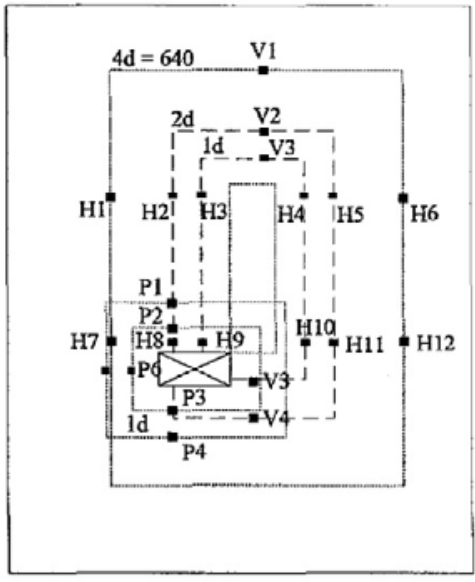

Specimen A3

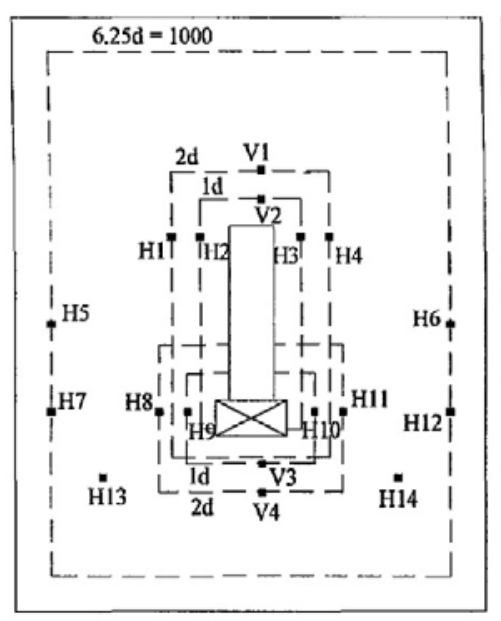

Specimen B2

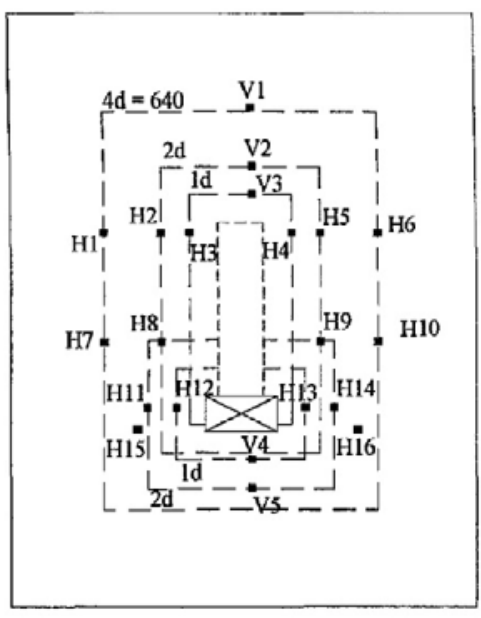

Specimen B3

Figure 3.9 Strain gauge locations on flexural reinforcements in slab-column specimens

\subsubsection{Data logging equipment}

In the data logging equipment, a data logger, a personal computer and a 50-channel switch box were utilized. The wires were used to connect all measuring instruments to the data logger through the switch boxes. The personal computer was used with a visual basic program called the Laboratory Windows in order to record the data of the load, deflection and strain continuously throughout the test. 


\subsection{Procedure of testing}

When the specimen was ready to be loaded, the $50 \mathrm{kN}$ load was applied and then released to almost zero to stabilize the entire set-up. Then all specimens were loaded at eight points with equal loads of $5 \mathrm{kN}$ each on top side of the slab. Initially the load was applied with increment of $20 \mathrm{kN}$ until it reached $200 \mathrm{kN}$. After that, the load was increased with $40 \mathrm{kN}$ increment up to the failure of the specimen. The first crack in all slab specimens was carefully observed. The crack patterns were drawn at every 200 $\mathrm{kN}$ load from the start of the test until failure. The crack widths were also measured at every load increment.

In order to observe the post-punching behavior of slabs, the loading was continued even after it reached the failure load. When the crack pattern could be seen clearly, the loading was stopped. 
CHAPTER 4 


\section{Chapter 4}

\section{Experimental results and discussion}

\subsection{Introduction}

As previously presented in chapter three, in order to get better understanding on the behavior of the rectangular slab-column connections with opening and to investigate the effectiveness of shear stud reinforcement in improving and recovering the punching shear capacity of the slab-column connections lost due to opening, a total of six slab-column specimens with opening as comprised in two series A and B were tested. The location of opening in the slab-column specimens of series A was at the corner of the column while the location of opening in the slab-column specimens of series B was at the shorter column width. Except the control specimen A1 and B1, all slab-column specimens had shear stud reinforcements (SSR) with different quantities and arrangements. The locations of opening and arrangements of shear stud reinforcements in the slab-column specimens according to north-south and east-west directions are shown in Figure 4.1.
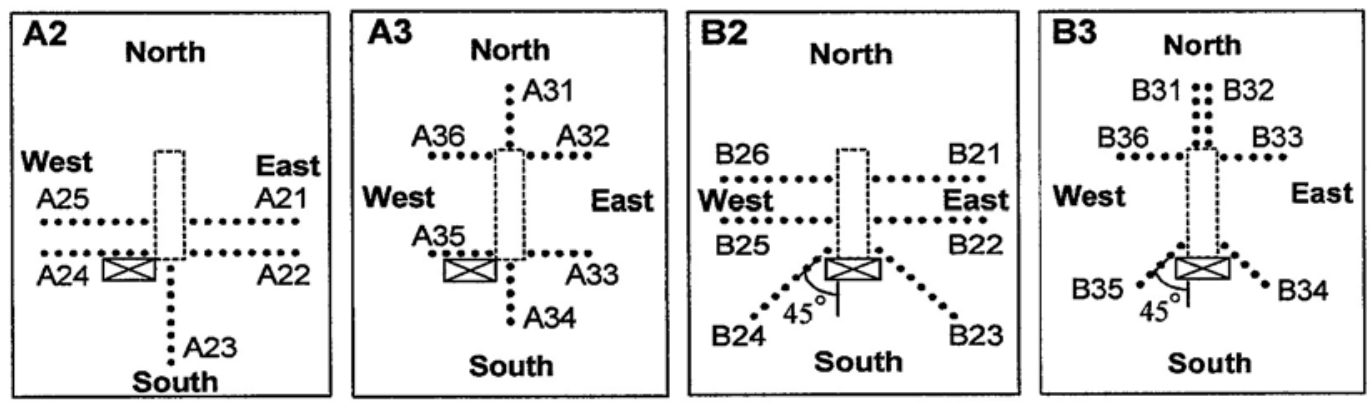

Figure 4.1 Location of opening and arrangement of SSR in the slabs

In this chapter the ultimate punching shear capacities of slab-column specimens obtained by testing are discussed first. Secondly, the serviceability load, crack patterns, and deflections of the slab-column specimens observed from testing are discussed. Thirdly, the discussion is made based on the analysis of strain gauge measurements recorded on the flexural and shear reinforcements of the slab-column specimens during testing. Finally, summary and conclusion are drawn. 


\subsection{Ultimate punching shear capacity}

The ultimate punching shear capacity is defined as the maximum applied punching load at which the slab fails in punching shear failure. All slab-column specimens failed suddenly before the longitudinal bars yield. It indicates that all the slab-column specimens had failed due to punching shear failure. The ultimate punching shear capacities of the slab-column specimens obtained by testing are tabulated together with their percentage increases compared to the respective control specimens and the quantities of shear studs reinforcements used in the slabs in Table 4.1.

Table 4.1 Test results for the ultimate punching capacities of the slabs

\begin{tabular}{|c|c|c|c|c|c|}
\hline \multicolumn{2}{|c|}{ Specimen } & $\begin{array}{c}\mathrm{P} \\
(\mathrm{kN})\end{array}$ & $\begin{array}{l}\text { Difference between } \\
\text { ultimate punching } \\
\text { shear capacities of } \\
\text { A1 and B1 (\%) }\end{array}$ & $\begin{array}{c}\text { Increase in } \\
\text { ultimate punching } \\
\text { shear capacity (\%) }\end{array}$ & $\begin{array}{c}\text { Quantity } \\
\text { of shear stud } \\
\text { reinforcements }\end{array}$ \\
\hline \multirow{3}{*}{$\begin{array}{c}\text { A } \\
\text { Series }\end{array}$} & $\overline{\mathrm{A} 1}$ & 740 & +21.6 & - & No \\
\hline & $\overline{\mathrm{A} 2}$ & 908 & - & 22.7 & $5 \times 8$ studs per rail \\
\hline & A3 & 948 & - & 28.1 & $6 \times 5$ studs per rail \\
\hline \multirow{3}{*}{$\begin{array}{c}\text { B } \\
\text { Series }\end{array}$} & B1 & 580 & -21.6 & - & No \\
\hline & B2 & 848 & - & 46.2 & $6 \times 8$ studs per rail \\
\hline & B3 & 692 & - & 19.3 & $6 \times 5$ studs per rail \\
\hline
\end{tabular}

$\mathrm{P}=$ Ultimate punching shear capacity

From Table 4.1, it can be seen that the ultimate punching shear capacity of the control slab-column specimen A1 is $21.6 \%$ larger than that of the control slab-column specimen B1. It may be due to that the shear stresses concentrate highly at the shorter column width and vary in decreasing rate from the shorter column width to the longer column width along the peripheral around the column. As such, we can point out that (1) the placing of opening near the column can decrease the punching shear capacity of the slab; (2) the decrease in the punching shear capacity due to opening can differ according to location of openings itself; and (3) the location of opening at the shorter column width can affect more than the location of opening at the comer of column.

About the shear stud reinforcements, on the comparison the ultimate punching shear capacities of the slab-column specimens with their respective control slab-column 
specimens, the punching shear capacities of all slab-column specimens with shear stud reinforcements were observed greater than that of their respective control slabcolumn specimens. It indicates that the use of shear stud reinforcements are significantly effective in recovering the punching shear capacity of the slab lost due to opening.

\subsubsection{Slab-column specimens for series A}

The slab-column specimen A2 had $5 \times 8$ suds per rail which were placed near the region around opening, while the slab-column specimen A3 had $6 \times 5$ suds per rail which were placed near the region around the opening and around the shorter column width where opening was not located. The arrangement of shear stud reinforcements used in the slab-column specimens of series A can be seen in Figure 4.1.

From Figure 4.1, it can be seen that the increases in the ultimate punching shear capacity of slab-column specimen A2 and A3 compared to their control slab-column specimen A1 are $22.7 \%$ and $28.1 \%$, respectively. And so, the increase in the ultimate punching shear capacity of slab-column specimens A3 is about $6 \%$ greater than the increase in the ultimate punching shear capacity of slab-column specimen A2. Therefore, it can be concluded that the arrangement of shear stud reinforcements in the slab-column specimens A3 is more effective in increasing and recovering the punching shear capacity than that in the slab-column specimen A2.

\subsubsection{Slab-column specimens for series $B$}

The slab-column specimen B2 had 6x8 suds per rail in which two rails were placed near the region around the opening by tilting $45^{\circ}$ and other four rails were placed from the column end having opening approximately to the middle of longer column width. The slab-column specimen B3 had $6 \times 5$ suds per rail in which two rails were placed near the region around the opening by tilting with $45^{\circ}$ and other four rails were placed around the shorter column width where the opening was not located. The arrangement of shear studs reinforcements in slab-column specimens of series B can be seen in Figure 4.1. 
From Table 4.1, it can be seen that the increase in the ultimate punching shear capacity of slab-column specimens B2 and B3 compared to their control slab-column specimen B1 are $46.2 \%$ and $19.3 \%$, respectively. The increase in the ultimate punching shear capacity of slab-column specimens B2 is about $27 \%$ greater than the increase in the ultimate punching shear capacity of slab-column specimen B3. Therefore, for series B, it is evident that the arrangement and quantity of shear stud reinforcements in slab-column specimens B2 was significantly more effective in increasing the punching shear capacity than that in the slab-column specimen B3. But the quantity of shear stud reinforcements in slab-column specimen B2 is greater than that slab-column specimen B3. Therefore, if same quantity of shear stud reinforcement in series $\mathrm{B}$ is used, we can not certainly conclude whether the arrangement of shear reinforcement in slab-column specimen B2 may be effective more than that of slab-column specimen B3.

\subsubsection{Findings}

From the analysis based on the ultimate punching shear capacities of the slab-column specimens above, the findings can be summarized as the following.

(1) The location of opening at the shorter column width could affect the punching shear capacity of slab-column connection about $22 \%$ more severe than that at the comer of column.

(2) For slabs with opening at the corner of column, the arrangement and quantity of shear stud reinforcements in slab A2 and A3 increased the ultimate punching shear capacity of slab $22.7 \%$ and $28.1 \%$, respectively, while for slabs with opening at the shorter column width, the arrangement and quantity of shear stud reinforcements in slab B2 and B3 increased the ultimate punching shear capacity of slab $46.2 \%$ and $19.3 \%$, respectively. Therefore, the use of shear stud reinforcements are significantly effective in increasing and recovering the punching shear capacity of the slab lost due to opening and effectiveness of shear studs depends on their arrangement and quantity. 


\subsection{Serviceability}

In this section, the serviceability conditions of tested slab-column specimens from the previous chapter are discussed based on the first cracking load, crack patterns and deflection of slabs due to the applied loads.

\subsubsection{First cracking load}

The serviceability load is defined as the load at which the first flexural crack occurs. The first cracking loads of all slab-column specimens are shown in Table 4.2. All slab-column specimens reached their first cracking load about $11 \%-22 \%$ of the ultimate punching shear capacity of each slab. The first cracking load of the control specimen A1 is about $38 \%$ more than that in specimen B1. Therefore, the location of opening adjacent to shorter column width affect the serviceability of the slab more than that of the location of opening at the comer of column.

\section{Table 4.2 Test results of first cracking load}

\begin{tabular}{|c|c|c|c|c|c|}
\hline \multicolumn{2}{|c|}{ Spec. } & $\begin{array}{c}\text { First } \\
\text { cracking } \\
\text { load } \\
(\mathrm{kN})\end{array}$ & $\begin{array}{l}\text { Percentage of first } \\
\text { cracking load on } \\
\text { ultimate punching } \\
\text { shear capacity (\%) }\end{array}$ & $\begin{array}{c}\text { Difference } \\
\text { between first } \\
\text { cracking loads of } \\
\text { A } 1 \text { and B1 (\%) }\end{array}$ & $\begin{array}{c}\text { Difference of first } \\
\text { cracking load between } \\
\text { the respective specimens } \\
\text { and their control } \\
\text { specimen }(\%)\end{array}$ \\
\hline \multirow{3}{*}{$\begin{array}{c}\text { A } \\
\text { Series }\end{array}$} & A1 & 160 & 21.6 & +37.5 & \\
\hline & A2 & 120 & 13.2 & & -25 \\
\hline & A3 & 140 & 14.8 & - & -12.5 \\
\hline \multirow{3}{*}{$\begin{array}{c}\text { В } \\
\text { Series }\end{array}$} & B1 & 100 & 17.2 & -37.5 & \\
\hline & B2 & 140 & 16.5 & & +40 \\
\hline & B3 & 80 & 11.6 & - & -20 \\
\hline
\end{tabular}

\subsubsection{Slab-column specimens for series A}

In series $\mathrm{A}$, the first cracking loads of slab-column specimen A2 and A3 are about $25 \%$ and $13 \%$ less than that of the control slab-column specimens A1, respectively. It indicates that the use of shear stud reinforcements in this series A is not actually 
effective in improving the serviceability load. However, it can be seen that the first cracking loads of the slab-column specimen A2 is about $12 \%$ greater than that of the slab-column specimen A3.

\subsubsection{Slab-column specimens for series B}

In series B, the first cracking load of slab-column specimen B2 is $40 \%$ more than that of the control slab-column specimen B1 while the first cracking load of slab-column specimen B3 is $20 \%$ less than that of the control slab-column specimen B1. Because the quantity of shear stud reinforcements used in slab-column specimen B2 is more than that in slab-column specimen B3, it can not clearly indicate that the use of quantity and arrangement of shear stud reinforcement in this series B is effective in improving the serviceability load.

\subsubsection{Findings}

From the analysis of serviceability loads of slab-column specimens, the following findings can be made.

(1) All slab-column specimens reached their first cracking load about 11\%-22\% of the ultimate punching shear capacity of each slab. The first cracking load of the control specimen A1 is about $38 \%$ more than that of specimen B1. Therefore, the location of opening adjacent to shorter column width affects the serviceability of the slab more than the location of opening at the comer of column.

(2) The first cracking load of slab A2, A3 and B3 are about 25\%, 13\% and 20\% less than that of their control slab while the first cracking load of slab B2 is $40 \%$ more than that of its control slab. As known the use of shear reinforcement is to resist shear only, therefore, the use of shear stud reinforcements is not effective in improving the serviceability load. 


\subsubsection{Crack patterns}

For all slab-column specimens during testing, the crack patterns developed on the tension face of the slab and seen from the inside of opening due to the applied loading were marked at every total applied load starting from the first cracking load that the first crack occurred, followed by $200 \mathrm{~N}, 400 \mathrm{kN}, 600 \mathrm{kN}$ to a load just before the ultimate punching load for each slab-column specimens was reached. The crack patterns viewed from the tension face of all slab-column specimens are shown in Figure 4.2. And the inclined crack patterns seen from the inside of opening are shown in Figures 4.5 and 4.6. The information recorded on crack patterns for all slab-column specimens are summarized in Table 4.3.

During the application of punching load to the slabs, the similar sequences of crack pattern developed for the slab-column specimens were observed. There were three kinds of crack observed in the crack patterns of the slabs after punching: radial, circumferential and inclined cracks. The radial and circumferential cracks formed on the tension face of the slabs can be seen in Figures 4.2 to 4.4. The inclined crack patterns formed through the slab thickness, which can be viewed from the inside of opening, can be seen in Figure 4.5 and 4.6. First, the radial cracks started to develop from the weakest column comer where the opening was located. While these radial cracks were continuing to extend to the slab edge, the circumferential cracks between the radial cracks gradually appeared around the region near the shorter column widths and so they extended along the perimeter near the region around the column face. While the radial cracks were extending to the slab edges and the circumferential cracks were spreading to some distance from the column face, the inclined cracks were gradually developed into the thickness of slab. Gradually, the inclined cracks proceeded to extend into the compression zone of the slab. Finally, the circurnferentially and radically major inclined crack caused the punching shear failure in the slab.

The initial cracks for all specimens started between about $11 \%$ and $22 \%$ of the ultimate capacity of the specimens. In all slab-column specimens, the initial radial cracks started from the comer of column where opening was located. It indicates that the stresses at shorter side of rectangular column face near opening were more critical 
than other places when the slab had no opening. And then, it can be concluded that the opening located near the region around the shorter column width is a source which causes the first crack in the slab.

At failure, the failure cracks extended from about $2 \mathrm{~d}$ to greater than about $3 \mathrm{~d}$ from the column face and created a small failure perimeter near the region around the opening in all specimens. It is pointed out that the region near the openings is the weakest portion in the slabs regardless whether the slabs are reinforced with shear reinforcement. Therefore, it can be suggested that the shear reinforcement placed at the region near the opening should be arranged to effectively resist the punching shear. Therefore, placement of shear studs with longer or shorter rails near the region around the opening in series A slabs and the tilting of shear studs with longer or shorter rails near the region around the opening may become the reason to investigate whether it may be able to protect the cracks not to cross the opening and if it may effectively contribute in resisting punching shear stress that is critical in that region.

Figures 4.4 to 4.6 show the major punching cracks formed in all slab-column specimens and the inclined crack formed in the slab specimens that can be seen from the inside of the opening. From these figures, it can be seen that in Series A, the initial inclined cracks near the bottom of the slabs were about 22, 25, and 27 degree measured from the bottom surface of slab for slab-column specimens A1, A2, and A3, respectively, while in Series B, the initial inclined cracks near the bottom of the slabs were about 40, 45, and 53 degree measured from the bottom surface of the slab for slab B1, B2, and B3, respectively. As early concluded, because the location of opening at the shorter side of column cause severely more critical stress near the opening than that at the corner of the column, the slope of initial inclined cracks for slab in series B were larger than that for slabs in series. Therefore, the slope of the initial inclined crack can be steeper as the critical stresses in the slab are higher.

Alexander and Sirnmonds (1987) stated that the inclined crack of the punching cone is between 25 and 30 degrees for slabs without openings. Therefore, it is shown that although their statement on the initial inclined crack is satisfied for the slab with opening located at the comer of the column, when the slabs have openings at the shorter side of column, their statement on the slope of the initial inclined crack is no longer accurate. 


\subsubsection{Slab-column specimens for series A}

From the crack patterns of slab-column specimen A1 shown in Figures 4.2 and 4.3, it can be seen that the failure crack was characterized by the major circumferential crack and the one major circumferential crack was formed at a distance of about $3 \mathrm{~d}$ around the opening in south-west direction of the slab, where $d$ is the effective depth of the slab. It can be also observed that the major circumferential crack was formed by the inclined crack which had propagated from the vertical faces in west and south direction of opening in the slab.

In crack pattern of slab A2 from the Figures 4.2, 4.3 and 4.5, it can be seen that the major circumferential cracks were formed in both north and south directions of the slab. In north direction of slab, the failure crack was characterized by a half circle major circumferential crack around the shorter column width at a distance of about $2.5 \mathrm{~d}$ from the column face. In southern direction of the slab, the failure crack was characterized by the radial crack extended to a distance of about $2.5 \mathrm{~d}$ from the column face, which was formed by the inclined crack that had propagated from the vertical face in the south direction of opening.

It can be seen from the crack pattern of slab A3 that the failure cracks were characterized by three major radial cracks extended to a distance of about $4 \mathrm{~d}$ from the column face. These three major radial cracks were formed by the inclined cracks which had propagated from the vertical faces in west and south direction of opening. One of the cracks started from the comer of opening, where the north and west direction of opening intersected, while the other cracks started fiom the south direction of opening.

When the crack patterns of slab A2 and A3 are compared, due to that slab A3 had the shear stud reinforcements on the shorter rails near the region around the opening and around the shorter column width in the north direction of the slab while the slab A2 had the shear stud reinforcements on the longer rails near the region around the opening only, it can be seen that in the north direction of slab A3, there was no major circumferential crack that characterized the failure crack. 


\subsubsection{Slab-column specimens for series B}

For slab B1 from Figures 4.2, 4.4 and 4.6, it can be seen that all failure cracks occurred around the opening only. It indicates that when the rectangular slab-column connection has no opening, the regions around the shorter column widths are the weakest strength zone. When the slab has opening, the region around the opening in the slab is the weakest strength zone. In the figures of crack pattern for slab B1, there were six major cracks which were three major radial cracks and three major circumferential cracks. Two radial cracks were formed from the inclined cracks which had developed in the vertical face of southern direction of opening. The remaining one radial crack and other two circumferential cracks propagated from the inclined crack that had developed in the west vertical face of opening. The remaining one circumferential crack was formed by the inclined crack which propagated from the vertical face in the eastern direction of the opening. All failure cracks extended from the vertical face of opening to about $3 \mathrm{~d}$ from the column face.

As for slab B2 from Figures 4.2 and 4.6, it is observed that the failure cracks were formed in two directions: west and south direction of opening. The failure crack in the southern direction of opening was from the column face to a distance of about $3 \mathrm{~d}$ while the failure crack in the western direction was from the column face to a distance of about $4 \mathrm{~d}$. Mainly, six major radial cracks propagated from the inclined cracks developed in the vertical faces of opening.

As for slab B3 from Figure 4.2 and 4.5, it can be seen that the failure cracks occurred around the opening. There were four major radial cracks, which characterized the failure cracks, propagated from the inclined cracks that had developed at vertical faces in east, south and west direction of opening. They extended to a distance of about $3 \mathrm{~d}$.

The failure crack in slab B2 is narrower than in slab B3. This could be due to that the longer rail of shear studs used in slab B2 has more effectiveness than the shorter rail of shear studs used in slab B3. 


\subsubsection{Findings}

From the crack patterns marked on the tension face of the slabs and in the vertical faces of openings, the findings are summarizes as the following.

(1) The opening located near the region around the shorter column width is a source which causes the first crack in the slab.

(2) The slope of the initial inclined crack can be steeper as the critical stresses in the slab are higher. For slabs A1, A2 and A3 with opening at the corner of column, the inclined cracks near the bottom of the slabs were about 22,25, and 27 degree measured from the bottom surface of slab, respectively. For slabs B1, B2 and B3 with opening at the shorter column width, the inclined cracks near the bottom of the slabs were about 40, 45, and 53 degree measured from the bottom surface of the slab, respectively.

(3) When the crack patterns of slab-column specimens of each series are compared with their respective control specimen, it can be seen evidently that when the slab has shear stud reinforcement, the characterization of failure crack changes to major radial crack from major circumferential crack.

(4) When the control slab had no shear stud reinforcements, the failure cracks were occurred at a distance about $3 \mathrm{~d}$ from the column face. For other slabs with shear stud reinforcement, the failure cracks were occurred at the distance of about $2.5 \mathrm{~d}$ to greater than $3 \mathrm{~d}$.

(5) The failure crack in slab B2 is narrower than the failure crack in slab B3. Therefore, the longer rails of shear stud used in slab B2 is more effective than the shorter rails of shear stud used in slab B3. 


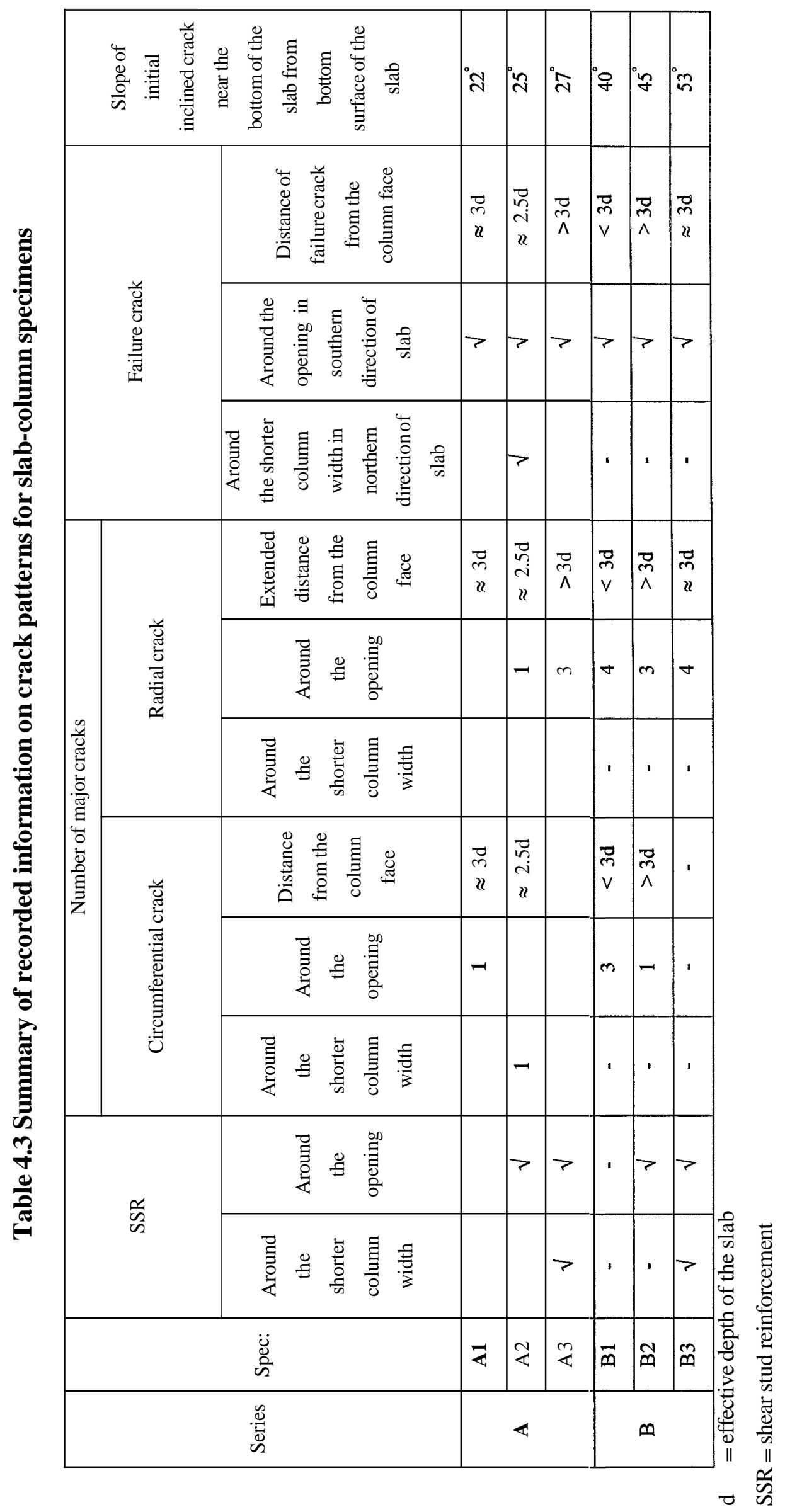



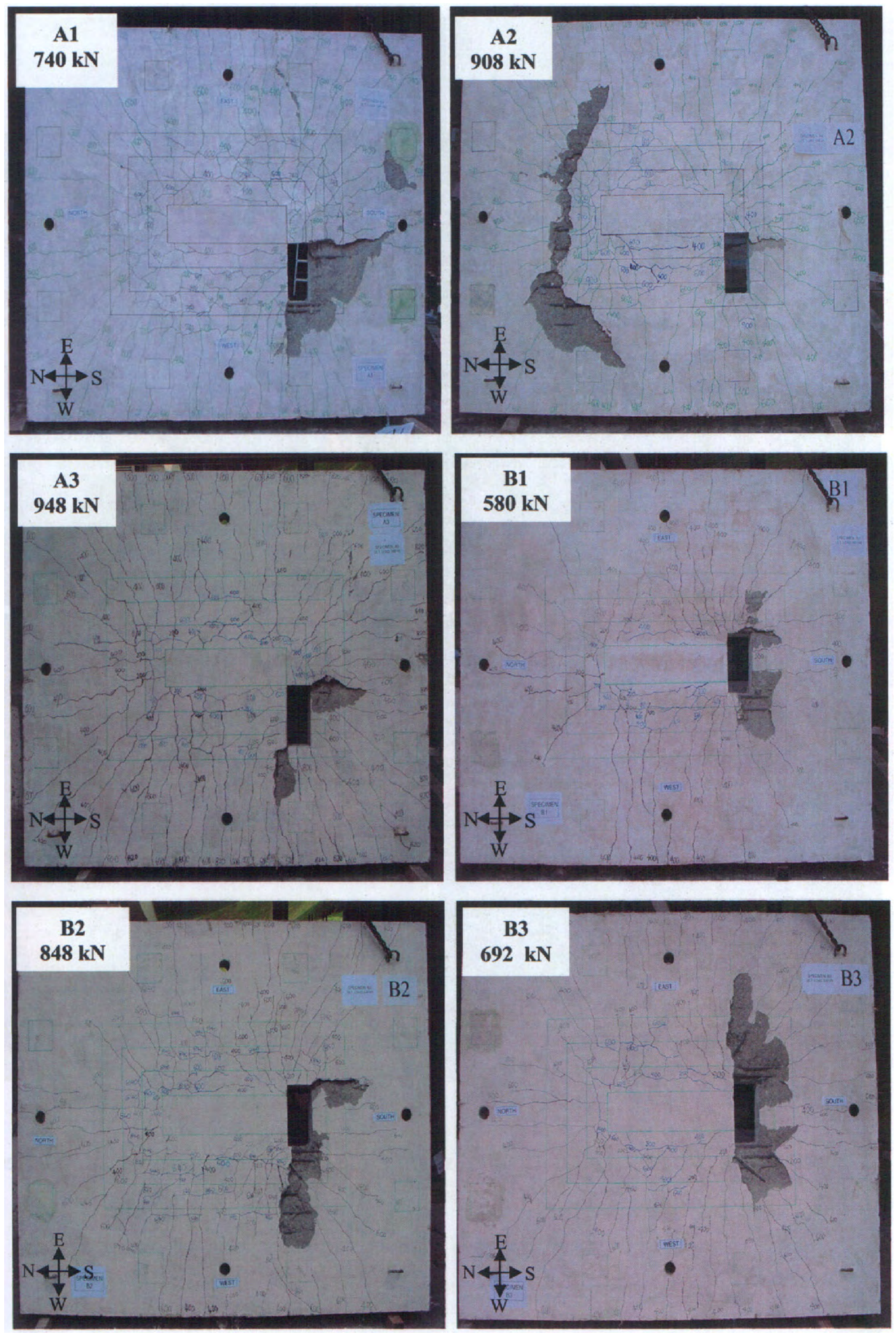

Figure 4.2 Top views of slab-column specimens at failure 

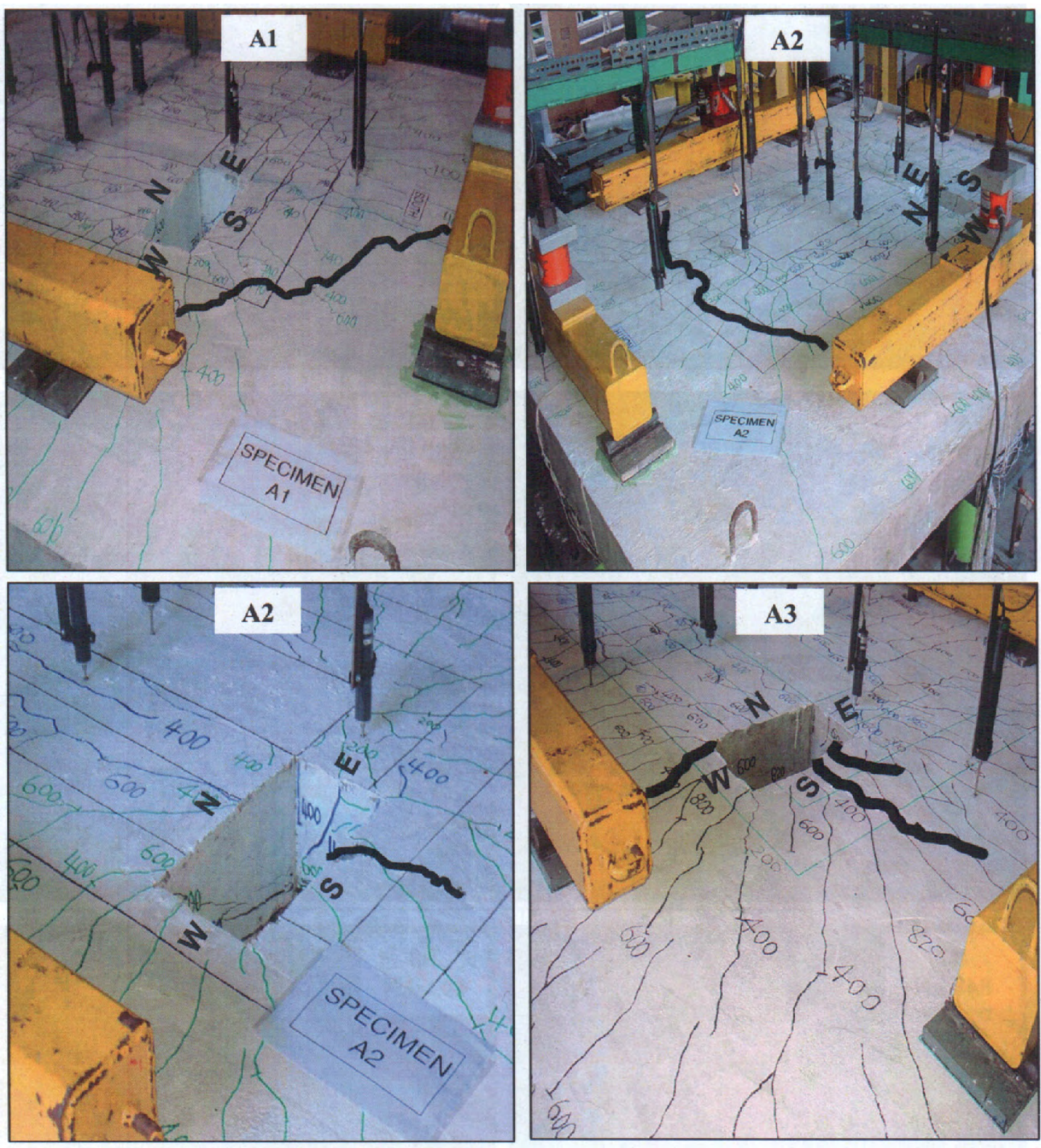

Figure 4.3 Crack pattern on horizontal surface of slab-column specimens for series A 

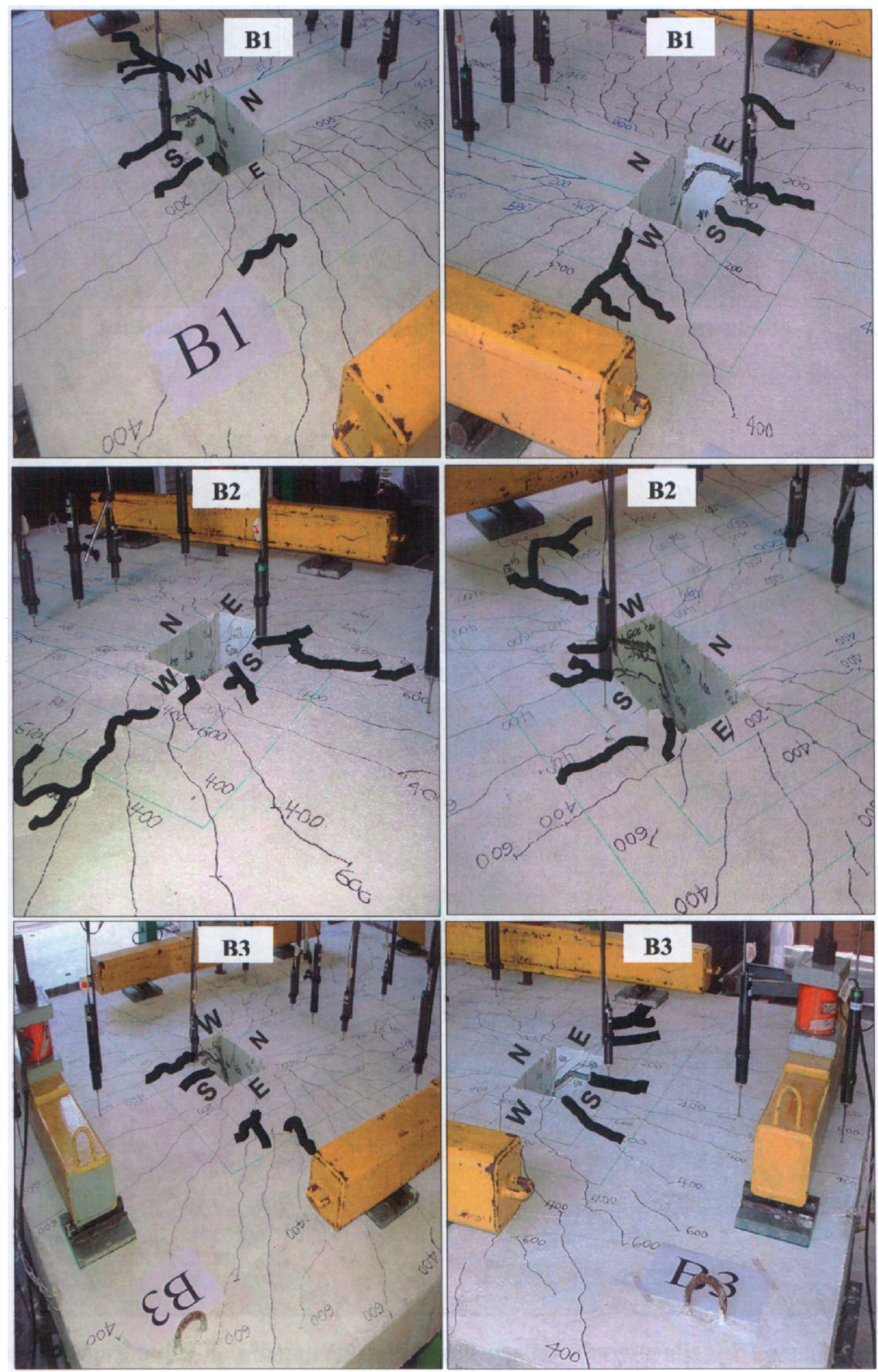

Figure 4.4 Crack pattern on horizontal surface of slab-column specimens for series B 
Chapter 4 Experimental results and discussion
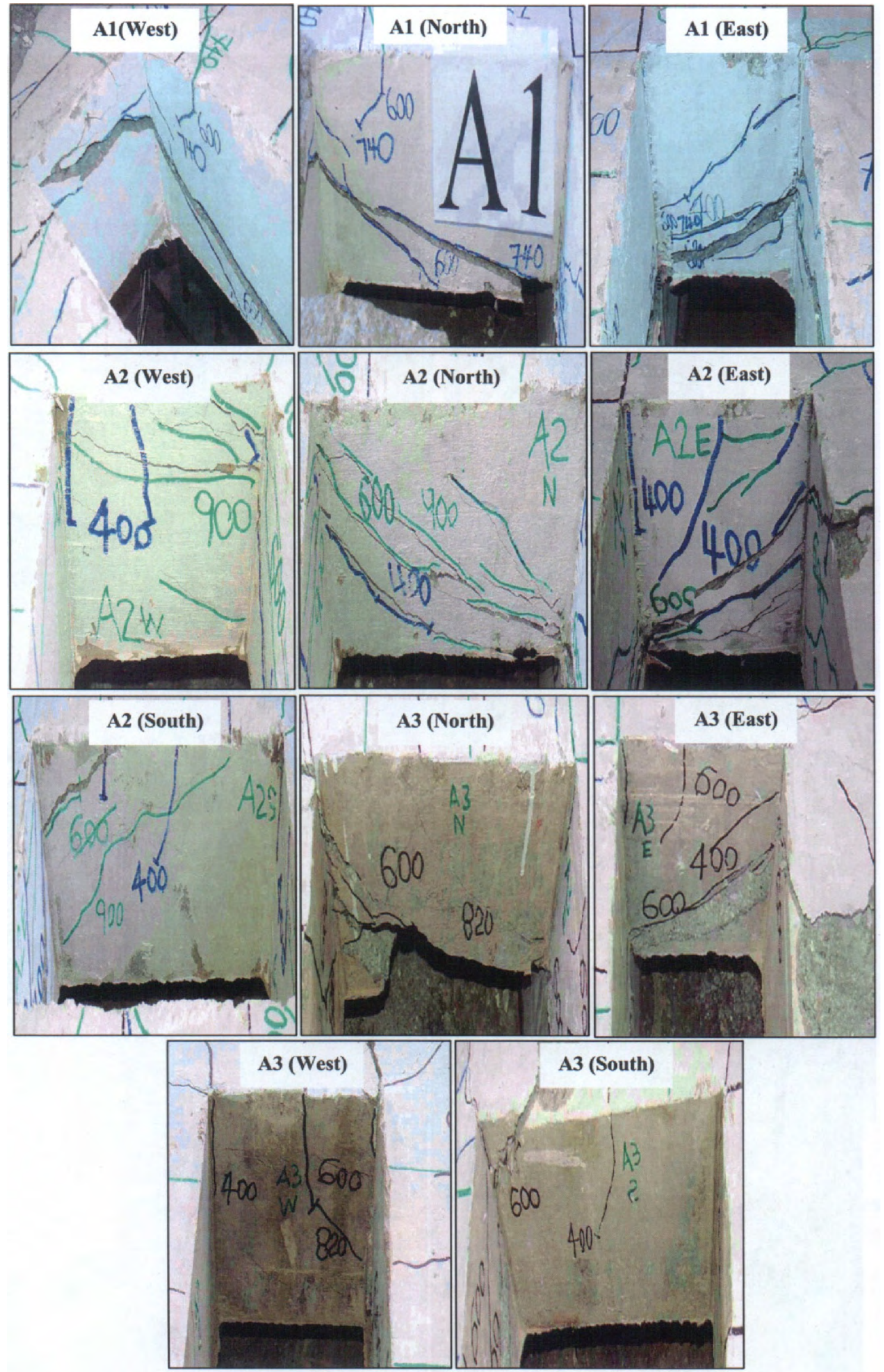

Figure 4.5 Inclined crack patterns inside the opening of slab-column specimens for series $A$ 


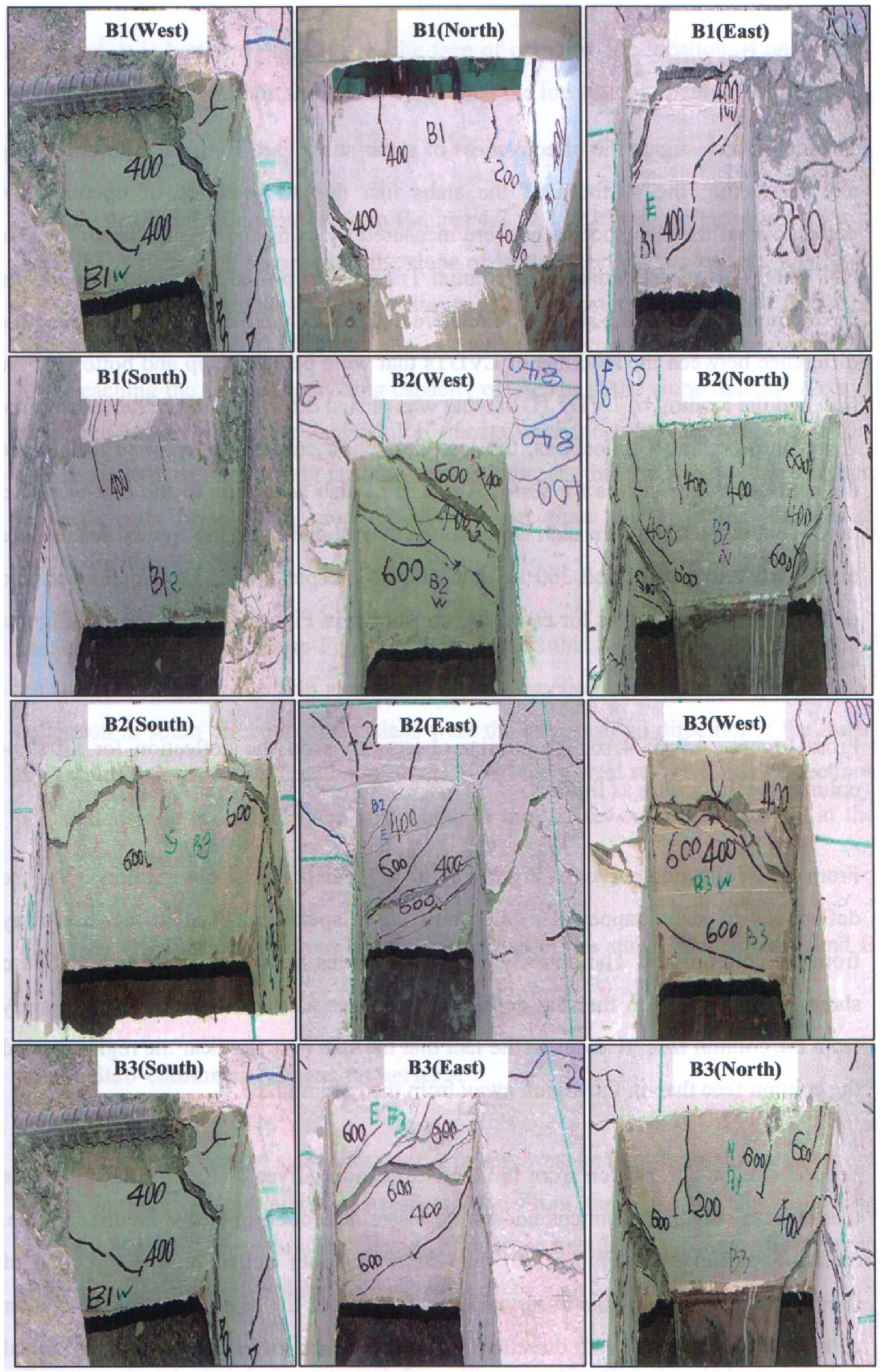

Figure 4.6 Inclined crack patterns inside the opening of slab-column specimens for series B 


\subsubsection{Deflection}

In order to investigate the effectiveness of shear studs used in the slab in enhancing and recovering the stiffness of the slabs lost due to presence of opening, the deflections of the slab specimens were measured by using the 17 number of LVDTs (D1 to D17) (Linear Variable Differential Transducer) placed at various locations at the top and bottom of the slabs. The relative deflections were calculated by taking the difference between the readings of LVDTs that were placed at top and bottom of the slab and the reading of LVDT (D17) that was placed directly at the center of column. Using these relative deflections, the load-deflection curves were plotted and so the deflection-distance curves for series $\mathbf{A}$ and $\mathrm{B}$ of slab according to the east-west and north-south direction of the slab were plotted corresponding to the applied load values of $360 \mathrm{kN}$ and $680 \mathrm{kN}$ and $360 \mathrm{kN}$ and $560 \mathrm{kN}$, respectively. Load-deflection and deflection-distance curves for each slab are shown in Figures 4.7 to 4.12 and Figures 4.13 to 4.16 , respectively.

From Figures 4.7 to 4.16 , the similar observations on the deflection for all slabcolumn specimens are as follows.

From load-deflection curves of Figures 4.7 to 4.12 , first similar observation is that the deflections of slabs happened in all slab-column specimens tend to increase away from the column face. The deflection-distance curves from Figures 4.13 to 4.16 also show such observation that the deflection increases as the distance is further away from the column face. It is due to the fact that the slab is stiffer near the region around the column face than in the region away from the column face.

Second similar observation from the load-deflection curves of Figures 4.7 to 4.12 is that all slab-column specimens underwent lesser deflection in east-west direction i.e. direction of longer column width than in north-south deflection i.e. direction of shorter column width. This observation indicates that the region around the shorter column width in north-south direction of the slab is not stiffer than the region around the longer column width in east-west direction of the slab. Therefore, based on the first and second similar observation, it can be concluded that if the opening in the slab 
is needed, it is better to place it near the face of column. The location of opening at the longer column width in the slab is better than the location of opening at the shorter column width in the slab.

From the load-deflection curves from Figures 4.7 to 4.12, third similar observation is that in each slabs with shear studs, the slope of load-deflection curves gets smaller at about $35 \%$ of the ultimate load. It is due to the fact that the stiffness of the slabs decreased when the inclined cracks occurred and the flexural cracks increased more. After reaching the ultimate punching capacity of the slabs, the slope deflection curve of the specimens with shear stud reinforcements were more gradual than that of the specimens without shear stud reinforcement. It indicates that the slabs with shear stud reinforcements behaved in more ductile manner than slabs without shear stud reinforcements.

Last similar observation from Figures 4.13 to 4.16 is that the north-south direction of the slabs had larger deflection than the east-west direction of the slabs, especially the deflection in south direction of the slabs were the largest in all direction of the slabs. It indicates that the south direction of the slab had the lowest stiffness in all directions of the slabs due to the presence of opening at the shorter column width and at the comer of column in south direction of the slab.

Then, the different observations on the deflections of the slabs from series A and B are discussed as follows.

\subsubsection{Slab-column specimens for series A}

The deflection profiles of slabs for series A in east-west and north-south directions are shown in Figures 4.13 and 4.14, respectively. From these figures, the following discussions are made on how the location of opening and the shear studs affect on the stiffness of the respective slabs from series A.

For control slab A1, it is observed from Figure 4.13a that the deflections of the control slab A1 in east and west direction are approximately equal and not 
significantly large. It is pointed out that location of opening at the comer of slab in series A did not affect the stiffness of the slab in east-west direction remarkedly. Figure 4.13b shows that the control slab A1 had larger deflection in south direction than in north direction. It indicates that the control slab A1 was not stiffer in south direction than in north direction because the opening in slab A1 was located at the comer of column in south direction.

As for slab A2, Figure 4.13a and 4.13b show that the deflection of slab A2 in east direction was larger than that of control slab Al. It indicates that the east direction of slab A2 was not as stiff as even the control slab A1. Therefore, the placement of longer rails A21 and A22 were not effective in improving the stiffness of the slabs in east direction. Then, it can be observed from Figure $4.14 \mathrm{~b}$ is that the slab A2 had a little larger deflection in north-south direction than the control slab A1. It indicates that the stud rail A 23 in slab A2 was not effective on the stiffness of the slab decreased due to opening. Furthermore, it is observed from Figure 4.13a and 4.13b that the deflection of slab A2 in west direction was less than that of control slab A1 and then the slab A2 underwent lesser deflection in west direction than in east direction. It indicates that the west direction of slab A2 was stiffer than the control slab A1 and then the slab A2 was stiffer in west direction than in east direction even if the opening was located at the corner of the column in south-west direction of the slab. It is evident that the presence of the longer rails A24 and A25 in slab A2, which were placed at the side of longer column width near the opening in west direction, could significantly improve the stiffness of slab in addition to recover the stiffness decreased due to opening.

As for slab A3, it is observed from Figures 4.13 and 4.14 that the slab A3 underwent the larger deflection than the control slab A1 in all directions. It indicates that the slab A3 was not as stiff as even the control slab A1. Figure 4.13a and 4.13b show that slab A3 had larger deflection in west direction than in east direction at larger load $680 \mathrm{kN}$ although the deflection of slab A3 had not much difference in east and west direction at the smaller load $360 \mathrm{kN}$. Thus, the shorter rails A32, A33, A35 and A36 placed in east-west direction of slab A3 had no effectiveness in improving the stiffness of the slab. This may be due to that the lengths of these stud rails were not enough to be 
effective in improving the stiffness of the slab decreased due to opening. Figures 4.14a and 4.14b show that the slab A3 had larger deflection in south direction than in north direction. It indicates that the south direction of slab A3 was not stiffer than the north direction of slab A3. This is due to the opening located at the comer of column in south direction of slab A3. Thus, the shorter rails A31 and A34 in north-south direction of slab A3 were not effective in recovering the stiffness decreased due to opening.

Furthermore, Figures 4.13 and 4.14 show that the east direction of slab A2 had larger deflection than in that direction of slab A3 and the deflection of slab A2 in north direction was approximately equal to the deflection of slab A3 in that direction. Thus, in east direction, the longer rails A21 and A22 in slab A2 were more effective in improving the stiffness of the slab than the shorter rails A32 and A33 in slab A3 although the longer rails A21 and A22 were concluded not to be effective in recovering the stiffness of the slab decreased do to opening as compared to the control slab A1 previously discussed. Figures 4.13 and 4.14 show that in west and south direction, the slab A2 had smaller deflection than the slab A3. It indicates that in south direction, the longer rail A23 in slab A2 was more effective than the shorter rail A34 in slab A. This is because of the longer length of rail A23 than rail A34.

\subsubsection{Slab-column specimens for series B}

The deflection profiles of slabs for series B in east-west and north-south directions with the applied loads $360 \mathrm{kN}$ and $560 \mathrm{kN}$ are shown in Figures 4.15 and 4.16, respectively. From these figures, the following discussions are made on how the location of opening and the shear studs affect the stiffness of the respective slabs of series B.

For control slab B1, like the control slab A1, it is similarly observed from the deflection-distance graphs in Figure 4.15 that the deflections in west and east direction are approximately equal and not significantly large. It is pointed out that location of opening at the shorter column width in series B did not affect the stiffness of the slab in east-west direction remarkably. Figure 4.16 show that the control slab 
B1 had larger deflection in south direction than in north direction. It indicates that the control slab B1 was not stiffer in south direction than in north direction because the opening in slab B1 was located at the shorter column width in south direction.

As for slab B2, it can be seen from Figures 4.15 that in east-west direction, the slab B2 had smaller deflection than the control slab B1 although the slab B2 had approximately equal deflection in east direction to the control slab B1 at the lower load of $360 \mathrm{kN}$. It indicates that the slab B2 was stiffer in east-west direction than the control slab B1. This is due to the fact that the presence of longer stud rails B21, B22, B25 and B26 was effective in improving the stiffness of the slab in that direction. Figure 4.16 show that the slab B2 had smaller deflection in south direction than the control slab B1 while the slab B2 had a little larger deflection in north direction than the control slab B1. It indicates that the longer inclined rails B23 and B24 were effective in improving the stiffness of the slab decreased due to opening.

As for slab B3, Figures 4.15 shows that in east direction, the slab B3 had larger deflection than the control slab B1 while in west direction, the slab B3 had a little smaller deflection at the larger load $560 \mathrm{kN}$ than the control slab B1. It indicates that in east direction, the slab B3 was not stiffer than the control slab B1. Therefore, the presence of shorter rail B33 and B36 in east-west direction of slab B3 was not effective in improving the stiffness of the slab decreased due to opening. And, Figure 4.16 shows that the slab B3 had lesser deflection in south direction than the control slab B1 while the slab B3 had larger deflection in north direction than the control slab B1. It indicates that the shorter inclined rails B34 and B35 were effective in improving the stiffness of the slab decreased due to opening while the shorter rails B31 and B32 were not effective in improving the stiffness of the slab decreased due to opening.

Figures 4.15 and 4.16 also show that the slab B2 had lesser deflection in all directions than the slab B3. It indicates that the amount and arrangement of shear studs in slab B2 was more effective in recovering the stiffness of the slab decreased due to opening than the amount and arrangement of shear studs in the slab B2. 


\subsubsection{Findings}

Based on the discussion regarding to the deflection of the slabs due to the applied load are summarized as follows.

(1) Both locations of opening at the corner of column and at the shorter column width in the slab can affect significantly the stiffness of the slab in the direction where opening is located but they do not affect remarkedly the stiffness of the slab in the longer column width direction of slab where opening is not located.

(2) The slab is stiffer near the region around the column face than in the region away from the column face.

(3) The slabs with shear stud reinforcements could be able to behave in more ductile manner than slabs without shear stud reinforcements.

(4) The longer rails A24 and A25 in west direction of slab A2, which were placed at the side of longer column width near the opening, significantly improved the stiffness of slab in addition to recover the stiffness decreased due to opening.

(5) All shorter rails placed in slab A3 had no effectiveness in improving the stiffness of the slab. This may be due to that these rails had not enough length to be effective in improving the stiffness of the slab decreased due to opening.

(6) All longer rails placed in slab B2 were effective in improving the stiffness of the slab in east-west direction and north direction. However, due to the absence of rail in north direction of the slab B2, the north direction of the slab B2 was not as stiff as even the control slab B1 in that direction. The amount and arrangement of shear studs placed in slab B2 could give more effective in improving the stiffness of the slab than the amount and arrangement of shear studs placed in slab B3. 


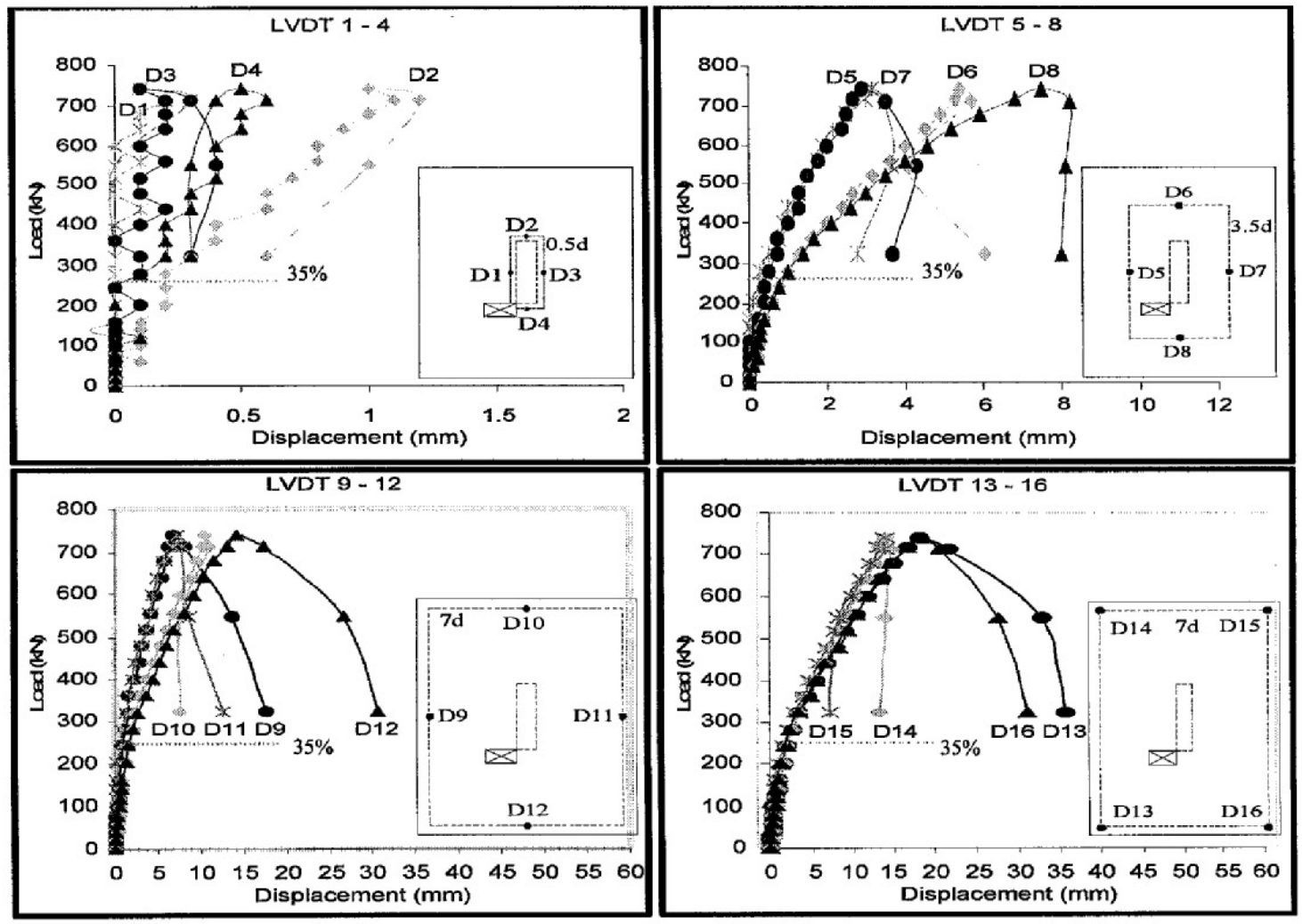

Figure 4.7 Load vs displacement curves for slab A1

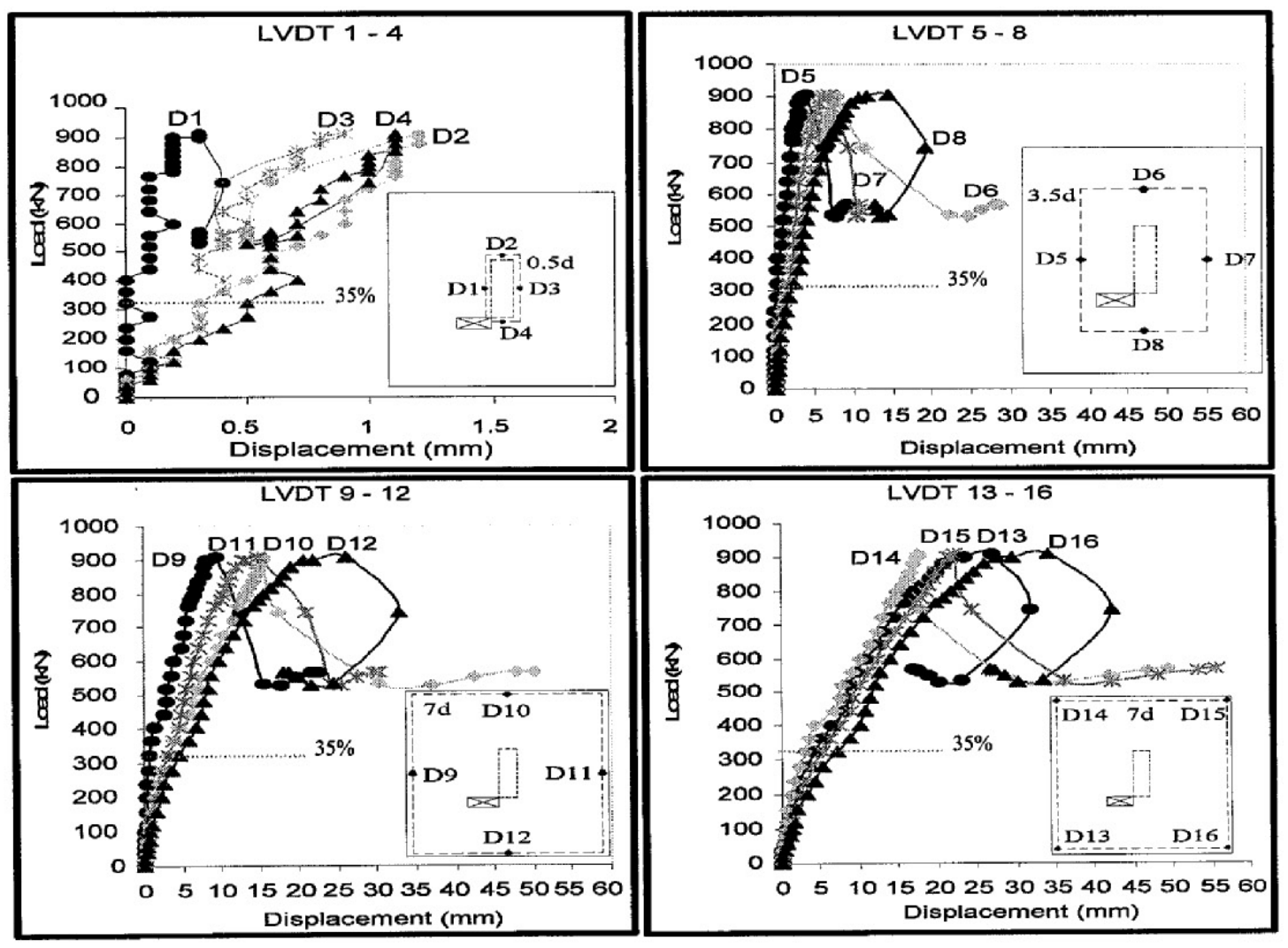

Figure 4.8 Load vs displacement curves for slab A2 
Chapter 4 Experimental results and discussion
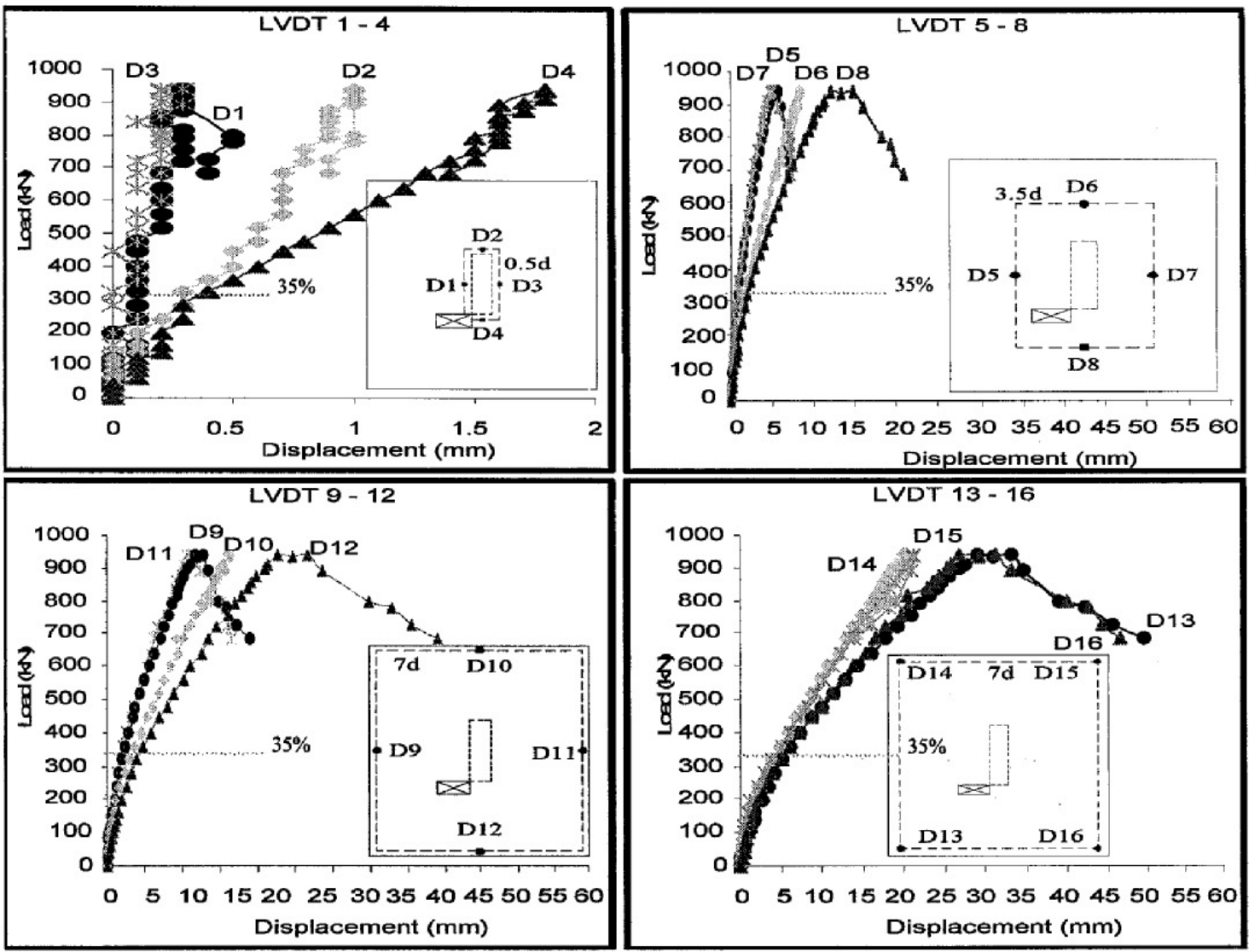

Figure 4.9 Load vs displacement curve for slab A3
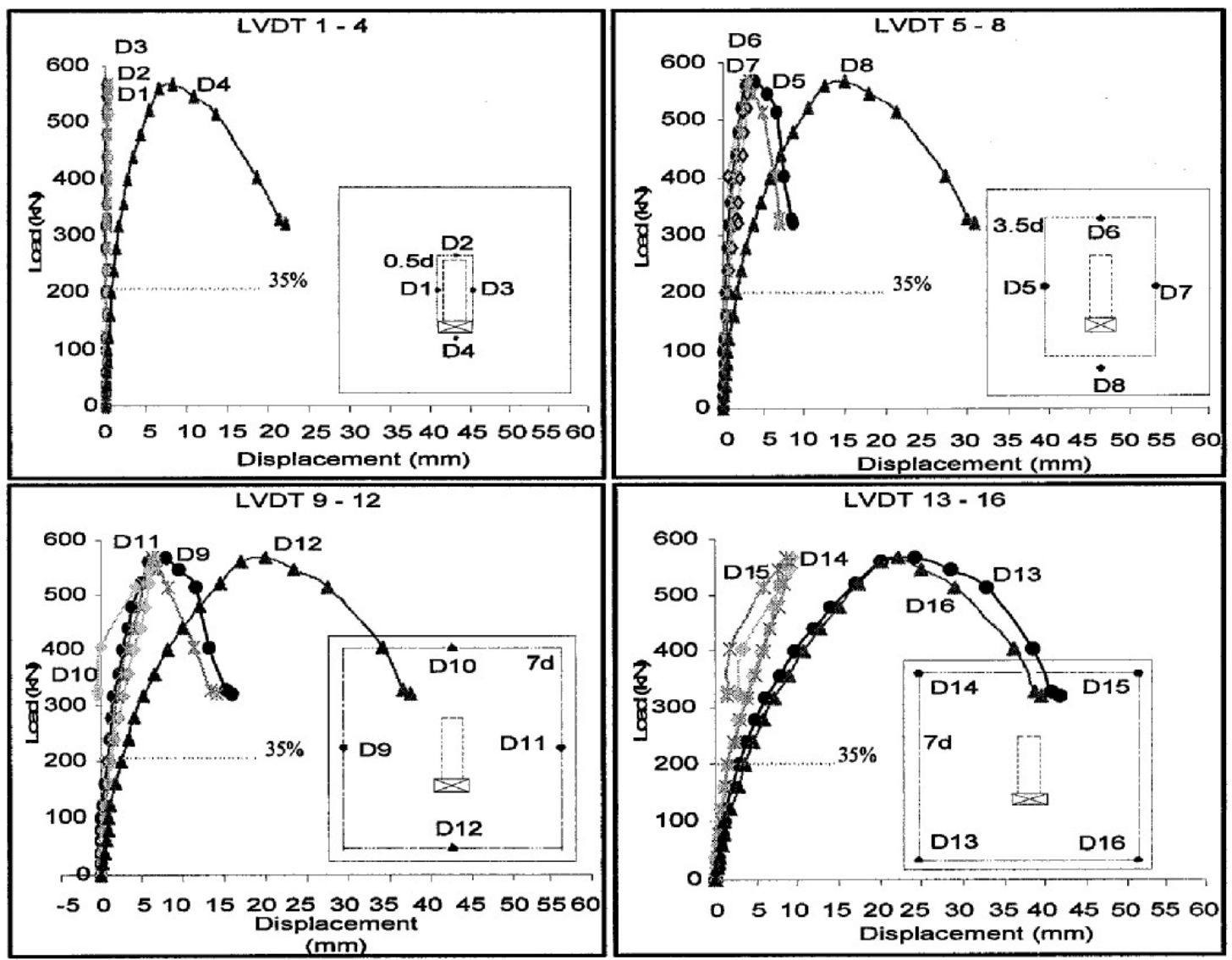

Figure 4.10 Load vs displacement curve for slab B1 

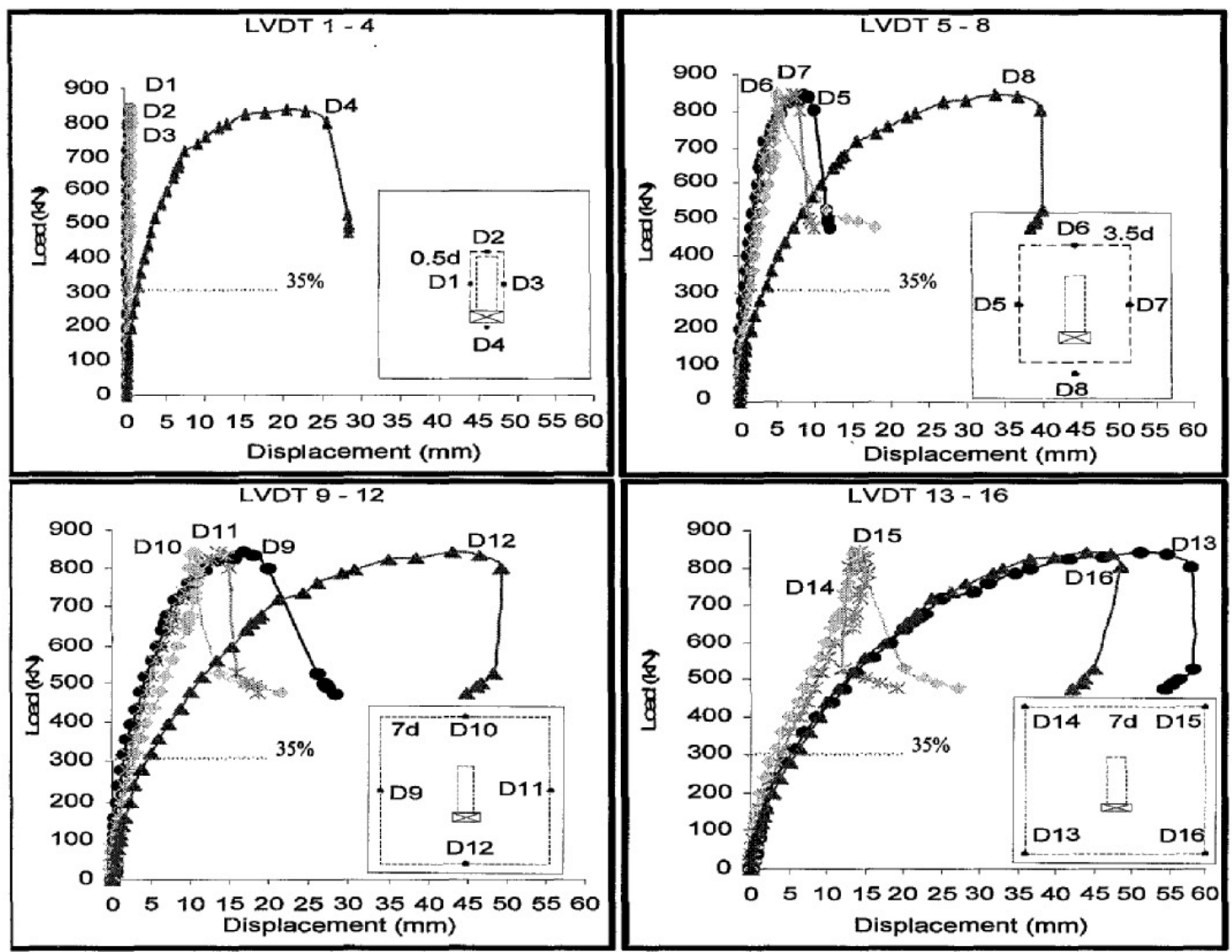

Figure 4.11 Load vs displacement curve for slab B2
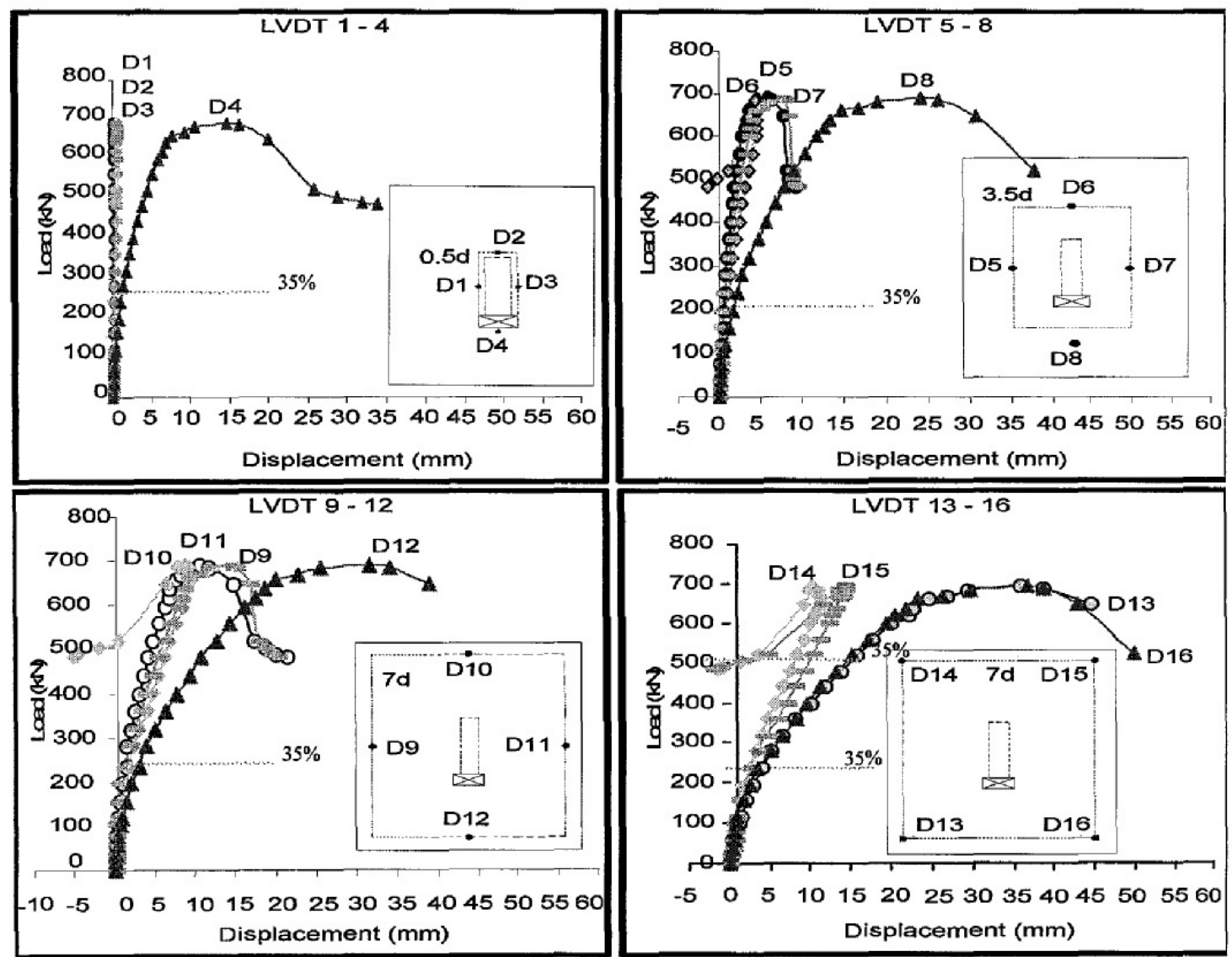

Figure 4.12 Load vs displacement curve for slab B3 

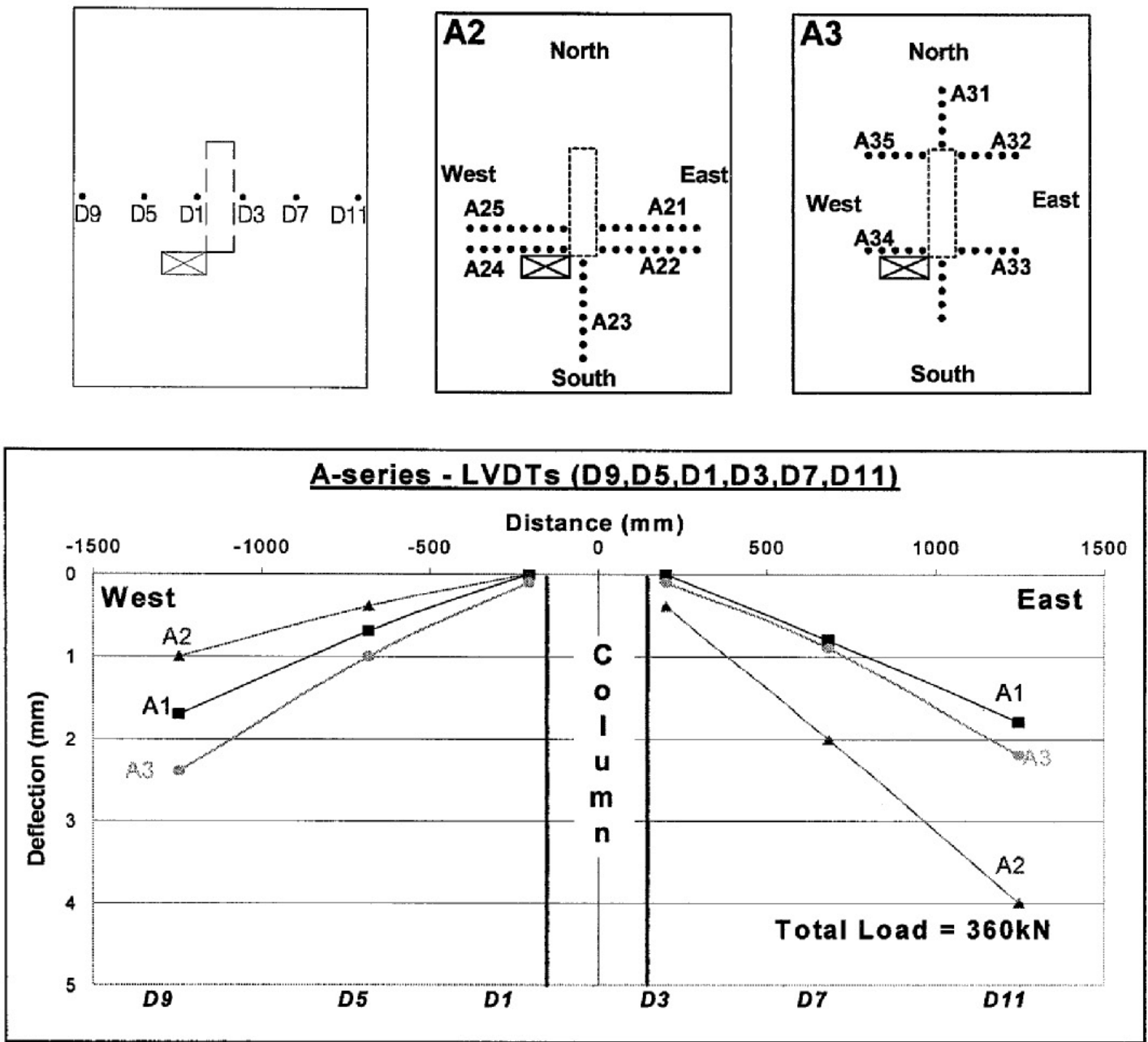

(a) Deflection vs distance graph for A series in east-west direction at $360 \mathrm{kN}$ load

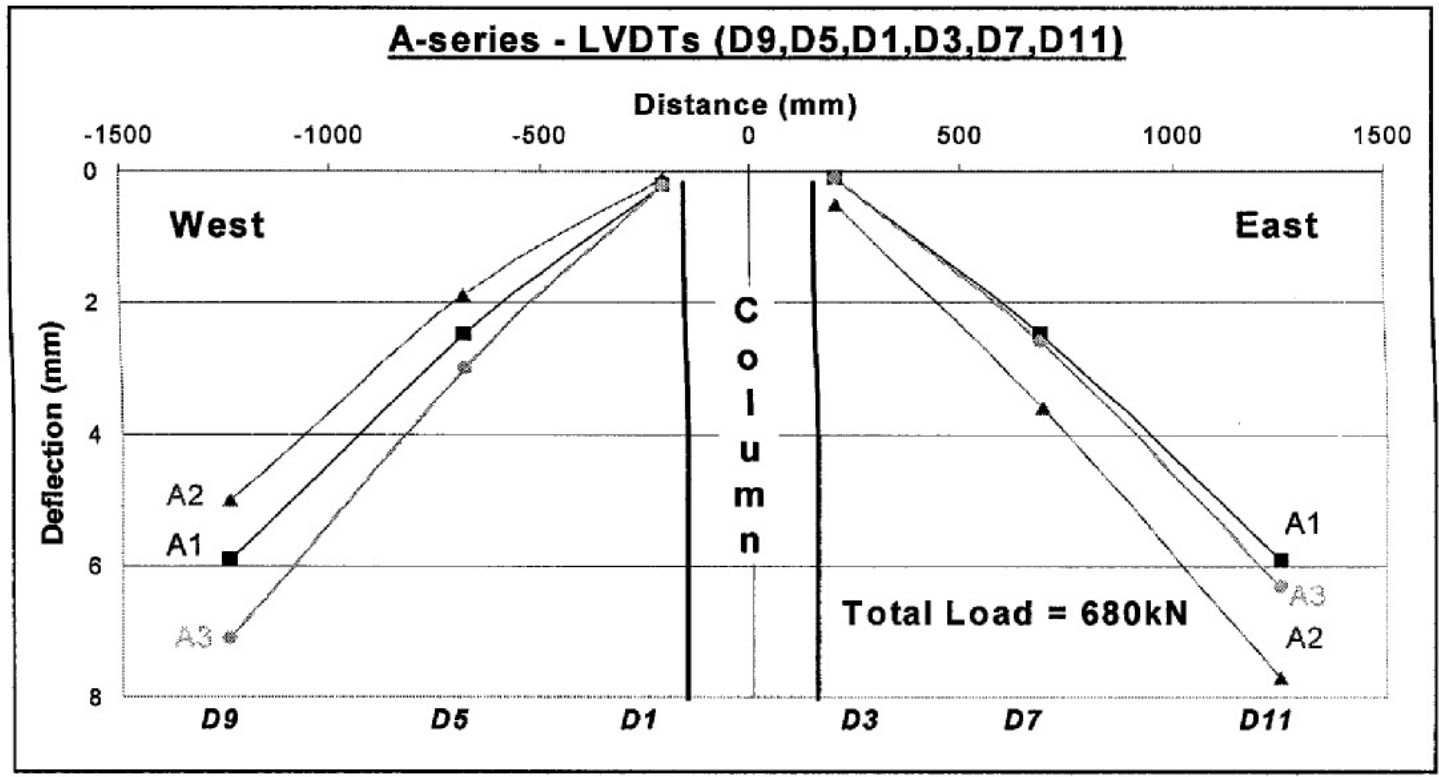

(b) Deflection vs distance graph for A series in east-west direction at $680 \mathrm{kN}$ load

Figure 4.13 Deflection vs distance graphs for A series in east-west direction 

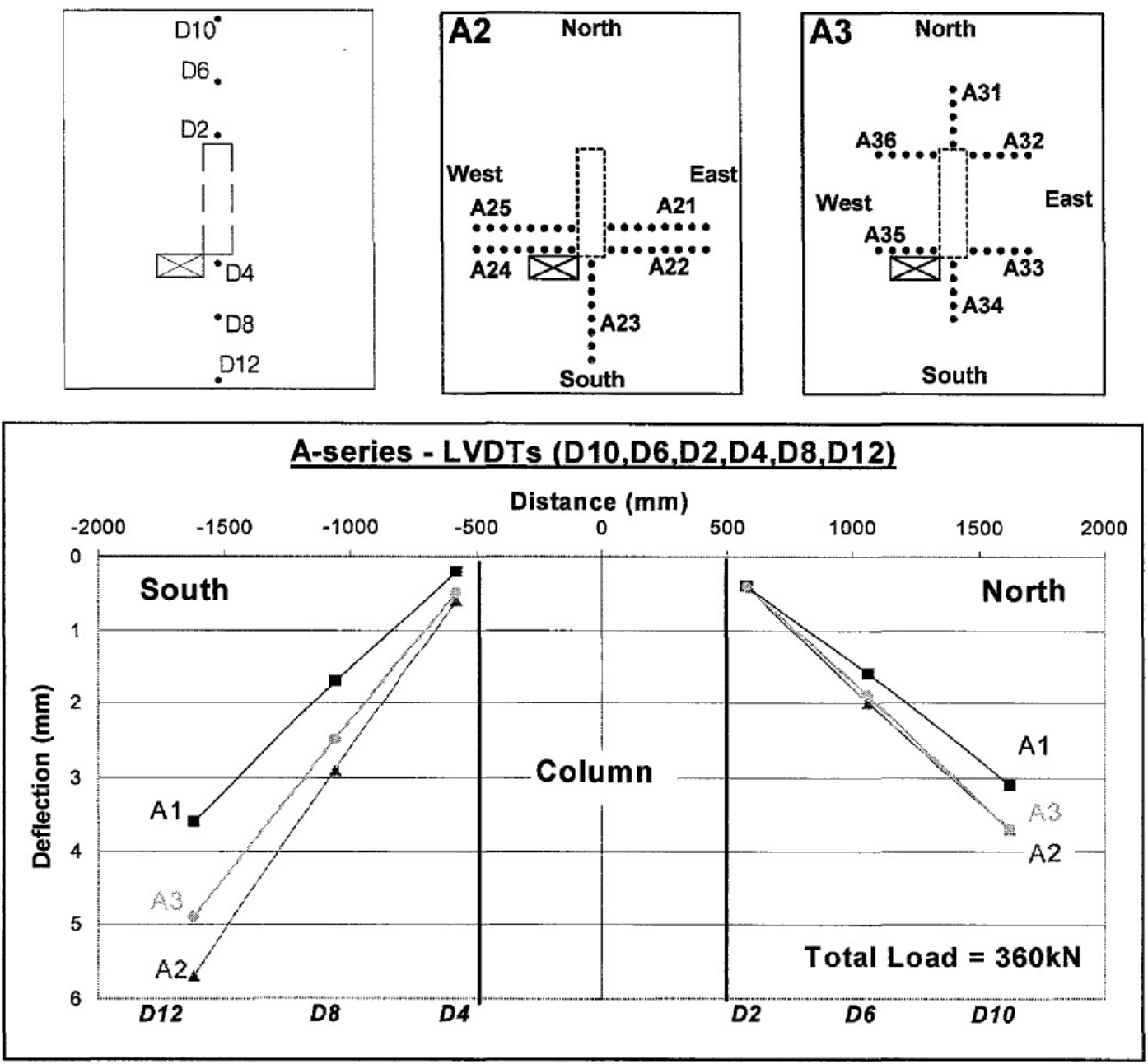

(a) Deflection vs distance graph for A series in north-south direction at $360 \mathrm{kN}$ load

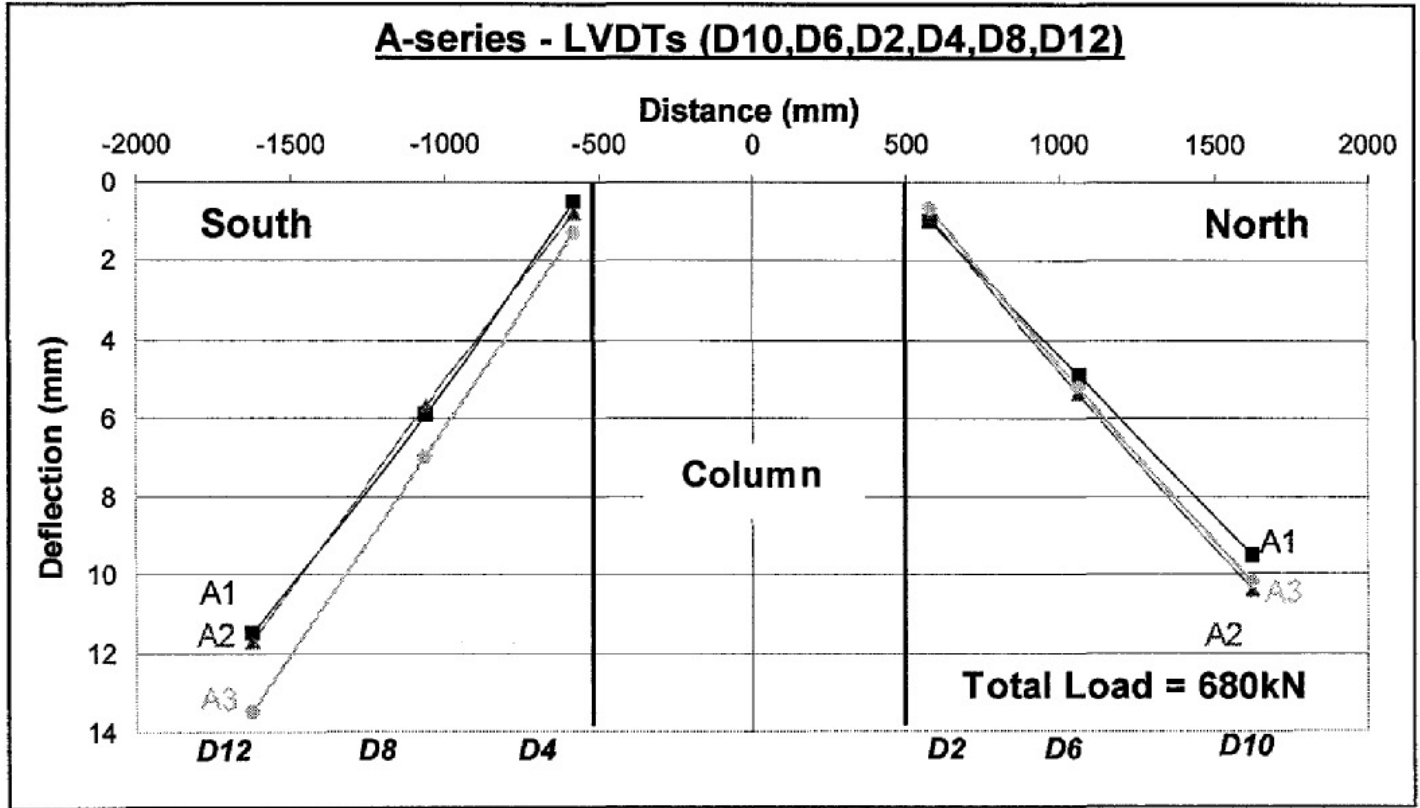

(b)Deflection vs distance graph for A series in north-south direction at $680 \mathrm{kN}$ load

Figure 4.14 Deflection vs distance graph for A series in north-south direction 

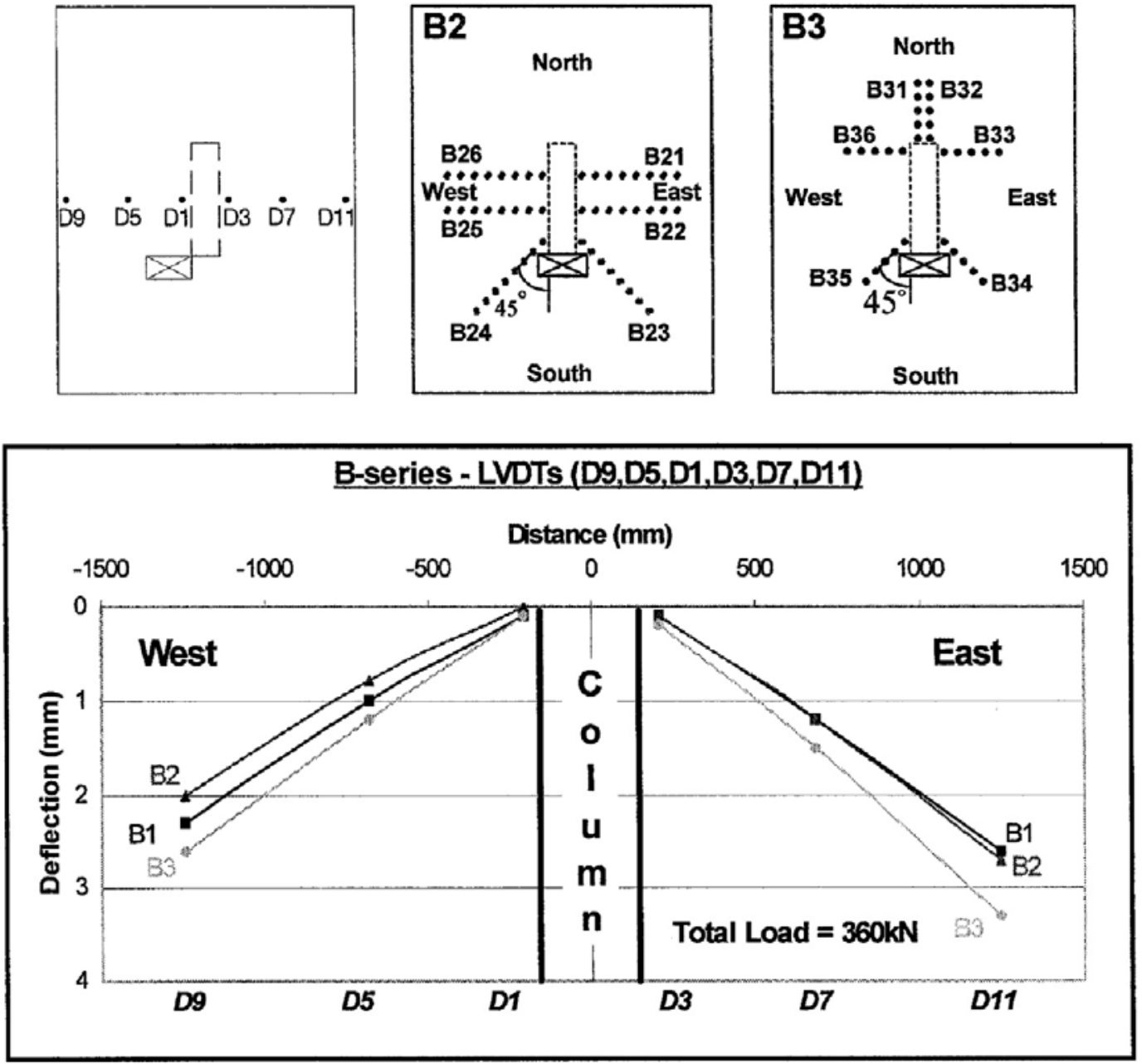

(a) Deflection vs distance graph for B series in east-west direction at $360 \mathrm{kN}$ load

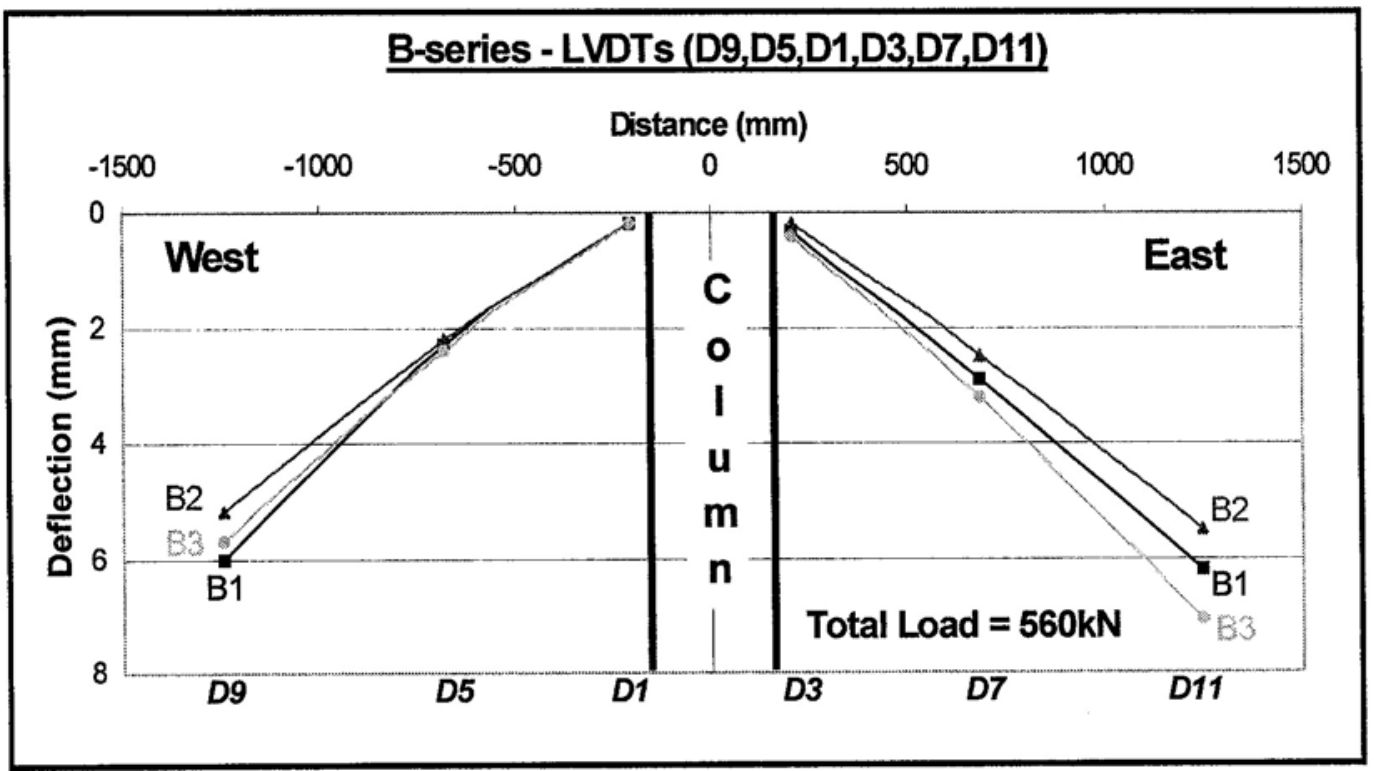

(b) Deflection vs distance graph for B series in east-west direction at $560 \mathrm{kN}$ load

Figure 4.15 Deflection vs distance graph for B series in east-west direction 

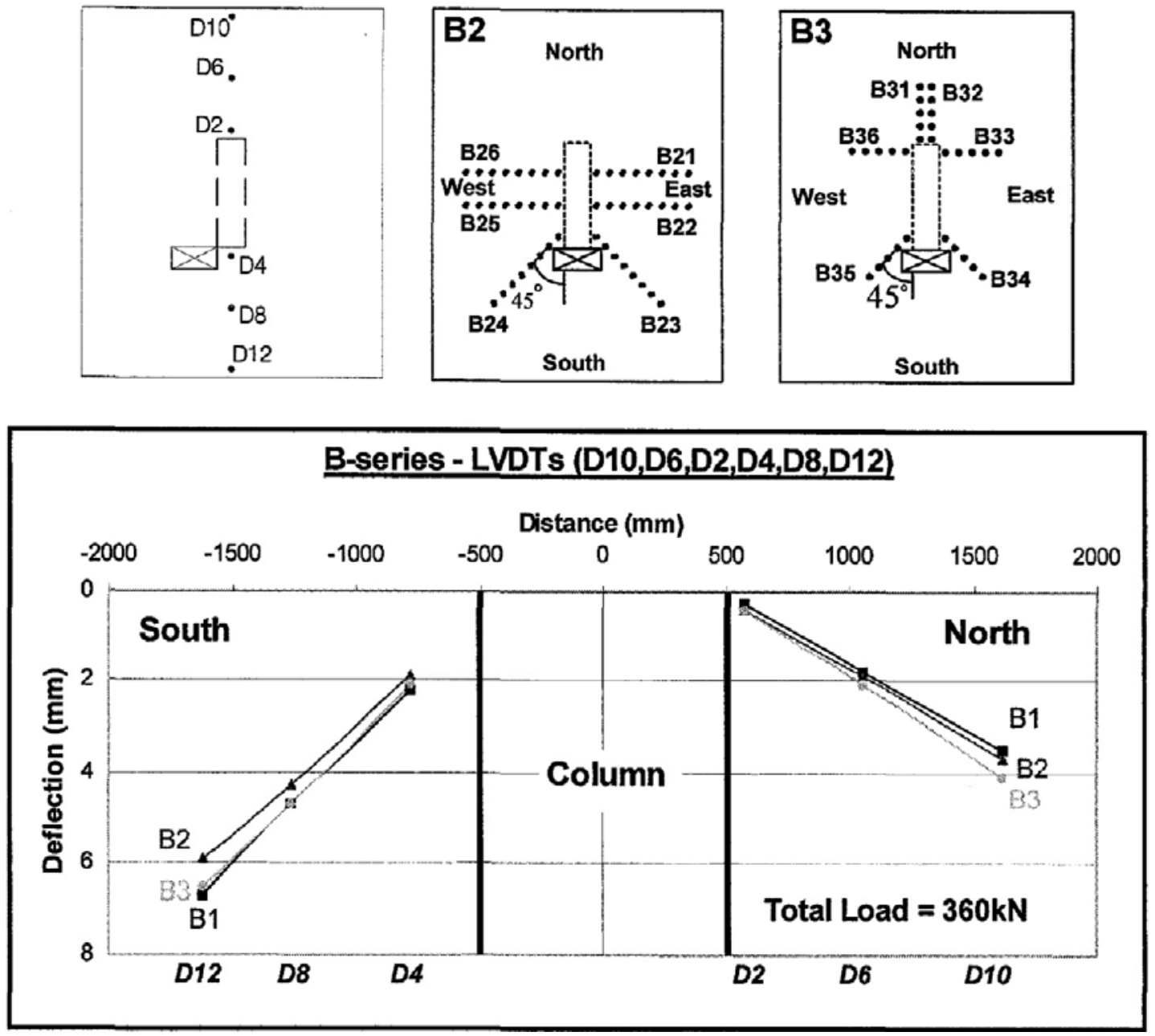

(a) Deflection vs distance graph for B series in north-south direction at $360 \mathrm{kN}$ load

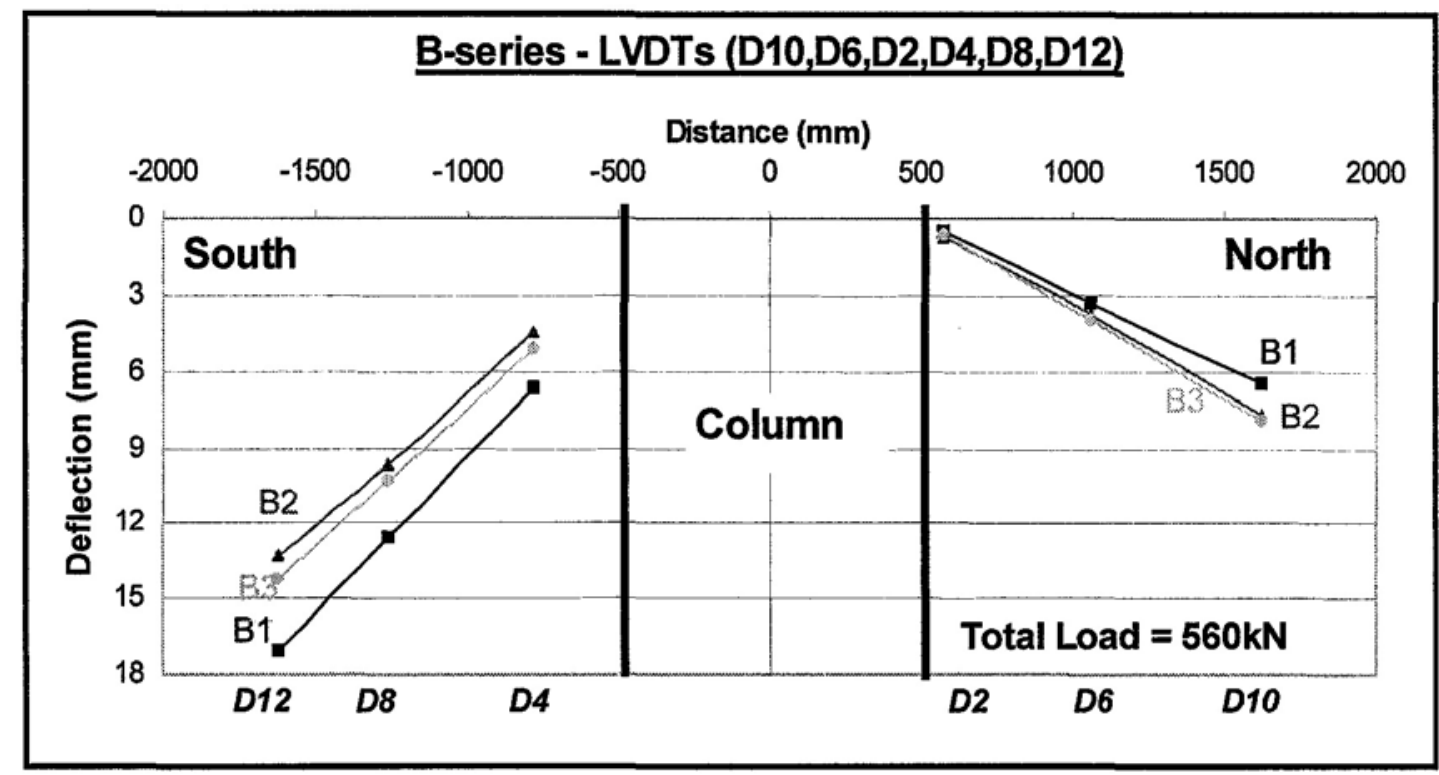

(b) Deflection vs distance graph for B series in north-south direction at $560 \mathrm{kN}$ load

Figure 4.16 Deflection vs distance graph for B series in north-south direction 


\subsection{Analyzing on the strain gauge measurements}

In order to classify the failure of the slab-column specimens occurred due to applied load was flexural failure or punching shear failure and to investigate the effectiveness of shear studs with various amount and arrangement used in the slabs in enhancing and recovering the punching shear strength of the slabs, the strains in the flexural reinforcements and shear stud reinforcementsdue to the applied load need to be known.

In order to measure the strains in the flexural and shear stud reinforcements throughout the test, strain gauges were installed on all shear stud reinforcements and the selected flexural reinforcements at the distance of $1 \mathrm{~d}$ and $2 \mathrm{~d}$ from the column face and at the critical perimeter of $0.5 \mathrm{~d}$ from the outermost peripheral of shear studs, where $d$ is the effective depth of the slab. Around the opening, six strain gauges were installed at distance of $1 \mathrm{~d}$ and $2 \mathrm{~d}$ from the opening. The strain gauge readings recorded during testing were tabulated as shown in appendix A. Besides that, the load-strain curves for tension bars and shear studs, and strain-displacements curves for shear studs were plotted. In this case, because the strains recorded on the tension bars cut due to opening were relatively small as compared to the strains on the other bars, no load-strain curves about the tension bars cut due to opening were plotted. For tension bars placed around the column face and shear studs, the plotted load-strain curves and strain-displacementscurves are shown in Figure 4.17 to 4.24.

\subsubsection{Analysis of strains for flexural reinforcements}

From the load-strain curves for flexural reinforcements shown in Figures 4.17 to 4.19 and Figures 4.21 to 4.24, the similar observations about the strains recorded on the flexural reinforcements in all slabs are as follows:

The first similar observations from the load-strain curves for flexural reinforcements shown in Figures 4.17 to 4.19 and Figures 4.21 to 4.24 is that the strain gauge readings of the flexural bars in all slabs increased a little only with the load increment up to $11 \%$ to $22 \%$ of the applied load to the slabs. Second similar observation is that after this, the increasing rate in all the strain gauge readings became larger with the 
load increment up to about $35 \%$ of the ultimate punching capacity of the slab. These two similar observations indicate that because after the flexural cracks begin to appear at $11 \%$ to $22 \%$ of the ultimate punching shear capacity of the slab and the flexural cracks continue to increase up to reach about $35 \%$ of the ultimate punching shear capacity of the slab, the strains in the flexural reinforcements increased.

Third similar observation is that after reaching about $35 \%$ of the ultimate punching capacity of the slab, the increasing rate of the strains in the flexural reinforcement became larger up to the ultimate punching capacity of the slab. It indicates that after the inclined shear cracks appeared at about 35\% of the ultimate punching shear capacity of the slab, the flexural and inclined shear cracks gradually increased again up to the ultimate punching shear capacity of the slabs. Fourth similar observation is that after reaching the ultimate punching shear capacity of the slabs, there was a sudden drop in the value of the applied load prior to the flexural reinforcement reaching the yielding strain. It indicates that all the slab-column specimens had failed by punching shear failure.

From the load-strain curves shown in Figures 4.17 to 4.19 and Figures 4.21 to 4.24 for slabs of series A and B, respectively, fifth similar observation can be seen that the strains observed near the region around the column perimeter tend to be larger than the strains observed at the region further away from the column perimeter. It indicates that the higher stresses concentrated near the region around the column perimeter than further away from the column perimeter. Sixth similar observation which can be seen from these figures is that the strains observed in the flexural bars of the slabs A2 and $\mathrm{A} 3$, and $\mathrm{B} 2$ and $\mathrm{B} 3$ with shear stud reinforcement were larger than the strains observed in the flexural bars of their respective control slab A1 and B1 without shear stud reinforcement, respectively. The use of shear studs in the slabs is really effective in decreasing the stresses produced from the applied punching load.

There is no discussion about the strains recorded on the flexural bars cut due to opening because it can be seen from the strain gauge readings recorded during testing shown in Tables Al, A2, A3, B1, B2 and B3 in appendix A that the strains recorded on the flexural bars cut due to opening were relatively small as compared to the strains on the other bars. 


\subsubsection{Slab-column specimens for series A}

In this series, the slab A1 is the control slab without shear stud reinforcements. From the load-strain curves for slab A1 shown in Figure 4.17, it can be observed that the strain of the longitudinal bar in the south direction of the slab around the opening were larger than the strain of longitudinal bars in the north direction of the slab. This indicates that due to opening, the stresses at region near the opening in the south direction of the slab A1 became higher than in the north direction of the slab A1 where the opening was not located. However, as in the east-west direction of the slab $\mathrm{Al}$, the strains recorded on the transverse bars placed near the opening were not so large and not also as large as the strains recorded on the transverse bars away from opening. Therefore, it indicates that due to opening located at the comer of the column, the uneven stress distribution in the east-west direction of the slab could not be occurred due to opening in addition to that the higher stress concentration could not be occurred near the opening itself in the west direction of the slab.

For slab A2 with longer stud rails, it can be seen from Figure 4.18 that smaller strains were observed on the flexural bars in south direction of the slab than in north direction of the slab. This is due to the fact that the presence of longer stud rail A23 in south direction of the slab could decrease the stresses due to opening near the region around the shorter column width in that direction of the slab. As in the east-west direction of the slab away from opening, the strains observed on the flexural bar in west direction of the slab were smaller than that observed on the flexural bar in east direction of the slab. But as in the east-west direction of the slab near the opening, the strains observed on the flexural bar in west direction of the slab were larger than that observed on the flexural bar in east direction of the slab. It indicates that independent on the shear reinforcements those were placed near the region around the opening, the failure cracks would occur just near the opening. The strains in the nearest transverse flexural bars with opening in west direction of the slab would be still larger than that in other flexural bars away from opening.

As for slab A3 with shorter stud rails than slab A2, it can be seen from Figure 4.19 that the smaller strain on the flexural bar at strain gauge V4 in south direction of the 
slab than at strain gauge V3 in north direction of the slab was observed. It indicates that the shorter stud rail A34 was effective in reducing the stress occurred due to opening. But the interesting thing is that the strains on the flexural bar in south direction of the slab were tend to be larger away from the column face. This is due to the fact that although the stud rail A34 placed in south direction of slab A3 was effective in reducing the stress due to opening, the stud rail A34 had not enough length to be able to reduce the stress occurred due to opening.

However, it can be seen from Figures 4.18 and 4.19 that the strains recorded on the flexural bars at V3 and V4 in south direction of slab A2 were larger than the strains recorded on the flexural bars at V4 and V5 in that direction of slab A3, respectively. Similarly, it can be seen that the strains recorded on the flexural bars at V1 and V2 in north direction of slab A2 were larger than the strains recorded on the flexural bars at $\mathrm{V} 2$ and V3 in that direction of slab A3, respectively. These facts indicate that although the shorter rail A34 placed in south direction of slab A3 had not enough length to be able to reduce the stress occurred due to opening as discussed early, the shorter rail A34 placed in south direction of slab A3 was more effective in reducing the stresses occurred due to opening than the longer rail A23 placed in that direction of slab A3. It can be due to the fact that the shorter rail A31 placed in the north direction of slab A3 contributed in reducing the stresses by the shorter rail A34 placed in south direction of slab A3.

\subsubsection{Slab-column specimens for series B}

For this series of slabs, the slab B1 is the control slab without shear studs. From the load-strain curves of Figure 4.21 for slab B1, it can be seen that the larger strains were observed in the north direction of the slab than in the south direction of the slab. This is due to the fact that the distance of the strain gauges in the north direction of the slab is closer from the column face than that in the south direction of the slab. Furthermore, the longitudinal bars in the south direction of the slab were discontinued due to the presence of opening. As a result, the discontinued longitudinal bars in the south direction of the slab were not able to take much load. In the east-west direction of the slab, the strains observed on the transverse bars at the column end located near 
the opening were smaller than that at the other end. It indicates that the opening had not caused the stress concentration to occur in the region around the opening.

As for the slab B2 with longer shear stud rails tilting near the opening, the load-strain curves for slab B2 from the Figure 4.22 show that the strains observed on the longitudinal bars in the south direction of the slab B2 was smaller than the strains observed on the longitudinal bars in the north direction of the slab B2. It could be due to the same reason previously mentioned in the slab B1. In east-west direction of the slab B2, the strains recorded on the transverse bars at the column end away from opening were relatively larger than that at the other end of column close to opening. It indicates that the tilted longer rails B23 and B24 placed around the opening and other longer rails B21, B22, B25 and B26 placed on the longer column widths toward the opening were effective in reducing the stresses occurred due to the opening.

As for the slab B3 with shorter shear stud rails tilting near the opening, it can be seen from the Figure 4.23 that the strains observed on the longitudinal flexural bars get smaller in south direction of the slab than in the north direction of the slab. It also could be due to the same reason previously mentioned in the slab B1. The strains observed on the transverse bars near the column face in east-west direction of the slab, where the opening was not located, were larger than those on other flexural bars in that direction of the slab. Besides, such strains were the largest as compared to the strains observed on other flexural bars in slabs B3 and as well as in the slab B1 and B2. It indicates that the placement of shorter stud rail B33 and B36 in east-west direction of the slab B3 was not effective in reducing the higher stress and then the placement of the tilted stud rails B 34 and B35 around the opening were effective in reducing the higher stress. Otherwise, it may be due to that the opening had not caused the stress concentration to occur in the region around the opening as mentioned earlier in slab B1. Moreover, as compared to the strains observed on the longitudinal flexural bars in the north direction of the slab B1 and B2, the strains observed in the longitudinal bars in the north direction of the slab B3 were the smallest. It can be concluded that the presence of the shorter stud rail B31 and B32 at the region in the north direction of the slab B3 were significantly effective in reducing the stresses in that direction. 

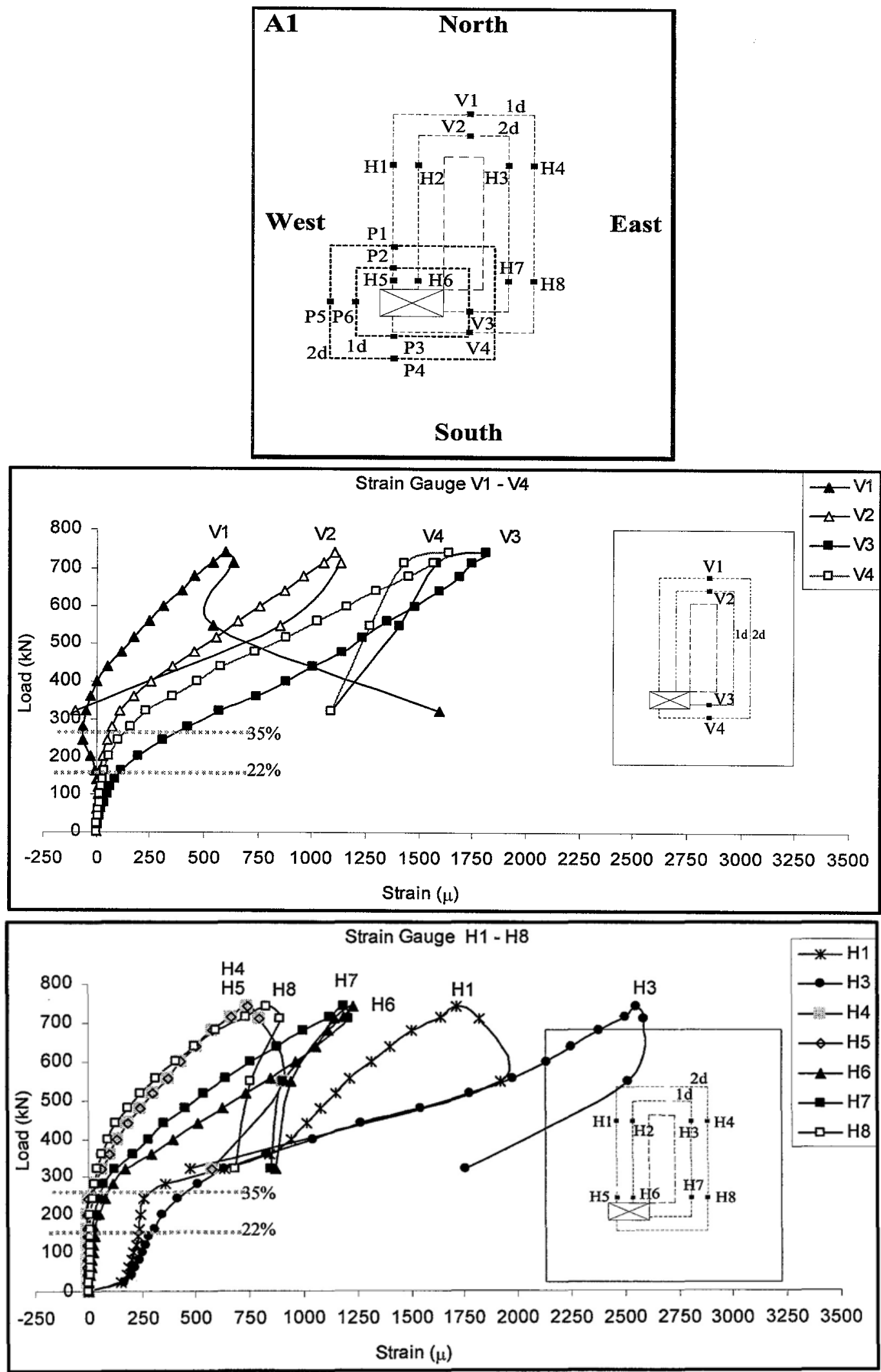

Figure 4.17 Load vs strain curve for tension bars used in slab A1 

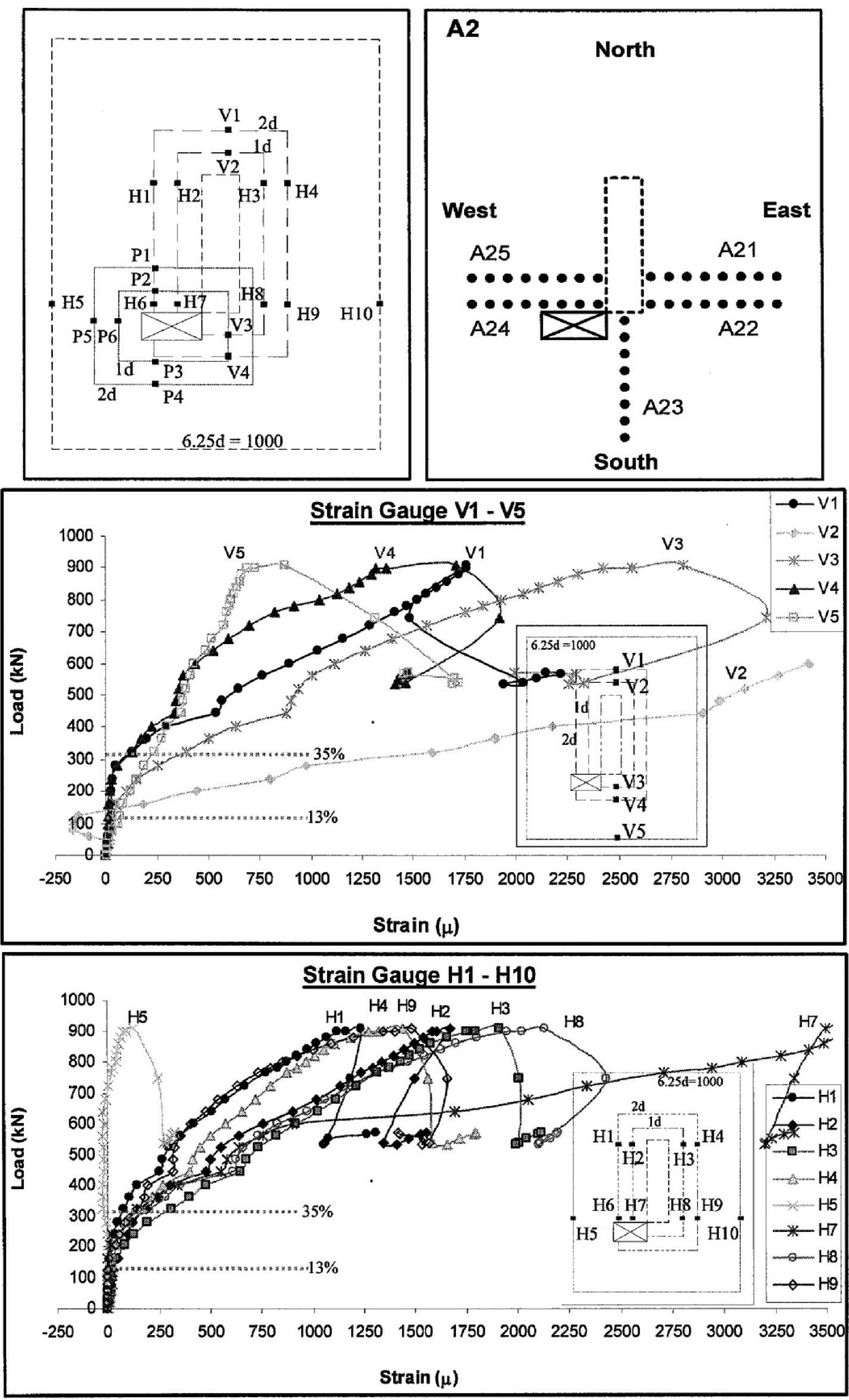

Figure 4.18 Load vs strain curve for tension bars used in slab A2 

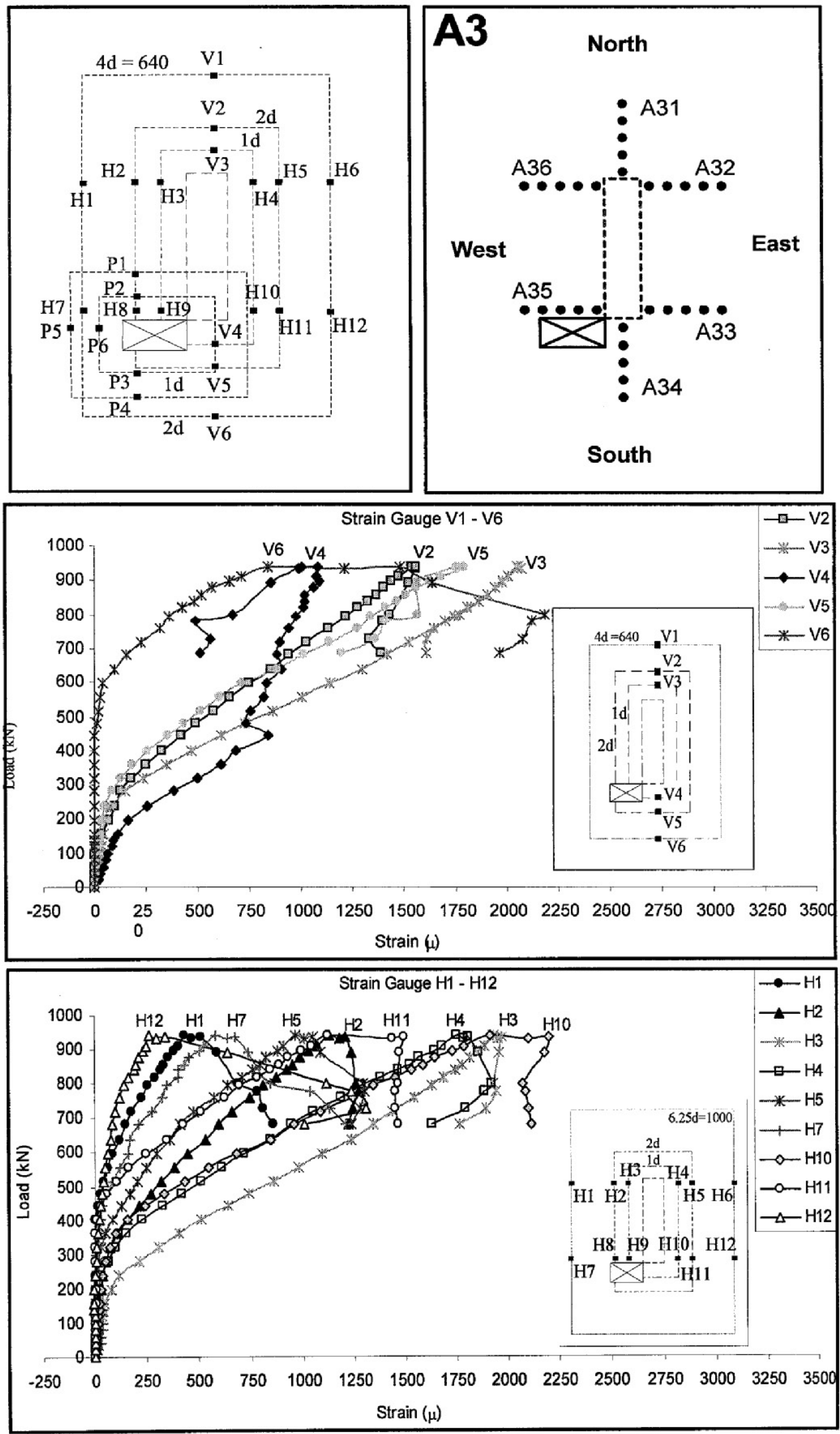

Figure 4.19 Load vs strain curve for tension bars used in slab A3 

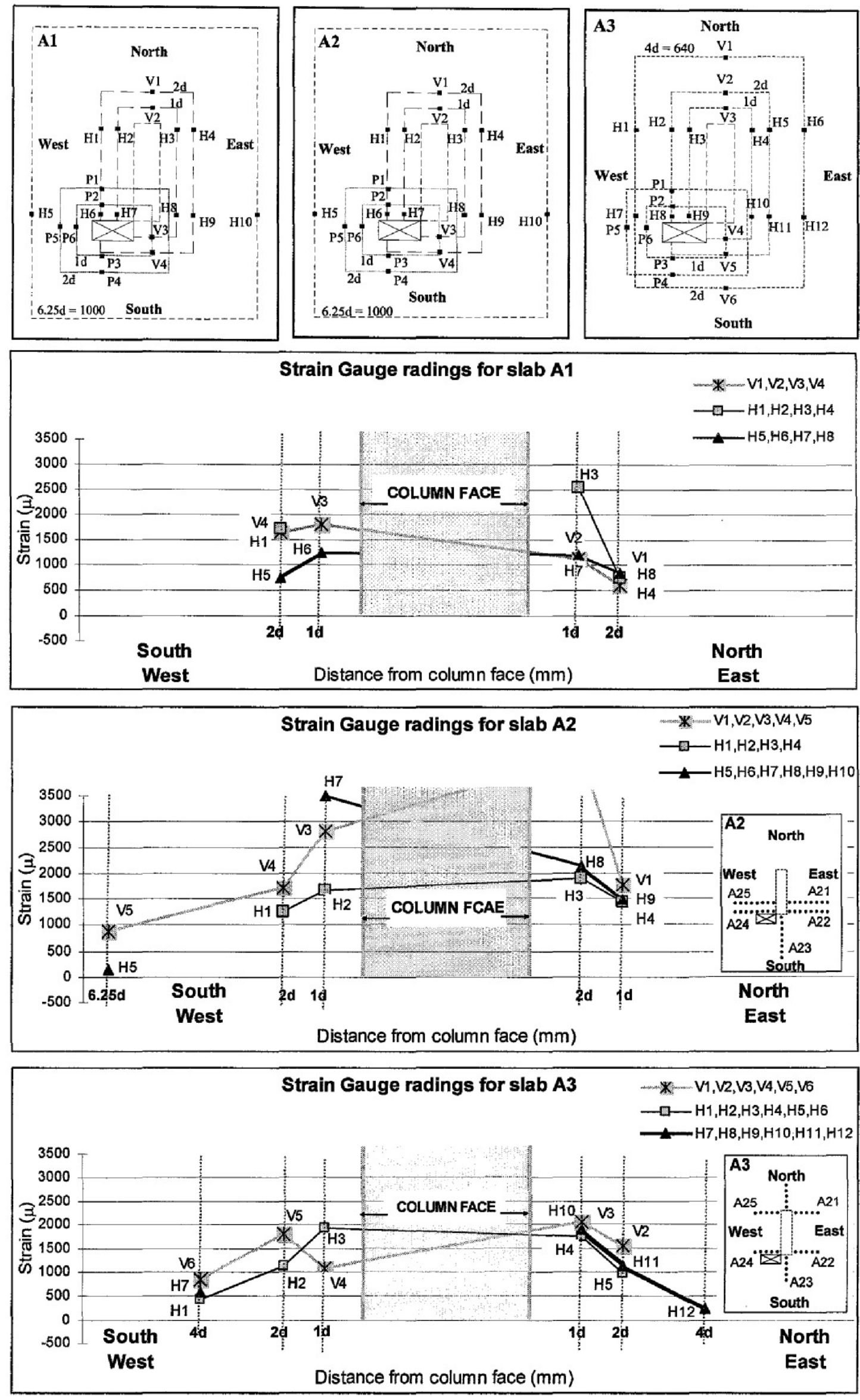

Figure 4.20 Strain vs distance from column face for tension bars for A series slabs 


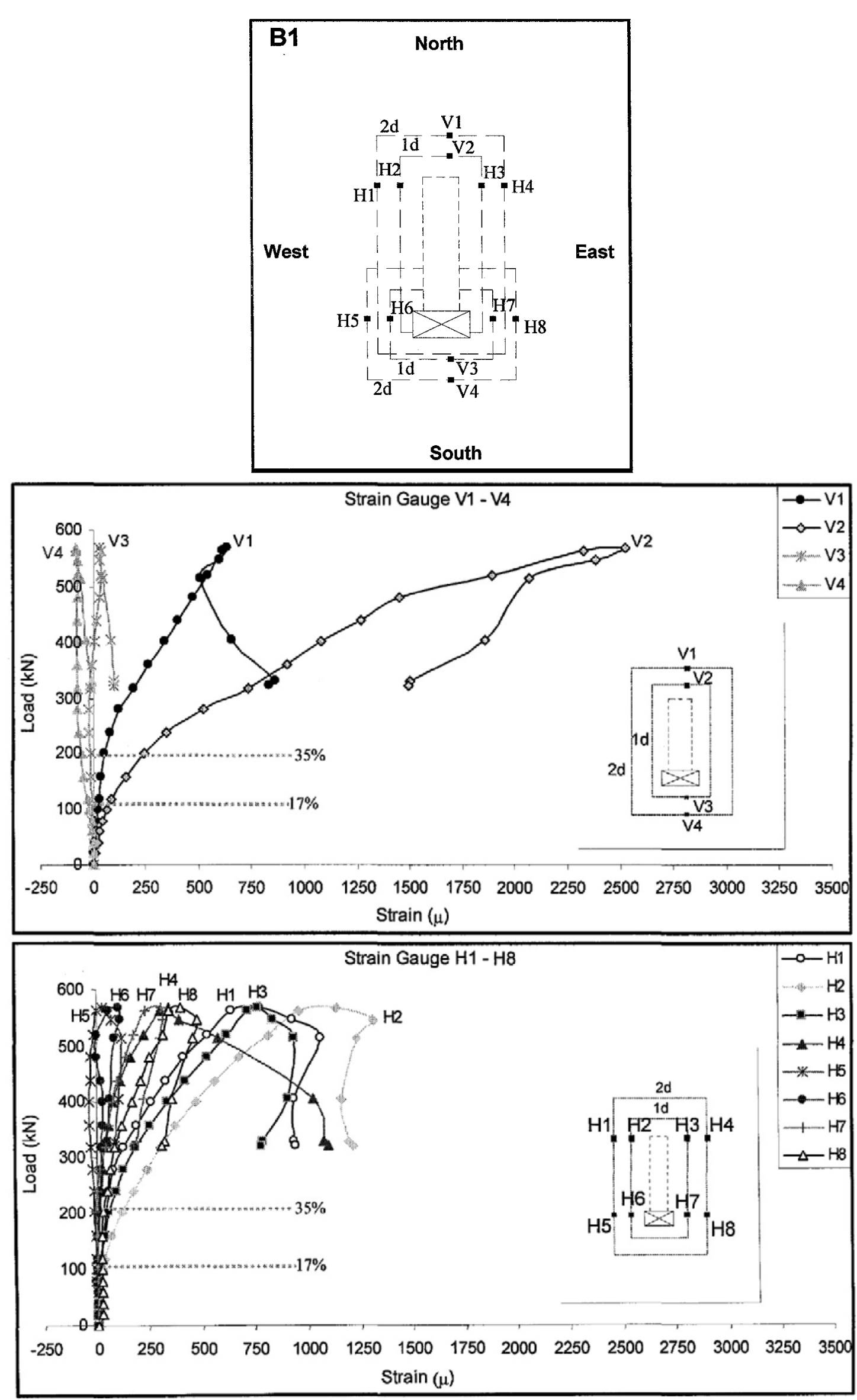

Figure 4.21 Load vs strain curve for tension bar for slab B1 

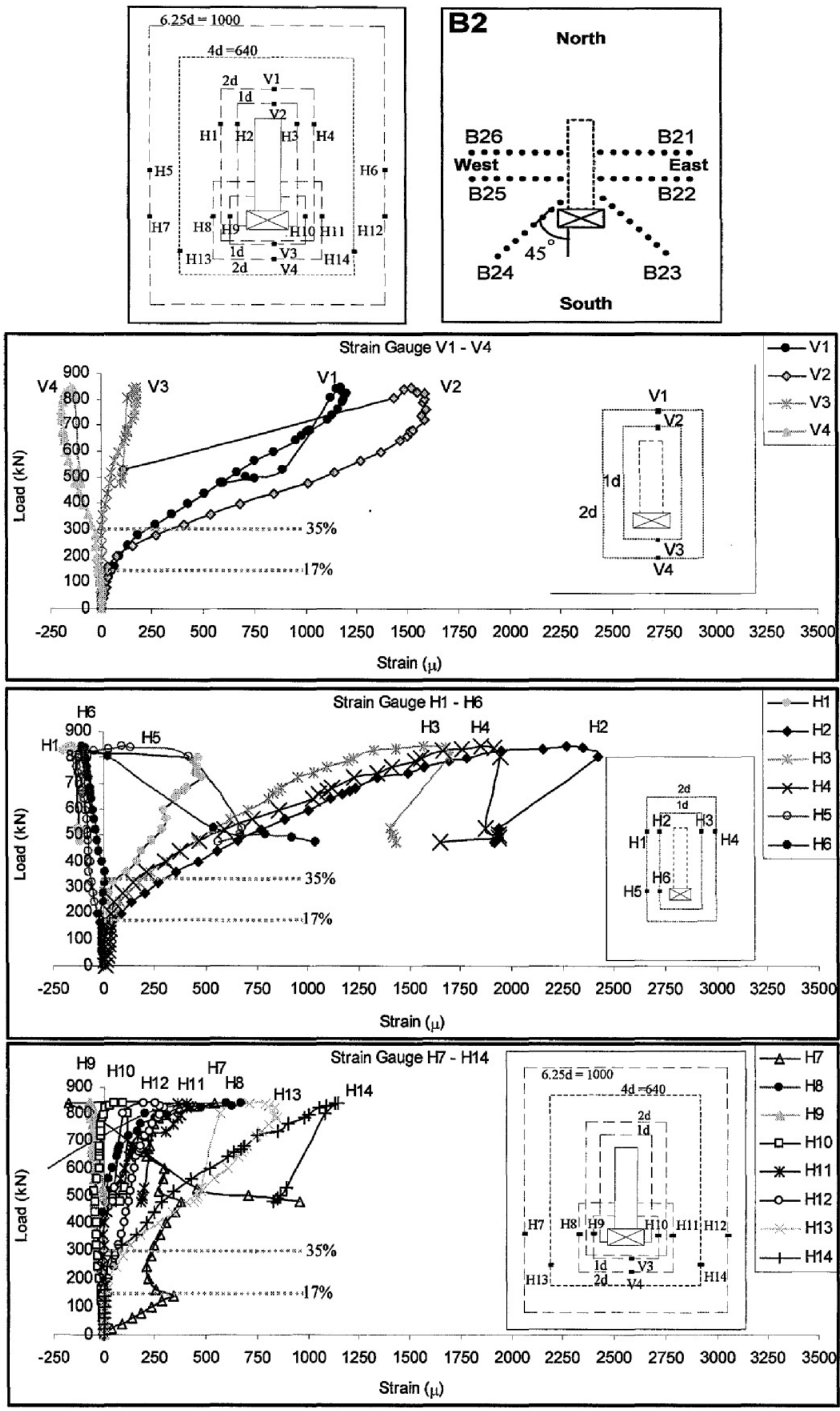

Figure 4.22 Load vs strain curve for tension bars used in slab B2 


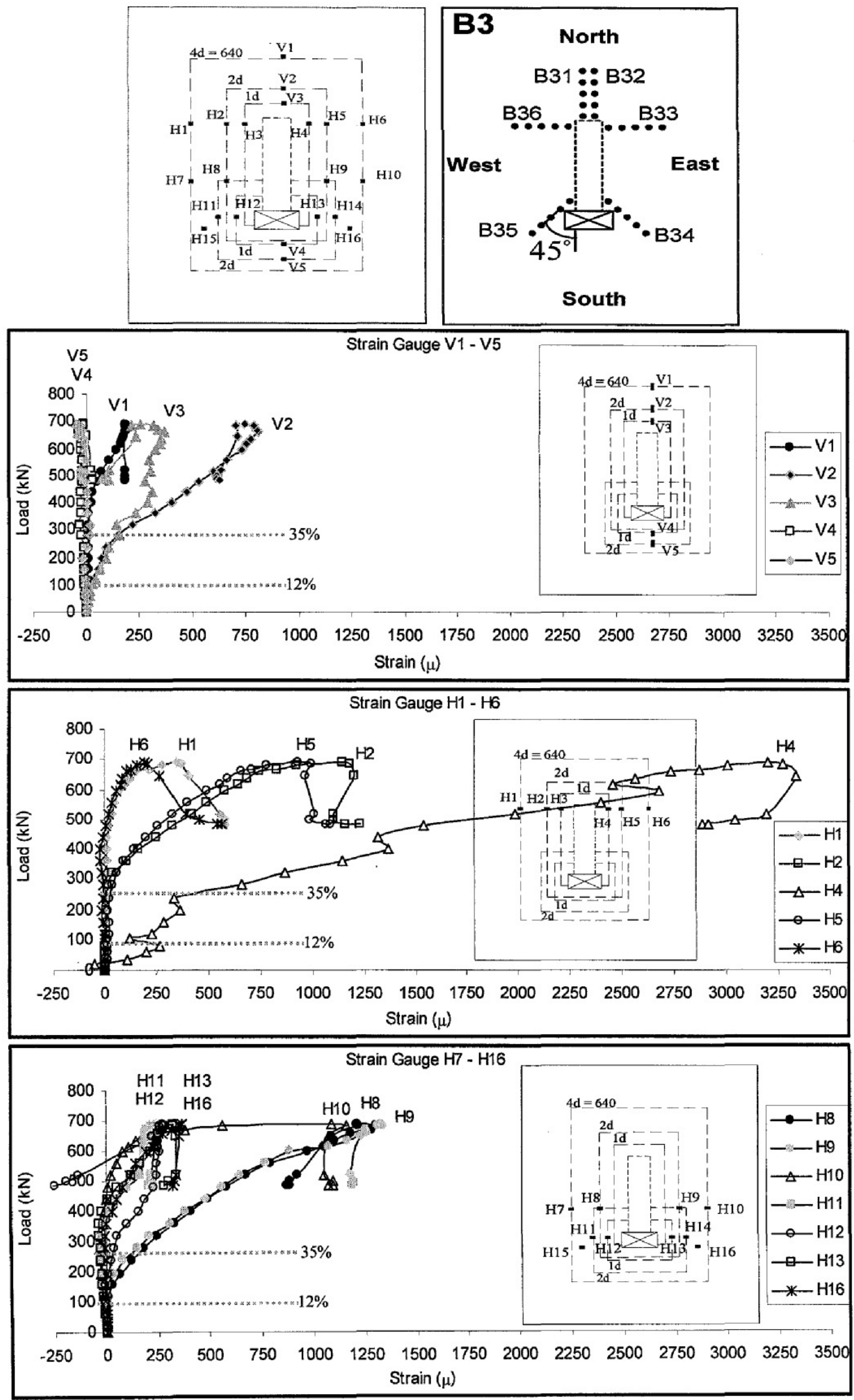

Figure 4.23 Load vs strain curve for tension bars used in slab B3 
Chapter 4 Experimental results and discussion

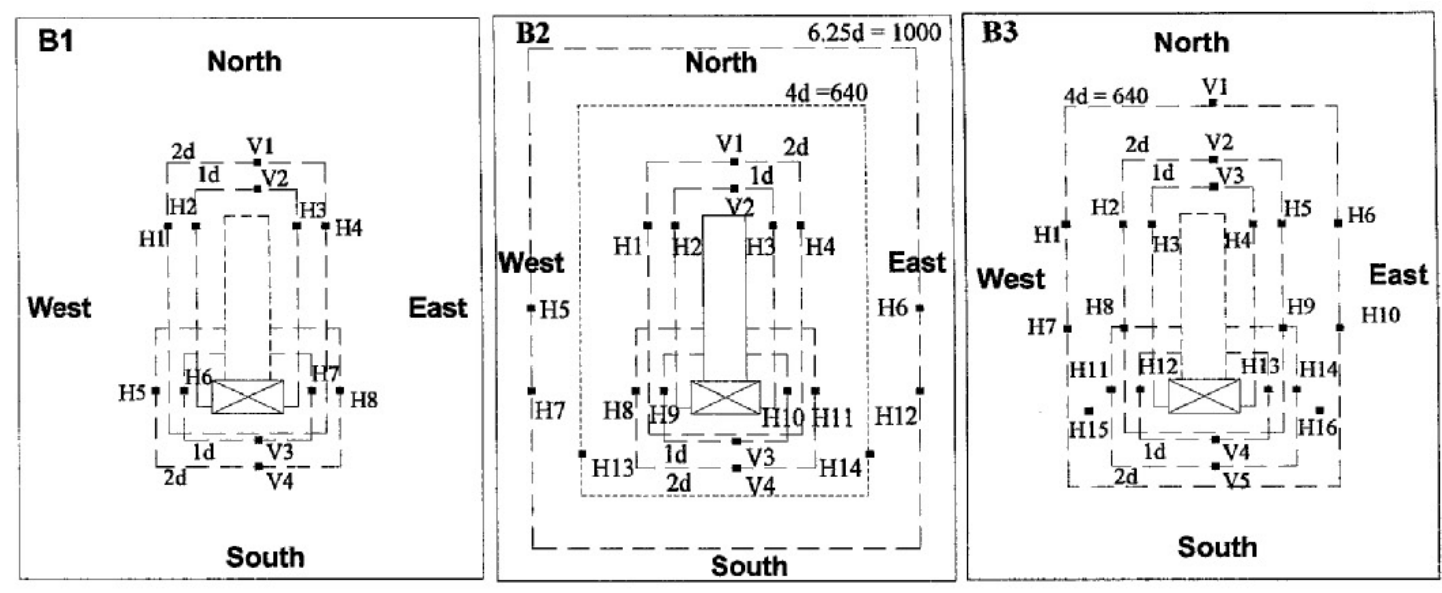
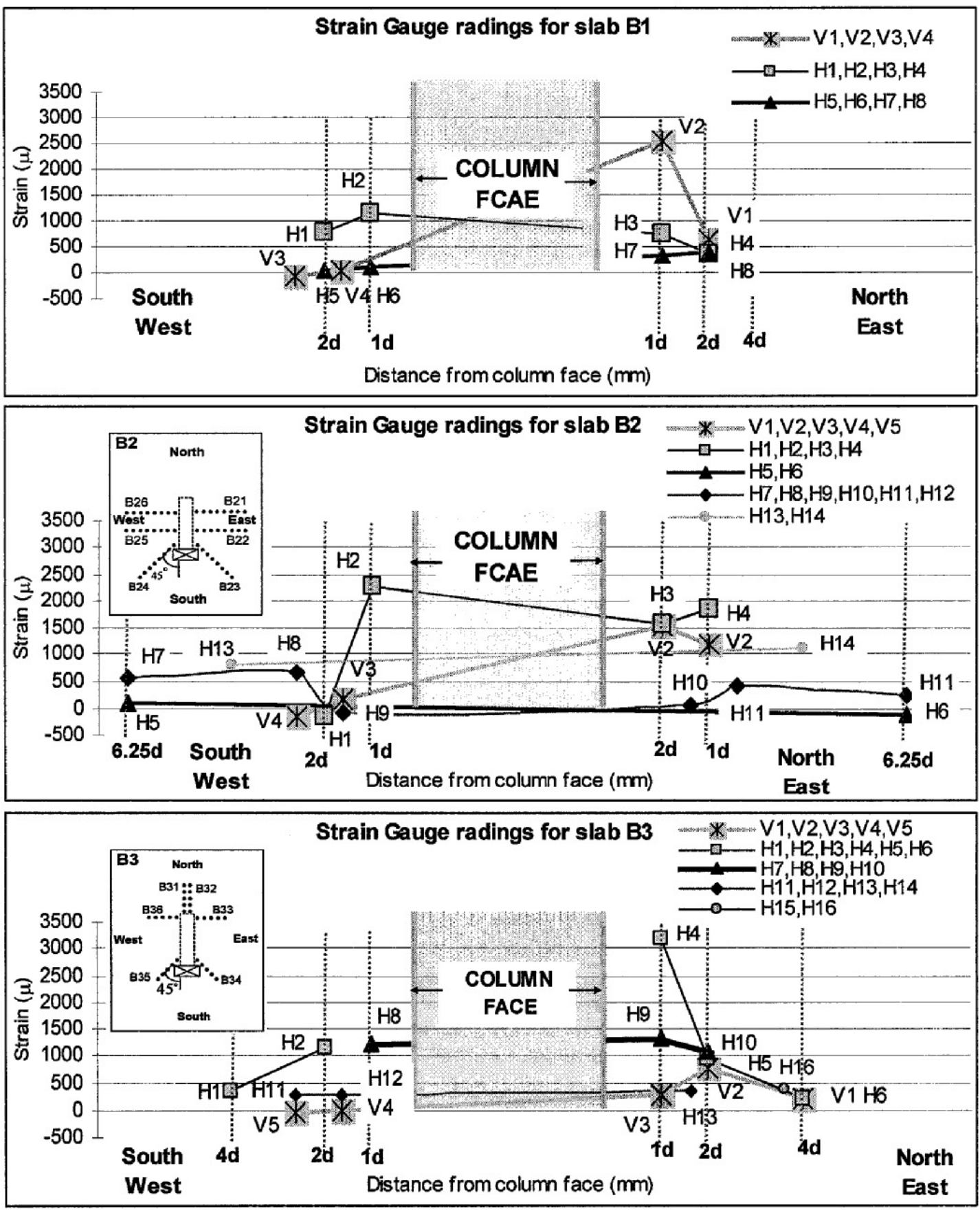

Figure 4.24 Strain vs distance from column face for tension bars for B series slabs 


\subsubsection{Analysis of strains for shear stud reinforcements}

In the slabs of series A and B, the shear stud reinforcements with various amount and arrangement were used to improve and recover the strength in resisting punching shear capacity lost due to opening. The distance of shear stud from the column face and centre-to-centre spacing of shear studs were $0.5 \mathrm{~d}$ and $0.75 \mathrm{~d}$, respectively, where $\mathrm{d}$ is the effective depth of the slab. In order to investigate the effectiveness of shear stud reinforcements related to their positions arranged in the slab, the strains occurred in the shear studs due to the applied load were measured by strain gauges installed on all shear studs.

For each shear stud placed in each slab, the strains observed during testing were tabulated and are shown in appendix A. And then, the load-strain curves were plotted. In order to better understand the effectiveness of shear stud reinforcements, the curves of strain-distance from the column face were plotted corresponding to a load just slightly smaller than the ultimate load. The arrangement of shear studs used in each slab, load-strain curves and strain-displacement curves are shown in Figures 4.25 to 4.34. In the figures for arrangements of shear studs, the shear studs are addressed as a sequence of $a, b, c$... starting from the outermost shear stud from the column face to the shear stud near the column face as shown in Figures 4.25 and 4.26. The labels addressing the shear studs on the load-strain curves refer to the point that the ultimate load reached during testing.

It can be evidently seen from the load-strain curves of Figures 4.27, 4.28, 4.31 and 4.32 that the most shear studs had undergone the positive strain and these positive strains were observed to be significant in some shear studs only, and that each shear stud with significant positive strain had a strain plateau around the ultimate load. The positive strains recorded on shear studs mean that such shear studs were being pulled in tension. The main purpose of using shear studs in slabs is to increase the punching shear capacity. When the punching shear failure is preceded by the vertical separation of the slab, the shear studs crossed by the inclined cracks will be in tension due to separation. The shear studs of the slabs with significant positive strains were effective in resisting separation due to punching. 
From strain-distance curves of Figures 4.29, 4.30, 4.33 and 4.34, for each strain profile, there was an optimum strain point observed on each stud rail of the slab at a particular distance from the column face. Therefore, the shear stud with the optimum strain point on that rail was the most effective in resisting punching among other shear studs on that rail. The distance of that shear stud from the column face at which the shear stud rail had the optimum strain point might be the nearest point with the circumferential failure crack on the slab surface and had been crossed by the major inclined cracks to occur the punching shear failure of the slab.

\subsubsection{Slab-column specimens for series A}

For this series, the arrangement of shear studs used in each slab is shown in Figure 4.25, and load-strain curves and strain-displacement curves are shown in Figures 4.27 to 4.30. From the load-strain curves, it can be seen that all of the shear studs in the slab could not reach their yield strain or near their yield strain at the ultimate punching load. Such similar observation also can be obtained from the strain-distance curves of Figures 4.29 and 4.30 for this series A. These figures also show that such shear studs reaching yield strain or nearly reaching yield strain were positioned on rails adjacent to the opening. This means that the inclined cracks in this series $\mathbf{A}$ were more severe around the opening and the location of shear studs in this region would be effective in resisting the vertical separation of the inclined cracks.
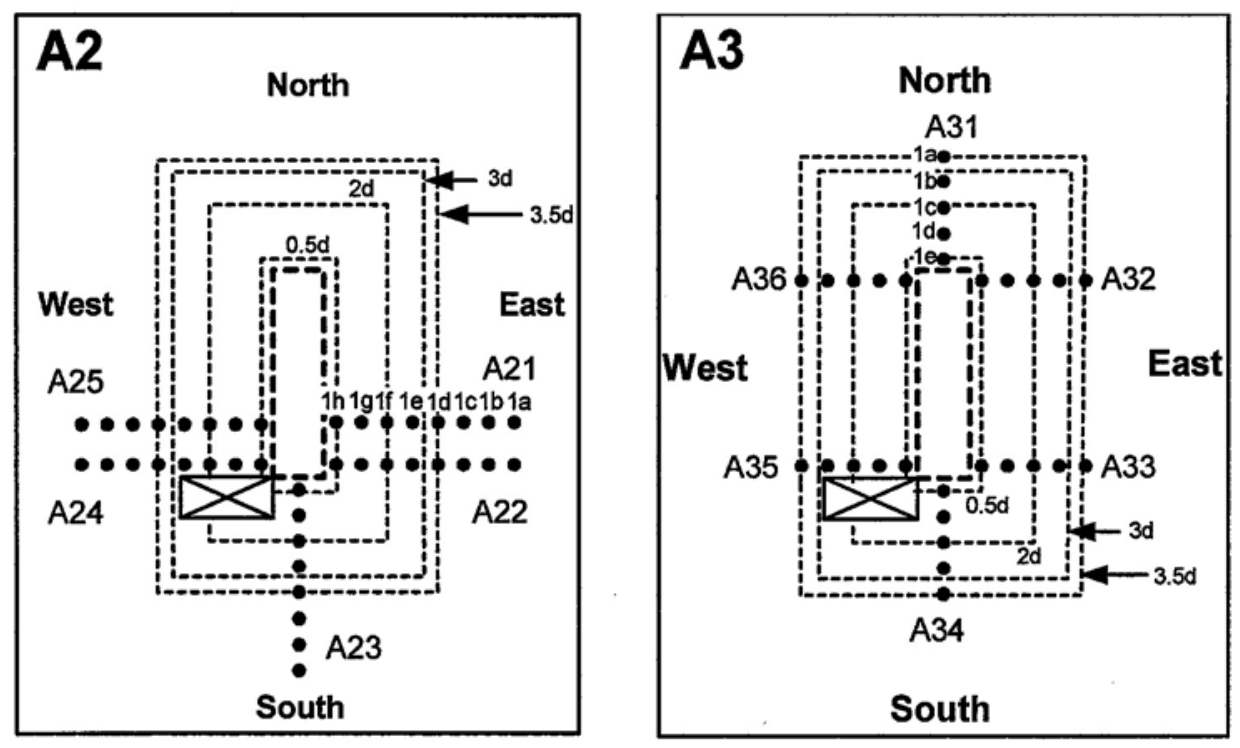

Figure 4.25 Arrangement of shear studs used in series A slabs 
Figure 4.29 for slab A2 shows that the strains observed in the shear studs located on rails A23 and A24 near the opening in the west and south directions of the slab, respectively, were larger than that observed in the shear studs on rail A21, A22, and A25. Similarly, Figure 4.30 for slab A3 show that the strain observed in the shear studs on rail A34 and A35 near the opening in the west and south directions of the slab were larger than that observed in the shear studs on rail A31, A32, A33 and A36. Therefore, the most effective stud rails in resisting the vertical separation of inclined crack causing punching shear failure in slab A2 and A3 were rail A23 and A24, and A34 and A35, respectively.

Figures 4.29 and 4.30 strain-distance curves also show that when the longer stud rail A23 in slab A2 and the shorter stud rail A34 are compared, the longer stud rail A23 in slab A2 had larger strain than in the shorter stud rail A34 in slab A3. Therefore, the use of more number of shear studs on longer rail like A23 is more effective in resisting the vertical separation of inclined cracks than the less number of shear studs on shorter rail like A34 as the larger separation of inclined cracks occurred in the south direction of the slab A2. Smaller vertical separation in the south direction of the slab A3 could be due to the presence of the shear studs on rail A31 in the north direction of the slab A3. The stud rail A31 in the south direction of the slab A3 had significant strain in only one shear stud (le) at the distance of $0.5 \mathrm{~d}$ from the column face while the shear studs on rails A32 and A35 of slab A3 had very small strain. Therefore, the rail A32 and A35 in slab A3 were not much effective in resisting punching because the region in which the stud rails A32 and A35 were located was not the severe stress concentration region.

Furthermore, it can be seen from the Figure 4.29 of strain-distance curves that the optimum point of strain profile in the rails A23 and A24, which were previously shown to be effective, occurred in the shear studs at the distance between $\mathrm{d}$ and $2 \mathrm{~d}$. And the observation for slab A3 is that the optimum point of strain profile for the effective rails A34 and A35 described previously for slab A3 occurred in the shear studs at the distance between $\mathrm{d}$ and $3 \mathrm{~d}$. Therefore, the arrangement of longer stud rails as in the slab A2 were not as effective as the shorter stud rail as in slab A3 when the slab had opening at the corner of column. 


\subsubsection{Slab-column specimens for series B}

For the slabs of this series, the arrangement of shear studs used in each slab is shown in Figure 4.26, and load-strain curves and strain-displacement curves are shown in Figures 4.31 and 4.32, and 4.33 and 4.34, respectively. From these figures, it can be seen that the shear studs tilting around the openings had larger strains than the shear studs in other locations of the slabs. Therefore, the tilted stud rails near the region around the opening were more effective in resisting the vertical separation of inclined cracks, which were more severe in the region around the opening, than the shear stud rails which are not placed around the opening.
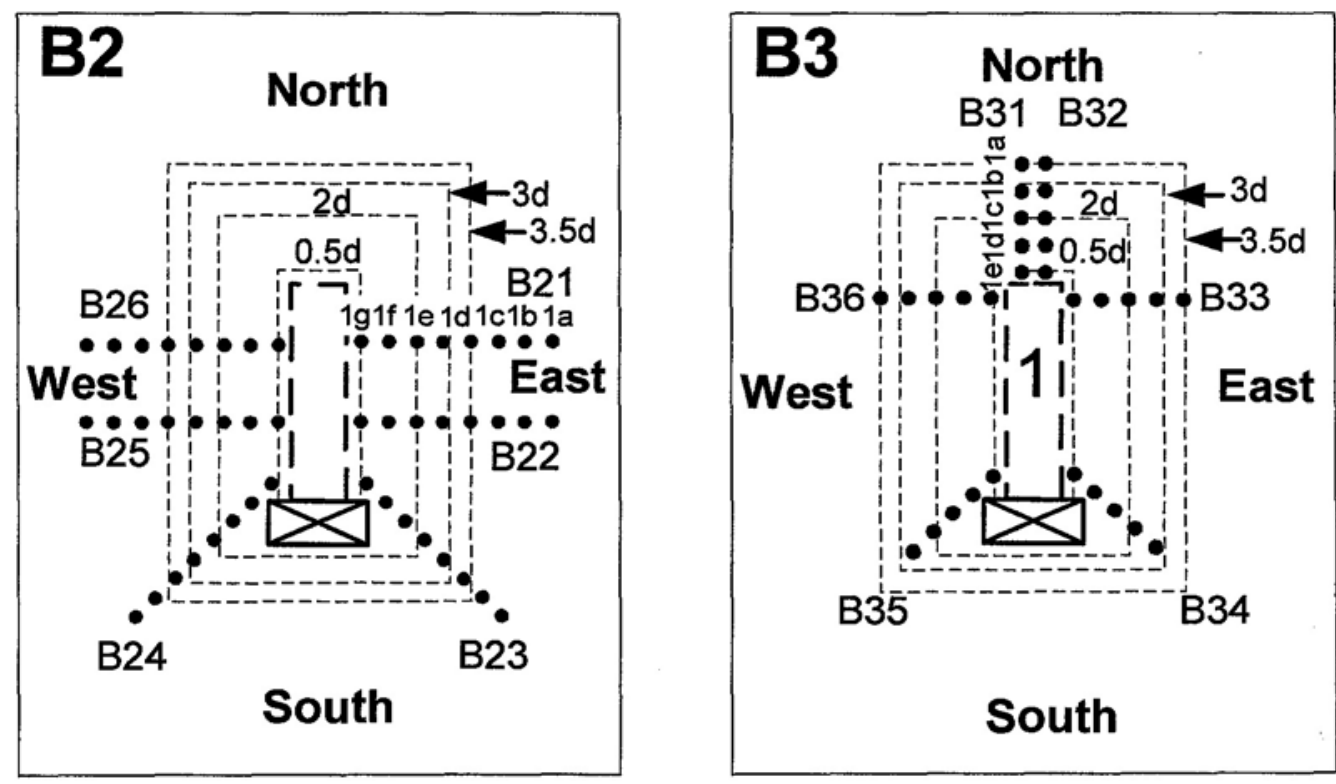

Figure 4.26 Arrangement of shear studs used in series B slabs

It can be seen from Figures 4.33 and 4.34 that the strains recorded on the rails B21, B22, B25 and B26 in east-west direction of the slab B2 were larger than the strains recorded on the rails B33 and B36 in that direction of the slab B3. Moreover, the strains recorded on the longer rails 23 and B24 tilting near the region around the opening in the slab B2 were larger than the strains recorded on the shorter rail B35 and B36 in the slab B3 which were in the same location like in slab B2. Therefore, in contrast to longer shear stud rail in series A, the use of longer shear stud rails tilting near the region around the opening which was positioned at the shorter column width, 
could be able to give a significantly more effectiveness in resisting the vertical separation of the inclined cracks due to the applied load.

From the Figures 4.33 and 4.34, it can also be seen that the strains recorded on the tilted rails B23, B24 in slab B2 and B34 and B35 in slab B3 were observed to be significant in the shear studs even at a distance of greater than $3 \mathrm{~d}$ from the column face. This observation indicated that the tilted rails had to be able to intercept many inclined cracks, which had extended in radial direction around the opening region from the column face, thereby resulting in the majority of shear studs being effective. Furthermore, from this observation, it can be suggested that the major inclined cracks might have intercepted the opening. It can be observed that the largest strain on the rails B23 and B24 in slab B2 had occurred in the shear studs at the distance within 2d and 3d from the column face while the largest strain on the rails B34 and B35 in slab B3 had occurred in the shear studs at a distance within $\mathrm{d}$ and $2 \mathrm{~d}$ from the column face.

\subsubsection{Findings}

The followings are the summary of important findings obtained from analysis of strains on the flexural reinforcements and shear stud reinforcements in the slabs of series A and B.

\subsubsection{Slab-column specimens for series A}

(i) Referring to slab A1 as shown in Figure 4.17, for the slab without shear stud reinforcements, due to location of opening in south direction of the slab, the stresses near the opening in that direction of the slab were higher than the stresses in the direction of the slab where the opening was not located. And the uneven stress distribution in the east-west direction of the slab could not occur due to opening in addition to that the higher stress concentration could not occur near the opening in the west direction of the slab.

(ii) The most effective stud rails in resisting the vertical separation of inclined crack causing punching shear failure in slab A2 were longer stud rails A23 and A24. The most effective stud rails in resisting the vertical separation of inclined crack 
causing punching shear failure in slab A3 were longer rails A34 and A35. Therefore, the shear studs on rails nearest with the opening were more effective than shear studs on rails located elsewhere in the slabs.

(v) The use of longer rails of shear studs failed to prevent the major inclined crack from intercepting opening.

(vi) Shear studs closer to the column face tend to be more effective.

\subsubsection{Slab-column specimens for series $B$}

(i) Referring to the slabs as shown in Figure 4.26, the shear studs tilting around the openings had larger strains than the shear studs in other locations of the slabs. Therefore, the tilted stud rails near the region around the opening were more effective in resisting the vertical separation of inclined cracks, which were more severe in the region around the opening, than the shear stud rails which were not placed around the opening.

(ii) The use of longer shear stud rails tilting near the region around the opening which was positioned at the shorter column width could be able to give a significantly more effectiveness in resisting the vertical separation of the inclined cracks due to the applied load.

(iii) The tilted rails had to be able to intercept many inclined cracks, which had extended in radial direction around the opening region from the column face.

(iv) The largest strain on the rails B23 and B24 in slab B2 had occurred in the shear studs at the distance within $2 \mathrm{~d}$ and $3 \mathrm{~d}$ from the column face.

(v) The largest strain on the rails B34 and B35 in slab B3 had occurred in the shear studs at a distance within $\mathrm{d}$ and $2 \mathrm{~d}$ from the column face.

(vi) The use of longer rails of shear studs failed to prevent the major inclined crack from intercepting opening. 
Chapter 4 Exaerimental results and discussion
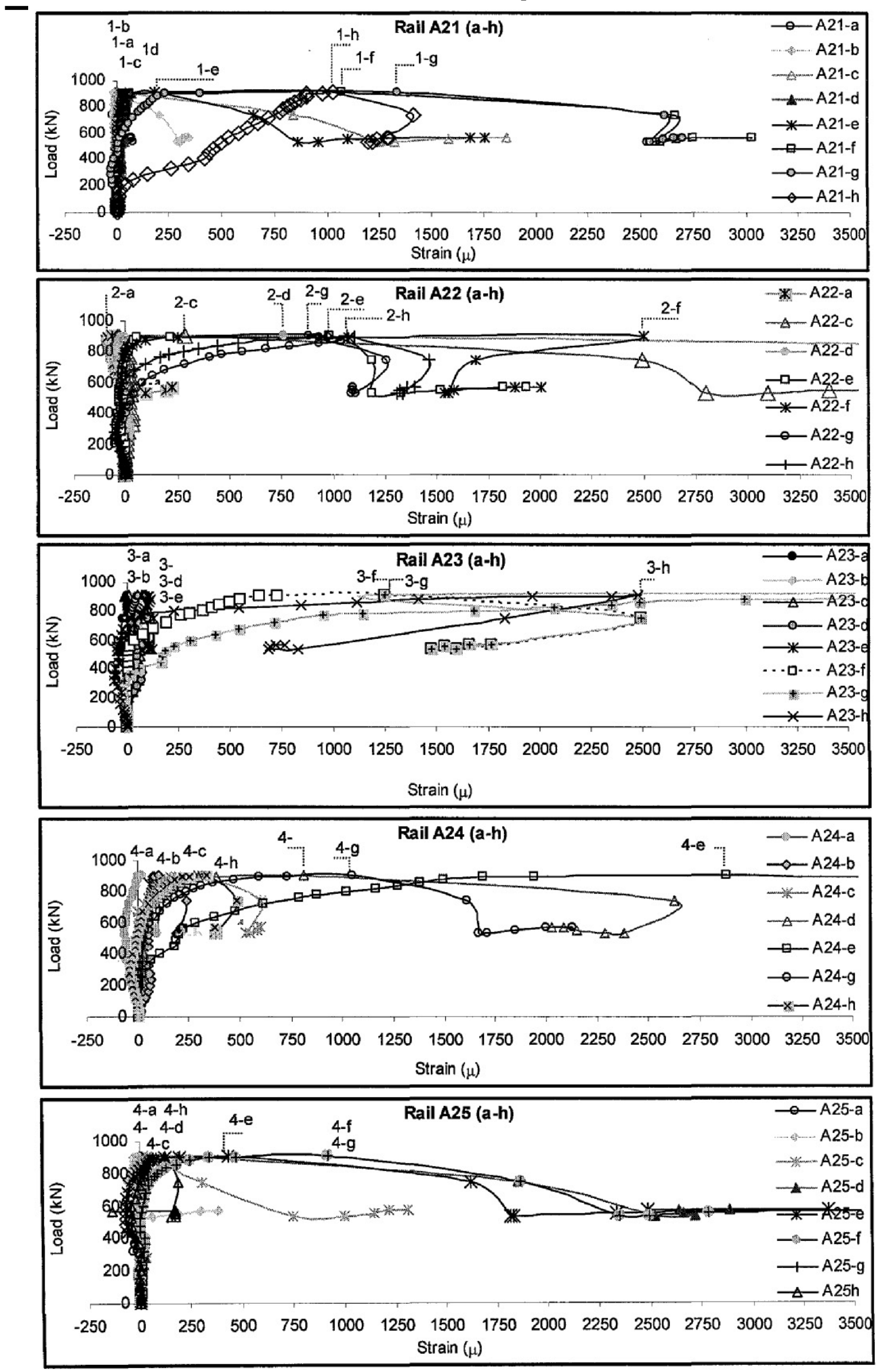

Figure 4.27 Load vs strain for shear studs used in slab A2 
Chapter 4 Experimental results and discussion
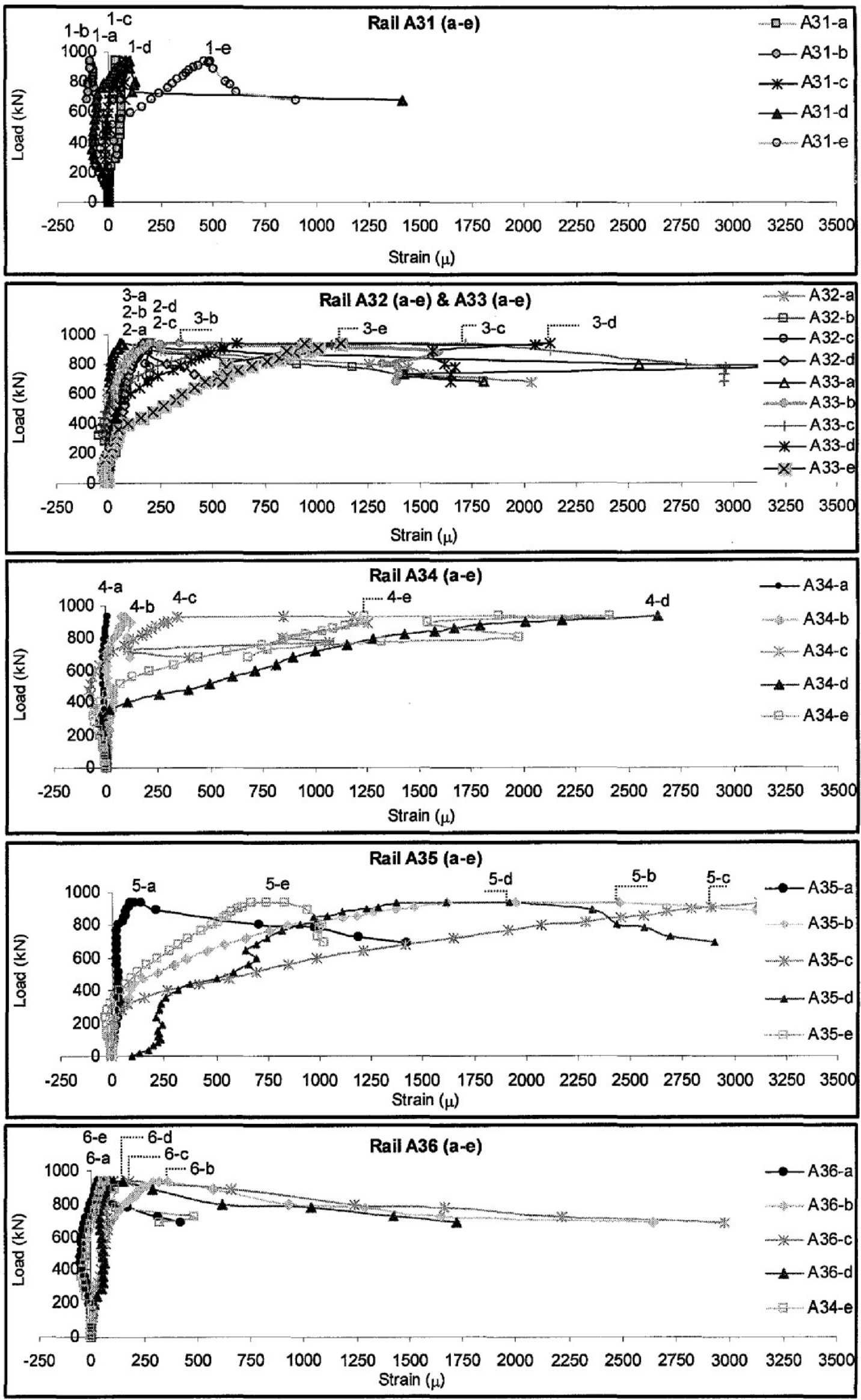

Figure 4.28 Load vs strain for shear studs used in slab A3 


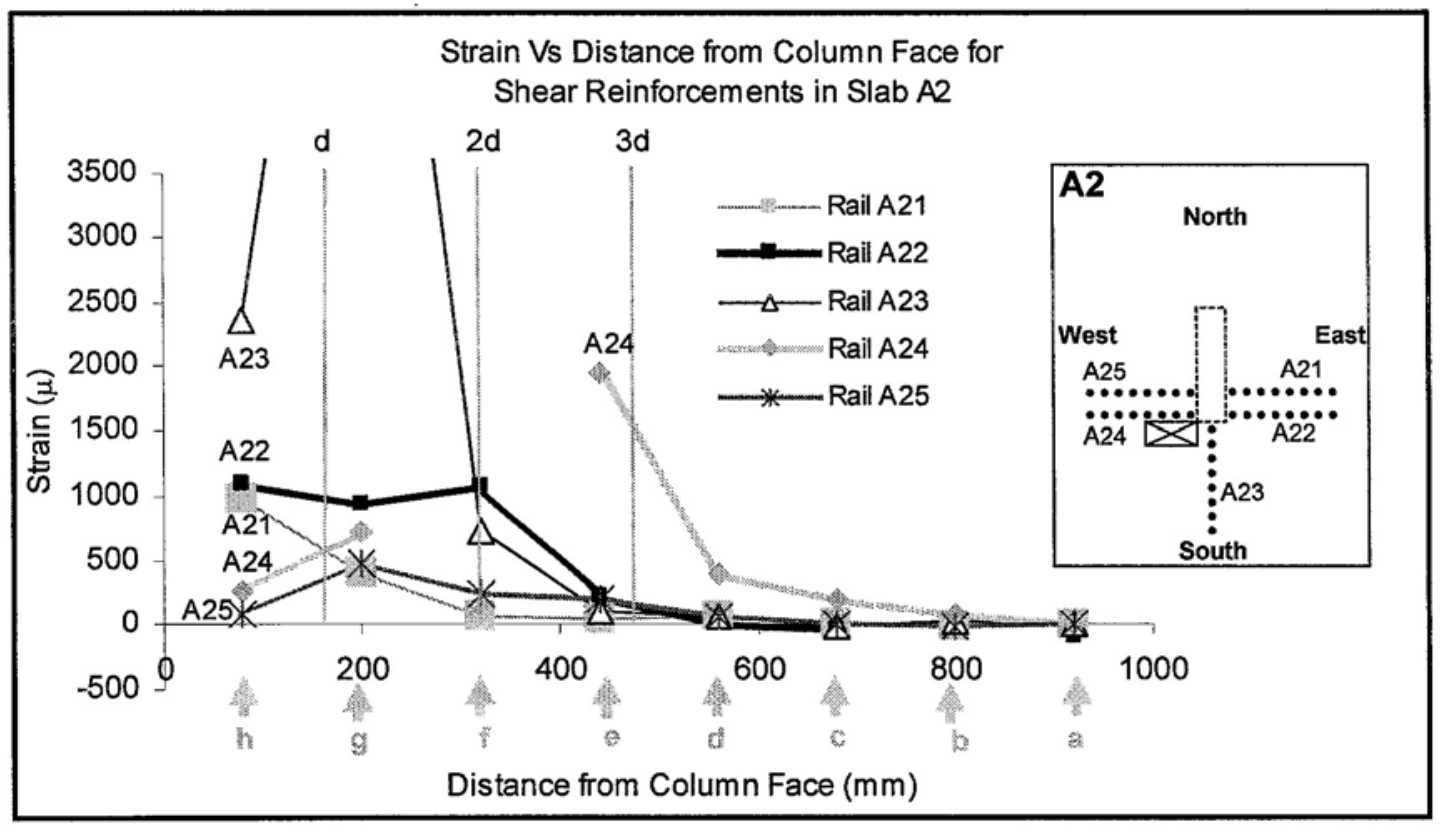

Figure 4.29 Strain Vs distance from column for shear studs used in slab A2

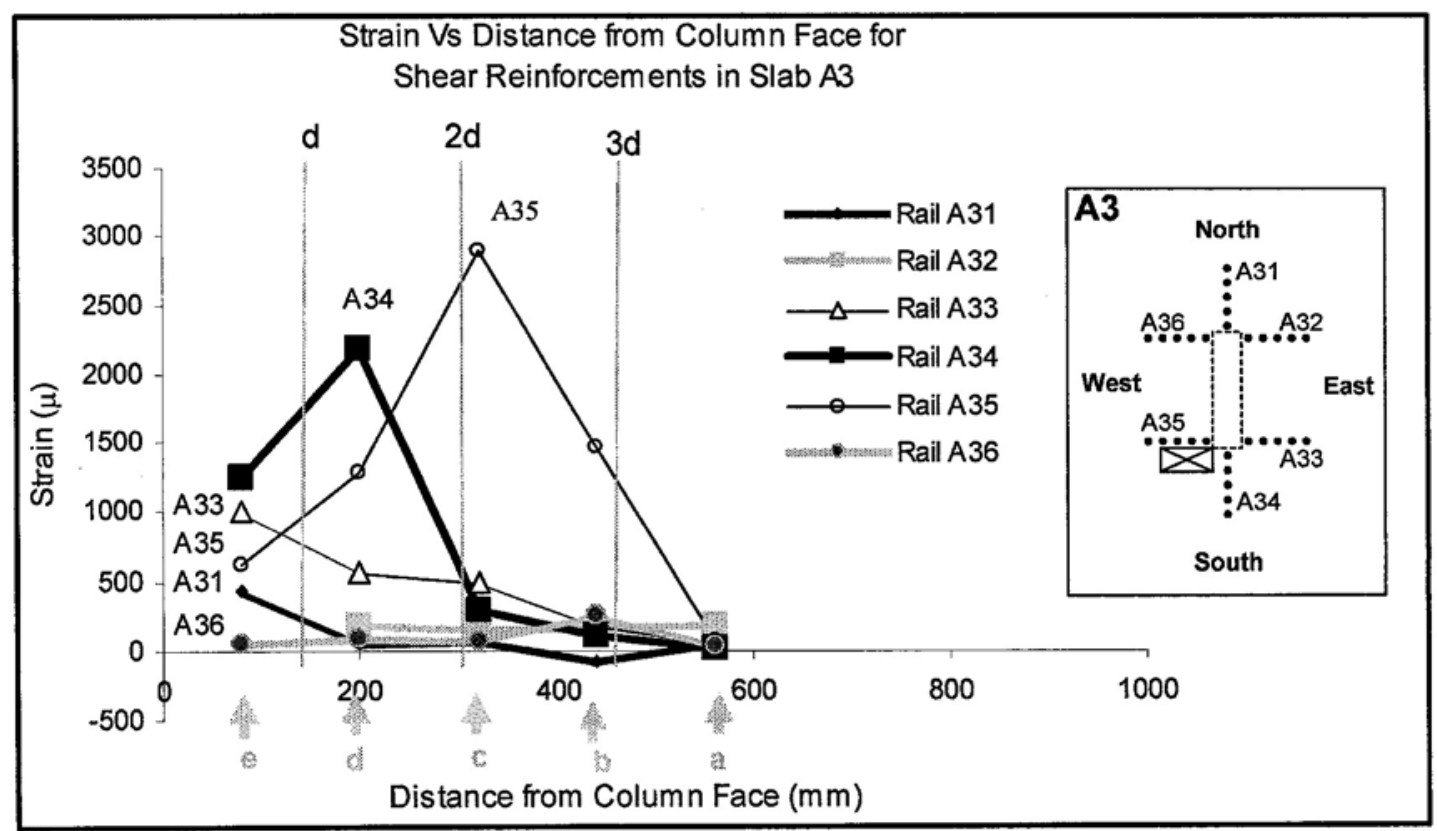

Figure 4.30 Strain Vs distance from column for shear studs used in slab A3 
Chapter 4 Experimental results and discussion

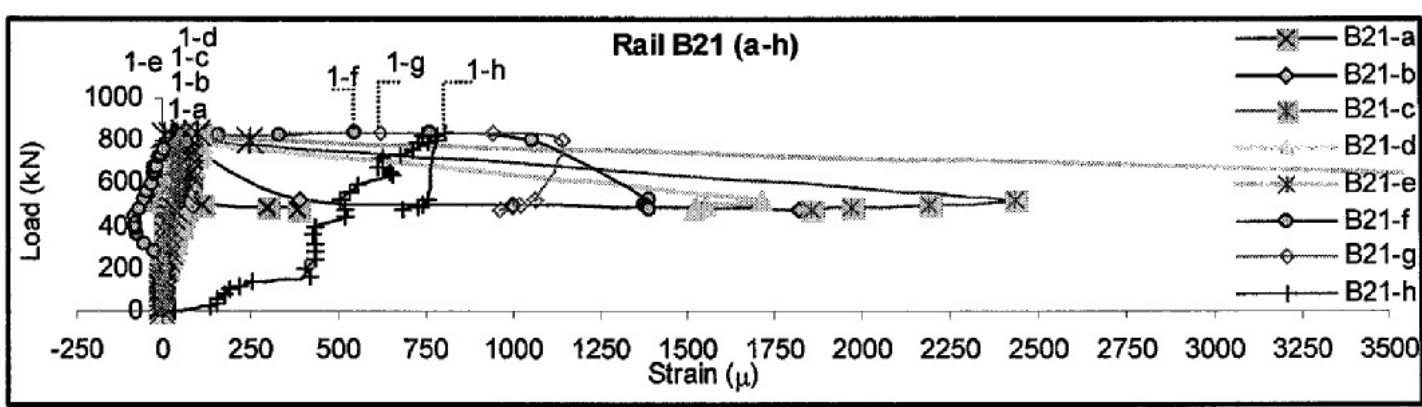

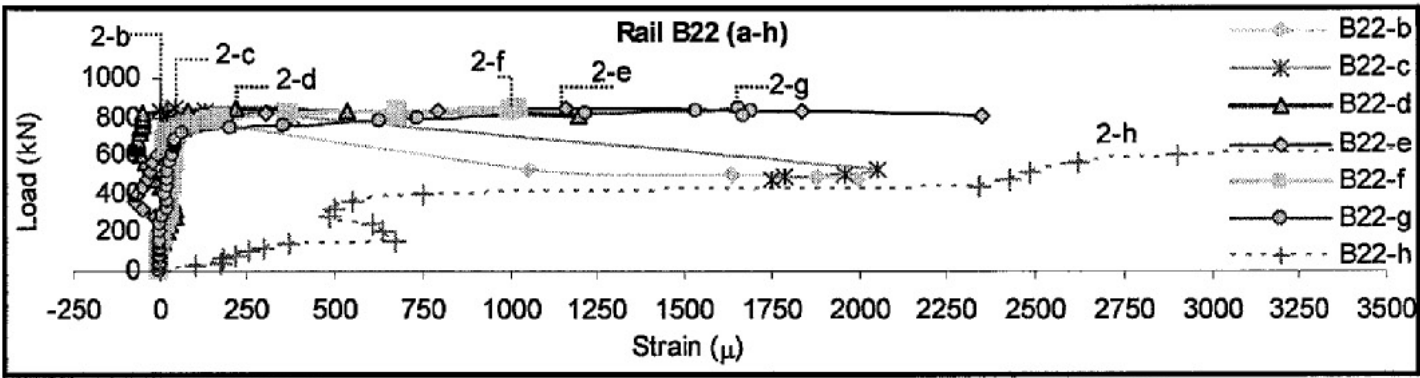

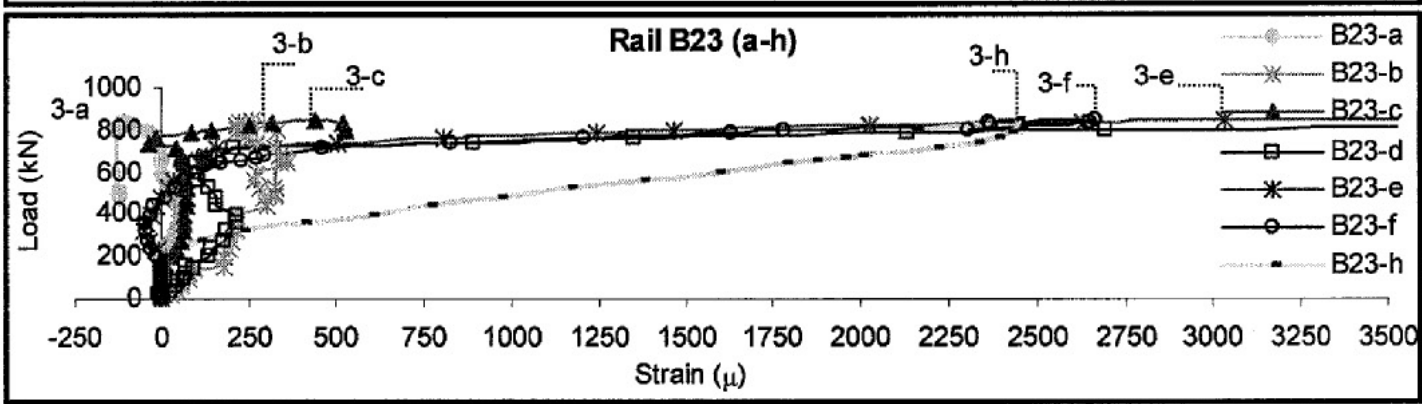

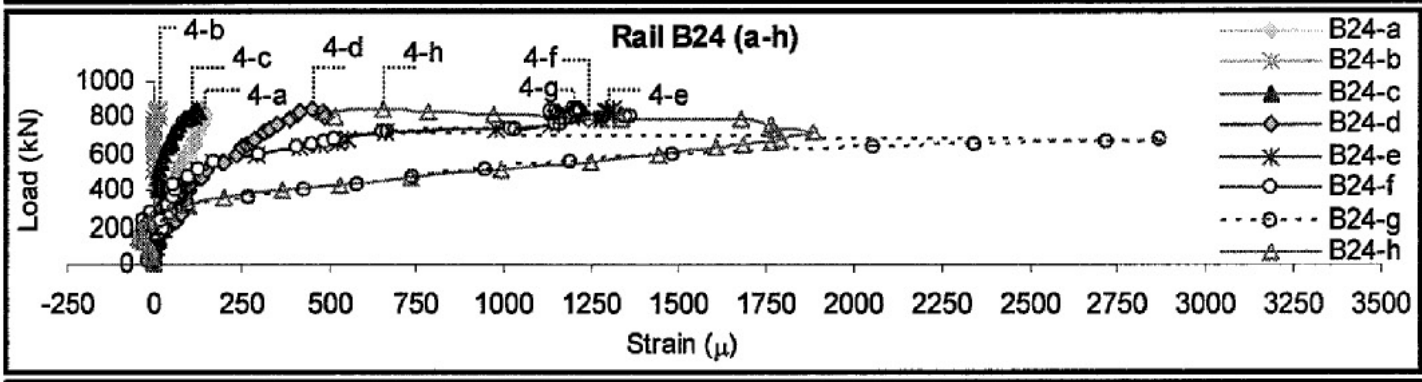

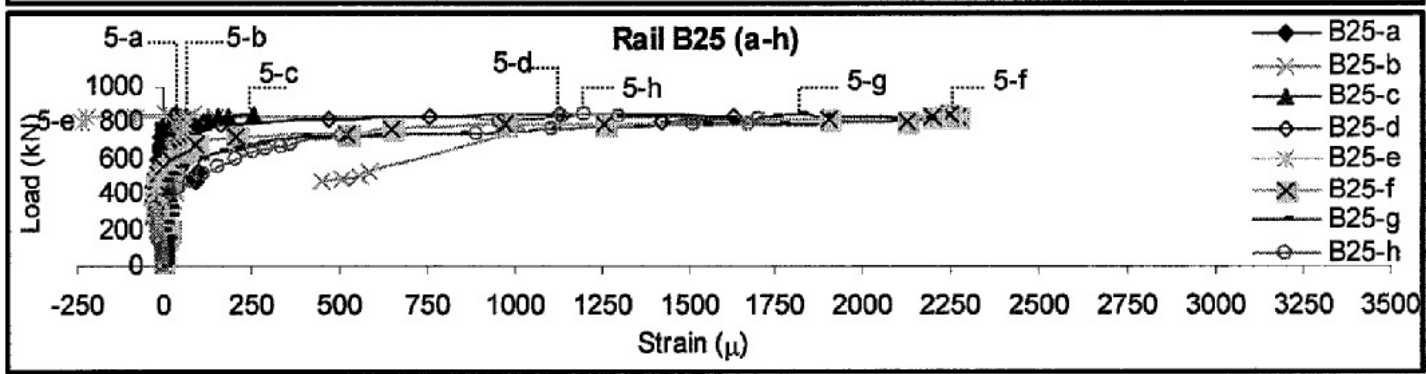

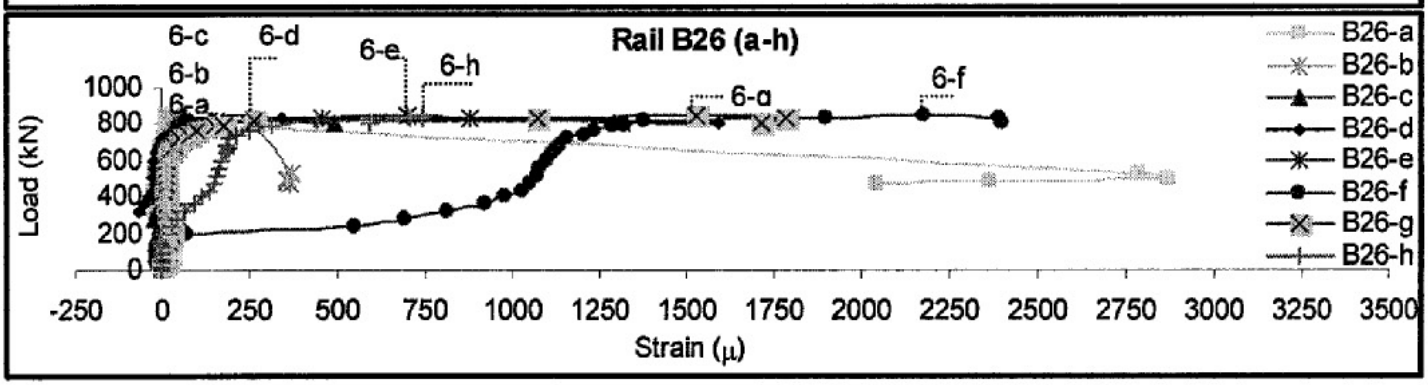

Figure 4.31 Load vs strain for shear studs used in slab B2 

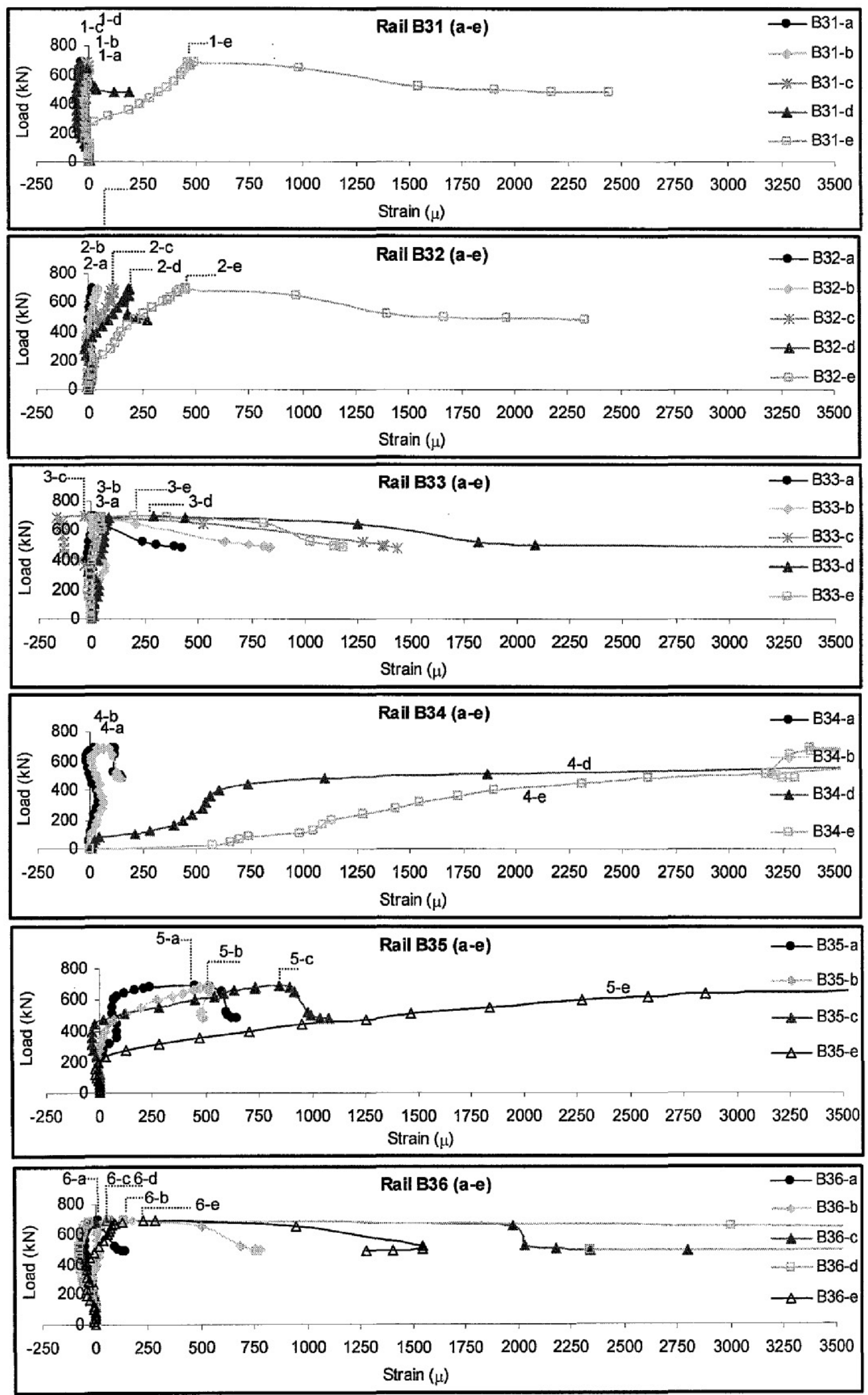

Figure 4.32 Load vs strain for shear studs used in slab B3 


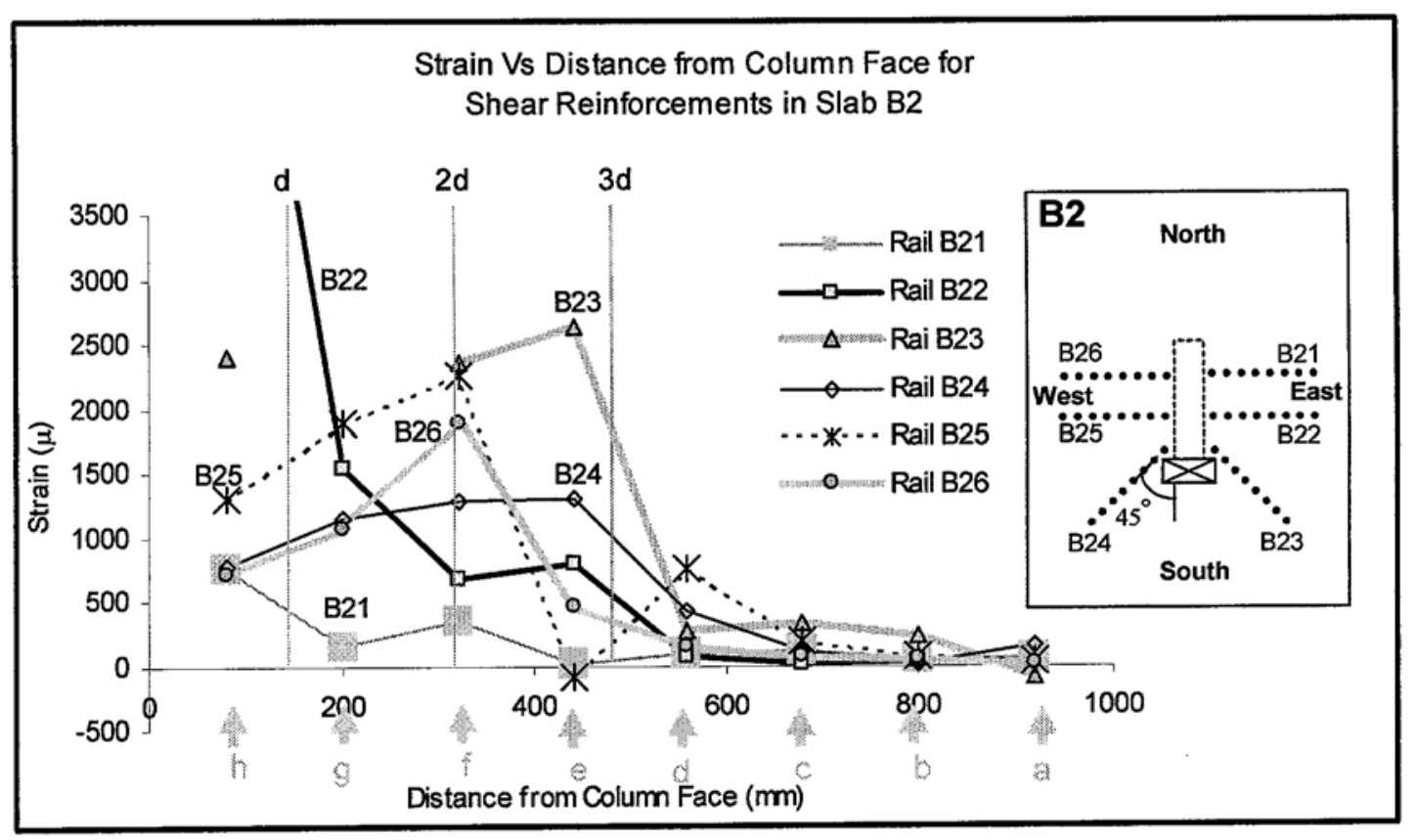

Figure 4.33 Strain Vs distance from column for shear studs used in slab B2

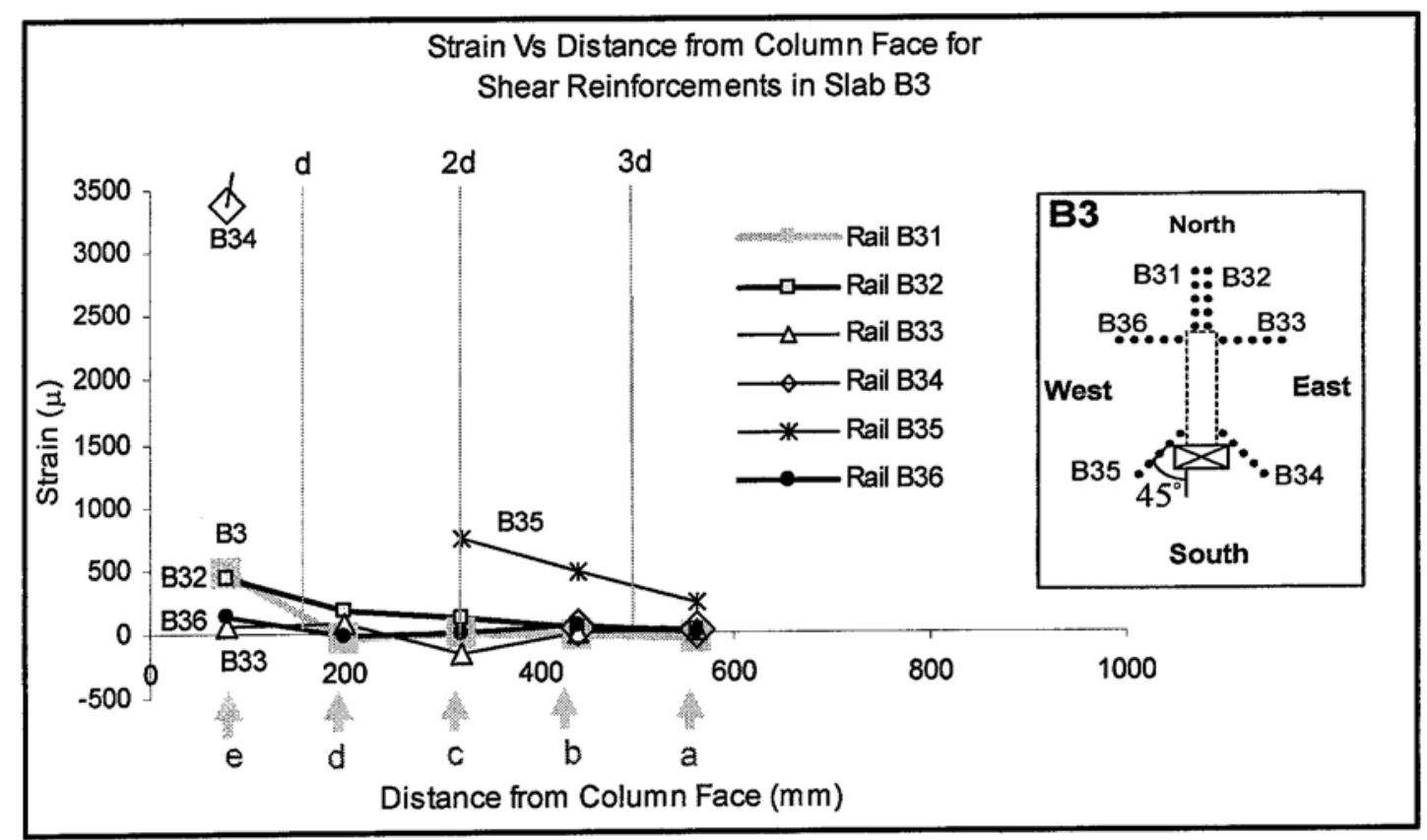

Figure 4.34 Strain Vs distance from column for shear studs used in slab B3 


\subsection{Summary and conclusions}

The openings are constructed in the vicinity of the slab-column connections because of the need to provide sanitary and electrical and mechanical ducts. When the slabs have openings around the column, the shear capacity will be reduced. To regain the loss of punching shear capacity of slab-column connections due to opening, the shear stud reinforcement can be used. Thus, it is required to study the arrangement of shear stud reinforcement in increasing the punching shear strength of the slabs.

The six number of normal strength concrete slabs with different arrangement of shear stud reinforcement were tested. Two different opening locations were considered. One was at the adjacent comer of column while the other one was at the shorter side of column. The different amount and arrangement of shear stud reinforcements in the specimens were considered. The specimens were tested to failure under monotonic loading to study the effectiveness of the shear stud reinforcement under ultimate load condition. The structural behavior of the specimens were examined in term of the ultimate capacity, the first cracking loads, failure patterns of cracks, and the deflections of slabs.

From this experimental study, the flowing conclusions are drawn.

(1) If possible, the openings should be located at the longer side of column than the shorter side of column when the openings around the column are needed.

(2) When the rectangular slab-column connection consists of opening near the column, the region near the opening is the weakest portion in the slab regardless the slab is reinforced with shear reinforcements.

(3) The distances of critical perimeter of the slab-column connection with rectangular column may range from $2 \mathrm{~d}$ to $4 \mathrm{~d}$ when the slabs have openings, where $d$ is the effective depth of slabs.

(4) The use of shear stud reinforcements is significantly effective in recovering the punching shear capacity of the slabs lost due to openings.

(5) The effectiveness of the shear stud reinforcements in increasing the punching shear capacity of the slabs can be different depending on their arrangement in 
the slab. Therefore, the various arrangements of shear stud reinforcements accompanying with various locations of openings should be studied to obtain the more reliable data.

(6) When the opening is located at the comer of column in interior slab-column connection with rectangular column, the use of more number of stud rails with shorter lengths is more effective in increasing punching shear capacity than the use of lesser number of stud rails with longer lengths.

(7) However, when the opening is located at the shorter column width in the interior slab-column connection with rectangular column, the use of longer rails and tilting the rails near the opening is more effective in increasing the punching shear capacity than the use of shorter rails and tilting the rails near the opening.

(8) Tilting of longer stud rails near the region around the opening is significantly effective in increasing the punching shear capacity and stiffness of the slab with opening.

(9) The location of opening at the shorter column width affect the serviceability load of the slab more than that of the location of opening at the comer of longer column width.

(10) The angle of inclined cracks becomes steeper if the slabs have openings at the shorter side of column than at the comer of column. The A-series specimens have the angle of inclined cracks ranged from 22 to 27 degrees while B-series specimens have the angle of inclined cracks ranged from 40 to 53 degrees. 


\section{CHAPTER 5 \\ PUNCHING SHEAR CAPACITY OF SLAB-COLUMN CONNECTION BY THEORY OF PLASTICITY}




\section{Chapter 5}

\section{Punching shear capacity of slab-column connection by theory of plasticity}

\subsection{Introduction}

In designing slab-column connections, punching shear capacity needs to be checked because the slabs surrounding the column may fail in brittle punching shear failure mode when high shear forces are applied to the slab-column connections. The punching shear failure surface occurred around the column observed in practice is a curve and extends from the face of column in compression to the tension face of slab (Braestrup, 1976). The normal and shear stresses along the failure surface work against the punching load. The punching shear failure of slab is a two-dimensional plane strain problem and is usually a combined failure mode of sliding and separation. The punching shear resistance may decrease when the slab has opening. The punching shear strength can be recovered by using shear reinforcement.

As reviewed in chapter two, there are various models previously developed to predict the punching shear capacity of slab-column connections such as plasticity model by Braestrup (1976), mechanical model by Kinnunen and Nylander (1960), truss model by Alexander and Simrnonds (1987), mechanical model by Menétrey (1996). All these models could give accurate punching shear capacity of slab-column connections to some degree.

The theory of plasticity has been used to predict the upper bound punching shear capacity for circular slab-column connections simply supported around the column under concentric load by Braestrup (1976). He assumed a failure mechanism that part of slab bounded by the yield surface was punched out in the direction of concentric load and part of slab outside the yield surface remained as rigid. The concrete was considered as a modified Coulomb's material. Both the sliding and separation failure 
modes were considered in his model. He also considered the softening effect of concrete on the compressive strength by applying an effectiveness factor, which depends linearly on the square root of compressive strength of concrete.

The Braestrup's plasticity model (1976) had been modified by Jiang and Shen (1986), Bortolotti (1990), Kuang and Morley (1992), Yankelevsky and Leibowitz (1996), and Salim and Sebastian (2002) in the consideration of failure criterion for concrete and the softening of concrete on the compressive and tensile strength of concrete. However, all plasticity models previously developed could only predict the punching shear strength of slab-column connections with circular column shape. In addition, they did not consider the punching shear strength of slab-column connections when the slab has rectangular column shape, opening and shear reinforcement. Thus, there are needs to extend the plasticity model to be able to predict the punching shear capacity of slab-column connections when the slab has rectangular column, opening, and shear reinforcement.

Many design codes such as ACI 318-02, British Standard BS 8110-97, and CEB/FIP Model Code 90 use the average shear stress at the control cylindrical failure surface in a distance from the face of column to check the punching shear capacity of slabcolumn connections. This average shear stress on the control cylindrical surface must not exceed a particular design strength that is proportional to the tensile strength of concrete. This does not mean that the punching is associated with splitting failure in the control cylindrical failure surface, rather the control surface is assumed to represent a truncated cone or pyramid (Regan and Braestrup, 1985). In addition, the control cylindrical failure surface differs from the actual failure surface observed in practice.

The square slab-column connections have greater punching shear strength than the rectangular slab-column connections if the areas of column section are same. The punching shear strength of slab-column connections can increase as the aspect ratio and the area of column section increase. However, the punching shear resistance may decrease when the slab has opening near the column. These facts can be seen clearly in research work based on punching shear strength of slabs with openings and supported on rectangular columns by Kuang in 2001. One of the ways to increase the punching 
shear strength of slab-column connections is the use of shear reinforcement. Therefore, when the slab-column connection is subjected to high shear force and has opening, the shear reinforcement should be used to recover and improve the punching shear capacity of the slab-column connections. As mentioned in literature reviews from chapter two, there are many types of shear reinforcements such as shear stud, stirrup, and shear heads. The shear stud reinforcement becomes more popular to improve and recover the punching shear capacity of slab-column connections due to its advantages than other types of shear reinforcements. In addition, from the experimental results and discussion described in chapter 4 based on the experimental program presented in chapter 3, it can also be seen that the shear studs can effectively recover the reduced punching shear strength of slab-column connections due to opening.

According to the facts described above, it can be concluded that there is no reliable plasticity model to predict the punching shear capacity of the slab-column connections with rectangular column, opening and shear reinforcement. Therefore, a plasticity model that can predict the punching shear strength of slab-column connections with rectangular column, opening and shear reinforcement should be developed. Regarding to the shear reinforcement, the shear studs can effectively recover the reduced punching shear strength of the slab-column connections due to opening. The shear stud reinforcements will be used in the development of plasticity model in this study.

In this chapter, Braestrup's plasticity model (1976) is extended to predict the upper bound punching shear capacity of rectangular slab-column connections with or without opening and with or without shear stud reinforcement. Extensive mathematical derivation of the theory of plasticity is made by author itself. First, punching shear failure criterion of concrete is established. Second, the collapse mechanism of rectangular slab-column connections is presented. Third, the principle strain along the punching crack is derived. Fourth, the dissipation energy in punching shear failure surface is described. Fifth, the upper bound solution for punching shear capacity of square or rectangular slab-column connections is presented. And finally, the flow chart is prepared to explain the procedure to predict the punching shear capacity of slab-column connections by the proposed plasticity model. Detailed derivations are presented in appendix B. 


\subsection{Punching shear failure criteria of concrete}

The punching shear failure is a combination of sliding and separation failure modes in concrete slab-column connections. When sliding failure mode occurs, there is motion parallel to the failure surface, while motion at the separation failure mode is perpendicular to the failure surface. When the shear stress $|\tau|$ in the section exceeds the sliding resistance, sliding failure mode may occur. The sliding resistance is contributed by the cohesion and the internal friction of the material. The internal friction is a fraction $\mu$ of the normal stress $\mathbf{a}$ in the section. When the sliding failure occurs in a material, this material complies with the following sliding failure condition,

$$
|\tau|=c-\mu \sigma
$$

where $\tau=$ shear stress in the sliding surface

$\sigma \quad=$ normal stress in the separation surface

c $\quad=$ cohesion of concrete material

$\mu \quad=$ tangent value of internal friction angle of concrete material

The material that complies with sliding failure condition is called a Coulomb's material. The stress state presented by Mohr's circle at the sliding failure is shown in Figure 5.1.

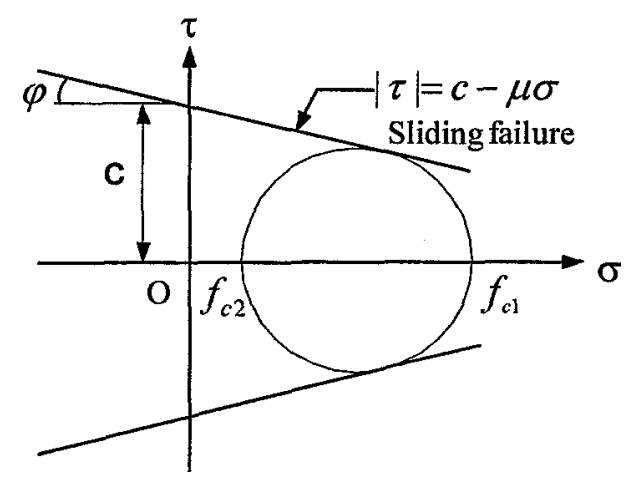

Figure 5.1 Mohr's circle when siding failure occurs 
When the tensile stress $\sigma$ in the material exceeds its separation resistance, separation failure mode may occur. The stress state presented by Mohr's circle at separation failure mode is shown in Figure 5.2.

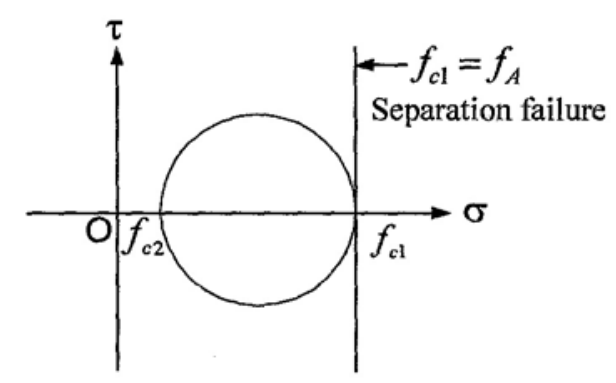

Figure 5.2 Mohr's circle when separation failure occurs

In separation failure mode, the material complies with the following separation failure condition.

$$
\sigma=f_{A}
$$

where the $f_{A}$ is the separation resistance of material.

The material that complies with both sliding and separation failure condition is called a modified Coulomb's material. In this study, the concrete is considered as modified Coulomb's material. The Mohr's circle of principal stresses in concrete corresponding to the stress field at punching shear failure can be presented by $\sigma$ and $\tau$ coordinate system as shown in Figure 5.3. The $f_{c 1}$ and $f_{c 2}$ are principal tensile and compressive stresses in concrete, respectively. The $f_{c}^{\prime}$ is the cylinder compressive strength of concrete and $f_{t}$ is the tensile strength of concrete. And $\varphi$ is angle of internal friction angle of concrete. The failure condition for punching shear failure is derived as follows.

From Figure 5.3,

$$
\begin{gathered}
\mathrm{b}=\text { radiusof Mohr'scircle }-a=\frac{f_{c 1}-f_{c 2}}{2}-\left(-\frac{f_{c 1}+f_{c 2}}{2} \sin \varphi\right) \\
\therefore b=\frac{f_{c 1}-f_{c 2}}{2}+\frac{f_{c 1}+f_{c 2}}{2} \sin \varphi
\end{gathered}
$$




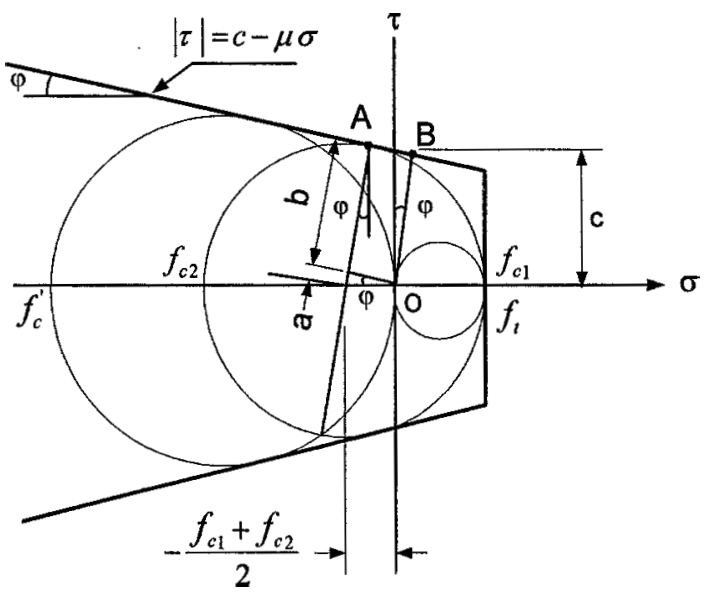

Figure 5.3 Failure condition with Mohr's circle of principal stresses in concrete at punching shear failure

However, $\mathrm{b}=\mathrm{c} \cos \alpha$

$$
\begin{aligned}
& \therefore \frac{f_{c 1}-f_{c 2}}{2}+\frac{f_{c 1}+f_{c 2}}{2} \sin \varphi=c \cos \varphi \\
& f_{c 1}-f_{c 2}+f_{c 1} \sin \varphi+f_{c 2} \sin \varphi=2 c \cos \varphi \\
& f_{c 1}(1+\sin \varphi)-f_{c 2}(1-\sin \varphi)=2 c \cos \varphi \\
& f_{c 1}\left(\frac{1+\sin \varphi}{1-\sin \varphi}\right)-f_{c 2}=2 c\left(\frac{\cos \varphi}{1-\sin \varphi}\right) \\
& k=\frac{1+\sin \varphi}{1-\sin \varphi} \\
& \sqrt{k}=\frac{\cos \varphi}{1-\sin \varphi}
\end{aligned}
$$

After substitutingk and $\sqrt{k}$;

$$
k f_{c 1}-f_{c 2}=2 c \sqrt{k}
$$

The cohesion $\mathrm{c}$ of concrete can be determined by the simple compression case as shown in Figure 5.4. In simple compressioncase, $f_{c 1}=0$ and $f_{c 2}=-f_{c}^{\prime}$. The sliding failure condition for simple compression is

$$
\begin{aligned}
& f_{c}^{\prime}=2 c \sqrt{k} \\
& k=\left(\frac{f_{c}^{\prime}}{2 c}\right)^{2} \\
& c=\frac{f_{c}^{\prime}}{2 \sqrt{k}}
\end{aligned}
$$



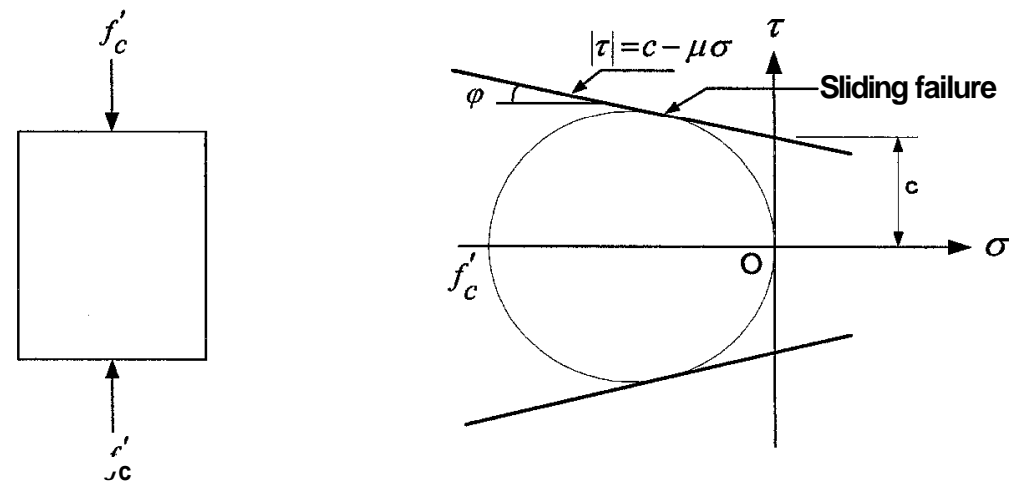

Figure 5.4 Sliding failure of simple compression case

After the cohesion $\mathrm{c}$ is substituted in Equation 5.10, the sliding failure condition becomes

$$
k f_{c 1}-f_{c 2}=f_{c}^{\prime}
$$

The simple tension case is shown in Figure 5.5. In simple tension case, $f_{c 1}=f_{t}$ and $f_{c 2}=0$. The sliding failure for simple tension case is

$$
\begin{gathered}
k f_{t}=f_{c}^{\prime} \\
f_{t}=\frac{f_{c}^{\prime}}{k} \\
\frac{f_{t}}{f_{c}^{\prime}}=\frac{1}{k}
\end{gathered}
$$

Therefore, the tensile failure is a sliding failure when the situation is satisfied as follows:

$$
\frac{f_{t}}{f_{c}^{\prime}} \geq \frac{1}{k}
$$
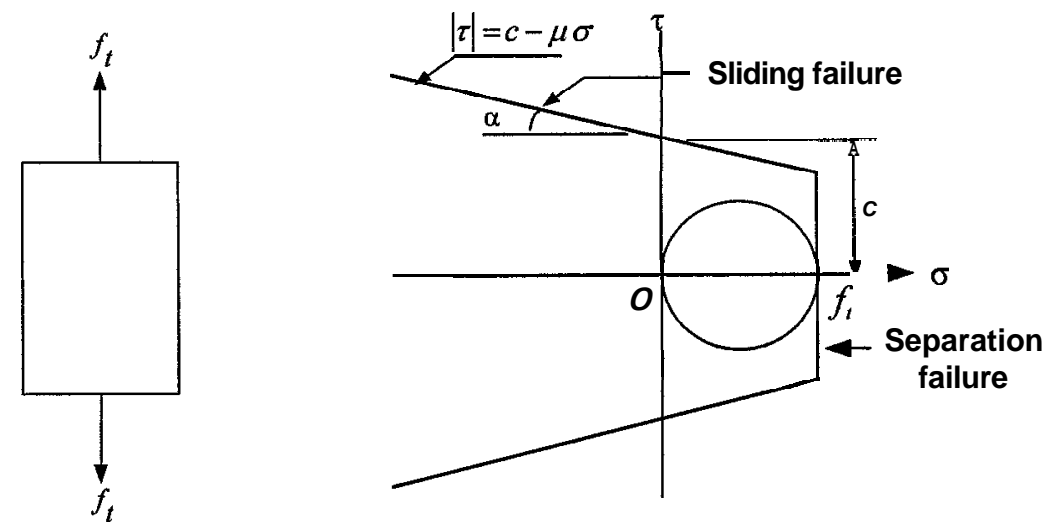

Figure 5.5 Separation failure of simple tension case 
And the separation failure for simple tension case is

$$
f_{c 1}=f_{A}
$$

Therefore, the tensile failure is a separation failure when the situation is satisfied as follows:

$$
\frac{f_{t}}{f_{c}^{\prime}}<\frac{1}{k}
$$

For modified Coulomb's material, according to sliding and separation failure conditions of Equations 5.13 and 5.16, the yield condition drawn in a principal stress coordinate system is shown in Figure 5.6. By considering the failure condition at the apex from Figure 5.6, the punching shear failure condition is:

$$
\begin{aligned}
& k f_{c 1}-f_{c 2}-f_{c}^{\prime}=f_{c 1}-f_{t} \\
& (k-1) f_{c 1}-f_{c 2}=f_{c}^{\prime}-f_{t}
\end{aligned}
$$

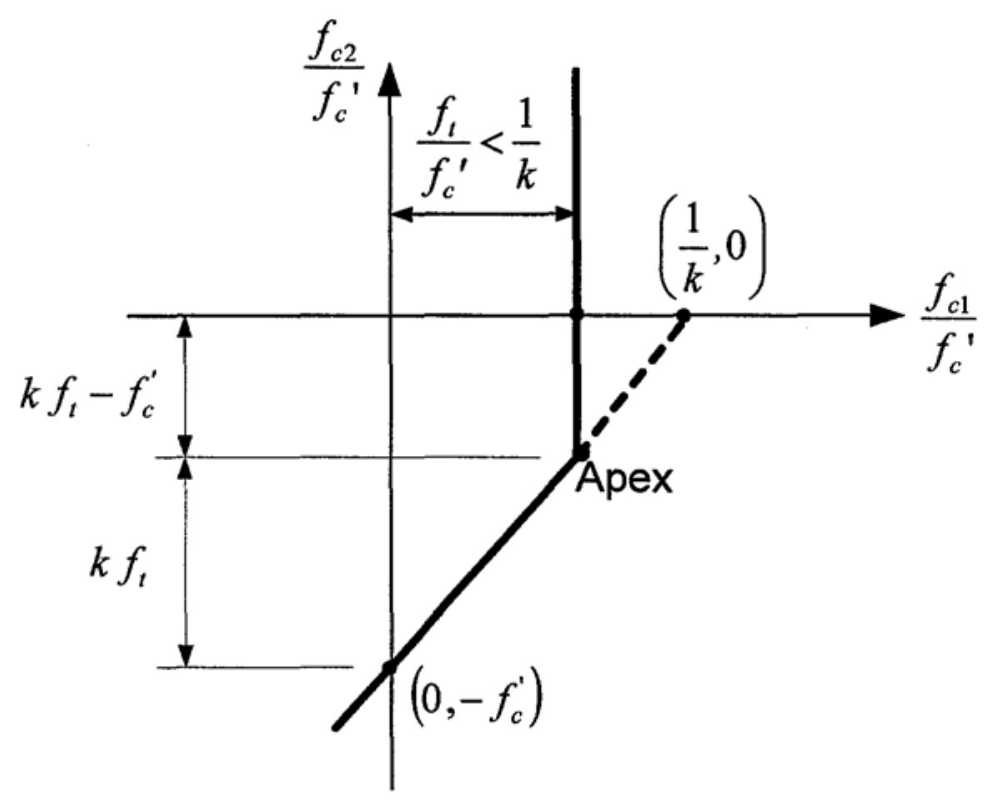

Figure 5.6 Yield condition for modified Coulomb's material in plane strain 


\subsection{Collapse mechanism}

A simply supported slab-column connection is considered. The column is square or rectangular shape. The slab is reinforced with flexural steel in both directions in such a way that the flexural failure is prevented. The vertical concentric punching load $\mathrm{P}$ is applied through the column center. Due to concentric punching load $\mathrm{P}$, the slab fail in punching shear failure.

In punching shear failure, a collapse mechanism is considered as shown in Figure 5.7. During punching shear failure, a failure mechanism consisting in punching out of a solid revolution is generated. As such, finally, the part I of slab is punched out vertically to a vertical displacement $u$. The remaining part II of slab outside the failure surface is considered rigid.

The failure surface generatrix after punching shear failure is symmetric and shown in Figure 5.7a. The least slope of failure surface in the compression face of slab should not be less than $37^{\circ}$ because the internal friction angle for concrete is at least $37^{\circ}$ when sliding failure occurs. Thus, the radius of failure surface at the tension face of $\operatorname{slab}^{r_{h}}$ must be equal or greater than $h \tan 37^{\circ}$, where the $\mathrm{h}$ is slab thickness.

The flexural reinforcement is assumed to be effective only in its axial direction. Due to the fact that the relative displacement of slab due to concentric load is perpendicular to the flexural reinforcement, no contribution is considered by the flexural reinforcement in the punching shear capacity. Dowel action of flexural reinforcement is neglected.

\subsection{Principal strains along the punching crack}

According to the assumed collapse mechanism shown in Figure 5.7, a yield zone with small thickness 6, at which the strains increase without increasing the stresses due to the concentric punching load $\mathrm{P}$, is constituted around the column in the slab. The yield zone is shown with shaded portion in Figure 5.7a. The discontinuity occurs 
along the yield zone. The vertical deformation $u$ is considered constant for all points along the failure surface. The strain in the circumferential direction is zero.

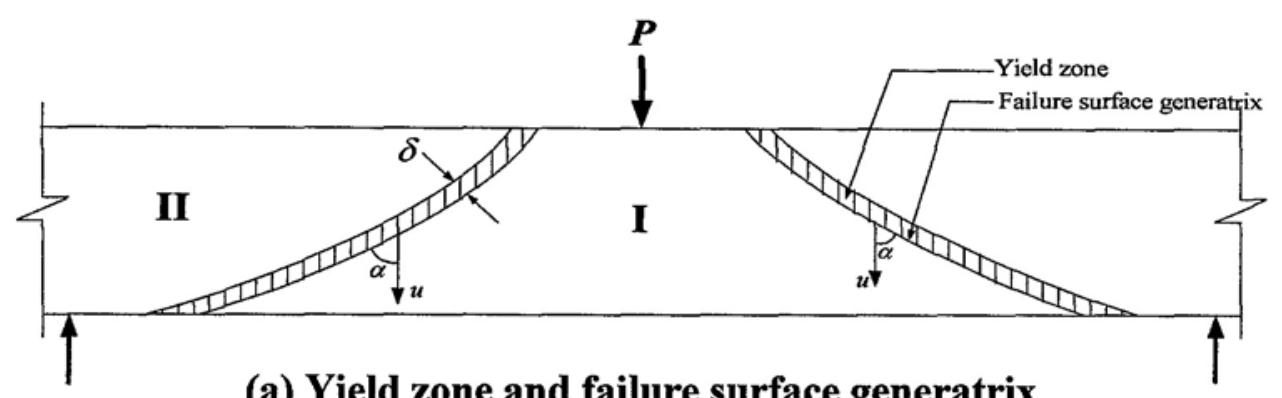

(a) Yield zone and failure surface generatrix

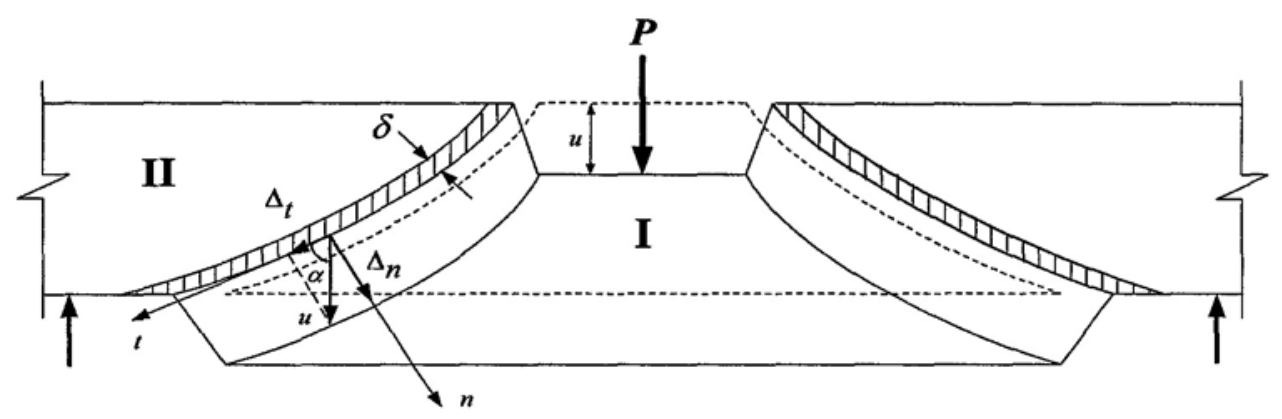

(b) Displacement along the failure surface after punching

Figure 5.7 Collapse mechanism in punching shear failure

The deformation $u$ is resolved into two components, tangential component $\Delta_{\mathrm{t}}$ and normal component $\Delta_{\mathrm{n}}$ along the failure surface. From Figure 5.7,

$$
\begin{aligned}
& \varepsilon_{n}=\frac{\Delta_{n}}{\delta}=\frac{u \sin \alpha}{\delta} \\
& \varepsilon_{t}=0 \\
& \gamma_{n t}=\frac{\Delta_{t}}{\delta}=\frac{u \cos \alpha}{\delta}
\end{aligned}
$$

However, $\quad \varepsilon_{1}$ or $\varepsilon_{2}=\frac{\varepsilon_{n}+\varepsilon_{t}}{2} \pm \sqrt{\left(\frac{\varepsilon_{n}-\varepsilon_{t}}{2}\right)^{2}+\left(\frac{\gamma_{n t}}{2}\right)^{2}}$

By substituting $\varepsilon_{n}, \varepsilon_{t}$ and $\gamma_{n t}$,

$$
\varepsilon_{1} \text { or } \varepsilon_{2}=\frac{u}{2 \delta}(\sin \alpha \pm 1)
$$




\subsection{Dissipation energy in failure surface}

Concrete is considered as modified Coulomb's material as described in the previous section. Accordingly, both sliding and separation failure are involved when the punching shear failure occur. To ascertain that both sliding and separation failure are involved, the plastic strain is defined at the apex of failure criterion for concrete shown in Figure 5.8.

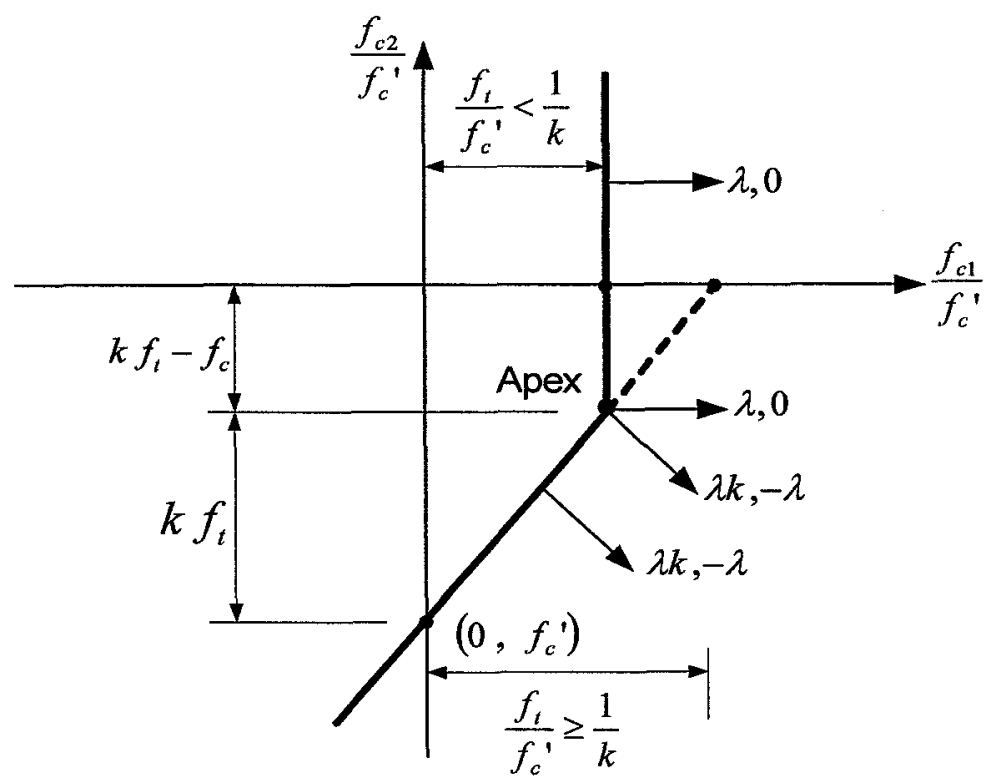

Figure 5.8 Yield condition with flow rule for modified Coulomb's material

The respective dissipation energy for the sliding failure, separation failure and combined failure of sliding and separation when they occur is derived as follows.

For sliding yield surface, by using the flow rule and the sliding failure condition of Equation 5.13, the plastic strains along the sliding yield surface are:

$$
\begin{gathered}
\varepsilon_{1}=\lambda k \quad \varepsilon_{2}=-\lambda \\
\varepsilon^{+}=\varepsilon_{1}=\lambda k \\
\lambda=\frac{\varepsilon^{+}}{k} \\
\varepsilon^{-}=\varepsilon_{2}=-\lambda \\
\frac{\varepsilon_{1}}{\left|\varepsilon_{2}\right|}=k \text { or } \frac{\varepsilon^{+}}{\left|\varepsilon^{-}\right|}=k \quad \text { or } \varepsilon^{+}=k\left|\varepsilon^{-}\right|
\end{gathered}
$$


However, $\mathrm{k}=\frac{1+\sin \varphi}{1-\sin \varphi} \geq 1$, then

$$
\frac{\varepsilon^{+}}{\left|\varepsilon^{-}\right|} \geq 1
$$

where $\varepsilon_{1} \& \varepsilon_{2} \quad=$ principal positive and negative strains, respectively

$$
\begin{aligned}
\varepsilon^{+} \& \varepsilon^{-}= & \text {summation of positive principal strain and summation of negative } \\
& \text { principal strain, respectively }
\end{aligned}
$$

For sliding failure to occur alone, the ratio between the positive principal strain and absolute value of negative principal strain must be equal or greater than one. From Eqs 5.8, 5.24, 5.29 and 5.30, we can show as follows:

$$
\begin{aligned}
& \sin \varphi=\sin \alpha=\frac{k-1}{\mathrm{k}+1} \\
& \alpha=\left\{\begin{array}{l}
\varphi \\
\pi-\varphi
\end{array}\right.
\end{aligned}
$$

Therefore, the angle of internal friction and slope of failure surface are equal at the compression zone. The initial slope at the compression face of the slab should not be less than the internal friction angle of concrete when punching shear failure occurs.

After the plastic principal strains are defined, the dissipation energy in sliding yield surface can be obtained as the following.

$$
W_{V}=f_{c 1} \varepsilon_{1+f c 2} \varepsilon_{2}
$$

By substituting $\varepsilon_{1}$ and $\varepsilon_{2}$ from Equation 5.25,

$$
\begin{aligned}
& W_{V}=f_{c 1} \lambda k+f_{c 2}(-\lambda) \\
& W_{V}=\lambda\left(k f_{c 1}-f_{c 2}\right) \\
& W_{V}=\lambda f_{c}^{\prime} \\
& W_{V}=\frac{\theta \alpha^{\prime}}{\mathrm{k}} \varepsilon^{+} \text {or } \quad W_{V}=\left|\varepsilon^{-}\right| f_{c}^{\prime}
\end{aligned}
$$

where $W_{V}$ is dissipation energy per one unit volume of yield region. Equation 5.34 gives the dissipation energy when only the sliding failure occurs. For separation yield surface, by using the flow rule and the separation failure condition of Equation 5.16, the plastic strains along the separation yield surface are:

$$
\begin{aligned}
& \varepsilon_{1}=\lambda \\
& \varepsilon_{2}=0
\end{aligned}
$$


For combination of sliding and separation failure, the plastic strains are considered at the apex of yield surface in Figure 5.8. The plastic strains at the apex of yield surface are:

$$
\begin{aligned}
& \varepsilon_{1}=\lambda k+\lambda=\lambda(k+1) \\
& \varepsilon_{2}=-\mathrm{A}
\end{aligned}
$$

From the plastic strains at the apex of yield surface,

$$
\begin{aligned}
& \frac{\varepsilon_{1}}{\left|\varepsilon_{2}\right|}=k+1 \\
& \frac{\varepsilon_{+}}{\left|\varepsilon^{-}\right|}=k+1 \\
& \varepsilon^{+}=\left|\varepsilon^{-}\right|(\mathrm{k}+1) \\
& \left|\varepsilon^{-}\right|=\varepsilon^{+}-k\left|\varepsilon^{-}\right| \\
& \lambda=\left|\varepsilon^{-}\right|=\varepsilon^{+}-k \mid \varepsilon^{-}
\end{aligned}
$$

From Equations 5.29 and 5.38, we can see that (1) when the ratio between the positive principal strain and absolute value of negative principal strain is equal or greater than one, only sliding failure occurs and (2) when it is equal or greater than two, both separation and sliding failure modes occur.

Then, the dissipation energy at the apex of yield surface is

$$
\begin{aligned}
& W_{V}=f_{c 1} \lambda(k+1)+f_{c 2}(-\lambda) \\
& W_{V}=\lambda\left(k f_{c 1}-f_{c 2}\right)+\lambda f_{c 1} \\
& W_{V}=\lambda f_{c}^{\prime}+\lambda f_{t} \\
& W_{V}=\underbrace{\left|\varepsilon^{-}\right| f_{c}^{\prime}}_{\text {Sliding failure }}+\underbrace{\left(\varepsilon^{+}-k \mid \varepsilon^{-} n\right) f}_{\text {Separation failure }}
\end{aligned}
$$

This is dissipation energy for combination of sliding and separation failure modes. We can see that the first part of the dissipation energy is for sliding failure and the second part for separation failure. In this case, to ascertain that both sliding and separation failure modes occur simultaneously, the ratio between the positive principal strain and absolute value of negative principal strain must be equal or greater than two. The dissipation energy per unit area of failure surface is $W_{A}=\delta W_{V}$. By using Equation 5.45,

$$
W_{A}=\delta\left(\left|\varepsilon^{-}\right| f_{c}{ }^{+}+\left(\varepsilon^{+}-k\left|\varepsilon^{-}\right|\right) f_{t}\right)
$$


However, $\varepsilon_{1}$ or $\varepsilon_{2}=\frac{u}{2 \delta}(\sin \alpha \pm 1)$ from Equation 5.24,

Therefore,

$$
\varepsilon^{+} \text {or }\left|\varepsilon^{-}\right|=\frac{u}{2 \delta}(\sin \alpha \pm 1)
$$

By substituting $\varepsilon^{+}$and $\left|\varepsilon^{-}\right|$into Equation 5.46, the dissipation energy per unit area of failure surface is obtained as a function of the compressive strength, tensile strength and angle of internal friction of concrete.

$$
\begin{aligned}
& W_{A}=\frac{1}{2} f_{c}^{\prime} u(L-M \sin \alpha) \\
& L=1-2 \frac{f_{t}}{f_{c}^{\prime}} \frac{\sin \varphi}{1-\sin \varphi}=1-\frac{f_{t}}{f_{c}^{\prime}}(k-1) \\
& M=1-2 \frac{f_{t}}{f_{c}^{\prime}} \frac{1}{1-\sin \mathrm{p}}=1-\frac{f_{t}^{\prime}}{f_{c}^{\prime}}(k+1)
\end{aligned}
$$

where $\mathrm{k}=\frac{1+\sin \varphi}{1-\sin \varphi}$ and $\varphi=$ angle of internal friction of concrete.

\subsection{Upper bound punching shear capacity}

\subsubsection{Slab-column connection with rectangular column}

The simply supported rectangular slab-column connection is considered under concentric load applied through the centre of column and is shown in Figure 5.9. The collapse mechanism considered is shown in Figure 5.10. The least upper bound value of punching shear capacity for slab-column connection is achieved as follows.

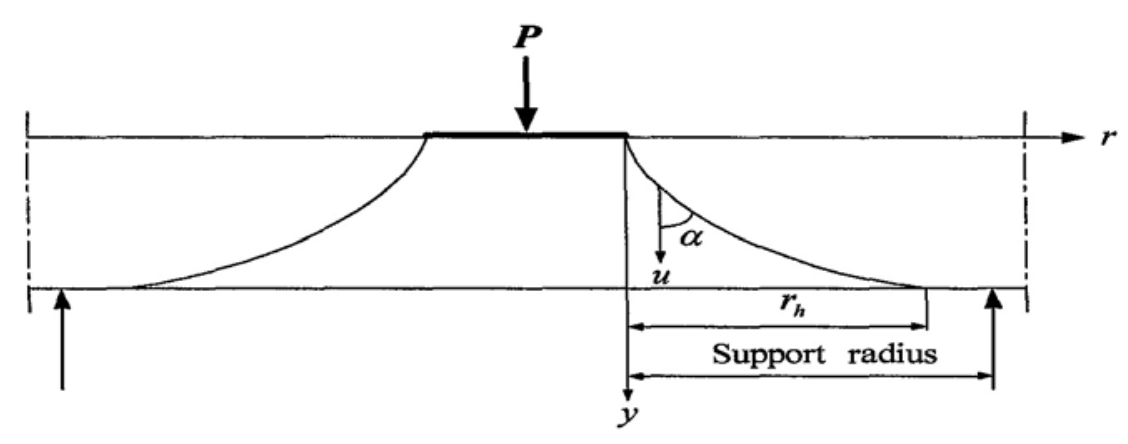

Figure 5.9 Simply supported slab-column connection under concentric load and punching shear failure surface 


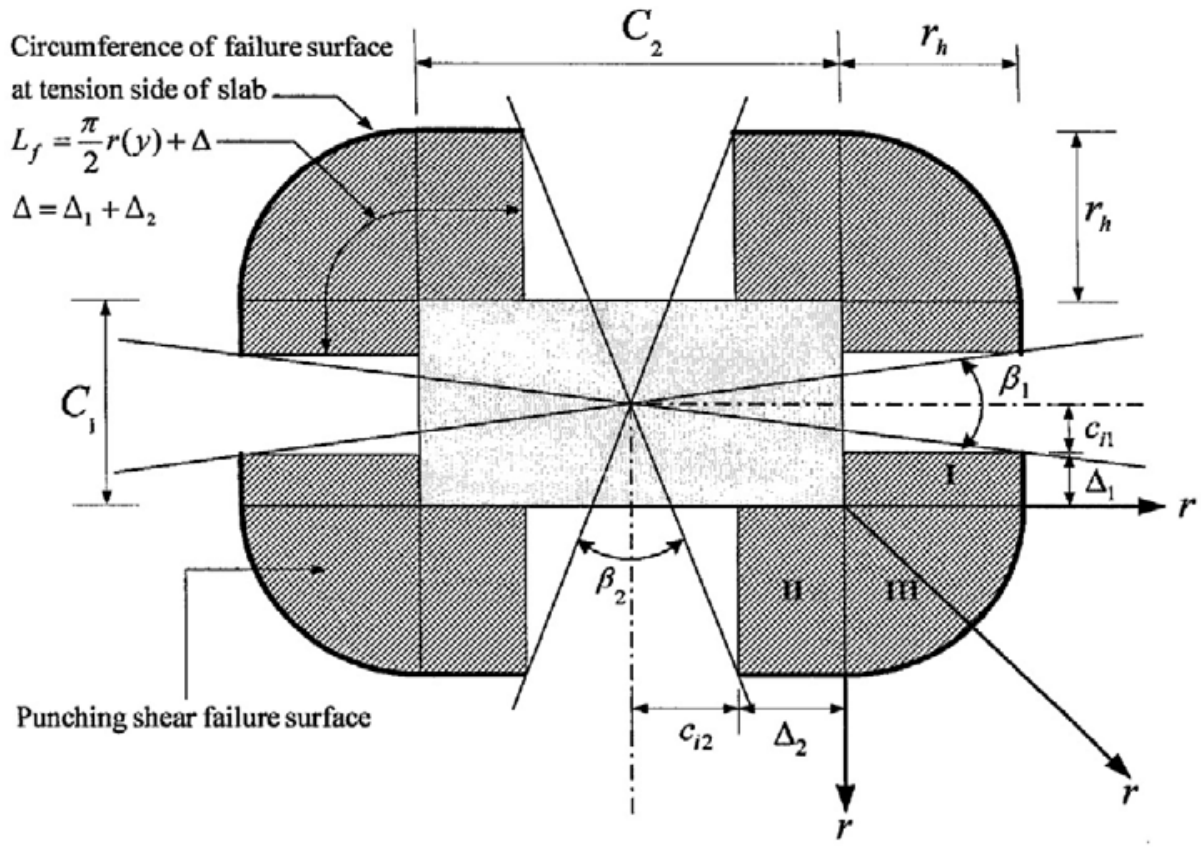

(a) Plan view of failure surface

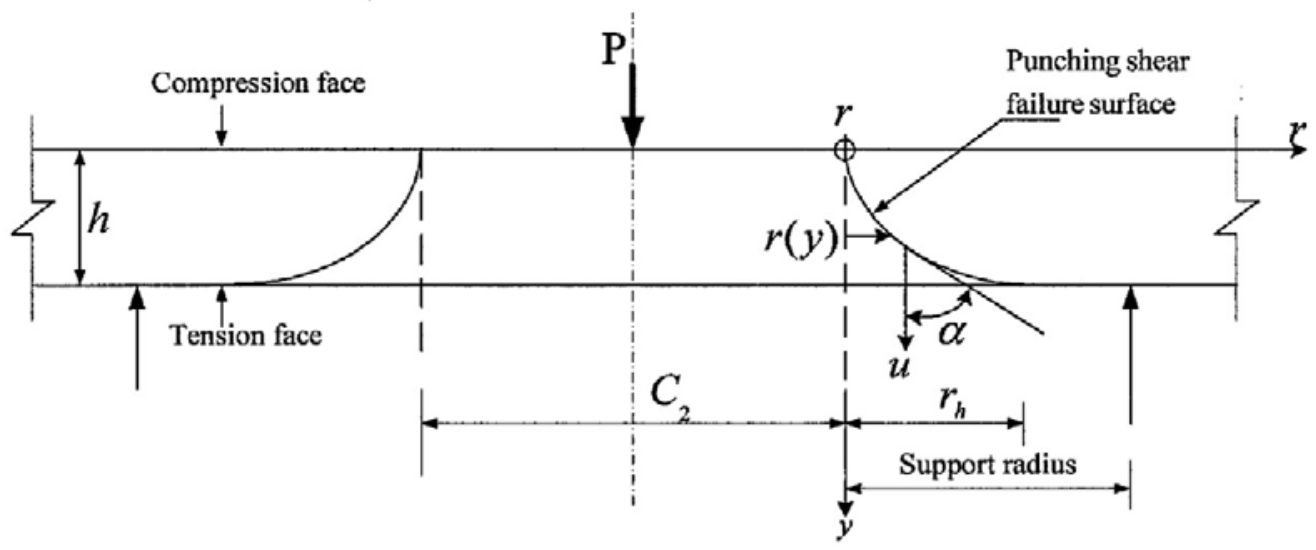

(b) Failure surface generatrix

Figure 5.10 Punching shear failure surface for simply supported slab-column connection

The total dissipation of energy in failure surface is

$$
W_{T}=\int_{A} W_{A} d A
$$

where $W_{A}$ is dissipation energy per unit area of failure surface.

By substituting $W_{A}$ from Equation 5.48,

$$
W_{T}=\frac{1}{2} f_{c}^{\prime} u \int_{A}(L-M \sin \alpha) d A
$$


The external virtual work, WE, is the product of applied punching load $\mathrm{P}$ and the displacement $\mathrm{u}$ in the applied punching load direction. According to virtual work principal, by equating the external virtual work and the total dissipation energy in failure surface,

$$
\begin{aligned}
& P=\frac{1}{2} f_{c}^{\prime} \int_{A}(L-M \sin \alpha) d A \\
& d A=4\left(\frac{1}{2} \pi r+\Delta\right) \frac{d y}{\cos \alpha}
\end{aligned}
$$

By substituting $d A$, the punching shear capacity is obtained as a function of $r(y)$.

$$
\begin{aligned}
& P=2 f_{c}^{\prime} \int_{0}^{h} \frac{(L-M \sin \alpha)}{\cos \alpha}\left(\frac{1}{2} \pi r+\Delta\right) d y \\
& \Delta=\Delta_{1}+\Delta_{2} \\
& \Delta_{1}=\frac{C_{1}}{2}-\left(\frac{C_{2}}{2}+r_{h}\right) \tan \frac{\beta_{1}}{2} \\
& \Delta_{2}=\frac{C_{2}}{2}-\left(\frac{C_{1}}{2}+r_{h}\right) \tan \frac{\beta_{2}}{2} \\
& \beta_{1}=2 \tan ^{-}\left(\frac{c_{i 1}}{C_{2}+2 r_{h}}\right) \\
& \beta_{2}=2 \tan ^{-1}\left(\frac{c_{i 2}}{C_{1}+2 r_{h}}\right)
\end{aligned}
$$

where $\mathrm{C}_{1} \& \mathrm{C}_{2} \quad=$ shorter and longer column width, respectively

$r_{h} \quad=$ radius of failure surface at tension face of slab

$c_{i 1} \& c_{i 2}=$ incremental length of failure surface shown in Figure 5.10

From Equation 5.55,

$$
P=2 f_{c}^{\prime} \int_{0}^{h} F(r) d y
$$

and,

$$
\begin{aligned}
& r^{\prime}=\frac{d r}{d x}=\tan \alpha \\
& d x=\frac{d r}{r^{\prime}}
\end{aligned}
$$


From the above relation, $\sin \mathbf{a}=\frac{r^{\prime}}{\sqrt{1+\left(r^{\prime}\right)^{2}}}$

$$
\cos \alpha=\frac{1}{\sqrt{1+\left(r^{\prime}\right)^{2}}}
$$

By substituting Equation 5.60, the function $F(r)$ becomes $F\left(r, r^{\prime}\right)$ as

$$
F\left(r, r^{\prime}\right)=\frac{1}{2}(\pi r+2 \Delta)\left(L \sqrt{1+\left(r^{\prime}\right)^{2}}-M r^{\prime}\right)
$$

Equation 5.55 becomes,

$$
P=f_{c} \int_{0}^{h}(\pi r+2 \Delta)\left(L \sqrt{1+\left(r^{\prime}\right)^{2}}-M r^{\prime}\right) d y
$$

The shape of failure surface $r(y)$ will give the minimum value of $\mathrm{P}$. Therefore, the functional equation 5.65 is optimized with $r(y)$ and after using the following Euler's equation of $\mathrm{F}-r^{\prime} F_{r^{\prime}}=C 1$,

$$
\frac{L(\pi r+2 \Delta)}{2 \sqrt{1+\left(r^{\prime}\right)^{2}}}=C 1
$$

and, by replacing $A=\frac{L}{2 C 1}$,

$$
\frac{A(\pi r+2 \Delta)}{\sqrt{1+\left(r^{\prime}\right)^{2}}}=1
$$

After solving Equation 5.67,

$$
1+\left(r^{\prime}(y)\right)^{2}=A^{2}(\pi r+2 \Delta)^{2}
$$

Using Equations 5.61a, 5.61b and 5.68, the useful relations between $r(y)$ and $r^{\prime}(y)$, $d y$ and $r(y)$, and $d y$ and $r^{\prime}(y)$ to derive the punching shear capacity of slab by using Equation 5.65 are obtained as follows:

$$
\begin{aligned}
& r(y)=\frac{1}{\pi}\left(\frac{\sqrt{1+\left(r^{\prime}(y)\right)^{2}}}{A}-2 \Delta\right) \\
& r^{\prime}(y)=\sqrt{A^{2}(2 \Delta+\pi r(y))^{2}-1} \\
& d y=\frac{1}{\sqrt{A^{2}(2 \Delta+\pi r(y))^{2}-1}} d r(y) \\
& d y=\frac{d r^{\prime}(y)}{A^{2} \pi\left(\sqrt{1+\left(r^{\prime}(y)\right)^{2}}\right)}
\end{aligned}
$$


Then, by differentiating Equation 5.68 with $y$, the second order differential equation of $r(y)$ is

$$
r^{\prime \prime}(y)=A^{2} \pi(\mathrm{n} r(y)+2 \Delta)
$$

Solving the above second order differential equation, the shape of punching shear failure surface is obtained as a catenary curve as follows:

$$
\begin{aligned}
& r(y)=-\frac{2 \Delta}{\pi}+B e^{A \pi y}+C e-A \pi y \\
& \mathrm{r}^{\mathrm{l}}(\mathrm{y})=A \pi\left(B e^{A \pi y}-C e^{-A \pi y}\right)
\end{aligned}
$$

where $\mathrm{A}, \mathrm{B} \& \mathrm{C}$ are constants.

By substituting $r(y)$ and $r^{\prime}(y)$ from equations 5.71 and 5.72 into equation 5.68 and solving it, the relation between A, B and C is obtained.

$$
A=\frac{1}{2 \pi \sqrt{B C}}
$$

We have the following boundary conditions,

(1) $\mathrm{y}=0, \quad r(0)=0$

(2) $\mathrm{y}=\mathrm{h}, \quad r(h)=r_{h}$

By substituting boundary condition (1) of Equation 5.74a into Equations 5.71,

$$
B=\frac{2 \Delta}{\pi}-C
$$

And by substituting $\mathrm{y}=0$ into Equation 5.72,

$$
r^{\prime}(0)=A \pi(B-C)
$$

By substituting boundary condition (2) of Equation 5.74b into Equations 5.72,

$$
r_{h}=r(h)=-\frac{2 \Delta}{\pi}+\mathrm{B} \mathrm{e}^{A \pi h}+C e^{-A \pi h}
$$

and by substituting $\mathrm{y}=\mathrm{h}$ into Equation 5.72,

$$
r_{h}^{\prime}=r^{\prime}(h)=A \pi\left(B e^{A \pi h}-C e^{-A \pi h}\right)
$$

Using trial and error method, the constants A, B and C and $r_{h}$ are determined to satisfy Equations 5.71, 5.73,5.75 and 5.77. 
When the concrete is cracked, the cracking reduces the concrete strength. Therefore, the friction angle of concrete is at least equal to the friction angle valid for the uncracked concrete. Due to concrete cracking, the cohesion of concrete is strongly reduced to about $50 \%$ of the cohesion of cement paste in which friction angle is zero and $\mathrm{k}$ is one (Nielsen, 1998). It can be seen from Eq. 5.11a that the concrete, which is assumed as modified Coulomb's material, therefore has at least a value of angle of friction of 37 degree when punching shear failure occurs. This means that the initial slope of failure surface at compression face of slab should be equal or greater than 37 degree. Thus, the analysis assuming modified Coulomb's material is valid only for $r_{h} \geq h \tan \alpha_{0}$, where $\alpha_{0}$ is initial slope of failure surface at the compression side of slab. Therefore, punching shear capacity for slab-column connection under concentric loading is considered for two cases. First, the punching shear capacity when the initial slope of failure surface at $y=0$ is equal or greater than 37 degree and the second, when it is less than 37 degree.

\subsubsection{Initial slope of failure surface at the compression face of slab is equal or greater than $37^{\circ}$}

When the initial slope of failure surface at the top of slab is equal or greater than 37 degree, the failure surface of slab is considered as a catenary curve only. The punching shear capacity of slab-column for this case can be obtained by the equation 5.65.

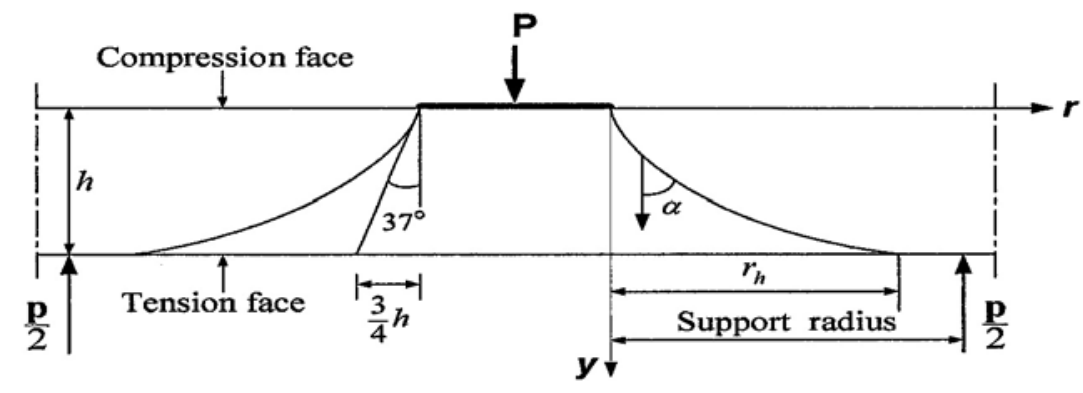

Figure 5.11 Punching shear failure surface in curve shape for simply supported slab-column connection under concentric load

By substituting Equations 5.69a and 5.69c into Equation 5.65,

$$
P=\frac{f_{c}{ }^{\prime}}{A \pi} \int_{r^{\prime}(0)}^{r^{\prime}(h)} \frac{\sqrt{1+\left(r^{\prime}\right)^{2}}\left(L \sqrt{1+\left(r^{\prime}\right)^{2}}-M r^{\prime}\right)}{\sqrt{1+\left(r^{\prime}\right)^{2}}} d r^{\prime}
$$


By solving it,

$$
\begin{aligned}
& \mathrm{P}=\frac{\mathrm{f}_{\mathrm{c}}{ }^{\prime}}{2 \mathrm{~A}^{2} \pi}\left(\mathrm{L}\left(\left(\sinh ^{-1}\left(\mathrm{r}_{\mathrm{h}}{ }^{\prime}\right)+\mathrm{r}_{\mathrm{h}}{ }^{\prime} \sqrt{1+\left(\mathrm{r}_{\mathrm{h}}{ }^{\prime}\right)^{2}}\right)-\left(\sinh ^{-1}\left(\mathrm{r}_{0}{ }^{\prime}\right)+\mathrm{r}_{0}{ }^{\prime} \sqrt{1+\left(\mathrm{r}_{0}{ }^{\prime}\right)^{2}}\right)\right)\right. \\
& \left.\quad-M\left(\left(r_{h}{ }^{\prime}\right)^{2}-\left(r_{0}{ }^{\prime}\right)^{2}\right)\right)
\end{aligned}
$$

where $r_{0}{ }^{\prime}$ and $r_{h}{ }^{\prime}$ are $r^{\prime}(0)$ and $r^{\prime}(\boldsymbol{h})$ from Equations 5.76 and 5.78, respectively.

In addition, by substituting Equations 5.69a, 5.69c and 5.69d into Equation 5.65,

$$
P=f_{c}{ }^{r_{h}} \int_{0}(\pi r(y)+2 \Delta)\left(L \sqrt{A^{2}+(\pi r(y)+2 \Delta)^{2}}-M \sqrt{-1+A^{2}+(\pi r(y)+2 \Delta)^{2}}\right) d r(y)
$$

By integrating and inserting the limits, the punching shear capacity of slab-column connection is obtained as function of $r_{h}$.

$$
\begin{aligned}
\mathrm{P}= & \frac{\mathrm{f}_{\mathrm{c}}{ }^{\prime}}{2 \mathrm{~A}^{2} \pi}\left(\mathrm { L } \left(-2 \mathrm{~A} \Delta \sqrt{-1+4 \mathrm{~A}^{2} \Delta^{2}}-\ln \left(2 \mathrm{~A} \Delta+\sqrt{-1+4 \mathrm{~A}^{2} \Delta^{2}}\right)\right.\right. \\
& +\ln \left(\sqrt{A^{2}\left(-2 \Delta-\pi r_{h}\right)^{2}}+\sqrt{-1+A^{2}\left(-2 \Delta-\pi r_{h}\right)^{2}}\right) \\
& \left.\left.-\sqrt{A^{2}\left(-2 \Delta-\pi r_{h}\right)^{2}} \sqrt{-1+A^{2}\left(-2 \Delta-\pi r_{h}\right)^{2}}\right)+M\left(-4 A^{2} \pi \Delta r_{h}-A^{2} \pi^{2} r_{h}^{2}\right)\right)
\end{aligned}
$$

where $r_{h}$ is obtained from Equation 5.77 .

Thus, Equations 5.80 or 5.82 give the punching shear capacity for slab-column connection without opening and without shear reinforcement when the shape of failure surface is a catenary curve. Whether the shape of failure surface is a catenary curve is checked as follows.

\section{Limitation to check if the shape of failure surface is a catenary curve}

When the slope of failure surface at the compression face of slab is equal or greater than $37^{\circ}$, the tangent value of failure surface at $y=0$ becomes

$$
A \pi(B-C) \geq \tan 37^{\circ}=\frac{3}{4}
$$


By substituting $\mathrm{B}=\frac{2 \mathrm{~A}}{\pi}-\mathrm{C}$ from Equation 5.75,

$$
C \leq \frac{8 A \Delta-3}{8 A \pi}
$$

By substituting $B=\frac{2 \Delta}{\pi}-C$ into Equation 5.77,

$$
r_{h}=r(h)=\frac{2}{\pi}\left(\Delta\left(1-e^{A \pi h}\right)+C \pi \sinh (A \pi h)\right)
$$

By solving the above equation, the constant $\mathrm{C}$ will be obtained as,

$$
C=\frac{2 \Delta\left(1-e^{A \pi h}\right)+\pi r_{h}}{2 \pi \sinh (A \pi h)}
$$

By substituting Equation 5.84 into Equation 5.86, and solving it, the radius of failure surface at the tension face of slab is

$$
r_{h} \leq \frac{8 \mathrm{~A} \Delta(1+\cosh (A \pi \boldsymbol{h}))+3 \sinh (A \pi \boldsymbol{h})}{4 \mathrm{~A} \pi}
$$

Therefore, $\quad \frac{3}{4} h \leq r_{h} \leq \frac{8 \mathrm{~A} \Delta(1+\cosh (A \pi h))+3 \sinh (A \pi \boldsymbol{h})}{4 \mathrm{~A} \pi}$

Thus, when the radius of failure surface at the bottom of slab satisfies Equation 5.88, the equation of failure surface for $0 \leq \mathrm{y} \leq \boldsymbol{h}$ is a catenary curve.

\subsubsection{Initial slope of failure surface at the compression face of slab is less than $37^{\circ}$}

When the initial slope of failure surface at $y=0$ is less than 37 degree, the failure surface of slab is considered as a combination of two portions; (a) straight portion with slope of 37 degree and (b) curved portion. The straight portion is from compression face of slab to $h_{0}$ at which straight portion intersects with curved portion. The curved portion is from $h_{0}$ to the tension face of slab. The $h_{0}$ is the vertical distance from the top of slab to the intersection of straight portion and curved portion of failure surface shown in Figure 5.12. 


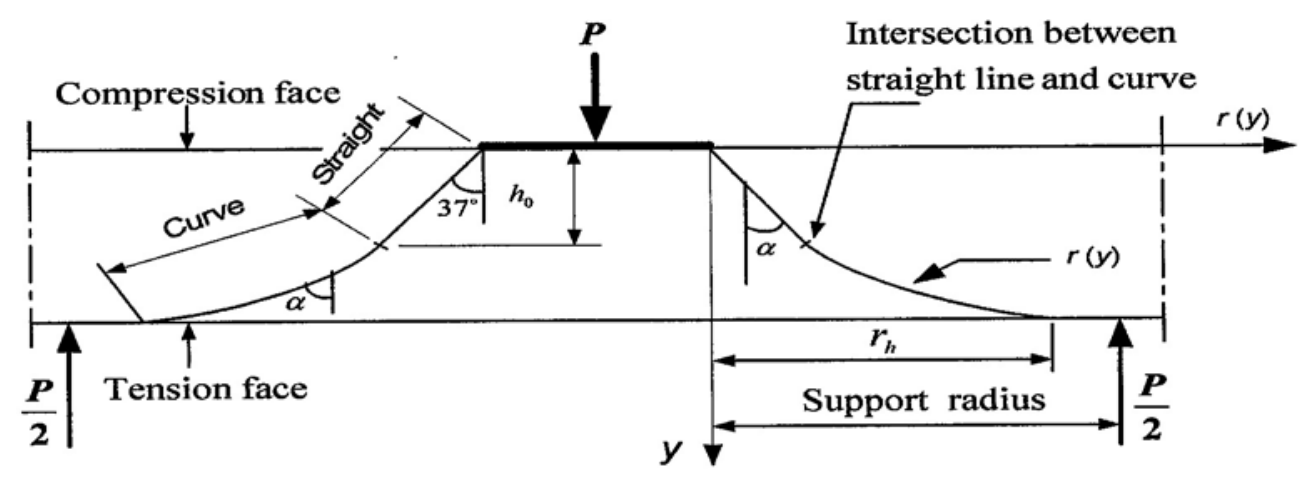

Figure 5.12 Punching shear failure surface composed with straight and curve portion for simply supported slab-column connection under concentric load

(a) For the straight portion of failure surface from $y=0$ to $h_{0}$

For the straight portion of failure surface,

$$
\begin{aligned}
& r(y)=\frac{3}{4} y \quad \text { for } \quad 0 \leq \mathrm{y} \leq h_{0} \\
& r^{\prime}(y)=\frac{3}{4} \quad \text { for } \quad 0 \leq y \leq h_{0}
\end{aligned}
$$

By substituting Equations 5.89 and 5.90 into Equation 5.65 and inserting the limit from 0 to $h_{0}$,

$$
P_{L}=f_{c}^{\prime} \int_{0}^{h_{0}}\left(2 \Delta+\frac{3}{4} \pi y\right)\left(L \sqrt{1+\left(\frac{3}{4}\right)^{2}}-\frac{3}{4} M\right) d y
$$

And the punching shear capacity for straight portion of failure surface from the top of slab to the depth $h_{0}$,

$$
P_{L}=\frac{1}{32}(5 L-3 M) f_{c}^{\prime} h_{0}\left(16 \Delta+3 \pi h_{0}\right)
$$

(b) For the curved portion of failure surface from $\mathrm{y}=h_{0}$ to $\mathrm{h}$

For the curved portion of failure surface,

$$
\begin{aligned}
& r(y)=-\frac{2 \Delta}{\pi}+B e^{A \pi y}+C e^{-A \pi y} \text { for } h_{0} \leq y \leq h \\
& r^{\prime}(y)=A \pi\left(B e^{A \pi y}-C e^{-A \pi y}\right) \text { for } h_{0} \leq y \leq h
\end{aligned}
$$

By equating the radii of failure surface by two Equations 5.89 and 5.93 at $\mathrm{y}=h_{0}$ and substituting $B=\frac{\mathbf{2} \mathrm{A}}{\pi}-C$, we get 


$$
\begin{aligned}
& \frac{3}{4} h_{0}=-\frac{2 \Delta}{\pi}+\left(\frac{2 \Delta}{\pi}-C\right) e^{A \pi h_{0}}+C e^{-A \pi h_{0}} \\
& h_{0}=\frac{4}{3}\left(-\frac{2 \Delta}{\pi}+\left(\frac{2 \Delta}{\pi}-C\right) e^{A \pi h_{0}}+C e^{-A \pi h_{0}}\right)
\end{aligned}
$$

From the above equations, the following new constant values for curved portion of failure surface are obtained.

$$
\begin{aligned}
& C=\frac{-8 \Delta\left(-1+e^{A \pi h_{0}}\right)+3 \pi h_{0}}{4 \pi\left(e^{-A \pi h_{0}}-e^{A \pi h_{0}}\right)} \\
& B=\frac{2 \Delta}{\pi}-C \\
& A=\frac{1}{2 \pi \sqrt{B C}} \\
& r_{h}=r(h)=-\frac{2 \Delta}{\pi}+B e^{A n h}+C e^{-A \pi h}
\end{aligned}
$$

By using the new constant values for curved portion of failure surface, the $\boldsymbol{r}^{r}\left(\boldsymbol{h}_{0}\right)$ and new $r^{\prime}(h)$ values can be obtained as,

$$
\begin{aligned}
& r_{h 0}{ }^{\prime}=r^{\prime}\left(h_{0}\right)=A \pi\left(B e^{A \pi h_{0}}-C e^{-A \pi h_{0}}\right) \\
& r_{h}{ }^{\prime}=r^{\prime}(h)=A \pi\left(B e^{A \pi h}-C e^{-A \pi h}\right)
\end{aligned}
$$

The above Equations 5.101 and 5.102 are substituted in Equation 5.80 instead of $\boldsymbol{r}^{r}(\boldsymbol{0})$ and $\boldsymbol{r}^{\prime}(h)$, respectively. The punching shear capacity for curved portion of failure surface is

$$
\begin{aligned}
P_{C}= & \frac{f_{c}^{\prime}}{2 A^{2} \pi}\left(L\left(\left(\sinh ^{-1}\left(r_{h}{ }^{\prime}\right)+r_{h}{ }^{\prime} \sqrt{1+\left(r_{h}{ }^{\prime}\right)^{2}}\right)-\left(\sinh ^{-1}\left(r_{h 0}{ }^{\prime}\right)+r_{h 0}{ }^{\prime} \sqrt{1+\left(r_{h 0}{ }^{\prime}\right)^{2}}\right)\right)\right. \\
& \left.-M\left(\left(r_{h}{ }^{\prime}\right)^{2}-\left(r_{0}^{\prime}\right)^{2}\right)\right)
\end{aligned}
$$

The punching shear capacity $\mathbf{P}$ for slab-column connection when the initial slope at $\mathrm{y}=\mathbf{0}$ of failure surface is less than 37 degree can be obtained by summing up the Equations 5.92 and 5.103 as:

$$
P=P_{L}+P_{C}
$$

Thus, Equation $\mathbf{5 . 1 0 4}$ gives the punching shear capacity for slab-column connection when the shape of failure surface is a combined shape of a straight line and a curve. Whether the shape of failure surface is a combined shape of a straight line and a curve is checked as follows. 


\section{Limitation todheckif the shape of failure surface is acombination of astraightlineandacurve}

The slope of failure surface at the compression face of slab is

$$
r^{\prime}(0)<\frac{3}{4}
$$

By solving in the same way, the radius of failure surface at the tension face of slab is

$$
r_{h}>\frac{8 A \Delta(1+\cosh (A \pi h))+3 \sinh (A \pi h)}{4 A \pi}
$$

Thus, when the radius of failure surface at the tension face of slab $r_{h}$ is beyond the right hand side of equation 5.106, the failure surface is a combination of a straight line and a curve.

\subsubsection{Slab-column connection with opening}

When the slab-column connection has opening adjacent to the column, the punching shear capacity of slab-column connection decreases due to opening. The area of failure surface is reduced due to opening. Moreover, some parts of failure surface around the opening are considered ineffective to resist punching due to opening.

We need to know which part of failure surface is ineffective due to opening. The ineffective failure surface due to opening has been limited by several ways according to codes described in chapter 2 . The ineffective failure surface due to opening should be the most possible one to give the punching shear capacity lost due to opening. The punching shear capacity sustained in the ineffective area of failure surface due to opening is the amount of punching shear capacity lost due to opening. Thus, the punching shear capacity of slab-column connection with opening can be obtained by subtracting the punching shear capacity lost in ineffective area of failure surface due to opening from the punching shear capacity of slab-column connection without opening described previously.

The ineffective area of failure surface due to opening is defined as the area under the plan area of failure surface bounded by two projection lines which propagate from the inside of column section through two corners of opening and intersect at two points on the circumference of failure surface. Regarding to these two projection lines that confine the ineffective area of failure surface due to opening, there are two methods in 
propagation of two projection lines considered in this study. They are classified as methods AI and AII depending on their starting points inside the column section. In method AI, the projection lines start from the center of column while in method AII, they start from the center of $1 / 3$ column section area close to the shorter column width nearest with the opening. These methods have been suggested by Kuang (2001). For example, for the slab with opening located adjacent to the shorter column width, the ineffective areas of failure surface due to opening confined by two projection lines using by methods A I and AII are presented by the shaded areas shown in Figure 5.13.

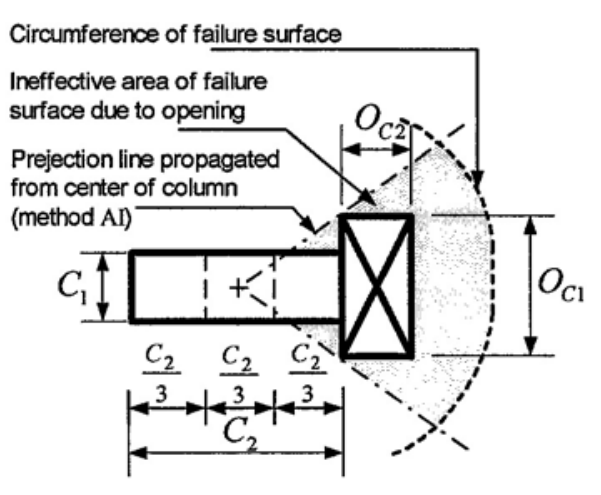

(a) Projection lines by method AI

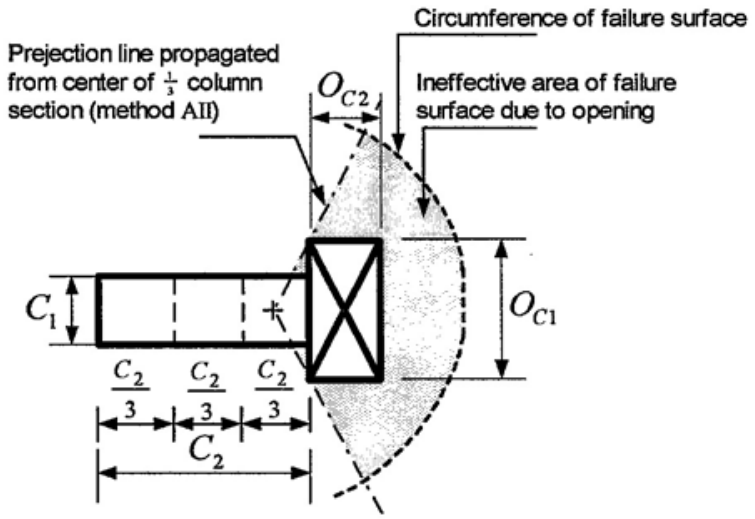

(b) Projection lines by method AII

\section{Figure 5.13 Ineffective area of failure surface in the slab due to opening confined by two projection lines}

Accordingly, the punching shear capacity sustained by the ineffective area of failure surface due to opening is defined as the punching shear capacity of slab-column connection lost due to opening. Thus, the punching shear capacity of slab-column connection with opening can be achieved as follows.

$$
P_{o p}=P-\bar{P}_{o p}
$$

where

$\mathrm{P} \quad=$ punching shear capacity of slab-column connection without opening and without shear reinforcement

$P_{o p} \quad=$ punching shear capacity of slab-column connection with opening

$\bar{P}_{o p} \quad=$ punching shear capacity of slab-column connection lost due to opening 
The punching shear capacity of slab-column connection lost due to opening can be determined as the following.

$$
\bar{P}_{o p} \times u=\int_{o p} W_{A} d A_{o p}
$$

where $A_{o p} \quad=$ ineffective area of failure surface due to opening

$W_{A} \quad=$ dissipation energy per unit area of failure surface from Equation 5.48

After substituting $W_{A}$,

$$
\begin{aligned}
& \bar{P}_{o p}=\frac{1}{2} f_{c}^{\prime} \int_{A_{o p}}(L-M \sin \alpha) d A_{o p} \\
& d A_{o p}=L_{o p} \frac{d y}{\cos \alpha} \\
& L_{o p}=\eta_{1}+\eta_{2} r(y)
\end{aligned}
$$

where $L_{o p}$ is the ineffective circumferential length of failure surface lost due to opening and $\eta_{1} \& \eta_{2}$ may vary depending on the opening locations. For several types of opening location, $L_{o p}, \eta_{1} \& \eta_{2}$ are presented in the sub-sections.

From Equation 5.109,

$$
\begin{gathered}
\overline{\text { Pop }}=\frac{f_{c}^{\prime}}{2}\left(\eta_{1} P_{\eta_{1}+} \eta_{2} P_{\eta_{2}}\right) \\
P_{\eta_{1}}=\frac{1}{A \pi}\left(L\left(r_{h}^{\prime}-r_{0}{ }^{\prime}\right)+M\left(-\sqrt{1+\left(r_{h}^{\prime}\right)^{2}}+\sqrt{1+\left(r_{0}^{\prime}\right)^{2}}\right)\right)(5.113) \\
P_{\eta_{2}}=\frac{1}{2 A^{2} \pi^{2}}\left(L\left(\sin ^{-1}\left(r_{h}{ }^{\prime}\right)-\sin ^{-1}\left(r_{0}{ }^{\prime}\right)+r_{h}{ }^{\prime} \sqrt{1+\left(r_{h}{ }^{\prime}\right)^{2}}-r_{0}{ }^{\prime} \sqrt{1+\left(r_{0}{ }^{2}\right)^{2}}+4 A \Delta\left(r_{0}{ }^{\prime}-r_{h}{ }^{\prime}\right)\right)\right. \\
+M\left(\left(r_{0}{ }^{\prime}\right)^{2}-\left(r_{h}{ }^{\prime}\right)^{2}+4 A \Delta\left(\sqrt{1+\left(r_{h}{ }^{\prime}\right)^{2}}-\sqrt{1+\left(r_{0}{ }^{\prime}\right)^{2}}\right)\right)
\end{gathered}
$$

The ineffective areas of failure surface due to openings are different from each other depending on the locations of opening near the column. Therefore, even for the same slab-column connections, if the locations of openings are different, the punching shear capacities lost due to openings may be different. It is due to the fact that the concentration of shear stresses around the column perimeter varies along the column perimeter. The concentration of shear stresses is more critical near the region around 
the shorter column width than near the region around the longer column width. This fact has been proved by the experimental results in chapter 4 for the experimental program presented in chapter 3 that the punching shear capacity of slab with opening located adjacent to the shorter column width is less than that of slab with opening located at the comer of column. Therefore, it is reasonable that the $L_{o p}, \eta_{1}$ and $\eta_{2}$ from Equations 5.111 and 5.112 may vary depending on the location of opening.

Accordingly, for several locations of opening located in the slab, the $\eta_{1}$ and $\eta_{2}$ terms included in Equation 5.111 and 5.112 need to be derived. There are five kinds of opening locations considered in this study. They are (a) opening location at adjacent comer of column, (b) opening location parallel and adjacent to the shorter side of column, (c) opening location perpendicular and adjacent to the longer side of column end, (d) opening location parallel and adjacent to the middle of longer side of column, and (e) opening location perpendicular and adjacent to the shorter side of column. All opening locations considered in this study are shown in Figure 5.14.

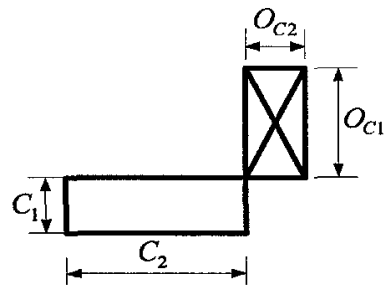

(a) Opening adjacent to the corner of column

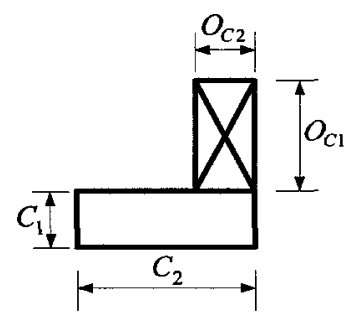

(c) Opening perpendicular and adjacent to the longer side of column end

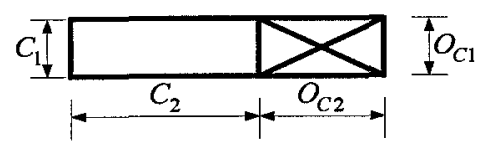

(e) Opening perpendicular and adjacent to the shorter side of column

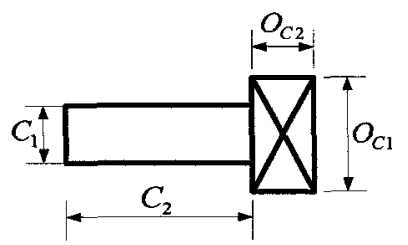

(b) Opening parallel and adjacent to the shorter side of column

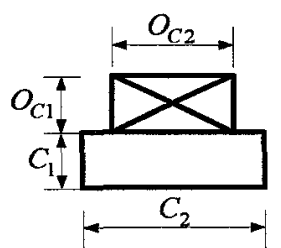

(d) Opening perpendicular and adjacent to the middle of longer side of column

Figure 5.14 Different kinds of opening locations 
The $\eta_{1}$ and $\eta_{2}$ from Equation 5.111 and 5.112 differ depending on the different locations of opening in the slab. Moreover, even for the slabs with the same types of opening location, the terms including in $\eta_{1}$ and $\eta_{2}$ may differ again according to different types of ineffective area of failure surface. This means that for the slabs with opening located at the same position near the column face, the ineffective area of failure surface due to opening may be different depending on the size of opening and radius of failure surface at the tension face of slab because the intersection points of two projection lines with the circumference of failure surface can be different. The $\eta_{1}$ and $\eta_{2}$ terms from Equation 5.111 and 5.112 related to five kind of opening locations considered are presented as follows. Detailed derivations of $L_{o p}, \eta_{1}, \eta_{2}$ and their related terms are presented in appendix B.

\subsubsection{Ineffective area of failure surface due to opening by using method AI}

The ineffective area of failure surface due to opening by using method AI is that the area under the plan area of failure surface bounded by two projection lines which propagated from the center of column through two comers of opening and extend up to intersect the circumference of failure surface. For five kinds of opening locations considered in this study, the $\eta_{1}$ and $\eta_{2}$ terms for Equation 5.111 and 5.112 related to this ineffective area of failure surface due to opening by using method AI are as follows:

\section{(a) Opening location at adjacent corner of column}

Opening in the slab is located at adjacent corner of column. The ineffective area of failure surface due to this location of opening by using method AI is shown in Figure 5.15. To confine the ineffective area of failure surface due to opening, two projection lines are propagated from the center of the column through two comers of opening at $B$ and $G$ and they intersect the circumference of failure surface at the tension face of the slab at D and $\mathrm{E}$. 


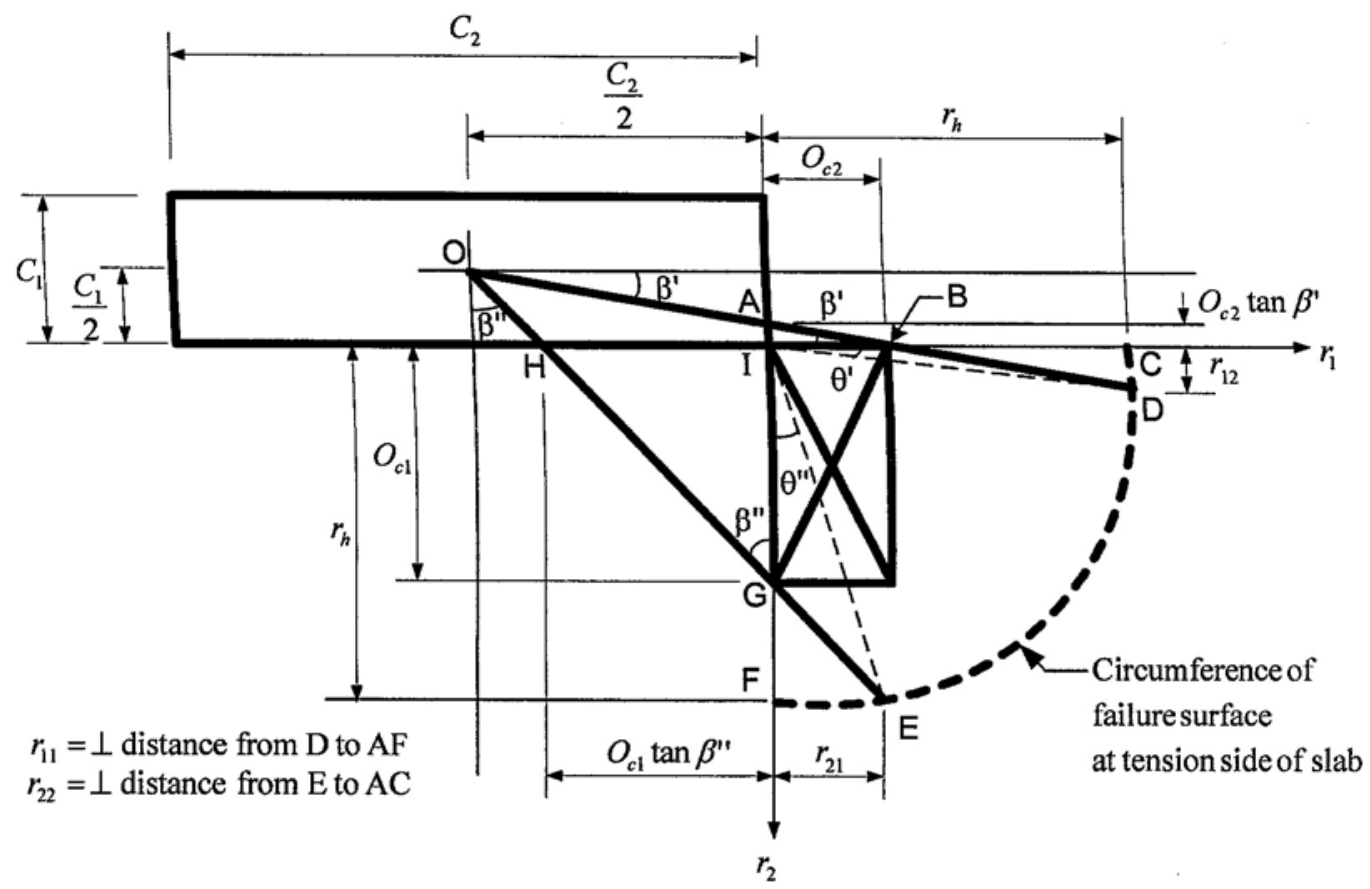

Figure 5.15 Ineffective area of failure surface due to opening location (a) by using method AI

The $\eta_{1}$ and $\eta_{2}$ terms for Equations 5.111 and 5.112 related to this ineffective area of failure surface due to opening by using method AI are:

$$
\begin{aligned}
& \eta_{1}=O_{c 2} \tan \beta^{\prime}+O_{c 1} \tan \beta^{\prime \prime} \\
& \eta_{2}=\frac{\pi}{2}-\theta^{\prime}-\theta^{\prime \prime}-\tan \beta^{\prime}-\tan \beta^{\prime \prime}+\tan \theta^{\prime}+\tan \theta^{\prime \prime}
\end{aligned}
$$

\section{(b) Opening location parallel and adiacent to the shorter side of column}

Opening in the slab is located parallel and adjacent to the shorter side of column. The ineffective area of failure surface due to this location of opening by using method $\mathrm{AI}$ is shown in Figure 5.16. To confine the ineffective area of failure surface due to opening, two projection lines are propagated from the center of the column through two corners of opening at $\mathrm{B}$ and $\mathrm{G}$ and they intersect the circumference of failure surface at the tension face of the slab at $\mathrm{C}$ and $\mathrm{F}$. 


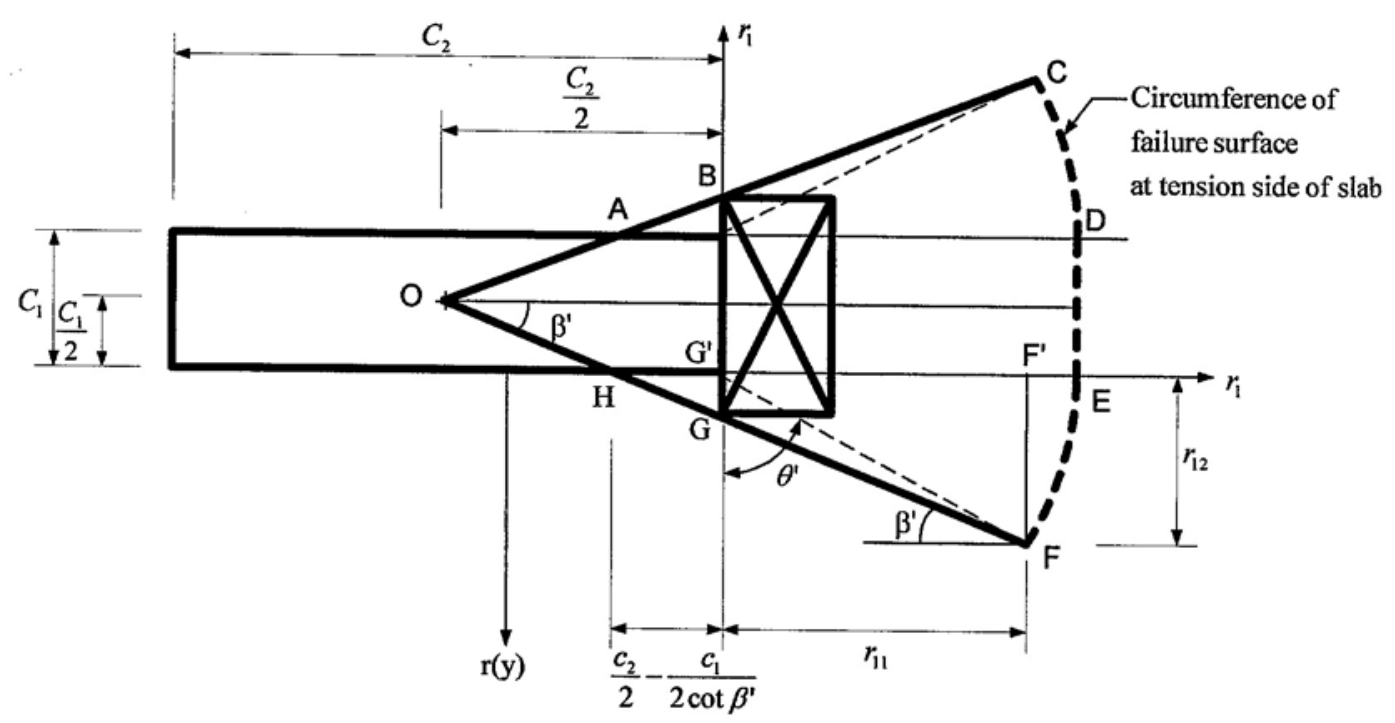

Figure 5.16 Ineffective area of failure surface due to opening location (b) by using method AI

The $\eta_{1}$ and $\eta_{2}$ terms for Equations 5.111 and 5.112 related to this ineffective area of failure surface due to opening by using method $\mathbf{A I}$ are:

$$
\begin{aligned}
& \eta_{1}=2 r_{11}+C_{2}-C_{1} \tan \beta^{\prime}-2 r_{12} \tan \theta^{\prime} \\
& \eta_{2}=\left(\pi-2 \theta^{\prime}\right)+2\left(-\tan \beta^{\prime}+\tan \theta^{\prime}\right)
\end{aligned}
$$

\section{(c) Opening location perpendicularand adiacent to the longer side of column end}

For the type of opening location (c), according to where two projection lines propagate from the center of column through two corners of opening and intersect the circumference of failure surface depending on opening size and location, there may have two possible cases regarding to the ineffective area of failure surface due to opening.

\section{$\underline{\text { Case (a) }}$}

Opening in the slab is located perpendicular and adjacent to the longer side of column end. The ineffective area of failure surface due to this location of opening by using method AI is shown in Figure 5.17. To confine the ineffective area of failure surface due to opening, two projection lines are propagated from the center of the column through two corners of opening at $\mathrm{A}$ and $\mathrm{F}$ and they intersect the circumference of 
failure surface at the tension face of the slab at $\mathrm{C}$ and $\mathrm{E}$. The intersection point $\mathrm{C}$ of one projection line with the circumference of failure surface is at the quadrant of failure surface parallel to longer column width while the intersection point $\mathrm{E}$ of the remaining projection line with the circumference of failure surface is at the quadrant of failure surface between the lines projected from the corners of column along the shorter and longer column widths as shown in Figure 5.17.

The $\eta_{1}$ and $\eta_{2}$ terms from Equation 5.111 and 5.112 related to this ineffective area of failure surface due to opening by using method AI are:

$$
\begin{aligned}
& \eta_{1}=\frac{C_{2}}{2}-\frac{C_{1}}{2} \tan \beta^{\prime \prime} \\
& \eta_{2}=\frac{\pi}{2}-\beta^{\prime}-\tan \beta^{\prime \prime}
\end{aligned}
$$

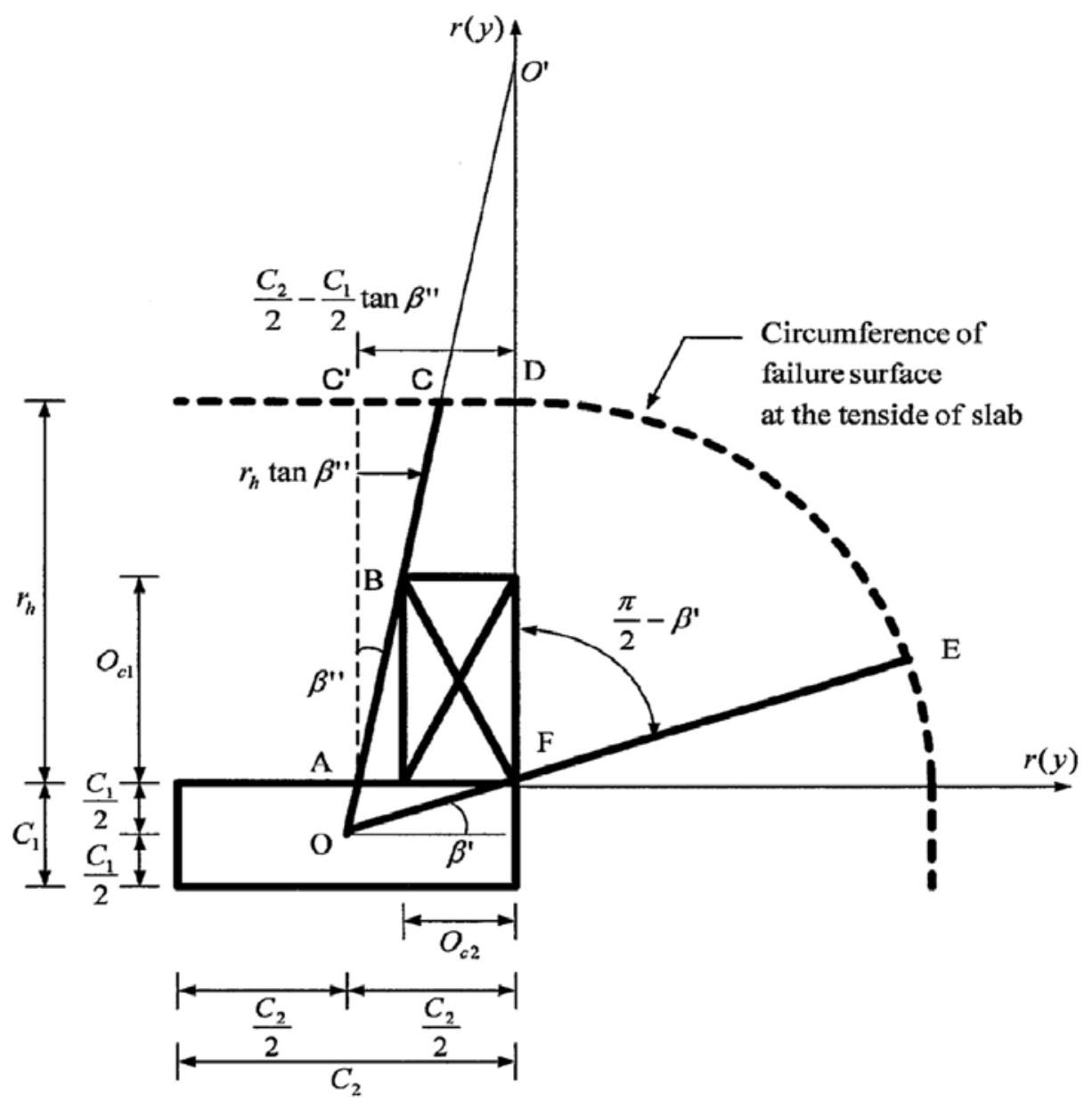

Figure 5.17 Ineffective area of failure surface due to opening location (c) by using method AI for case (a) 


\section{$\underline{\text { Case (b) }}$}

Opening in the slab is located perpendicular and adjacent to the longer side of column end. The ineffective area of failure surface due to this location of opening by using method AI is shown in Figure 5.18. To confine the ineffective area of failure surface due to opening, two projection lines propagate from the center of the column through two corners of opening at $\mathrm{A}$ and $\mathrm{F}$ and they intersect the circumference of failure surface at the tension face of the slab at D and E. In contrast to case (a) for this type of opening location (c), both intersection points of two projection lines are at the same quadrant of failure surface as shown in Figure 5.18.

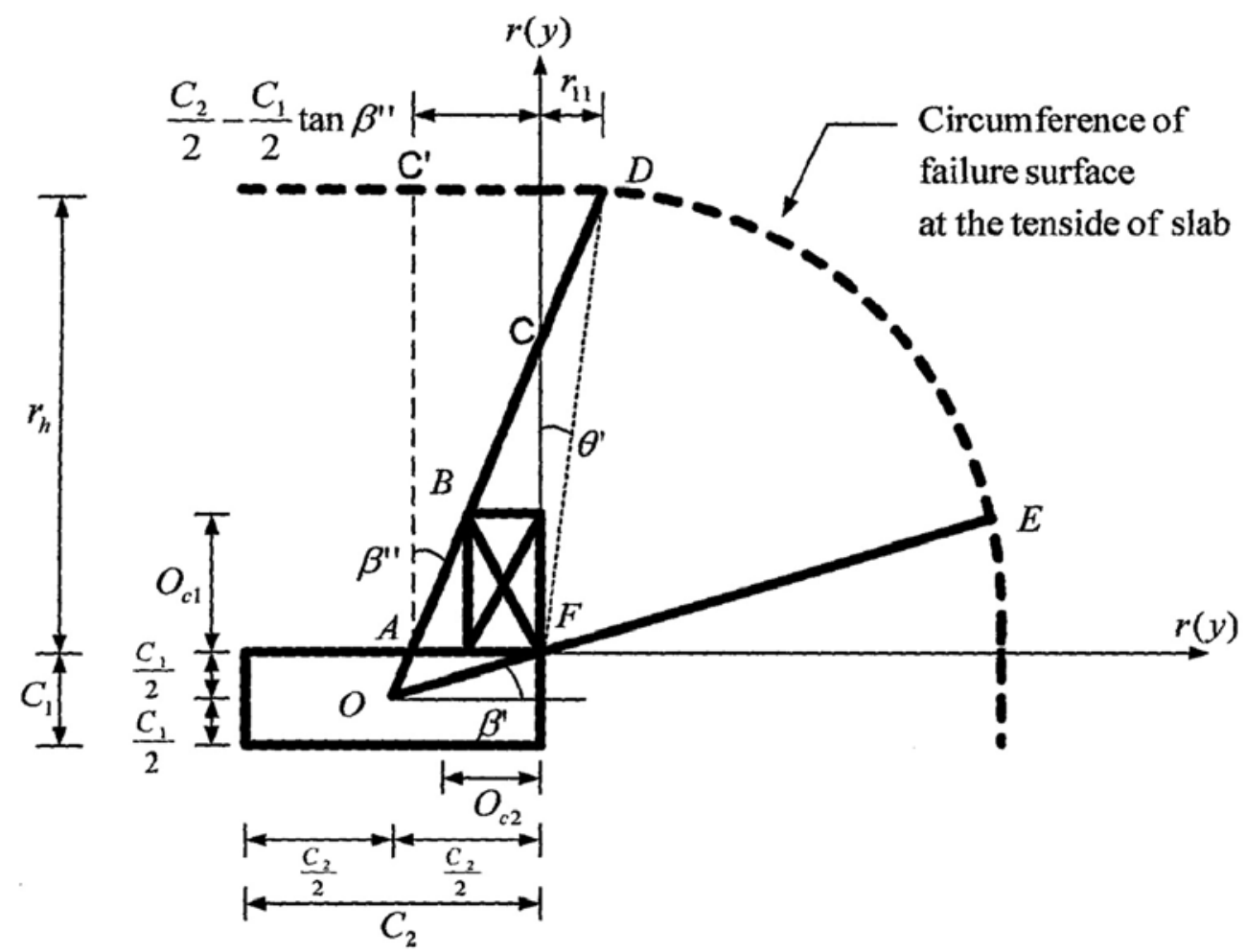

Figure 5.18 Ineffective area of failure surface due to opening location (c) by using method AI for case (b)

The $\eta_{1}$ and $\eta_{2}$ terms for Equations 5.111 and 5.112 related to this ineffective area of failure surface due to opening by using method AI are:

$$
\begin{aligned}
& \eta_{1}=\frac{C_{2}}{2}-\frac{C_{1}}{2} \tan \beta^{\prime \prime} \\
& \eta_{2}=\frac{\pi}{2}-\beta^{\prime}+\tan \theta^{\prime \prime}-\tan \beta^{\prime \prime}
\end{aligned}
$$




\section{(d) Opening location parallel and adiacent to the middle of longer side of column}

Similar to opening location (c), as for this type of opening location (d), according to where two projection lines those propagate from the center of column through two comers of opening and intersect the circumference of failure surface depending on opening size and location, there may have two possible cases regarding to the ineffective area of failure surface due to opening.

\section{Case (a)}

Opening in the slab is located parallel and adjacent to the middle of longer side of column. The ineffective area of failure surface due to this location of opening by using method AIis shown in Figure 5.19. To confine the ineffective area of failure surface due to opening, two projection lines are propagated from the center of the column through two corners of opening at A and F and they intersect the circumference of failure surface at the tension face of the slab at B and E each of which is at each quadrant of failure surface between the lines projected from the comers of column along the shorter and longer column widths in each end of longer column width close to opening as shown in Figure 5.19.

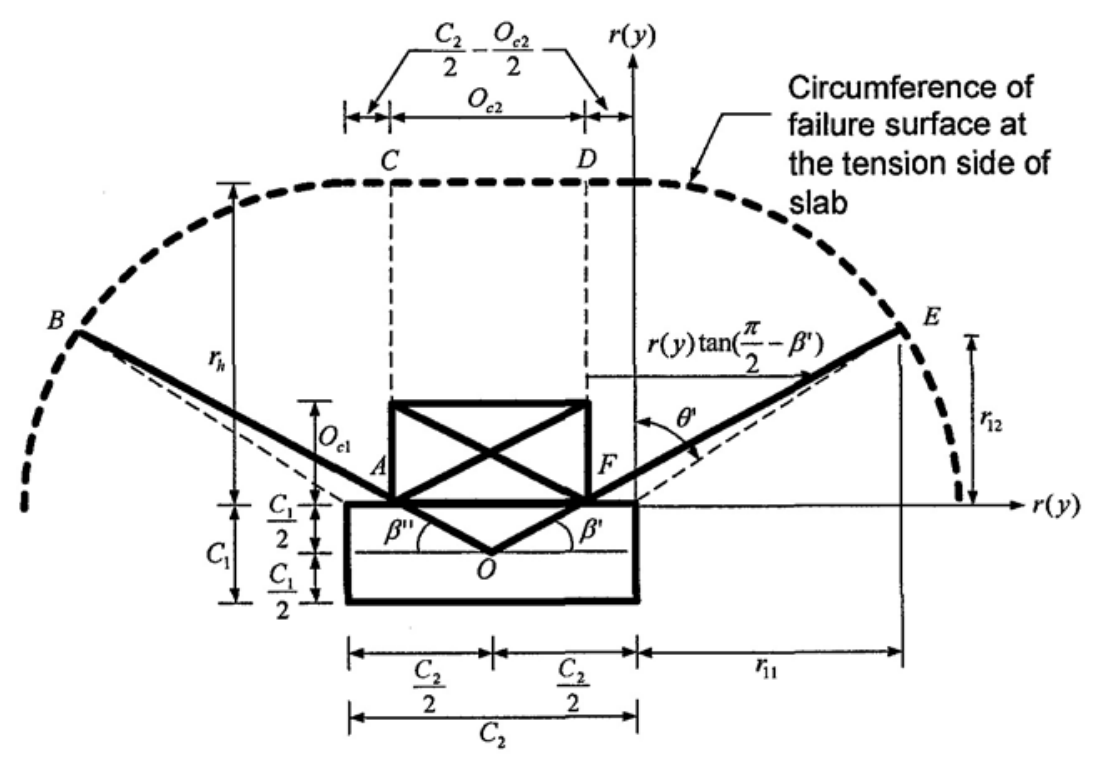

Figure 5.19 Ineffective area of failure surface due to opening location (d) by using method A I for case (a) 
The $\eta_{1}$ and $\eta_{2}$ terms for Equations 5.111 and 5.112 related to this ineffective area of failure surface due to opening by using method AI are:

$$
\begin{aligned}
& \eta_{1}=O_{c 2} \\
& \eta_{2}=2\left(\theta^{\prime}-\sin \theta^{\prime}+\tan \left(\frac{\pi}{2}-\beta^{\prime}\right)\right)
\end{aligned}
$$

\section{Case (b)}

Opening in the slab is located parallel and adjacent to the middle of longer side of column. The ineffective area of failure surface due to this location of opening by using method AI is shown in Figure 5.20. To confine the ineffective area of failure surface due to opening, two projection lines are propagated from the center of the column through two comers of opening at $\mathrm{A}$ and $\mathrm{F}$ and they intersect the circumference of failure surface at the tension face of the slab at B and E. In contrast to case (a) of this type of opening location, both intersection points of two projection lines with the circumference of failure surface are at the same quadrant of failure surface parallel to the longer column width close to opening as shown in Figure 5.20.

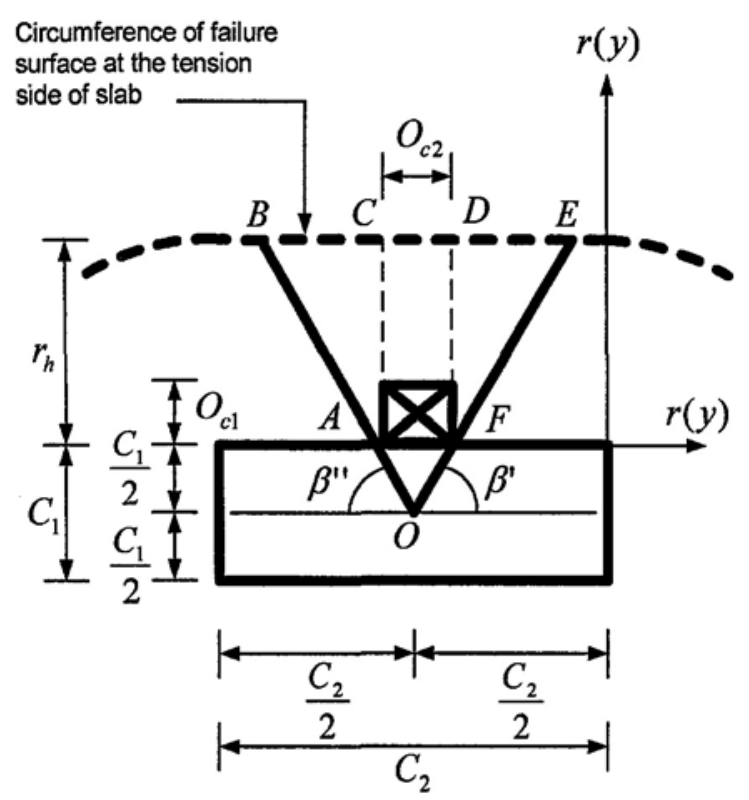

Figure 5.20 Ineffective area of failure surface due to opening location (d) by using method AI for case (b) 
The $\eta_{1}$ and $\eta_{2}$ terms for Equations 5.111 and 5.112 related to this ineffective area of failure surface due to opening by using method AI are:

$$
\begin{aligned}
& \eta_{1}=O_{c 2} \\
& \eta_{2}=2\left(\frac{\pi}{2}-\beta^{\prime}\right)
\end{aligned}
$$

\section{(e) Opening location perpendicular and adiacent to the shorter side of column}

Opening in the slab is located perpendicular and adjacent to the shorter side of column. The ineffective area of failure surface due to this location of opening by using method AI is shown in Figure 5.21. To confine the ineffective area of failure surface due to opening, two projection lines are propagated from the center of the column through two comers of opening at $\mathrm{A}$ and $\mathrm{F}$ and they intersect the circumference of failure surface at the tension face of the slab at B and E.

The $\eta_{1}$ and $\eta_{2}$ terms for Equations 5.111 and 5.112 related to this ineffective area of failure surface due to opening by using method $\mathrm{AI}$ are:

$$
\begin{aligned}
& \eta_{1}=C_{1} \\
& \eta_{2}=2 \beta^{\prime}
\end{aligned}
$$

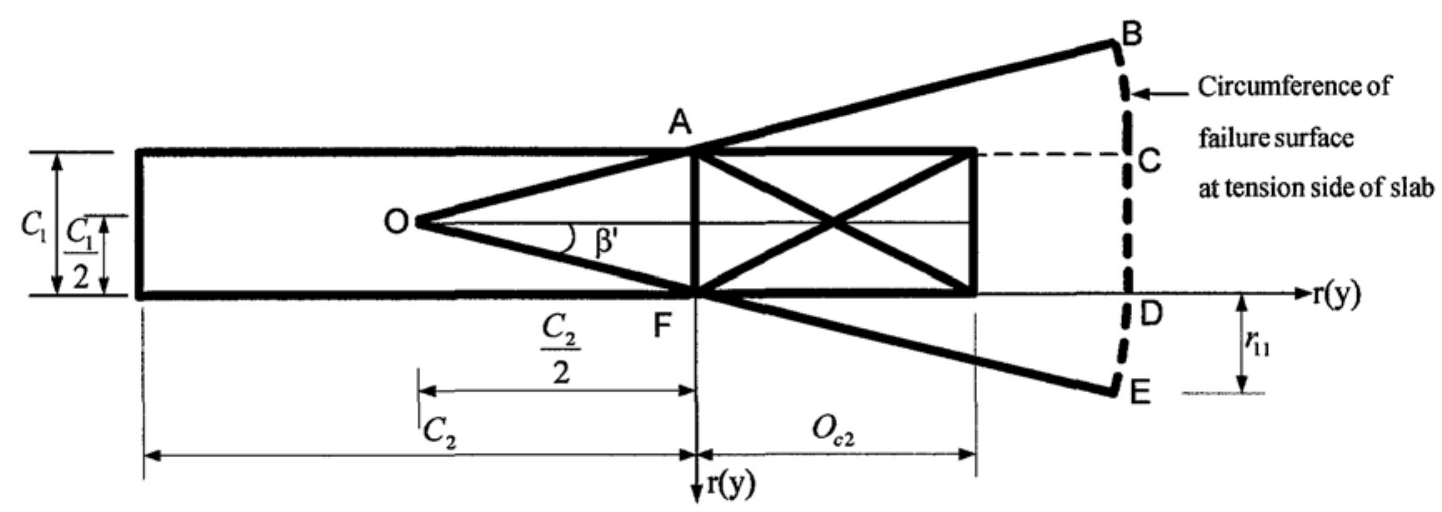

Figure 5.21 Ineffective area of failure surface due to opening location (e) by using method AI 


\subsubsection{Ineffective area of failure surface due to opening by using method AII}

The ineffective area of failure surface due to opening by using method AII is that the area under the plan area of failure surface bounded by two projection lines which start from the center of $1 / 3$ column section area close to the shorter column width nearest with the opening. For five kinds of opening locations considered in this study, the $\eta_{1}$ and $\eta_{2}$ terms from Equation 5.111 and 5.112 related to this ineffective area of failure surface due to opening by using method AII are as follows:

\section{(a) Opening position at adjacent corner of column}

The $\eta_{1}$ and $\eta_{2}$ terms for Equations 5.111 and 5.112 related to this ineffective area of failure surface due to opening by using method AII are same as Equation 5.115a and $5.115 b$, respectively.

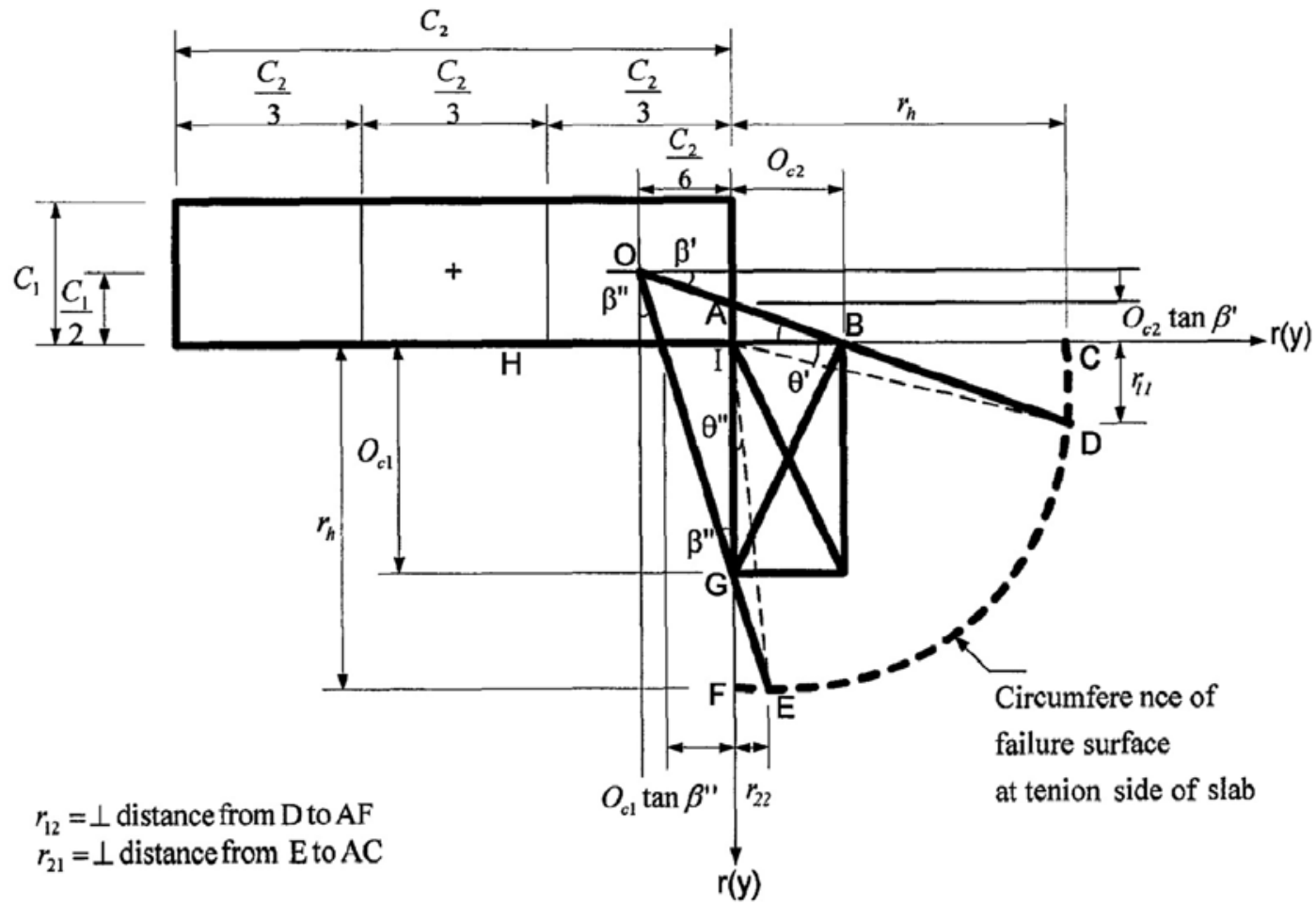

Figure 5.22 Ineffective area of failure surface due to opening location (a) by using method AII 


\section{(b) Opening;location parallel and adjacent to the shorter side of column}

The $\eta_{1}$ and $\eta_{2}$ terms from Equation 5.111 and 5.112 related to this ineffective area of failure surface due to opening by using method AII are same as Equation 5.116a and $5.116 b$, respectively.

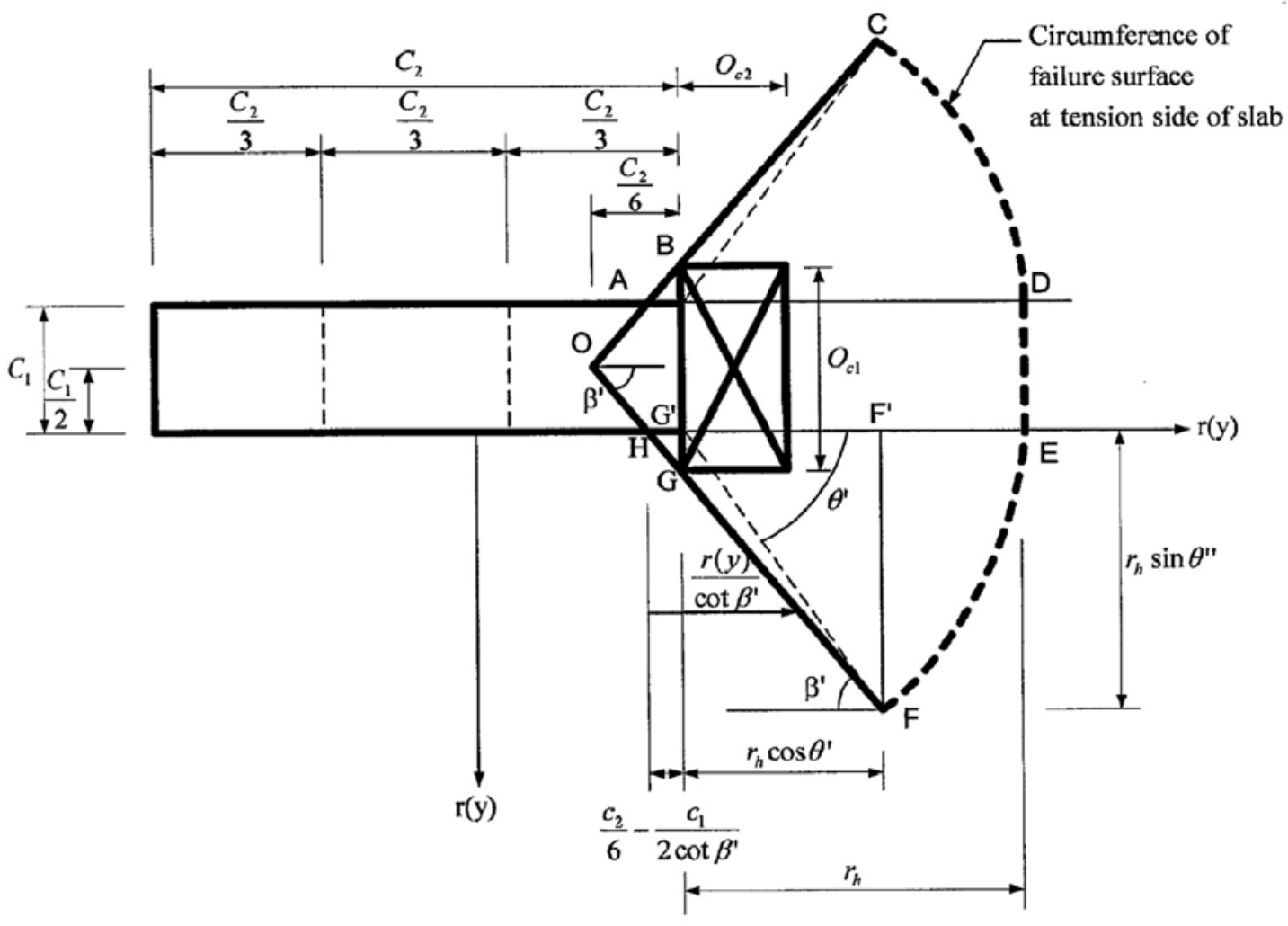

Figure 5.23 Ineffective area of failure due to opening location (b) by using method AII

\section{(c) Opening location perpendicular and adiacent to longer side of column end}

\section{$\underline{\text { Case (a) }}$}

The $\eta_{1}$ and $\eta_{2}$ terms for Equations 5.111 and 5.112 related to this ineffective area of failure surface due to opening by using method AII are:

$$
\begin{aligned}
& \eta_{1}=O_{c 2} \\
& \eta_{2}=\left(\frac{\pi}{2}-\beta^{\prime}\right)+\tan \left(\frac{\pi}{2}-\beta^{\prime \prime}\right)
\end{aligned}
$$




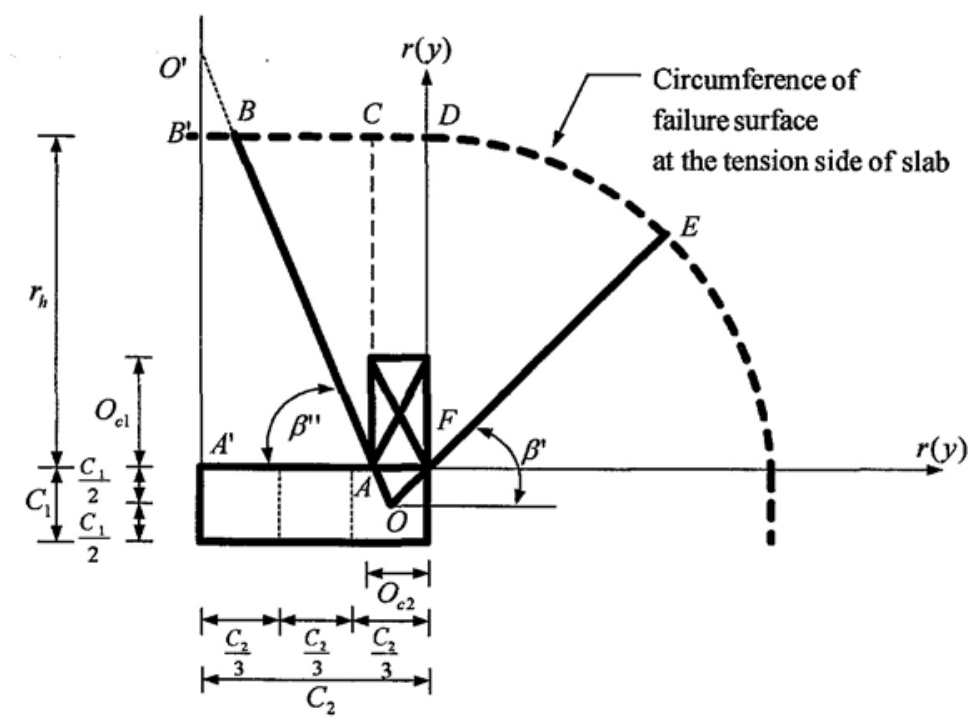

Figure 5.24 Ineffective area of failure surface due to opening location (c)

by using method AII for case (a)

\section{Case (b)}

The $\eta_{1}$ and $\eta_{2}$ terms for Equations 5.111 and 5.112 related to this ineffective area of failure surface due to opening by using method AII are:

$$
\begin{aligned}
& \eta_{1}=O_{c 2} \\
& \eta_{2}=\left(\frac{\pi}{2}-\beta^{\prime}\right)+\theta^{\prime}-\tan \theta^{\prime}+\tan \left(\frac{\pi}{2}-\beta^{\prime \prime}\right)
\end{aligned}
$$

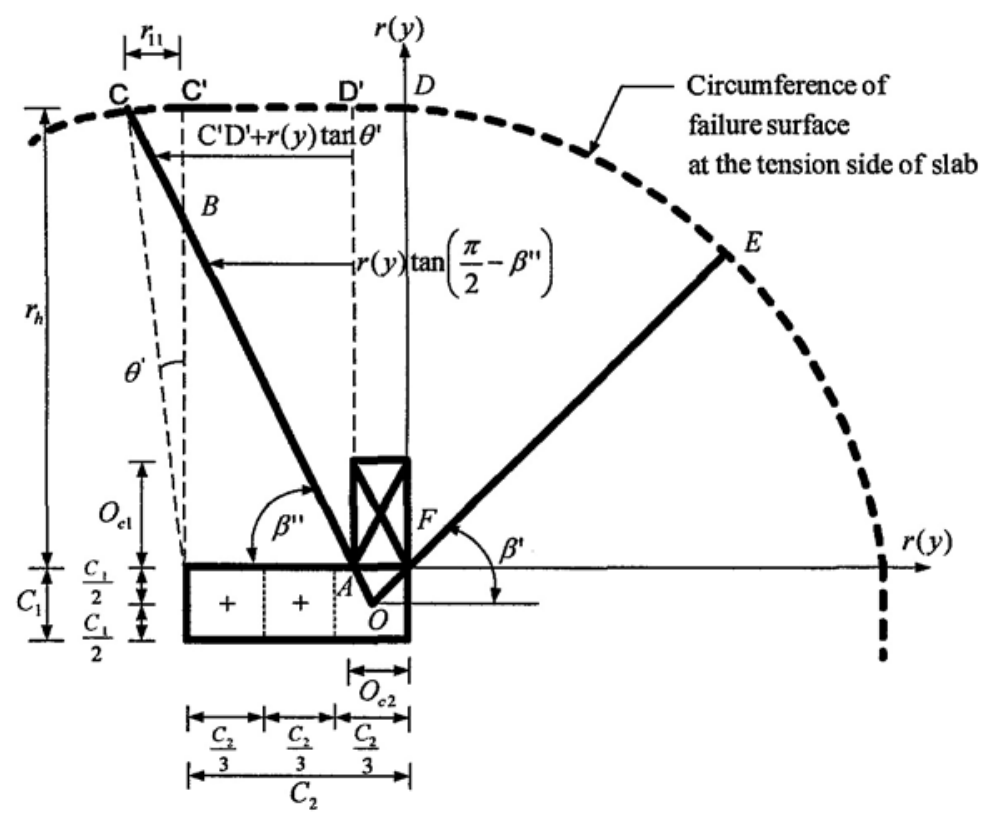

Figure 5.25 Ineffective area of failure surface due to opening location (c) by using method AII for case (b) 


\section{(d) Opening:location parallel and adiacent to the middle of longer side of column}

\section{Case (a)}

The $\eta_{1}$ and $\eta_{2}$ terms for Equations 5.111 and 5.112 related to this ineffective area of failure surface due to opening by using method AII are:

$$
\begin{gathered}
\eta_{1}=O_{c 2} \\
\eta_{2}=\theta^{\prime}+\theta^{\prime \prime}-\tan \theta^{\prime}-\tan \theta^{\prime \prime}+\tan \left(\frac{\pi}{2}-\beta^{\prime}\right)+\tan \left(\frac{\pi}{2}-\beta^{\prime \prime}\right)
\end{gathered}
$$

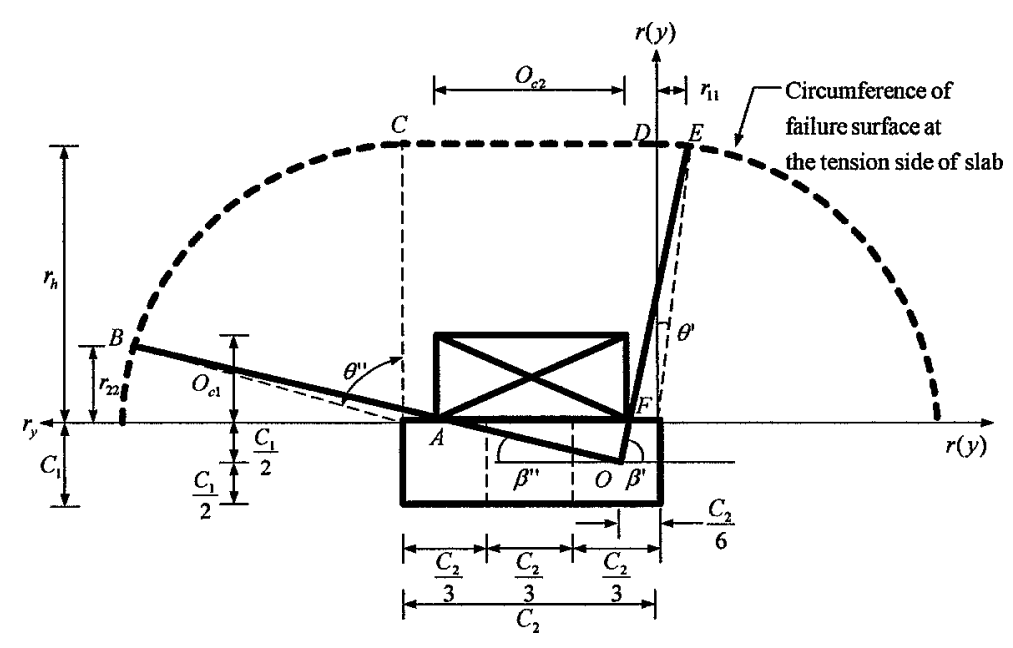

Figure 5.26 Ineffective area of failure surface due to opening location (d) by using method AII for case (a)

\section{Case (b)}

The $\eta_{1}$ and $\eta_{2}$ terms for Equations 5.111 and 5.112 related to this ineffective area of failure surface due to opening by using method AII are:

$$
\begin{aligned}
& \eta_{1}=\frac{5}{6} C_{2}-\frac{C_{1}}{2} \tan \beta^{\prime}-\left(\frac{C_{2}}{2}-\frac{O_{c 2}}{2}\right) \\
& \eta_{2}=\theta^{\prime \prime}-\tan \theta^{\prime \prime}-\tan \beta^{\prime}+\tan \left(\frac{\pi}{2}-\beta^{\prime \prime}\right)
\end{aligned}
$$




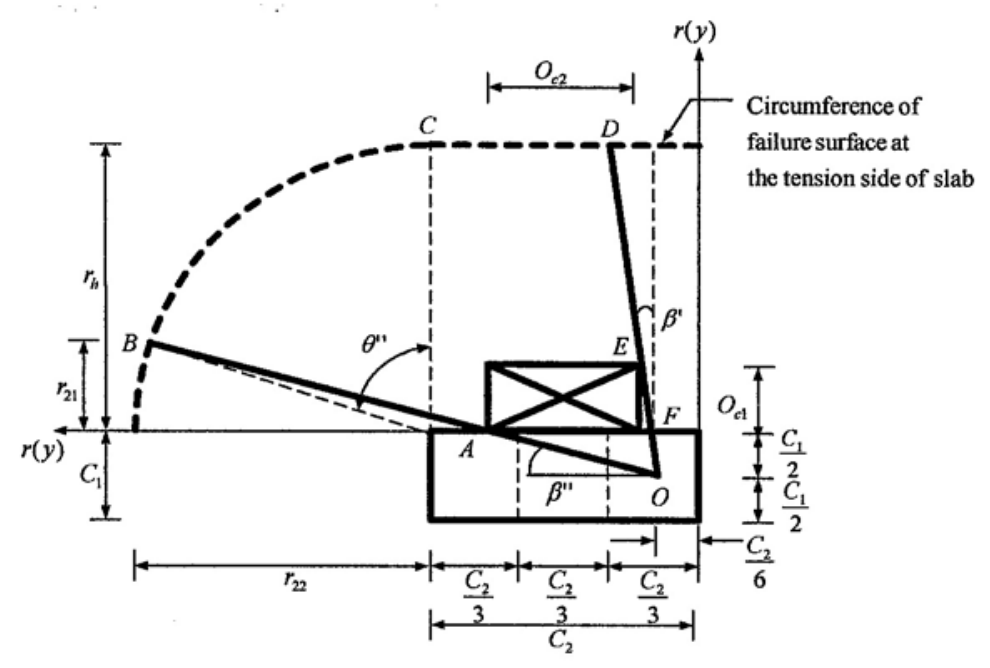

Figure 5.27 Ineffective area of failure surface due to opening location (d) by using method AII for case (b)

\section{$\underline{\text { Case (c) }}$}

The $\eta_{1}$ and $\eta_{2}$ terms for Equations 5.111 and 5.112 related to this ineffective area of failure surface due to opening by using method AII are:

$$
\begin{aligned}
& \eta_{1}=\frac{5}{6} C_{2}-\frac{C_{1}}{2} \tan \beta^{\prime}-\left(\frac{C_{2}}{2}-\frac{O_{c 2}}{2}\right) \\
& \eta_{2}=\left(\theta^{\prime \prime}-\theta^{\prime}\right)+\tan 8^{\prime}-\tan \beta^{\prime}-\tan \theta^{\prime \prime}+\tan \left(\frac{\pi}{2}-\beta^{\prime \prime}\right)
\end{aligned}
$$

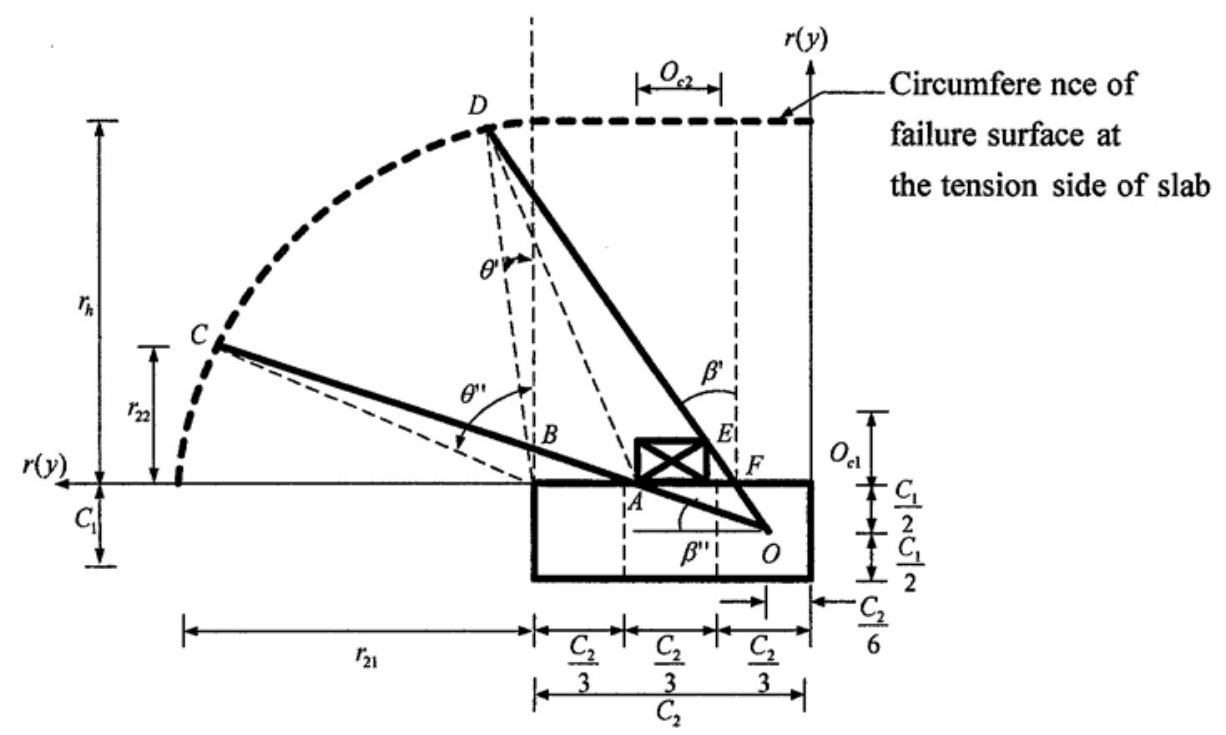

Figure 5.28 Ineffective area of failure surface due to opening location (d) by using method AII for case (c) 
(e) Opening location perpendicular and adiacent to the shorter side of column

The $\eta_{1}$ and $\eta_{2}$ terms for Equations 5.111 and 5.112 related to this ineffective area of failure surface due to opening by using method AII are:

$$
\begin{aligned}
& \eta_{1}=C_{1} \\
& \eta_{2}=2 \beta^{\prime}
\end{aligned}
$$

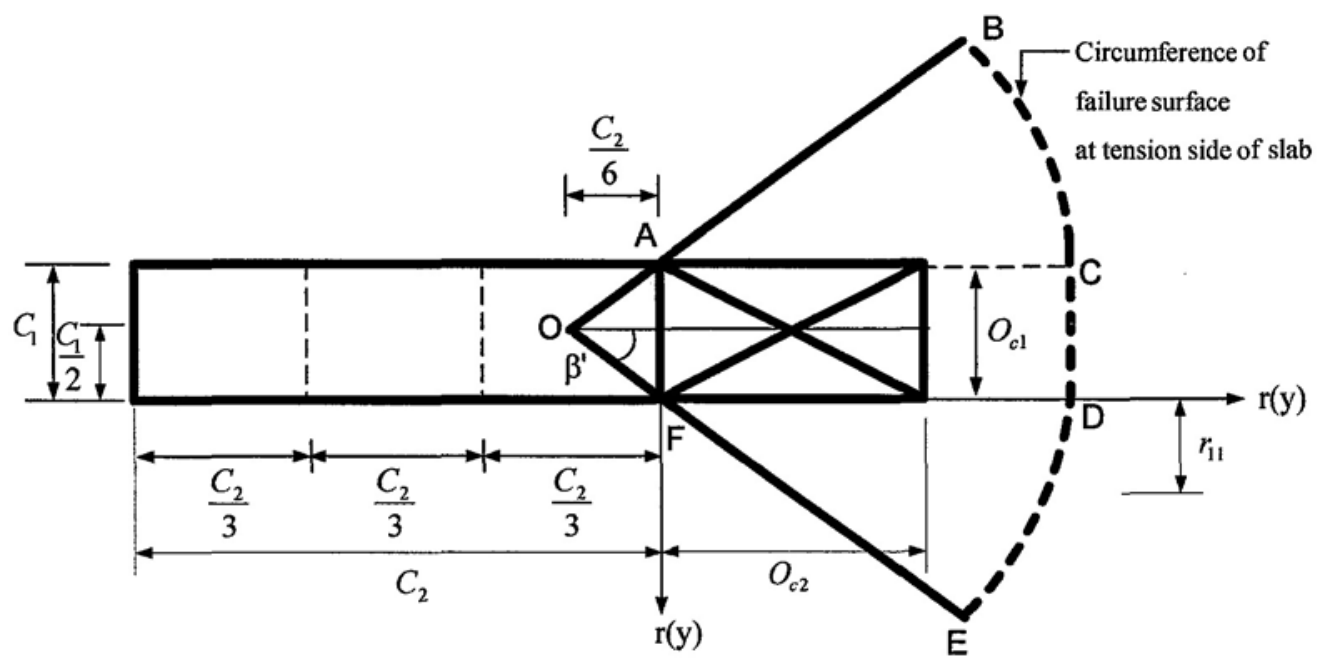

Figure 5.29 Ineffective area of failure surface due to opening location (e) by using method AII

\subsubsection{Slab-column connection with shear reinforcement}

The punching shear capacity for slab-column connection without shear reinforcement has been discussed in section 5.6.1. When the slab-column connections without opening have shear reinforcement, the same equations for punching shear capacity of the slab-column connection without shear reinforcement can be used by superimposing the contribution of shear reinforcement on the tensile strength of concrete in Equations 5.49 and 5.50. In this case, the dowel action of flexural reinforcement is neglected because it is assumed to contribute only the stresses in its axial direction. The contribution of shear reinforcement should be superimposed on the tensile strength of concrete. 
The failure surface in punching shear failure of slab observed in practice involves separation failure as well as sliding failure. The sliding is resisted by the compressive and shear stress along the failure surface. The tensile strength of concrete is against the separation. The shear reinforcement can strengthen against separation. When the shear reinforcement is used, the tensile strength of slab by the contribution of concrete and shear reinforcement is:

$$
f_{t}=f_{c t}+f_{s t}
$$

where $f_{t}=$ tensile strength of slab

$f_{c t} \quad=$ tensile strength of concrete
$f_{s t} \quad=$ tensile strength of shear reinforcement

However, the concrete is weak in tension. The ultimate punching shear failure in the slab with shear reinforcement occurs after cracking of concrete. After cracking, the concrete can resist no tension (Collins, 1978). When the slab has shear reinforcement, no contribution of concrete in tension is considered. Only shear reinforcement is assumed to resist tension. Thus,

$$
f_{c t}=0
$$

Therefore, Equation 5.128 becomes:

$$
f_{t}=f_{s t}
$$

where $f_{s t}$ is tensile strength contributed by shear reinforcement.

Thus, the tensile strength5 in Equations 5.49, 5.50, and 5.130 for the punching shear capacity of the slab-column connection without shear reinforcement is:

$$
\begin{gathered}
f_{t}=f_{s t}=\rho_{s} f_{s y} \sin \alpha_{\text {avg }} \\
A_{f}=\frac{2}{A^{2} \pi}\left(-\sinh ^{-1}\left(r^{\prime}(0)\right)-r^{\prime}(0) \sqrt{1+\left(r^{\prime}(0)\right)^{2}}+\sinh ^{-1}\left(r^{\prime}(h)\right)+r^{\prime}(0) \sqrt{1+\left(r^{\prime}(h)\right)^{2}}\right) \\
\rho_{s}=\frac{A_{s}}{A_{f}} \\
\alpha_{\text {avg }}=\tan ^{-1}\left(\frac{1}{2} A \pi e^{A h \pi}\left(1+e^{A h \pi}\right)\left(-C+B e^{A h \pi}\right)\right)
\end{gathered}
$$

where $\rho_{s} \quad=$ ratio of shear stud reinforcement passing through the failure surface

$A_{s}=$ total area of shear studs passing through the failure surface 


$$
\begin{aligned}
& A_{f}=\text { total area of failure surface of slab without opening after punching } \\
& \alpha_{\text {avg }} \quad=\text { average slope of failure surface }
\end{aligned}
$$

Detailed derivation of area of failure surface $A_{f}$ and average slope of failure $\alpha_{\text {avg }}$ are presented in appendix B.

After substituting Equation 5.131 into $\mathrm{L}$ and $\mathrm{M}$ from Equations 5.49 and 5.50 and using it, the punching shear capacity for the slab-column connection with shear reinforcement is as follows:

(a) If the failure surface is a curve i.e. the initial slope of failure surface at the compression side of the slab is equal or greater than 37 degree, the punching shear capacity for the slab-column connection with shear reinforcement is:

$$
\begin{aligned}
P_{S}= & \frac{f_{c}^{\prime}}{2 A^{2} \pi}\left(L\left(\left(\sinh ^{-1}\left(r_{h}^{\prime}\right)+r_{h}^{\prime} \sqrt{1+\left(r_{h}^{\prime}\right)^{2}}\right)-\left(\sinh ^{-1}\left(r_{0}^{\prime}\right)+r_{0}{ }^{\prime} \sqrt{1+\left(r_{0}{ }^{\prime}\right)^{2}}\right)\right)\right. \\
& \left.-M\left(\left(r_{h}^{\prime}\right)^{2}-\left(r_{0}^{\prime}\right)^{2}\right)\right)
\end{aligned}
$$

where $r_{0}{ }^{\prime}$ and $r_{h}{ }^{\prime}$ are $r^{\prime}(0)$ and $r^{\prime}(h)$ from Equations 5.76 and 5.78, respectively. Or,

$$
\begin{aligned}
P_{S}= & \frac{f_{c}^{\prime}}{2 A^{2} \pi}\left(L \left(-2 A \Delta \sqrt{-1+4 A^{2} \Delta^{2}}-\ln \left(2 A \Delta+\sqrt{-1+4 A^{2} \Delta^{2}}\right)\right.\right. \\
& +\ln \left(\sqrt{A^{2}\left(-2 \Delta-\pi r_{h}\right)^{2}}+\sqrt{-1+A^{2}\left(-2 \Delta-\pi r_{h}\right)^{2}}\right) \\
& \left.\ln \left(-\sqrt{A^{2}\left(-2 \Delta-\pi r_{h}\right)^{2}} \sqrt{-1+A^{2}\left(-2 \Delta-\pi r_{h}\right)^{2}}\right)+M\left(-4 A^{2} \pi \Delta r_{h}-A^{2} \pi^{2} r_{h}^{2}\right)\right)
\end{aligned}
$$

where $r_{h}$ is obtained from Equation 5.77 .

(b) If the failure surface is a combination of a straight line and a curve i.e. the initial slope of failure surface at the compression side of the slab is less than 37 degree, the punching shear capacity for the slab-column connection with shear reinforcement is:

$$
\begin{aligned}
& P_{S}=P_{L S}+P_{C S} \\
& P_{L S}=\frac{1}{32}(5 L-3 M) f_{c}^{\prime} h_{0}\left(16 \Delta+3 \pi h_{0}\right)
\end{aligned}
$$




$$
\begin{aligned}
P_{C S}=\frac{f_{c}^{\prime}}{2 A^{2} \pi}\left(L\left(\left(\sinh ^{-1}\left(r_{h}^{\prime}\right)+r_{h}{ }^{\prime} \sqrt{1+\left(r_{h}^{\prime}\right)^{2}}\right)-\left(\sinh ^{-1}\left(r_{h 0}{ }^{\prime}\right)+r_{h 0}{ }^{\prime} \sqrt{1+\left(r_{h 0}{ }^{\prime}\right)^{2}}\right)\right)\right. \\
\left.-M\left(\left(r_{h}^{\prime}\right)^{2}-\left(r_{0}^{\prime}\right)^{2}\right)\right)
\end{aligned}
$$

where $P_{S} \quad=$ punching shear capacity for the slab-column connection with shear reinforcement

$P_{L S}=$ punching shear capacity for the slab-column connection with shear reinforcement for straight portion of failure surface

$P_{C S}=$ punching shear capacity for the slab-column with shear reinforcement for curve portion of failure surface

Then, $r_{h 0}{ }^{\prime}$ and $r^{\prime}\left(h_{0}\right)$ can be obtained from Equations 5.101 and 5.102.

\subsubsection{Punching shear capacity for slab-column connection with opening and shear reinforcement}

When the slab-column connection has opening and shear reinforcement, the punching shear capacity of slab-column connection is

$$
P_{o p+S}=\bar{P}_{S}-\bar{P}_{o p}
$$

where $P_{o p+S} \quad=$ punching shear capacity of slab-column connection with opening and shear reinforcement

$\bar{P}_{S} \quad=$ punching shear capacity of slab-column connection without opening and with shear studs having steel ratio $\bar{\rho}_{s}$ (About $\bar{\rho}_{s}$ is explained latter.)

$\bar{P}_{o p} \quad=$ punching shear capacity of slab-column connection lost due to opening (previously described in above section 5.5.2) 
Using Equations 5.135a or 5.135b and 5.136, $\bar{P}_{S}$ for the punching shear capacity of slab-column connections without opening and with shear reinforcement can be obtained as follows:

(a) If the failure surface is a curve or the initial slope of failure surface $\alpha_{0}$ is equal or greater than $37^{\circ}$,

$$
\begin{aligned}
\bar{P}_{S}= & \frac{f_{c}^{\prime}}{2 A^{2} \pi}\left(L\left(\left(\sinh ^{-1}\left(r_{h}{ }^{\prime}\right)+r_{h}{ }^{\prime} \sqrt{1+\left(r_{h}{ }^{\prime}\right)^{2}}\right)-\left(\sinh ^{-1}\left(r_{0}{ }^{\prime}\right)+r_{0}{ }^{\prime} \sqrt{1+\left(r_{0}{ }^{\prime}\right)^{2}}\right)\right)\right. \\
& \left.-M\left(\left(r_{h}{ }^{\prime}\right)^{2}-\left(r_{0}{ }^{\prime}\right)^{2}\right)\right)
\end{aligned}
$$

(b) If the failure surface is a combination of a straight line and a curve, or the initial slope of failure surface $\alpha_{0}$ is less than $37^{\circ}$,

$$
\begin{aligned}
\bar{P}_{L S}= & \frac{1}{32}(5 L-3 M) f_{c}^{\prime} h_{0}\left(16 \Delta+3 \pi h_{0}\right) \\
\bar{P}_{C S}= & \frac{f_{c}^{\prime}}{2 A^{2} \pi}\left(L \left(\left(\sinh ^{-1}\left(r_{h}{ }^{\prime}\right)+r_{h}{ }^{\prime} \sqrt{1+\left(r_{h}{ }^{\prime}\right)^{2}}\right)\right.\right. \\
& \left.\left.-\left(\sinh ^{-1}\left(r_{h 0}{ }^{\prime}\right)+r_{h 0}{ }^{\prime} \sqrt{1+\left(r_{h 0}{ }^{\prime}\right)^{2}}\right)\right)-M\left(\left(r_{h}{ }^{\prime}\right)^{2}-\left(r_{0}{ }^{\prime}\right)^{2}\right)\right) \\
& \bar{P}_{S}=\bar{P}_{L S}+\bar{P} c S
\end{aligned}
$$

However, in determining $\bar{P}_{S}$ regarding to the contribution of shear reinforcement, the ratio of shear stud is considered based on the net area of failure surface of slab without including the ineffective area of failure surface lost due to opening. Thus, the tensile strength $f_{t}$ from Equations 5.49 and 5.50 is:

$$
\begin{gathered}
f_{t}=\bar{\rho}_{s} f_{s y} \sin \alpha_{\text {avg }} \\
\bar{A}_{f}=\frac{1}{2 A^{2} \pi^{2}}\left[2 A \eta_{1}^{\prime}\left\{-r^{\prime}(0)+r^{\prime}(h)\right\}+\eta_{2}^{\prime}\left\{-\sinh ^{-1}\left(r^{\prime}(0)\right)+\sinh ^{-1}\left(r^{\prime}(h)\right)+4 A \Delta r^{\prime}(0)\right.\right. \\
\left.\left.-r^{\prime}(0) \sqrt{1+\left(r^{\prime}(0)\right)^{2}}-4 A \Delta r^{\prime}(h)+r^{\prime}(h) \sqrt{1+\left(r^{\prime}(h)\right)^{2}}\right\}\right] \\
\bar{\rho}_{s}=\frac{A_{s}}{\bar{A}_{f}}
\end{gathered}
$$


where $\bar{\rho}_{s} \quad=$ ratio of shear stud reinforcement passing through the failure surface of slab based on the net area of failure surface $\bar{A}_{f}$ without including ineffective area of failure surface

$\alpha_{\text {avg }}=$ average slope of failure surface from Equation 5.134

$\bar{A}_{f} \quad=$ net area of failure surface of slab without including ineffective area of failure surface lost due to opening

$A_{s} \quad=$ total area of shear studs passing through the failure surface

The difference between $P_{S}$ from Equations 5.135a or 5.135b and 5.136 and $\bar{P}_{S}$ from Equations 5.137, 5.137a and 5.137d is that Equations 5.131 to 5.134 where the ratio of shear stud is based the total area of failure surface of slab without opening are used to obtained $P_{S}$ from Equation 5.135a or 5.135b and 5.136, while Equations 5.138 to $5.138 \mathrm{~b}$ where the ratio of shear stud is based the net area of failure surface without including the ineffective area of failure surface due to opening are used to obtained $\bar{P}_{S}$ from Equations 5.137, 5.137a and 5.137d.

\subsubsection{Critical radius of failure surface}

In determining the punching shear capacity by plasticity model, the radius of failure surface at the bottom of slab needs to be determined to achieve the minimum punching shear capacity of slab. Therefore, the critical radius of failure surface is defined as the radius of failure surface at the tension side of slab that can be able to give the minimum punching shear capacity of the slab-column connections. When the radius of failure surface becomes larger, the slope of failure surface is flatter. The vertical components of normal and shear stresses become smaller as the radius of failure surface becomes larger. Thus, the punching shear capacity of slab decreases as the radius of failure surface increases.

In this case, the radius of failure surface beyond the support of the slab is not reasonable. Thus, there is a need to know the critical radius of failure surface not greater than the support radius, which gives the least punching shear capacity of slab- 
column connections. If the critical radius of failure surface is beyond the support radius, the radius of failure surface which gives the minimum punching shear capacity is equal to support radius of slab.

The critical radius of failure surface is derived as follows:

The punching shear capacity from Equation 5.82 and 5.81 is differentiated by $r_{h}$, and $r^{\prime}(0)$ and $r^{\prime}(h)$, respectively, and equated to zero. The $r_{h}$ is radius of failure surface at tension side of slab. The $r^{\prime}(0)$ and $r^{\prime}(h)$ are tangent values of failure surface at slab thickness zero and $\mathrm{h}$, respectively.

From Equation 5.83,

$$
\frac{\partial P}{\partial r_{h}}=0
$$

By solving Equation 5.139, the critical radius of failure surface is:

$$
r_{c r}=\frac{1}{\pi}\left(\frac{M}{A_{c r} \sqrt{M^{2}-L^{2}}}-2 \Delta\right)
$$

where

$r_{c r} \quad=$ critical radius of failure surface at tension face of slab

$A_{c r}=$ constant that give critical radius of failure surface at tension face of slab

L, $M$ and $\Delta$ can be obtained by using Equation 5.49, 5.50 and 5.56.

From Equation 5.81,

$$
\frac{\partial P}{\partial r^{\prime}(0)}=0
$$

By solving Equation 5.141,

$$
r^{\prime}(0)=\frac{L}{\sqrt{M^{2}-L^{2}}}
$$

And then, $\quad \frac{\partial P}{\partial r^{\prime}(h)}=0$

Similarly,

$$
r^{\prime}(h)=\frac{L}{\sqrt{M^{2}-L^{2}}}
$$

Therefore,

$$
r^{\prime}(0)=r^{\prime}(h)
$$


By substituting $r^{\prime}(0)$ and $r^{\prime}(h)$ from Equation 5.76 and 5.78, respectively,

$$
A_{c r}=-\frac{1}{2 \Delta \operatorname{csch}\left(\frac{A_{c r} h \pi}{2}\right)} \text { or } A_{c r}=\frac{1-\cosh \left(A_{c r} h \pi\right)}{8 \Delta^{2}}
$$

where $A_{c r}, B_{c r}$ and $C_{c r}$ are the constant terms related to critical radius of failure surface.

\subsection{Procedure for calculation of punching shear capacity}

The procedure in calculating the punching shear capacity of slab-column connections is as follows:

(I) Punching shear capacity of slab-column connection without opening and without shear reinforcement,P.

(1) Input $C_{1}, C_{2}, h, f_{c}^{\prime}, f_{t}$, Sdia-1 and SDia-2

$C_{1} \& C_{2} \quad=$ shorter and longer column width, respectively

$\mathrm{h}=$ thickness of slab

$f_{c}^{\prime}=$ cylinder compressive strength of concrete

$f_{t} \quad=$ tensile strength of concrete

Sdia-1 = Support diameter of slab in $\mathrm{C}_{1}$ direction

Sdia-2 = Support diameter of slab in $\mathrm{C}_{2}$ direction

(2) Calculateminimum $r_{h}$, A and SRad.

minimum $r_{h}=\frac{3}{4} h$

$\Delta=\frac{1}{2}\left(C_{1}+C_{2}\right)$

$\mathrm{SRad}=\frac{1}{2}\left(\frac{1}{2}\left(\mathrm{SDia}-1-C_{1}\right)+\frac{1}{2}\left(\mathrm{SDia}-2-C_{2}\right)\right)$

(3) Assume $r_{h}$. $\left(\geq\right.$ Minimum $\left.r_{h} \& \leq \operatorname{SRad}\right)$.

(4) Assume $B\left(<\frac{2 \Delta}{\pi}\right)$.

(5) Calculate $\mathrm{C}, \mathrm{A}$, and $r_{h}$.

$$
C=B-\frac{2 \Delta}{\pi}
$$




$$
\begin{aligned}
& A=\frac{1}{2 \pi \sqrt{B C}} \\
& r_{h}=-\frac{2 \Delta}{\pi}+B e^{A \pi h}+C e^{-A \pi h}
\end{aligned}
$$

(6) Check if assumed $r_{h}=$ calculated $r_{h}$.

(a) If assumed $r_{h} \neq$ calculated $r_{h}$, repeat step 4 with another trial value of B.

(b) If assumed $r_{h}=$ calculated $r_{h}, r_{h}=$ assumed $r_{h}$.

Take $\boldsymbol{A}, \mathrm{B}$, and $\mathrm{C}$.

(c) Calculate $\mathrm{A}$

$$
A_{c r}=\frac{1-\cosh (A h \pi)}{8 \Delta^{2}}
$$

(d) Check if $A_{c r}=\mathrm{A}$.

(e) If $A_{c r} \neq A$, the radius of failure surface $r_{h}$ does not reach to critical radius of failure surface $\boldsymbol{r}$.

(i) Repeat step (3) with another trial $r_{h}$ until to reach $r_{h}=$ SRad.

(ii) If $r_{h}=\mathrm{SRad}, r_{c r}=r_{h}$.

(f) If $\mathrm{A},=\mathrm{A}$, the radius of failure surface $r_{h}$ have reached to critical radius of failure surface $\boldsymbol{r}_{\boldsymbol{h}}$.

$r_{c r}=r_{h}$.

(7) Calculate the punching shear capacity $\mathrm{P}$.

$$
\begin{aligned}
& \varphi=37^{\circ} \\
& k=\frac{1+\sin \varphi}{1-\sin \varphi} \\
& L=1-2 \frac{f_{t}}{f_{c}^{\prime}} \frac{\sin \varphi}{1-\sin \varphi}=1-\frac{f_{t}}{f_{c}^{\prime}}(k-1) \\
& M=1-2 \frac{f_{t}}{f_{c}^{\prime}} \frac{1}{1-\sin \varphi}=1-\frac{f_{t}}{f_{c}^{\prime}}(k+1)
\end{aligned}
$$

Calculate $\alpha_{0}$ and limited $r_{h}$

$$
\begin{aligned}
& \alpha_{0}=\tan ^{-1}(A \pi(B-C)) \\
& \text { limited } r_{h}=\frac{8 A \Delta(1+\cosh (A \pi h))+3 \sinh (A \pi h)}{4 A \pi}
\end{aligned}
$$

Check if $\alpha_{0} \geq 37^{\circ}$ and $r_{h} \leq$ llimited $r_{h}$ 
(a) If $\alpha_{0} \geq 37^{\circ}, r_{h} \leq$ limited $r_{h}$, the shape of failure surface is a catenary curve.

$$
\begin{aligned}
r_{0}^{\prime}= & A \pi(B-C) \\
r_{h}^{\prime}= & A \pi\left(B e^{A \pi h}-C e^{-A \pi h}\right) \\
P= & \frac{f_{c}^{\prime}}{2 A^{2} \pi}-\left(L \left(\left(\sinh ^{-1}\left(r_{h}^{\prime}\right)+r_{h}{ }^{\prime} \sqrt{1+\left(r_{h}^{\prime}\right)^{2}}\right)\right.\right. \\
& \left.\left.-\left(\sinh ^{-1}\left(r_{0}^{\prime}\right)+r_{0}{ }^{\prime} \sqrt{1+\left(r_{0}{ }^{\prime}\right)^{2}}\right)\right)-M\left(\left(r_{h}^{\prime}\right)^{2}-\left(r_{0}^{\prime}\right)^{2}\right)\right)
\end{aligned}
$$

(b) If $\alpha_{0}<37^{\circ}, r_{h}>$ limited $r_{h}$, the shape of failure surface is a combination of a straight line and a curve.

(i) Assume $h_{0}\left(0<h_{0} \leq \mathrm{h}\right)$

(ii) Calculate $h_{0}$.

$$
h_{0}=\frac{4}{3}\left(-\frac{2 \Delta}{\pi}+\left(\frac{2 \Delta}{\pi}-C\right) e^{A \pi h_{0}}+C e^{-A \pi h_{0}}\right)
$$

Check if $r_{h o}=h_{0} \tan 37^{\circ}$.

(iii) If not O.K, repeat step (i).

(iv) If O.K,

Calculate new values of $\mathbf{A}, \mathrm{B}$ and $\mathrm{C}$

$$
\begin{aligned}
C= & \frac{-8 \Delta\left(-1+e^{A \pi h_{0}}\right)+3 \pi h_{0}}{4 \pi\left(e^{-A \pi h_{0}}-e^{A \pi h_{0}}\right)} \\
B= & \frac{2 \Delta}{\pi}-C \\
A= & \frac{1}{2 \pi \sqrt{B C}} \\
P_{L}= & \frac{1}{32}(5 L-3 M) f_{c}^{\prime} h_{0}\left(16 \Delta+3 \pi h_{0}\right) \\
P_{C}= & \frac{f_{c}^{\prime}}{2 A^{2} \pi}\left(L \left(\left(\sinh ^{-1}\left(r_{h}^{\prime}\right)+r_{h}^{\prime} \sqrt{1+\left(r_{h}^{\prime}\right)^{2}}\right)\right.\right. \\
& \left.\left.-\left(\sinh ^{-1}\left(r_{h 0}{ }^{\prime}\right)+r_{h 0}{ }^{\prime} \sqrt{1+\left(r_{h 0}{ }^{\prime}\right)^{2}}\right)\right)-M\left(\left(r_{h}^{\prime}\right)^{2}-\left(r_{0}^{\prime}\right)^{2}\right)\right)
\end{aligned}
$$

$$
P=P_{L}+P_{C}
$$


When the slab-column connection without opening has shear reinforcement, the program continues as follows.

\section{(II) Punching shear capacity of slab-column connection without opening and} with shear reinforcement, $P_{S}$.

From the above step (1) to (7), the minimum punching shear capacity of slabcolumn connection without opening and without shear reinforcement, $\mathrm{P}$, and its radius of failure surface are known. Constants $\mathrm{A}, \mathrm{B}$ and $\mathrm{C}$ for radius of failure surface, L, M, $\alpha_{0}, r_{0}^{\prime}$ and $r_{h}^{\prime}$ are also known. Here, the type of shear reinforcement used is shear stud (SSR).

(a) Input total number of SSR, A, per one stud, and yield strength of $\operatorname{SSR} f_{s y}$.

(b) Calculate $A_{s}, A_{f}, f_{t}, \rho_{s}$ and $\alpha_{\text {avg }}$

$A_{S}=$ number of SSR $\times A_{s}$ per one stud

$$
\begin{aligned}
A_{f}= & \frac{2}{A^{2} \pi}\left(-\sinh ^{-1}\left(r^{\prime}(0)\right)-r^{\prime}(0) \sqrt{1+\left(r^{\prime}(0)\right)^{2}}\right. \\
& \left.+\sinh ^{-1}\left(r^{\prime}(h)\right)+r^{\prime}(0) \sqrt{1+\left(r^{\prime}(h)\right)^{2}}\right) \\
\rho_{s}= & \frac{A_{s}}{A_{f}} \\
\alpha_{\text {avg }}= & \tan ^{-1}\left(\frac{1}{2} A \pi e^{A h \pi}\left(1+e^{A h \pi}\right)\left(-C+B e^{A h \pi}\right)\right) \\
f_{t}= & \rho_{s} f_{s y} \sin \alpha_{\text {avg }}
\end{aligned}
$$

(c) Calculate $P_{S}$.

(i) If the failure surface is a curve or $\alpha_{0} \geq 37^{\circ}$,

$$
\begin{aligned}
& P_{S}=\frac{f_{c}^{\prime}}{2 A^{2} \pi}\left(L\left(\left(\sinh ^{-1}\left(r_{h}^{\prime}\right)+r_{h}{ }^{\prime} \sqrt{1+\left(r_{h}^{\prime}\right)^{2}}\right)-\left(\sinh ^{-1}\left(r_{0}^{\prime}\right)+r_{0}{ }^{\prime} \sqrt{1+\left(r_{0}^{\prime}\right)^{2}}\right)\right)\right. \\
& \left.\quad-M\left(\left(r_{h}^{\prime}\right)^{2}-\left(r_{0}^{\prime}\right)^{2}\right)\right)
\end{aligned}
$$

(ii) If the failure surface is a combination of a straight line and a curve,

$$
\begin{aligned}
& \text { or } \alpha_{0}<37^{\circ}, \\
& P_{L S}=\frac{1}{32}(5 L-3 M) f_{c}^{\prime} h_{0}\left(16 \Delta+3 \pi h_{0}\right)
\end{aligned}
$$




$$
\begin{aligned}
P_{C S}= & \frac{f_{c}^{\prime}}{2 A^{2} \pi} \cdot\left(L \left(\left(\sinh ^{-1}\left(r_{h}{ }^{\prime}\right)+r_{h}{ }^{\prime} \sqrt{1+\left(r_{h}{ }^{\prime}\right)^{2}}\right)\right.\right. \\
& \left.\left.-\left(\sinh ^{-1}\left(r_{h 0}{ }^{\prime}\right)+r_{h 0}{ }^{\prime} \sqrt{1+\left(r_{h 0}{ }^{\prime}\right)^{2}}\right)\right)-M\left(\left(r_{h}{ }^{\prime}\right)^{2}-\left(r_{0}^{\prime}\right)^{2}\right)\right) \\
P_{S}= & P_{L S}+P_{C S}
\end{aligned}
$$

For the slab-column connection with opening and without shear reinforcement, the program continues as follows:

(III) Punching shear capacity of slab-column connection with opening and without shear reinforcement, $P_{o p}$.

From the above step (1) to (7), the minimum punching shear capacity of slabcolumn connection without opening and without shear reinforcement, $\mathrm{P}$, and its radius of failure surface are known. Constants A, B and C for radius of failure surface, $\mathrm{L}, \mathrm{M}, r_{0}^{\prime}$ and $r_{h}^{\prime}$ are also known.

(a) Input description defined based on opening location and column shape: square or rectangular, dimensions of opening parallel to shorter column width $\mathrm{O}_{\mathrm{c} 1}$, longer column width $\mathrm{O}_{\mathrm{c} 2}$.

Descriptions of opening location are (i) " 1 " for slab-column specimen with square column, without opening and without SSR, (ii) "2" for slab-column specimen with square column, without opening and with SSR, (iii) "3" for slab-column specimen with rectangular column, without opening and without SSR, (iv) "4" for slab-column specimen with rectangular column, without opening and with SSR, (v) "5" for slab-column specimen with rectangular column, with opening and without SSR, and (vi) "6" for slabcolumn specimen with rectangular column, with opening and with SSR.

(b) Calculate $\eta_{1}$ and $\eta_{2}$ related to location of opening. The $\eta_{1}$ and $\eta_{2}$ terms related to for five kinds of opening locations considered in this study are presented in section 5.5.2.1.

(c) Calculate $P_{o p}$.

$$
\bar{P}_{o p}=\frac{f_{c}{ }^{\prime}}{2}\left(\eta_{1} P_{\eta_{1}}+\eta_{2} P_{\eta_{2}}\right)
$$




$$
\begin{aligned}
P_{\eta_{1}}= & \frac{1}{A \pi}\left(L\left(r_{h}{ }^{\prime}-r_{0}{ }^{\prime}\right)+M\left(-\sqrt{1+\left(r_{h}{ }^{\prime}\right)^{2}}+\sqrt{1+\left(r_{0}\right)^{2}}\right)\right) \\
P_{\eta_{2}}= & \frac{1}{2 A^{2} \pi^{2}}\left(L \left(\sin ^{-1}\left(r_{h}^{\prime}\right)-\sin ^{-1}\left(r_{0}^{\prime}\right)+r_{h}^{\prime} \sqrt{1+\left(r_{h}{ }^{\prime}\right)^{2}}-r_{0}{ }^{\prime} \sqrt{1+\left(r_{0}{ }^{\prime}\right)^{2}}\right.\right. \\
& \left.+4 A \Delta\left(r_{0}{ }^{\prime}-r_{h}{ }^{\prime}\right)\right) \\
P_{o p} & =P-\bar{P}_{o p}
\end{aligned}
$$

Note that the formulae in this step (III) for punching shear capacity of slabcolumn connection lost due to opening $\bar{P}_{o p}$, are only for that when the shape of failure surface is a catenary curve. When the loaded area or column section area is not a point, the shape of failure surface is usually in catenary curve.

For the slab-column connection with opening and shear reinforcement, the program continues as the following.

(IV) Punching shear capacity of slab-column connection with opening and shear reinforcement, $P_{o p+s}$

From the above step (1) to (7), the minimum punching shear capacity of slabcolumn connection without opening and without shear reinforcement, $\mathrm{P}$, and its radius of failure surface are known. Constants $\mathrm{A}, \mathrm{B}$ and $\mathrm{C}$ for radius of failure surface, $\mathrm{L}, \mathrm{M}, \alpha_{\mathrm{avg}} r_{0}^{\prime}$ and $r_{h}^{\prime}$ are also known. And from step (II(b)), $\mathrm{A}_{\mathrm{s}}$ has been known. And then, from the step (III(c)), the punching shear capacity of slabcolumn connection lost due to opening $\bar{P}_{o p}$ has been known. When the slabcolumn connection has opening and shear reinforcement, the procedure is:

(a) Calculate $\bar{A}_{f}, f_{t}$ and $\bar{\rho}_{s}$.

$$
\begin{aligned}
\bar{A}_{f} & =\frac{1}{2 A^{2} \pi^{2}}\left(2 A \eta_{1}^{\prime}\left(-r^{\prime}(0)+r^{\prime}(h)\right)+\eta_{2}^{\prime}\left(-\sinh ^{-1}\left(r^{\prime}(0)\right)+\sinh ^{-1}\left(r^{\prime}(h)\right)\right.\right. \\
& \left.\left.+4 A \Delta r^{\prime}(0)-r^{\prime}(0) \sqrt{1+\left(r^{\prime}(0)\right)^{2}}-4 A \Delta r^{\prime}(h)+r^{\prime}(h) \sqrt{1+\left(r^{\prime}(h)\right)^{2}}\right)\right)
\end{aligned}
$$

$$
\bar{\rho}_{s}=\frac{A_{s}}{\bar{A}_{f}}
$$




$$
f_{i}=\rho_{s} f_{s y} \sin \alpha_{a v g}
$$

(c) calculate $\bar{P}_{S}$.

(i) If the failure surface is a curve or the initial slope of failure surface $\alpha_{0}$ is equal or greater than $37^{\circ}$,

$$
\begin{aligned}
\bar{P}_{S}= & \frac{f_{c}{ }^{\prime}}{2 A^{2} \pi}\left(L\left(\left(\sinh ^{-1}\left(r_{h}{ }^{\prime}\right)+r_{h}{ }^{\prime} \sqrt{1+\left(r_{h}{ }^{\prime}\right)^{2}}\right)-\left(\sinh ^{-1}\left(r_{0}{ }^{\prime}\right)+r_{0}{ }^{\prime} \sqrt{1+\left(r_{0}{ }^{\prime}\right)^{2}}\right)\right)\right. \\
& \left.-M\left(\left(r_{h}{ }^{\prime}\right)^{2}-\left(r_{0}{ }^{\prime}\right)^{2}\right)\right)
\end{aligned}
$$

(ii) If the failure surface is a combination of a straight line and a curve, or the initial slope of failure surface $\alpha_{0}$ is less than $37^{\circ}$,

$$
\begin{aligned}
\bar{P}_{L S}= & \frac{1}{32}(5 L-3 M) f_{c}^{\prime} h_{0}\left(16 \Delta+3 \pi h_{0}\right) \\
\bar{P}_{C S}= & \frac{f_{c}{ }^{\prime}}{2 A^{2} \pi}\left(L \left(\left(\sinh ^{-1}\left(r_{h}{ }^{\prime}\right)+r_{h}{ }^{\prime} \sqrt{1+\left(r_{h}{ }^{\prime}\right)^{2}}\right)\right.\right. \\
& \left.\left.-\left(\sinh ^{-1}\left(r_{h 0}{ }^{\prime}\right)+r_{h 0}{ }^{\prime} \sqrt{1+\left(r_{h 0}{ }^{\prime}\right.}\right)\right)-M\left(\left(r_{h}^{\prime}\right)^{2}-\left(r_{0}^{\prime}\right)^{2}\right)\right)
\end{aligned}
$$

$$
\begin{aligned}
& \bar{P}_{S}=\bar{P}_{L S}+\bar{P}_{C S} \\
& P_{o p+S}=\bar{P}_{S}-\bar{P}_{o p}
\end{aligned}
$$

Using the procedure described above, the punching shear capacities for slab-column connections with square or rectangular column shape, with or without opening and with or without shear reinforcement, which are selected from the literatures and experimental program presented in chapter three, are calculated and, the results and discussions are presented in the next chapter. 
To make easier to follow the above procedure, the following flow charts are prepared.

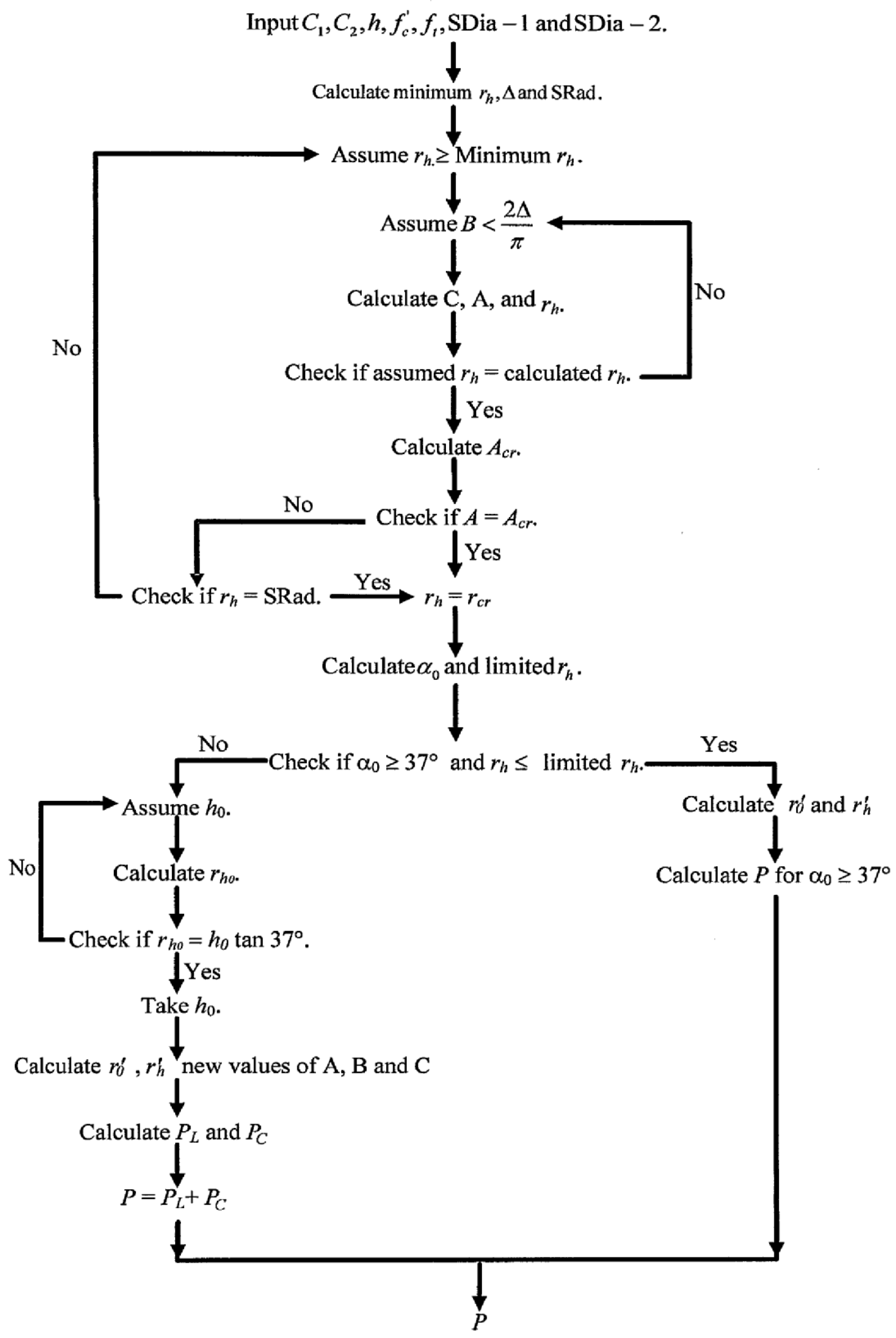

Figure 5.30 Flow chart for calculation of punching shear capacity of slabcolumn connections without opening and without shear reinforcement 
Known values: Minimum P (without opening and without shear reinforcement),

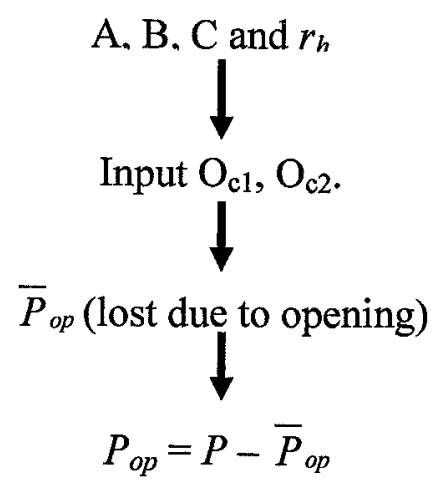

Figure 5.31 Flow chart for calculation of punching shear capacity of slabcolumn connections with opening and without shear reinforcement

Known values: Minimum $\mathrm{P}$ (without opening and without shear reinforcement),

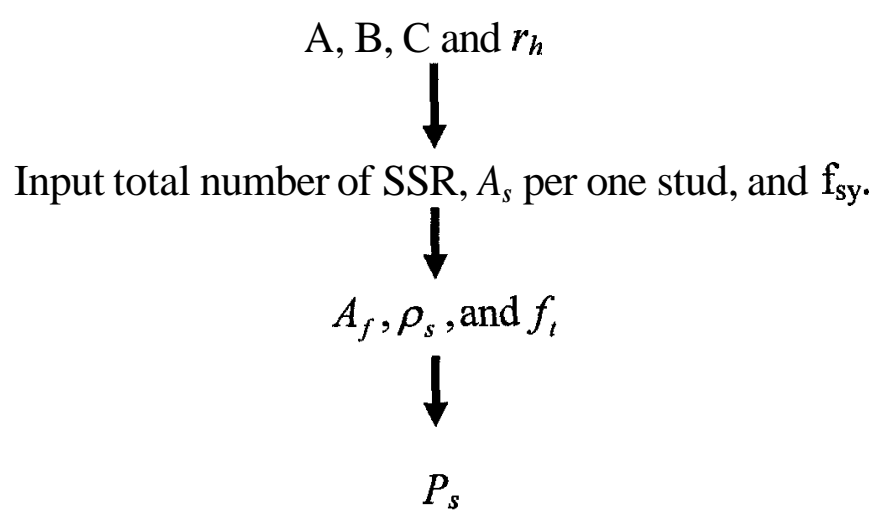

Figure 5.32 Flow chart for calculation of punching shear capacity of slabcolumn connections without opening and with shear reinforcement

Known values: Minimum $\boldsymbol{P}$ (without opening and without shear reinforcement),

$$
\bar{P}_{o p} \text { (lost due to opening), }
$$

Input total number of SSR, $A_{s}$ per one stud, and $\mathrm{f}_{\text {sy. }}$

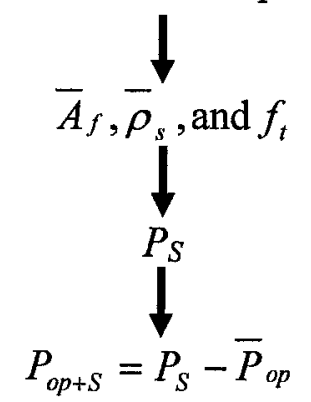

Figure 5.33 Flow chart for calculation of punching shear capacity of slabcolumn connections with opening and shear reinforcement 
CHAPTER 6

RESULTS AND DISCUSSION ON PUNCHING SHEAR CAPACITY OF SLAB-COLUMN CONNECTION BY THEORY OF PLASTICITY 


\section{Chapter 6}

\section{Results and discussions on punching}

\section{shear capacity of slab-column connections by theory of plasticity}

\subsection{Introduction}

The formula of upper bound solution for punching shear capacity of slab-column connections with square and rectangular columns, with or without shear reinforcement, and with or without opening positioned adjacent to a column have been derived based on theory of plasticity in the previous chapter.

In the plasticity solutions, the softening effect of concrete on the compressive and tensile strength of concrete will significantly influence the accuracy of the predicted punching shear capacity. In considering the softening effect of concrete on the compressive strength of concrete, a so-called softening effect of concrete - the effectiveness factor on the cylinder or cube compressive strength of concrete can be used. Various effectiveness factors on the compressive strength of concrete related to the plasticity models have been proposed in the literature.

However, the effectiveness factors previously proposed for plasticity models in the literature are only for predicting the punching shear capacity of circular slab-column connections. Thus, for the plasticity model described in chapter five, there is a need to propose an effectiveness factor on the compressive strength of concrete. The punching shear capacity of slab by the proposed plasticity model depends on compressive and tensile strength of concrete, slab thickness and column width. Depending on these factors, a new effectiveness factor on the compressive strength of concrete for the proposed plasticity model will be recommended in the next section. 
Concrete is weak in tension and no tensile strength will be assumed when concrete cracks. Thus, no tensile strength of concrete is assumed for the prediction of punching shear capacity of slab-column connections by the proposed plasticity model.

The tensile strength of the slab can be contributed by the use of shear reinforcement. Although, there are many types of shear reinforcement, due to the advantages of shear stud reinforcement described in chapter two, only shear stud reinforcement (SSR) is considered in verifying the upper-bound punching shear capacity derived in previous chapter. In addition, the plastic solution derived in previous chapter will be used to predict the increase in punching shear capacity due to the presence of SSR. The effectiveness factor on the tensile strength contributed by SSR will also be recommended for the plastic upper bound solution derived in previous chapter.

In this chapter, five locations of openings and two methods to calculate the ineffective area of failure surface due to opening considered in verifying the proposed plasticity model are explained first. Secondly, the effectiveness factor on the compressive strength of concrete is proposed. Thirdly, the effectiveness factor on the tensile strength of slab contributed by SSR to be used for the proposed plasticity model is recommended. Finally, the upper bound punching shear capacity of slab-column connection previously derived will be verified by calculating the punching shear capacity of slab-column connections:

(1) without shear reinforcement

(a) with square column

(b) with rectangular column

(c) with rectangular column and opening

(2) with shear reinforcement

(a) with square column

(b) with rectangular column and with or without opening

The calculated punching shear capacity will be compared with the test results.

After discussions are made on the comparison between the punching shear capacity of slab-column connections predicted by plasticity model and the test results, 
conclusions are drawn. The calculation program prepared by Matlab software is presented in appendix $\mathrm{C}$.

\subsection{Consideration on Openings}

The five locations of opening adjacent to a column are considered. They are (a) opening location at adjacent comer of column (type I), (b) opening location parallel and adjacent to the shorter side of column (type 11), (c) opening location perpendicular and adjacent to the longer side of column end (type 111), (d) opening location parallel and adjacent to the middle of longer side of column (type IV), and (e) opening location perpendicular and adjacent to the shorter side of column (type V). All opening locations are shown in Figure 6.1.

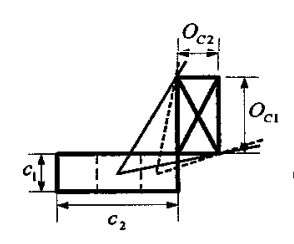

(a) Type I

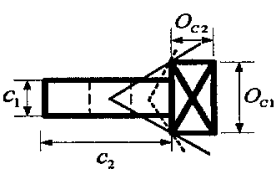

(b) Type II

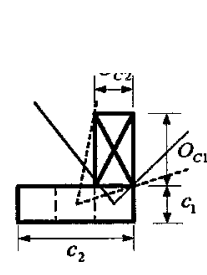

(c) Type III

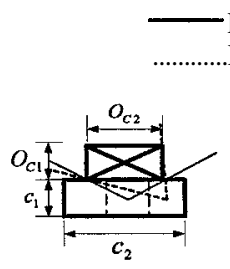

(d) Type IV

Projection lines by method A Projectionlines by method AII

Figure 6.1 Five locations of opening

The ineffective areas of punching shear failure surface due to opening are considered by two methods; AI and AII. Method AI is that the projection lines to confine the ineffective area of failure surface propagate from the center of column section through the two comers of opening and intersect the circumference of failure surface at the tension side of the slab. While method AII is that the projection lines to confine the ineffective of area of failure surface propagate from the center of $1 / 3$ column section area close to the shorter column width nearest to the opening, which is equally divided along the longer column width. The methods to determine the ineffective area of failure surface due to opening were presented in detail in chapter 5 and appendix B. The ineffective area of failure surface due to opening for the opening located adjacent to the shorter column width presented by these two methods are shown in Figure 6.2. For each opening location, the upper bound formula derived previously used to predict the reduction of punching shear capacity due to opening is discussed. 
Depending on the locations of opening, the reduction of punching shear capacity varies.

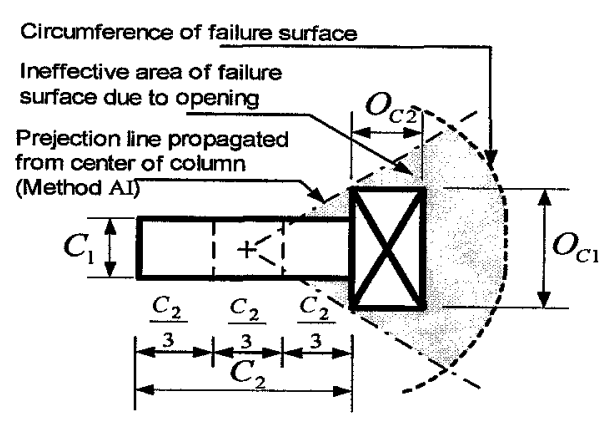

(a) Ineffective area of failure surface by method AI

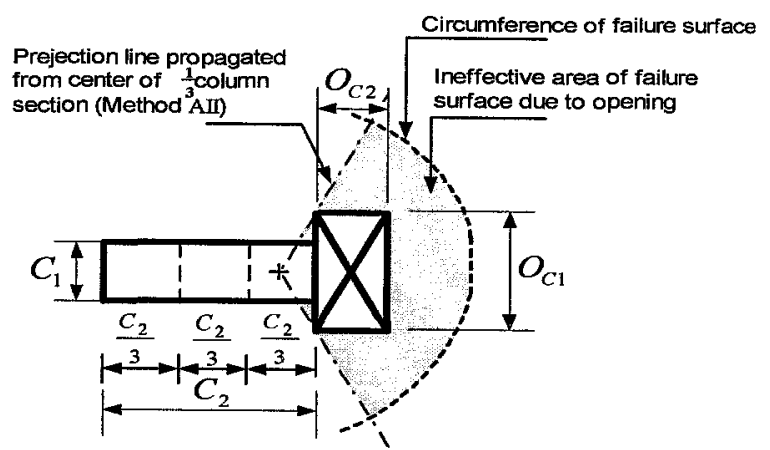

(b) Ineffective area of failure surface by method AII

Figure 6.2 Ineffective area of failure surface due to opening

\subsection{Effectiveness factor on the compressive strength of concrete}

The punching shear capacity of slab-column connections predicted by Equations 5.80, 5.82 and 5.104 depends on the parameters; column width, slab thickness and effective compressive strength of concrete. As the area of column section, aspect ratio of column widths, slab thickness, and effective compressive strength of concrete increase, the punching shear capacity of slab increases. In the calculation of punching shear capacity of slab-column connections by theory of plasticity, the effectiveness factor on the compressive strength of concrete is proposed as:

$$
v_{c}=\frac{0.8}{\sqrt{f_{c}^{\prime}}}\left(10+\ln \left(\frac{1}{h}\right)\right)\left(\frac{C_{2}}{C_{1}}\right)^{-\frac{1}{8}}
$$

where $v_{c} \quad=$ proposed effectiveness factor on compressive strength of concrete

$\boldsymbol{h} \quad=$ slab thickness in $\mathrm{mm}$

$C_{1} \& C_{2}=$ shorter and longer column width, respectively, in $\mathrm{mm}$

$f_{c} \quad=$ cylinder compressive strength of concrete in $\mathrm{MPa}$ 


\subsection{Effectiveness factor on the yield strength of SSR}

The tensile strength of slab contributed by concrete is assumed as zero, while the tensile strength of slab contributed by shear stud reinforcements is considered. In the plasticity model derived in chapter 5, all shear stud reinforcements (SSR) are considered to reach its yield strength when punching failure occurs. In practice, all shear reinforcements do not yield at the failure of slab. Seible et al. (1980) recommended that because of the stress level in the shear reinforcement at failure load did not reach the yield strength in all shear reinforcements, the reduced strength of shear reinforcement should be accounted for in calculating the ultimate strength. Therefore, the effective tensile strength contributed by shear reinforcement should be considered. The effectiveness factor on the tensile strength contributed by SSR for the plastic upper bound solution derived in previous chapter is proposed as

$$
v_{s t}=\frac{1}{12}
$$

where $v_{s t}$ is the effectiveness factor on the tensile strength contributed by SSR.

\subsection{Punching shear capacity of slab-column connections without shear reinforcement}

\subsubsection{With square column}

The punching shear capacity of twelve slab-column specimens with square columns are calculated. All slabs have no opening and no shear reinforcement. They failed in pure punching failure. Details of square slab-column specimens are shown in Table 6.1. The punching shear capacity of square slab-column specimens predicted by theory of plasticity are shown in Table 6.2. Equations 6.1 proposed for effectiveness factor on the compressive strength of concrete is used and the tensile strength of concrete is assumed as zero.

Generally, the upper bound formula derived by theory of plasticity can predict the punching shear capacity quite well compared with test results for slab-column 
connections with square column as shown in Table 6.2. The predicted punching shear capacity for slabs with square column are well within $\pm 15 \%$ of the test results. The proposed effectiveness factor $v_{c}$ on the compressive strength concrete of Equation 6.1 and zero tensile strength of concrete can give acceptable prediction on punching shear capacity of slabs with square column.

Table 6.1 Detail of slab-column specimens with square column

\begin{tabular}{|c|c|c|c|c|c|c|c|c|c|}
\hline Author & Spec. & $\begin{array}{c}\mathrm{C} \\
(\mathrm{mm})\end{array}$ & $\begin{array}{c}\mathrm{h} \\
(\mathrm{mm})\end{array}$ & $\begin{array}{c}\mathrm{d} \\
(\mathrm{mm})\end{array}$ & $\begin{array}{l}\text { SDia } \\
(\mathrm{mm})\end{array}$ & $\begin{array}{c}f_{c}^{\prime} \\
(\mathrm{MPa})\end{array}$ & $\begin{array}{c}f_{f y} \\
(\mathrm{MPa})\end{array}$ & $\begin{array}{l}\rho_{f} \\
(\%)\end{array}$ & $\begin{array}{c}P \\
\text { (test) } \\
(\mathrm{kN})\end{array}$ \\
\hline \multirow{8}{*}{$\begin{array}{c}\text { Marzouk \& } \\
\text { Hussein } \\
(1991)\end{array}$} & HS7 & 150 & 120 & 95 & 1500 & 74 & 490 & 1.193 & 356 \\
\hline & HS3 & 150 & 120 & 95 & 1500 & 69 & 490 & 1.473 & 356 \\
\hline & NS2 & 150 & 150 & 120 & 1500 & 30 & 490 & 0.944 & 396 \\
\hline & HS6 & 150 & 150 & 120 & 1500 & 70 & 490 & 0.944 & 489 \\
\hline & HS9 & 150 & 150 & 120 & 1500 & 74 & 490 & 1.611 & 543 \\
\hline & HS 10 & 150 & 150 & 120 & 1500 & 80 & 490 & 2.333 & 645 \\
\hline & HS14 & 150 & 120 & 95 & 1500 & 72 & 490 & 1.473 & 498 \\
\hline & HS 15 & 220 & 120 & 95 & 1500 & 71 & 490 & 1.473 & 560 \\
\hline $\begin{array}{c}\text { Mokhtar et al. } \\
\text { (1985) }\end{array}$ & $\mathrm{AB} 1$ & 250 & 150 & 132 & 1800 & 36 & 490 & 1.013 & 408 \\
\hline \multirow{3}{*}{ Moe (1961) } & $\mathrm{H} 1$ & 254 & 150 & 114 & 1778 & 26 & 328 & 1.15 & 371 \\
\hline & S2-60 & 254 & 150 & 114 & 1778 & 22 & 399 & 1.53 & 356 \\
\hline & S3-60 & 254 & 150 & 114 & 1778 & 23 & 399 & 2.3 & 364 \\
\hline
\end{tabular}

C = column width

$\mathrm{h} \& \mathrm{~d}=$ thickness and effective depth of slab, respectively

SDia = distance between supports of slab

$f_{c}^{\prime} \& f_{f y}=$ cylinder compressive strength of concrete and flexural steel yield strength, respectively

$\rho_{f} \quad=$ flexural steel ratio

$\mathrm{P}$ (test) = test result of punching shear capacity of slab-column specimen 
The punching shear capacity decreases with increasing radius of failure surface. The smaller the support radius of slab, the more the punching shear capacity of slab increases. This is due to the facts that (1) when the area of failure surface is larger, the shear stress and normal stresses on this failure surface become smaller, and (2) when the radius of failure surface is larger, the vertical component of stress on the failure surface becomes smaller. The radius of failure surface at which the punching shear capacity of slab converges to minimum is usually beyond the support radius. This means that the failure surface always extend all the way to the support. Therefore, the critical radius of failure surface at which the punching shear capacity converges to minimum is finally set less than or equal to support radius which is a distance from column face to support.

Table 6.2 Punching shear capacity predicted by theory of plasticity for slab column specimens with square column

\begin{tabular}{|c|c|c|c|c|c|c|c|c|}
\hline No & Spec. & $\begin{array}{c}f_{c}^{\prime} \\
(\mathrm{MPa})\end{array}$ & $\begin{array}{c}\mathrm{C} \\
(\mathrm{mm})\end{array}$ & $\begin{array}{c}\mathrm{h} \\
(\mathrm{mm})\end{array}$ & $\frac{\mathrm{R}_{\mathrm{CR}}}{\mathrm{h}}$ & $\frac{\text { SRad }}{h}$ & $\begin{array}{c}P(\text { Pred }) \\
(\mathrm{kN})\end{array}$ & $\frac{P(\text { Pred })}{P \text { (Test) }}$ \\
\hline 1 & HS7 & 74 & 150 & 120 & 5.60 & 5.63 & 355.80 & 1.00 \\
\hline 2 & HS3 & 69 & 150 & 120 & 5.60 & 5.63 & 343.57 & 0.97 \\
\hline 3 & NS2 & 30 & 150 & 150 & 4.50 & 4.50 & 334.48 & 0.84 \\
\hline 4 & HS6 & 70 & 150 & 150 & 4.50 & 4.50 & 510.93 & 1.04 \\
\hline 5 & HS9 & 74 & 150 & 150 & 4.50 & 4.50 & 525.33 & 0.97 \\
\hline 6 & HS10 & 80 & 150 & 150 & 4.50 & 4.50 & 546.21 & 0.85 \\
\hline 7 & HS14 & 72 & 150 & 120 & 5.33 & 5.33 & 422.66 & 0.85 \\
\hline 8 & HS15 & 71 & 220 & 120 & 5.00 & 5.00 & 503.45 & 0.90 \\
\hline 9 & $\mathrm{AB} 1$ & 36 & 250 & 150 & 5.15 & 5.17 & 434.54 & 1.07 \\
\hline 10 & H1 & 26 & 254 & 150 & 5.08 & 5.08 & 374.20 & 1.01 \\
\hline 11 & S2-60 & 22 & 254 & 150 & 5.08 & 5.08 & 344.21 & 0.97 \\
\hline 12 & S3-60 & 23 & 254 & 150 & 5.08 & 5.08 & 351.95 & 0.97 \\
\hline & & & & & & & Mean & 0.95 \\
\hline & & & & & & Stanc & deviation & 0.08 \\
\hline & & & & & & & $\mathrm{COV}$ & 0.08 \\
\hline SRad & \multicolumn{8}{|c|}{$=$ support radius of slab } \\
\hline $\mathrm{R}_{\mathrm{CR}}$ & \multicolumn{8}{|c|}{$\begin{aligned}= & \text { critical radius of failure surface at which the punching shear capacity of slab is } \\
& \text { minimum }\end{aligned}$} \\
\hline
\end{tabular}




\subsubsection{With rectangular column}

The punching shear capacity of twelve slab-column specimens with rectangular column are calculated. All slabs have no opening and no shear reinforcement. All slabs failed in pure punching. Detail of selected rectangular slab-column specimens are shown in Table 6.3.

The punching shear capacity for the selected slab-column specimens predicted by plasticity model are shown in Table 6.4. The effectiveness factor for compressive strength of concrete of Equation 6.1 is used and tensile strength of concrete is taken as zero.

From Table 6.4, it can be seen that the punching shear capacity of slab increases as the aspect ratio of longer to shorter column width and slab thickness increase and as in the case of slab-column specimens with square column, the critical radii of failure surface that give the minimum punching shear capacity of slab-column specimens are equal to the support radii of slab. Table 6.4 shows that the ratio of the predicted punching shear capacity and test results for slabs with rectangular column falls well within $\pm 13 \%$. It indicates that the proposed plasticity model with proposed effectiveness factor on the compressive strength of concrete of Equation 6.1 and consideration of zero tensile strength of concrete can give the acceptable results on the punching shear capacity of rectangular slab-column connections. 


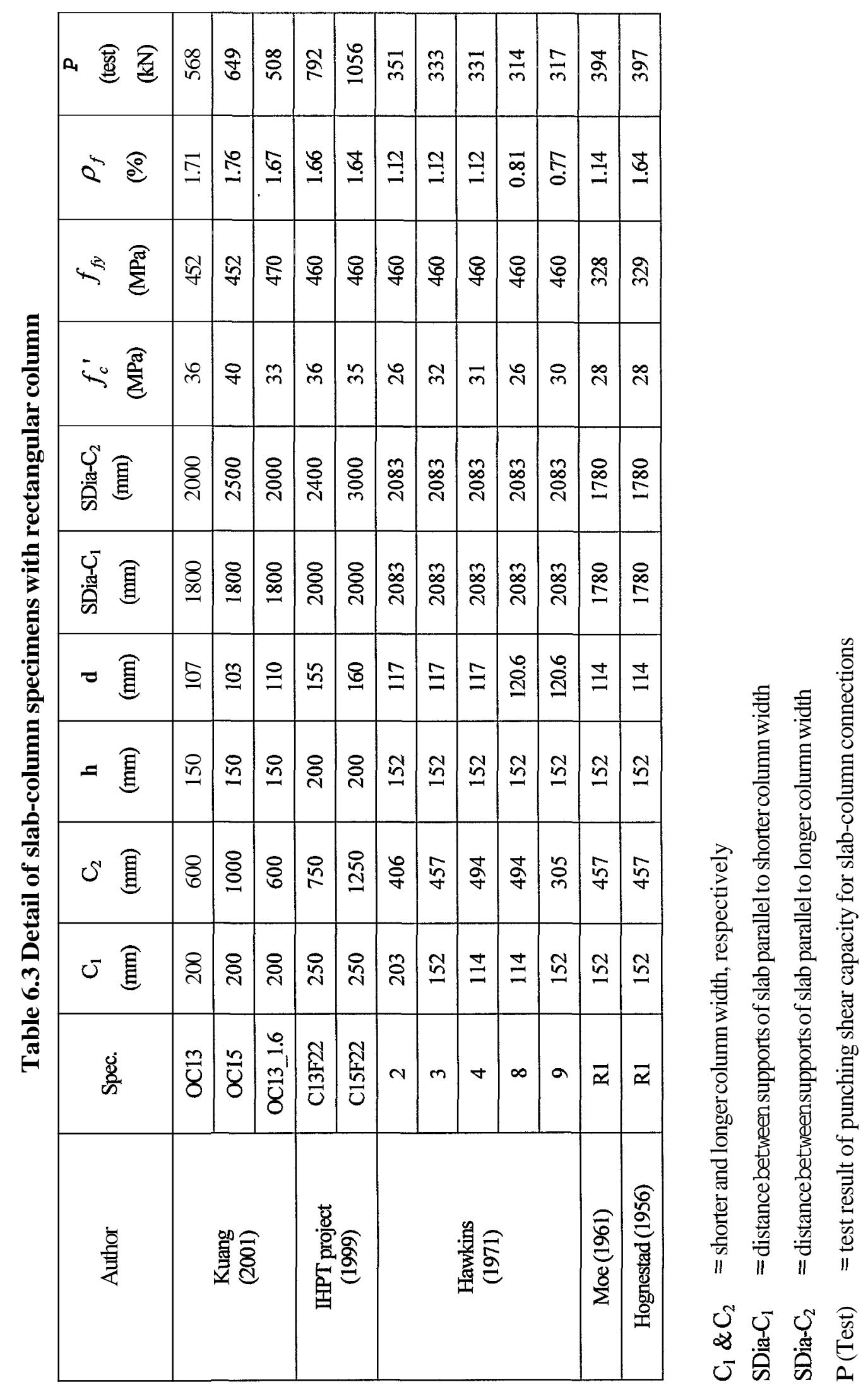


Table 6.4 Upper bound solution of punching shear capacity by plasticity model for slah-colımn snecimens with rectanoular colımn

\begin{tabular}{|c|c|c|c|c|c|c|c|c|}
\hline Spec. & $\frac{C_{2}}{C_{1}}$ & $\begin{array}{c}\mathrm{h} \\
(\mathrm{mm})\end{array}$ & $\begin{array}{c}f_{c}^{\prime} \\
(\mathrm{MPa})\end{array}$ & $\frac{\mathbf{R}_{\mathrm{CR}}}{\mathrm{h}}$ & $\frac{\text { SRad }}{h}$ & $\begin{array}{c}P(\text { Pred }) \\
(\mathrm{kN})\end{array}$ & $\begin{array}{c}P \text { (test) } \\
(\mathrm{kN})\end{array}$ & $\frac{P(\text { Pred })}{P(\text { Test })}$ \\
\hline $\mathrm{OC} 13$ & 3.00 & 150 & 36 & 5.00 & 5.00 & 482.86 & 568 & 0.85 \\
\hline OC15 & 5.00 & 150 & 40 & 5.17 & 5.17 & 587.37 & 649 & 0.91 \\
\hline OC13_1.6 & 3.00 & 150 & 33 & 5.00 & 5.00 & 462.16 & 508 & 0.91 \\
\hline $\mathrm{C} 13 \mathrm{~F} 22$ & 3.00 & 200 & 36 & 4.25 & 4.25 & 843.87 & 792 & 1.07 \\
\hline $\mathrm{C} 15 \mathrm{~F} 22$ & 5.00 & 200 & 35 & 4.38 & 4.38 & 978.02 & 1056 & 0.93 \\
\hline 2 & 2.00 & 152 & 26 & 5.85 & 5.85 & 359.01 & 351 & 1.02 \\
\hline 3 & 3.01 & 152 & 32 & 5.85 & 5.85 & 376.51 & 333 & 1.13 \\
\hline 4 & 4.33 & 152 & 31 & 5.82 & 5.84 & 355.4 & 331 & 1.07 \\
\hline 8 & 4.33 & 152 & 26 & 5.82 & 5.84 & 326.63 & 314 & 1.04 \\
\hline 9 & 2.01 & 152 & 30 & 6.10 & 6.10 & 329.58 & 317 & 1.04 \\
\hline R1 & 3.00 & 152 & 28 & 4.84 & 4.84 & 382.32 & 394 & 0.97 \\
\hline R1 & 3.00 & 152 & 28 & 4.84 & 4.84 & 382.32 & 397 & 0.96 \\
\hline
\end{tabular}

SRad = support radius of slab

SRad =support radius of slab averaging in two directions parallel to shorter and longer column width

$=\frac{1}{2}\left(\left(\frac{S D i a_{-} C_{1}-C_{1}}{2}\right)+\left(\frac{S D i a_{-} C_{2}-C_{2}}{2}\right)\right)$

$\mathrm{P}($ Pred $)=$ predicted punching shear capacity of slab-column connections by plasticity model

$\mathrm{P}($ Test $) \quad=$ test result of punching shear capacity of slab-column connections

\subsubsection{With rectangular column and opening}

Twelve slab-column specimens with rectangular column and with various locations of openings near the column stubs are considered. All slab specimens have no shear reinforcement. All slab-column specimens failed in punching. Details of the specimens used are shown in Table 6.5. For the specimens ended with 1.6, the ratio of bending moments in two perpendicular directions of the slab is 1.6 while for other specimens, the bending moments in two perpendicular directions of slab is the same. 
There are five kinds of opening location near the column stubs as shown by figures in Table 6.6. The opening dimensions in all slab specimens are $200 \mathrm{~mm}$ x $400 \mathrm{~mm}$. For specimens started with OC13, the slab dimensions between supports are $1800 \mathrm{~mm}$ and $2000 \mathrm{~mm}$ parallel to shorter and longer column widths, respectively. For specimens started with OC15, the slab dimensions between supports are $1800 \mathrm{~mm}$ and $2500 \mathrm{~mm}$ parallel to shorter and longer column widths, respectively. For A1 and B1 specimens, the slab dimensions between supports are $2000 \mathrm{~m} \mathrm{~m}$ and $3000 \mathrm{~mm}$ parallel to shorter column and longer column widths, respectively.

Table 6.5 Details of slab-column connections with rectangular column and

\begin{tabular}{|c|c|c|c|c|c|c|c|c|c|}
\hline Author & Spec. & $\begin{array}{c}\mathrm{C}_{1} \\
(\mathrm{~mm})\end{array}$ & $\begin{array}{c}\mathrm{C}_{2} \\
(\mathrm{~mm})\end{array}$ & $\begin{array}{c}\mathrm{h} \\
(\mathrm{mm})\end{array}$ & $\begin{array}{c}\mathrm{d} \\
(\mathrm{mm})\end{array}$ & $\begin{array}{c}f_{c}^{\prime} \\
\text { (Map) }\end{array}$ & $\begin{array}{c}f_{f y} \\
\text { (Map) }\end{array}$ & $\begin{array}{l}\rho_{f} \\
(\%)\end{array}$ & $\begin{array}{c}P \text { (test) } \\
(\mathrm{kN})\end{array}$ \\
\hline \multirow{10}{*}{$\begin{array}{l}\text { Kuang } \\
\text { (2001) }\end{array}$} & OC13H50 & 200 & 600 & 150 & 109.5 & 36.29 & 452.48 & 1.67 & 443 \\
\hline & OC13V43 & 200 & 600 & 150 & 113.5 & 36.62 & 452.48 & 1.76 & 467 \\
\hline & OC13V23 & 200 & 600 & 150 & 108 & 36.94 & 452.48 & 1.70 & 484 \\
\hline & OC13V40 & 200 & 600 & 150 & 108.5 & 43.03 & 452.48 & 1.69 & 340 \\
\hline & OC13H50_1.6 & 200 & 600 & 150 & 114.5 & 33.09 & 470.23 & 1.60 & 428 \\
\hline & OC13V43_1.6 & 200 & 600 & 150 & 111 & 33.21 & 470.23 & 1.65 & 383 \\
\hline & $\mathrm{OC} 13 \mathrm{H} 02 \_1.6$ & 200 & 600 & 150 & 113.5 & 37.53 & 470.23 & 1.61 & 420 \\
\hline & OC13H02 & 200 & 600 & 150 & 111.75 & 43.09 & 452.48 & 1.12 & 512 \\
\hline & OC15V43 & 200 & 1000 & 150 & 109 & 35.97 & 470.23 & 1.66 & 612 \\
\hline & OC15H70 & 200 & 1000 & 150 & 108.25 & 37.89 & 470.23 & 1.67 & 529 \\
\hline \multirow{2}{*}{$\begin{array}{l}\text { NTU- } \\
\text { BCA } \\
\text { Project } \\
(2001)\end{array}$} & $\mathrm{Al}$ & 250 & 1000 & 200 & 160 & 38.2 & 540 & 1.65 & 740 \\
\hline & B1 & 250 & 1000 & 200 & 160 & 36.3 & 540 & 1.65 & 580 \\
\hline
\end{tabular}

$\mathrm{C}_{1} \quad$ = longer column width

$\mathrm{C}_{2} \quad$ = shorter column width

When the slab-column connections has opening, the punching shear capacity of slabcolumn connection is considered as the punching shear capacity sustained in the net area of failure surface without the inclusion of the ineffective area of failure surface 
due to opening. The ineffective punching shear failure surface area due to opening is considered by two methods; AIand AII, which were described previously.

Using the proposed effectiveness factor on the compressive strength of concrete from Equation 6.1 and taking the tensile strength of concrete as zero, the punching shear capacities of rectangular slab-column specimens with opening are calculated. The predicted punching shear capacity of slab-column specimens with rectangular column and opening by plasticity model together with its parameters; the compressive strength of concrete, slab thickness, aspect ratio of longer to shorter column width and critical radius of failure surface are shown in Table 6.6 where the terms used are defined as follows:

$\mathrm{P}($ Test $)=$ test result of punching shear capacity of slab-column connection

$\mathrm{P}($ Pred $)=$ predicted punching shear capacity of slab-column connection

$P_{o p} \quad=$ predicted punching shear capacity of slab-column connections with opening

AI = method AI to calculate the ineffective area of failure surface due to opening

AII $=$ method AII to calculate the ineffective area of failure surface due to opening

$\mathrm{R}_{\mathrm{AI}} \quad=$ ratio of punching shear capacity of slab-column specimen from using method AI predicted by plasticity model and the test results

$$
=\frac{P_{o p}}{P(\text { test })}
$$

$\mathrm{R}_{\mathrm{AII}} \quad=$ ratio of punching shear capacity of slab-column specimen from using method AII predicted by plasticity and the test results

$$
=\frac{P_{o p}}{P(\text { test })}
$$




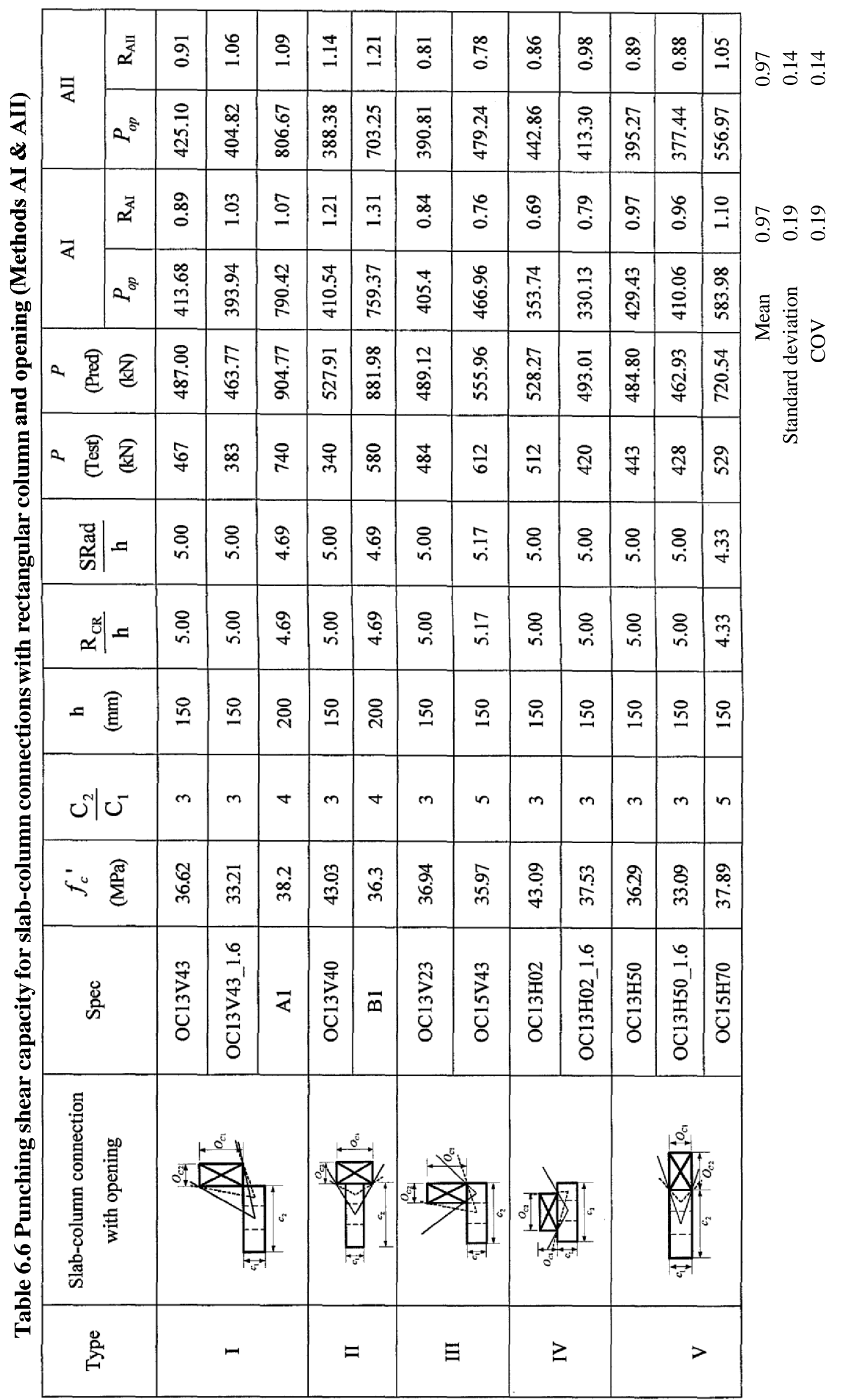


From Table 6.6, it can be seen that generally the punching shear capacities of slabcolumn specimens with rectangular column and opening predicted by theory of plasticity are compatible with the test results. It indicates that the proposed plasticity model with the proposed effectiveness factor on the compressive strength of concrete of Equation 6.1 and taking the tensile strength of concrete as zero is acceptable and reasonable to predict the punching shear capacity of rectangular slab-column connections with opening. In addition, the proposed plasticity model can also predict the punching shear capacity for the rectangular slab-column connections with opening location types I, IV and $\mathrm{V}$ when the ratio of applied bending moments in two perpendicular directions of slab is 1.6 .

Regarding the ineffective area of failure surface due to opening by the two methods; AI and AII,

(1) In opening location type I, the predicted punching shear capacity of slabcolumn specimens falls between $+11 \%$ of the test results. For the specimen OC13V43_1.6, the ratio of bending moments in two perpendicular directions of slab is 1.6. Generally both methods to calculate the ineffective area of failure surface are suitable for this type of opening location as well as for that when the ratio of bending moments in two perpendicular directions of slab is 1.6.

(2) In opening location type II, generally the punching shear capacity of slabcolumn specimens overestimates the test results. This is due to the fact that the estimated ineffective areas of failure surface due to opening by two methods for these specimens are small. The position of opening adjacent and perpendicular to the shorter side of column in specimens OC13V40 and B1 affects the punching shear capacity of the slab most significantly among other opening locations.

(3) In opening location type III, for specimen OC13V23, both methods that determine the ineffective area of failure surface due to opening are just on the acceptable margin in predicting the reduced punching shear capacity of the 
slab due to opening. However, for specimen OC15V43, the punching shear capacity of slab-column specimens underestimates the test results. It indicates that the ineffective area of failure surface due to this type of opening location determined by both methods AI and AII are inconsistently larger as the aspect ratio of longer to shorter column width increases.

(4) In opening location type IV, generally methods AII is reasonably good in predicting the reduced punching shear capacity of slab due to opening while method AI underestimates the reduced punching shear capacity of the slab due to opening. This is due to the fact that the location of opening adjacent to the middle of longer column side does not affect the punching shear capacity of slab very much.

(5) When the opening is located in adjacent and perpendicular to the shorter side of column (opening location type V), the punching shear capacity of slabcolumn specimens with opening are in fairly good agreement with the test results.

(6) Generally, method AII is more reasonable in predicting the ineffective area of failure surface due to opening for all opening location type considered in this study.

The ineffective punching shear capacity $\bar{P}_{o p}$ due to opening by using method AI and AII, and the percentage reduction in predicted punching shear capacity by theory of plasticity are shown in Table 6.7. The percentage reduction in punching shear capacity of slab-column connections due to opening predicted by theory of plasticity and the test results are also compared and shown in Tables 6.8 and 6.9. Because of no control specimens for specimens A1 and B1, no percentage reduction in punching shear capacity of slab-column connections due to opening for these specimens is included in these tables.

Table 6.7 shows that the percentage reduction of predicted punching shear capacity lost due to opening by theory of plasticity using the two methods, for opening location 
type I, II, III and V, the similar observation is that the ineffective punching shear capacity of slab due to opening predicted by theory of plasticity by using method AII is larger than that by using method AI, while for opening location type IV, the ineffective punching shear capacity of slab due to opening predicted by theory of plasticity by using of method AII is less than that by using of method AI.

Table 6.7 Percentage reduction of predicted punching shear capacity due to opening by theory of plasticity using the two methods

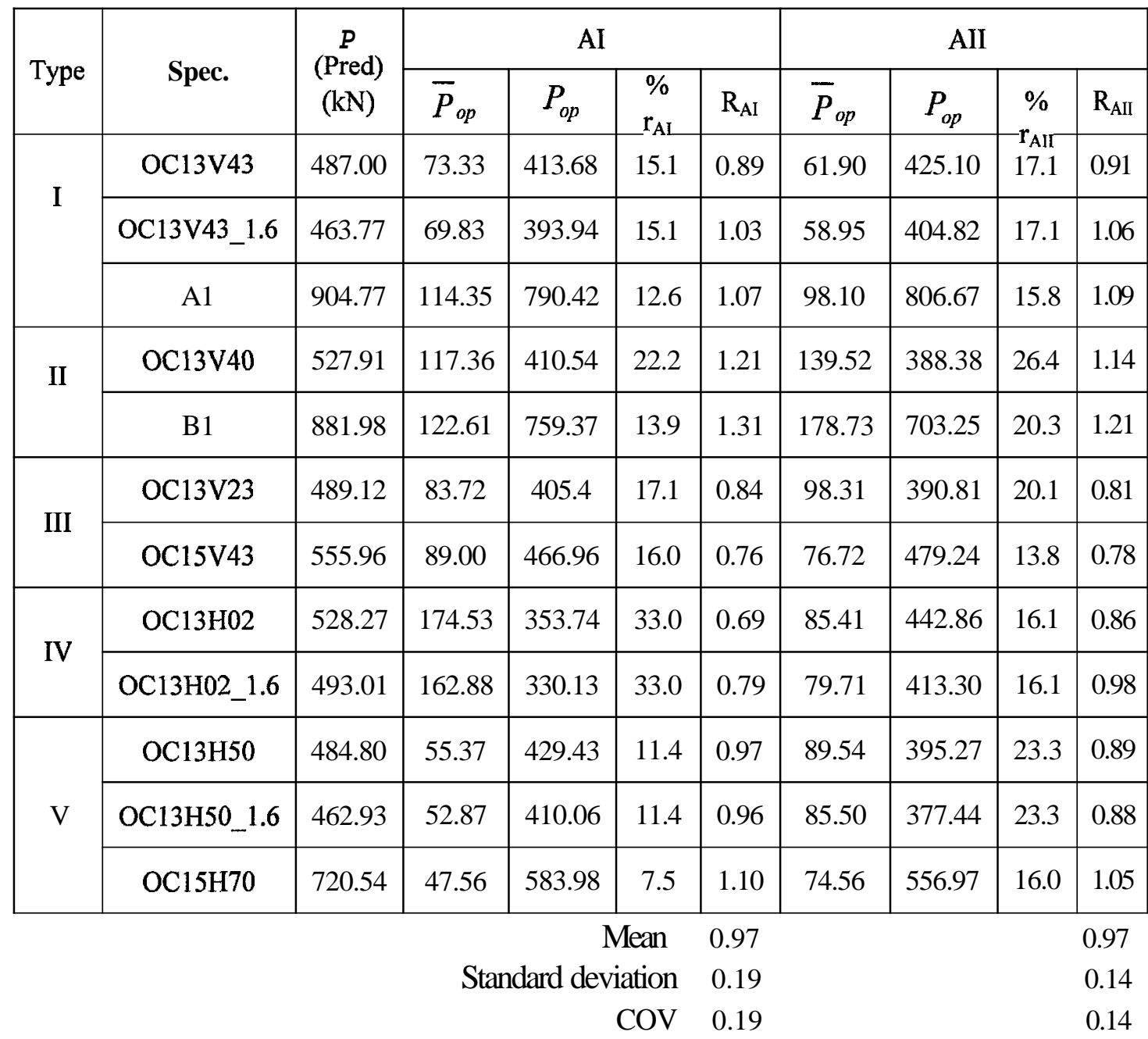

$\bar{P}_{o p} \quad=$ predicted punching shear capacity of slab-column connection lost due to opening

$\% \mathrm{r}_{\mathrm{AI}} \& \% \mathrm{r}_{\mathrm{AII}}=$ percentage reduction in punching shear capacity of slab due to opening by method AI and AII, respectively

$\mathrm{R}_{\mathrm{AI}} \& \mathrm{R}_{\mathrm{AII}} \quad=$ ratios of predicted punching shear capacity by using method AI and AII, to the test results, respectively

As shown in Table 6.8, the punching shear capacity of all specimens predicted by method AI falls within $\pm 24 \%$ of the test results. While Table 6.9 shows that the 
punching shear capacity of all specimens predicted by method AII falls within $\pm 20 \%$ of the test results. In Figure 6.3, the percentage reductions in punching shear capacity of slab-column connections due to opening for five opening location types considered are shown. Figure 6.3 shows that the trend of percentage reductions in punching shear capacity of slab-column connections due to opening for five opening location types is compatible with the trend of percentage reductions observed in the tests. Therefore, it can be concluded that method AII is more reasonable than method AI.

Table 6.8 Comparison in percentage reduction in punching shear capacity for slab-column connections due to opening (method AI)

\begin{tabular}{|c|c|c|c|c|c|c|c|c|}
\hline \multirow{2}{*}{ Type } & \multirow{2}{*}{ Spec: } & \multirow{2}{*}{$\begin{array}{c}P \\
\text { (test) } \\
(\mathrm{kN})\end{array}$} & \multirow{2}{*}{$\begin{array}{c}\% \mathrm{r} \\
\text { (test) }\end{array}$} & \multicolumn{4}{|c|}{ AI } & \multirow{2}{*}{$\begin{array}{l}\text { Difference in \% r } \\
=\% \mathrm{r}_{\mathrm{AI}^{-}} \% \mathrm{r} \text { (test) }\end{array}$} \\
\hline & & & & $P$ & $P_{o p}$ & $\% \mathrm{r}_{\mathrm{AI}}$ & $\mathrm{R}_{\mathrm{AI}}$ & \\
\hline - & $\mathrm{OC} 13$ & 568 & - & - & - & - & - & - \\
\hline - & OC15 & 649 & - & - & - & - & - & - \\
\hline \multirow{3}{*}{ I } & OC13V43 & 467 & 17.8 & 73.33 & 413.68 & 15.1 & 0.89 & -2.7 \\
\hline & OC13V43_1.6 & 383 & 24.6 & 69.83 & 393.94 & 15.1 & 1.03 & -9.5 \\
\hline & $\mathrm{A} 1$ & 740 & - & 114.35 & 790.42 & 12.6 & 1.07 & - \\
\hline \multirow{2}{*}{ II } & OC13V40 & 340 & 40.2 & 117.36 & 410.54 & 22.2 & 1.21 & -18 \\
\hline & B1 & 580 & - & 122.61 & 759.37 & 13.9 & 1.31 & - \\
\hline \multirow{2}{*}{ III } & OC13V23 & 484 & 14.8 & 83.72 & 405.4 & 17.1 & 0.84 & 2.3 \\
\hline & OC15V43 & 612 & 5.7 & 89.00 & 466.96 & 16.0 & 0.76 & 10.3 \\
\hline \multirow{2}{*}{ IV } & $\mathrm{OC} 13 \mathrm{H} 02$ & 512 & 9.9 & 174.53 & 353.74 & 33.0 & 0.69 & 23.1 \\
\hline & OC13H02_1.6 & 420 & 17.3 & 162.88 & 330.13 & 33.0 & 0.79 & 15.7 \\
\hline \multirow{3}{*}{$\mathrm{V}$} & OC13H50 & 443 & 22.0 & 55.37 & 429.43 & 11.4 & 0.97 & -10.6 \\
\hline & OC13H50_1.6 & 428 & 15.8 & 52.87 & 410.06 & 11.4 & 0.96 & -4.4 \\
\hline & $\mathrm{OC} 15 \mathrm{H} 70$ & 529 & 18.5 & 47.56 & 583.98 & 7.5 & 1.10 & -11 \\
\hline & & & & $\mathrm{S}$ & ndard de & $\begin{array}{l}\text { Mean } \\
\text { iation } \\
\mathrm{COV}\end{array}$ & $\begin{array}{l}0.97 \\
0.19 \\
0.19\end{array}$ & \\
\hline
\end{tabular}

OC13 and OC15 are control slab-column specimens without opening. 
Table 6.9 Comparison in percentage reduction of punching shear capacity for slab-column connections due to opening (method AII)

\begin{tabular}{|c|c|c|c|c|c|c|c|c|}
\hline \multirow[b]{2}{*}{ Type } & \multirow[b]{2}{*}{ Spec: } & \multirow{2}{*}{$\begin{array}{c}P \\
\text { (test) } \\
(\mathrm{kN})\end{array}$} & \multirow{2}{*}{$\begin{array}{l}\% \mathrm{r} \\
\text { (test) }\end{array}$} & \multicolumn{4}{|c|}{ AII } & \multirow[b]{2}{*}{$\begin{array}{l}\text { Difference in } \% \mathrm{r} \\
=\% \mathrm{r}_{\mathrm{AII}^{-}} \% \mathrm{r} \text { (test) }\end{array}$} \\
\hline & & & & $\begin{array}{c}P \\
\text { (Pred) }\end{array}$ & $\begin{array}{c}P_{o p} \\
\text { (Pred) }\end{array}$ & $\% \mathrm{r}_{\mathrm{AII}}$ & $\mathrm{R}_{\mathrm{AII}}$ & \\
\hline - & $\mathrm{OC} 13$ & 568 & - & - & - & - & & - \\
\hline- & OC15 & 649 & - & - & - & - & - & - \\
\hline \multirow{3}{*}{ I } & OC13V43 & 467 & 17.8 & 61.90 & 425.10 & 17.1 & 0.91 & -0.7 \\
\hline & OC13V43_1.6 & 383 & 24.6 & 58.95 & 404.82 & 17.1 & 1.06 & -7.5 \\
\hline & $\mathrm{A} 1$ & 740 & - & 98.10 & 806.67 & 15.8 & 1.09 & - \\
\hline \multirow{2}{*}{ II } & OC13V40 & 340 & 40.2 & 139.52 & 388.38 & 26.4 & 1.14 & -13.8 \\
\hline & B1 & 580 & - & 178.73 & 703.25 & 20.3 & 1.21 & - \\
\hline \multirow{2}{*}{ III } & OC13V23 & 484 & 14.8 & 98.31 & 390.81 & 20.1 & 0.81 & 5.3 \\
\hline & OC15V43 & 612 & 5.7 & 76.72 & 479.24 & 13.8 & 0.78 & 8.1 \\
\hline \multirow{2}{*}{ IV } & $\mathrm{OC} 13 \mathrm{H} 02$ & 512 & 9.9 & 85.41 & 442.86 & 16.1 & 0.86 & 6.2 \\
\hline & OC13H02_1.6 & 420 & 17.3 & 79.71 & 413.30 & 16.1 & 0.98 & -1.2 \\
\hline \multirow{3}{*}{$\mathrm{V}$} & OC13H50 & 443 & 22.0 & 89.54 & 395.27 & 23.3 & 0.89 & 1.3 \\
\hline & OC13H50_1.6 & 428 & 15.8 & 85.50 & 377.44 & 23.3 & 0.88 & 7.5 \\
\hline & OC $15 \mathrm{H} 70$ & 529 & 18.5 & 74.56 & 556.97 & 16.0 & 1.05 & -2.5 \\
\hline
\end{tabular}

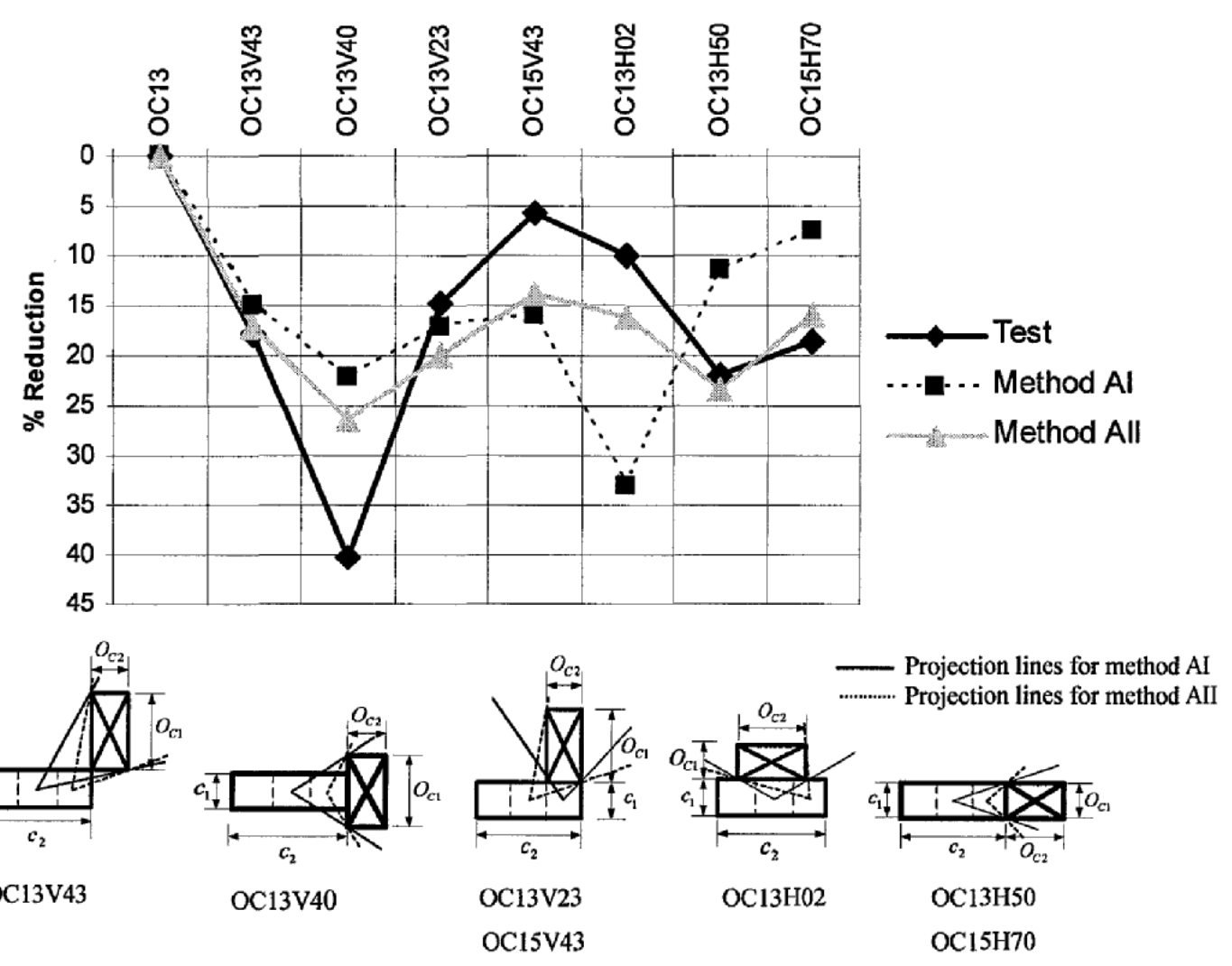

Figure 6.3 Percentage reduction in punching shear capacity due to opening 


\subsection{Punching shear capacity of slab-column connection with shear reinforcement}

\subsubsection{With square column}

There are twelve slab-column specimens with shear reinforcement selected to corroborate the predicted punching shear capacity by theory of plasticity derived in previous chapter. Details of specimens are shown in Table 6.10. All specimens have square column and no opening, and they are reinforced with shear studs. All specimens failed in pure punching.

The arrangements of shear studs in all specimens are shown in Figure 6.4. There are three types of shear stud arrangement used in the specimens. They are (1) arrangement of shear stud rails in perpendicular directions of column widths (2) arrangement of shear stud rails in radial directions of slab, and (3) arrangement of shear stud rails in parallel directions of column widths. The shear studs in the slab specimens tested by Mokhtar et al.(1985) were arranged in perpendicular directions of column widths. The shear studs in the slab specimens tested by Ronaldo et al. (2000) and from the NTU-BCA project (2003) were arranged in radial directions of the slab. For slab specimens tested by Frieder et al. (1980), the shear studs in one slab was arranged in parallel direction of column widths while the shear studs in two slabs were arranged in perpendicular directions of the column widths.

The predicted punching shear capacities of selected specimens are shown in Table 6.11. Through the calculation of punching shear capacity of slab-column specimens by theory of plasticity, the proposed effectiveness factors on the compressive strength of concrete and tensile strength of slab contributed by shear studs of Equations 6.1 and 6.2, respectively, are used. 


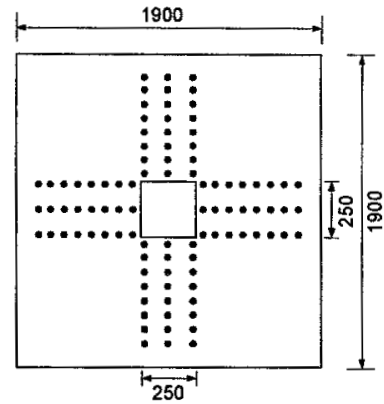

SLABS AB3 \& AB5
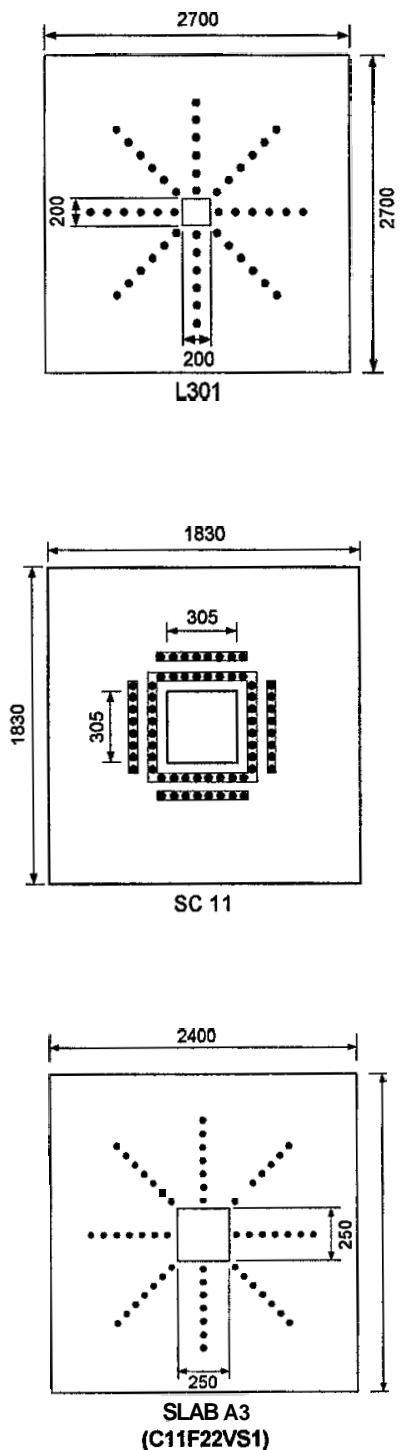

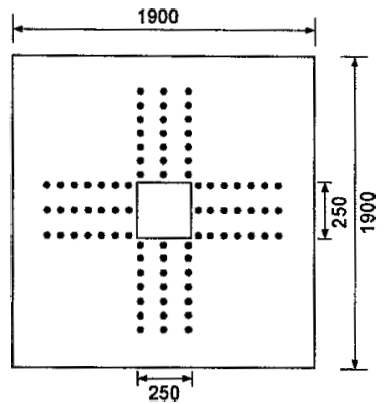

SLABS B6 \& B7
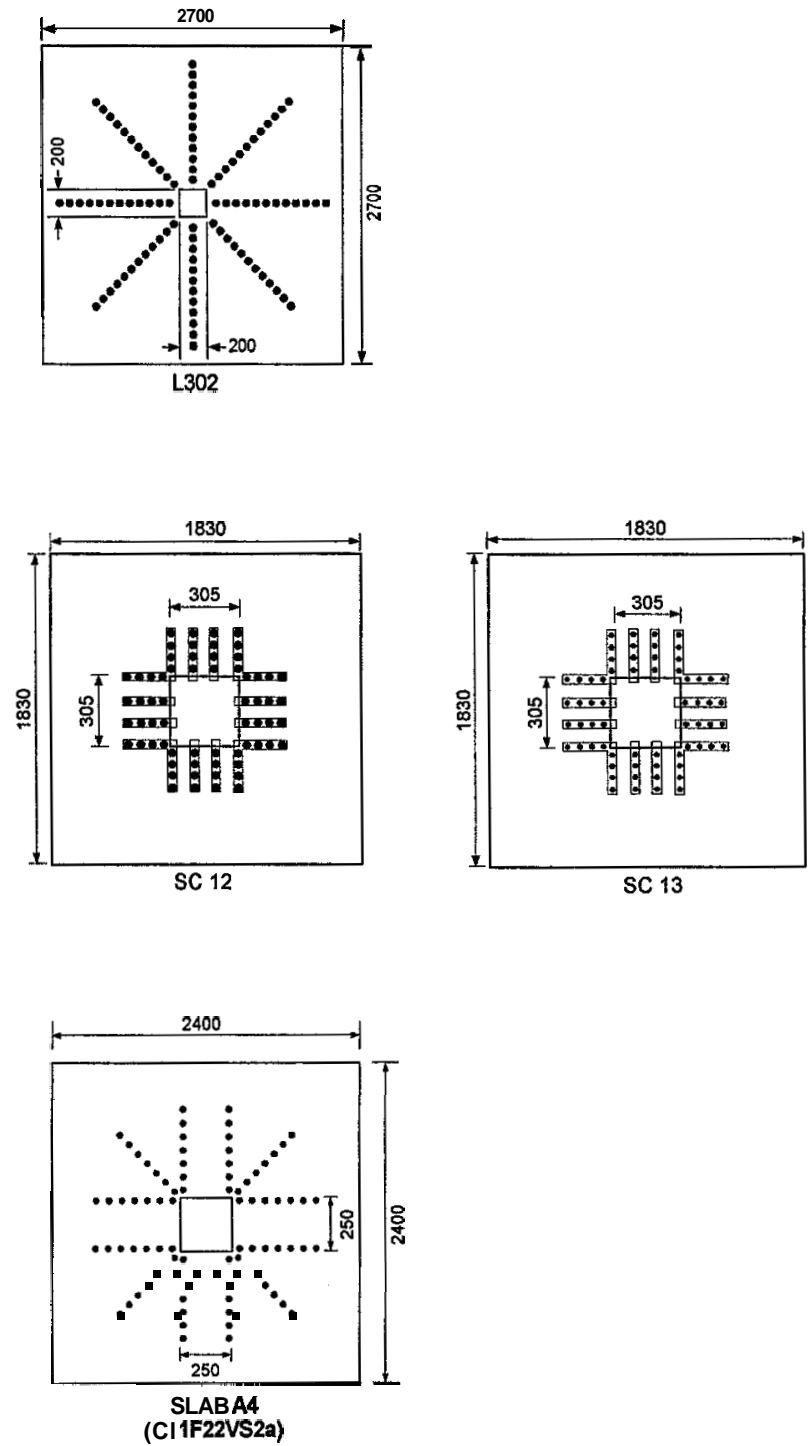

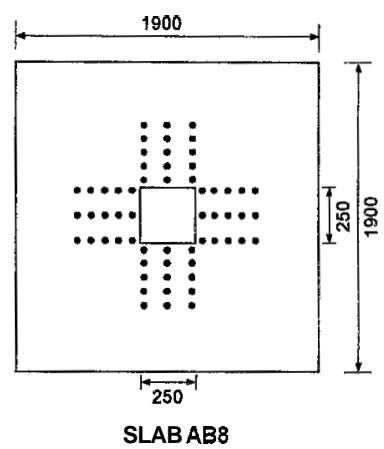

Figure 6.4 Arrangements of shear studs used in square slab-column specimens 


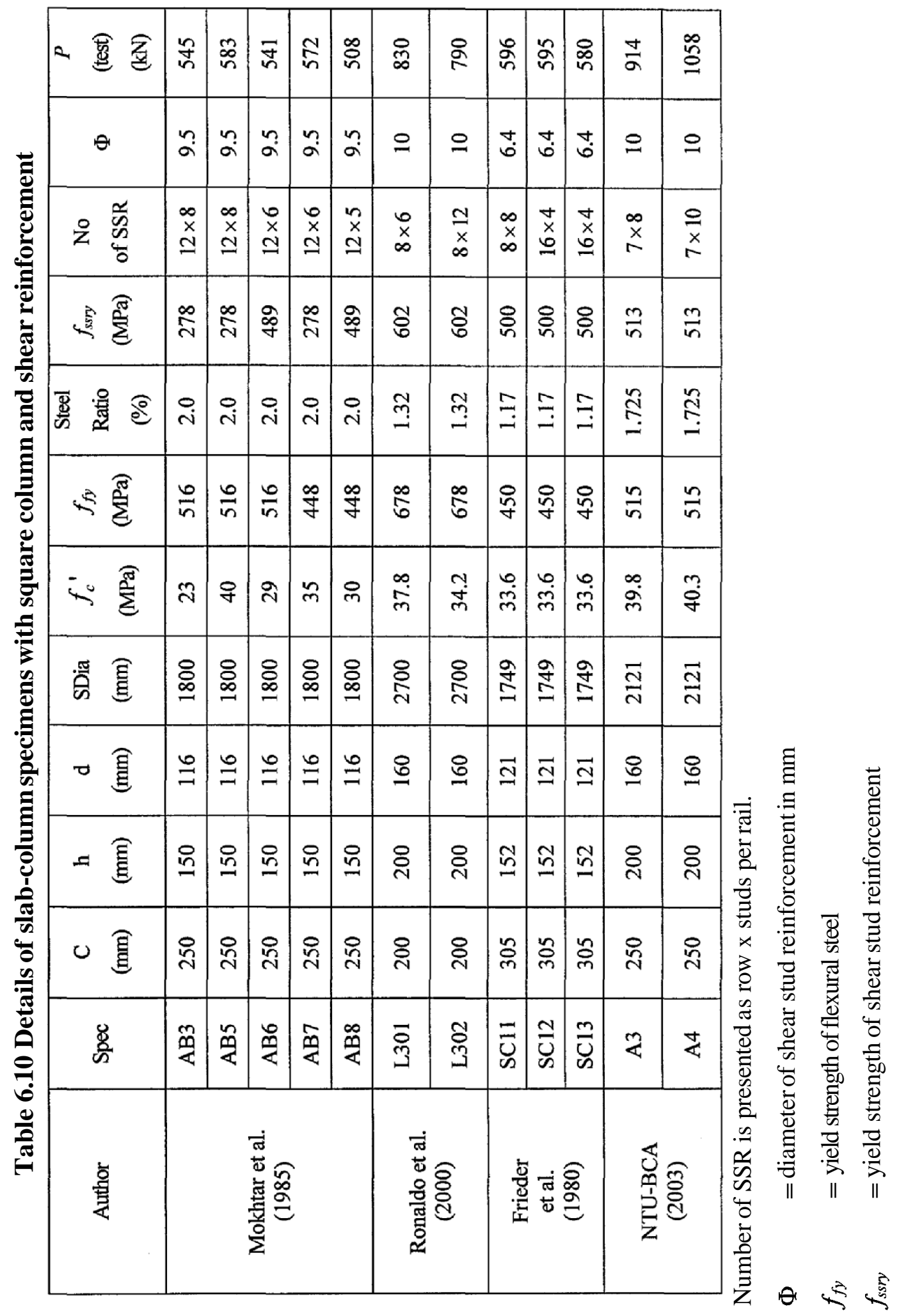


Table 6.11 shows that the predicted punching shear capacity for slabs with square column and shear studs falls within $\pm 13 \%$ of the test results. Thus, the upper-bound formula derived by theory of plasticity can predict the punching shear capacities well for slab-column connections with square column and shear studs. In addition, using the recommended effectiveness factor $v_{s t}$ on the tensile strength contributed shear studs of Equation 6.2, the plasticity model can give the punching shear capacity of slab-column specimens with shear studs in good agreement with test results, Furthermore, the plasticity model in predicting the punching shear capacity contributed by the shear studs is good enough for all amount and arrangements of shear studs in square slab-column specimens as shown in Figure 6.4.

Table 6.11 Punching shear capacity of slab-column specimens with square column and shear reinforcement

\begin{tabular}{|c|c|c|c|c|c|c|c|}
\hline Spec: & $\begin{array}{c}\mathrm{h} \\
(\mathrm{mm})\end{array}$ & $\begin{array}{c}f_{c}^{\prime} \\
(\mathrm{MPa})\end{array}$ & $\frac{\mathrm{R}_{\mathrm{CR}}}{\mathrm{h}}$ & $\frac{\text { SRad }}{h}$ & $\begin{array}{c}P(\text { Pred }) \\
(\mathrm{kN})\end{array}$ & $\begin{array}{c}P \\
\text { (test) } \\
(\mathrm{kN})\end{array}$ & $\frac{\text { Pu(Pred) }}{\text { Pu(Test) }}$ \\
\hline AB3 & 150 & 23 & 5.15 & 5.17 & 487.91 & 545 & 0.90 \\
\hline AB5 & 150 & 40 & 5.15 & 5.17 & 604.97 & 583 & 1.03 \\
\hline $\mathrm{AB} 6$ & 150 & 29 & 5.15 & 5.17 & 571.57 & 541 & 1.07 \\
\hline $\mathrm{AB} 7$ & 150 & 35 & 5.15 & 5.17 & 543.51 & 572 & 0.94 \\
\hline AB8 & 150 & 30 & 5.15 & 5.17 & 552.08 & 508 & 1.09 \\
\hline L301 & 200 & 37.8 & 6.25 & 6.25 & 777.85 & 830 & 0.89 \\
\hline L302 & 200 & 34.2 & 6.25 & 6.25 & 896.59 & 790 & 1.12 \\
\hline $\mathrm{SC} 11$ & 152 & 33.6 & 4.73 & 4.74 & 583.04 & 596 & 0.95 \\
\hline $\mathrm{SC} 12$ & 152 & 33.6 & 4.73 & 4.74 & 583.04 & 595 & 0.95 \\
\hline $\mathrm{SC} 13$ & 152 & 33.6 & 4.73 & 4.74 & 583.04 & 580 & 0.98 \\
\hline A3 & 200 & 39.8 & 4.68 & 4.68 & 932.61 & 914 & 0.95 \\
\hline A4 & 200 & 40.3 & 4.68 & 4.68 & 973.18 & 1058 & 0.87 \\
\hline & & & & & $\mathrm{St}$ & d devis & $\begin{array}{l}0.98 \\
0.08 \\
0.08\end{array}$ \\
\hline
\end{tabular}




\subsubsection{With rectangular column and with or without opening}

Eight slab-column specimens with rectangular column and with shear stud reinforcements are selected to verify whether the plasticity model derived in chapter 5 be able to predict the contribution of shear reinforcement in strengthening the punching shear capacity of slab-column connections. Four slab-column specimens have no opening but they are reinforced by shear studs with different arrangement to increase the punching shear capacity of slab. The remaining four slab-column specimens have opening and shear stud reinforcements with different arrangement to recover the punching shear capacity of slab lost due to opening. Details of slabcolumn specimens are shown in Table 6.12. All slab specimens failed in punching. In specimens B3 (C 13F22VSl) and B4 (C 13F22VS2a), the distance between supports are $2000 \mathrm{~mm}$ and $2400 \mathrm{~mm}$ in shorter and longer column width direction, respectively. In other specimens, the distances between supports are $2000 \mathrm{~mm}$ and $3000 \mathrm{~mm}$ in shorter and longer column width direction, respectively. The arrangements of shear studs in all specimens are shown in Figure 6.5. The diameter of shear stud used in all slab-column specimens is $10 \mathrm{~mm}$.

The predicted punching shear capacities of specimens are shown in Table 6.13. In addition, the predicted punching shear capacities of slab-column specimens lost due to opening and contributed by shear studs are presented. The effectiveness factor for the compressive strength of concrete presented in Equation 6.1 is used, while the effectiveness factor on the tensile strength contributed of shear studs of Equation 6.2 is applied. 
Table 6.12 Details of slab-column connection with rectangular column, with or without opening, and with shear stud reinforcement

\begin{tabular}{|c|c|c|c|c|c|c|c|c|c|c|}
\hline \multirow[b]{2}{*}{ Author } & \multirow[b]{2}{*}{ Spec: } & \multirow{2}{*}{$\begin{array}{c}\mathrm{C}_{1} \\
(\mathrm{~mm})\end{array}$} & \multirow{2}{*}{$\begin{array}{c}\mathrm{C}_{2} \\
(\mathrm{~mm})\end{array}$} & \multirow{2}{*}{$\begin{array}{c}\mathrm{h} \\
(\mathrm{mm})\end{array}$} & \multirow{2}{*}{$\begin{array}{c}\mathrm{d} \\
(\mathrm{mm})\end{array}$} & \multirow{2}{*}{$\begin{array}{c}f_{c}^{\prime} \\
(\mathrm{MPa})\end{array}$} & \multirow{2}{*}{$\begin{array}{l}\text { fsxy } \\
(\mathrm{MPa})\end{array}$} & \multirow{2}{*}{$\begin{array}{l}\text { Steel } \\
\text { ratio } \\
(\%)\end{array}$} & \multirow{2}{*}{$\begin{array}{c}P \\
\text { (test) } \\
(\mathrm{kN})\end{array}$} & Opening \\
\hline & & & & & & & & & & $\begin{array}{c}\text { No of } \\
\text { SSR }\end{array}$ \\
\hline \multirow{8}{*}{$\begin{array}{l}\text { BCA- } \\
\text { NTU } \\
\text { Project } \\
(2003)\end{array}$} & \multirow{2}{*}{$\begin{array}{c}\mathrm{B} 3 \\
(\mathrm{C} 13 \mathrm{~F} 22 \mathrm{VS} 1)\end{array}$} & \multirow{2}{*}{250} & \multirow{2}{*}{750} & \multirow{2}{*}{200} & \multirow{2}{*}{160} & \multirow{2}{*}{39.5} & \multirow{2}{*}{515} & \multirow{2}{*}{1.742} & \multirow{2}{*}{1168} & Without \\
\hline & & & & & & & & & & $8 \times 7$ \\
\hline & \multirow{2}{*}{$\begin{array}{c}\text { B4 } \\
(\mathrm{C} 13 \mathrm{~F} 22 \mathrm{VS} 2 \mathrm{a})\end{array}$} & \multirow{2}{*}{250} & \multirow{2}{*}{750} & \multirow{2}{*}{200} & \multirow{2}{*}{160} & \multirow{2}{*}{40.6} & \multirow{2}{*}{515} & \multirow{2}{*}{1.742} & \multirow{2}{*}{1266} & Without \\
\hline & & & & & & & & & & $12 \times 7$ \\
\hline & \multirow{2}{*}{$\begin{array}{c}\mathrm{C} 3 \\
(\mathrm{C} 15 \mathrm{~F} 22 \mathrm{VS} 1)\end{array}$} & \multirow{2}{*}{250} & \multirow{2}{*}{1250} & \multirow{2}{*}{200} & \multirow{2}{*}{160} & \multirow{2}{*}{38.3} & 515 & 1750 & 1245 & Without \\
\hline & & & & & & & J15 & 1.759 & 1245 & $12 \times 7$ \\
\hline & $\mathrm{C} 4$ & 250 & 1250 & 200 & 160 & 397 & 515 & 1759 & 1477 & Without \\
\hline & (C15F22VS2a) & 250 & 1250 & 200 & 100 & 39.1 & 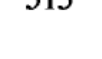 & 1.159 & $14 / 7$ & $16 \times 7$ \\
\hline & & & & & & & & & & With \\
\hline & $\mathrm{A} 2$ & 250 & 1000 & 200 & 160 & 38.2 & 540 & 1.65 & 908 & $5 \times 8$ \\
\hline BCA- & 43 & 250 & 1000 & 200 & 160 & 383 & 540 & 165 & 948 & With \\
\hline NTU & ת & $2 \pi 0$ & 1000 & 200 & 100 & 30.5 & $3+0$ & $1.0 J$ & 740 & $6 \times 5$ \\
\hline Project & B? & 250 & 1000 & 200 & 160 & 363 & 540 & 165 & 848 & With \\
\hline (2003) & $\mathrm{B} 2$ & 200 & 1000 & 200 & 100 & 30.5 & 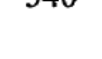 & $1.0 J$ & oto & $6 \times 8$ \\
\hline & & & & & & & & & & With \\
\hline & B3 & 250 & 1000 & 200 & 160 & 36.3 & 540 & 1.65 & 692 & $6 \times 5$ \\
\hline
\end{tabular}

Number of SSR is presented as row $\times$ studs per rail.
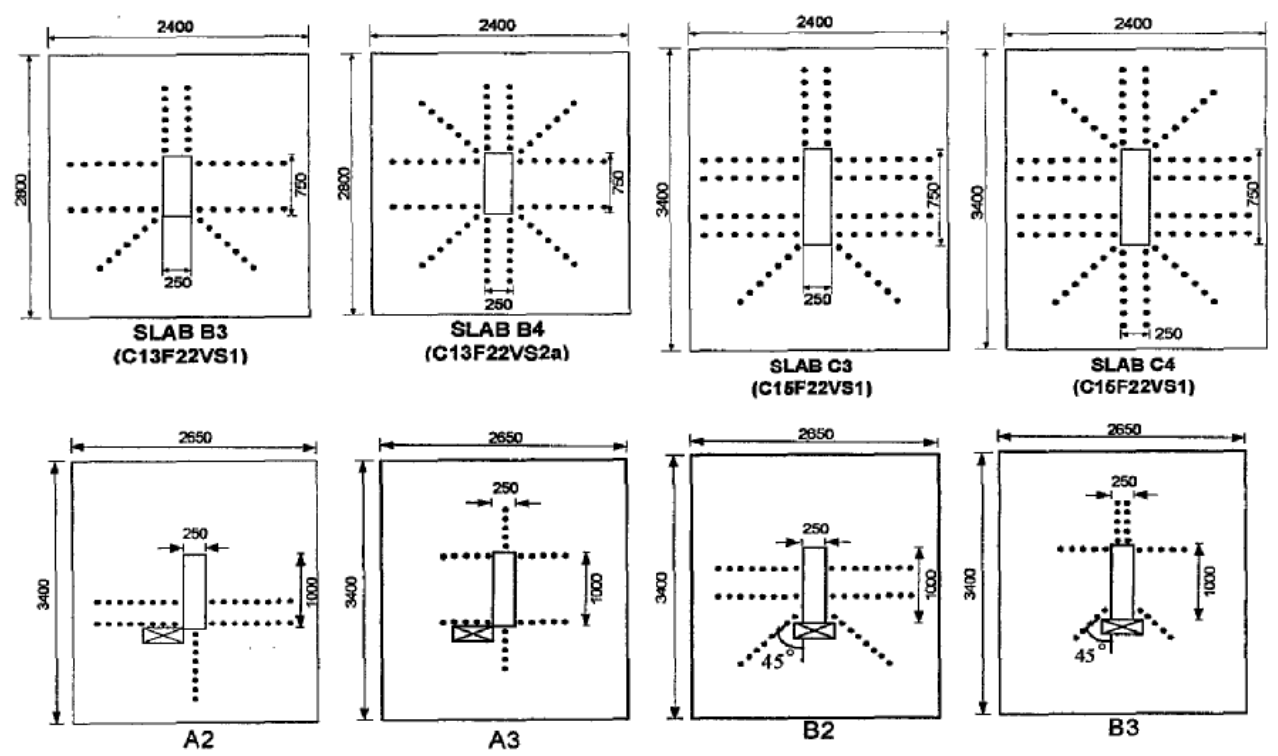

Figure 6.5 Location of opening and arrangement of SSR in the rectangular slab-column specimens 
From Table 6.13, it can be seen that the predicted punching shear capacity for slabs with rectangular column, with or without opening and with shear studs falls around \pm $20 \%$ of the test results. Thus, generally the upper-bound formula derived by theory of plasticity can predict the punching shear capacity well for slabs with rectangular column, and shear studs, with or without opening.

Table 6.13 Punching shear capacity of slab-column connections with rectangular column, with or without opening and with shear stud reinforcement

\begin{tabular}{|c|c|c|c|c|c|c|c|c|}
\hline Spec: & $\begin{array}{c}P \\
\text { (Test) } \\
(\mathrm{kN})\end{array}$ & $\begin{array}{c}P \\
\text { (Pred) } \\
(\mathrm{kN})\end{array}$ & $\begin{array}{l}\bar{P}_{o p} \\
(\mathrm{kN})\end{array}$ & $\begin{array}{c}P_{o p} \\
(\mathrm{kN})\end{array}$ & $\begin{array}{c}P_{o p+S} \\
\text { (Pred) } \\
(\mathrm{kN})\end{array}$ & $\begin{array}{l}\bar{P}_{\text {SSR }} \\
(\mathrm{kN})\end{array}$ & $\begin{array}{l}P_{S S R} \\
(\mathrm{kN})\end{array}$ & $\frac{P_{o p+S}(\text { Pred })}{P \text { (Test) }}$ \\
\hline $\begin{array}{c}\mathrm{B} 3 \\
\text { (C13F22VS1) }\end{array}$ & 1168 & 888.89 & - & - & - & 138.67 & 1053.97 & 0.90 \\
\hline $\begin{array}{c}\text { B4 } \\
\text { (C13F22VS2a) }\end{array}$ & 1266 & 901.18 & - & - & - & 208.00 & 1148.8 & 0.91 \\
\hline $\begin{array}{c}\mathrm{C} 3 \\
(\mathrm{C} 15 \mathrm{~F} 22 \mathrm{VS} 1) \\
\end{array}$ & 1245 & 1017.29 & - & - & - & 207.54 & 1264.36 & 1.02 \\
\hline $\begin{array}{c}\mathrm{C} 4 \\
\text { (C15F22VS2a) }\end{array}$ & 1477 & 1035.72 & - & - & - & 276.72 & 1365.15 & 0.92 \\
\hline \multirow{2}{*}{$\mathrm{A} 2$} & \multirow{2}{*}{908} & \multirow{2}{*}{904.77} & 114.35 & 790.42 & 908.93 & 118.51 & - & 1.00 \\
\hline & & & 98.1 & 806.67 & 925.18 & 118.51 & - & 1.02 \\
\hline \multirow[b]{2}{*}{$\mathrm{A} 3$} & \multirow{2}{*}{948} & \multirow{2}{*}{904.77} & 114.35 & 790.42 & 879.3 & 88.88 & - & 0.93 \\
\hline & & & 98.1 & 806.67 & 895.55 & 88.88 & - & 0.94 \\
\hline \multirow{2}{*}{ B2 } & \multirow{2}{*}{848} & \multirow{2}{*}{881.98} & 122.61 & 759.37 & 890.01 & 130.64 & - & 1.05 \\
\hline & & & 178.73 & 703.25 & 833.89 & 130.64 & - & 0.98 \\
\hline \multirow{2}{*}{ B3 } & \multirow{2}{*}{692} & \multirow{2}{*}{881.98} & 122.61 & 759.37 & 841.02 & 81.65 & - & 1.22 \\
\hline & & & 178.73 & 703.25 & 784.9 & 81.65 & - & 1.13 \\
\hline & & & & & & Stande & $\begin{array}{r}\text { Mea } \\
\text { co }\end{array}$ & $\begin{array}{l}1.00 \\
0.10 \\
0.10\end{array}$ \\
\hline
\end{tabular}

$P($ Test $)=$ test result of punching shear capacity of slab-column connection with shear reinforcement and with or without opening

$\boldsymbol{P}($ Pred $)=$ predicted punching shear capacity of slab-column connection without opening and without shear reinforcement

$P_{o p+S} \quad=$ predicted punching shear capacity for the slab-column connection with opening and shear stud reinforcement 
$P_{o p} \quad=$ predicted punching shear capacity of slab-column connection with opening and without shear stud reinforcement

$\bar{P}_{o p} \quad=$ predicted punching shear capacity of slab-column connection lost due to opening

$P_{S S R} \quad=$ predicted punching shear capacity for the slab-column connection without opening and with shear stud reinforcement

It can be observed from Table 6.13 that the predicted punching shear capacities of all slab specimens without opening are compatible with the test results. The plasticity model is acceptable in predicting the punching shear capacity of the rectangular slabcolumn connections with shear studs arranged as shown in Figure 6.5.

It can be also observed from Table 6.13 that for the slab specimens B3, the predicted shear capacities by theory of plasticity with both methods to calculate the ineffective area of failure surface due to opening are overestimated while for the slab specimen B2, the predicted shear capacities by theory of plasticity with both methods are in good agreement with test results. This is due to the fact that the amount and arrangement of shear studs in specimens B3 is not as effective as the arrangement of shear studs in specimens B2 in recovering the punching shear capacity lost due to opening. It can be concluded that the proposed plasticity model gives a lesser punching shear capacity of slab-column connections with opening and shear stud reinforcement as the shear studs reinforced in the slabs is more effective.

\subsection{Conclusions}

Regarding the plasticity model proposed in chapter 5 to predict the punching shear capacity of slab-column connections, the following conclusions are drawn:

1. Generally the plasticity model can predict the punching shear capacity quite well for slab-column connections with square and rectangular column, with or without opening and with or without shear stud reinforcement.

2. The proposed effectiveness factors on the compressive strength of concrete of Equation 6.1 is applicable to use in calculating the punching shear capacity of 
square and rectangular slab-column connections with the thickness of the slab ranged less than $250 \mathrm{~mm}$ and aspect ratio of longer to shorter column widths less than 5 .

3. The proposed effectiveness factors on the yield strength of shear studs of Equation 6.2 is applicable to use in calculating the punching shear capacities of square and rectangular slab-column connections with shear reinforcement.

4. The plasticity model can also predict the punching shear capacities of slabcolumn connections reduced due to opening and contributed by SSR. Therefore, from the predicted punching shear capacities of slab-column connections reduced due to opening by theory of plasticity, the quantity of shear stud reinforcement to recover the reduction of punching shear capacity due to opening can be recalculated for design purpose.

5. In predicting the ineffective punching shear capacity of slab due to opening by the proposed plasticity model, the method AII to calculate the ineffective area of failure surface due to opening is more reasonable.

6. The punching shear failure surface obtained by plasticity model is a curve and has continuous circumference around the column.

7. The proposed plasticity model is valid for slab-column connections failed in punching failure mode.

8. The proposed plasticity model is only for concentric punching load. 
CHAPTER 7

SUMMARY, CONCLUSION AND

RECOMMENDED FUTURE

WORKS 


\section{Chapter 7}

\section{Summary, conclusion and recommended future works}

\subsection{Summary}

In this study, the experimental results of 6 slab specimens which were tested to investigate the behavior of rectangular slab-column connections with opening and shear stud reinforcement are presented. There are two types of opening locations in the slab specimens; at the corner of column and at the shorter side of column width. Except the two control specimens, all specimens have different amount and arrangement of shear stud reinforcement. The specimens were loaded to fail under monotonic uniformly distributed loading.

Based on the theory of plasticity, a model to predict the upper bound punching shear capacity of square and rectangular slab-column connections with or without opening and with or without shear stud reinforcement is proposed. The punching shear failure criterion of concrete is established. The collapse mechanism and generatrix of punching shear failure surface for different slab-column connections are considered. The plastic strain along the punching crack is derived based on the established failure criterion. The dissipation energy in the punching shear failure surface is derived and the upper bound solution for punching shear capacity of slab-column connections is achieved by using virtual work principle and variational calculus.

To take into account the softening effect of concrete, an effectiveness factor on the compressive strength of concrete, which depends on slab thickness, aspect ratio of longer and shorter column width and compressive strength of concrete, is proposed. Because all shear reinforcements in the slab may not yield at the punching shear failure, an effectiveness factor on the tensile strength contributed by shear stud reinforcement is also recommended. 


\subsection{Conclusion}

Based on the results obtained from the experimental programme described in chapter four, and the plasticity model proposed in chapter five and its verification by predicting the punching shear capacity of square and rectangular slab-column connections with and without opening, and with and without shear stud reinforcements, the following conclusions can be drawn.

\subsubsection{Conclusion on experimental program}

From the experimental results and discussion from the experimental programme, the conclusions are:

(1) The concentrated stresses near the region around the shorter column width are higher than the concentrated stresses near the region around the longer column width.

(2) If the slab has opening near the column, the region near the opening is the weakest portion in the slab regardless the slab is reinforced with shear reinforcements.

(3) The location of opening at the shorter column width affect the punching shear capacity of slab more than the location of opening at the corner of column.

(4) The shear stud reinforcements can significantly recover the reduced punching shear capacity of the slabs due to openings.

(5) For the rectangular slab-column connections with opening and shear stud reinforcements, the circumference of failure surface is within the distance of $2 \mathrm{~d}$ and $4 \mathrm{~d}$ from the column face, where $\mathrm{d}$ is the effective depth of slabs.

(6) The angle of inclined cracks in the slabs with opening at the shorter side of column is steeper than angle of inclined cracks in the slabs with opening at 
the comer of column. The more the opening affect the punching shear capacity of slab, the steeper the angle of inclined crack in the slab.

(7) When the opening is located at the comer of column in the interior slabcolumn connection with rectangular column, more number of shear stud reinforcements with shorter length of rails should be evenly placed around the column face and near the opening.

(8) When the opening is located at the shorter column width in the interior slabcolumn connection with rectangular column, the shear stud reinforcements with longer length of rails tilting near the opening should be used.

\subsubsection{Conclusion on proposed plasticity model}

Regarding the proposed plasticity model to predict the punching shear capacity of slab-column connections, the conclusions are:

(1) The proposed plasticity model is able to predict the punching shear capacity for slab-column connections with square and rectangular column, with or without opening and with or without shear stud reinforcement well compared to the test results.

(2) The proposed plasticity model is valid for slab-column connections under concentric load and failed in punching shear failure mode.

(3) The proposed effectiveness factors on the compressive strength of concrete of Equation 6.1 is applicable in calculating the punching shear capacities for square and rectangular slab-column connections with thickness of slab less than $250 \mathrm{~mm}$ and aspect ratio of longer and shorter column widths less than 5.

(4) The proposed effectiveness factors on the tensile strength of slab contributed by shear stud reinforcement of Equation 6.2 with the proposed plasticity 
model is applicable in calculating the punching shear capacities of square and rectangular slab-column connections with shear stud reinforcement.

(5) The punching shear capacity of slab-column connections reduced due to opening and contributed by SSR can be reasonably predict by the proposed plasticity model.

(6) The quantity of shear stud reinforcement to recover the reduced punching shear capacity due to opening can be recalculated by the proposed plasticity model for design purpose.

(7) The proposed plasticity model gives a lesser punching shear capacity of slabcolumn connections with opening and shear stud reinforcement as the shear stud reinforcement is more effective.

(8) In predicting the ineffective punching shear capacity of slabs due to opening by the proposed plasticity model, the method AII explained in chapter six to calculate the ineffective area of failure surface due to opening is more reasonable than method AI.

(9) For five kinds of opening location described in chapter six, the proposed plasticity model with method AII to calculate the ineffective area of failure surface due to opening, can reasonably predict the ineffective punching shear capacity of slab-column connections due to opening.

\subsection{Recommended future works}

Regarding to the proposed plasticity model, the future works are recommended as follows.

(1) Although the proposed plasticity model to predict the punching shear capacity of slab-column connections with square or rectangular column can give relatively good results compared to the test results, the procedure is quite long. 
For design purpose, it may be simplified by considering the straight failure surface from compression to tension face of slab.

(2) The proposed plasticity model is for pure punching of slabs only. It should be extended for flexural punching failure.

(3) The proposed plasticity model needs to be extended for the exterior and comer slab-column connections.

(4) The proposed plasticity model to predict the punching shear capacity of slabcolumn connections with square or rectangular column is valid for the slope of failure surface at the compressive side of the slab greater than or equal to the internal friction angle of concrete of 37 degree. But in practice, the slope of failure surface at the compressive side of the slab may be less than 37 degree. To overcome this, the parabolic Mohr failure criterion described in chapter 2 instead of modified Mohr-Coulomb failure criterion for concrete should be used. Thus, the proposed plasticity model can be extended for all slope of failure surface at the compressive side of the slab by employing parabolic Mohr-Coulomb failure criterion for concrete.

(5) Although the flexural reinforcement does not significantly affect on the shear strength of heavily reinforced laterally restrained slabs, the punching shear capacity can be enhanced by the effect of flexural reinforcement in lightly reinforced laterally restrained slabs. This is due to the effect of compressive membrane action of laterally restrained slabs. The proposed plasticity model to predict the punching shear capacity of slab-column connections with square or rectangular column should be extended to predict the punching shear capacity of laterally restrained slab-column connections. 


\section{REFERENCES}

ACI Committee 318, "Building Code Requirement for Reinforced Concrete (ACI 318-02) and Commentary-ACI 318R-02", American Concrete Institute, Detroit, Michigan.

Alexander, S.D.B. and Simmonds, S.H., "Ultimate Strength of Slab-Column Connections". ACI Structural Journal, American Concrete Institute, Detroit, Vol. 84, No. 3, May-June 1987, pp. 255-261.

Bortolotti, L., "Punching Shear Strength in Concrete Slabs", ACI Structural Journal, Vol.87, No. 2, March-April 1990, pp. 208-219.

Braestrup, M.W., Nielsen, M.P., Jensen, B.C., and Bach, F., "Axisymmetric Punching of Plain and Reinforced Concrete, Copenhagen, Technical University of Denmark, Structural Research Laboratory, Report No. R-75, 1976, 33 pp.

British Standards Institution "Structural Use of Concrete: Part 1, Code of Practice for Design and Construction", (BS 8110: Part 1:1997), 1997, London.

British Standards Institution "Structural Use of Concrete: Handbook to British Standard BS 8110: 1985", Viewpoint Publications, London.

Broms, C.E., 1990. "Shear Reinforcement for Deflection Ductility of Flat Plates", $\underline{\mathrm{ACI}}$ Structural Journal, American Concrete Institute, Detroit, Vol. 87, No. 6, pp. 696-705.

Collins, M.P., "Towards a Rational Theory for RC Members in Shear". Journal of the Structural Division, Proceedings of ASCE, Vol.104, No.ST4, April 1978, pp. 649-666.

Elgabry, A.A., and Ghali, A., "Tests on Concrete Slab-Column Connections with Stud-Shear Reinforcement Subjected to Shear-Moment Transfer", ACI Structural Journal, Vol.84, No. 5, September-October 1987, pp. 701-713. 
Elgabry A.A., and Ghali, A., "Design of Stud-Shear Reinforcement for Slabs", $\underline{\mathrm{AC}}$ Structural Journal, Vol. 87. No. 3, May-June 1990, pp. 350-361.

El-Salakawy, E.F., Polak, M.A., and Soliman, M.H., "Reinforced Concrete SlabColumn Edge Connections with Openings". ACI Structural Journal, American Concrete Institute, Detroit,Vol. 96, No. 1, 1999, pp. 79-87.

Ghali, A., "An Efficient Solution to Punching of Slabs." Concrete International: Design \& Construction, V.11, N0.6, June 1989, pp.50-54.

Gillbert, S.G., and Glass, C., "Punching Failure of Reinforced Concrete Flat slabs at Edge Columns". The Structural Engineer, Vo1.65B, No. 1, March 1987, pp. 16-21.

Hawkins, N.M., Bao, A., and Yamazaki, J., "Moment Transfer from Concrete Slabs to Columns". ACI Structural Journal, V.86, No.6, November-December 1989, pp 705-716.

Heyrnan, J., "Coulomb's Memoir on Statics: An essay on the history of civil engineering, Cambridge." Cambridge University Press, 1972,212 pp.

Hognestad, E., Elstner R.C., and Hanson J.A., "Shear Strength of Reinforced Structural Light Weight Aggregate Concrete Slabs". Journal of The American Concrete Institute, Vol. 61, No.6, June 1964, pp. 643-656.

Islam, S. and Park, R., "Tests on Slab-Column Connections with Shear and Unbalanced Flexure". Journal of the Structural Division, Proceedings of ASCE, Vo1.102, No.ST3, March 1973, pp. 551-572.

Jiang, D.H. and Shen, J.H., "Strength of Concrete Slabs in Punching Shear". Joumal of Structural Engineering, Vol.112, No.12, December 1986, pp. 2579-2591.

Joseph Di Stasio, S.R. and Van Buren, M.P., "Transfer of Bending Moment Between Flat Plate Floor and Column". Journal of American Concrete Institute, Vo1.57, No.9 1960, pp. 299-314. 
Kinnunen, S., and Nylander, H., 1960. "Punching of Concrete Slabs without Shear Reinforcement", Transactions of the Royal Institute of Technology, No. 158, Stockholm, $112 \mathrm{pp}$.

Kuang, K.L., "Punching Shear Strength of Slabs with Openings and Supported on Rectangular Columns". Master Thesis, School of Civil and Structural Engineering, Nanyang Technological University, 2001.

Kuang, J.S. and Morley, C.T., "A Plasticity Model for Punching Shear of Laterally Restrained Slabs with Compressive Membrane Action". International Journal of Mechanical Sciences, Vol. 35, No.5, 1993, pp. 371-385.

Long, A.E., "A Two-Phase Approach to the Prediction of the Punching Strength of slabs". Proceedingsof ACI Journal. American Concrete Institute, Detroit, Vo1.72, No. 5, February 1975, pp. 37-45.

Marzouk H. and Hussein A., "Experimental Investigation on Behavior of HighStrength Concrete Slabs". ACI Structural Journal, Vo1.88, No.6, November-December 1991, pp. 701-713.

Menétrey, P., "Analytical Computation of the Punching Strength of Reinforced Concrete". ACI Structural Journal, Vol. 93, No.5, September-October 1996, pp. 503511.

Mokhtar, A. S., Ghali, A., and Dilger, W. H., "Stud Shear Reinforcement for Flat Concrete Plates". ACI Structural Journal, Vo1.82, No.5, September-October,1985, pp. 676-683.

Mortin, J.D. and Ghali, A., "Connection of Flat Plates to Edge Column", ACI Structural Journal, Vol. 88, No.2, March-April 1991, pp. 191-198. 
Mowrer, R.D. and Vanderbilt, M.D., 1967. "Shear Strength of Lightweight Aggregate Reinforced Concrete Flat Plates". Proceedings of ACI Journal. American Concrete Institute, Detroit, Vol.64, No.11, pp. 722-729.

Nielsen, M. P., 2000. "Limit Analysis and Concrete Plasticity", Prentice-Hall, New York.

Park, R., and Islam, S., "Strength of Slab-Column Connections with Shear and Unbalanced Flexure". Journal of the Structural Division, Proceedings of ASCE, Vo1.102, No.ST9, September 1976, pp. 1879-1901.

Regan, P.E, "Shear reinforcement of Flat Slabs". International Workshop on Punching Shear Capacity of RC Slabs - Stockholm, 2000, pp.99-116

Regan, P.E. and Braestrup, M.W., 1985. "Punching shear in Reinforced Concrete:A State-of-the-Art Report". Bulletin d'Information No.168, Comite Euro-International du Beton. Lausanne, pp. 232.

Salim, W. and Sebastian, W.M., "Plasticity Model for Predicting Shear Strengths of Concrete Slabs", ACI Structural Journal, Vol.99, No. 6, November-December 2002, pp. 827-835.

Seible, F., Ghali, A., and Dilger, W.H., "Preassembled Shear Reinforcing Units for Flat Plates", 슨 Structural Journal, Vol.77, No. 5, January-February 1980, pp. 28-35.

Starnenkovic, A., and Chapman, J.C., "Local Strength at Column Heads in Flat Slabs Subjected to a Combined Vertical and Horizontal Loading". Institution of Civil Engineers (London), Proceedings. Part 2, Research and Theory, Vol.57, March-June 1974, pp. 205-233.

Yankelevsky, D.Z. and Leibowitz, O., "Punching Shear in Concrete Slabs", International Journal of Mechanical Sciences, Vol. 41, 1999, pp. 1-15. 
APPENDIX A

\section{LVDT AND STRAIN GAUGE MEASUREMENTS FROM THE EXPERIMENTAL PROGRAMME}




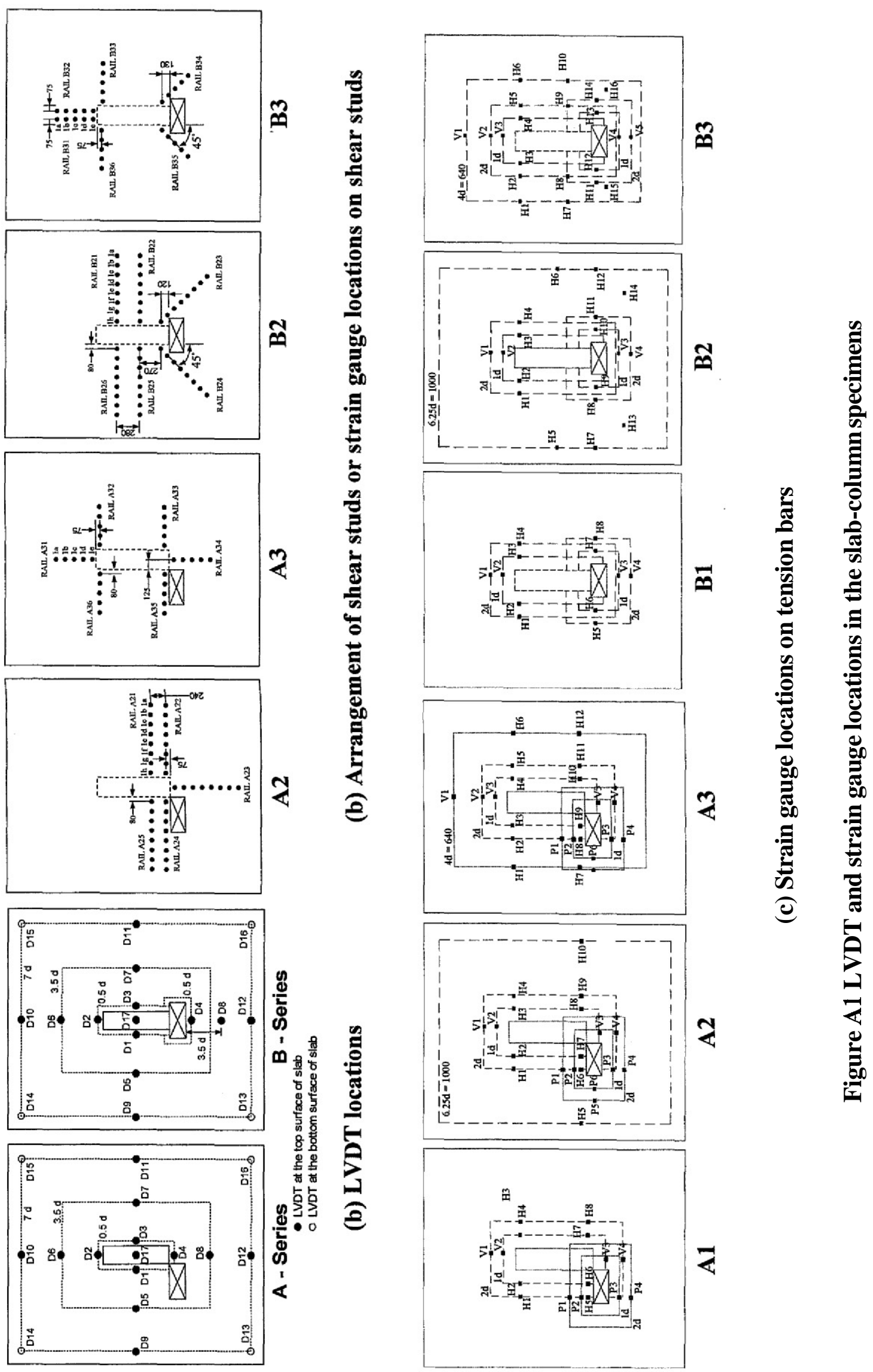



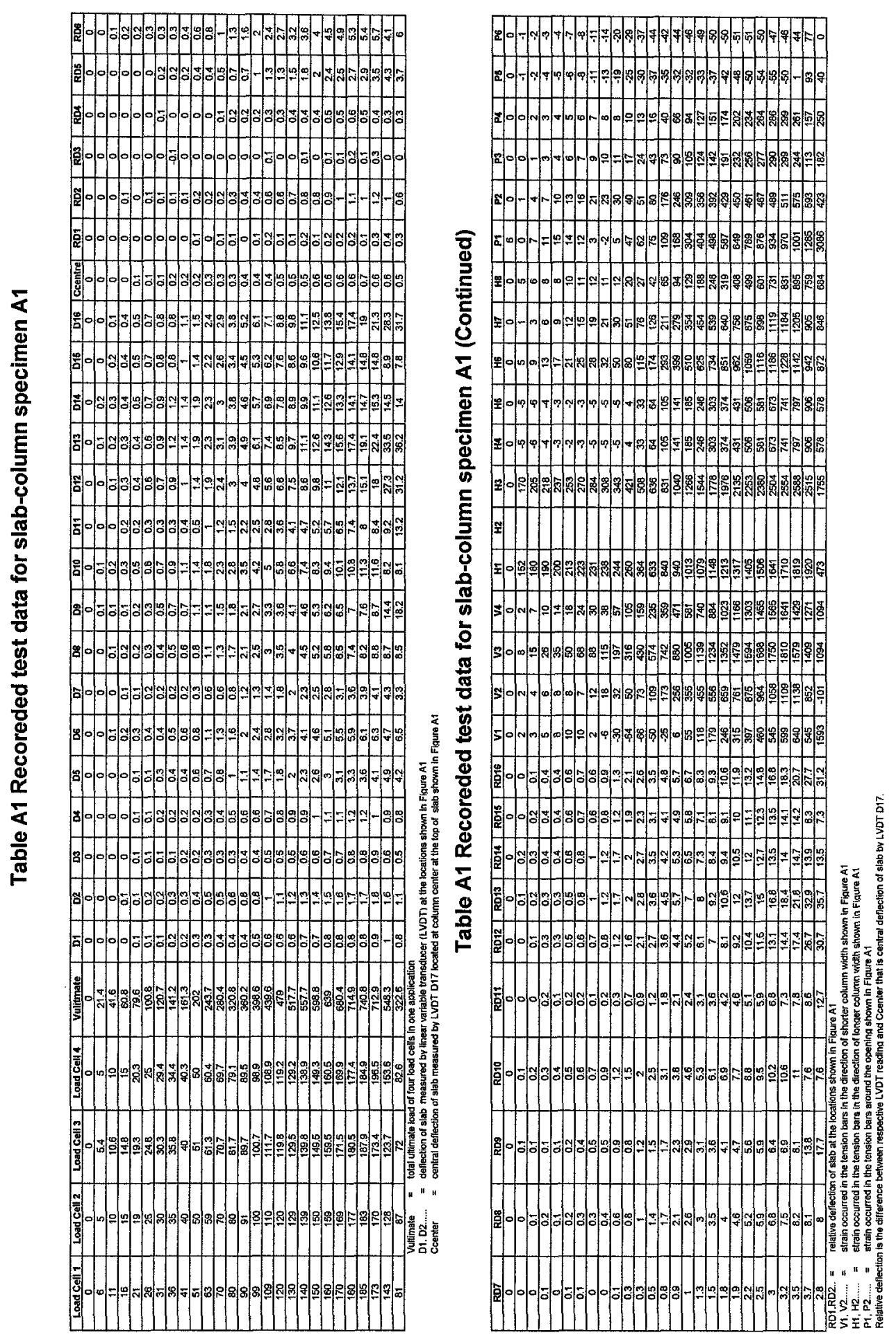


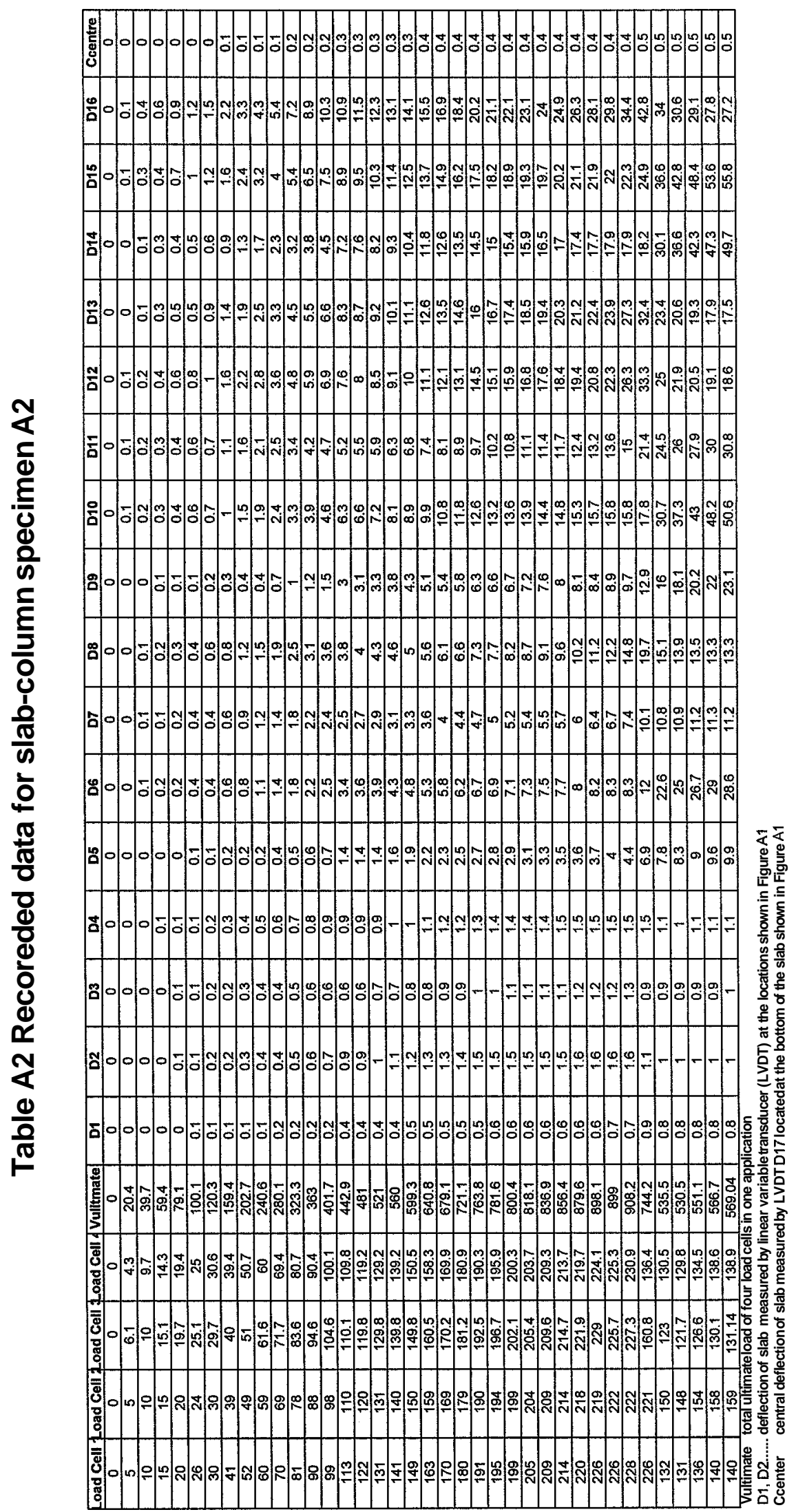




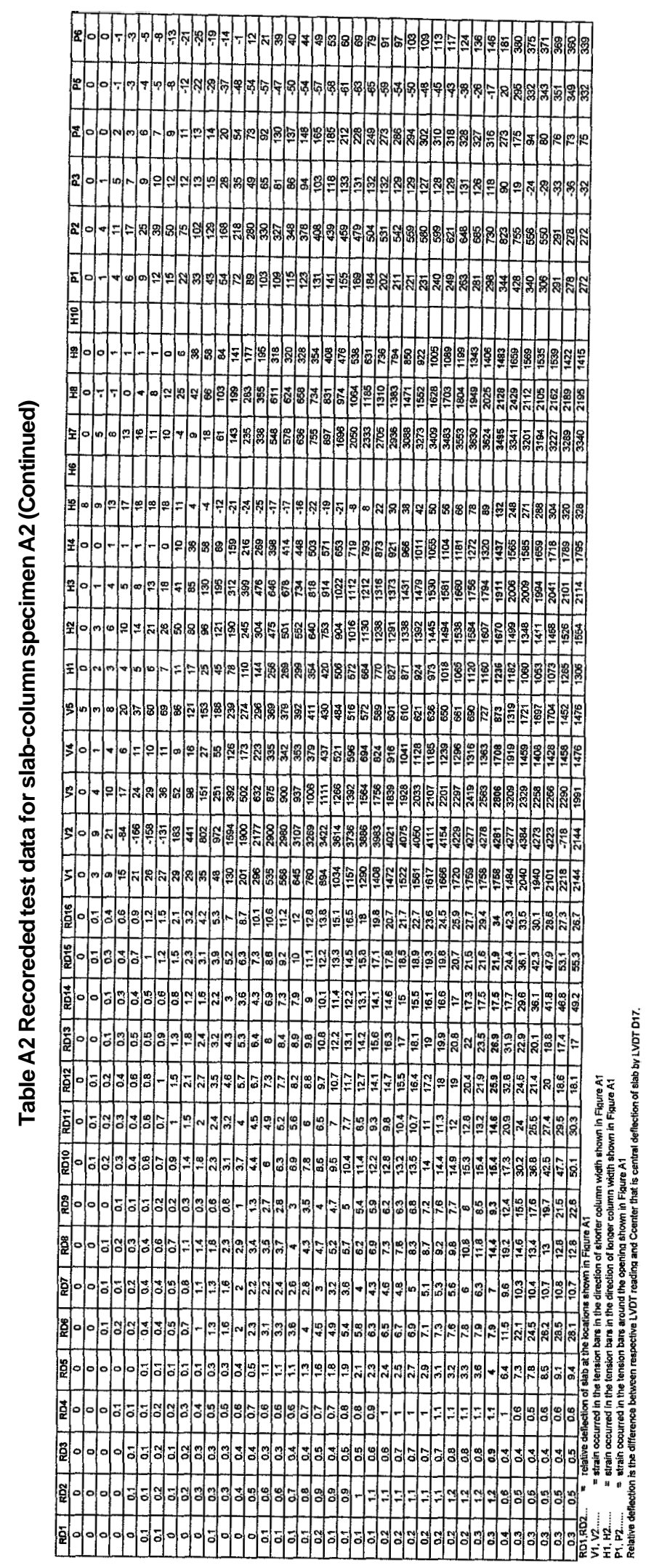




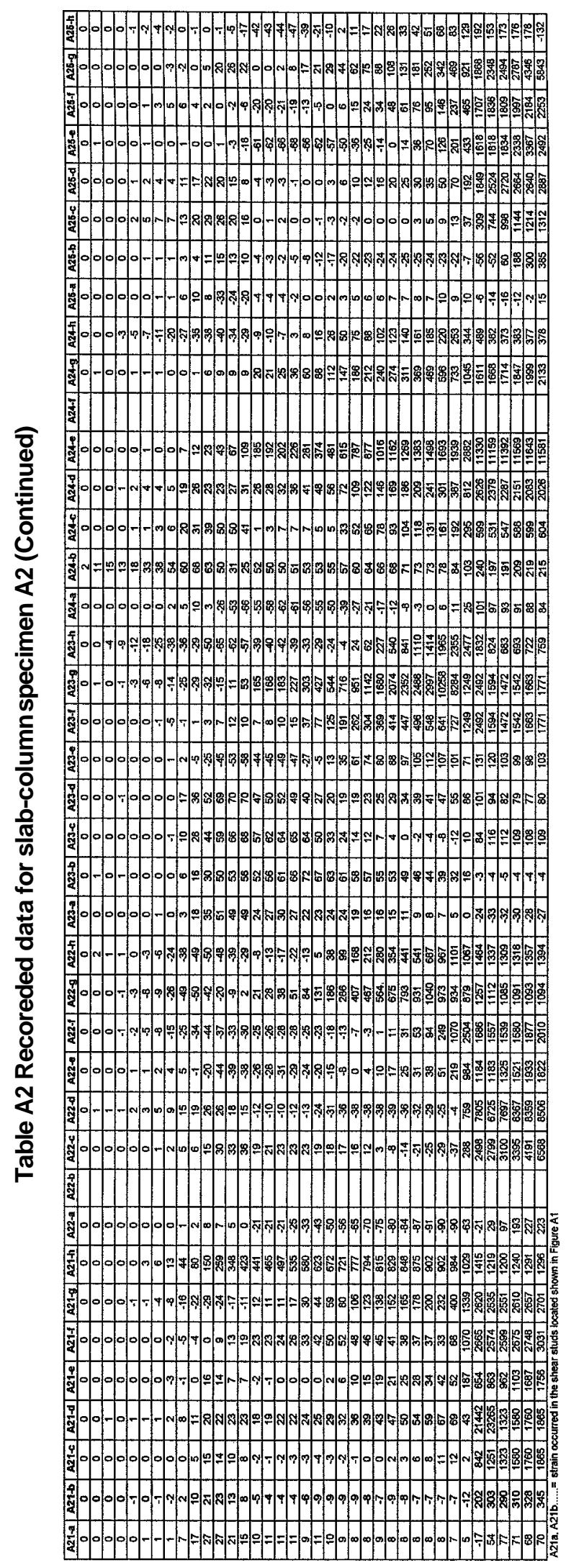




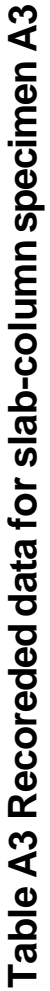

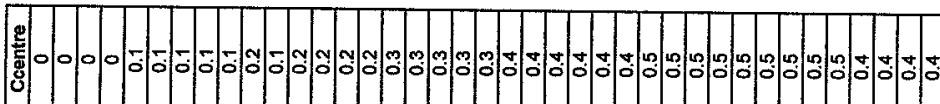

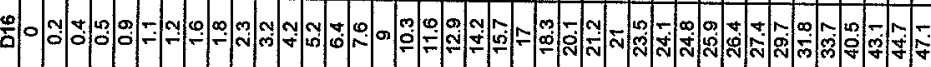
(

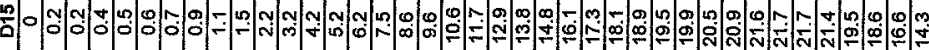

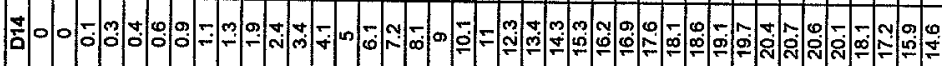

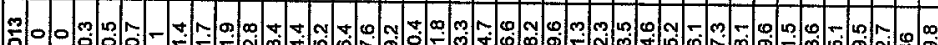

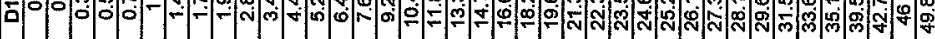

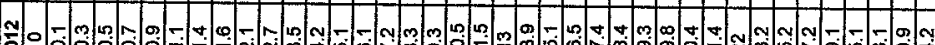

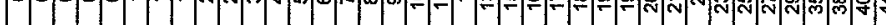

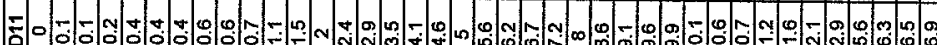

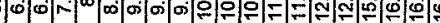

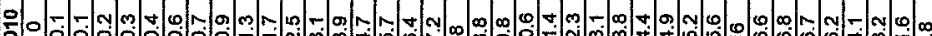
管

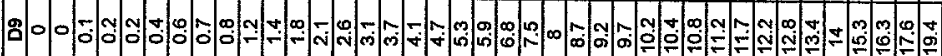
D. 1 :

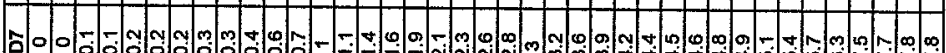
-

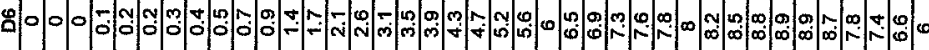

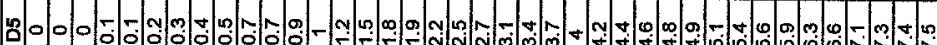

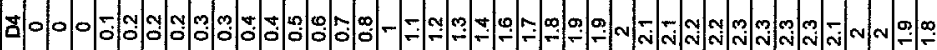

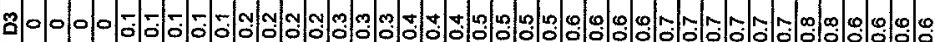

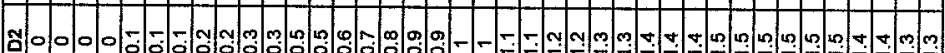
(1)

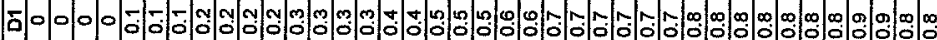

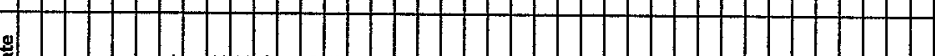

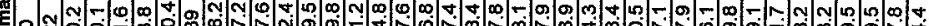

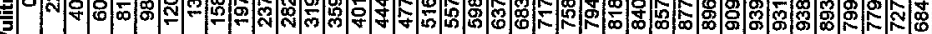

这京
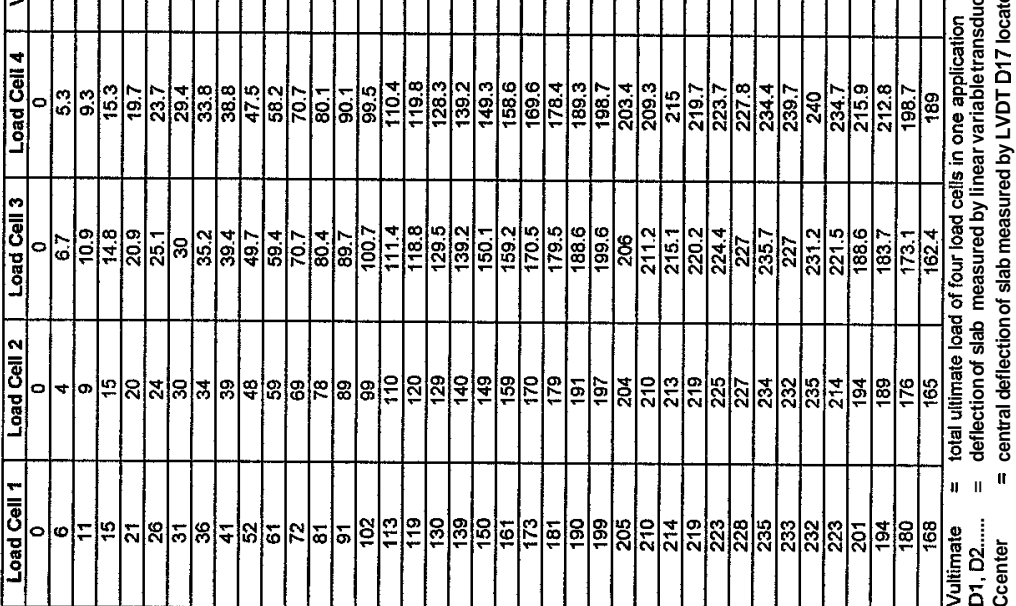


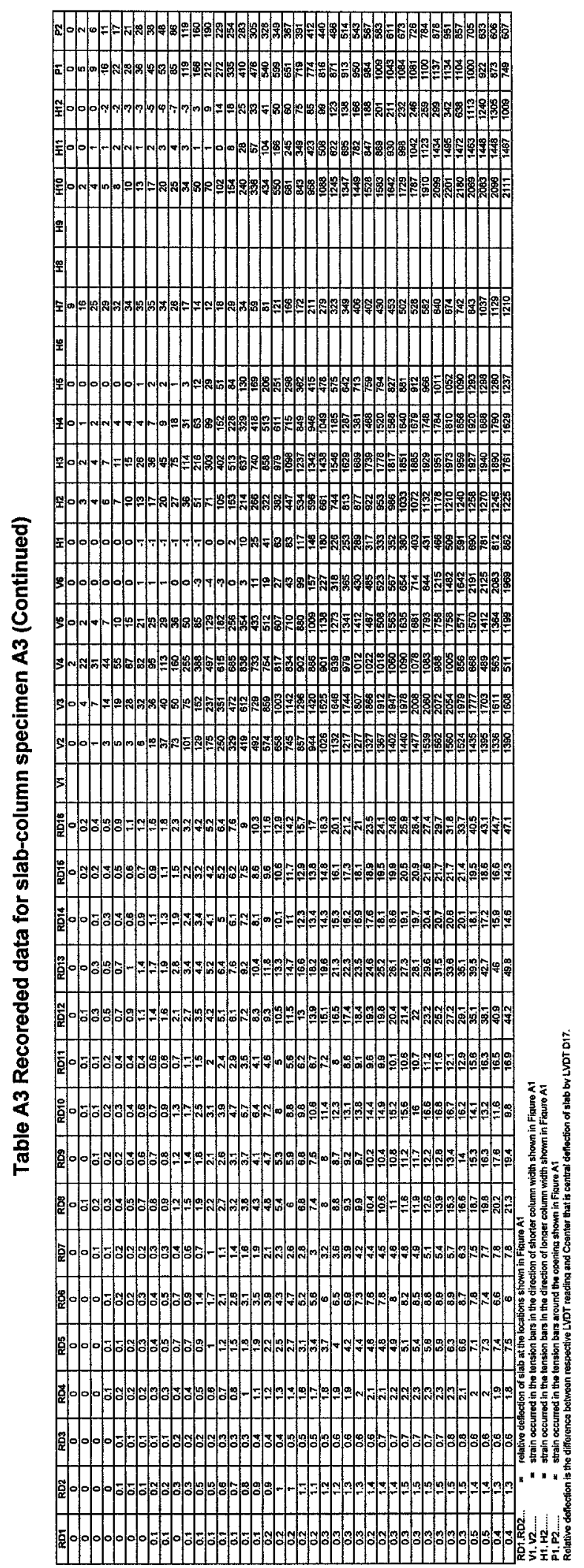




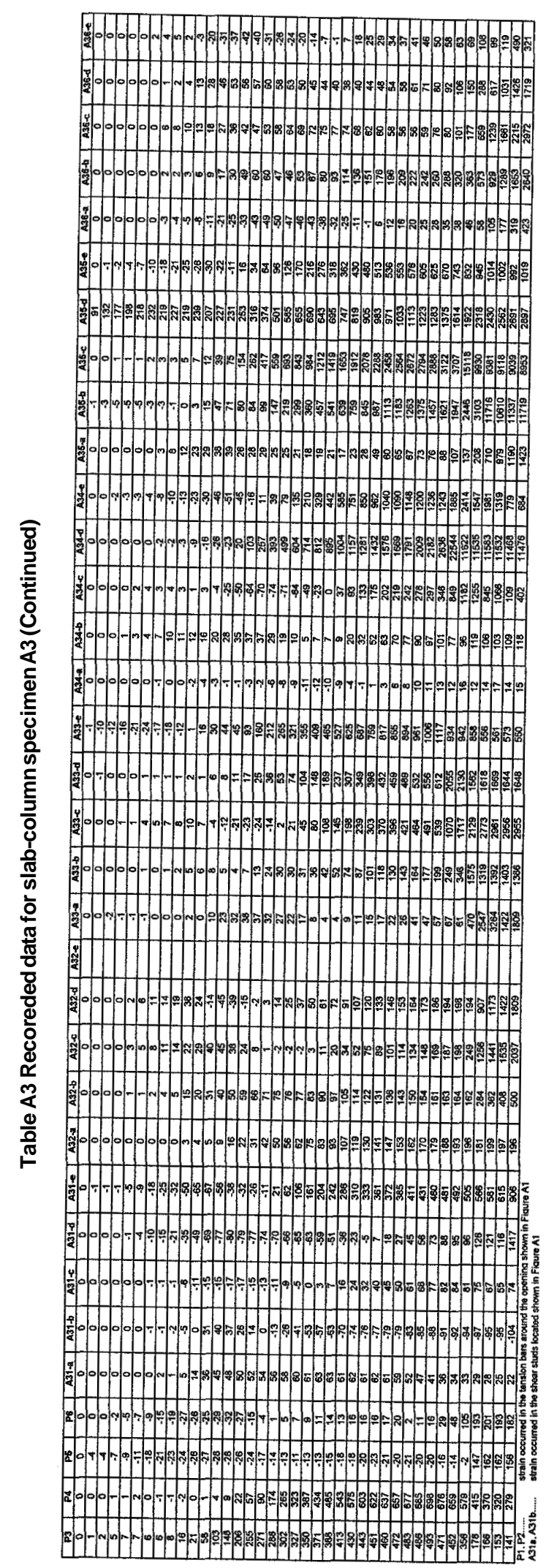



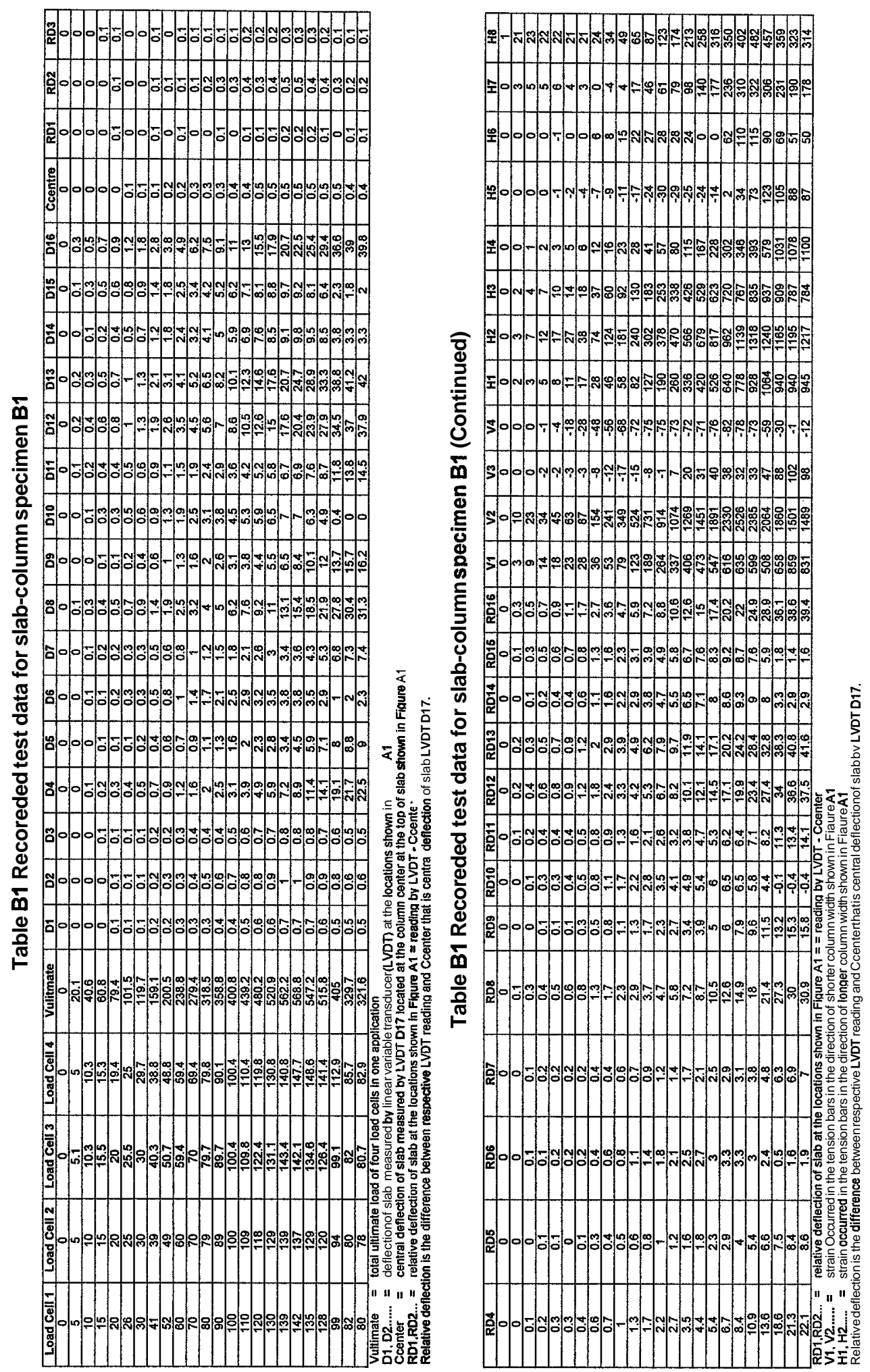


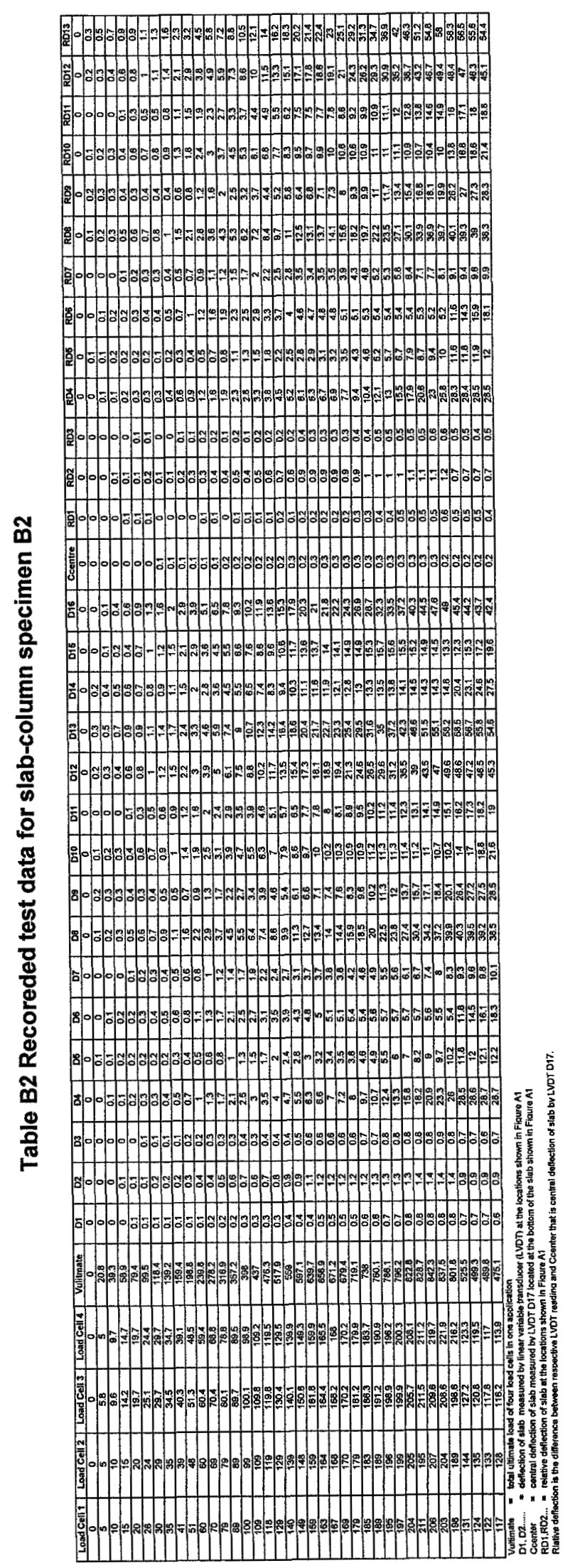



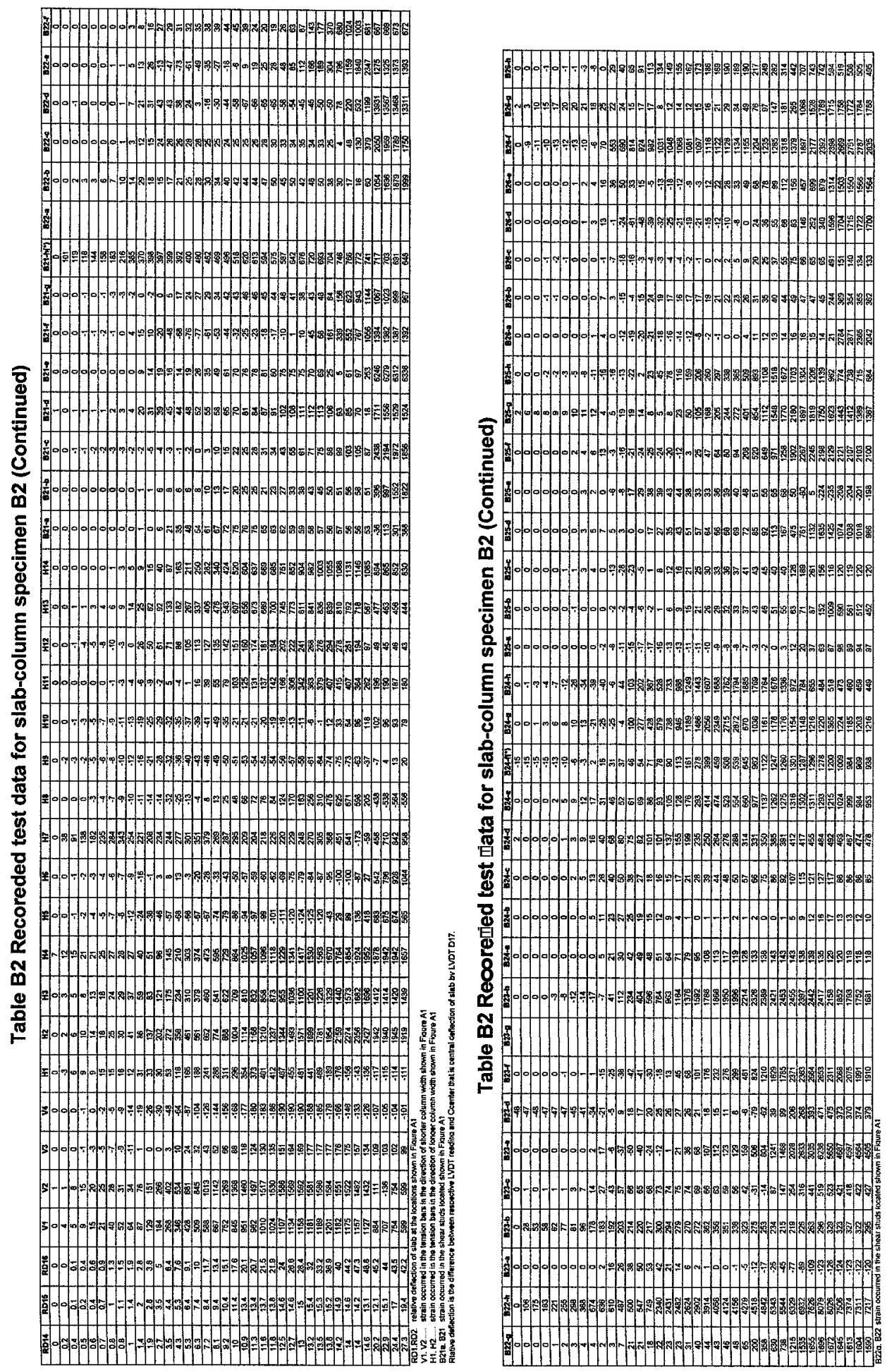


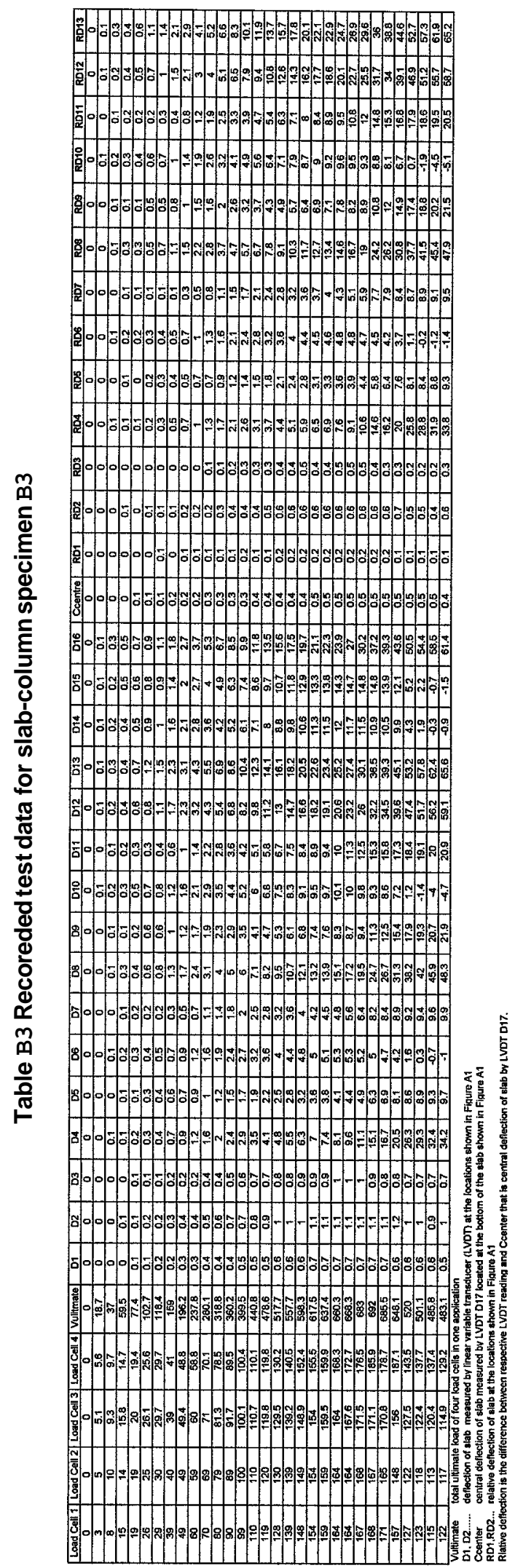



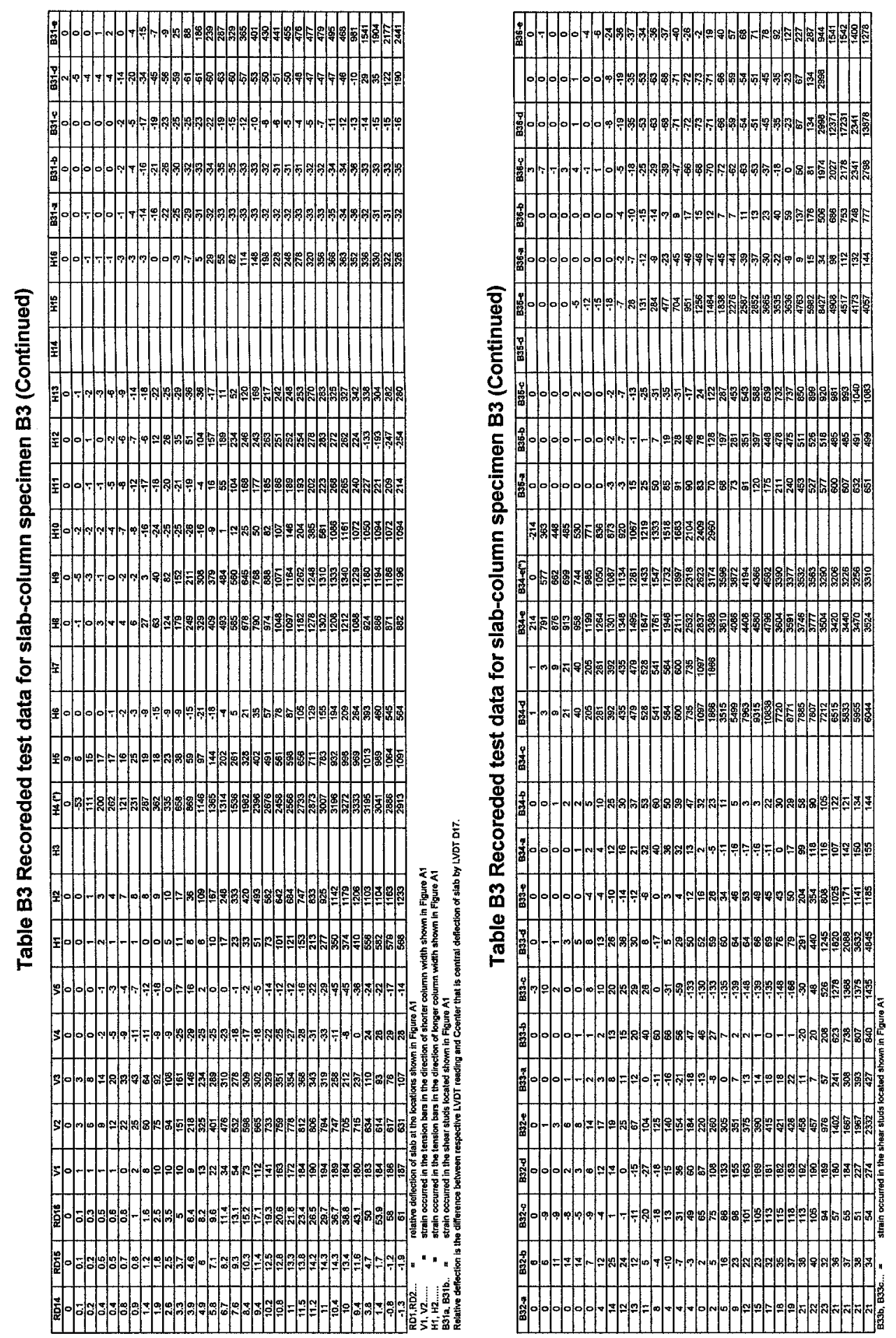


\title{
APPENDIX B
}

\author{
DERIVATION \\ OF THE PUNCHING SHEAR CAPACITY \\ OF SLAB-COLUMN CONNECTION \\ BY THEORY OF PLASTICITY
}




\section{Appendix B}

\section{Derivation for punching shear capacity of slab- column connection by plasticity model}

\section{B.l Punching shear capacity of slab-column connection without opening and without shear reinforcement}

In deriving the punching shear capacity of slab-column connection based on the theory of plasticity, MathematicaSoftware is used.

Consider a slab-column connection with square or rectangular column under concentric punching load, P. The slab is simply supported along its edges. The slab is reinforced in such a way that flexural failure is prevented. A failure mechanism is considered such that the slab portion bounded by the failure surface is punched out vertically to a distance $u$ and the remaining slab portion remains as rigid. The generatrix of failure surface is axisymrnetricand described by a function $r=r(y)$. The strain in the circumferential direction is considered zero and the dowel action of flexural reinforcement is neglected. The punching failure surface for simply supported slab-column connections under concentric punching load is shown in Figure B-1.

The dissipation energy per one unit area of failure surface $W_{A}$ is

$$
\begin{aligned}
& W_{A}=\frac{1}{2} f_{c}^{\prime} u(L-M \sin \alpha) \\
& L=1-2 \frac{f_{t}}{f_{c}^{\prime}} \frac{\sin \varphi}{1-\sin \varphi}=1-\frac{f_{t}}{f_{c}^{\prime}}(k-1) \\
& M=1-2 \frac{f_{t}}{f_{c}^{\prime}} \frac{1}{1-\sin \varphi}=1-\frac{f_{t}}{f_{c}^{\prime}}(k+1) \\
& k=\frac{1+\sin \varphi}{1-\sin \varphi}
\end{aligned}
$$


where $f_{c}^{\prime}=$ cylinder compressive strength of concrete

$f_{t} \quad=$ tensile strength of concrete

$a \quad=$ slope of failure surface

$\varphi \quad=$ angle of internal friction angle of concrete

$\mathrm{u} \quad=$ vertical displacement of slab

The total dissipation of energy $W_{T}$ of the failure surface is

$$
W_{T}=\int_{A} W_{A} d A
$$

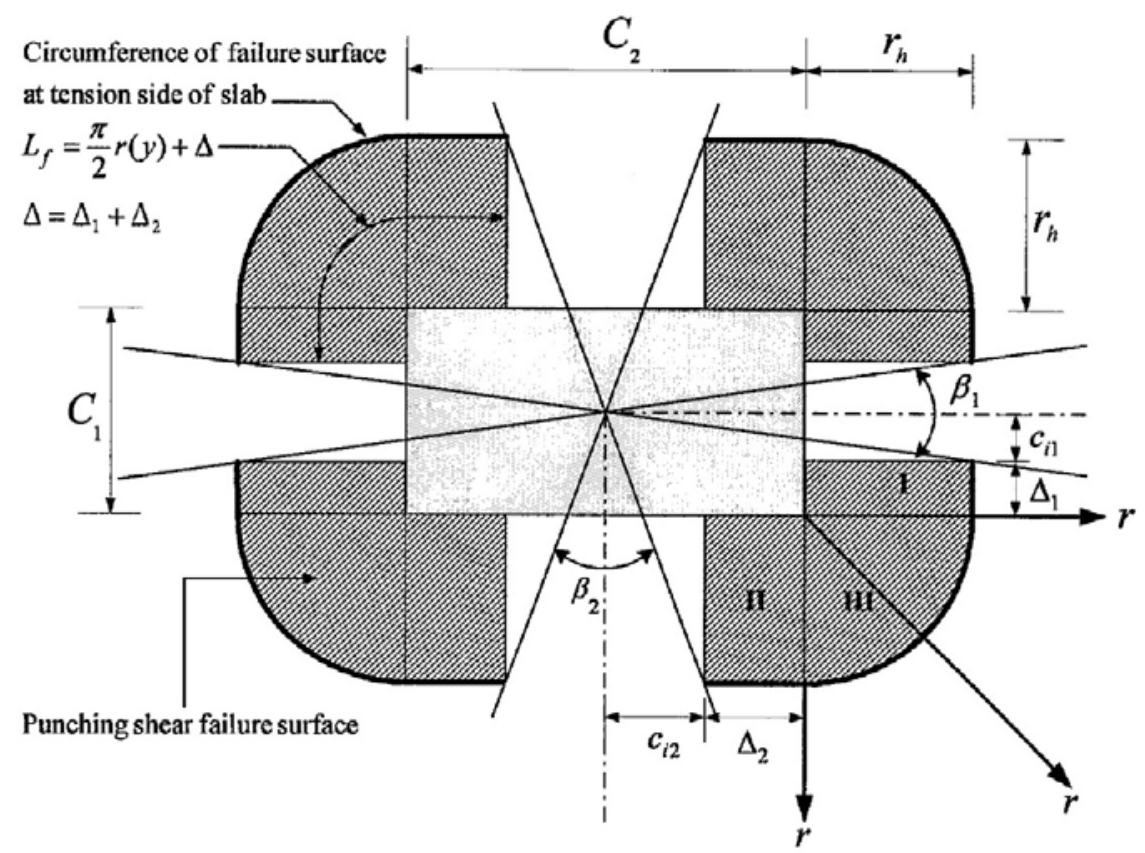

(a) Plan view of failure surface

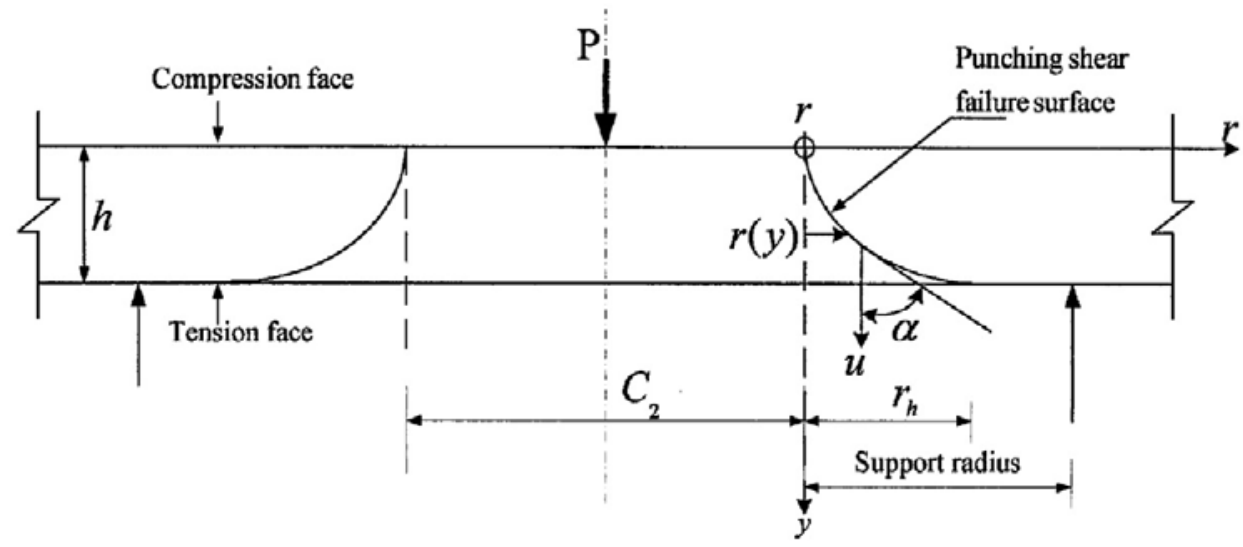

(b) Failure surface generatrix

Figure B-1 Punching shear failure surface for simply supported slab-column connection under concentric load 
By substituting $W_{A}$ from Equation B-1 into Equation B-2, the total dissipation energy of the failure surface is

$$
W_{T}=\frac{1}{2} f_{c}^{\prime} u \int_{A}(L-M \sin \alpha) d A
$$

External virtual work EW due to concentric load $P$ that punches the slab portion confined by the failure surface to a vertical displacement $u$ is

$$
E W=P x u
$$

According to virtual work principle, the external virtual work is equal to the total dissipation energy in the failure surface. Therefore,

$$
\begin{aligned}
& P \times u=\frac{1}{2} f_{c}^{\prime} u \int_{A}(L-M \sin \alpha) d A \\
& P=\frac{1}{2} f_{\mathrm{c}}^{\prime} \int_{A}(L-M \sin \alpha) d A
\end{aligned}
$$

From Figure B-1, the infinitesimal area $d A$ of punching shear failure surface is

$$
\begin{aligned}
& d A=4\left(d A_{l}+d A_{I I}+d A_{I I I}\right) \\
& d A_{I}=\Delta_{1} \frac{d y}{\cos \alpha} \\
& d A_{I I}=\Delta_{2} \frac{d y}{\cos \alpha} \\
& d A_{I I I}=\frac{1}{2} \pi r(y) \frac{d y}{\cos \alpha}
\end{aligned}
$$

where $\mathbf{A}$, and $\Delta_{2}$ are the components of circumferential length of failure surface parallel to shorter and longer column width, respectively, as shown in Figure B-1.

By substituting Equations B-6b, B-6c and B-6d into Equation B-6a, $d A$ is

$$
d A=4\left(\frac{1}{2} \pi r(y)+\Delta_{1}+\Delta_{2}\right) \frac{d y}{\cos \alpha}
$$

Then,

$$
\Delta=\Delta_{1}+\Delta_{2}
$$

From Figure B-la,

$$
\Delta_{1}=\frac{C_{1}}{2}-\left(\frac{C_{2}}{2}+r_{h}\right) \tan \frac{\beta_{1}}{2}
$$




$$
\begin{aligned}
& \Delta_{2}=\frac{C_{2}}{2}-\left(\frac{C_{1}}{2}+r_{h}\right) \tan \frac{\beta_{2}}{2} \\
& \beta_{1}=2 \tan ^{-}\left(\frac{c_{i 1}}{C_{2}+2 r_{h}}\right) \\
& \beta_{2}=2 \tan ^{-1}\left(\frac{c_{i 2}}{C_{1}+2 r_{h}}\right)
\end{aligned}
$$

where $C_{1} \& C_{2}=$ shorter and longer column width, respectively

$r_{h} \quad=$ radius of failure surface at the tension face of slab

$c_{i 1} \& c_{i 2}=$ incremental length of failure surface shown in Figure B-1 $\beta_{1}, \beta_{2,} \Delta_{1}$ and $\mathrm{A}$, can be seen in Figure B-1.

By substituting Equation B-8 into Equation B-7,

$$
d A=4\left(\frac{1}{2} \pi r(y)+\Delta\right) \frac{d y}{\cos \alpha}
$$

And, Equation B-9 can be changed into

$$
d A=4 L_{f} \frac{d y}{\cos \alpha}
$$

and

$$
L_{f}=\frac{1}{2} \pi r(y)+\Delta
$$

where $L_{f}$ is $1 / 4$ of circumferential length of failure surface as shown in Figure B-1.

By substituting $d A$ from Equation B-9 into Equation B-6, the punching shear capacity of slab-column connection presented in integral equation form is obtained:

$$
P=2 f_{c}^{\prime} \int_{0}^{h} \frac{(L-M \sin \alpha)}{\cos \alpha}\left(\frac{1}{2} \pi r(y)+\Delta\right) d y
$$

Equation B-10 is also a functional equation with variables $r(y)$ for the punching shear capacity of slab-column connection. Equation B-10 can be changed into as

$$
P=2 f_{c}, \int_{0}^{h} F(r(y)) d y
$$

and

$$
F(r(y))=\frac{(L-M \sin \alpha)}{\cos \alpha}\left(\frac{1}{2} \pi r(y)+\Delta\right)
$$


We have the relations related to radius of failure surface $r(y)$ as:

$$
\begin{aligned}
& r^{\prime}(y)=\tan \mathrm{a} \\
& \sin \alpha=\frac{r^{\prime}(y)}{\sqrt{1+\left(r^{\prime}(y)\right)^{2}}} \\
& \cos \alpha=\frac{1}{\sqrt{1+\left(r^{\prime}(y)\right)^{2}}}
\end{aligned}
$$

By substituting Equations B-13, B-14 and B-15 into Equation B-12, the function $F(r(y))$ becomes functions of $r(y)$ and $r^{\prime}(y)$.

$$
F\left(r, r^{\prime}\right)=\frac{1}{2}(\pi r(y)+2 \Delta)\left(L \sqrt{1+\left(r^{\prime}(y)\right)^{2}}-M r^{\prime}(y)\right)
$$

By substituting Equation B-16 into Equation B-11,

$$
P=f_{c} \int_{0}^{h}(\pi r(y)+2 \Delta)\left(L \sqrt{1+\left(r^{\prime}(y)\right)^{2}}-M r^{\prime}(y)\right) d y
$$

To obtain the shape of failure surface that gives the least upper bound value of punching shear capacity, the functional Equation B-17 is minimized by $r(y)$ according to calculus of variation. In this case, Euler's equation is used. Euler's equation is

$$
F\left(r, r^{\prime}\right)-r^{\prime} F_{r^{\prime}}\left(r, r^{\prime}\right)=C 1
$$

where $\mathrm{C} 1$ is constant.

By differentiating Equation B-16 by $r^{\prime}(y)$,

$$
F_{r^{\prime}}\left(r, r^{\prime}\right)=\frac{1}{2}(\pi r(y)+2 \Delta)\left(\frac{L r^{\prime}(y)}{\sqrt{1+\left(r^{\prime}(y)\right)^{2}}}-M\right)
$$

By using Equations B-16 and B-19,

$$
F\left(r, r^{\prime}\right)-r^{\prime} F_{r^{\prime}}\left(r, r^{\prime}\right)=\frac{L(\pi r(y)+2 \Delta)}{2 \sqrt{1+\left(r^{\prime}(y)\right)^{2}}}
$$

By substituting Equation B-20 into Euler's equation,

$$
\frac{L(\pi r(y)+2 \Delta)}{2 \sqrt{1+\left(r^{\prime}(y)\right)^{2}}}=C 1
$$




$$
\frac{L}{2 C 1} \frac{(\pi r(y)+2 \Delta)}{\sqrt{1+\left(r^{\prime}(y)\right)^{2}}}=1
$$

By replacing $\mathrm{A}=\frac{\mathrm{L}}{2 \mathrm{C} 1}$ in Equation $\mathrm{B}-22$,

$$
\begin{aligned}
& \frac{A(\pi r(y)+2 \Delta)}{\sqrt{1+\left(r^{\prime}(y)\right)^{2}}}=1 \\
& A(\pi r(y)+2 \Delta)=\sqrt{1+\left(r^{\prime}(y)\right)^{2}} \\
& (A(\pi r(y)+2 \Delta))^{2}=1+\left(r^{\prime}(y)\right)^{2} \\
& 1+\left(r^{\prime}(y)\right)^{2}=A^{2}(\pi r+2 \Delta)^{2}
\end{aligned}
$$

From Equation B-26, the relational equation of $r(y)$ and $r^{\prime}(y)$ can be obtained as

$$
\begin{aligned}
r(y) & =\frac{1}{\pi}\left(\frac{\sqrt{1+\left(r^{\prime}(y)\right)^{2}}}{A}-2 \Delta\right) \\
r^{\prime}(y) & =\sqrt{A^{2}(2 \Delta+\pi r(y))^{2}-1} \\
\text { But, } \quad r^{\prime}(y) & =\frac{d r(y)}{d y}=\tan \alpha
\end{aligned}
$$

Therefore,

$$
\begin{aligned}
& d y=\frac{d r(y)}{r^{\prime}(y)}=\frac{1}{\sqrt{A^{2}(2 \Delta+\pi r(y))^{2}-1}} d r(y) \\
& d y=\frac{1}{\sqrt{A^{2}(2 \Delta+\pi r(y))^{2}-1}} d r(y)
\end{aligned}
$$

By differentiating Equation B-26 by y,

$$
2 \mathrm{r}^{\mathrm{t}}(\mathrm{y}) r^{\prime \prime}(y)=2 A^{2} \pi(\pi r(y)+2 \Delta) r^{\prime}(y)
$$

From Equation B-32, the second-order differential equation of radius of failure surface can be obtained as

$$
r^{\prime \prime}(y)=A^{2} \pi(\pi r(y)+2 \Delta)
$$

However,

$$
r^{\prime \prime}(y)=\frac{d r^{\prime}(y)}{d y}
$$

Therefore,

$$
\begin{aligned}
& \frac{d r^{\prime}(y)}{d y}=A^{2} \pi(\pi r(y)+2 \Delta) \\
& d r^{\prime}(y)=A^{2} \pi(\pi r(y)+2 \Delta) d y
\end{aligned}
$$




$$
d y=\frac{d r^{\prime}(y)}{A^{2} \pi(\pi r(y)+2 \Delta)}
$$

$B y$ substituting equation $B-27$ into Equation $B-36$, the relationship between dy and $r^{\prime}(y)$ is

$$
\begin{aligned}
& d y=\frac{d r^{\prime}(y)}{A^{2} \pi\left(\left(\frac{\sqrt{1+\left(r^{\prime}(y)\right)^{2}}}{A}-2 \Delta\right)+2 \Delta\right)} \\
& d y=\frac{d r^{\prime}(y)}{A^{2} \pi\left(\sqrt{1+\left(r^{\prime}(y)\right)^{2}}\right)}
\end{aligned}
$$

$B y$ solving the second-order differential equation $B-33$, the curvature of failure surface is obtained as

$$
\begin{aligned}
& r(y)=-\frac{2 \Delta}{\pi}+B e^{A \pi y}+C e^{-A \pi y} \\
& r^{\prime}(y)=A \pi\left(B e^{A \pi y}-C e^{-A \pi y}\right)
\end{aligned}
$$

where $A, B \& C$ are constants.

\section{Determination of constants A, B and C}

By substituting $r(y)$ and $r^{\prime}(y)$ from Equations B-39 and B-40 into Equation B-26 and solving it, the relationship between $A, B$ and $\mathrm{C}$ is obtained as follows.

$$
4 A^{2} \pi^{2} B C=1
$$

Therefore,

$$
A=\frac{1}{2 \pi \sqrt{B C}}
$$

From Figure B-1, two boundary conditions for the failure surface $r(y)$ are:

(1) $y=0, r(0)=0$

(2) $y=h, r(h)=r_{h}=-\frac{2 \Delta}{\pi}+B e^{A \pi h}+C e^{-A \pi h}$

where $r_{h}$ is radius of failure surface at the tension face of slab. 
By substituting Equation B-43 from boundary condition (1) into Equations B-39 and B-40,

$$
\begin{aligned}
& B=\frac{2 \Delta}{\pi}-C \\
& r^{\prime}(0)=A \pi(B-C)
\end{aligned}
$$

By substituting Equation B-44 from the boundary condition (2) into Equations B-39 and B-40,

$$
\begin{aligned}
& r_{h}=-\frac{2 \Delta}{\pi}+B e^{A \pi h}+C e^{-A \pi h} \\
& r^{\prime}(h)=A \pi\left(B e^{A \pi h}-C e^{-A \pi h}\right)
\end{aligned}
$$

By using trial and error method, the constants $\mathrm{A}, \mathrm{B}$ and $\mathrm{C}$ and $r_{h}$ can be determined by satisfying Equations B-42, B-45 and B-47. After determining the constant terms related to the radius of failure surface $r(y)$ from Equation B-39, by substituting Equations B-39 and B-40 into Equation B-17 and solving it, the punching shear capacity of slab-column can be obtained.

However, the slope of failure surface at the compression side of slab should not be less than 37 degree because the internal friction angle of concrete is $37^{\circ}$. Therefore, when the initial slope of failure surface at $y=0$ is equal or greater than 37 degree, the failure surface of slab is considered as a curve from top to bottom of slab while the failure surface of slab is considered as a combined shape of a straight line and a curve when the initial slope of failure surface at $y=0$ is less than 37 degree. Thus, there are two cases in determining the punching shear capacity of slab; (1) when the initial slope of failure surface at $y=0$ is equal or greater than 37 degree, and (2) when the initial slope of failure surface at $\mathrm{y}=0$ is less than 37 degree.

Accordingly, the punching capacity of slab for each case is derived as follows. 


\section{B.I.I Initial slope of failure surface at the compression face of slab is equal or greater than $37^{\circ}$}

When the initial slope of failure surface at $y=0$ is equal or greater than 37 degree, the failure surface of slab is considered as a curve from the top to the bottom of slab. The failure surface with slope at the compression face of slab equal or greater than $37^{\circ}$ is shown in Figure $B-2$.

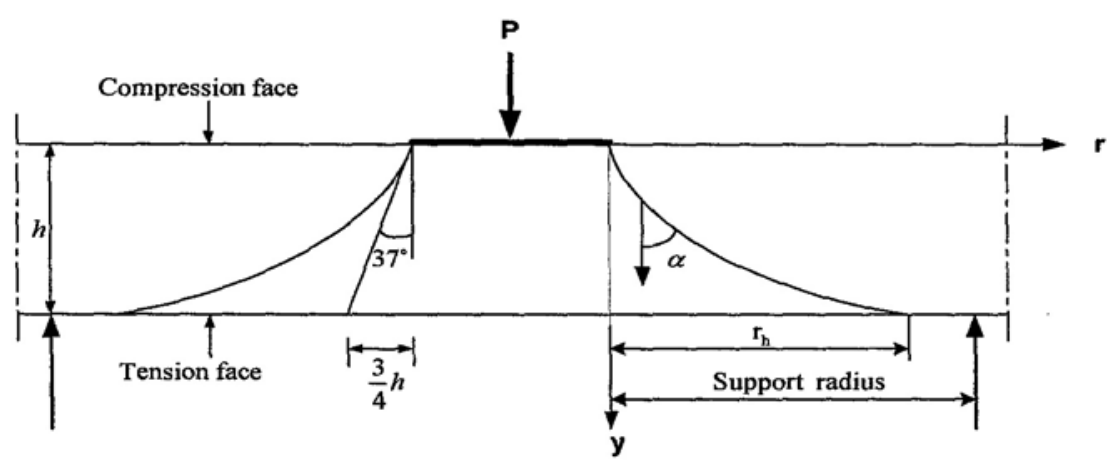

Figure B-2 Punching shear failure surface in curve shape for simply supported slab-column connection under concentric load

$B y$ substituting Equations $B-39$ and $B-40$ into $B-17$,

$$
P=\frac{f_{c}^{\prime}}{A^{2} \pi} \int_{r^{\prime}(0)}^{r^{\prime}(h)}\left(L \sqrt{1+\left(r^{\prime}\right)^{2}}-M r^{\prime}\right) d r^{\prime}(y)
$$

By solving the integration,

$$
P=\frac{f_{c}^{\prime}}{2 A^{2} \pi}\left[L\left(\sinh ^{-1} r^{\prime}+r^{\prime} \sqrt{1+\left(r^{\prime}\right)^{2}}\right)-M\left(r^{\prime}\right)^{2}\right]_{r^{\prime}(0)}^{r^{\prime}(h)}
$$

And by inserting the limits, the punching shear capacity of slab-column connection is obtained as the functions of $r^{\prime}(0)$ and $r^{\prime}(h)$.

$$
\begin{aligned}
P= & \frac{f_{c}^{\prime}}{2 A^{2} \pi}\left(L\left(\left(\sinh ^{-1}\left(r_{h}^{\prime}\right)+r_{h}^{\prime} \sqrt{1+\left(r_{h}^{\prime}\right)^{2}}\right)-\left(\sinh ^{-1}\left(r_{0}^{\prime}\right)+r_{0}^{\prime} \sqrt{1+\left(r_{0}^{\prime}\right)^{2}}\right)\right)\right. \\
& \left.-M\left(\left(r_{h}^{\prime}\right)^{2}-\left(r_{0}^{\prime}\right)^{2}\right)\right)
\end{aligned}
$$

where $r_{0}{ }^{\prime}$ and $r_{h}{ }^{\prime}$ are $r^{\prime}(0)$ and $r^{\prime}(h)$ from Equations B-46 and B-48, respectively. 
In addition, by substituting Equation B-31 and B-39 into Equation B-17,

$$
\begin{aligned}
P= & f_{c}{ }^{r} \int_{0}^{r(h)=r_{h}}(\pi r(y)+2 \Delta)\left(L \sqrt{A^{2}+(\pi r(y)+2 \Delta)^{2}}\right. \\
& \left.-M \sqrt{-1+A^{2}+(\pi r(y)+2 \Delta)^{2}}\right) d r(y)
\end{aligned}
$$

By solving the integration and inserting the limits, the punching shear capacity of slab-column connection is obtained as a function of $r_{h}$,

$$
\begin{aligned}
P= & \frac{f_{c}^{\prime}}{2 A^{2} \pi}\left(L\left(-2 A \Delta \sqrt{-1+4 A^{2} \Delta^{2}}-\ln \left(2 A \Delta+\sqrt{-1+4 A^{2} \Delta^{2}}\right)\right)\right. \\
& +\ln \left(\sqrt{A^{2}\left(-2 \Delta-\pi r_{h}\right)^{2}}+\sqrt{-1+A^{2}\left(-2 \Delta-\pi r_{h}\right)^{2}}\right) \\
& \left.\left.-\sqrt{A^{2}\left(-2 \Delta-\pi r_{h}\right)^{2}} \sqrt{-1+A^{2}\left(-2 \Delta-\pi r_{h}\right)^{2}}\right)+M\left(-4 A^{2} \pi \Delta r_{h}-A^{2} \pi^{2} r_{h}^{2}\right)\right)
\end{aligned}
$$

where $r_{h}$ is obtained from Equation B-47.

Equations B-51 or B-53 gives the punching shear capacity of slab if the failure surface of slab is considered as catenary curve shape from the top to the bottom of slab when the initial slope of failure surface at $y=0$ is equal or greater than 37 degree. The limitation to check if the shape of failure surface is a catenary curve is derived as follows.

\section{Limitation to check if the shape of failure surface is a catenarv curve}

When the initial slope of failure surface at $y=0$ is equal or greater than 37 degree, the slope of failure surface at the compression face of slab can be expressed as

$$
r^{\prime}(0) \geq \frac{3}{4}
$$

By substituting Equation B-46 into B-54,

$$
A \pi(B-C) \geq \frac{3}{4}
$$


By substituting $\mathrm{B}=\frac{2 \Delta}{\pi}-C$ from Equation B-45 into Equation B-55, the constant $\mathrm{C}$ is

$$
C \leq \frac{8 A \Delta-3}{8 A \pi}
$$

By substituting $B=\frac{2 \Delta}{\pi}-C$ from Equation B-45 into Equation B-47,

$$
r_{h}=r(h)=\frac{2}{\pi}\left(\Delta\left(1-e^{A \pi h}\right)+C \pi \sinh (A \pi h)\right)
$$

By solving Equation B-57, the constant $\mathrm{C}$ is

$$
C=\frac{2 \Delta\left(1-e^{A \pi h}\right)+\pi r_{h}}{2 \pi \sinh (A \pi h)}
$$

By substituting Equation B-56 into Equation B-58,

$$
\frac{2 \Delta\left(1-e^{A \pi h}\right)+\pi r_{h}}{2 \pi \sinh (A \pi h)} \leq \frac{8 A \Delta-3}{8 A \pi}
$$

By solving Equation B-59, the radius of failure surface $r_{h}$ at the tension face of slab is

$$
r_{h} \leq \frac{8 A \Delta(1+\cosh (A \pi h))+3 \sinh (A \pi h)}{4 A \pi}
$$

However, the radius of failure surface at the tension face of the slab is equal or greater than $\frac{3}{4} \mathrm{~h}$, where $\mathrm{h}$ is thickness of slab, when the initial slope of failure surface at $\mathrm{y}=0$ is equal or greater than 37 degree. Therefore,

$$
r_{h} \geq \frac{3}{4} h
$$

By using Equation B-60 and B-61, the radius of failure surface at the tension face of slab is

$$
\frac{3}{4} h \leq r_{h} \leq \frac{8 A \Delta(1+\cosh (A \pi h))+3 \sinh (A \pi h)}{4 A \pi}
$$

Thus, when the radius of failure surface at the bottom of slab $r_{h}$ satisfies Equation B-62, the shape of failure surface for $0 \leq y \leq h$ is a catenary curve. Therefore, when the radius of failure surface at the tension face of slab is a catenary curve, the punching shear capacity of slab can be obtained by using Equation B-51 or B-53. 


\section{B.1.2 Initial slope of failure surfaceat the compressionface of slab is less than $37^{\circ}$}

When the initial slope of failure surface at $y=0$ is less than 37 degree, the failure surface of slab is considered as a combination of two portions; (a) straight portion with slope of 37 degree and (b) curved portion. The straight portion is from compression face of slab to $h_{0}$ at which straight portion intersects with curved portion, where $h_{0}$ is the vertical distance from the top of slab to the intersection point of straight portion and curved portion. The curved portion is fi-om $h_{0}$ to the tension face of slab. The failure surface having the combination of a straight line and a curve is shown in Figure B-3.

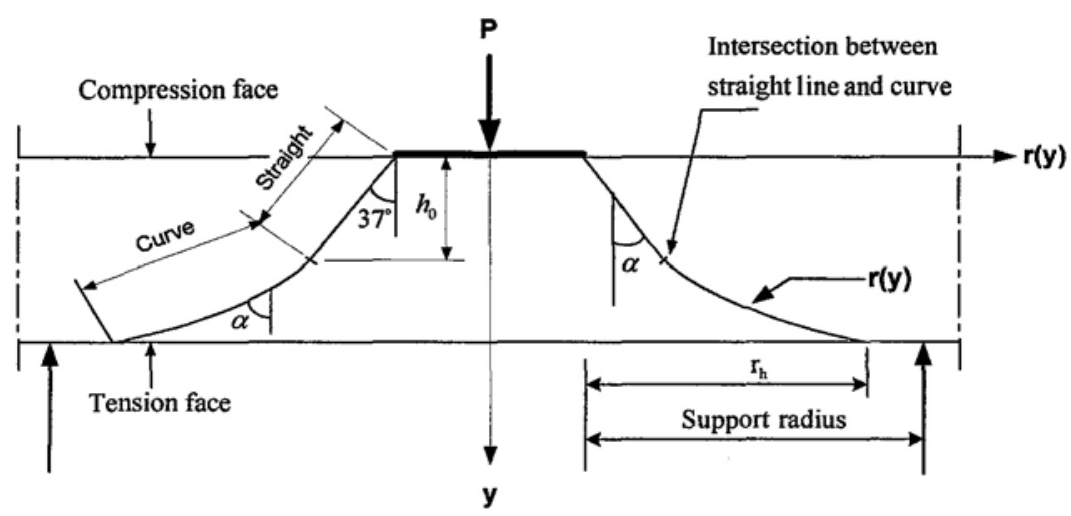

Figure B-3 Punching shear failure surface composed with a straight line and a curve for simply supported slab-column connection under concentric load

(a) For straight portion of failure surface from $y=0$ to $h_{0}$

As mentioned above, the slope of straight portion of failure surface is 37 degree. Therefore, by using Equations B-39 and B-40, the radius of failure surface and its derivative can be expressed as

$$
\begin{aligned}
& r(y)=\frac{3}{4} y \quad \text { for } \quad 0 \leq y \leq h_{0} \\
& r^{\prime}(y)=\frac{3}{4} \quad \text { for } \quad 0 \leq y \leq h_{0}
\end{aligned}
$$


For straight portion of failure surface, there are two boundary conditions. They are as follows.

(1) $y=0, r(0)=0$

$$
y=h_{0}, r\left(h_{0}\right)=\frac{3}{4} h_{0}
$$

(2) $y=0, r^{\prime}(0)=\frac{3}{4}$

$$
y=h_{0}, r^{\prime}\left(h_{0}\right)=\frac{3}{4}
$$

By substituting Equations B-63a and B-63b into Equation B-17,

$$
P_{L}=f_{c} \int_{0}^{h_{0}}\left(2 \Delta+\frac{3}{4} \pi y\right)\left(L \sqrt{1+\left(\frac{3}{4}\right)^{2}}-\frac{3}{4} M\right) d y
$$

By solving Equation B-66 and inserting the integration limits into it, the punching shear capacity for straight portion of failure surface is

$$
P_{L}=\frac{1}{32}(5 L-3 M) f_{c}^{\prime} h_{0}\left(16 \Delta+3 \pi h_{0}\right)
$$

where $h_{0}$ is the vertical distance from the top of slab to intersection point of straight and curved portion of failure surface shown in Figure B-3.

\section{(b) For curved portion of failure surface from $y=h_{0}$ to $\mathrm{h}$}

As mentioned above, the straight portion and the curved portion of failure intersect at the point in a vertical distance $h_{0}$ from the top of slab. Therefore, the curve portion of failure surface is from the intersection point of straight portion and curved portion to the tension face of the slab. By using Equations B-39 and B-40, the radius of failure and its derivative for curved portion of failure surface are

$$
\begin{aligned}
& r(y)=-\frac{2 \Delta}{\pi}+B e^{A \pi y}+C e^{-A \pi y} \text { for } h_{0} \leq y \leq h \\
& r^{\prime}(y)=A \pi\left(B e^{A \pi y}-C e^{-A \pi y}\right) \text { for } h_{0} \leq y \leq h
\end{aligned}
$$


For curved portion of failure surface, there are two boundary conditions. They are as follows.

$$
\begin{aligned}
& \text { (1) } y=h_{0}, r\left(h_{0}\right)=r_{h 0}=-\frac{2 \Delta}{\pi}+B e^{A \pi h_{0}}+C e^{-A \pi h_{0}} \\
& y=h, r(h)=r_{h}=-\frac{2 \Delta}{\pi}+B e^{A \pi h}+C e^{-A \pi h} \\
& \text { (2) } y=h_{0}, r^{\prime}\left(h_{0}\right)=r_{h 0}^{\prime}=A \pi\left(B e^{A \pi h_{0}}-C e^{-A \pi h_{0}}\right) \\
& y=h, r^{\prime}(h)=r_{h}{ }^{\prime}=A \pi\left(B e^{A \pi h}-C e^{-A \pi h}\right)
\end{aligned}
$$

By equating the radii of failure surface from Equations B-64b and B-70a at $\mathrm{y}=h_{0}$ and substitutingB $=\frac{\mathbf{2} A}{\pi}-C$, we get

$$
\frac{3}{4} h_{0}=-\frac{2 \Delta}{\pi}+\left(\frac{2 \Delta}{\pi}-C\right) e^{A \pi h_{0}}+C e^{-A \pi h_{0}}
$$

From Equation B-72, the following new constant $\mathrm{C}$ for curved portion of failure surface is obtained.

$$
C=\frac{-8 \Delta\left(-1+e^{A \pi h_{0}}\right)+3 \pi h_{0}}{4 \pi\left(e^{-A \pi h_{0}}-e^{A \pi h_{0}}\right)}
$$

The other new constants A and B related to new constant C from Equation B-68 can be obtained by using Equations B-42 and B-45 for curved portion of failure surface from $h_{0}$ to the tension face of slab.

The $r_{h 0}^{\prime}$ and $r_{h}^{\prime}$ from Equations B-71a and B-71b are substituted into Equation B-51 instead of $r_{0}{ }^{\prime}$ and $r_{h}{ }^{\prime}$, respectively, and the punching shear capacity for curved portion of failure surface is

$$
\begin{aligned}
P_{C}= & \frac{f_{c}{ }^{\prime}}{2 A^{2} \pi}\left(L\left(\left(\sinh ^{-1}\left(r_{h}{ }^{\prime}\right)+r_{h}{ }^{\prime} \sqrt{1+\left(r_{h}{ }^{\prime}\right)^{2}}\right)-\left(\sinh ^{-1}\left(r_{h 0}{ }^{\prime}\right)+r_{h 0}{ }^{\prime} \sqrt{1+\left(r_{h 0}{ }^{\prime}\right)^{2}}\right)\right)\right. \\
& \left.-M\left(\left(r_{h}^{\prime}\right)^{2}-\left(r_{0}^{\prime}\right)^{2}\right)\right)
\end{aligned}
$$


Finally, the punching shear capacity $\mathrm{P}$ for the slab-column connection when the initial slope of failure surface at $\mathrm{y}=0$ is less than 37 degree can be obtained by summing up $P_{L}$ from Equation B-67 and $P_{C}$ from Equation B-74.

$$
\mathrm{P}=P_{L}+P_{C}
$$

Equation B-75 gives the punching shear capacity for slab-column connection if the failure surface of slab is considered as a combination of a straight line and a curve fiom the top to the bottom of slab when the initial slope of failure surface at $y=0$ is less than 37 degree. The limitation to check if the shape of failure surface is a combination of a straight line and a curve fiom the top to the bottom of slab is derived as follows.

\section{Limitation to check if the shape of failure surface is a combination of a straight} line and a curve

When the initial slope of failure surface at $y=0$ is less than 37 degree, the slope of failure surface at the compression face of slab can be expressed as

$$
r^{\prime}(0)<\frac{3}{4}
$$

By substituting Equation B-46 into B-76,

$$
A \pi(B-C)<\frac{3}{4}
$$

By substitutingB $=\frac{2 \mathrm{~A}}{\pi}-C$ from Equation B-45 into Equation B-77, the constant $\mathrm{C}$ is

$$
C>\frac{8 A \Delta-3}{8 A \pi}
$$

By substituting Equation B-58 into Equation B-78,

$$
\frac{2 \Delta\left(1-e^{A \pi h}\right)+\pi r_{h}}{2 \pi \sinh (A \pi h)}>\frac{8 A \Delta-3}{8 A \pi}
$$

By solving Equation B-79, the radius of failure surface $r_{h}$ at the tension face of slab is

$$
r_{h}>\frac{8 A \Delta(1+\cosh (A \pi h))+3 \sinh (A \pi h)}{4 A \pi}
$$


Thus, when the radius of failure surface at the bottom of slab satisfies Equation B-80, the equation of failure surface for $0 \leq y \leq h$ is a combination of a straight line and a curve from the top to the bottom of slab. Therefore, when the radius of failure surface at the tension face of slab is a combination of a straight line and a curve, the punching shear capacity of slab can be obtained by using Equation B-75.

\section{B.2 Punching shear capacity of slab-column connection with opening}

When the slab-column connection has opening adjacent to the column, the punching shear capacity of slab-column connection decreases because the concrete area against punching is reduced due to opening. In the same way, the area of failure surface is reduced due to opening. Therefore, some parts of failure surface around the opening are considered ineffective to resist punching due to opening. The punching shear capacity sustained by the ineffective area of failure surface is defined as the ineffective punching shear capacity of slab due to opening. Thus, the punching shear capacity of slab-column connection with opening can be obtained as follows.

$$
P_{o p}=\boldsymbol{P}-\bar{P}_{o p}
$$

where $P_{o p}=$ punching shear capacity of slab-column connection with opening

$$
\begin{aligned}
P= & \text { punching shear capacity of slab-column connection } \\
\bar{P}_{o p}= & \text { ineffective punching shear capacity of slab-column connection due to } \\
& \text { opening }
\end{aligned}
$$

The ineffective punching shear capacity of slab-column connection due to opening can be determined as follows.

$$
\begin{aligned}
& P_{o p} \times u=P \times u-\bar{P}_{o p} \times u \\
& \bar{P}_{o p} \times u=\int_{A_{o p}} W_{A} d A_{o p}
\end{aligned}
$$

where $A, \quad=$ ineffective area of failure surface due to opening

$W_{A}=$ dissipation energy per unit area of failure surface from Equation B-1

$u=$ vertical displacement of slab portion confined by the area of failure surface 
By substituting $W_{A}$ from Equation B-1 into Equation B-82a,

$$
\bar{P}_{o p} \times u=\frac{1}{2} f_{c}^{\prime} u \int_{A_{o p}}(L-M \sin \alpha) d A_{o p}
$$

The integral form of ineffective punching shear capacity of slab due to opening is

$$
\begin{aligned}
& \bar{P}_{o p}=\frac{1}{2} f_{c}{ }^{\prime} \int_{A_{o p}}(L-M \sin \alpha) d A_{o p} \\
& d A_{o p}=\left(\eta_{1}+\eta_{2} r(y)\right) \frac{d y}{\cos \alpha} \\
& d A_{o p}=L_{o p} \frac{d y}{\cos \alpha} \\
& L_{o p}=\eta_{1}+\eta_{2} r(y)
\end{aligned}
$$

where $L_{o p}$ is the circumferential length of ineffective area of failure surface due to opening and $\eta_{1}$ and $\eta_{2}$ are terms related to the circumferential length of ineffective area of failure surface due to opening.

By substituting Equation B-85 into Equation B-84,

$$
\bar{P}_{o p}=\frac{1}{2} f_{c}{ }^{h} \int_{0}^{h}(L-M \sin \alpha)\left(\eta_{1}+\eta_{2} r(y)\right) \frac{d y}{\cos \alpha}
$$

Equation B-86 can be written as

$$
\overline{\mathrm{Pop}}=\frac{1}{2} f_{c}\left(\bar{P} \eta_{1}+\bar{P} \eta_{2}\right)
$$

$\bar{P}_{o p} \eta_{1}$ and $\bar{P}_{o p} \eta_{1}$ can be expressed as

$$
\begin{aligned}
& \bar{P}_{\eta_{1}}=\int_{0}^{h} \eta_{1}(L-M \sin \alpha) \frac{d y}{\cos \alpha} \\
& \overline{\mathrm{P}}_{\eta_{2}}=\int_{0}^{h} \eta_{2} r(y)(L-M \sin \alpha) \frac{d y}{\cos \alpha}
\end{aligned}
$$

By substituting Equations B-13, B-14, B-15 and B-27 into B-87a,

$$
\bar{P}_{\eta_{1}}=\frac{\eta_{1}}{A \pi} \int_{r^{\prime}(0)}^{r^{\prime}(h)}\left(L-\frac{M r^{\prime}(y)}{\sqrt{1+\left(r^{\prime}(y)\right)^{2}}}\right) d r^{\prime}(y)
$$


By integrating and substituting the limits,

$$
P_{\eta_{1}}=\frac{1}{A \pi}\left(L\left(r_{h}^{\prime}-r_{0}{ }^{\prime}\right)+M\left(-\sqrt{1+\left(r_{h}{ }^{\prime}\right)^{2}}+\sqrt{1+\left(r_{0}{ }^{\prime}\right)^{2}}\right)\right)
$$

where $r_{0}{ }^{\prime}$ and $r_{h}{ }^{\prime}$ are $r^{\prime}(0)$ and $\boldsymbol{r}^{\prime}(\boldsymbol{h})$ from Equations B-46 and B-48, respectively.

By substituting Equations B-13, B-14, B-15 and B-27 into B-87b,

$$
\bar{P}_{\eta_{2}}=\frac{\eta_{1}}{A^{2} \pi^{2}} \int_{r^{\prime}(0)}^{r^{\prime}(h)}\left(\frac{\left(-2 A \Delta+\sqrt{1+\left(r^{\prime}(y)\right)^{2}}\right)\left(-M r^{\prime}(y)+\sqrt{1+\left(r^{\prime}(y)\right)^{2}}\right)}{\sqrt{1+\left(r^{\prime}(y)\right)^{2}}}\right) d r^{\prime}(y)
$$

By integrating and substituting the limits,

$$
\begin{gathered}
P_{\eta_{2}}=\frac{1}{2 A^{2} \pi^{2}}\left(L\left(\sin ^{-1}\left(r_{h}{ }^{\prime}\right)-\sin ^{-1}\left(r_{0}{ }^{\prime}\right)+r_{h}{ }^{\prime} \sqrt{1+\left(r_{h}{ }^{\prime}\right)^{2}}-r_{0}{ }^{\prime} \sqrt{1+\left(r_{0}{ }^{\prime}\right)^{2}}+4 A \Delta\left(r_{0}{ }^{\prime}-r_{h}{ }^{\prime}\right)\right)\right. \\
+M\left(\left(r_{0}{ }^{\prime}\right)^{2}-\left(r_{h}{ }^{\prime}\right)^{2}+4 A \Delta\left(\sqrt{1+\left(r_{h}{ }^{\prime}\right)^{2}}-\sqrt{1+\left(r_{0}{ }^{\prime}\right)^{2}}\right)\right)
\end{gathered}
$$

where $r_{0}{ }^{\prime}$ and $r_{h}{ }^{\prime}$ are $r^{\prime}(0)$ and $r^{\prime}(h)$ from Equations B-46 and B-48, respectively.

The punching shear capacity of slab-column connection reduced due to opening can be obtained by using Equation B-87. However, $L_{o p}$ varies depending on the location of opening and method used to determine the ineffective area of failure surface due to opening. In addition, even for same opening location, $L_{o p}$ may vary depending on the position of intersection points of two projection lines with the circumference of failure surface. Thus, $L_{o p}$ needs to be derived for various location of opening and for the method used to determine the ineffective area of failure surface.

The ineffective area of failure surface due to opening is defined as the area under the plan area of failure surface bounded by two projection lines which propagate from the inside of column section through two comers of opening and intersect at two points on the circumference of failure surface. Regarding to these two projection lines that confine the ineffective area of failure surface due to opening, there are two methods of propagation of two projection lines considered in this study. They are classified as method AI and method AII depending on their starting points inside the column section. In method AI, the projection lines start from the center of column 
while in method AII, the projection lines start from the center of $1 / 3$ area of column section, which is divided along the longer column width, close to the shorter column width nearest to the opening. For example, for the slab with opening located parallel and adjacent to the shorter column width, the ineffective areas of failure surface due to opening confined by two projection lines using by methods AI and AII are presented by the shaded areas shown in Figure B-4.

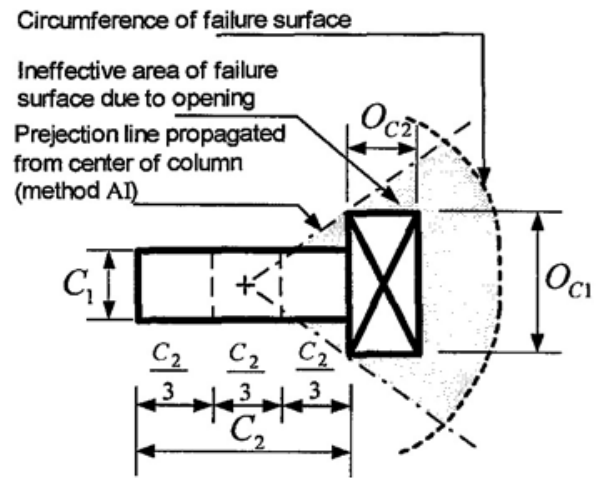

(a) Projection lines by method AI

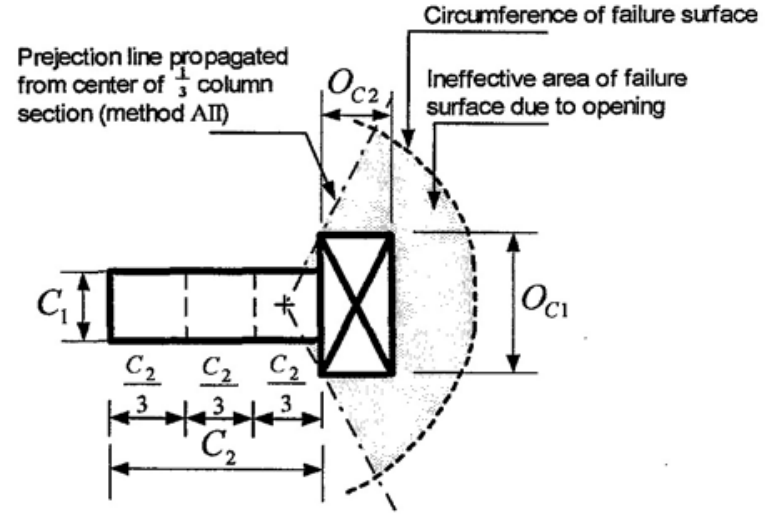

(b) Projection lines by method AII

Figure B-4 Ineffective area of failure surface in the slab due to opening confined by two projection lines

There are five kinds of opening locations considered in this study. They are (a) opening location at adjacent comer of column, (b) opening location parallel and adjacent to the shorter side of column, (c) opening location perpendicular and adjacent to the longer side of column, (d) opening location parallel and adjacent to the middle of longer side of column, and (e) opening location perpendicular and adjacent to the shorter side of column. Five kinds of opening location considered in this study are shown in Figure B-5. For these five kinds of opening location shown in Figure B-5, $L_{o p}, \eta_{1}$ and $\eta_{2}$ terms for Equation B-85, B-85a and B-85b are derived as follows. 


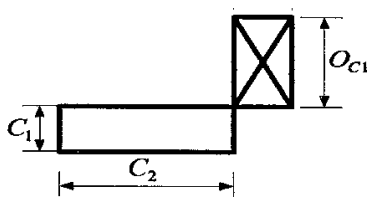

(a) Opening adjacent to the corner of column

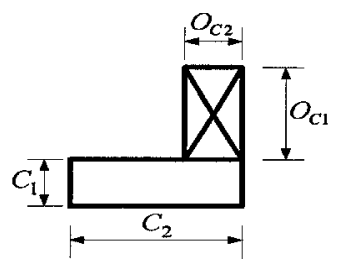

(c) Opening perpendicular and adjacent to the longer side of column end

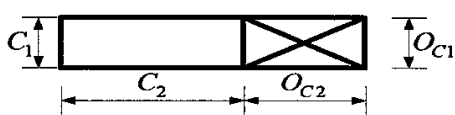

(e) Opening perpendicular and adjacent to the shorter side of column

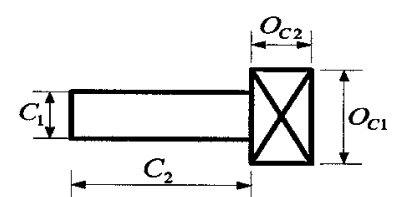

(b) Opening parallel and adjacent to the shorter side of column

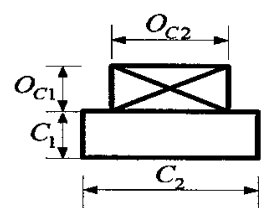

(d) Opening perpendicular and adjacent to the middle of longer side of column

Figure B-5 Different kinds of opening locations

\section{B.2.1 Ineffectivearea of failure surface due to opening by using method AI}

The ineffective area of failure surface due to opening by using method AI is the area under the plan area of failure surface bounded by two projection lines which propagate from the center of column through two comers of opening and extend up to intersect the circumference of failure surface. For this kind of ineffective area of failure surface due to opening by using method AI for five kinds of opening location described above, $L_{o p}, \eta_{1}$ and $\eta_{2}$ terms are derived as follows.

\section{(a) Opening location at adjacent corner of column}

Opening in the slab is located at adjacent comer of column. The ineffective area of failure surface due to this location of opening by using method AI is shown in Figure B-6. To confine the ineffective area of failure surface due to opening, two projection lines are propagated from the center of the column through two comers of opening at 
$\mathrm{B}$ and $\mathrm{G}$ and they intersect the circumference of failure surface at the tension face of the slab at D and E.

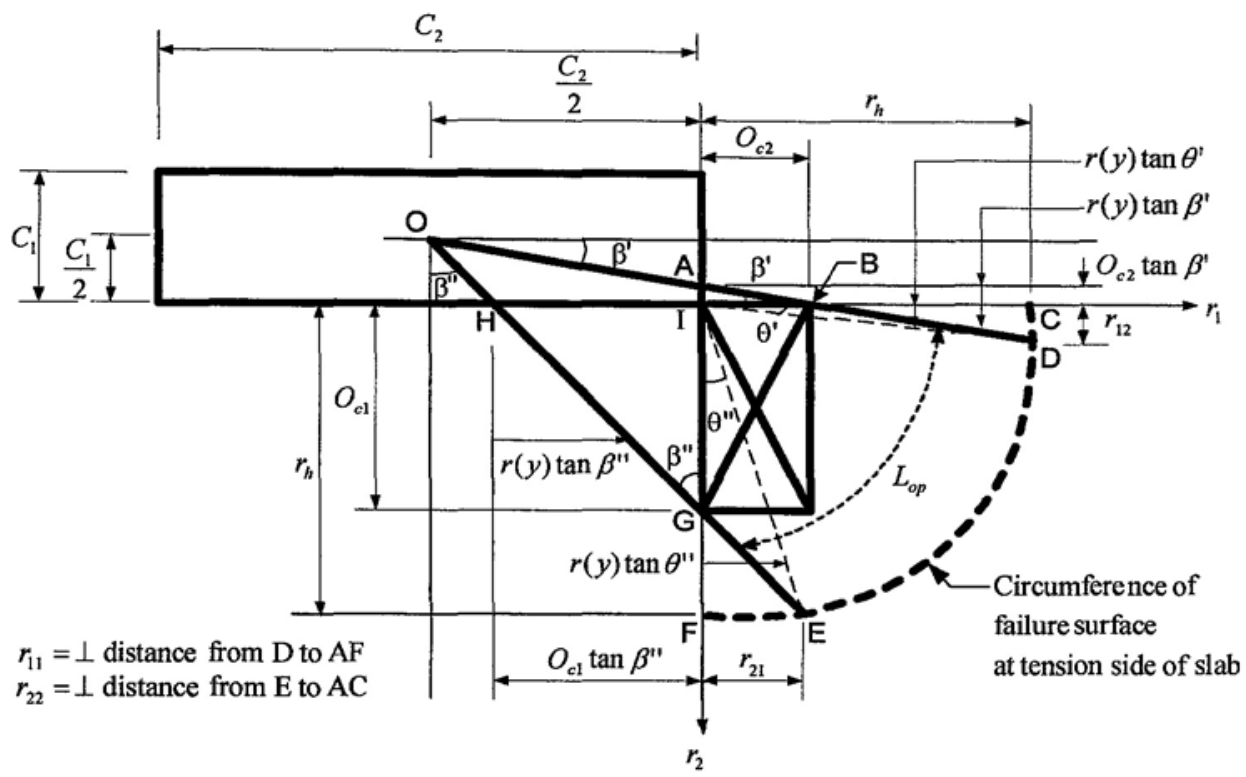

Figure B-6 Ineffective area of failure surface due to opening location (a) by using method $\mathbf{A I}$

From Figure B-6, the circumferential length $L_{o p}$ of ineffective area of failure surface due to opening is

$$
\begin{aligned}
L_{o p}= & \left(O_{c 2} \tan \beta^{\prime}+r(y) \tan \theta^{\prime}+r(y)\left(\frac{\pi}{2}-\left(\theta^{\prime}+\theta^{\prime \prime}\right)\right)+r(y) \tan \theta^{\prime \prime}+O_{c 1} \tan \beta^{\prime \prime}\right) \\
& -\left(r(y) \tan \beta^{\prime}+r(y) \tan \beta^{\prime \prime}\right)
\end{aligned}
$$

In Equation B-91, the terms related and not related to $r(y)$ are separated as follows:

$$
\begin{aligned}
L_{o p}=\left(O_{c 2} \tan \beta^{\prime}+O_{c 1} \tan \beta^{\prime \prime}\right)+r(y) & \left(\frac{\pi}{2}-\theta^{\prime}-\theta^{\prime \prime}-\tan \beta^{\prime}-\tan \beta^{\prime \prime}+\tan \theta^{\prime}+\tan \theta^{\prime \prime}\right) \\
L_{o p} & =\eta_{1}+\eta_{2} r(y) \\
\eta_{1} & =O_{c 2} \tan \beta^{\prime}+O_{c 1} \tan \beta^{\prime \prime} \\
\eta_{2} & =\frac{\pi}{2}-\theta^{\prime}-\theta^{\prime \prime}-\tan \beta^{\prime}-\tan \beta^{\prime \prime}+\tan \theta^{\prime}+\tan \theta^{\prime \prime} \\
\beta^{\prime} & =\tan ^{-1}\left(\frac{C_{1}}{C_{2}+2 O_{c 2}}\right)
\end{aligned}
$$




$$
\begin{aligned}
& \beta^{\prime \prime}=\tan ^{-1}\left(\frac{C_{2}}{C_{1}+2 O_{c 1}}\right) \\
& \theta^{\prime}=\sin ^{-1} \frac{r_{11}}{r_{h}} \\
& \theta^{\prime \prime}=\sin ^{-1} \frac{r_{21}}{r_{h}}
\end{aligned}
$$

where $r_{11}$ and $r_{21}$ are the coordinates of $D$ and $E$, respectively. The $r_{11}$ and $r_{21}$ can be determined as follows.

From Figure B-6, the equation of the projection line OD can be obtained as

$$
r_{11}=m_{11} r_{12}+m_{12}
$$

where the first subscript present the coordinate axis passed by the projection line and the second subscript present the coordinate axis parallel to the components of respective projection line. The $m_{11}$ and $m_{12}$ are determined by known boundary conditions of projection line OD. The boundary conditions of projection line OD are

(1) when $r_{11}=O_{c 2}, r_{12}=0$

(2) when $r_{11}=0, \quad r_{12}=O_{c 2} \tan \beta^{\prime}$

By using these boundary condition in Equation B-100,

$$
\begin{aligned}
& m_{11}=\tan \beta^{\prime} \\
& m_{12}=O_{c 2}
\end{aligned}
$$

By using circle equation,

$$
r_{1}^{2}+r_{2}^{2}=r_{h}^{2}
$$

By equating equation B-100 and B-103 at $r_{1}=r_{11}$,

$$
m_{11} r_{12}+m_{12}=\sqrt{r_{h}^{2}-r_{12}^{2}}
$$

Equation B-104 can be solved as,

$$
\begin{aligned}
& r_{12}^{2}\left(m_{11}^{2}+1\right)+2 m_{11} m_{12} r_{12}+\left(m_{11}^{2}-r_{h}^{2}\right)=0 \\
& r_{12}^{2}\left(a_{1}\right)+b_{1} r_{12}+\left(c_{1}\right)=0 \\
& a_{1}=m_{11}^{2}+1 \\
& b_{1}=2 m_{11} m_{12} \\
& c_{1}=m_{12}^{2}-r_{h}^{2}
\end{aligned}
$$




$$
r_{12}=\frac{-b_{1} \pm \sqrt{b_{1}^{2}-4 a_{1} c_{1}}}{2 a_{1}}
$$

Similarly, $r_{21}$ is determined as follows.

From Figure B-6, the equation of the projection line OE can be obtained as

$$
\begin{aligned}
& r_{21}=m_{21} r_{22}+m_{22} \\
& r_{22}=\frac{-b_{2} \pm \sqrt{b_{2}^{2}-4 a_{2} c_{2}}}{2 a_{2}} \\
& a_{2}=m_{21}^{2}+1 \\
& b_{2}=2 m_{21} m_{22} \\
& c_{2}=m_{22}^{2}-r_{h}^{2}
\end{aligned}
$$

By using these boundary conditions of the projection line $\mathrm{OE}$,

$$
\begin{aligned}
& m_{21}=\frac{\left(\frac{C_{2}}{2}-\frac{C_{1}}{2} \tan \beta^{\prime \prime}\right)}{O_{c 1}} \\
& m_{22}=-\left(\frac{C_{2}}{2}-\frac{C_{1}}{2} \tan \beta^{\prime \prime}\right)
\end{aligned}
$$

\section{(b) Opening location parallel and adjacent to the shorter side of column}

Opening in the slab is located parallel and adjacent to the shorter side of column. The ineffective area of failure surface due to this location of opening presented by using method AI is shown in Figure B-7. To confine the ineffective area of failure surface due to opening, two projection lines are propagated from the center of the column through two comers of opening at B and G and they intersect the circumference of failure surface at the tension face of the slab at $\mathrm{C}$ and $\mathrm{F}$.

From Figure B-7, the circumferential length $L_{o p}$ of ineffective area of failure surface due to opening can be obtained as,

$$
L_{o p}=C_{1}+2\left(r(y)\left(\frac{\pi}{2}-\theta^{\prime}\right)+\left(\frac{O_{C 1}}{2}-\frac{C_{1}}{2}\right) \tan \beta^{\prime}+r(y) \tan \theta^{\prime}\right)
$$




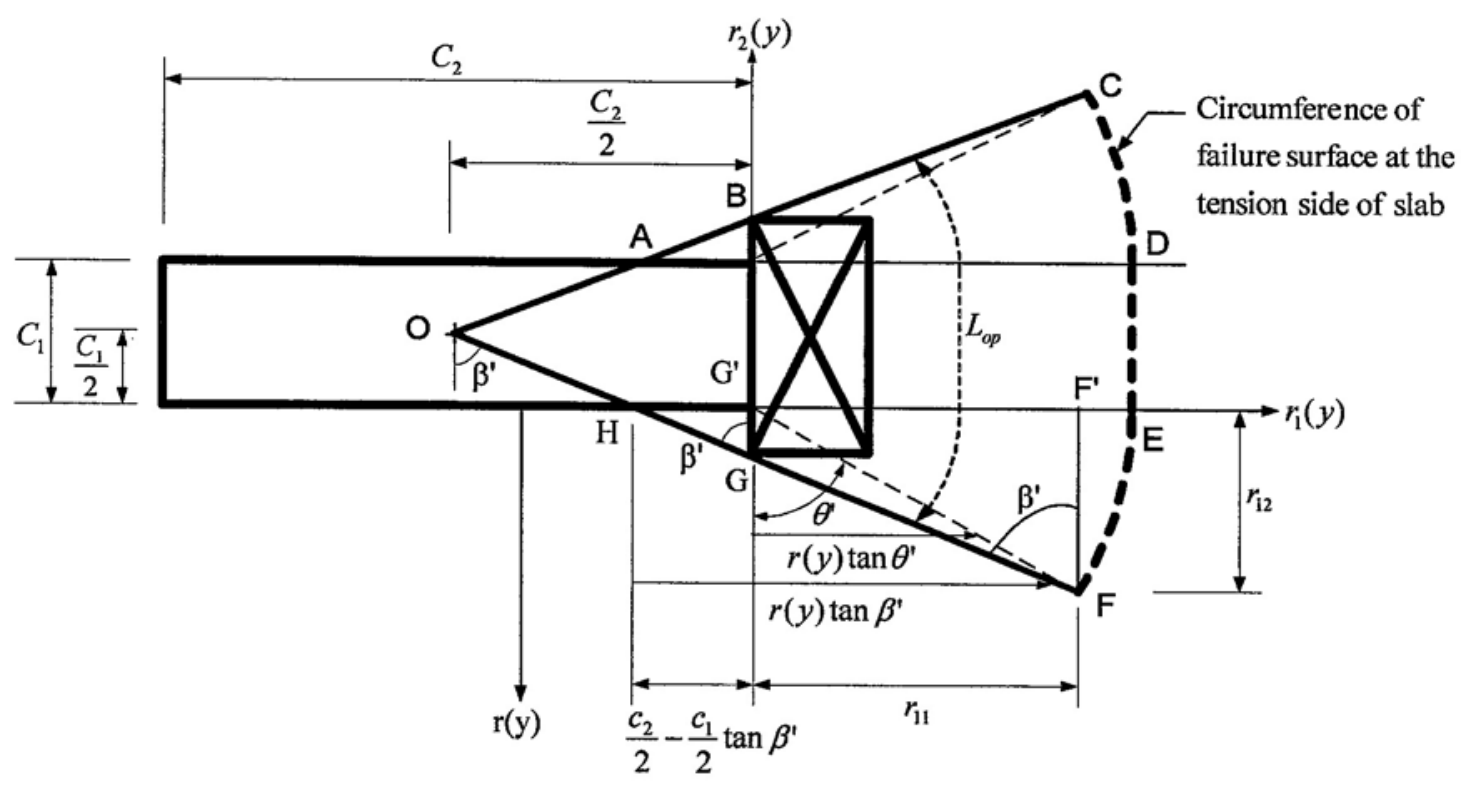

Figure B-7 Ineffective area of failure surface due to opening location (b) by using method AII

In Equation B-118, the terms related and not related to $r(y)$ are separated as follows:

$$
\begin{aligned}
L_{o p}=\left(C_{1}+\left(O_{C 1}-C_{1}\right) \tan \beta^{\prime}\right)+2 r(y)\left(\tan \theta^{\prime}+\left(\frac{\pi}{2}-\theta^{\prime}\right)-\tan \beta^{\prime}\right) \\
L_{o p}=\eta_{1}+\eta_{2} r(y) \\
\eta_{1}=\left(C_{1}+\left(O_{C 1}-C_{1}\right) \tan \beta^{\prime}\right) \\
\eta_{2}=2\left(\tan \theta^{\prime}+\left(\frac{\pi}{2}-\theta^{\prime}\right)-\tan \beta^{\prime}\right) \\
\beta^{\prime}=\beta^{\prime \prime}=\tan ^{-1}\left(\frac{C_{2}}{O_{c 1}}\right) \\
\theta^{\prime}=\sin ^{-1} \frac{r_{11}}{r_{h}}
\end{aligned}
$$

The equation of projection $\mathrm{OC}$ or $\mathrm{OF}$ is

$$
\begin{aligned}
& r_{11}=m_{11} r_{12}+m_{12} \\
& r_{12}=\frac{-b_{1} \pm \sqrt{b_{1}^{2}-4 a_{1} c_{1}}}{2 a_{1}} \\
& a_{1}=m_{11}^{2}+1
\end{aligned}
$$




$$
\begin{aligned}
& b_{1}=2 m_{11} m_{12} \\
& c_{1}=m_{12}^{2}-r_{h}^{2}
\end{aligned}
$$

By using the boundary conditions of projection line $\mathrm{OC}$ or $\mathrm{OE}$,

$$
\begin{aligned}
& m_{11}=\frac{\left(\frac{C_{1}}{2}-\frac{C_{2}}{2} \tan \beta^{\prime}\right)}{\left(\frac{O_{c 2}}{2}-\frac{C_{1}}{2}\right)} \\
& m_{12}=-\left(\frac{C_{1}}{2}-\frac{C_{2}}{2} \tan \beta^{\prime}\right)
\end{aligned}
$$

\section{(c) Opening location perpendicular and adjacent to the longer side of column}

Opening in the slab is located perpendicular and adjacent to the longer side of column. For this type of opening location (c), according to where two projection lines propagating from the center of column through two comers of opening intersect the circumference of failure surface, there may have two possible cases regarding to the ineffective area of failure surface due to opening location type (c).

\section{$\underline{\text { Case (a) }}$}

For this case, the ineffective area of failure surface due to this location of opening by using method AI is shown in Figure B-8. To confine the ineffective area of failure surface due to opening, two projection lines are propagated from the center of the colurnn through two corners of opening at B and F and they intersect the circumference of failure surface at the tension face of the slab at $\mathrm{C}$ and $\mathrm{E}$. The intersection point $\mathrm{C}$ of one projection line is at the circumference of failure surface between the extended lines from the comers of column along the shorter column widths while the intersection point $\mathrm{E}$ of the remaining projection line is at the circumference of failure surface between the extended lines from the comer of column along the longer and shorter column width as shown in Figure B-8. 


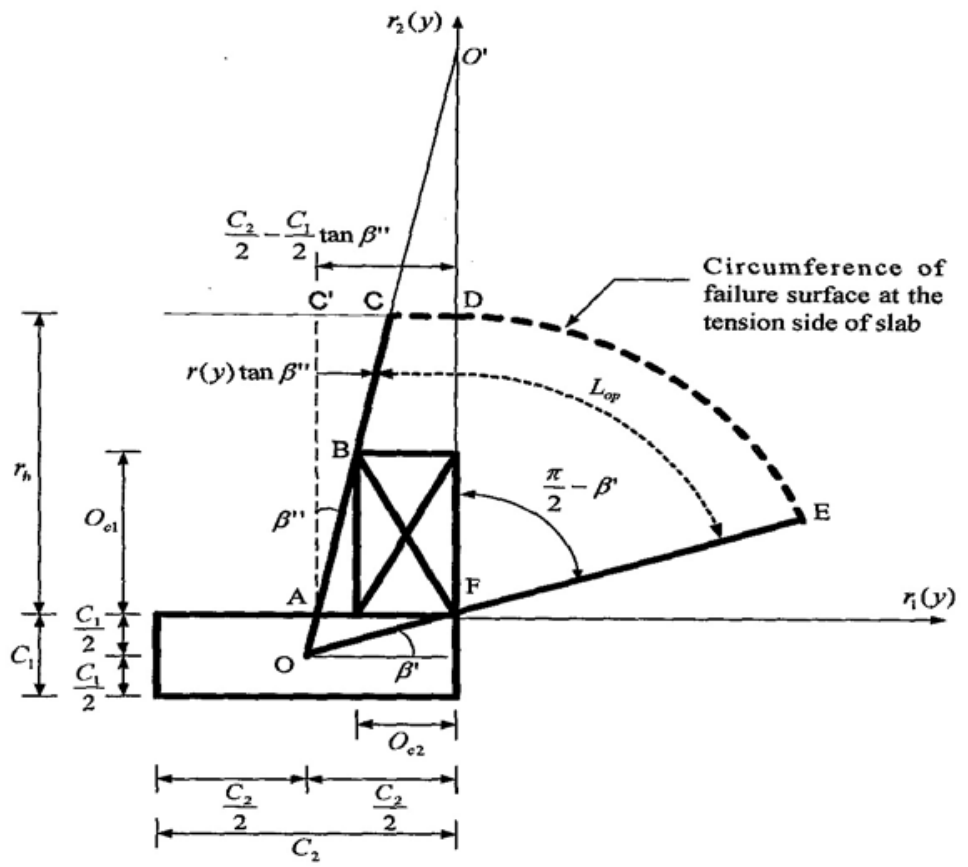

Figure B-8 Ineffective area of failure surface due to opening location (c) by using method AI for case (a)

From Figure B-8, the circumferential length $L_{o p}$ of ineffective area of failure surface due to opening can be obtained as,

$$
L_{o p}=\left(\frac{C_{2}}{2}-\frac{C_{1}}{2} \tan \beta^{\prime \prime}+r(y)\left(\frac{\pi}{2}-\beta^{\prime}\right)\right)-r(y) \tan \beta^{\prime \prime}
$$

In Equation B-132, the terms related and not related to $r(y)$ are separated as follows:

$$
\begin{aligned}
& L_{o p}=\left(\frac{C_{2}}{2}-\frac{C_{1}}{2} \tan \beta^{\prime \prime}\right)+r(y)\left(\frac{\pi}{2}-\beta^{\prime}-\tan \beta^{\prime \prime}\right) \\
& L_{o p}=\eta_{1}+\eta_{2} r(y) \\
& \eta_{1}=\frac{C_{2}}{2}-\frac{C_{1}}{2} \tan \beta^{\prime \prime} \\
& \eta_{2}=\frac{\pi}{2}-\beta^{\prime}-\tan \beta^{\prime \prime} \\
& \beta^{\prime}=\tan ^{-1}\left(\frac{C_{1}}{C_{2}}\right) \\
& \beta^{\prime \prime}=\tan ^{-1}\left(\frac{\frac{C_{2}}{2}-O_{c 2}}{\frac{C_{1}}{2}+O_{c 1}}\right)
\end{aligned}
$$




\section{Case (b)}

The ineffective area of failure surface due to this location of opening by using method AI is shown in Figure B-9. To confine the ineffective area of failure surface due to opening, two projection lines propagate from the center of the column through two comers of opening at B and F and they intersect the circumference of failure surface at the tension face of the slab at D and E. In contrast to case (a) for this type of opening location (c), both intersection points of two projection lines are at the circumference of failure surface between the extended lines from the comer of column along the longer and shorter column width as shown in Figure B-9.

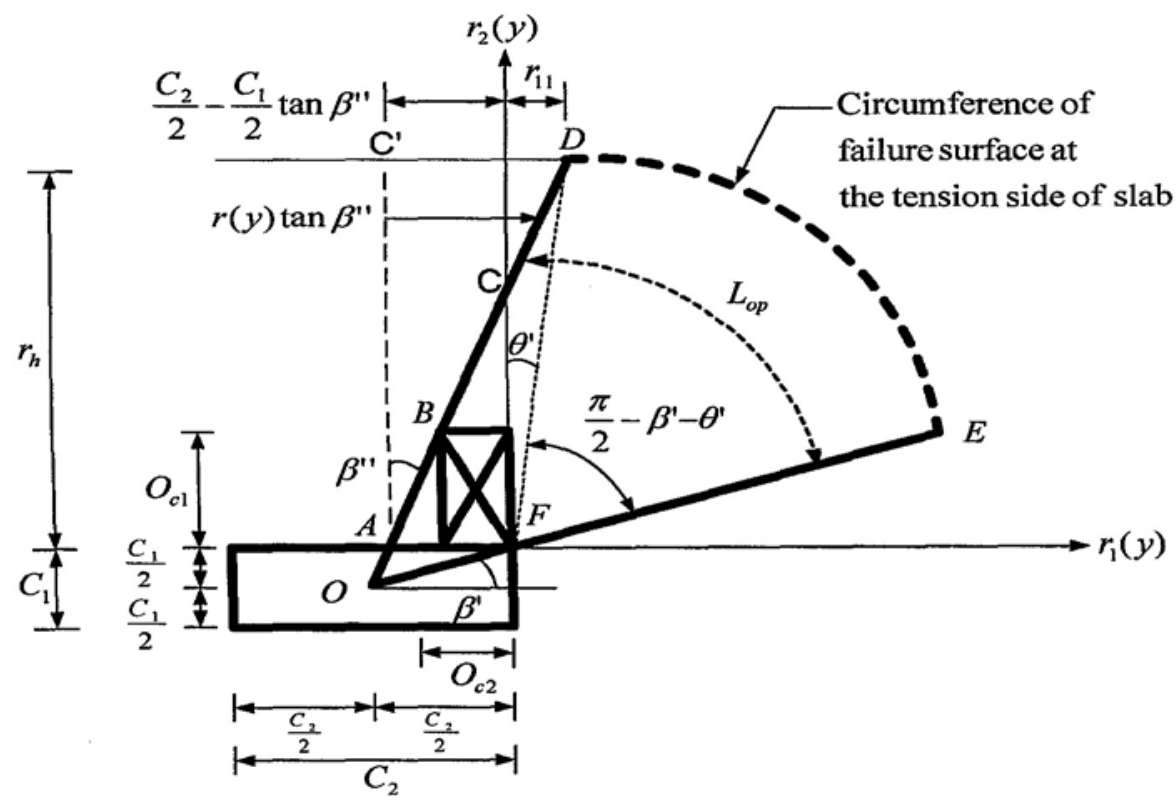

Figure B-9 Ineffective area of failure surface due to opening location (c) by using method AI for case (b)

From Figure B-9, the circumferential length $L_{o p}$ of ineffective area of failure surface due to opening can be obtained as,

$$
L_{o p}=\left(\left(\frac{C_{2}}{2}-\frac{C_{1}}{2} \tan \beta^{\prime \prime}\right)+r(y) \tan \theta^{\prime}+r(y)\left(\frac{\pi}{2}-\beta^{\prime}-\theta^{\prime}\right)\right)-r(y) \tan \beta^{\prime \prime}
$$

In Equation B-139, the terms related and not related to $r(y)$ are separated as follows:

$$
\begin{gathered}
L_{o p}=\left(\frac{C_{2}}{2}-\frac{C_{1}}{2} \tan \beta^{\prime \prime}\right)+r(y)\left(\tan \theta^{\prime}+\left(\frac{\pi}{2}-\beta^{\prime}-\theta^{\prime}\right)-\tan \beta^{\prime \prime}\right) \\
L_{o p}=\eta_{1}+\eta_{2} r(y)
\end{gathered}
$$




$$
\begin{aligned}
& \eta_{1}=\frac{C_{2}}{2}-\frac{C_{1}}{2} \tan \beta^{\prime \prime} \\
& \eta_{2}=\frac{\pi}{2}-\beta^{\prime}-\theta^{\prime}+\tan \theta^{\prime} \\
& \beta^{\prime}=\tan ^{-1}\left(\frac{C_{1}}{C_{2}}\right) \\
& \beta^{\prime \prime}=\tan ^{-1}\left(\frac{\frac{C_{2}}{2}-O_{c 2}}{\frac{C_{1}}{2}+O_{c 1}}\right) \\
& \theta^{\prime}=\sin ^{-1} \frac{r_{11}}{r_{h}}
\end{aligned}
$$

The equation of projection line OD is

$$
\begin{aligned}
& r_{11}=m_{11} r_{12}+m_{12} \\
& r_{12}=\frac{-b_{1} \pm \sqrt{b_{1}^{2}-4 a_{1} c_{1}}}{2 a_{1}} \\
& a_{1}=m_{1}^{2}+1 \\
& b_{1}=2 m_{11} m_{12} \\
& c_{1}=m_{12}^{2}-r_{h}^{2}
\end{aligned}
$$

By using the boundary conditions of projection line OD,

$$
\begin{aligned}
& m_{11}=\tan \left(\frac{\pi}{2}-\beta^{\prime \prime}\right) \\
& m_{12}=-\left(\frac{C_{2}}{2}-\frac{C_{1}}{2} \tan \beta^{\prime \prime}\right)
\end{aligned}
$$

\section{(d) Opening location parallel and adjacent to the middle of longer side of column}

Opening in the slab is located parallel and adjacent to the middle of longer side of column. Similar to opening location (c), as for this type of opening location (d), according to where two projection lines propagating from the center of column through two comers of opening and intersect the circumference of failure surface, there may have two possible cases regarding to the ineffective area of failure surface due to opening. 


\section{Case (a)}

The ineffective area of failure surface due to this location of opening by using method AI is shown in Figure B-10. To confine the ineffective area of failure surface due to opening, two projection lines are propagated from the center of the column through two comers of opening at A and F and they intersect the circumference of failure surface at the tension face of the slab at $\mathrm{B}$ and $\mathrm{E}$ which are between the extended lines from the comers of column along the longer and shorter column width as shown in Figure B-10.

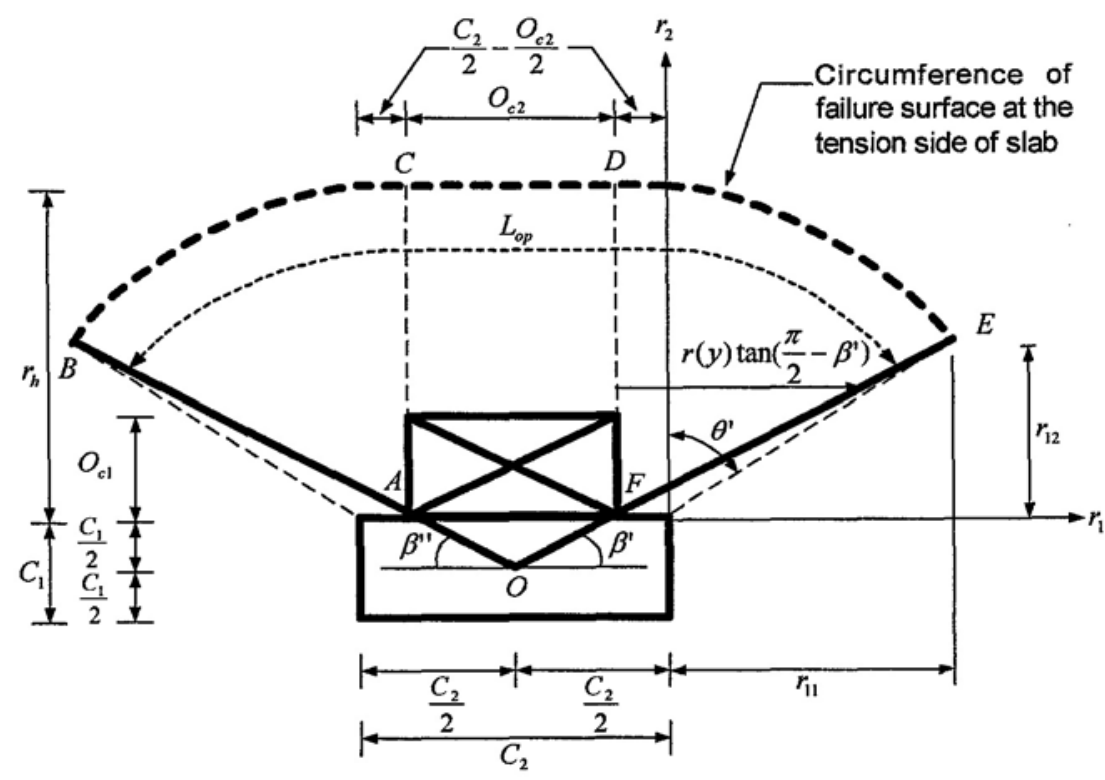

Figure B-10 Ineffective area of failure surface due to opening location (d) by using method AI for case (a)

From Figure B-10, the circumferential length $L_{o p}$ of ineffective area of failure surface due to opening can be obtained as,

$$
\begin{aligned}
& L_{o p}=O_{c 2}+r(y)\left(2\left(\theta^{\prime}-\sin \theta^{\prime}+\tan \left(\frac{\pi}{2}-\beta^{\prime}\right)\right)\right) \\
& L_{o p}=\eta_{1}+\eta_{2} r(y) \\
& \eta_{1}=O_{c 2} \\
& \eta_{2}=2\left(\theta^{\prime}-\sin \theta^{\prime}+\tan \left(\frac{\pi}{2}-\beta^{\prime}\right)\right)
\end{aligned}
$$




$$
\begin{aligned}
& \beta^{\prime}=\beta^{\prime \prime}=\tan ^{-1}\left(\frac{C_{1}}{O_{c 2}}\right) \\
& \theta^{\prime}=\sin ^{-1} \frac{r_{11}}{r_{h}}
\end{aligned}
$$

The equation of projection $\mathrm{OB}$ or $\mathrm{OE}$ is

$$
\begin{aligned}
& r_{11}=m_{11} r_{12}+m_{12} \\
& r_{12}=\frac{-b_{1} \pm \sqrt{b_{1}^{2}-4 a_{1} c_{1}}}{2 a_{1}} \\
& a_{1}=m_{1}^{2}+1 \\
& b_{1}=2 m_{11} m_{12} \\
& c_{1}=m_{12}^{2}-r_{h}^{2}
\end{aligned}
$$

By using the boundary conditions of projection line $\mathrm{OB}$ or $\mathrm{OE}$,

$$
\begin{aligned}
& m_{11}=\frac{1}{\tan \beta^{\prime}} \\
& m_{12}=\left(\frac{C_{2}}{2}-\frac{O_{c 2}}{2}\right)
\end{aligned}
$$

\section{Case (b)}

The ineffective area of failure surface due to this location of opening by using method AI is shown in Figure B-11. To confine the ineffective area of failure surface due to opening, two projection lines are propagated from the center of the column through two comers of opening at $\mathrm{A}$ and $\mathrm{F}$ and they intersect the circumference of failure surface at the tension face of the slab at B and E. In contrast to case (a) of this type of opening location, both intersection points of two projection lines are at the circumference of failure surface between the extended lines from the corners of column along the shorter column widths as shown in Figure B-11.

From Figure B-11, the circumferential length $L_{o p}$ of ineffective area of failure surface due to opening can be obtained as

$$
L_{o p}=O_{c 2}+r(y)\left(2\left(\frac{\pi}{2}-\beta^{\prime}\right)\right)
$$




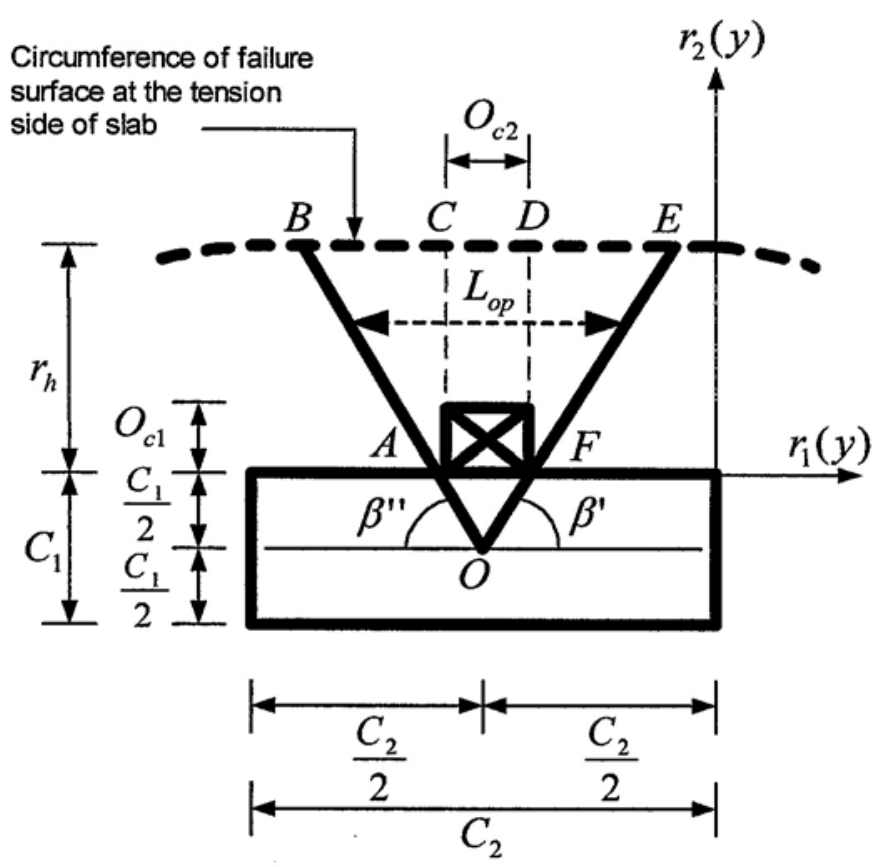

Figure B-11 Ineffective area of failure surface due to opening location (d) by using method AI for case (b)

$$
\begin{aligned}
& L_{o p}=\eta_{1}+\eta_{2} r(y) \\
& \eta_{1}=O_{c 2} \\
& \eta_{2}=2\left(\frac{\pi}{2}-\beta^{\prime}\right) \\
& \beta^{\prime}=\beta^{\prime \prime}=\tan ^{-1}\left(\frac{C_{1}}{O_{c 2}}\right)
\end{aligned}
$$

(e) Opening location perpendicular and adjacent to the shorter side of column

Opening in the slab is located perpendicular and adjacent to the shorter side of column. The ineffective area of failure surface due to this location of opening by using method AI is shown in Figure B-12. To confine the ineffective area of failure surface due to opening, two projection lines are propagated from the center of the column through two comers of opening at $\mathrm{A}$ and $\mathrm{F}$ and they intersect the circumference of failure surface at the tension face of the slab at $\mathrm{B}$ and $\mathrm{E}$. 


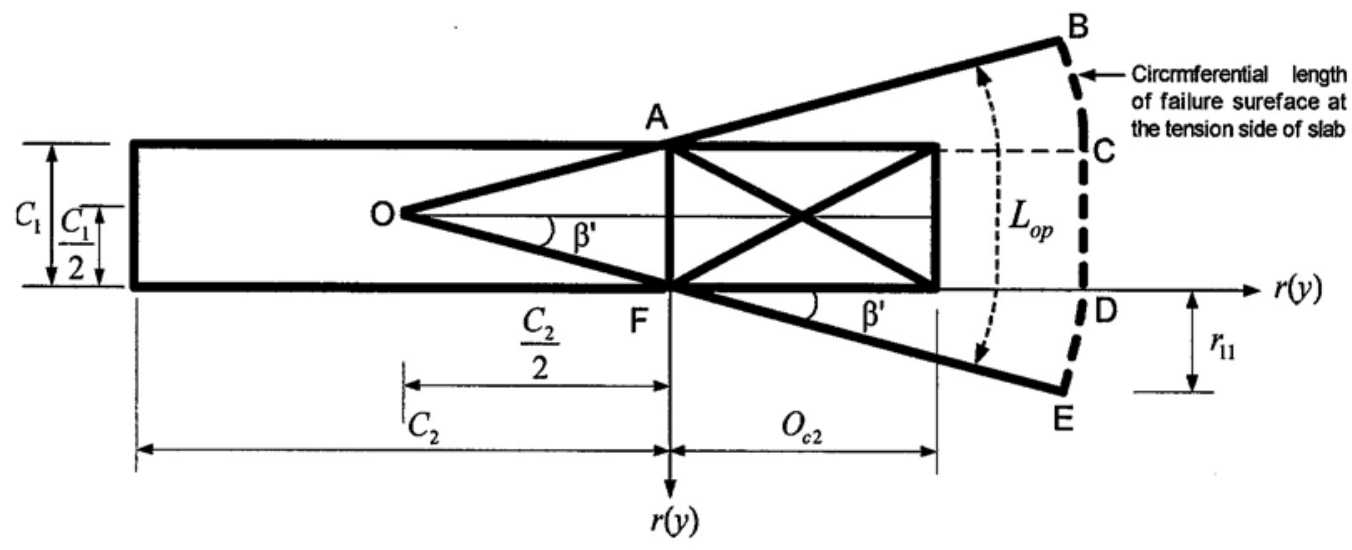

Figure B-12 Ineffective area of failure surface due to opening location (e) by using method AI

From Figure B-12, the circumferential length $L_{o p}$ of ineffective area of failure surface due to opening can be obtained as,

$$
\begin{aligned}
& L_{o p}=C_{1}+r(y)\left(2 \beta^{\prime}\right) \\
& L_{o p}=\eta_{1}+\eta_{2} r(y) \\
& \eta_{1}=C_{1} \\
& \eta_{2}=2 \beta^{\prime} \\
& \beta^{\prime}=\tan ^{-1}\left(\frac{C_{1}}{C_{2}}\right)
\end{aligned}
$$

\section{B.2.2 Ineffectivearea of failure surface due to opening by using method AII}

The ineffective area of failure surface due to opening by using method AII is the area under the plan area of failure surface bounded by two projection lines which start from the center of $1 / 3$ area of column section, which is close to the shorter column width nearest to the opening, through two corners of opening, through two comers of opening and extend up to intersect the circumference of failure surface.

\section{(a) Opening position at adjacent corner of column}

Opening in the slab is located at adjacent corner of column. The ineffective area of failure surface due to this location of opening by using method AII is shown in 
Figure B-13. To confine the ineffective area of failure surface due to opening, two projection lines are propagated from the center of $1 / 3$ column section area close to the shorter column width nearest to the opening through two corners of opening at B and $\mathrm{G}$ and intersect with the circumference of failure surface at the tension face of the slab at D and E.

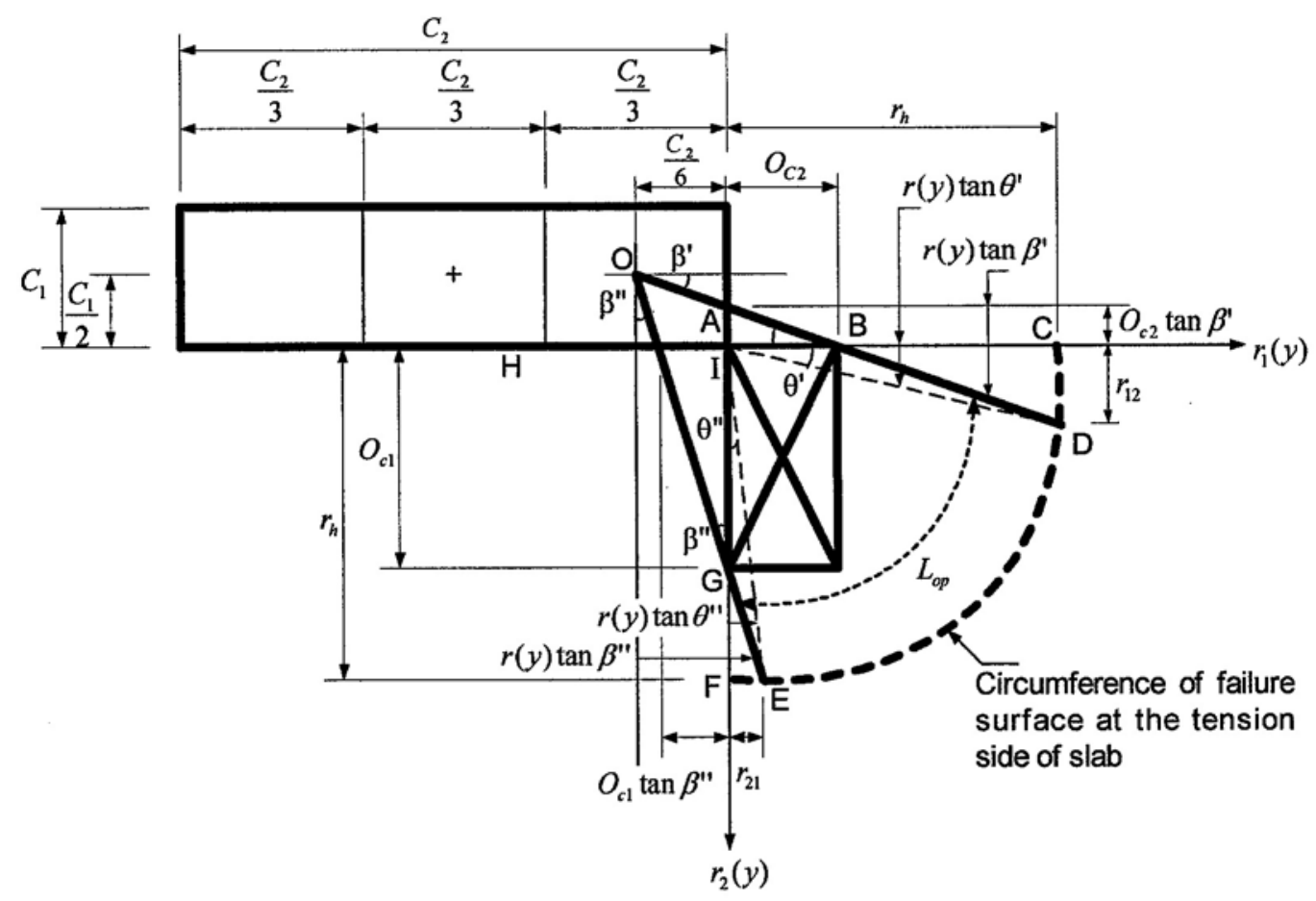

Figure B-13 Ineffective area of failure surface due to opening location (a) by using method AII

From Figure B-13, the circumferential length $L_{o p}$ of ineffective area failure surface due to opening can be obtained as,

$$
\begin{aligned}
L_{o p}= & \left(O_{c 2} \tan \beta^{\prime}+r(y) \tan \theta^{\prime}+r(y)\left(\frac{\pi}{2}-\left(\theta^{\prime}+\theta^{\prime \prime}\right)\right)+r(y) \tan \theta^{\prime \prime}+O_{c 1} \tan \beta^{\prime \prime}\right) \\
& -\left(r(y) \tan \beta^{\prime}+r(y) \tan \beta^{\prime \prime}\right)
\end{aligned}
$$

In Equation B-177, the terms related and not related to $\mathrm{r}(\mathrm{y})$ are separated as follows:

$$
\begin{gathered}
L_{o p}=\left(O_{c 2} \tan \beta^{\prime}+O_{c 1} \tan \beta^{\prime \prime}\right)+r(y)\left(\frac{\pi}{2}-\theta^{\prime}-\theta^{\prime \prime}-\tan \beta^{\prime}-\tan \beta^{\prime \prime}+\tan \theta^{\prime}+\tan \theta^{\prime \prime}\right) \\
L_{o p}=\eta_{1}+\eta_{2} r(y)
\end{gathered}
$$




$$
\begin{aligned}
& \eta_{1}=O_{c 2} \tan \beta^{\prime}+O_{c 1} \tan \beta^{\prime \prime} \\
& \eta_{2}=\frac{\pi}{2}-\theta^{\prime}-\theta^{\prime \prime}-\tan \beta^{\prime}-\tan \beta^{\prime \prime}+\tan \theta^{\prime}+\tan \theta^{\prime \prime} \\
& \beta^{\prime}=\tan ^{-1}\left(\frac{3 C_{1}}{C_{2}+6 O_{c 2}}\right) \\
& \beta^{\prime \prime}=\tan ^{-1}\left(\frac{C_{2}}{3 C_{1}+6 O_{c 1}}\right) \\
& \theta^{\prime}=\sin ^{-1} \frac{r_{11}}{r_{h}} \\
& \theta^{\prime \prime}=\sin ^{-1} \frac{r_{21}}{r_{h}}
\end{aligned}
$$

The equation of projection line OD is

$$
\begin{aligned}
& r_{11}=m_{11} r_{12}+m_{12} \\
& r_{12}=\frac{-b_{1} \pm \sqrt{b_{1}^{2}-4 a_{1} c_{1}}}{2 a_{1}} \\
& a_{1}=m_{11}^{2}+1 \\
& b_{1}=2 m_{11} m_{12} \\
& c_{1}=m_{12}^{2}-r_{h}^{2}
\end{aligned}
$$

By using the boundary conditions of the projection line OD,

$$
\begin{aligned}
& m_{11}=\frac{O_{c 2}}{\left(\frac{C_{1}}{2}-\frac{C_{2}}{6} \tan \beta^{\prime}\right)} \\
& m_{12}=O_{c 2}
\end{aligned}
$$

The equation of projection line $\mathrm{OE}$ is

$$
\begin{aligned}
& r_{21}=m_{21} r_{22}+m_{22} \\
& r_{22}=\frac{-b_{2} \pm \sqrt{b_{2}^{2}-4 a_{2} c_{2}}}{2 a_{2}} \\
& a_{2}=m_{21}^{2}+1 \\
& b_{2}=2 m_{21} m_{22}
\end{aligned}
$$




$$
c_{2}=m_{22}^{2}-r_{h}^{2}
$$

By using the boundary conditions of the projection line $\mathrm{OE}$,

$$
\begin{aligned}
& m_{21}=\frac{\left(\frac{C_{2}}{6}-\frac{C_{1}}{2} \tan \beta^{\prime \prime}\right)}{O_{c 1}} \\
& m_{22}=-\left(\frac{C_{2}}{6}-\frac{C_{1}}{2} \tan \beta^{\prime \prime}\right)
\end{aligned}
$$

\section{(b) Opening position parallel and adjacent to the shorter side of column}

Opening in the slab is located parallel and adjacent to the shorter side of column. The ineffective area of failure surface due to this location of opening by using method AII is shown in Figure B-14. To confined the ineffective area of failure surface due to opening, two projection lines are propagated from the center of $1 / 3$ column section area close to the shorter column width nearest to the opening through two comers of opening at $B$ and $G$ and intersect with the circumference of failure surface at the tension face of the slab at $\mathrm{C}$ and $\mathrm{F}$.

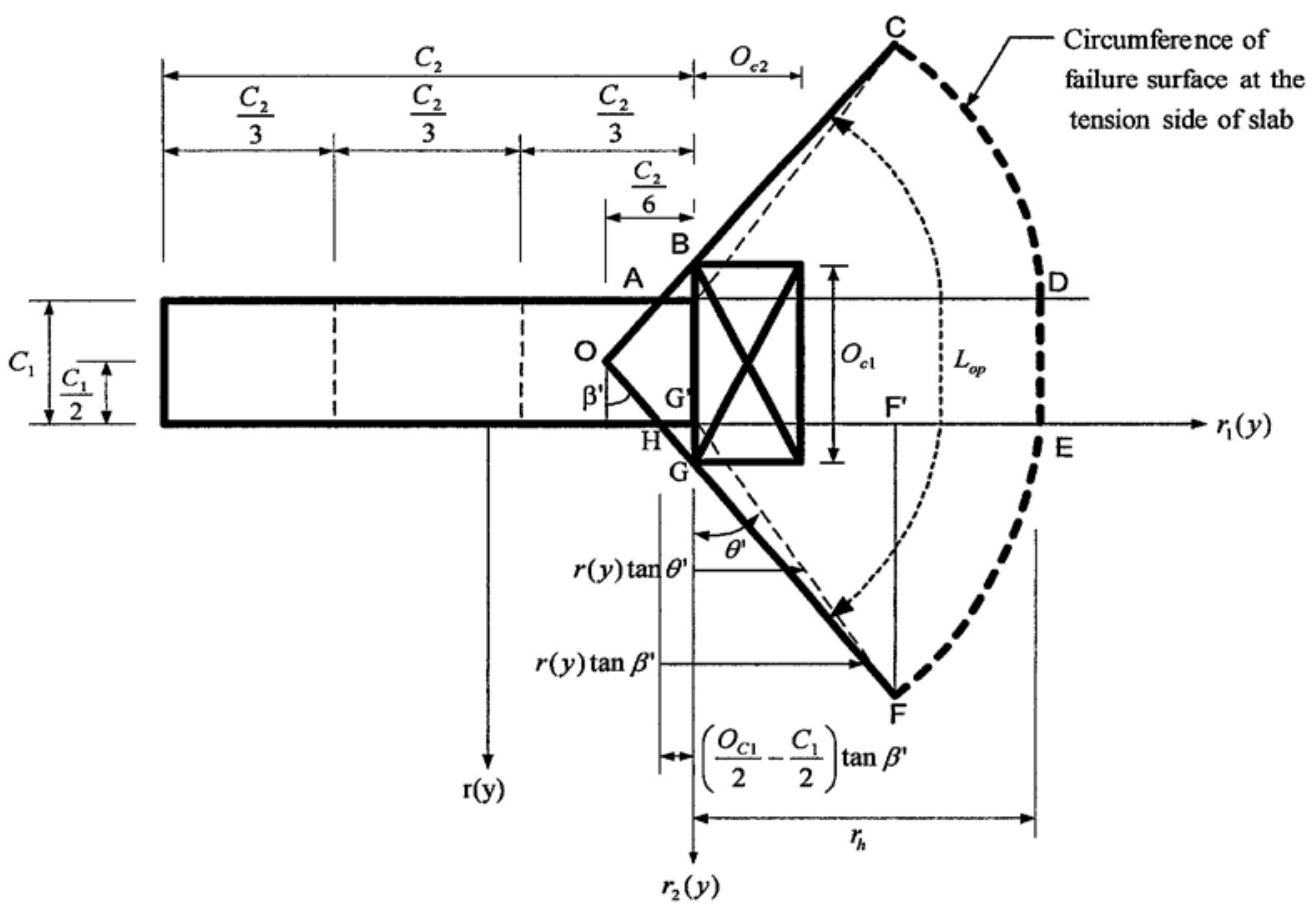

Figure B-14 Ineffective area of failure surface due to opening location (b) by using method AII 
From Figure B-14, the circumferential length $L_{o p}$ of ineffective area of failure surface due to opening can be obtained as,

$$
L_{o p}=C_{1}+2 r(y)\left(\frac{\pi}{2}-\theta^{\prime}\right)+2 r(y) \tan \theta^{\prime}+2\left(\frac{O_{C 1}}{2}-\frac{C_{1}}{2}\right) \tan \beta^{\prime}
$$

In Equation B-200, the terms related and not related to $\mathrm{r}(\mathrm{y})$ are separated as follows:

$$
\begin{gathered}
L_{o p}=\left(C_{1}+\left(O_{C 1}-C_{1}\right) \tan \beta^{\prime}\right)+r(y)\left(2\left(\frac{\pi}{2}-\theta^{\prime}+\tan \theta^{\prime}\right)\right) \\
L_{o p}=\eta_{1}+\eta_{2} r(y) \\
\eta_{1}=C_{1}+\left(O_{C 1}-C_{1}\right) \tan \beta^{\prime} \\
\eta_{2}=2\left(\frac{\pi}{2}-\theta^{\prime}+\tan \theta^{\prime}\right) \\
\beta^{\prime}=\tan ^{-1}\left(\frac{C_{2}}{3 O_{c 1}}\right) \\
\theta^{\prime}=\sin ^{-1} \frac{r_{11}}{r_{h}}
\end{gathered}
$$

The equation of projection line $\mathrm{OC}$ or $\mathrm{OF}$ is

$$
\begin{aligned}
& r_{11}=m_{11} r_{12}+m_{12} \\
& r_{12}=\frac{-b_{1} \pm \sqrt{b_{1}^{2}-4 a_{1} c_{1}}}{2 a_{1}} \\
& a_{1}=m_{11}^{2}+1 \\
& b_{1}=2 m_{11} m_{12} \\
& c_{1}=m_{12}^{2}-r_{h}^{2}
\end{aligned}
$$

By using the boundary conditions of the projection line OD or OF,

$$
\begin{aligned}
& m_{11}=\frac{\left(\frac{C_{1}}{2}-\frac{C_{2}}{6} \tan \beta^{\prime}\right)}{\left(\frac{O_{c 2}}{2}-\frac{C_{1}}{2}\right)} \\
& m_{12}=-\left(\frac{C_{1}}{2}-\frac{C_{2}}{6} \tan \beta^{\prime}\right)
\end{aligned}
$$




\section{(c) Opening location perpendicular and adjacent to longer side of column}

Opening in the slab is located perpendicular and adjacent to the longer side of column. For this type of opening location (c), according to where two projection lines propagating from the center of column through two comers of opening and intersect with the circumference of failure surface, there may have two possible different cases regarding to the ineffective area of failure surface due to opening.

\section{Case (a)}

The ineffective area of failure surface due to this location of opening by using method AII is shown in Figure B-15. To confine the ineffective area of failure surface due to opening, two projection lines are propagated from the center of $1 / 3$ column section area close to the shorter column width nearest to the opening through two comers of opening at $\mathbf{A}$ and $\mathrm{F}$ and they intersect the circumference of failure surface at the tension face of the slab at B and $\mathrm{E}$. The intersection point $\mathrm{B}$ of one projection line is at the circumference of failure surface between the extended lines from the comers of column along the shorter column widths while the intersection point $\mathrm{E}$ of the remaining projection line is at the circumference of failure surface between the extended lines from the comer of column along the longer and shorter column width as shown in Figure B-15.

From Figure B-15, the circumferential length $L_{o p}$ of ineffective area of failure surface due to opening can be obtained as,

$$
\begin{aligned}
& L_{o p}=O_{c 2}+r(y)\left(\left(\frac{\pi}{2}-\beta^{\prime}\right)+\tan \left(\frac{\pi}{2}-\beta^{\prime \prime}\right)\right) \\
& L_{o p}=\eta_{1}+\eta_{2} r(y) \\
& \eta_{1}=O_{c 2} \\
& \eta_{2}=\left(\frac{\pi}{2}-\beta^{\prime}\right)+\tan \left(\frac{\pi}{2}-\beta^{\prime \prime}\right) \\
& \beta^{\prime}=\tan ^{-1}\left(\frac{3 C_{1}}{C_{2}}\right)
\end{aligned}
$$




$$
\beta^{\prime \prime}=\tan ^{-1}\left(\frac{\frac{C_{1}}{2}}{\left|O_{c 2}-\frac{C_{2}}{6}\right|}\right)
$$

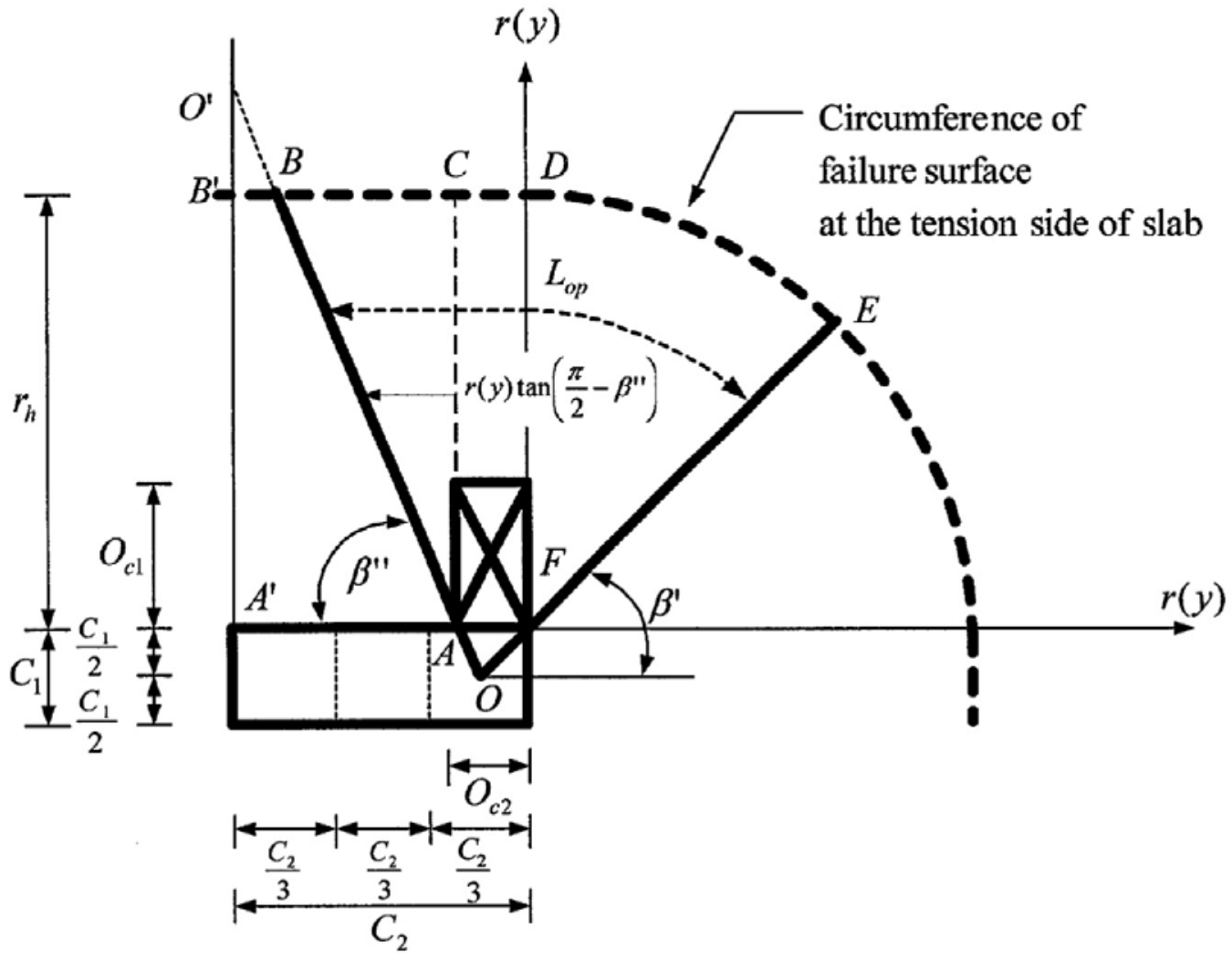

Figure B-15 Ineffective area of failure surface due to opening location (c) by using method AII for case (a)

\section{Case (b)}

The ineffective area of failure surface due to this location of opening by using method AII is shown in Figure B-16. To confine the ineffective area of failure surface due to opening, two projection lines are propagated from the center of $1 / 3$ column section area close to the shorter column width nearest to the opening through two comers of opening at A and F and intersect with the circumference of failure surface at the tension face of the slab at $\mathrm{C}$ and $\mathrm{E}$. In contrast to case (a) for this type of opening location (c), each intersection point of two projection lines is at each circumference of failure surface between the extended lines from the comers of column along the longer and shorter column width as shown in Figure B-16. 
From Figure B-16, the circumferential length $L_{o p}$ of ineffective area of failure surface due to opening can be obtained as,

$L_{o p}=\left(C_{2}+r(y) \tan \left(\frac{\pi}{2}-\beta^{\prime \prime}\right)+r(y) \theta^{\prime}\right)-\left(\left(C_{2}-O_{C 2}\right)+r(y) \tan \theta^{\prime}-r(y)\left(\frac{\pi}{2}-\beta^{\prime}\right)\right)(\mathrm{B}-220)$

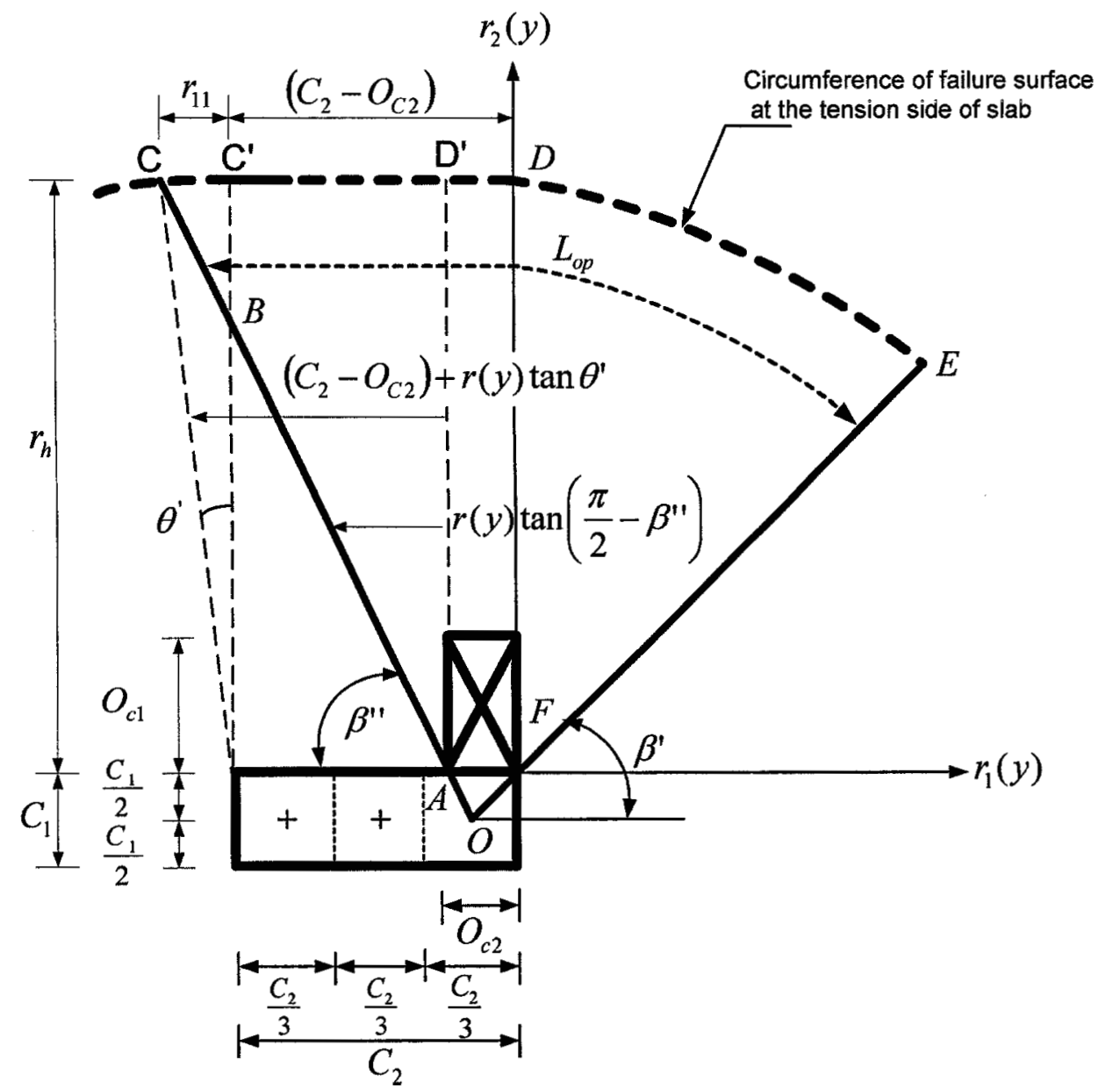

Figure B-16 Ineffective area of failure surface due to opening location (c) by using method AII for case (b)

In Equation B-220, the terms related and not related to $\mathrm{r}(\mathrm{y})$ are separated as follows:

$$
\begin{aligned}
L_{o p}=O_{c 2} & +r(y)\left(\left(\frac{\pi}{2}-p^{\prime}\right)+\theta^{\prime}-\tan \theta^{\prime}+\tan \left(\frac{\pi}{2}-\beta^{\prime \prime}\right)\right) \\
L_{o p} & =\eta_{1}+\eta_{2} r(y) \\
\eta_{1} & =O_{c 2} \\
\eta_{2} & =\left(\frac{\pi}{2}-\beta^{\prime}\right)+\theta^{\prime}-\tan \theta^{\prime}+\tan \left(\frac{\pi}{2}-\beta^{\prime \prime}\right)
\end{aligned}
$$




$$
\begin{aligned}
& \beta^{\prime}=\tan ^{-1}\left(\frac{3 C_{1}}{C_{2}}\right) \\
& \beta^{\prime \prime}=\tan ^{-1}\left(\frac{\frac{C_{1}}{2}}{\left|O_{c 2}-\frac{C_{2}}{6}\right|}\right) \\
& \theta^{\prime}=\sin ^{-1} \frac{r_{11}}{r_{h}}
\end{aligned}
$$

The equation of projection line $\mathrm{OC}$ is

$$
\begin{aligned}
& r_{11}=m_{11} r_{12}+m_{12} \\
& r_{12}=\frac{-b_{1} \pm \sqrt{b_{1}^{2}-4 a_{1} c_{1}}}{2 a_{1}} \\
& a_{1}=m_{11}^{2}+1 \\
& b_{1}=2 m_{11} m_{12} \\
& c_{1}=m_{12}^{2}-r_{h}^{2}
\end{aligned}
$$

By using the boundary conditions of the projection line $\mathrm{OC}$,

$$
\begin{aligned}
& m_{11}=\frac{1}{\tan \beta^{\prime \prime}} \\
& m_{12}=-\left(C_{2}-O_{c 2}\right)
\end{aligned}
$$

\section{(d) Opening location parallel and adjacent to the middle of longer side of column}

Opening in the slab is located parallel and adjacent to the middle of longer side of column. Similar to opening location (c), as for this type of opening location (d), according to where two projection lines propagating from the center of column through two comers of opening and intersect with the circumference of failure surface, there may have three possible cases regarding to the ineffective area of failure surface due to opening.

\section{Case (a)}

The ineffective area of failure surface due to this location of opening by using method AII is shown in Figure B-17. To confine the ineffective area of failure 
surface due to opening, two projection lines are propagated from the $1 / 3$ column section area close to the shorter column width nearest to the opening through two comers of opening at $\mathrm{A}$ and $\mathrm{F}$ and they intersect with the circumference of failure surface at the tension face of the slab at B and E, each of which is at each circumference of failure surface between the extended lines from the comers of column along the longer and shorter column widths as shown in Figure B-17.

From Figure B-17, the circumferential length $L_{o p}$ of ineffective failure surface due to opening is

$L_{o p}=O_{c 2}+r(y)\left(\theta^{\prime}+\theta^{\prime \prime}-\tan 8^{\prime}-\tan \theta^{\prime \prime}+\tan \left(\frac{\pi}{2}-\beta^{\prime}\right)+\tan \left(\frac{\pi}{2}-\beta^{\prime \prime}\right)\right)$

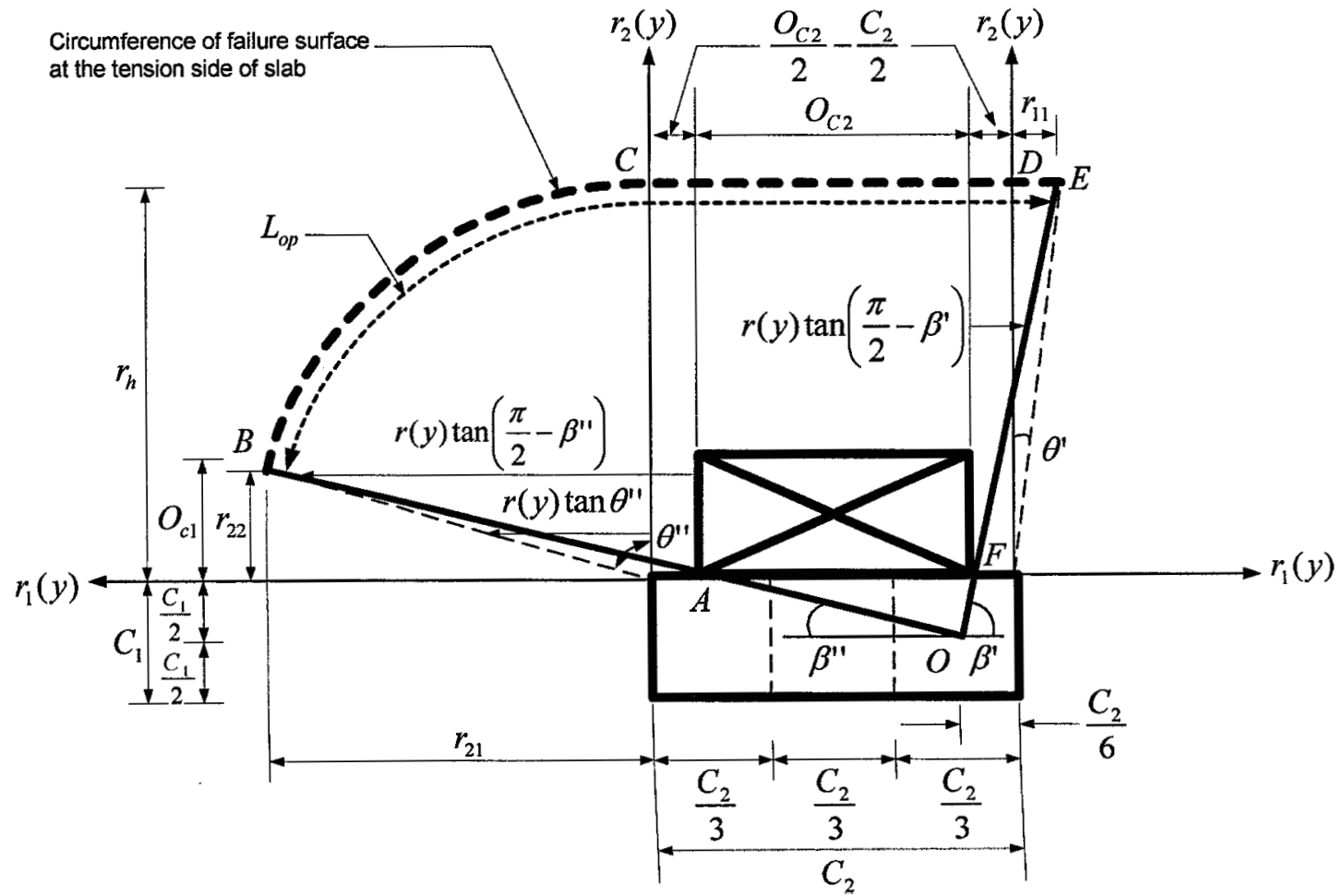

Figure B-17 Ineffective area of failure surface due to opening location (d) by using method AII for case (a)

In Equation B-235, the terms related and not related to $r(y)$ are separated as follows:

$$
L_{o p}=\eta_{1}+\eta_{2} r(y)
$$




$$
\begin{gathered}
\eta_{1}=O_{c 2} \\
\eta_{2}=\theta^{\prime}+\theta^{\prime \prime}-\tan \theta^{\prime}-\tan \theta^{\prime \prime}+\tan \left(\frac{\pi}{2}-\beta^{\prime}\right)+\tan \left(\frac{\pi}{2}-\beta^{\prime \prime}\right) \\
\beta^{\prime}=\tan ^{-1}\left(\frac{\frac{C_{1}}{2}}{\frac{C_{2}}{6}-\frac{C_{2}}{2}+\frac{O_{c 2}}{2}}\right) \\
\beta^{\prime \prime}=\tan ^{-1}\left(\frac{\frac{C_{1}}{2}}{\frac{5 C_{2}}{6}-\frac{C_{2}}{2}+\frac{O_{c 2}}{2}}\right) \\
\theta^{\prime}=\sin ^{-1} \frac{r_{11}}{r_{h}} \\
\theta^{\prime \prime}=\sin ^{-1} \frac{r_{21}}{r_{h}}
\end{gathered}
$$

The equation of projection $\mathrm{OE}$ is

$$
\begin{aligned}
& r_{11}=m_{11} r_{12}+m_{12} \\
& r_{12}=\frac{-b_{1} \pm \sqrt{b_{1}^{2}-4 a_{1} c_{1}}}{2 a_{1}} \\
& a_{1}=m_{11}^{2}+1 \\
& b_{1}=2 m_{11} m_{12} \\
& c_{1}=m_{12}^{2}-r_{h}^{2}
\end{aligned}
$$

By using the boundary conditions of projection line OE,

$$
\begin{aligned}
& m_{11}=\frac{1}{\tan \beta^{\prime}} \\
& m_{12}=-\left(\frac{C_{2}}{3}-\frac{O_{c 2}}{2}\right)
\end{aligned}
$$

The equation of projection $\mathrm{OB}$ is

$$
\begin{aligned}
& r_{21}=m_{21} r_{22}+m_{22} \\
& r_{22}=\frac{-b_{2} \pm \sqrt{b_{2}^{2}-4 a_{2} c_{2}}}{2 a_{2}} \\
& a_{2}=m_{21}^{2}+1
\end{aligned}
$$




$$
\begin{aligned}
& b_{2}=2 m_{21} m_{22} \\
& c_{2}=m_{22}^{2}-r_{h}^{2}
\end{aligned}
$$

By using the boundary conditions of projection line $\mathrm{OE}$,

$$
\begin{aligned}
& m_{21}=\frac{1}{\tan \beta^{\prime \prime}} \\
& m_{12}=-\left(\frac{C_{2}}{2}-\frac{O_{c 2}}{2}\right)
\end{aligned}
$$

\section{Case (b)}

The ineffective area of failure surface due to this location of opening by using method AII is shown in Figure B-18. To confine the ineffective area of failure surface due to opening, two projection lines are propagated from the $1 / 3$ column section area close to the shorter column width nearest to the opening through two corners of opening at $\mathrm{A}$ and $\mathrm{F}$ and they intersect the circumference of failure surface at the tension face of the slab at B and D. In contrast to case (a) for this type of opening location (d), the intersection point $B$ of one projection line is at the circumference of failure surface between the extended lines from the corners of column along the longer and shorter column width while the intersection point $\mathrm{D}$ of other projection line is at the circumference of failure surface between the extended lines from the corner of column along the shorter column widths as shown in Figure B-18.

From Figure B-18, the circumferential length $L_{o p}$ of ineffective failure surface due to opening can be obtained as,

$$
\begin{aligned}
L_{o p}= & \left(\frac{5}{6} C_{2}-\frac{C_{1}}{2} \tan \beta^{\prime \prime}+r(y) \theta^{\prime \prime}\right)-r(y) \tan \beta^{\prime}-\left(r(y) \tan \theta^{\prime \prime}+\left(\frac{O_{C 2}}{2}-\frac{C_{2}}{2}\right)\right. \\
& \left.-r(y) \tan \left(\frac{\pi}{2}-\beta^{\prime \prime}\right)\right)
\end{aligned}
$$

In Equation B-257, the terms related and not related to $r(y)$ are separated as follows:

$$
\begin{gathered}
L_{o p}=\left(\frac{5}{6} C_{2}-\frac{C_{1}}{2} \tan \beta^{\prime \prime}-\left(\frac{C_{2}}{2}-\frac{O_{c 2}}{2}\right)\right)+r(y)\left(\theta^{\prime \prime}-\tan \theta^{\prime \prime}-\tan \beta^{\prime}+\tan \left(\frac{\pi}{2}-\beta^{\prime \prime}\right)\right) \\
L_{o p}=\eta_{1}+\eta_{2} r(y)
\end{gathered}
$$




$$
\begin{aligned}
& \eta_{1}=\frac{5}{6} \dot{C}_{2}-\frac{C_{1}}{2} \tan \beta^{\prime}-\left(\frac{C_{2}}{2}-\frac{O_{c 2}}{2}\right) \\
& \eta_{2}=\theta^{\prime \prime}-\tan \theta^{\prime \prime}-\tan \beta^{\prime}+\tan \left(\frac{\pi}{2}-\beta^{\prime \prime}\right) \\
& \theta^{\prime \prime}=\sin ^{-1} \frac{r_{21}}{r_{h}}
\end{aligned}
$$

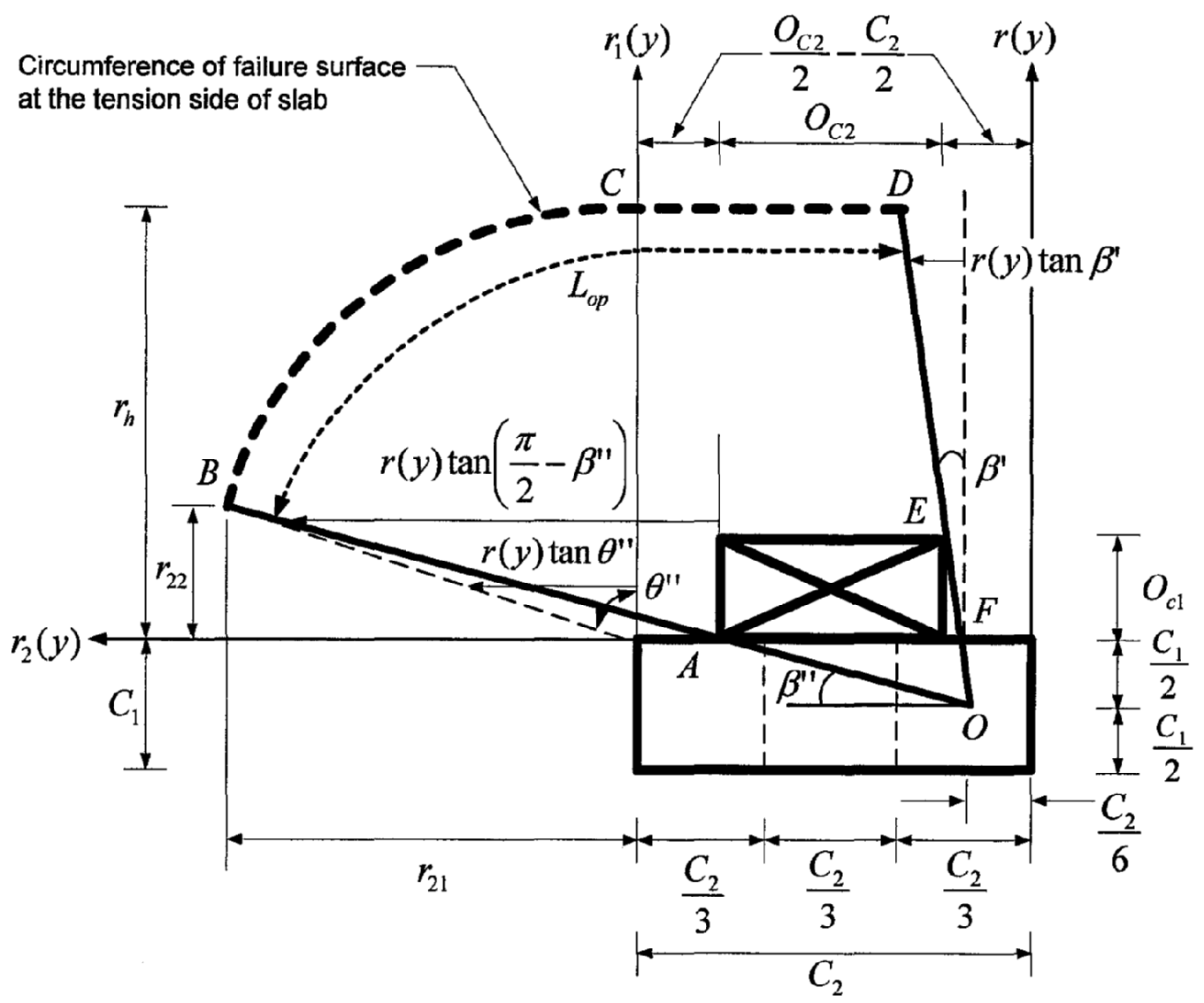

Figure B-18 Ineffective area of failure surface due to opening location (d) by using method AII for case (b)

The equation of projection $\mathrm{OB}$ is

$$
\begin{aligned}
& r_{21}=m_{21} r_{22}+m_{22} \\
& r_{22}=\frac{-b_{2} \pm \sqrt{b_{2}^{2}-4 a_{2} c_{2}}}{2 a_{2}} \\
& a_{2}=m_{21}^{2}+1
\end{aligned}
$$




$$
\begin{aligned}
& b_{2}=2 m_{21} m_{22} \\
& c_{2}=m_{22}^{2}-r_{h}^{2}
\end{aligned}
$$

By using the boundary conditions of projection line $\mathrm{OB}$,

$$
\begin{aligned}
& m_{21}=\frac{1}{\tan \beta^{\prime \prime}} \\
& m_{12}=-\left(\frac{C_{2}}{2}-\frac{O_{c 2}}{2}\right)
\end{aligned}
$$

\section{$\underline{\text { Case (c) }}$}

The ineffective area of failure surface due to this location of opening by using method AII is shown in Figure B-19. To confine the ineffective area of failure surface due to opening, two projection lines are propagated from the $1 / 3$ column section area close to the shorter column width nearest to the opening through two corners of opening at $\mathbf{A}$ and $\mathrm{F}$ and they intersect the circumference of failure surface at the tension face of the slab at C and D. In contrast to case (a) and (b), for this type of opening location (d), both intersection points of two projection lines are at the circumference of failure surface between the extended lines from the corner of column along the longer and shorter column width as shown in Figure B-19.

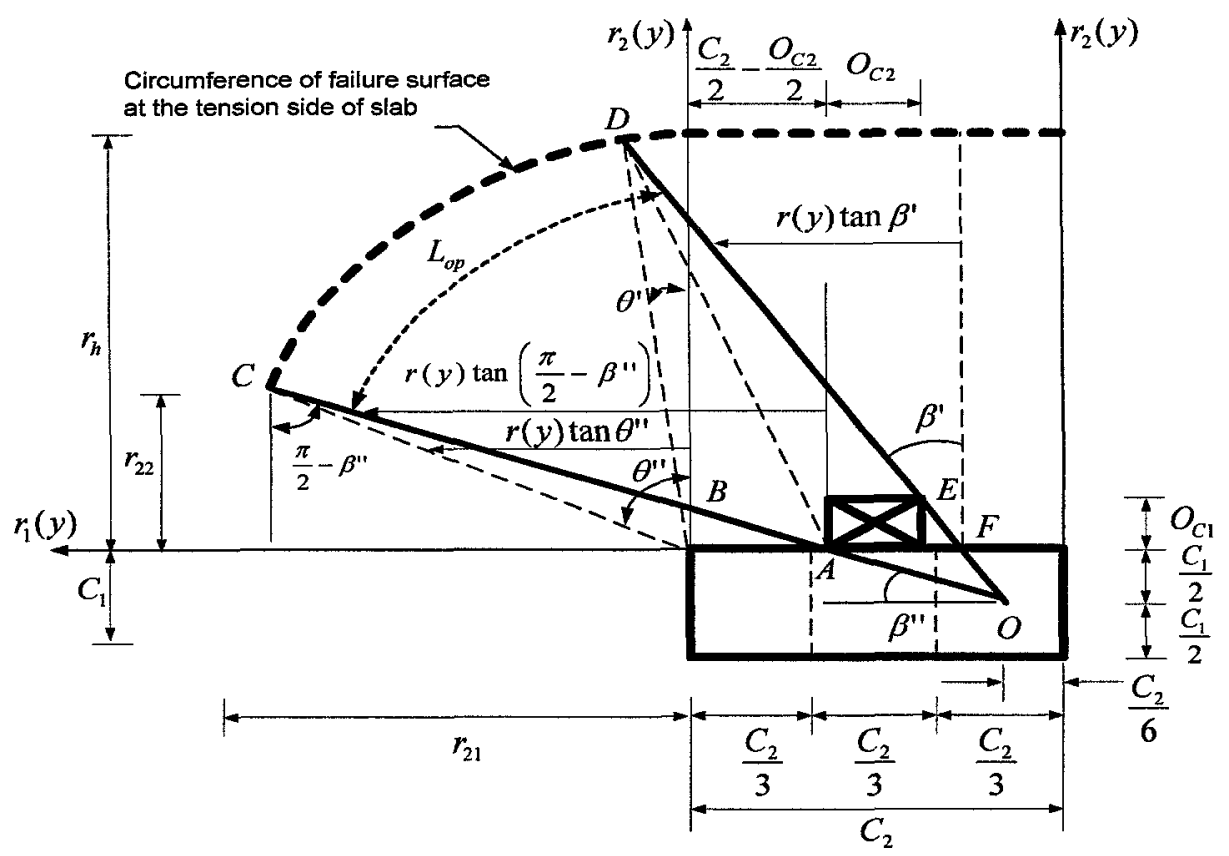

Figure B-19 Ineffective area of failure surface due to opening location (d) by using method AII for case (c) 
From Figure $B-19$, the circumferential length $L_{o p}$ of ineffective failure surface due to opening can be obtained as,

$$
\begin{aligned}
L_{o p}= & \left(\frac{5}{6} C_{2}-\frac{C_{1}}{2} \tan \beta^{\prime}+r(y) \tan \theta^{\prime}+r(y)\left(\theta^{\prime \prime}-\theta^{\prime}\right)\right)-\left(r(y) \tan \beta^{\prime \prime}+\left(\frac{C_{2}}{2}-\frac{O_{c 2}}{2}\right)\right. \\
& \left.+r(y) \tan \theta^{\prime \prime}-r(y) \tan \left(\frac{\pi}{2}-\beta^{\prime \prime}\right)\right)
\end{aligned}
$$

In Equation $B-270$, the terms related and not related to $r(y)$ are separated as follows:

$$
\begin{aligned}
L_{o p}=\left(\frac{5}{6} C_{2}-\frac{C_{1}}{2} \tan \beta^{\prime}-\left(\frac{C_{2}}{2}-\frac{O_{c 2}}{2}\right)\right) \\
+r(y)\left(\left(\theta^{\prime \prime}-\theta^{\prime}\right)+\tan \theta^{\prime}-\tan \beta^{\prime}-\tan \theta^{\prime \prime}+\tan \left(\frac{\pi}{2}-\beta^{\prime \prime}\right)\right) \\
L_{o p}=\eta_{1}+\eta_{2} r(y) \\
\eta_{1}=\frac{5}{6} C_{2}-\frac{C_{1}}{2} \tan \beta^{\prime}-\left(\frac{C_{2}}{2}-\frac{O_{c 2}}{2}\right) \\
\eta_{2}=\left(\theta^{\prime \prime}-\theta^{\prime}\right)+\tan \theta^{\prime}-\tan \beta^{\prime}-\tan \theta^{\prime \prime}+\tan \left(\frac{\pi}{2}-\beta^{\prime \prime}\right) \\
\theta^{\prime}=\sin ^{-1} \frac{r_{11}}{r_{h}} \\
\theta^{\prime \prime}=\sin ^{-1} \frac{r_{21}}{r_{h}}
\end{aligned}
$$

The equation of projection line OD is

$$
\begin{aligned}
& r_{11}=m_{11} r_{12}+m_{12} \\
& r_{12}=\frac{-b_{1} \pm \sqrt{b_{1}^{2}-4 a_{1} c_{1}}}{2 a_{1}} \\
& a_{1}=m_{1}^{2}+1 \\
& b_{1}=2 m_{11} m_{12} \\
& c_{1}=m_{12}^{2}-r_{h}^{2}
\end{aligned}
$$


By using the boundary conditions of projection line OC,

$$
\begin{aligned}
& m_{11}=\frac{1}{\tan \left(\frac{\pi}{2}-\beta^{\prime}\right)} \\
& m_{12}=-\left(\frac{5 C_{2}}{6}-\frac{C_{1}}{2} \tan \beta^{\prime}\right)
\end{aligned}
$$

The equation of projection $\mathrm{OC}$ is

$$
\begin{aligned}
& r_{21}=m_{21} r_{22}+m_{22} \\
& r_{22}=\frac{-b_{2} \pm \sqrt{b_{2}^{2}-4 a_{2} c_{2}}}{2 a_{2}} \\
& a_{2}=m_{21}^{2}+1 \\
& b_{2}=2 m_{21} m_{22} \\
& c_{2}=m_{22}^{2}-r_{h}^{2}
\end{aligned}
$$

By using the boundary conditions of projection line OC,

$$
\begin{aligned}
& m_{21}=\frac{1}{\tan \beta^{\prime \prime}} \\
& m_{12}=-\left(\frac{C_{2}}{2}-\frac{O_{c 2}}{2}\right)
\end{aligned}
$$

\section{(e) Opening location perpendicular and adjacent to the shorter side of column}

Opening in the slab is located perpendicular and adjacent to the shorter side of column. The ineffective area of failure surface due to this location of opening by using method AII is shown in Figure B-20. To confine the ineffective area of failure surface due to opening, two projection lines are propagated from the center $1 / 3$ column section area close to the shorter column width nearest to the opening through two comers of opening at $\mathbf{A}$ and $\mathrm{F}$ and they intersect the circumference of failure surface at the tension face of the slab at $B$ and $\mathrm{E}$. 


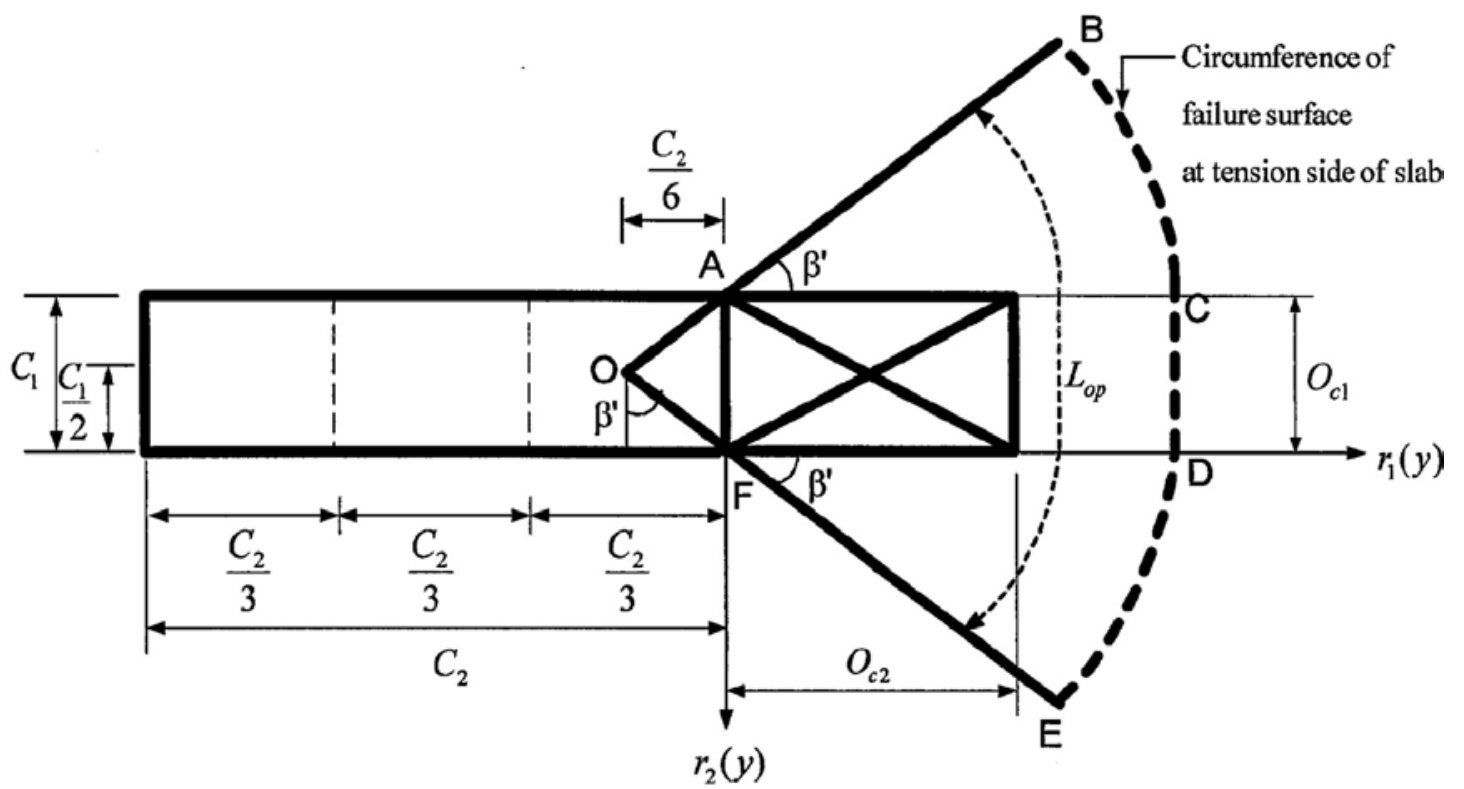

Figure B-20 Ineffective area of failure surface due to opening location (e) by using method AII

From Figure B-20, the circumferential length $L_{o p}$ of ineffective failure surface due to opening can be obtained as:

$$
\begin{aligned}
& L_{o p}=C_{1}+r(y)\left(2 \beta^{\prime}\right) \\
& L_{o p}=\eta_{1}+\eta_{2} r(y) \\
& \eta_{1}=C_{1} \\
& \eta_{2}=2 \beta^{\prime} \\
& \beta^{\prime}=\tan ^{-1}\left(\frac{6 C_{1}}{C_{2}}\right)
\end{aligned}
$$

\section{B.3 Punching shear capacity of slab-column connection without opening and with shear reinforcement}

The punching shear capacity for slab-column connection has been derived in section B.1. When the slab-column connection has shear reinforcement, Equations B-51 or B-53 and B-75 for punching shear capacity of the slab-column connection from section B.1 can be used by adding the contribution of shear reinforcement to the tensile strength of concrete in Equations B- 1a and B- 1b. 
The failure surface in punching shear failure of slab observed in practice involves separation failure as well as sliding failure. The sliding is resisted by the compressive and shear stress along the failure surface. The tensile strength of concrete is against the separation. The shear reinforcement can strengthen against separation. In this case, the dowel action of flexural reinforcement is neglected because it is assumed to contribute only the stresses in its axial direction. The contribution of shear reinforcement is derived as follows:

When the shear reinforcement is used, the tensile strength of slab contributed by concrete and shear reinforcement is:

$$
f_{t}=f_{c t}+f_{s t}
$$

where $f_{t}=$ tensile strength of slab

$$
\begin{aligned}
& f_{c t}=\text { tensile strength contributed by concrete } \\
& f_{s t} \quad=\text { tensile strength contributed by shear reinforcement }
\end{aligned}
$$

However, the concrete is weak in tension. When the slab has shear reinforcement, no contribution of concrete in tension is considered. Only shear reinforcement is assumed to resist tension. Thus,

$$
f_{c t}=0
$$

Therefore, Equation B-296 becomes:

$$
f_{t}=f_{s t}
$$

where $f_{s t}$ is tensile strength contributed by shear reinforcement.

Thus, the tensile strength $f_{t}$ in Equations B-1a and B-1b for the punching shear capacity of the slab-column connection with shear reinforcement is equal to the contribution of tensile strength by shear reinforcement. The tensile strength of slab contributed by shear reinforcement can be obtained as,

$$
\begin{aligned}
& f_{t}=\rho_{s} f_{s y} \sin \alpha_{a v g} \\
& \rho_{s}=\frac{A_{s}}{A_{f}}
\end{aligned}
$$


where

$\rho_{s} \quad=$ ratio of shear stud reinforcement passing through the failure surface

$A_{s} \quad=$ total area of shear stud reinforcement passing through the failure surface

$A_{f} \quad=$ total area of failure surface of slab after punching

$\alpha_{\text {avg }} \quad=$ average slope of failure surface

The total area of failure surface of slab after punching $A_{f}$ can be derived as follows:

$$
A_{f}=\int_{A_{f}} d A_{f}
$$

From Equation B-9,

$$
d A=4\left(\frac{\pi r(y)}{2}+\Delta\right) \frac{d y}{\cos \alpha}=d A_{f}
$$

By substituting Equations B-15, B-27 and B-38 into Equation B-300,

$$
d A_{f}=\frac{2}{A^{2} \pi} \sqrt{1+\left(r^{\prime}(y)\right)^{2}} d r^{\prime}(y)
$$

and substituting it into Equation B-299,

$$
A_{f}=\int_{r^{\prime}(0)}^{r^{\prime}(h)} \frac{2}{A^{2} \pi} \sqrt{1+\left(r^{\prime}(y)\right)^{2}} d r^{\prime}(y) d A_{f}
$$

By solving Equation B-302, the total area of failure surface is

$$
A_{f}=\frac{2}{A^{2} \pi}\left(-\sinh ^{-1}\left(r^{\prime}(0)\right)-r^{\prime}(0) \sqrt{1+\left(r^{\prime}(0)\right)^{2}}+\sinh ^{-1}\left(r^{\prime}(h)\right)+r^{\prime}(0) \sqrt{1+\left(r^{\prime}(h)\right)^{2}}\right)
$$

Equation B-303 gives the total area of failure surface around the column due to concentric punching load.

Average tangent value a, of failure surface from compression to tension face of slab is derived as follow.

$$
\tan \alpha_{\text {avg }}=\frac{\int_{0}^{s} r^{\prime}(y) d s}{\int_{0}^{s} d s}
$$


By substituting $d s=\frac{d y}{\cos \alpha}, d y=\frac{d r^{\prime}(y)}{A \pi \sqrt{1+r^{\prime}(y)^{2}}}$ and $\cos \alpha=\frac{1}{\sqrt{1+\left(r^{\prime}\right)^{2}}}$, and after solving,

$$
\begin{aligned}
& \tan \alpha_{\text {avg }}=\frac{1}{2} A \pi e^{A h \pi}\left(1+e^{A h \pi}\right)\left(-C+B e^{A h \pi}\right) \\
& \alpha_{\text {avg }}=\tan ^{-1}\left(\frac{1}{2} A \pi e^{A h \pi}\left(1+e^{A h \pi}\right)\left(-C+B e^{A h \pi}\right)\right)
\end{aligned}
$$

The Equation B-310 gives the average value of slope of failure surface.

After substituting Equation B-297 into $L$ and $\mathrm{M}$ from Equations B-1a and B-1b and using them, the punching shear capacity for the slab-column connection with shear reinforcement is

(a) If the failure surface is a curve i.e. the initial slope of failure surface at the compression side of the slab is equal or greater than 37 degree, the punching shear capacity for the slab-column connection with shear reinforcement is:

$$
\begin{aligned}
P_{S}= & \frac{f_{c}{ }^{\prime}}{2 A^{2} \pi}\left(L\left(\left(\sinh ^{-1}\left(r_{h}{ }^{\prime}\right)+r_{h}{ }^{\prime} \sqrt{1+\left(r_{h}{ }^{\prime}\right)^{2}}\right)-\left(\sinh ^{-1}\left(r_{0}{ }^{\prime}\right)+r_{0}{ }^{\prime} \sqrt{1+\left(r_{0}{ }^{\prime}\right)^{2}}\right)\right)\right. \\
& \left.-M\left(\left(r_{h}{ }^{\prime}\right)^{2}-\left(r_{0}{ }^{\prime}\right)^{2}\right)\right)
\end{aligned}
$$

where $r_{0}{ }^{\prime}$ and $r_{h}{ }^{\prime}$ are $r^{\prime}(0)$ and $r^{\prime}(h)$ from Equations B-46 and B-48, respectively. Or,

$$
\begin{aligned}
P_{S} & =\frac{f_{c}{ }^{\prime}}{2 A^{2} \pi}\left(L \left(-2 A \Delta \sqrt{-1+4 A^{2} \Delta^{2}}-\ln \left(2 A \Delta+\sqrt{-1+4 A^{2} \Delta^{2}}\right)\right.\right. \\
& +\ln \left(\sqrt{A^{2}\left(-2 \Delta-\pi r_{h}\right)^{2}}+\sqrt{-1+A^{2}\left(-2 \Delta-\pi r_{h}\right)^{2}}\right) \\
& \left.\left.-\sqrt{A^{2}\left(-2 \Delta-\pi r_{h}\right)^{2}} \sqrt{-1+A^{2}\left(-2 \Delta-\pi r_{h}\right)^{2}}\right)+M\left(-4 A^{2} \pi \Delta r_{h}-A^{2} \pi^{2} r_{h}^{2}\right)\right)
\end{aligned}
$$

where $r_{h}$ is obtained from Equation B-47. 
(b) If the failure surface is a combination of a straight line and a curve i.e. the initial slope of failure surface at the compression side of the slab is less than 37 degree, the punching shear capacity for the slab-column connection with shear reinforcement is:

$$
\begin{aligned}
& P_{S}=P_{L S}+P_{C S} \\
& P_{L S}=\frac{1}{32}(5 L-3 M) f_{c}^{\prime} h_{0}\left(16 \Delta+3 \pi h_{0}\right)
\end{aligned}
$$

$$
\begin{aligned}
P_{C S}= & \frac{f_{c}{ }^{\prime}}{2 A^{2} \pi} \\
& \left(L\left(\left(\sinh ^{-1}\left(r_{h}{ }^{\prime}\right)+r_{h}{ }^{\prime} \sqrt{1+\left(r_{h}{ }^{\prime}\right)^{2}}\right)-\left(\sinh ^{-1}\left(r_{h 0}{ }^{\prime}\right)+r_{h 0}{ }^{\prime} \sqrt{1+\left(r_{h 0}{ }^{\prime}\right)^{2}}\right)\right)-M\left(\left(r_{h}{ }^{\prime}\right)^{2}-\left(r_{0}{ }^{\prime}\right)^{2}\right)\right)
\end{aligned}
$$

where $P_{S}=$ punching shear capacity for the slab-column connection with shear reinforcement

$P_{L S}=$ punching shear capacity for the slab-column connection with shear reinforcement for straight portion of failure surface

$P_{C S}=$ punching shear capacity for the slab-column connection with shear reinforcement for curve portion of failure surface

Then, $r_{h 0}{ }^{\prime}$ and $r_{h}^{\prime}$ can be obtained from Equations B-71a and B-71b.

\section{B.4 Punching shear capacity of slab-column connection with opening and with shear reinforcement}

The punching shear capacity for the slab-column connection with opening has been derived in section B.2. The punching shear capacity for the slab-column connection with shear reinforcement has been derived in section B-3. When the slab-column connection has opening and shear reinforcement, the punching shear capacity of slabcolumn connection is

$$
P_{o p+S}=\bar{P}_{S}-\bar{P}_{o p}
$$

where $P_{o p+S}=$ punching shear capacity of slab-column connection with opening and shear reinforcement

$\bar{P} \mathbf{s} \quad=$ punching shear capacity of slab-column connection without opening and with shear reinforcement based on the ratio of shear 
stud reinforcements passing through the area of failure surface, which is based on the area of failure surface $A_{f}$ of slab without ineffective area of failure surface $A_{o p}$ due to opening

$$
\begin{aligned}
\bar{P}_{o p} \quad= & \text { ineffective punching shear capacity of slab-column connection due } \\
& \text { to opening }
\end{aligned}
$$

The ratio of shear stud reinforcements $\bar{\rho}_{s}$ used in determining $\bar{P}_{S}$ by using Equations B-307 and B-308 is considered based on the area of failure surface of slab without opening.

$$
\bar{\rho}_{s}=\frac{A_{s}}{\bar{A}_{f}}
$$

where $\bar{\rho}_{s} \quad=$ ratio of shear stud reinforcement passing through the area of failure surface based on the area of failure surface $\bar{A}_{f}$ of slab without ineffective area of failure surface $A_{o p}$ due to opening

$\bar{A}_{f} \quad=$ area of failure surface of slab without ineffective area of failure surface $A_{o p}$ due to opening

$A_{s} \quad=$ total area of shear studs passing through the failure surface

Therefore, the contribution of shear reinforcements is

$$
f_{t}=\bar{\rho}_{s} f_{s y} \sin \alpha_{\text {avg }}
$$

The area of failure surface $\bar{A}_{f}$ of slab without ineffective area of failure surface $A_{\text {op }}$ due to opening is

$$
d \bar{A}_{f}=d A_{f}-d A_{o p}
$$

From Equation 8-85, $d A_{o p}=\left(\eta_{1}+\eta_{2} r(y)\right) \frac{d y}{\cos a}$

From Equation B-300, $d A_{f}=4\left(\frac{\pi r(y)}{2}+\Delta\right) \frac{d y}{\cos \alpha}$

By substituting $d A_{f}$ and $d A_{o p}$ into Equation B-314, 


$$
\begin{aligned}
& d \bar{A}_{f}=4\left(\frac{\pi r(y)}{2}+\Delta\right) \frac{d y}{\cos \alpha}-\left(\eta_{1}+\eta_{2} r(y)\right) \frac{d y}{\cos \alpha} \\
& d \bar{A}_{f}=\left(\left(4 \Delta+\eta_{1}\right)+\left(2 \pi-\eta_{2}\right) r(y)\right) \frac{d y}{\cos \alpha} \\
& d \bar{A}_{f}=\left(\eta_{1}{ }^{\prime}+\eta_{2}{ }^{\prime} r(y)\right) \frac{d y}{\cos \alpha} \\
& \eta_{1}{ }^{\prime}=4 \mathrm{~A}+\eta_{1} \\
& \eta_{2}{ }^{\prime}=2 \pi-\eta_{2}
\end{aligned}
$$

By substituting Equations B-15, B-27 and B-38 into Equation B-317,

$$
\begin{array}{r}
d \bar{A}_{f}=\frac{1}{A^{2} \pi^{2}}\left(A \pi \eta_{1}{ }^{\prime}+\eta_{2}{ }^{\prime}\left(-2 A \Delta+\sqrt{1+\left(r^{\prime}(y)\right)^{2}}\right)\right) d r^{\prime}(y) \\
\bar{A}_{f}=\int_{r^{\prime}(0)}^{r^{\prime}(h)} \frac{1}{A^{2} \pi^{2}}\left(A \pi \eta_{1}{ }^{\prime}+\eta_{2}{ }^{\prime}\left(-2 A \Delta+\sqrt{1+\left(r^{\prime}(y)\right)^{2}}\right)\right) d r^{\prime}(y)
\end{array}
$$

By solving Equation B-321,

$$
\begin{aligned}
\bar{A}_{f}= & \frac{1}{2 A^{2} \pi^{2}}\left(2 A \eta_{1}^{\prime}\left(-r^{\prime}(0)+r^{\prime}(h)\right)+\eta_{2}^{\prime}\left(-\sinh ^{-1}\left(r^{\prime}(0)\right)+\sinh ^{-1}\left(r^{\prime}(h)\right)+4 A \Delta r^{\prime}(0)\right.\right. \\
& \left.\left.-r^{\prime}(0) \sqrt{1+\left(r^{\prime}(0)\right)^{2}}-4 A \Delta r^{\prime}(h)+r^{\prime}(h) \sqrt{1+\left(r^{\prime}(h)\right)^{2}}\right)\right)
\end{aligned}
$$

where

$$
\begin{aligned}
\overline{\mathrm{A} f}= & \text { area of failure surface of slab without ineffective area of failure } \\
& \text { surface A, due to opening } \\
A_{o p} \quad= & \text { ineffective area of failure surface due to opening }
\end{aligned}
$$

The $\eta_{1}$ and $\eta_{2}$ are the terms related to circumferential length $L_{o p}$ of ineffective area of failure surface due to opening and same as in the case for slab-column connections with opening and without shear reinforcement derived in section B.2.

\section{B.5 Critical radius of failure surface}

The critical radius of failure surface, which gives the least punching shear capacity of slab-column connection predicted by plasticity model, is a distance of failure surface at tension face of slab measured radically from column face. The punching shear capacity from Equations B-53 and B-51 is differentiated by $r_{h}$, and $r^{\prime}(0)$ and $r^{\prime}(h)$, 
respectively, and equated to zero. The $r_{h}$ is radius of failure surface at tension side of slab. The $r^{\prime}(0)$ and $r^{\prime}(h)$ are tangent vales of failure surface at slab thickness zero and $\mathrm{h}$, respectively.

From differentiating Equation B-53 by $r_{h}$ and equating to zero,

$$
\begin{aligned}
\frac{\partial P}{\partial r_{h}}= & \\
\frac{\partial P}{\partial r_{h}}= & \frac{\partial}{\partial r_{h}}\left(\frac { f _ { c } ^ { \prime } } { 2 A ^ { 2 } \pi } \left(L \left(-2 A \Delta \sqrt{-1+4 A^{2} \Delta^{2}}-\ln \left(2 A \Delta+\sqrt{-1+4 A^{2} \Delta^{2}}\right)\right.\right.\right. \\
& +\ln \left(\sqrt{A^{2}\left(-2 \Delta-\pi r_{h}\right)^{2}}+\sqrt{-1+A^{2}\left(-2 \Delta-\pi r_{h}\right)^{2}}\right)-\sqrt{A^{2}\left(-2 \Delta-\pi r_{h}\right)^{2}} \\
& \left.\left.\left.\sqrt{-1+A^{2}\left(-2 \Delta-\pi r_{h}\right)^{2}}\right)+M\left(-4 A^{2} \pi \Delta r_{h}-A^{2} \pi^{2} r_{h}^{2}\right)\right)\right)
\end{aligned}
$$$$
\frac{\partial P}{\partial r_{h}}=f_{c}^{\prime}\left(2 \Delta+\pi r_{h}\right)\left(-M+\frac{L}{\sqrt{1-\frac{1}{A^{2}\left(2 \Delta+\pi r_{h}\right)^{2}}}}\right)=0
$$

$$
f_{c}^{\prime}\left(2 \Delta+\pi r_{h}\right)\left(-M+\frac{L}{\sqrt{1-\frac{1}{A^{2}\left(2 \Delta+\pi r_{h}\right)^{2}}}}\right)=0
$$$$
-M+\frac{L}{\sqrt{1-\frac{1}{A^{2}\left(2 \Delta+\pi r_{h}\right)^{2}}}}=0
$$

$$
\frac{L}{\sqrt{1-\frac{1}{A^{2}\left(2 \Delta+\pi r_{h}\right)^{2}}}}=M
$$

$$
\begin{aligned}
& \sqrt{1-\frac{1}{A^{2}\left(2 \Delta+\pi r_{h}\right)^{2}}}=\frac{L}{M} \\
& A^{2}\left(2 \Delta+\pi r_{h}\right)^{2}=1-\frac{L^{2}}{M^{2}}
\end{aligned}
$$




$$
\begin{aligned}
& r_{h}=\frac{1}{\pi}\left(\sqrt{\frac{1}{A^{2}}\left(1-\frac{L^{2}}{M^{2}}\right)}-2 \Delta\right) \\
& r_{h}=\frac{1}{\pi}\left(\frac{M}{A \sqrt{M^{2}-L^{2}}}-2 \Delta\right) \\
& r_{c r}=\frac{1}{\pi}\left(\frac{M}{A_{c r} \sqrt{M^{2}-L^{2}}}-2 \Delta\right)
\end{aligned}
$$

where

$r_{c r}=$ critical radius of failure surface at tension face of slab

$A_{c r}=$ constant that give critical radius of failure surface at tension face of slab

L, Mand A can be obtained by using Equations B-1a, b-1b and $B-8$, respectively.

$B y$ differentiating Equation $B-51$ by $r^{\prime}(0)$ and equating to zero,

$$
\frac{\partial P}{\partial r^{\prime}(0)}=0
$$

$$
\begin{aligned}
\frac{\partial P}{\partial r^{\prime}(0)}= & \frac{\partial}{\partial r^{\prime}(0)}\left(\frac { f _ { c } ^ { \prime } } { 2 A ^ { 2 } \pi } \left(L \left(-\sinh ^{-1}\left(r^{\prime}(0)\right)-r^{\prime}(0) \sqrt{1+\left(r^{\prime}(0)\right)^{2}}+\sinh ^{-1}\left(r^{\prime}(h)\right)\right.\right.\right. \\
& \left.\left.\left.+r^{\prime}(h) \sqrt{1+\left(r^{\prime}(h)\right)^{2}}\right)\right)+M\left(\left(r^{\prime}(0)\right)^{2}-\left(r^{\prime}(h)\right)^{2}\right)\right)
\end{aligned}
$$$$
\frac{\partial P}{\partial r^{\prime}(0)}=\frac{f_{c}^{\prime}}{A^{2} \pi}\left(M r^{\prime}(0)-L \sqrt{1+\left(r^{\prime}(0)\right)^{2}}\right)=0
$$

$$
\frac{f_{c}^{\prime}}{A^{2} \pi}\left(M r^{\prime}(0)-L \sqrt{1+\left(r^{\prime}(0)\right)^{2}}\right)=0
$$$$
M r^{\prime}(0)-L \sqrt{1+\left(r^{\prime}(0)\right)^{2}}=0
$$

$$
M r^{\prime}(0)=L \sqrt{1+\left(r^{\prime}(0)\right)^{2}}
$$

$$
\left(M r^{\prime}(0)\right)^{2}=\left(L \sqrt{1+\left(r^{\prime}(0)\right)^{2}}\right)^{2}
$$$$
M^{2}\left(r^{\prime}(0)\right)^{2}=L^{2}\left(1+\left(r^{\prime}(0)\right)^{2}\right)
$$

$$
\left(r^{\prime}(0)\right)^{2}\left(1-\frac{L^{2}}{M^{2}}\right)=\frac{L^{2}}{M^{2}}
$$




$$
\begin{aligned}
& \left(r^{\prime}(0)\right)^{2}=\frac{L^{2}}{M^{2}-L^{2}} \\
& r^{\prime}(0)=\frac{L}{\sqrt{M^{2}-L^{2}}}
\end{aligned}
$$

By differentiating Equation B-51 by $r^{\prime}(h)$ and equating to zero,

$$
\begin{aligned}
\frac{\partial P}{\partial r^{\prime}(\boldsymbol{h})}= & 0 \\
\frac{\partial P}{\partial r^{\prime}(h)}= & \frac{\partial}{\partial r^{\prime}(h)}\left(\frac { f _ { c } ^ { \prime } } { 2 A ^ { 2 } \pi } \left(L \left(-\sinh ^{-1}\left(r^{\prime}(0)\right)-r^{\prime}(0) \sqrt{1+\left(r^{\prime}(0)\right)^{2}}+\sinh ^{-1}\left(r^{\prime}(h)\right)\right.\right.\right. \\
& \left.\left.\left.+r^{\prime}(h) \sqrt{1+\left(r^{\prime}(h)\right)^{2}}\right)\right)+M\left(\left(r^{\prime}(0)\right)^{2}-\left(r^{\prime}(h)\right)^{2}\right)\right)=0
\end{aligned}
$$

Similarly,

$$
\begin{aligned}
& r^{\prime}(h)=\frac{L}{\sqrt{M^{2}-L^{2}}} \\
& r^{\prime}(0)=r^{\prime}(h)
\end{aligned}
$$

But, we have $r^{\prime}(0)=A \pi(B-C)$ and $r^{\prime}(h)=A \pi\left(B e^{A \pi h}-C e^{-A \pi h}\right)$,

$$
\begin{aligned}
& A \pi(B-C)=A \pi\left(B e^{A \pi h}-C e^{-A \pi h}\right) \\
& B-C=B e^{A \pi h}-C e^{-A \pi h} \\
& \left(\frac{2 \Delta}{\pi}-C\right)\left(1-e^{A \pi h}\right)=C\left(1-e^{-A \pi h}\right) \\
& \frac{2 \Delta}{\pi}\left(1-e^{A \pi h}\right)=C\left(1-e^{-A \pi h}\right)+C\left(1-e^{A \pi h}\right) \\
& \frac{2 \Delta}{\pi}\left(1-e^{A \pi h}\right)=2 C-C\left(e^{-A \pi h}-e^{A \pi h}\right) \\
& \frac{2 \Delta}{\pi}\left(1-e^{A \pi h}\right)=2 C-C \cosh (A \pi h) \\
& \frac{2 \Delta}{\pi}\left(1-e^{A \pi h}\right)=C(2-\cosh (A \pi h)) \\
& C=\frac{2 \Delta}{\pi} \frac{\left(1-e^{A \pi h}\right)}{(2-\cosh (A \pi h))}
\end{aligned}
$$




$$
\begin{gathered}
C_{c r}=\frac{2 \Delta}{\pi} \frac{\left(1-e^{A_{c r} \pi h}\right)}{\left(2-\cosh \left(A_{c r} \pi h\right)\right)} \\
B_{c r}=\frac{2 \Delta}{\pi}\left(1-\frac{\left(1-e^{A_{c r} \pi h}\right)}{\left(2-\cosh \left(A_{c r} \pi h\right)\right)}\right) \\
4 A_{c r}^{2} B_{c r} C_{c r} \pi^{2}=1 \\
4 A_{c r}^{2} B_{c r} C_{c r} \pi^{2}=4 A_{c r}^{2}\left(\frac{2 \Delta}{\pi}\left(1-\frac{\left(1-e^{A_{c r} \pi h}\right)}{\left(2-\cosh \left(A_{c r} \pi h\right)\right)}\right)\right)^{2}\left(\frac{2 \Delta}{\pi}\left(\frac{\left(1-e^{A_{c r} \pi h}\right)}{\left(2-\cosh \left(A_{c r} \pi h\right)\right)}\right)\right)^{2} \pi^{2} \\
4 A_{c r}^{2} B_{c r} C_{c r} \pi^{2}=-4 A_{c r}^{2} \Delta^{2}\left(\operatorname{csch}\left(\frac{A_{c r} h \pi}{2}\right)\right)^{2} \\
1=-4 A_{c r}^{2} \Delta^{2}\left(\operatorname{csch}\left(\frac{A_{c r} h \pi}{2}\right)\right)^{2} \\
A_{c r}=-\frac{\mathrm{B}-353)}{2 \Delta \operatorname{csch}\left(\frac{A_{c r} h \pi}{2}\right)}
\end{gathered}
$$

where

$A_{c r}, B_{c r} \& C_{c r}=$ constant terms related to critical radius of failure surface 


\section{APPENDIX C}

\section{MATLAB PROGRAM TO CALCULATE}

THE PUNCHING SHEAR CAPACITY OF SLAB-COLUMN CONNECTION BY THEORY OF PLASTICITY 


\section{Appendix $C$}

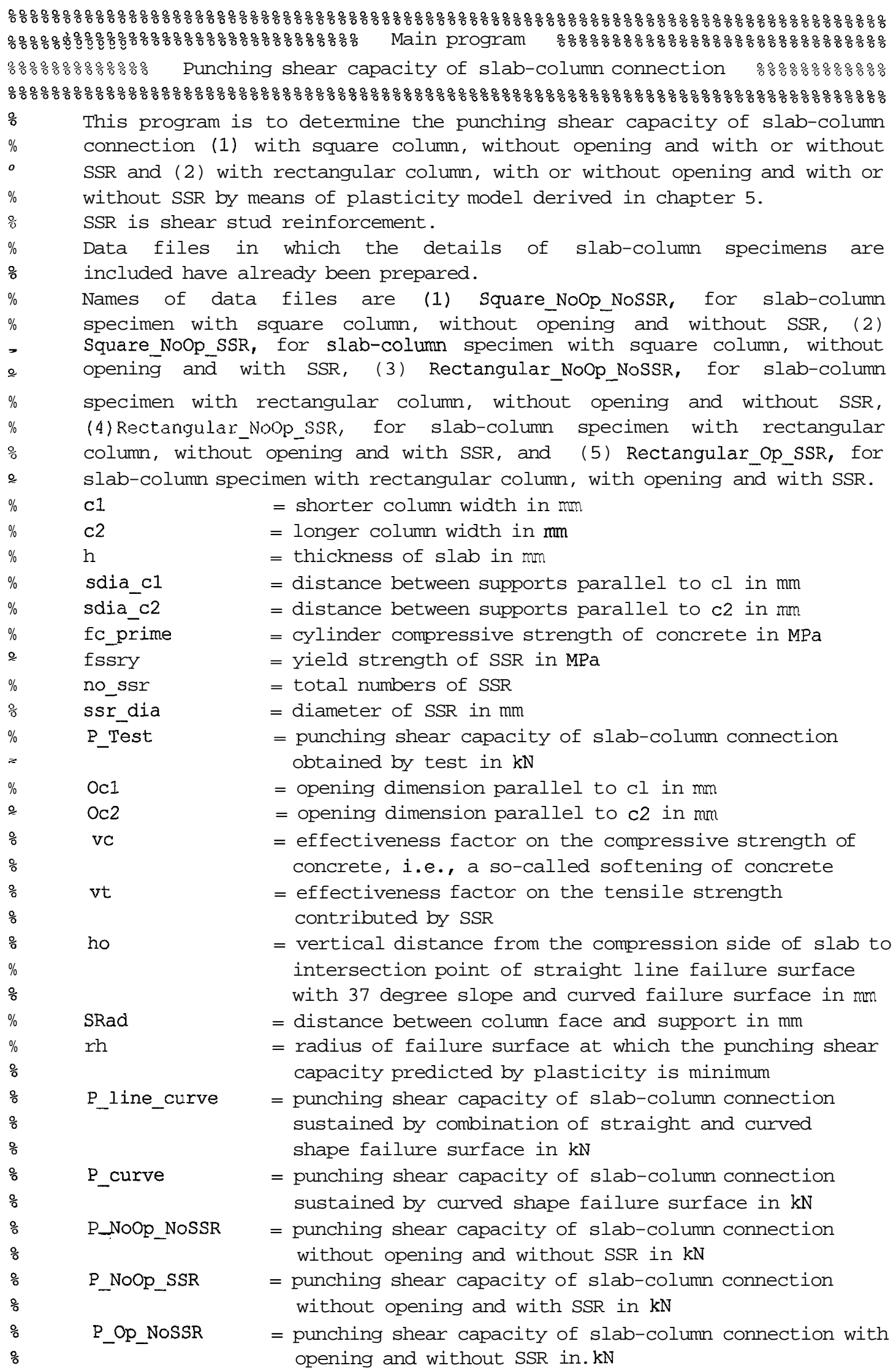




$\begin{array}{lll}\% & \text { P_Op_SSR } & \begin{array}{l}\text { punching shear capacity of slab-column connection } \\ \text { with opening and with SSR in } \mathrm{kN}\end{array} \\ \% & \text { P_Op_SSR_Area_1 }= & \text { punching shear capacity of slab-column connection } \\ & \text { with opening and with SSR from method AI in } \mathrm{kN}\end{array}$

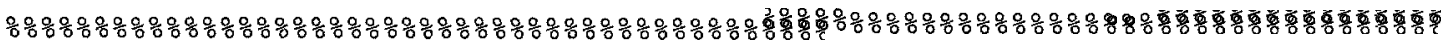

fprintf('Enter related description of file with respect to type of slab-column connection $\left.\backslash n^{\prime}\right\rangle$

fprintf ('When data in file is $\backslash n$ ')

fprintf('(1) for slab-column specimen with square column, without opening and without SSR, enter number 1. (n')

fprintf('(2) for slab-column specimen with square column, without opening and with SSR, enter number 2. (n')

fprintf('(3) for slab-column specimen with rectangular column, without opening and without SSR, enter number $3 .\left\langle n^{\prime}\right\rangle$

fprintf('(4) for slab-column specimen with rectangular column, without opening and with SSR, enter number $4 .\left\langle n^{\prime}\right\rangle$

fprintf('(5) for slab-column specimen with rectangular column, with opening and without SSR, enter number 5. (n')

fprintf('(6) for slab-column specimen with rectangular column, with opening and with SSR, enter number 6. (n')

fprintf(' $\backslash n$ ')

file description=input ('Number : ');

fprintf('Running of program for $\backslash n$ ')

if (file description $=1$ )

fprintf('punching shear capacity for slab-column specimen with square column, without opening and without SSR (n')

Square NoOp NoSSR

elseif (file description $=2$ )

fprintf('punching shear capacity for slab-column specimen with square column, without opening and with SSR (n')

Square_NoOp_SSR

elseif (file description==3)

fprintf('punching shear capacity for slab-column specimen with rectangular column, without opening and without SSR (n')

Rectangular NoOp NoSSR

elseif (file description $=4$ )

fprintf('punching shear capacity for slab-column specimen with rectangular column, without opening and with SSR (n')

Rectangular_NoOp_SSR

elseif (file_description=-5)

fprintf('punching shear capacity for slab-column specimen with rectangular column, with opening and without SSR $\backslash$ ') 
Rectangular_Op_NoSSR

elseif (file_description=6)

fprintf('punching shear capacity for slab-column specimen with rectangular column, with opening and with SSR $\backslash n$ ')

end

Rectangular_Op_SSR

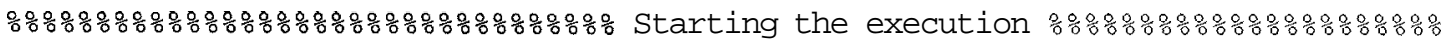
for $i=1: 1:$ no

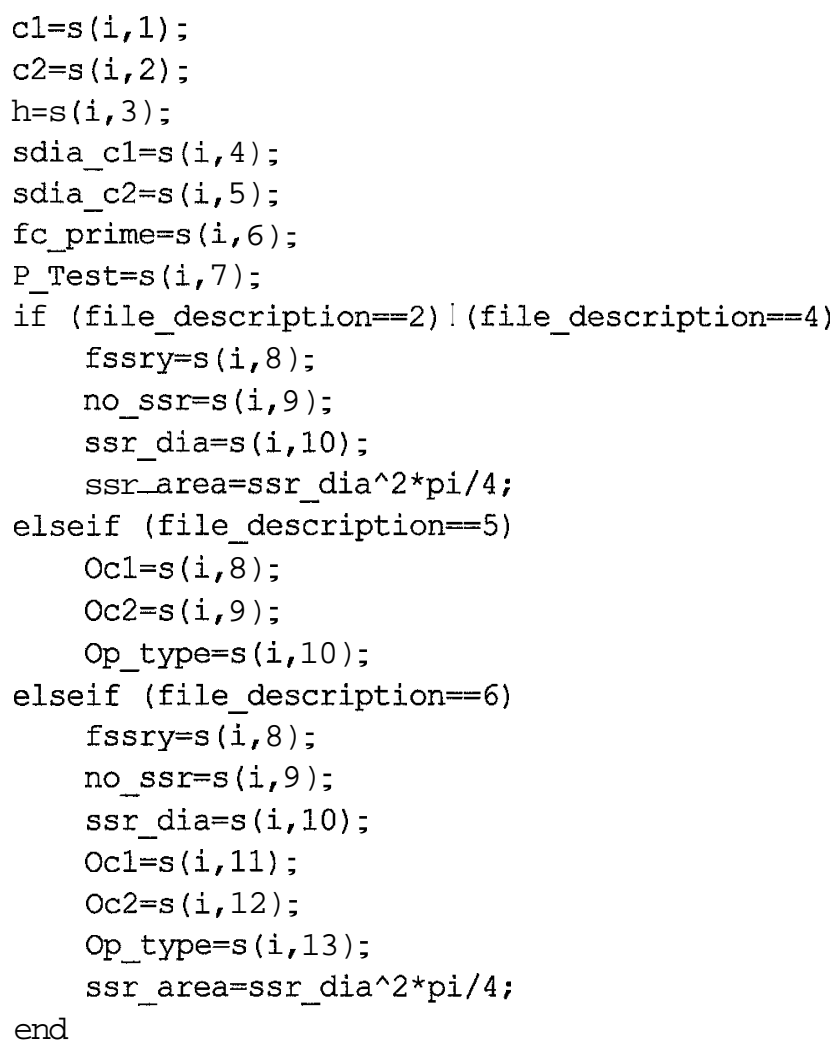

응응응 Initialization values.

$\mathrm{VC}=(0.8 / \text { sqrt }(\text { fc_prime }))^{*}(10+\log (1 / \mathrm{h}))^{*}(\mathrm{c} 2 / \mathrm{c} 1)^{\wedge}(-0.125)$;

$\mathrm{vt}=1 / 12$;

$f_{C}=v C^{\star} f c \_$prime

$\mathrm{Et}=\mathrm{O}$;

$\mathrm{M}=1 .-2 . *(\mathrm{ft} / \mathrm{fc}) /\left(1 .-\sin \left(37 .{ }^{*} \mathrm{pi} / 180.\right)\right)$;

$\mathrm{I}=1 .-2 . *(\mathrm{ft} / \mathrm{fc}){ }^{*} \sin \left(37 .{ }^{*} \mathrm{pi} / 180.\right) /\left(1 .-\sin \left(37 .{ }^{*} \mathrm{pi} / 180.\right)\right) ;$

$r \operatorname{Min}=0.75 * h$;

if $(\mathrm{c} 1=\mathrm{c}=\mathrm{c})$

$r \operatorname{Max}=(($ sdia_c1-c1)/2);

elseif $(c 1 \sim=c 2)$

$r \operatorname{Max}=0.5 *(($ sdia_c1-c1 $) / 2+($ sdia_c2 $-\mathrm{c} 2) / 2)$;

end

delta_1=c1/2;

delta_2=c2/2;

delta=delta $1+\operatorname{delta} 2$;

$\mathrm{n} 1=0$;

$\mathrm{n} 2=0$;

$\mathrm{n} 3=0$;

rh triall=rMin;

increment_ $\mathrm{r}=2$;

remainder $=\bmod ((r \operatorname{Max}-r \operatorname{Min})$, increment $r)$; 
if (file description==2) I. (file_description=4)!(file_description=-6) fssry $=s(i, 8)$;

no_ssr=s $(i, 9)$;

ssr_dia $=s(i, 10)$;

ssr_area $=s s r+d i a^{\wedge} 2 * \mathrm{pi} / 4$;

end

음음응응응음음음 Determination of possible radius of failure surface 음음음음음음응음음 while rh_trial1<=rMax

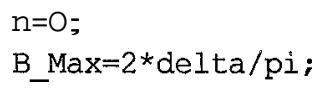




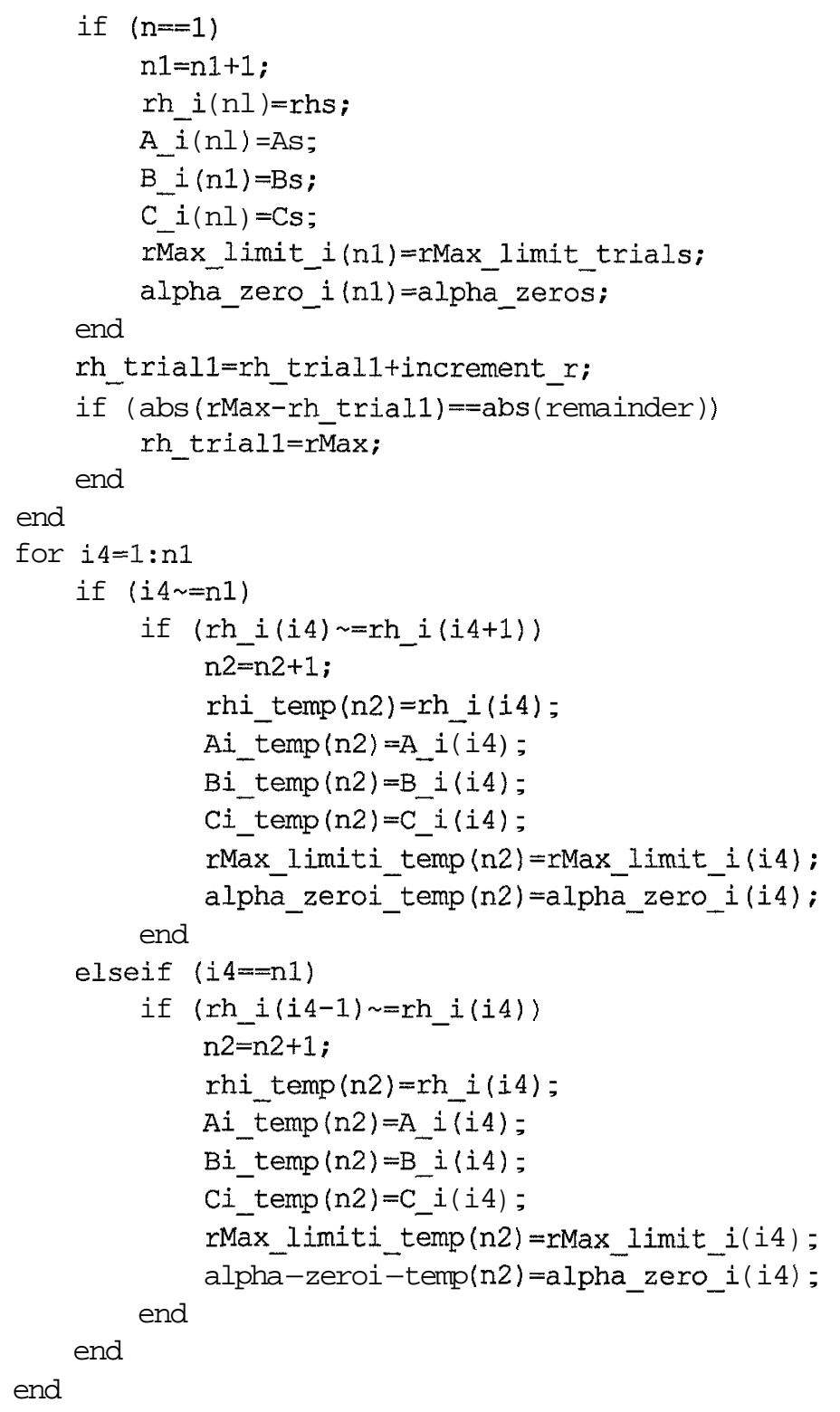

$5 \% \frac{5}{5} \%$ Aleminate the $r$ value with unreasonable alpha value.

$\mathrm{n} 3=\mathrm{n} 3+1$;

rhi $(n 3)=r h i$ temp (1) ;

$\mathrm{Ai}(\mathrm{n} 3)=\mathrm{Ai}$ temp $(1)$;

$\mathrm{Bi}(\mathrm{n} 3)=\mathrm{Bi} \operatorname{temp}(1)$;

$\mathrm{Ci}(\mathrm{n} 3)=\mathrm{Ci}$ temp $(1)$;

rMax_limiti (n3)=rMax_limiti_temp (1);

alpha-zeroi $(\mathrm{n} 3)=$ alpha_zeroi_ternp (1) ;

for $i 5=2: n 2$

if (alpha-zeroi-temp (i5)>=alpha_zeroi_temp (1: (i5-1)))

$\mathrm{n} 3=\mathrm{n} 3+1$;

rhi $(n 3\rangle=r h i$ temp $(i 5)$;

$\mathrm{Ai}(\mathrm{n} 3)=\mathrm{Ai}$ temp $(i 5)$;

$\mathrm{Bi}(\mathrm{n} 3)=\mathrm{Bi}$ temp $(\mathrm{i} 5)$;

$\mathrm{Ci}(\mathrm{n} 3)=\mathrm{Ci}$ temp $(\mathrm{i} 5)$;

rMax_limiti (n3)=rMax_limiti_temp (i5);

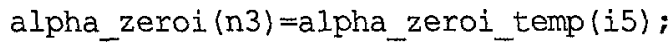
end

end 


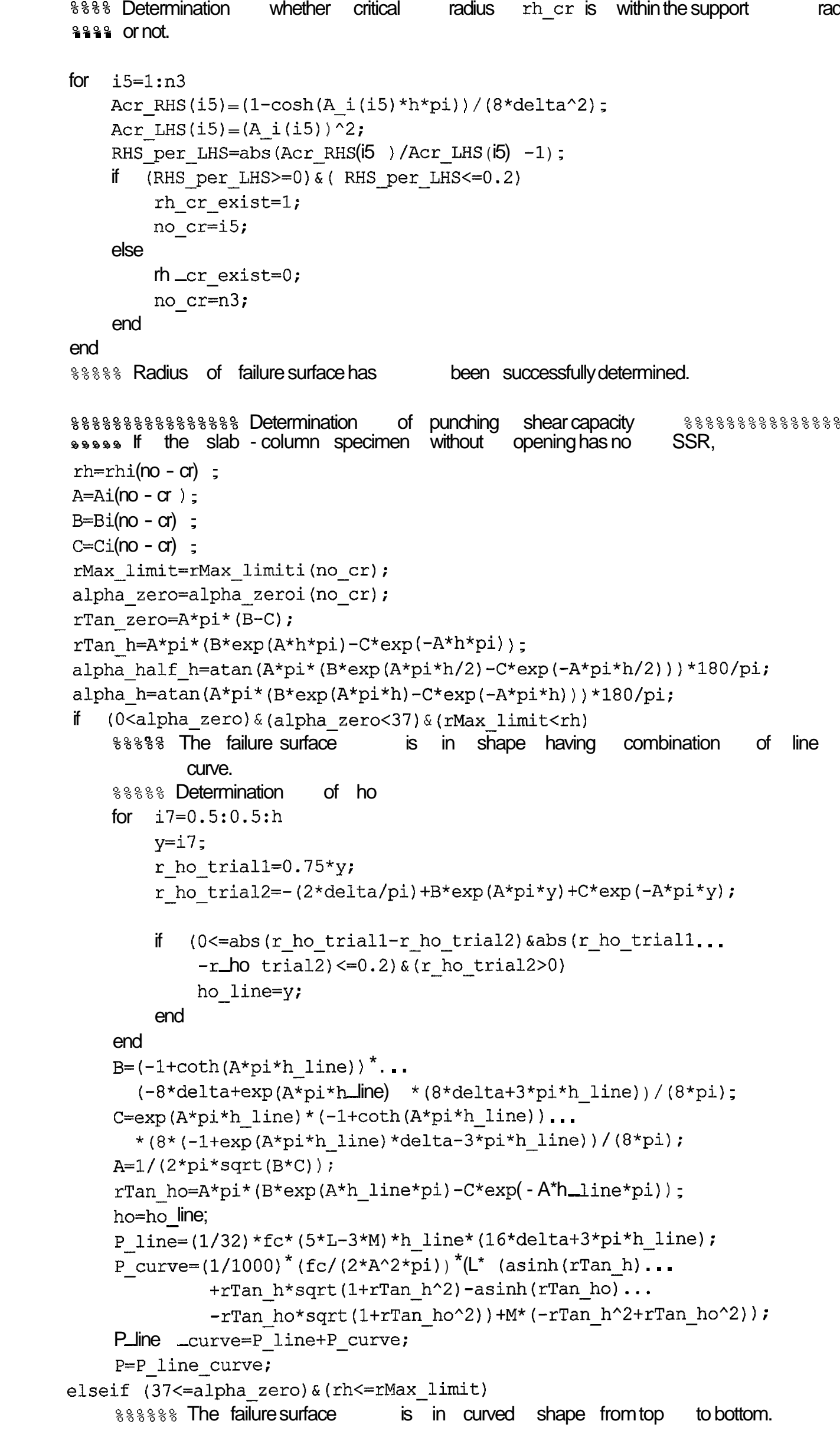




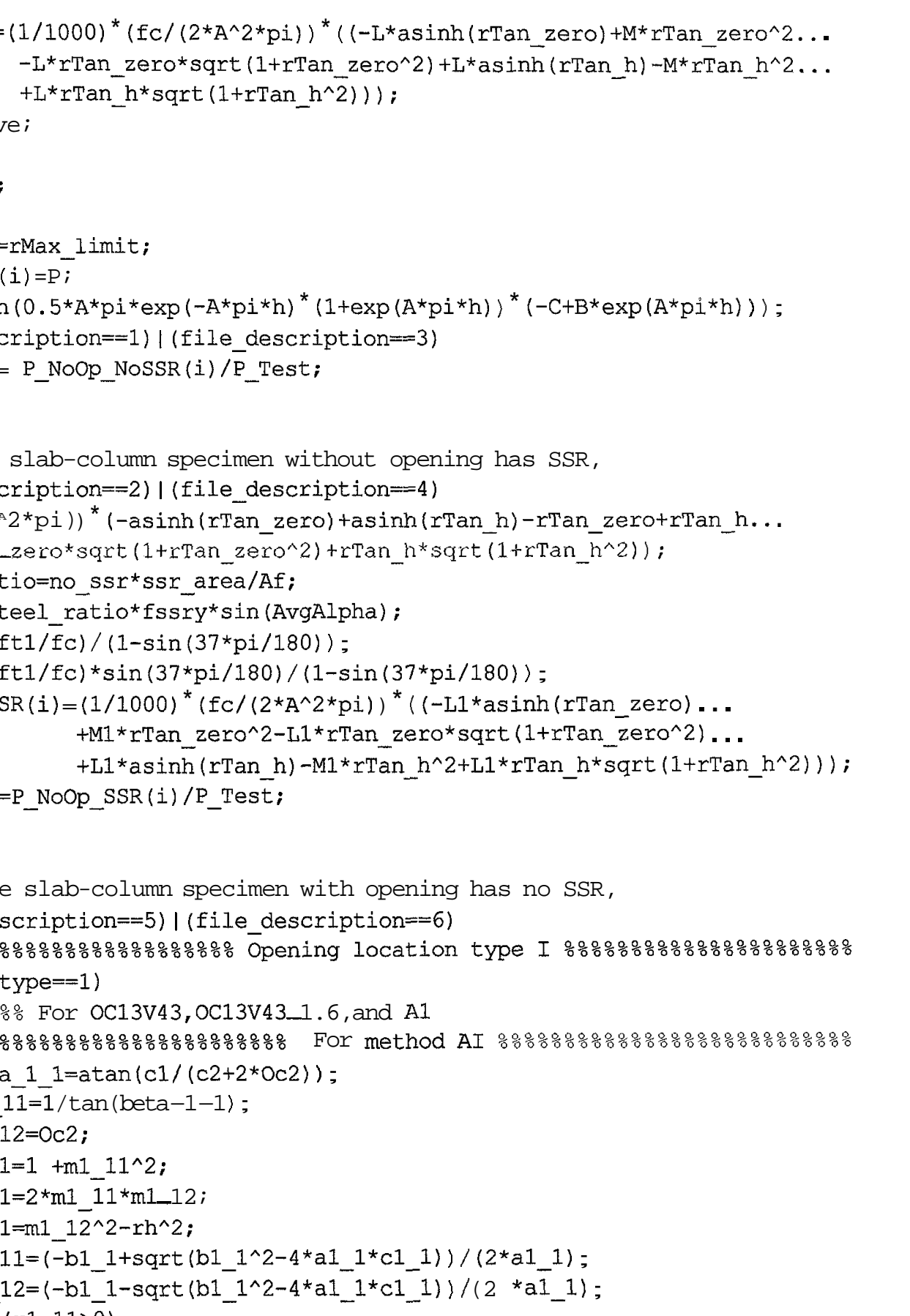




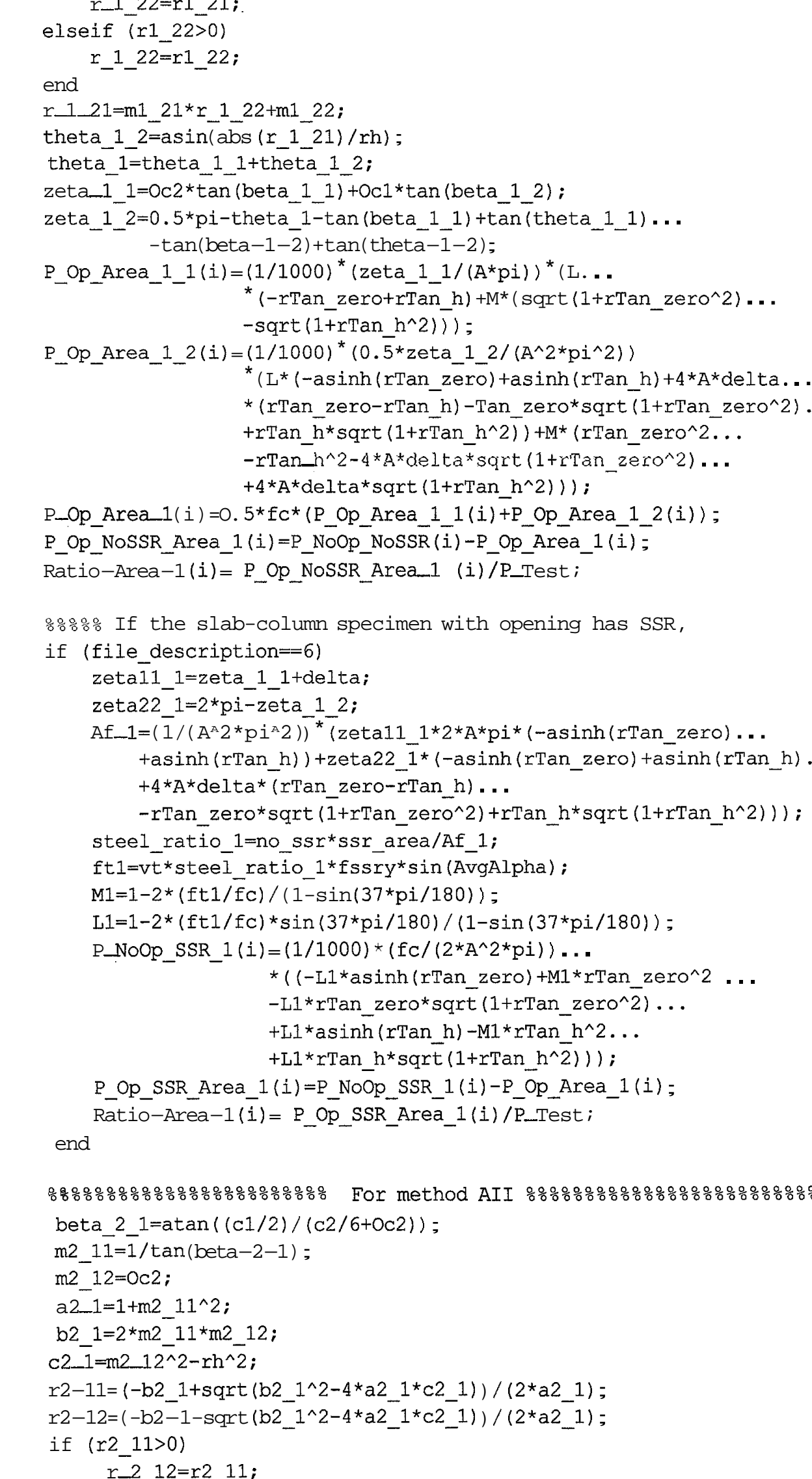

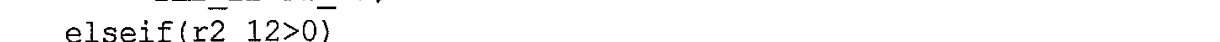

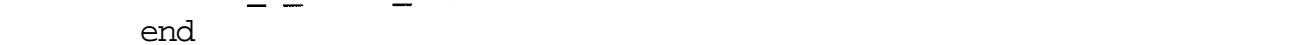
elseif (Op_type= $=2$ ) 
баба Specimans $0 \mathrm{OC13V40}$ \& B1

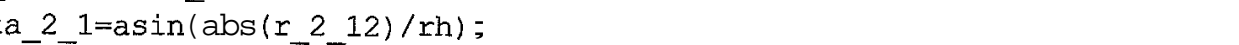
beta_1_1=atan $(\mathrm{c} 2 / 0 \mathrm{c} 1)$;

m1 11=tan (beta $-1-1)$;

m1_12=-(Oc1/2-c1/2) *tan (beta $-1-1)$;

a1 $1=1+\mathrm{m} 1 \quad 11^{\wedge} 2$;

b1 $1=2 * \mathrm{~m} 1$ 11*m1_12;

c1-1=m1 12^2-rh^2;

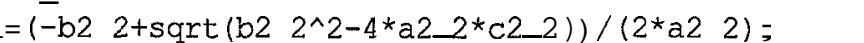

r1_12=(-b1_1-sqrt (b1_1^2-4*a1_1* ${ }^{-} 1$ 1 $\left.)\right) /(2 * a 1$

if $(r 1+11>0)$

$r$ 1_12=r1_11;

elseif $(r 1,12>0)$

r_1_12=r1_12;

end

r_1_11=m1_11*r_1_12+m1_12;

theta_1_1=asin $\left(\operatorname{abs}\left(r_{1} 1-12\right) / \mathrm{rh}\right)$;

zeta 1 1=c1+(0c1-c1)*tan (beta-1-1);

zeta_1_2=2*(theta_1_1-tan (beta_1_1) $+\tan (p i / 2-\operatorname{theta} 1$ 1));

P_Op_Area_1_1(i) $=(\overline{1} / 1000)^{*}\left(\right.$ zeta_1_ $\left._{1} /\left(\mathrm{A}^{*} \mathrm{pi}\right)\right) *(\mathrm{I} \ldots$ $\star\left(-r T a n \_z e r o+r T a n h\right)+M^{\star}\left(\operatorname{sqrt}\left(1+r T a n \_z e r 0^{\wedge} 2\right) \ldots\right.$ $-\operatorname{sqrt}(1+r \operatorname{Tan} h \wedge 2)))$;

P_Op_Area_1_2(i) $=(1 / 1000) *\left(0.5^{*}\right.$ zeta_1_2/(A^2*pi^2))

* $\left(\mathrm{L}^{\star}\left(-\operatorname{asinh}(\mathrm{rTan} z \mathrm{zerO})+\operatorname{asinh}(\mathrm{rTan} \mathrm{h})+4{ }^{*} \mathrm{~A}^{*}\right.\right.$ delta...

* (rTan_zero-rTan $h$ ) -Tan_zero*sqrt $(1+r \operatorname{Tan} z$ zero^ 2$) \ldots$ $+r \operatorname{Tan} \bar{h}^{*} \operatorname{sqrt}\left(1+r \bar{T} a h_{-}{ }^{\wedge} \overline{)}\right)+M^{*}(r \operatorname{Tan}$ zero^ $2 .$.

-rTan_h^2-4*A*delta*sqrt (1+rTan_zero^2)...

$+4{ }^{*} A{ }^{*}$ delta*sqrt $\left.\left.\left(1+r \operatorname{Tan} h^{\wedge} 2\right)\right)\right)$;

P_Op_Area_1 $(i)=0.5 * f_{C} *\left(P \_O p \_A r e a \_111(i)+\right.$ P_Op_Area_1_2(i));

P_Op_NoSSR_Area_ $1(\bar{i})=$ P_NoOp_NoSSR $\left(i \bar{i}-\bar{N}_{-}\right.$Op_Area_ $1(i) ;$

RatióArea $1(i)=$ P_Op_NosSR_Area 1 (i) $/ P$ Test;

음응음음 If the slab-column specimen with opening has SSR,

if (file description $=6$ )

zeta11_1=zeta_1_1+delta;

zeta22 1=2*pi-zeta 12 ;

Af_1 $1=\left(\overline{1} /\left(A^{\wedge} 2 * p i \wedge 2\right)\right)^{*}\left(z e t a 11 \_1 * 2 * A * p i *\left(-\operatorname{asinh}\left(r T a n \_z e r o\right) . .\right.\right.$.

$+\operatorname{asinh}\left(r \operatorname{Tan} \_\right.$h) $)+\operatorname{zeta22} 1^{*}(-\operatorname{asinh}(r \operatorname{Tan} z \operatorname{zero})+\operatorname{asinh}(\mathrm{rTan} h) .$.

$+4^{\star} A^{\star}$ delta* $(r T a n$ zero-rTan $h)-r T a n$ zero*sqrt $(1+r T a n$ zero^ 2$) \ldots$

$\left.\left.+r \operatorname{Tan} h^{*} \operatorname{sqrt}\left(1+r-\operatorname{Tan} h^{\wedge} 2\right)\right)\right)$;

steel_ratio_1=no_ssr*ssr_area/Af_1;

ft $1=\overline{v t}^{*}$ stee $\bar{l}$ ratio $1 *$ fssry* $\sin ($ AvgAlpha) ;

$\mathrm{M} 1=1-2 *$ ft1/fc) $/(1-\sin (37 * \mathrm{pi} / 180))$;

$\mathrm{L} 1=1-2 *(\mathrm{ft} 1 / \mathrm{fC}) * \sin (37 * \mathrm{pi} / 180) /(1-\sin (37 * \mathrm{pi} / 180)) ;$

P_NOOP_SSR_1 $(i)=(1 / 1000)^{*}\left(\mathrm{fc}_{\mathrm{C}} /\left(2 * \mathrm{~A}^{\wedge} 2 * \mathrm{pi}\right)\right) \ldots$

* ( $\left(-\mathrm{L} 1 * a \sinh \left(r T a n \_z e r o\right)+M 1 *\right.$ rTan_zero^ $2 .$.

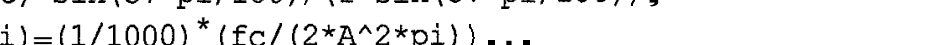

$\left.\left.-M 1 * r T a n \_h \wedge 2+L 1 * r \operatorname{Tan} h * \operatorname{sqrt}\left(1+r \operatorname{Tan} h^{\wedge} 2\right)\right)\right)$;

P_Op_SSR_Area_1(i) $=$ P_NoOp_SSR_1(i) -P_Op_Area_1(i);

Ratio-Area-1 $\bar{i})=$ P_Op_SSR_Area_ $1(i) / \bar{P}$ Test; end

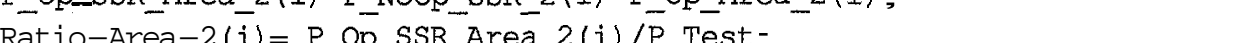
beta_2_1=atan $\left(\mathrm{c} 2 /\left(3^{*} \mathrm{Oc} 1\right)\right)$;

m2_1 $1=\tan ($ beta_2_1);

m2 $12=-(0 \mathrm{O} 1 / 2-\mathrm{cl} / 2) * \tan ($ beta_2 1) ;

a2_1=1+m2_11^2;

$\mathrm{b} 2 \_1=2 * \mathrm{~m} 2 \_11^{*} \mathrm{~m} 2 \_12$; 
c2 $1=m 2 \_12^{\wedge} 2-r h \wedge 2$;

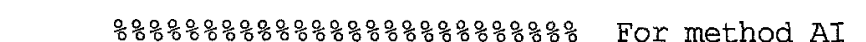

$\mathrm{r} 2-12=\left(-\mathrm{b} 2 \_1-\operatorname{sqrt}\left(\mathrm{b} 2 \_1{ }^{\wedge} 2-4{ }^{*} \mathrm{a} 2 \_1 * \mathrm{c} 21\right)\right) /(2 * \mathrm{a} 2-1)$;

if $(r 2-11>0)$

$r 2 \_12=r 2 \_11$;

elseif $(r 2$ 12>0)

end

$$
\text { r_2_12=r2_12; }
$$

$r \_2-11=m 2-11 * r 2212+m 2-12$;

theta_2_1=asin $(\operatorname{abs}(r-\overline{2}-12) / r h)$;

zeta_2_1=c1+(oc1-c1) *tan (beta-2-1) ;

zeta_2_2=2*(theta_2_1-tan (beta_2_1) $+\tan (p i / 2-\operatorname{theta} 2$ 1)) ;

P_op_Area $-2-1(i)=\overline{(1 / 1000)}{ }^{*}\left(\right.$ zeta $\overline{2} 1 /\left(A^{*}\right.$ pi $\left.)\right) \ldots$

* $\left(\mathrm{L}^{\star}(-\mathrm{rTan}\right.$ zerotrTan_h$)+\mathrm{M}^{\star}(\operatorname{sqrt}(1+r \mathrm{Tan} z$ zero^ 2$) ..$

$\left.\left.-\operatorname{sqrt}\left(1+r \operatorname{Tan} h^{\wedge} 2\right)\right)\right) ;$

P_Op_Area_2_2(i) $=(1 / 1000)^{*}\left(0.5^{*}\right.$ zeta_2_2/(A^2*pi^2) $\ldots$

* $\left(\mathrm{L}^{\star}(-\operatorname{asinh}(\mathrm{rTan} z \mathrm{e} \overline{\mathrm{r}} \mathrm{)}) \operatorname{tasinh}(\mathrm{rTan} \mathrm{h}) . .\right.$.

$+4 * A * d e l t a *$ (rTan_zero-rTan_h)

-rTan zero*sqrt $\left(1+r \operatorname{Tan} z \operatorname{ero}^{\wedge} 2\right) \ldots$

$\left.+r \operatorname{Tan} h^{*} \operatorname{sqrt}\left(1.0+r \operatorname{Tan} \bar{h}^{\wedge} 2\right)\right)+M^{\star}(r \operatorname{Tan} z$ zero^ $2 \ldots$

$-r \operatorname{Tan} h^{\wedge} 2-4{ }^{\star} A^{\star}$ delta*sqrt $(1+r \operatorname{Tan} z$ zero^ 2$) \ldots$

$+4{ }^{\star} A^{*} \overline{\text { delta*}}$ sqrt $\left.\left.\left(1+r T a n \_h h^{\wedge}\right)\right)\right)$;

P_Op_Area_2 $(i)=0.5 * 1 C^{*}\left(P \_\right.$Op_Area_2_1(i) + P_Op_Area_2_2(i)) ;

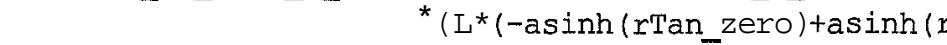

Ratio_Area_2 $(i)=$ P_op_NoSSR_Area_2(i)/E_Test;

ooooo If the slab-column specimen with opening has SSR,

if (file description $=6$ )

zeta11_2=zeta_1_1+delta;

zeta22 2=2*pi-zeta_2_2;

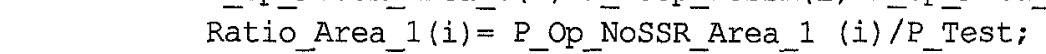

$+\operatorname{asinh}(r \operatorname{Tan} h))+\operatorname{zeta} 22 \_2 *(-\operatorname{asinh}(\operatorname{rTan} z$ zero $) ..$

$+\operatorname{asinh}(r \operatorname{Tan} h)+4 A^{*} \operatorname{delta*}(r \operatorname{Tan} z \operatorname{zero-rTan} h) \ldots$

-rTan_zero*sqrt $\left.\left.\left(1+r T a n \_z e r o^{\wedge} 2\right) \overline{+} r \operatorname{Tan} h^{\star} \operatorname{sqrt}\left(1+r T a n \_h^{\wedge} 2\right)\right)\right)$;

steel ratio $2=$ no $s s{ }^{*}$ ssr area/Af_2;

ft $1=v t *$ steel_ratio_ $1 *$ fssry*sin (AvgAIpha);

$\mathrm{M} 1=1-2 *(\mathrm{ft} 1 / \mathrm{fc}) /(1-\sin (37 * \mathrm{pi} / 180))$;

$\mathrm{I} 1=1-2 *(\mathrm{ft} 1 / \mathrm{fC}) * \sin (37 * \mathrm{pi} / 180) /(1-\sin (37 * \mathrm{pi} / 180))$;

P_NOOp_SSR_2 $(i)=(1 / 1000)^{*}\left(\mathrm{fC} /\left(2{ }^{*} A^{\wedge} 2 * \mathrm{p} i\right)\right) \ldots$

*( $(-\mathrm{L} 1 *$ asinh ( $\mathrm{LTan}$ zero) ...

$+M 1{ }^{*}$ rTan_zero^2-I $\overline{1} * r T a n \_z e r o^{\star} \operatorname{sqrt}\left(1+r T a n \_z e r o^{\wedge} 2\right) \ldots$ $+L 1 * \operatorname{asinh}\left(r T a n \_h\right)-M 1 * r T a{ }_{-} h^{\wedge} 2 \ldots$

$+L 1 * r \operatorname{Tan} h \star \operatorname{sqrt}(1+r \operatorname{Tan} h \wedge \overline{2})))$;

P_Op_SSR_Area_2(i) $=$ P_NoOp_SSR_2(i) $-\bar{P} \_$Op_Area_2(i);

end

Ratio-Area-2(i) $=$ P_Op_SSR_Area_2(i)/P_Test;

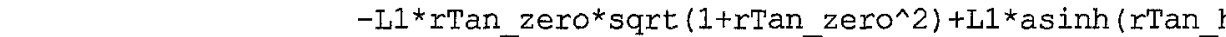

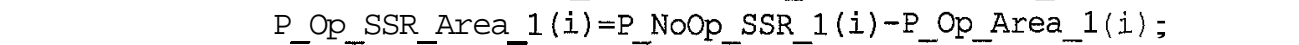
elseif (op type $=3$ )

\%

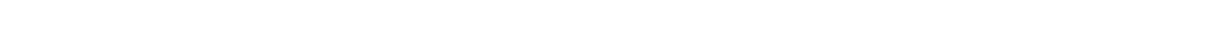

beta_1 1=atan $((\mathrm{c} 1 / 2) /(\mathrm{c} 2 / 2))$;

beta_1_2 $=\operatorname{atan}((\mathrm{c} 2 / 2-0 \mathrm{c} 2) /(\mathrm{c} 1 / 2+\mathrm{oc} 1))$;

if $(\mathrm{c} 2 / 2 * \tan (\mathrm{pi} / 2$-beta 122$)-\mathrm{c} 1 / 2<\mathrm{rh})$

$\mathrm{ml} 21=1 / \tan (\mathrm{pi} / 2$-beta_1_2)

m1 22 $=-(\mathrm{c} 2 / 2-\mathrm{cl} / 2 * \tan ($ beta $-1-21)$;

a1_2=1+m1_21^2; 


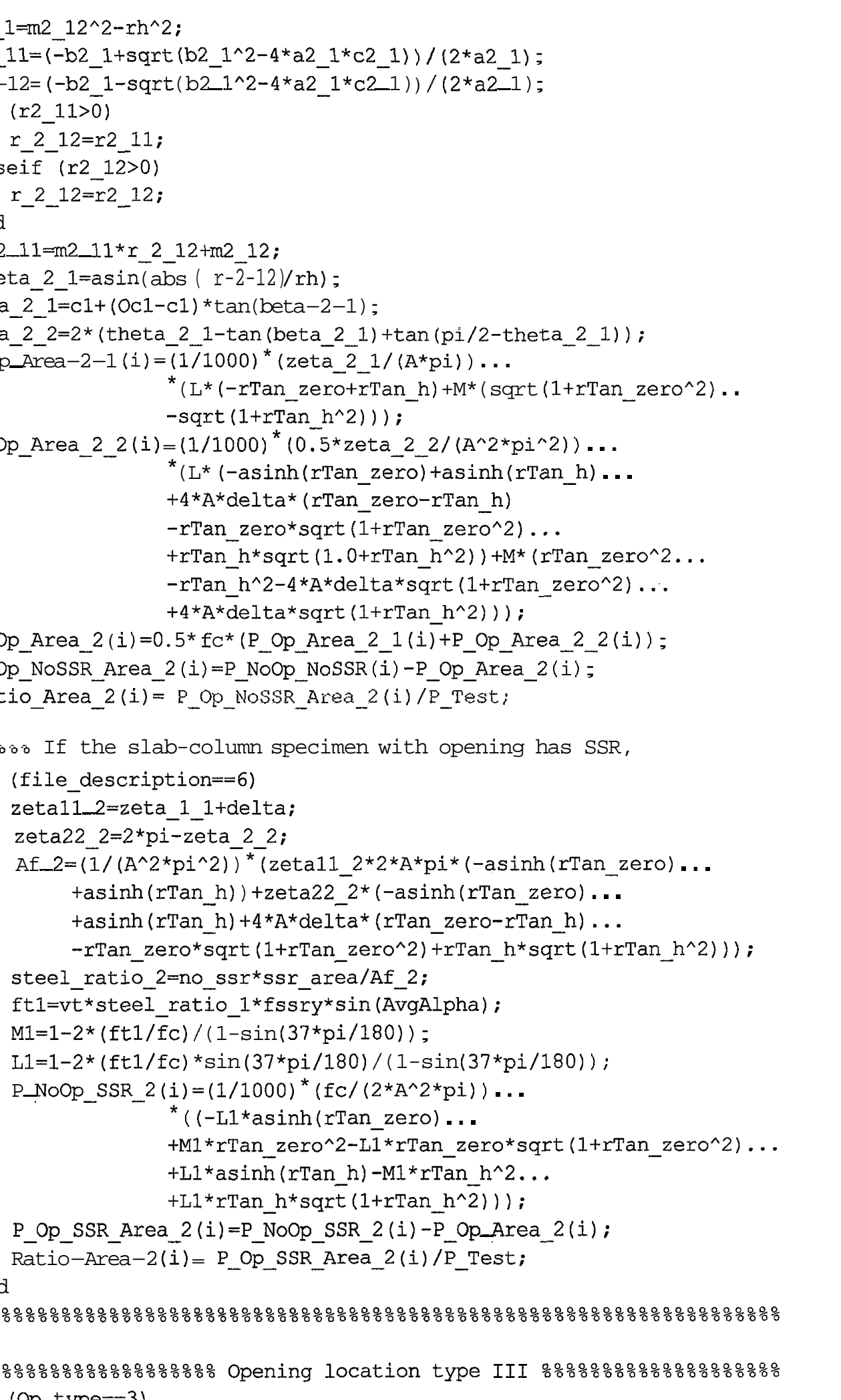

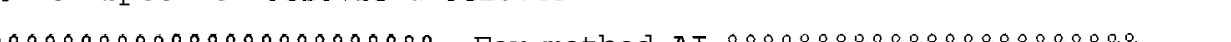
beta_2_1=atan $((\mathrm{c} 1 / 2) /(\mathrm{c} 2 / 6))$;

beta_2_2=atan $((\mathrm{c} 1 / 2) / \mathrm{abs}(\mathrm{Oc} 2-\mathrm{c} 2 / 6)) ;$

if $(\overline{5} / \overline{6} * c 2 * \tan ($ beta $22-c 1 / 2)>=r h)$

zeta_2_1=0c2;

zeta_2-2 $=($ pi $/ 2-$ beta_2 21$)+\tan ($ beta $-2-21$;

else 


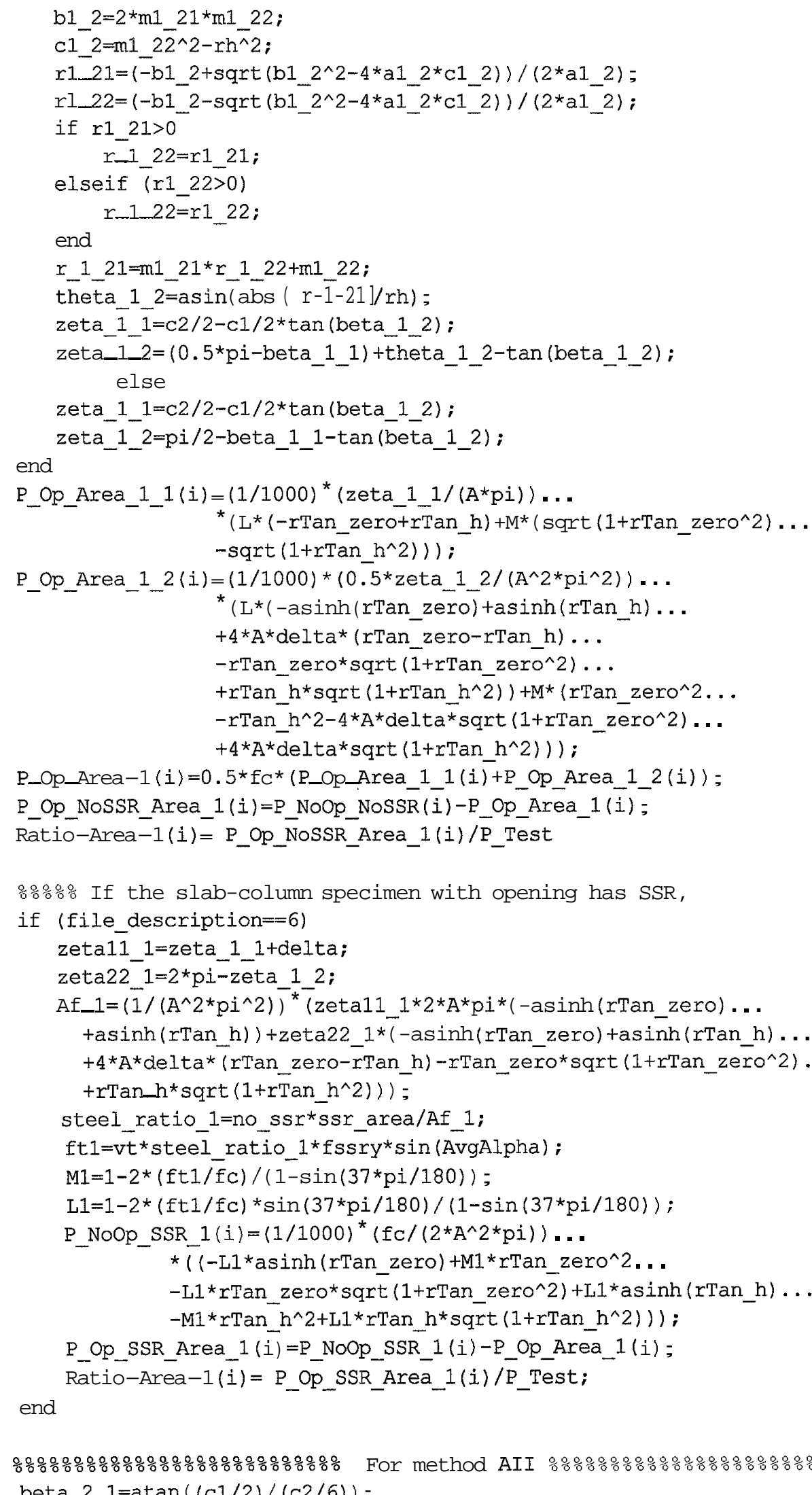

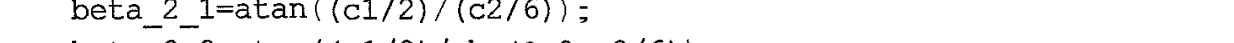

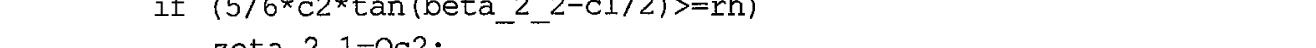
elseif (Op type==4) боб бо For specimen OC13H02 and OC13H02-1.6

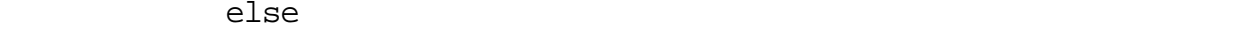




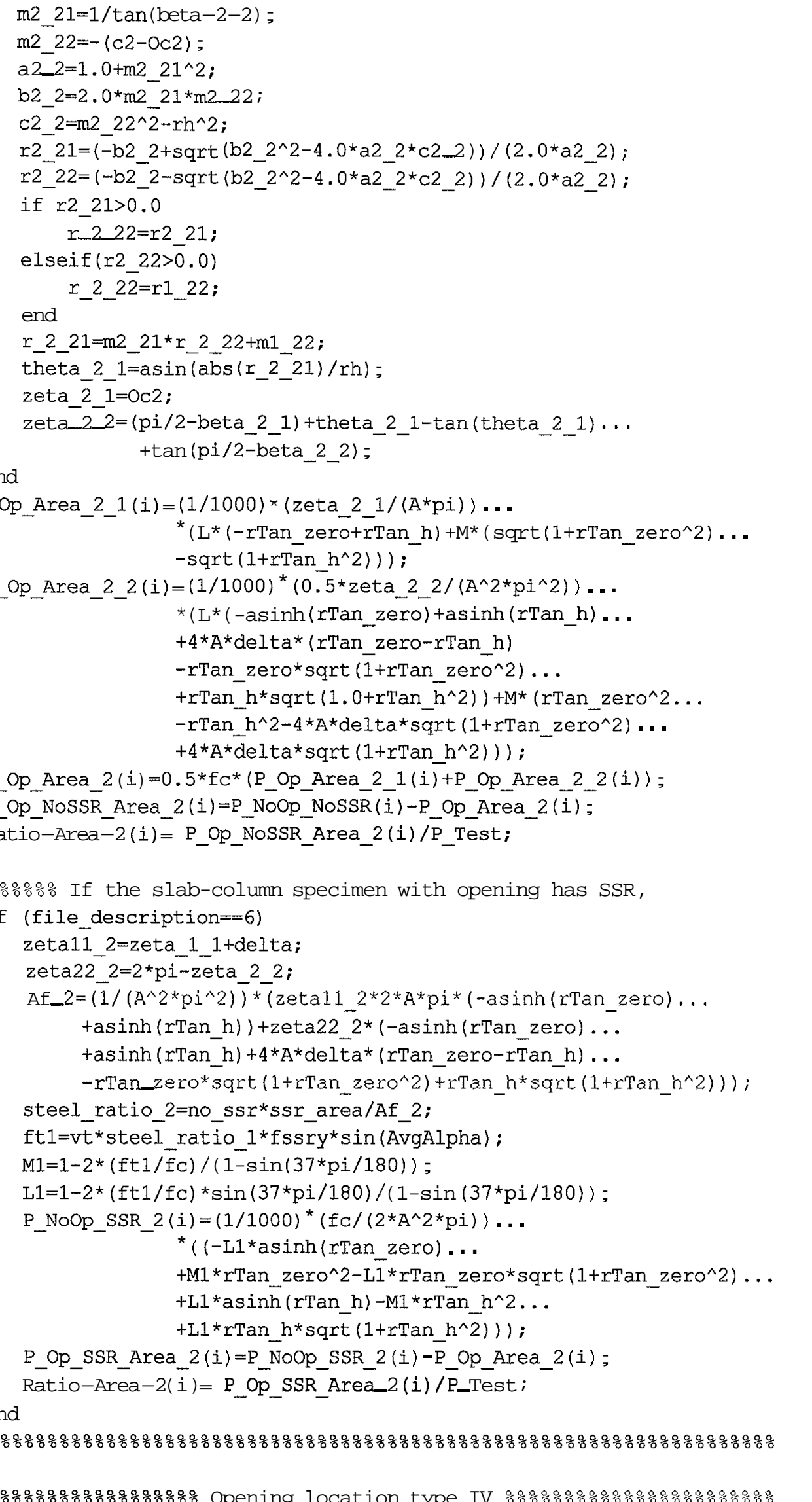

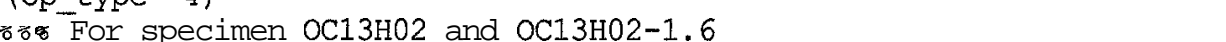
beta_2_1=atan $((\mathrm{c} 2 / 2-\mathrm{c} 1 / 6-\mathrm{Oc} 2 / 2) /(\mathrm{c} 1 / 2+\mathrm{Oc} 1))$; 
beta_2_2=atan $((\mathrm{c} 1 / 2) /(5 / 6 * \mathrm{c} 2-\mathrm{c} 2 / 2+\mathrm{Oc} 2 / 2))$;

$\mathrm{m} 2 \_11=(\mathrm{c} 2 / 2-\mathrm{oc} 2 / 2) /((\mathrm{c} 2 / 2-\mathrm{oc} 2 / 2) * \tan ($ beta $-2-21)$;

$\mathrm{m} 2-12=(\mathrm{c} 2 / 2-0 \mathrm{c} 2 / 2)$;

a2 $1=1+m 2 \_11 \wedge 2$;

b2 $1=2 * m 2 \_11 * m 2 \_12$;

c2 $1=\mathrm{m} 2 \_12^{\wedge} 2-r h^{\wedge} 2$;

$\mathrm{r} 2-11=\left(-\mathrm{b} 2 \_1+\operatorname{sqrt}\left(\mathrm{b} 2 \_1 \wedge 2-4 * a 2 \_1 * \mathrm{c} 2 \_1\right)\right) /\left(2{ }^{\star} \mathrm{a} 2 \_1\right)$;

$r 2-12=\left(-\mathrm{b} 2 \_1-\operatorname{sqrt}\left(\mathrm{b} 2 \_1 \wedge 2-4 * a 2-1 * \mathrm{c} 2-1\right)\right) /\left(2 * a \overline{2} \_1\right)$;

if $(r 2,11>\overline{0})$

$\simeq 2$ 2 $12=r 2 \_11$;

elseif $(\bar{r} 2$ 12>0)

r_2_12=r2_12;

end

if $((\mathrm{c} 2 / 2-0 \mathrm{c} 2 / 2) * \tan ($ beta $-2-2)<\mathrm{rh})$

$\mathrm{r} 2-11=\mathrm{m} 2 \quad 11 * \mathrm{r} 2 \quad 12+\mathrm{m} 2 \quad 12$;

theta_2 1=asin (abs (r_2_11)/rh);

zeta_ $\overline{2}-\overline{1}=5 / 6 * c 2-c 1 / 2 * \tan ($ beta 21$)-(c 2 / 2-0 c 2 / 2)$;

zeta_2_2=theta_2 $1-\tan \left(\right.$ beta_2_1) $-\tan \left(\operatorname{theta}{ }^{2}{ }_{-} 1\right.$ )...

$+\tan (0 . \overline{5} *$ pi-beta_2_2);

else

zeta_2_1=c2/2-c2 $/ 6-\mathrm{c} 1 / 2 * \tan ($ beta_2 1$)+0 \mathrm{c} 2 / 2+\mathrm{rh} / \cot ($ beta_2 2$)$;

zeta_2 $2=-1 / \cot ($ beta_2_2);

end

P_Op_Area_2_1(i) $=(1 / 1000)^{*}($ zeta_2_1/(A*pi) $) \ldots$
${ }^{*}\left(L^{*}(-r T a n\right.$ zero + rTan $h)+M^{*}($ sq $\left.\left.-\operatorname{sqrt}\left(1+r \operatorname{Tan} \mathrm{h}^{\wedge} 2\right)\right)\right)$

P_Op_Area_2_2(i) $=(1 / 1000)^{*}\left(0.5^{*}\right.$ zeta_2_2 $\left./\left(A^{\wedge} 2 * p i \wedge 2\right)\right) .$.

* $\left(\mathrm{L}^{*}(-\operatorname{asinh}(r \operatorname{Tan} z \mathrm{ero}) \operatorname{tasinh}(r \mathrm{Tan} h) . .\right.$.

$+4{ }^{\star} A * \operatorname{delta*}(r \operatorname{Tan} z$ zero-rTan_h)

-rTan_zero*sqrt $\left(1+r T a n \_z e r 0^{\wedge} 2\right) \ldots$

$\left.+r \operatorname{Tan} h^{\star} \operatorname{sqrt}\left(1+r \operatorname{Tan} h^{\wedge} \overline{2}\right)\right)+M^{\star}(r \operatorname{Tan} z$ zero^ $2 \ldots$

-rTan_h^2-4*A*delta*sqrt (1+rTan_zero^2)...

$+4 A^{\star}$ delta*sqrt $\left.\left.(1+r \operatorname{Tan} h \wedge 2)\right)\right)$;

P_Op_Area $-2(i)=0.5 * f c^{*}\left(P \_\right.$op_Area $-2-1(i)+P$ Op_Area_2_2(i));

P_Op_NoSSR_Area_2(i) $=$ P_NoOp_NoSSR $(i)-P \_O p \_A r e a \_2(i)$;

Ratio-Area-2(i)= P_Op NoSSR_Area_2(i)/P_Test;

음음음 If the slab-column specimen with opening has SSR,

if (file description $=6$ )

zeta11_2=zeta_1_1+delta;

zeta22_2=2*pi-zeta_2_2;

Af_2 $\left.=\left(1 /\left(A^{\wedge} 2 * \mathrm{p} i^{\wedge} 2\right)\right)\right)^{*}($ zeta11_2*2*A*pi* $(-\operatorname{asinh}(\mathrm{rTan} z e r o) .$.

$+\operatorname{asinh}(r \operatorname{Tan} h))+\operatorname{zeta22} 2^{*}(-\operatorname{asinh}(r \operatorname{Tan} z$ zero $) ..$

$\operatorname{tasinh}(r \operatorname{Tan} h)+4 A^{\star} \operatorname{delta}{ }^{*}(r T a n$ zero-rTan $h) \ldots$

-rTan_zero*squt $(1+r \operatorname{Tan} z$ zero^ 2$\left.\left.)+r \operatorname{Tan} h^{\star} \operatorname{sqrt}\left(1+r \operatorname{Tan} h^{\wedge} 2\right)\right)\right)$;

steel_ratio_2=no_ssr*ssr_area/Af_2;

ft $1=v t \star s t e e l$ ratio_1*fssry ${ }^{\star} \sin ($ AvgAlpha) ;

$\mathrm{M} 1=1-2 *(\mathrm{ft} 1 / \mathrm{fC}) /(1-\sin (37 * \mathrm{pi} / 180))$;

$\mathrm{L} 1=1-2 *(\mathrm{ft} 1 / \mathrm{fC}) * \sin (37 * \mathrm{pi} / 180) /(1-\sin (37 * \mathrm{pi} / 180))$;

P_NoOp_SSR_2(i) $=(1 / 1000) *\left(f \mathrm{f} /\left(2^{\star} A^{\wedge} 2^{\star} \mathrm{pi}\right)\right) \ldots$

* ( (-L1*asinh ( $r$ Tan zero $). .$.

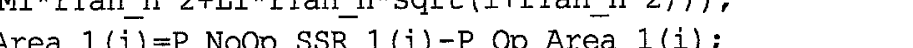
$+L 1 * \operatorname{asinh}(r \operatorname{Tan} h)-M 1 * r T a{ }^{\prime} h^{\wedge} 2 \ldots$

$\left.\left.+L 1 * r \operatorname{Tan} h{ }^{\star} \operatorname{sqrt}\left(1+r \operatorname{Tan} h^{\wedge} \overline{2}\right)\right)\right)$;

P_Op_SSR_Area_2 (i) =P_NoOp_SSR_2(i)-P Op_Area_2(i);

Ratio-Area-2(i)= P_Op_SSR_Area_2(i)/P_Test;

end

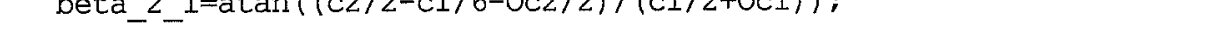




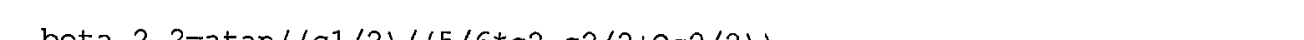
elseif (Op type $=5$ )

음음음음 $\vec{F}$ For specimen oc13H50, OC13H50-1.6, and OC15H70

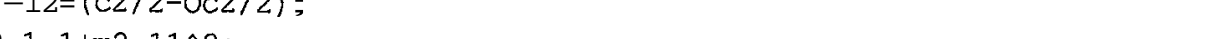
beta_1_1=atan $(\mathrm{c} 1 / \mathrm{c} 2)$;

zeta_1_1=c1;

zeta_1_2=2*beta_1_1;

P_Op_Area-1-1 $(\bar{i})=(1 / 1000) *($ zeta_1_1/(A*pi) $) ..$

* $\left(L^{\star}\left(-r T a n \_z e r o+r T a n h\right)+M^{\star}\left(\operatorname{sqrt}\left(1+r T a n \_z e r o^{\wedge} 2\right) \ldots\right.\right.$

$\left.\left.-\operatorname{sqrt}\left(1+r \operatorname{Tan} h^{\wedge} 2\right)\right)\right) ;$

P_Op_Area-1-2 $(i)=(1 / 1000)^{*}\left(0.5^{\star}\right.$ zeta_1_2/(A^2*pi^2) $\ldots$

${ }^{*}\left(\mathrm{~L}^{\star}\left(-\operatorname{asinh}(\mathrm{rTan} z \mathrm{e} \overline{\mathrm{r}} \mathrm{)}) \operatorname{tasinh}\left(\mathrm{rTan} \mathrm{h}_{\mathrm{H}}\right) . .\right.\right.$.

$+4{ }^{*} A^{\star} \operatorname{delta}{ }^{\star}(r \operatorname{Tan} z e r o-r \operatorname{Tan} h) \ldots$

-rTan_zero*sqrt $\left(\overline{1}+r T a n \_z e r o^{\wedge} 2\right)$...

$\left.+r \operatorname{Tan} h^{\star} \operatorname{sqrt}\left(1+r \operatorname{Tan} h^{\wedge} \overline{2}\right)\right)+M^{\star}\left(r \operatorname{Tan} z e r o^{\wedge} 2 \ldots\right.$

$-r T a n \_h^{\wedge} 2-4{ }^{*} A^{\star}$ delta* $\operatorname{sqrt}\left(1+r T a n \_z e r o^{\wedge} 2\right) \ldots$

$+4{ }^{\star} A^{\star}$ delta*sqrt $\left.\left.\left(1+r \operatorname{Tan} h^{\wedge} 2\right)\right)\right)$;

P_Op_Area_1 $(i)=0.5 * f C^{*}\left(P \_\right.$Op_Area_1_1(i) + P_Op_Area_1_2(i));

P_Op_NoSSR_Area_1 $(i)=$ P_NoOp_NoSSR $(\bar{i})-P \_O p \_A r e a \_1(\bar{i}) ;$

Ratio-Area-1 (i) = P_Op_NoSSR_Area_1(i)/P_Test

богу If the slab-column specimen with opening has SSR,

if (file description=6) \% Due to the inclusion of SSR zeta11_1=zeta_1_1+delta;

zeta.22_1=2*pi-zeta_1_2;

Af_1 $=\left(1 /\left(A^{\wedge} 2 \star p i \wedge 2\right)\right)^{*}($ zeta11_1*2*A*pi*(-asinh (rTan_zero) . . .

$\left.+\operatorname{asinh}\left(r T a n \_h\right)\right)+\operatorname{zeta22} 1^{*}\left(-\operatorname{asinh}\left(r \operatorname{Tan} \_z e r o\right)+\operatorname{asinh}\left(r T a n \_h\right) . .\right.$. $+4 A^{\star}$ delta* $\left(r T a n\right.$ zero-rTan_h) -rTan_zero*sqrt $\left(1+r T a n \_z e r o^{\wedge} 2\right) \ldots$ $+r \operatorname{Tan} h^{*} \operatorname{sqrt}\left(1+r \bar{T}\right.$ an $\left.\left.\left.h^{\wedge} 2\right)\right)\right)$;

steel ratio_ $1=$ no_ssr*ssr_area/Af 1 ;

ft $1=v{ }^{*}$ steel ratio $1{ }^{\star}$ fssry* $\sin$ (AvgAlpha);

$\mathrm{M} 1=1-2 *\left(\mathrm{ft} 1 / \overline{f C}_{\mathrm{C}}\right) /(1-\sin (37 * \mathrm{pi} / 180)) ;$

$\mathrm{I} 1=1-2 *(\mathrm{ft} 1 / \mathrm{fc}) * \sin (37 * \mathrm{pi} / 180) /(1-\sin (37 * \mathrm{pi} / 180)) ;$

P_NOOP_SSR_1(i) $=(1 / 1000)^{*}\left(\mathrm{fc} /\left(2^{\star} \mathrm{A}^{\wedge} 2^{\star} \mathrm{pi}\right)\right) \ldots$

* ( $(-\mathrm{L} 1 * \operatorname{asinh}(\mathrm{rTan}$ zero $)+\mathrm{M} 1 *$ rTan zero^ 2 ...

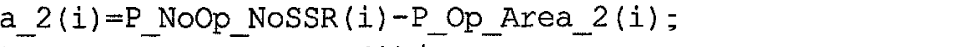

$\left.\left.-M 1 * r \operatorname{Tan} h^{\wedge} 2+L 1 * r T a n \_h * \operatorname{sqrt}\left(1+r \operatorname{Tan} h h^{\wedge} 2\right)\right)\right)$;

P_Op_SSR_Area_1(i) $=$ P_NoOp_SSR_1(i)-P_Op_Area_1(i) ;

Ratio-Area-1 $(\bar{i})=$ P_Op_SSR_Area_1(i)/P_Test;

end

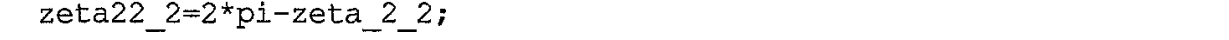

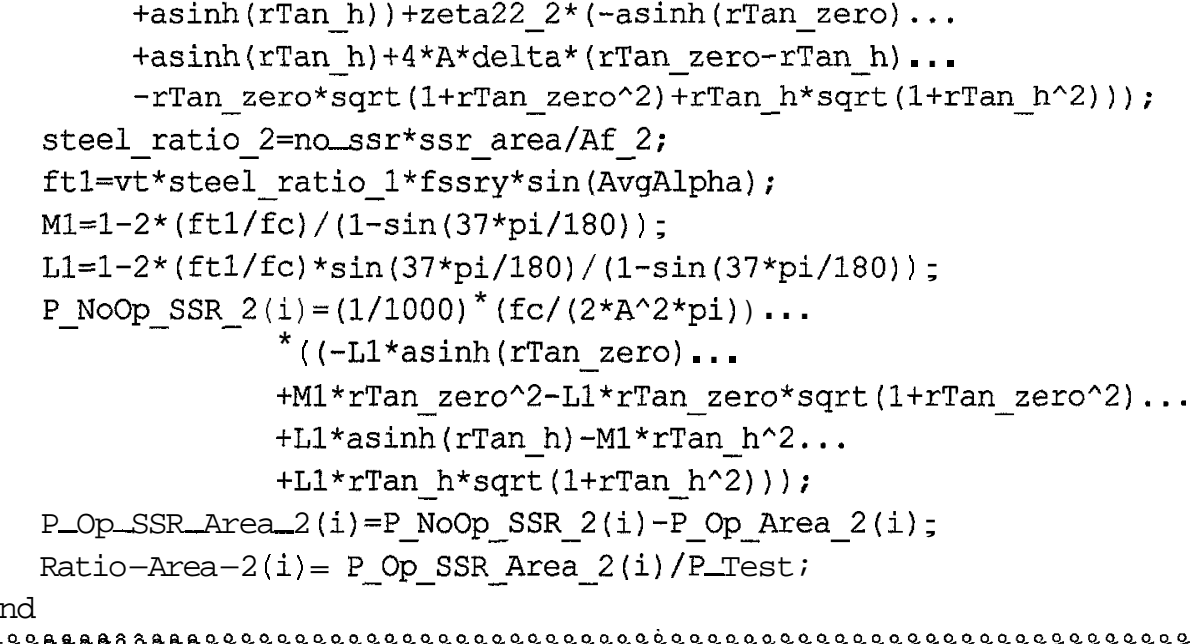




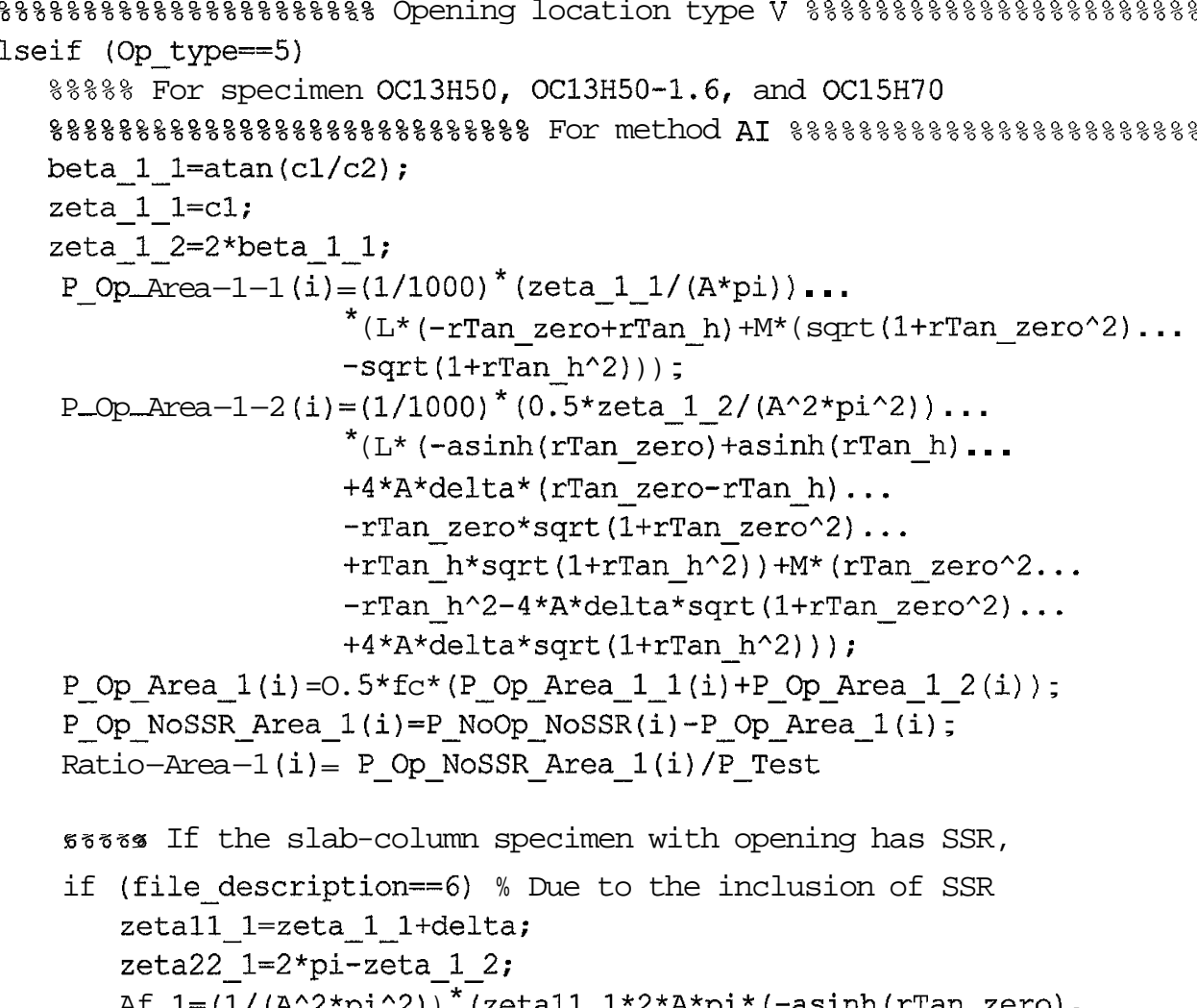

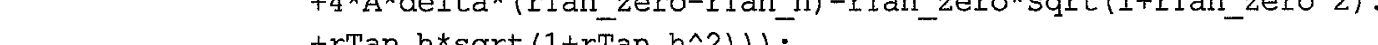
if (file description=-1) save Results_Sq_NoOp_NoSSR P_NoOp_NoSSR Ratior_h_limit r_h SRad elseif (file_description $=2$ ) save Results_Sq_NoOp_SSR P_NOOP_NOSSR Pu_NoOp_SSR Ratio $r$ h_limit... $r$ h SRad

elseif (file_description $=3$ )

save Results_Rect_NoOp_NoSSR P_NoOp_NoSSR Ratio r_h_limit r_h SRad elseif (file_description $==\overline{4}$ )

save Results-Rect_NoOp_SSR P_NoOp_NoSSR P_NoOp_SSR Ratio r_h_limit... $r$ h SRad

elseif (file_description==5)

save Results Rect_Op_NoSSR P NoOp NoSSR P_Op_Area_1... P_Op_NoSSR_Area_1 Ratio-Area-1 P_Op_Area_2 r_h_limit...

$r$ h P_Op_NoSSR_Area_2 Ratio-Area-2 SRad

elseif (file_description=-6)

save Results_Rect_Op_SSR P_NoOp_NoSSR P_NOOP_SSR_1...

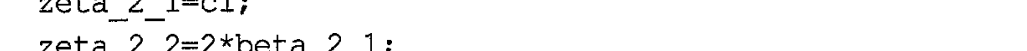

P_op_Area_2 P_op_SSR_Area_2 Ratio-Area_2 r_h_limit $\bar{r} h$ SRad

end

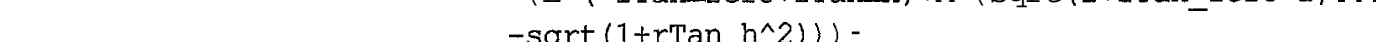
end

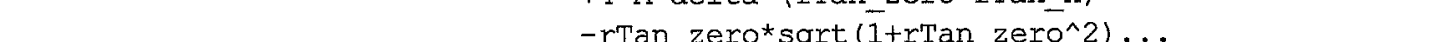

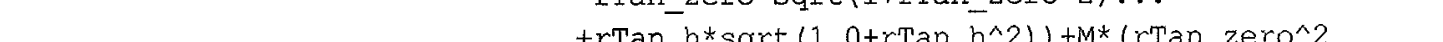

fprintf ('Running of program has successfully finished. (n'); 


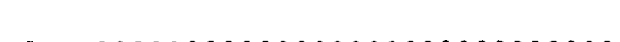

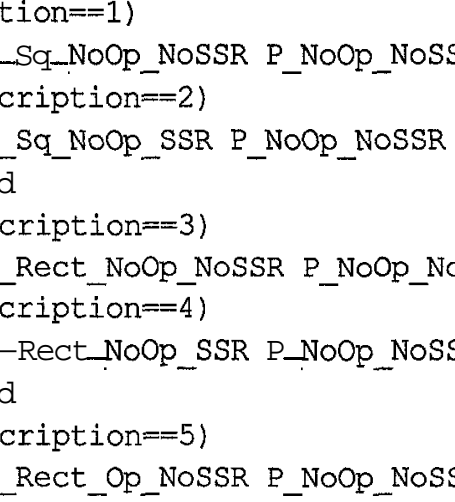

$؛\left[\begin{array}{llllllllll}807 & 9 \varepsilon & 0 & 008 T & 0 S T & \text { OSZ } & 09 Z\end{array}\right.$

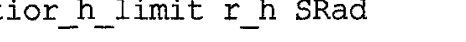
9SE ZZ 0 8LLT OST PSZ PSZ TLE 920 8LLI OST ЋSZ TSZ 09S TL O OOST OZT OOE OOE 866 ZL O OOST OZT OZZ OZZ S๐9 080 OOST OST OST OGI EPS PL O OOST OST OST OST 68P OL O OOST OST OST OST $96 \mathrm{E}$ OE O OOST OST OST OST 9SE 690 OOST OZT OST OST

LSH \% $99 \varepsilon$ PL 0 OOST OZT OST OS[]=S

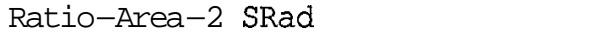

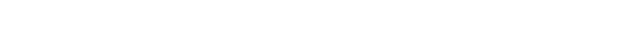

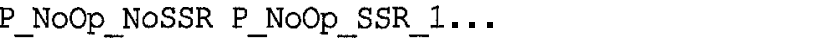

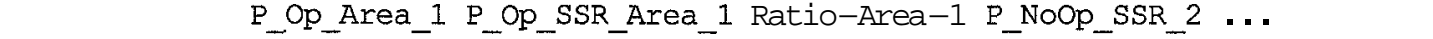
USSON doON

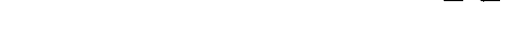
aureu $ә$ TT

(NP) $7 \mathrm{se7} \mathrm{Kq}$

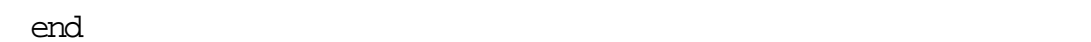
L uUntos

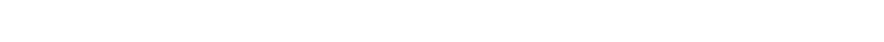
9 unimtos

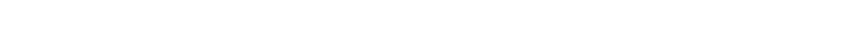
$S$ trumtos $\%$

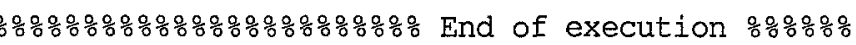
万) uUntos $\%$ (unu) qets 30 ssəuxวт̣प7 = 


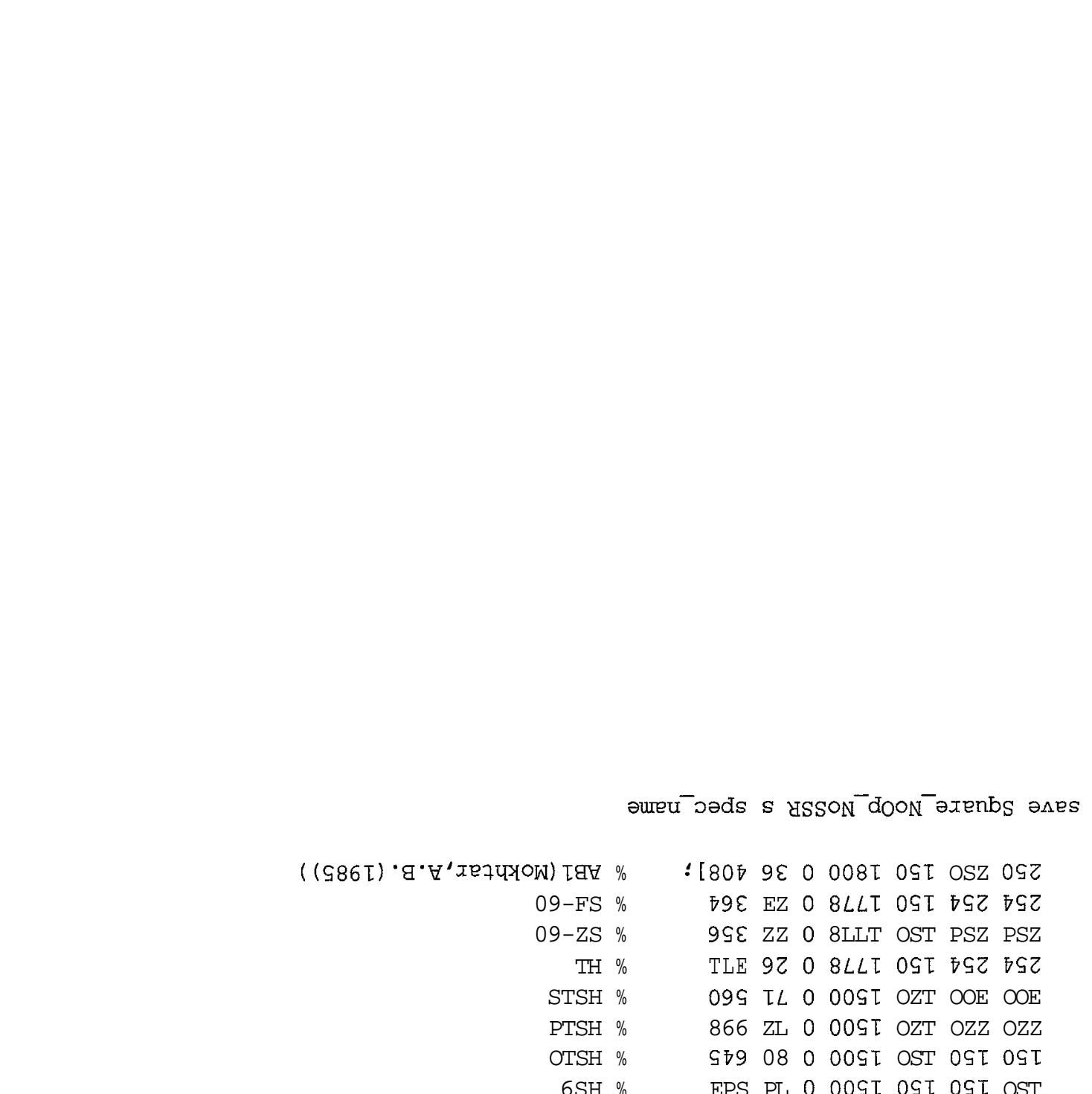




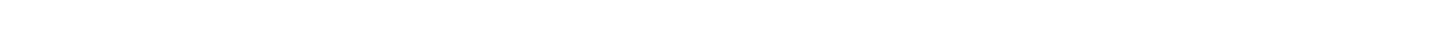

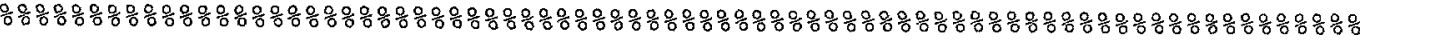

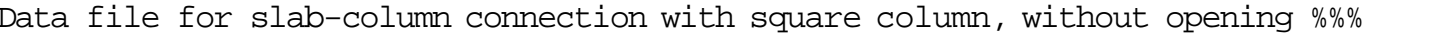
\% column 1 = column width cl in horizontal direction on plan area (mm)

$\% \quad$ column $2=$ column width c2 in vertical direction on plan area (mm)

$\%$ column $3=$ thickness of $\mathrm{slab}(\mathrm{mm})$

\% column $4=$ distance between supports parallel to $\mathrm{cl}$ (mm)

o column 5 = distance between supports parallel to c2 (mm)

- column $6=$ cylinder compressive strength of concrete (Mpa)

\% column 7 punching shear capacity of slab-column connection obtained $\% \quad$ by test (kN)

$\%$ no $\quad$ total numbers of specimens

$\%$ file name = Rectangular NoOp NoSSR

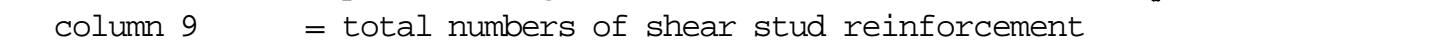

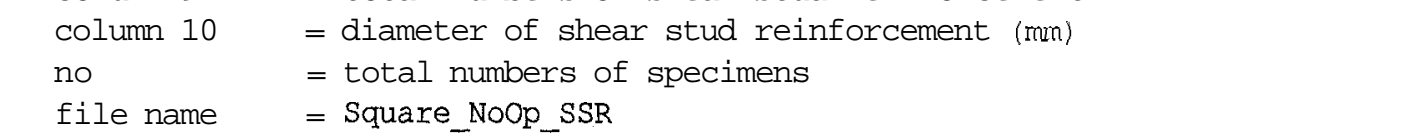

\begin{tabular}{|c|c|c|c|c|c|c|c|c|c|}
\hline$s=[200$ & 600 & 150 & 107 & 1800 & 2000 & 36 & 568 & $\%$ & oc13 \\
\hline 200 & 1000 & 150 & 103 & 1800 & 2500 & 40.15 & 649 & $\%$ & oC15 \\
\hline 200 & 600 & 150 & 109.75 & 1800 & 2000 & 32.98 & 508 & $\%$ & OC13_1_6 \\
\hline 250 & 750 & 200 & 155 & 2000 & 2400 & 35.60 & 792 & $\%$ & $\mathrm{C} 13 \mathrm{~F} 22$ \\
\hline 250 & 1250 & 200 & 160 & 2000 & 3000 & 35.4 & $1056 \%$ & $\mathrm{C} 15 \mathrm{~F} 22$ & \\
\hline 203 & 406 & 152 & 117 & 2083 & 2083 & 26.3 & 351 & $\%$ & slab-2 \\
\hline 152 & 457 & 152 & 117 & 2083 & 2083 & 32.03 & 333 & \% & slab-3 \\
\hline 114 & 494 & 152.4 & 117 & 2083 & 2083 & 30.90 & 331 & $\%$ & slab-4 \\
\hline 114 & 494 & 152.4 & 120.65 & 2083 & 2083 & 26.10 & 314 & $\%$ & slab-8 \\
\hline 152 & 305 & 152 & 120.65 & 2083 & 2083 & 29.50 & 317 & $\%$ & slab-9 \\
\hline 152.4 & 457.2 & 152.4 & 114 & 1780 & 1780 & 27.58 & 394 & $\%$ & R1 (Moe, 1961) \\
\hline 152.4 & 457.2 & 152.4 & 114 & 1780 & 1780 & 27.58 & $3971 ;$ & $\%$ & Rl (Hognestad) \\
\hline
\end{tabular}

save Rectangular_NoOp_NoSSR s spec_name 


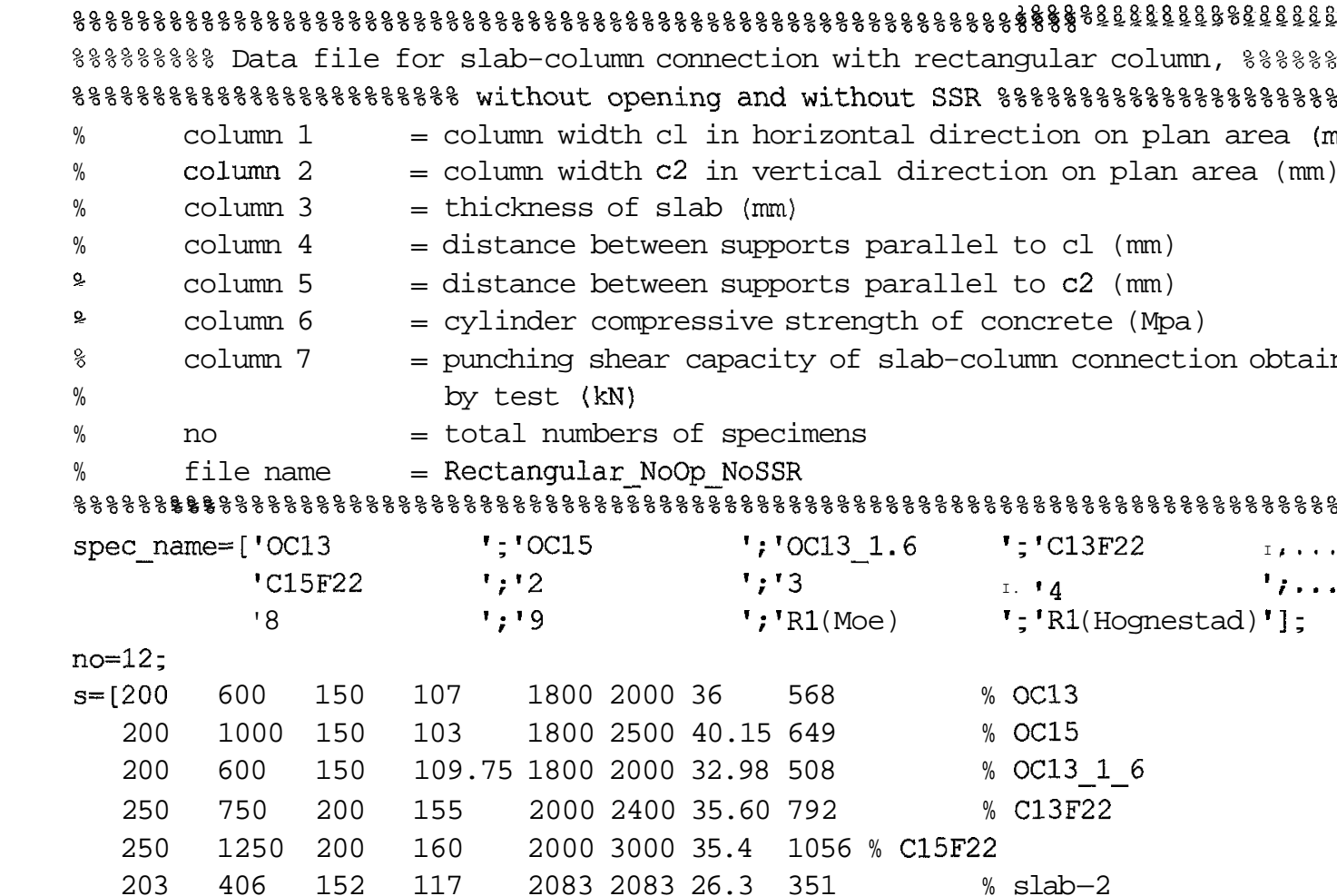

save Rectangular_NoOp_SSR s spec_name 


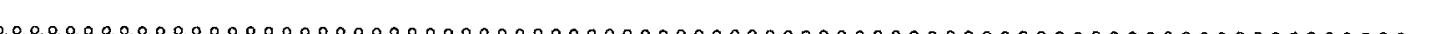

음음음웋음 Data file for slab-column connection with rectangular column,

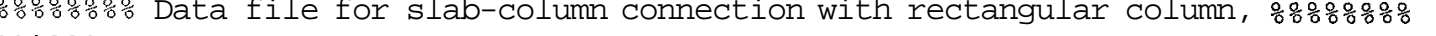
\% column 1 = column width $\mathrm{cl}$ in horizontal direction on plan area (mm) $\%$ column $2=$ column width $\mathrm{c} 2$ in vertical direction on plan area ( $\mathrm{mm}$ )

\% column $3=$ thickness of slab (mm)

- column 4

$\% \quad$ column 5

= distance between supports parallel to $\mathrm{cl}$ (mm)

column $5=$ distance between supports parallel to $\mathrm{c} 2$ (mm)

column $6 \quad$ cylinder compressive strength of concrete (Mpa)

column 7 punching shear capacity of slab-column connection obtained by test ( $\mathrm{kN})$

column $8=$ opening dimension parallel to $\mathrm{cl}$ (mm)

column $9=$ opening dimension parallel to c2 (mm)

column 10 = type of opening location

1 is meant opening location type I that the opening is positioned adjacent to the corner of column.

2 is meant opening location type II that the opening is positioned adjacent to the shorter side of column with longer side of opening being parallel to shorter side of opening.

3 is meant opening location type III that the opening is positioned adjacent to the end of longer column side with shorter side of opening being parallel to the longer column side)

4 is meant opening location type IV that the opening is positioned adjacent to the middle of longer column side with longer side of opening being parallel to the longer column side)

5 is meant opening location type $V$ that the opening is positioned adjacent to the shorter column side with shorter side of opening being parallel to the shorter column side)

no $\quad$ total numbers of specimens

- file name = Rectangular_Op_NoSSR

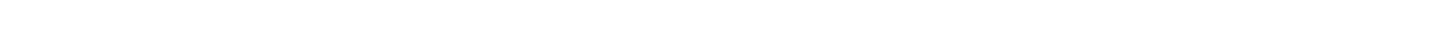

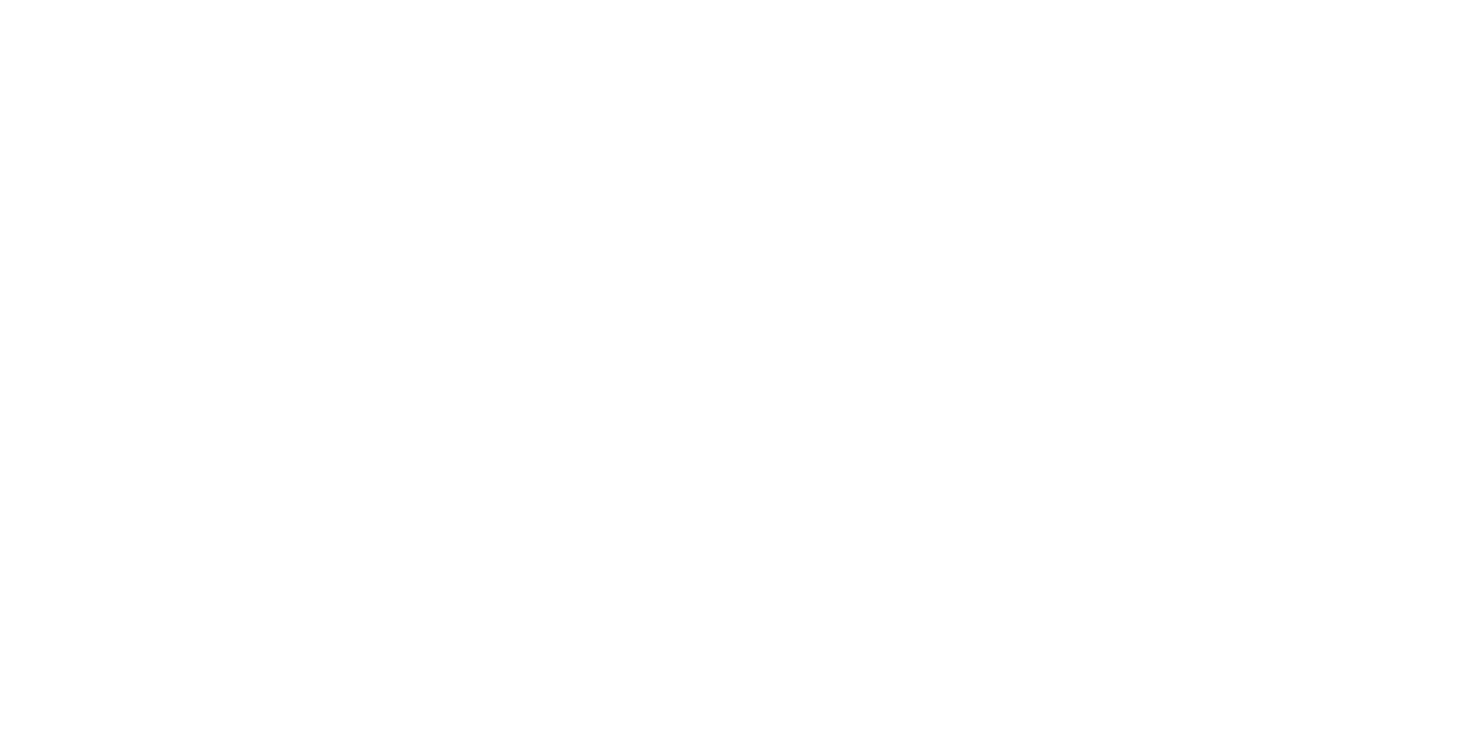




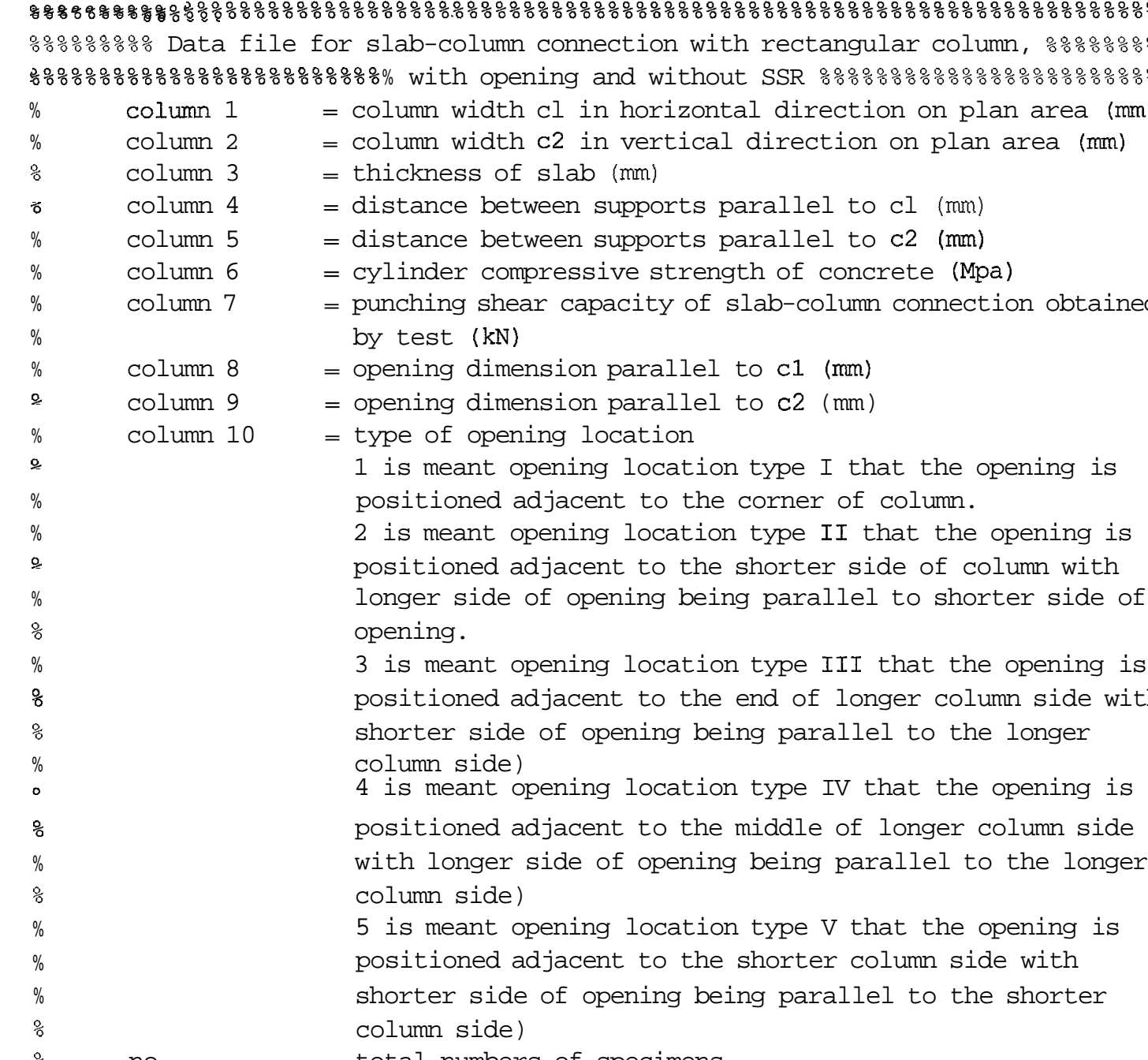

save Rectangular_Op_NoSSR s spec-name 


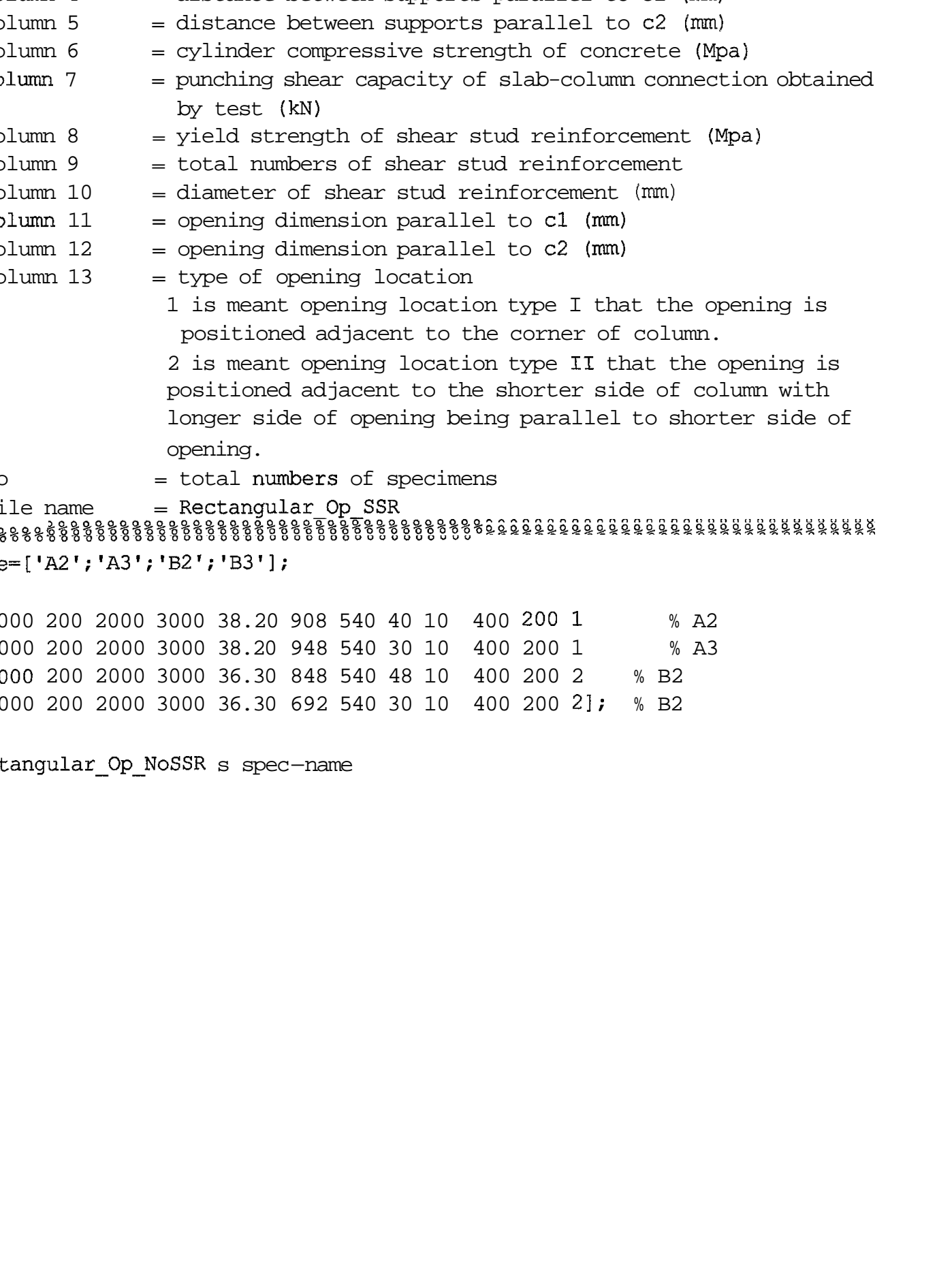



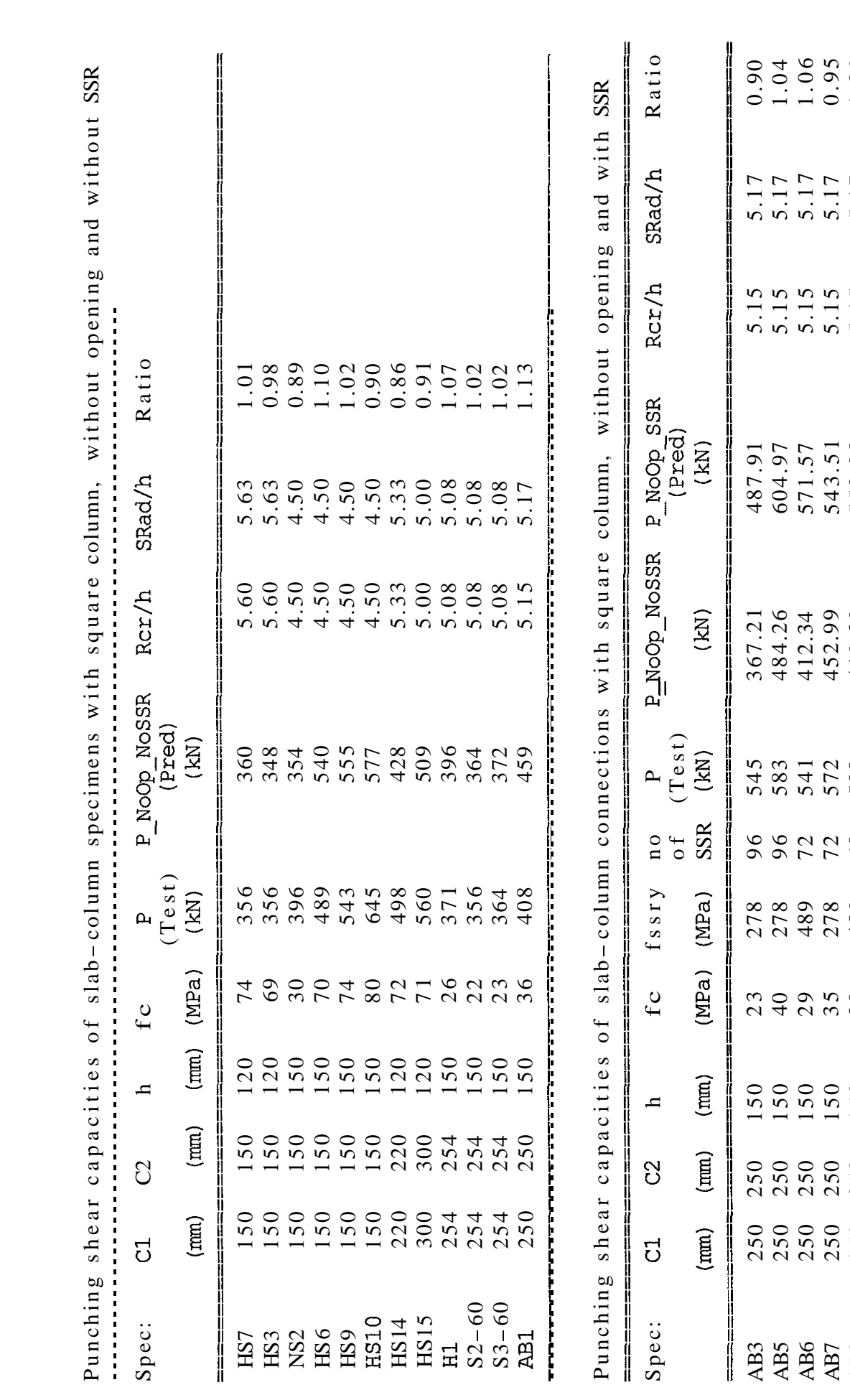


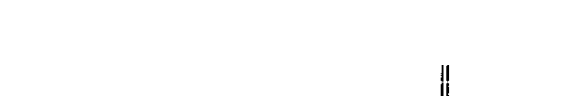

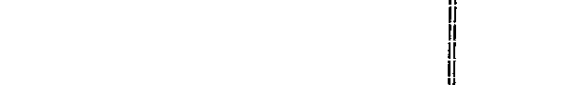

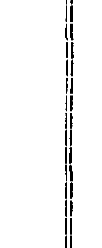

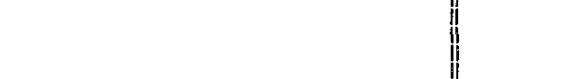

भ ம

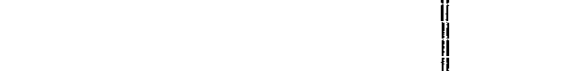

ஜ ம் ம்

(2)

¿

尊

舟

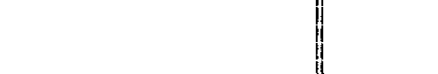
का

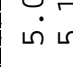

氙矛

居

뵝

吅苞

म

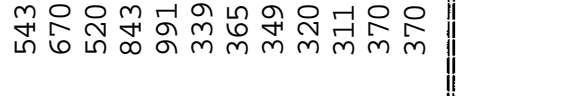

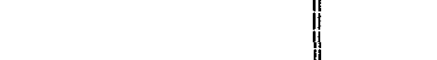

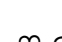

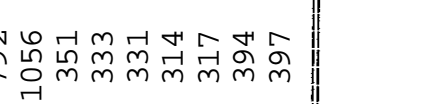

丞

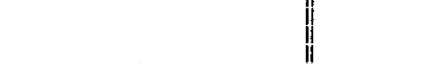

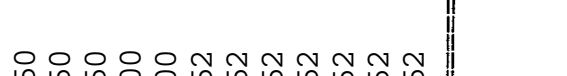

6
$\forall$
$\forall$

要

至

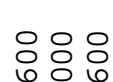

$\hat{m} \stackrel{m}{m} \stackrel{\infty}{m} \underset{\sim}{m} \stackrel{\varphi}{m} \stackrel{\sim}{m} \stackrel{m}{m} \underset{\sim}{m} \stackrel{\infty}{m} \underset{m}{m} \stackrel{m}{m} \stackrel{\infty}{m}$

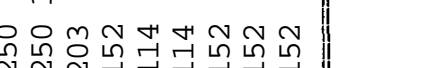

$\begin{array}{l:ll}0 & \\ -1 & \text { 臬 } & \end{array}$

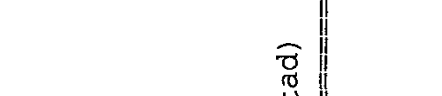

要

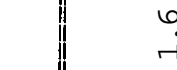

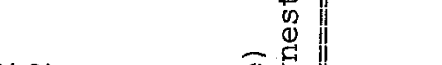

贾

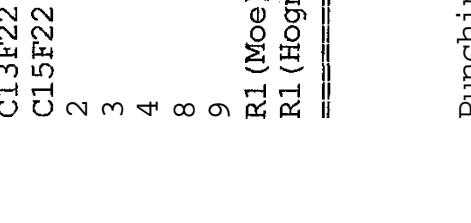

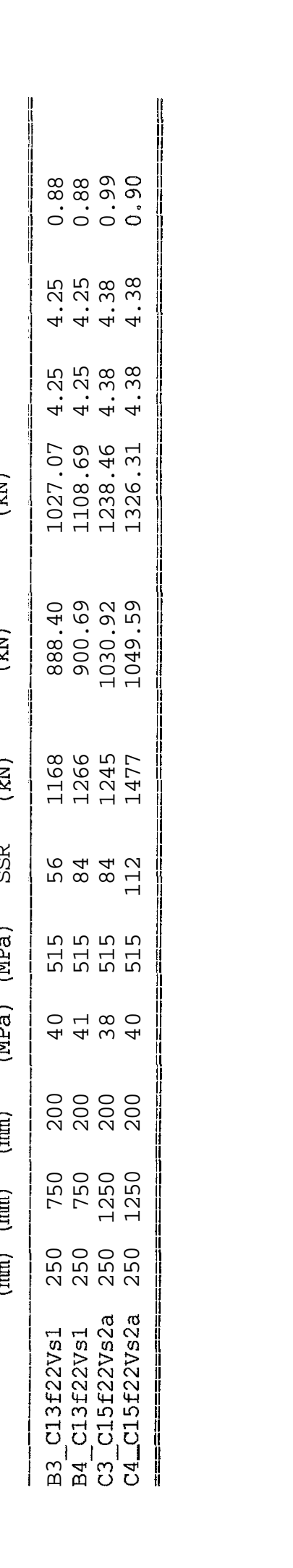




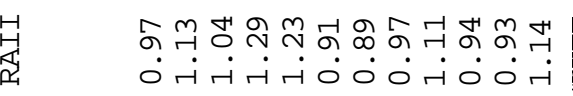

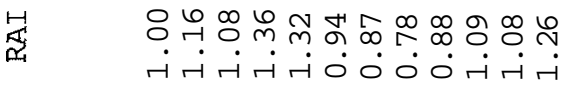

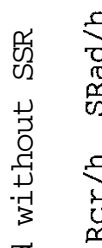

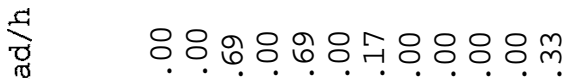

भ ம

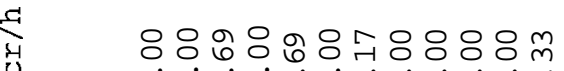

ஜ ம் ம்

(2)

¿

尊

舟

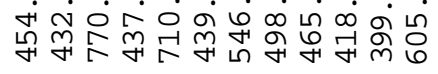
का

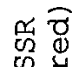

氙矛

居

뵝

吅苞

म

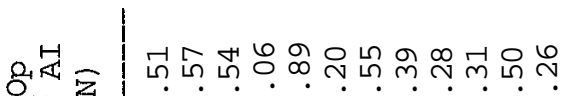

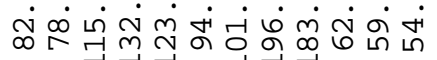

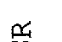

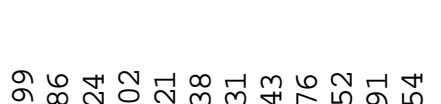

丞

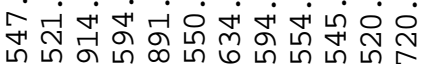

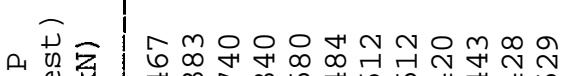

6
$\forall$
$\forall$

要

至

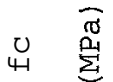

$\hat{m} \stackrel{m}{m} \stackrel{\infty}{m} \underset{\sim}{m} \stackrel{\varphi}{m} \stackrel{\sim}{m} \stackrel{m}{m} \underset{\sim}{m} \stackrel{\infty}{m} \underset{m}{m} \stackrel{m}{m} \stackrel{\infty}{m}$

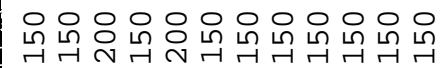

$\begin{array}{l:ll}0 & \\ -1 & \text { 臬 } & \end{array}$

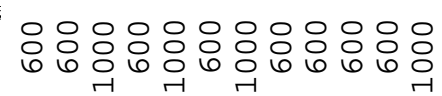

要

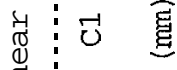

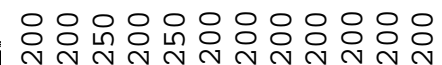

贾

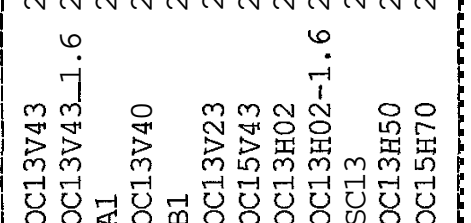

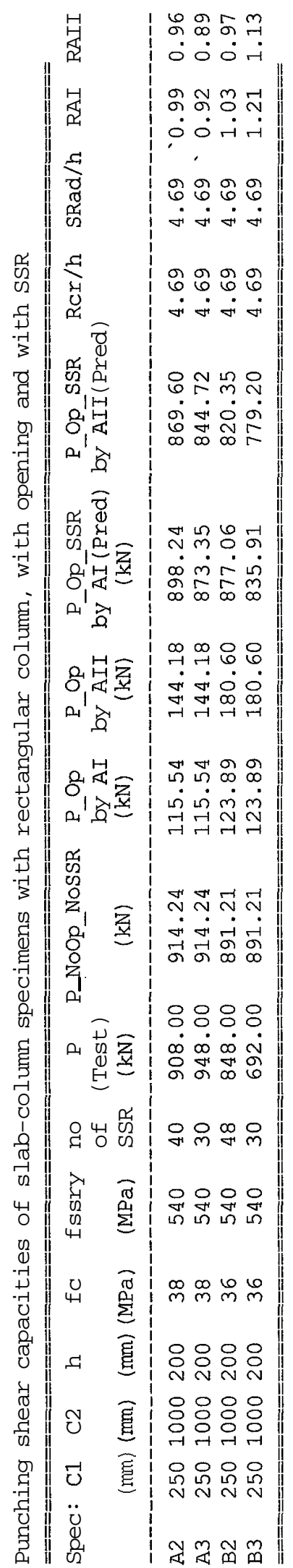

